\title{
Biology
}

Education

Research

Contemporary topics and directions

Edited by

Blanca Puig, Paloma Blanco Anaya,

María José Gil Quílez and Marcus Grace

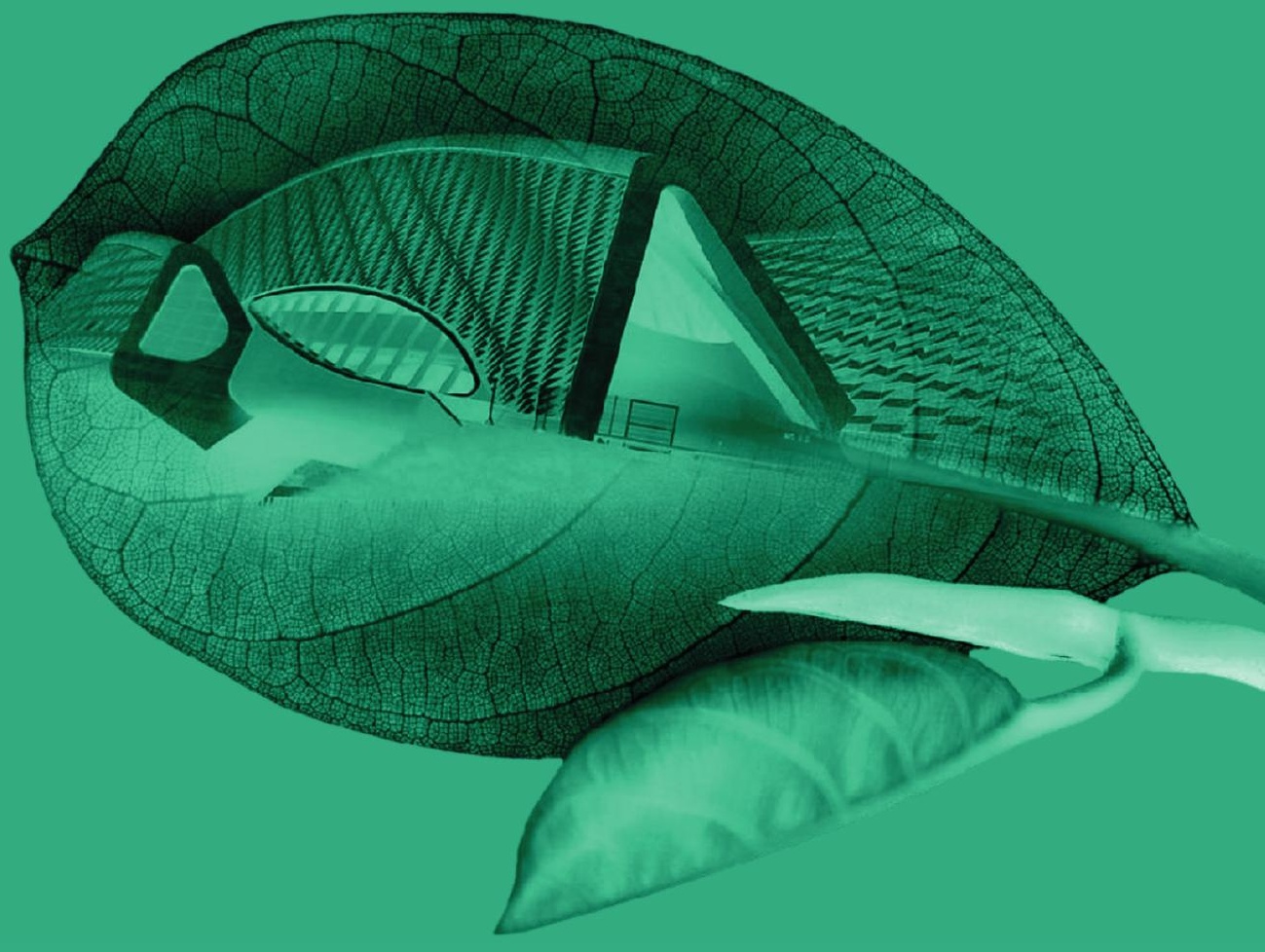

A selection of papers presented

at the Xllth conference of European Researchers

in Didactics of Biology (ERIDOB) 



\section{Biology Education Research. Contemporary topics and directions}



(Edited by) Blanca Puig, Paloma Blanco Anaya, María José Gil Quílez and Marcus Grace

\section{Biology Education Research. Contemporary topics and directions}


doi.10.26754/uz.978-84-16723-97-3

(C) Blanca Puig, Paloma Blanco Anaya, María José Gil Quílez and Marcus Grace 1. ${ }^{\mathrm{a}}$ edición, 2020

Impreso en España

Imprime: Servicio de Publicaciones. Universidad de Zaragoza

ISBN: 978-84-16723-97-3

D.L.: Z 714-2020 


\section{THE XII ERIDOB CONFERENCE}

\section{Academic Committee}

Dr Orit Ben Zvi Assaraf, Ben-Gurion University of the Negev, Israel

Dr Marida Ergazaki, University of Patras, Greece

Dr Niklas Gericke, Karlstad University, Sweden

Dr Marcus Grace, Southampton University, UK (Chair)

Dr Marie-Christine Knippels, University of Utrecht, Netherlands

Dr Konstantinos Korfiatis, University of Cyprus, Cyprus

Dr Blanca Puig, University of Santiago de Compostela, Spain

Dr Jörg Zabel, Leipzig University, Germany

\section{Local organizing committee}

\section{Universidad de Zaragoza}

Dr María José Gil-Quílez: quilez@unizar.es

Dr Beatriz Bravo-Torija: beatriz.bravo@uam.es

Dr Beatriz Mazas-Gil: bmazas@unizar.es

Dr Ester Mateo-González: emateog@unizar.es

Dr Pedro Lucha-López: plucha@unizar.es

Dr María Eugenia Díes: medies@unizar.es

Dr Ángel Luis Cortés-Gracia: acortes@unizar.es

Dr Ana de Echave-Sanz: aechave@unizar.es

Dr Begoña Martínez-Peña: bpena@unizar.es

Dr Esther Cascarosa-Salillas: ecascano@unizar.es

Dr María José Sáez Bondía: msaezbo@unizar.es

Dr José Miguel Calvo-Hernández: jmcalvo@unizar.es

\section{Universidad de Santiago de Compostela}

Dr Paloma Blanco-Anaya: paloma.blanco@usc.es

Dr Blanca Puig-Mauriz: blanca.puig@usc.es

Dr Beatriz Crujeiras-Pérez: beatriz.crujeiras@usc.es

Dr Pablo Brocos-Mosquera: pablo.brocos@usc.es

Dr Borja Gómez-Padro: borja.gomez.prado@usc.es

Dr Inés Mosquera-Bargiela: ines.mosquera@usc.es

Dr Noa Ageitos-Prego: noa.ageitos@usc.es

Dr Isabel García-Rodeja Gayoso: isabel.garcia-rodeja@usc.es

DrVanessa Sesto Varela: vanessa.sesto@usc.es 



\section{CONFERENCE: PUBLISHED BOOK OF SELECTED PAPERS FROM THE CONFERENCE}

2018 Zaragoza, Spain: Biology Education Research. Contemporary topics and directions. Edited by Blanca Puig, Paloma Blanco Anaya, María José Gil Quílez and Marcus Grace.

2016 Karlstad, Sweden: Challenges in Biology Education Research, 2018. Edited by Niklas Gericke and Marcus Grace.

2014 Haifa, Israel: The Future of Biology Education Research, 2016. Edited by Tali Tal and Anat Yarden.

2012 Berlin, Germany: Research in Biological Education, 2014. Edited by Dirk Krüger and Margareta Ekborg.

2010 Braga, Portugal: Authenticity in Biology Education: Benefits and Challenges, 2011. Edited by Anat Yarden and Graça S. Carvalho.

2008 Utrecht, The Netherlands: The Nature of Research in Biological Education: Old and New Perspectives on Theoretical and Methodological Issues, 2009. Edited by Marcus Hammann; Arend Jan Waarlo and Kerst Boersma.

2006 London, UK: Biology in Context: Learning and teaching for the twenty-first century, 2008. Edited by Marcus Hammann; Michael Reiss; Carolyn Boulter and Sue Dale Tunnicliffe.

2004 Patras, Greece: Trends in Biology Education Research in the New Biology Era, 2005. Edited by Marida Ergazaki; Jenny Lewis and Vassiliki Zogza.

2002 Toulouse, France: Biology Education for the Real World: Student-Teacher - Citizen, 2003. Edited by Jenny Lewis; Alexandra Magro and Laurence Simonneaux.

2000 Santiago de Compostela, Spain: Proceeding of the III Conference of European Researchers in Didactic of Biology, 2001. Edited by Isabel García-Rodeja Gayoso; Joaquín Díaz de Bustamante; Ute Harms and María Pilar Jiménez Aleixandre.

1998 Göteborg, Sweden: Research in Didaktik of Biology, 2000. Edited by Björn Andersson; Ute Harms; Gustav Helldén and Maj-Lis Sjöbeck.

1996 Kiel, Germany: What? - Why? - How? Research in Didaktik of Biology, 1998. Edited by Horst Bayrhuber and Fred Brinkman. 



\section{CONTENTS}

The XII ERIDOB Conference.................................................................

Conference: Published book of selected papers from the conference....... 9

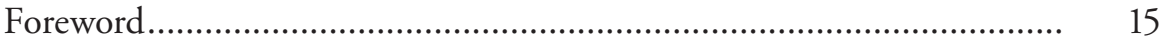

\section{KEYNOTE CONFERENCE}

How to gather and analyse quality evidence about successful biology classrooms

María Pilar Jiménez-Aleixandre.....................................................

\section{SECTION 1 \\ RESEARCH METHODS}

Curriculum narrowing in university entrance assessment in biology Francisco Luis Alda, María José Gil Quílez and María Jesús Rodriguez Yoldi

\section{SECTION 2 STUDENTS' CONCEPTIONS}

Using problematized contexts to introduce the idea of classification criteria in taxonomy. Context-transference and resistant ideas Jordi Domènech-Casal. 
Students' conceptions of plant reproduction processes

Peter Lampert, Bernhard Müllner, Peter Pany, Martin Scheuch, and Michael Kiehn

Schoolgirls' understanding of HIV/AIDS knowledge presented in life sciences textbooks in South Africa

Lindelani Mnguni.

Nutrition and reproduction students' alternative conceptions regarding animal classification

Zghida Noureddine and Lamrani Zouhaire

What are students' mental representations of climate change and the greenhouse effect?

Vanessa Sesto, Isabel Garcia-Rodeja, Begoña Varela.

\section{SECTION 3 \\ STUDENTS' INTEREST AND MOTIVATION}

Engaging students in studying human biology through digital storytelling Maria Dokopoulou and Evangelia A. Pavlatou.................................

Collaborative care for animals in class - effects on students' relatedness and their flow experience in biology lessons

Alexander Eckes, Nadine Großmann, Annette Textor and Matthias Wilde

Training pre-service teachers to approach microorganisms through an active practice based on homemade culture: role of students' emotions José María Marcos-Merino, Rocio Esteban Gallego and Jesús A. G. Ochoa de Alda.

I won't believe it until I see it? An inquiry-based sequence on "microorganisms" for secondary school Maria Martínez-Chico, Farida Abou Akl, M. Rut Jiménez-Liso

\section{SECTION 4 \\ SCIENTIFIC THINKING, NATURE OF SCIENCE AND ARGUMENTATION}

Contingency in peer scaffolding when addressing socio-scientific issues in biotechnology

Birgitta Berne 
Dialogue and linguistic scaffolds as tools to help students construct investigable questions

Concepció Ferrés-Gurt and Jordi Domènech-Casal

Is teaching biology through socio-scientific issues enough for the development of argumentation skills?

Georgiou Martha, Mavrikaki Evangelia, Constantinos Constantinou.

Ecosystems in science education research in the last 20 years: a research synthesis

Pedro Lucha and María José Sáez.

Promoting the role of data and scientific models in students' argumentation on socio-scientific issues through communication scaffolds Anna Marbà-Tallada and Jordi Domènech-Casal...........................

\section{SECTION 5}

\section{TEACHING STRATEGIES AND TEACHING ENVIRONMENTS}

The floral diagram as a didactic resource for degree students in early childhood education

Beatriz Carrasquer Álvarez and Adrián Ponz Miranda.

Representations of gene models in Greek secondary school biology textbooks

Akrivi Christidou and Pinelopi Papadopoulou

Toward teaching for an integrated understanding of trait formation: An analysis of genetics tasks in high school biology textbooks

Tim Heemann and Marcus Hammann

Processes of professionalization: Outdoor teaching and assessment of PCK Lissy Jäkel, Ulrike Kiehne, Sabrina Frieß, David Hergesell and Benjamin Tempel.

The BIOdiver project: development of outdoor inquiry skills in undergraduate elementary teachers' courses Isabel Jiménez-Bargalló, Arnau Amat and Jordi Martí-Feixas

Storytelling as an educational tool in biology teaching: a pilot study Nausica Kapsala and Evangelia Mavrikaki

Student teachers on the way to accurate diagnosis: Development, testing and assessment of diagnostic tasks by teacher training students Bianca Kublemann and Corinna Hößle.... 
Make biology relevant again! Pre-service teachers' views on the relevance of biology education Justus Mutanen and Anna Uitto.....

Proposal of a model for professional development: perspectives and stages that contribute to the improvement of the practice of biology teaching

Eduardo Ravanal Moreno, Édgar Valbuena Ussa, Elias Amórtegui Cedeño

Teaching \& learning laboratories in biology teacher education: analysis of teaching reflections Antje Saathoff and Corinna Hößle.

Teaching to teach the model of evolution in primary education: an experience with pre-service teachers at a Spanish university Lucia Vázquez-Ben and Ánxela Bugallo-Rodriguez

Combining biology education and education for sustainability in preschool: insights from the $2^{\text {nd }}$ cycle of a design research Maria-Christina Kasimati and Marida Ergazaki....

Training future teachers to adress interdisciplinary in Biology lessons: Learning Physics and Chemistry with a DNA extraction practice. Rocio Esteban Gallego, José María Marcos Merino and Jesús A. Gómez. Ochoa de Alda

\section{SECTION 6 \\ TEACHING AND LEARNING WITH EDUCATIONAL TECHNOLOGY}

Effectiveness of digital versus traditional (paper-based) dichotomous keys for identification of woody species 


\section{FOREWORD}

\section{Biology Education Research. Contemporary topics and directions}

This volume consists of 29 original papers presented at the $12^{\text {th }}$ Conference of European Researchers in Didactics of Biology (ERIDOB) organized by the University of Zaragoza in collaboration with University de Santiago de Compostela, hosted in July 2018 by the Faculty of Education, University of Zaragoza, Spain.

Recognizing the importance and potential of being well-trained in biology, the bi-annual Conference of ERIDOB is now a firmly established and leading forum for European and non-European researchers to discuss and reflect on research in biology education, to find new ways of ensuring continued advances in teaching and learning this discipline.

Biology is a field of research in constant growth. Its advances have brought not only enormous benefits to humanity in fields from Human Biology to Ecology, but also great repercussions in our daily lives. This context makes it necessary for biology education to equip young people with the tools and resources needed to become scientifically literate, critical thinkers and social activists. Some of these concerns are highlighted in this book, whose 29 papers have been selected after having passed a double blind review process by at least one member of the ERIDOB Academic Committee together with an experienced reviewer of the ERIDOB academic community.

In the introduction of this volume the keynote conference, How to gather and analyse quality evidence about successful biology classrooms, presented by María Pilar Jiménez Aleixandre, methodological issues related to classroom studies are addressed. Special attention is on qualitative research studies and on successful biology teaching and learning with a double goal: 1) debriefing the processes leading to quality research studies; 2 ) providing teachers with models, rather than focusing on the problems of unsuccessful teaching. 
The papers presented in this book have been organized around six sections that correspond to six of the eleven strands of the ERIDOB conference, and reflect the main threads covered during the conference. All sections include papers presented in alphabetical order.

Section 1, Research methods includes a contribution about curricular alignment. The authors examine whether university entrance assessments in the field of biology have adequately represented the official curriculum.

Section 2, Students' conceptions contains five contributions that analyze students' ideas on different topics such as plants, classification and taxonomy, climate change and HIV/AIDS.

Section 3, Students' interest and motivation comprises four contributions dealing with collaborative care for animals, human biology through digital storytelling, approaching microorganisms through homemade culture and through an inquiry sequence.

Session 4, Scientific thinking, nature of science and argumentation, comprises five papers that deal with investigable questions, socio-scientific issues, promoting data and scientific models, and ecosystems.

Section 5, Teaching strategies and teaching environments includes fourteen papers dealing with diverse biology topics as genetics, evolution, among others.

Section 6, Teaching and learning with educational technology includes one contribution that deals with the identification on woody species.

Throughout the sections, new works on biology education and up-to-date research regarding biology topics are presented, with the goal of shedding light on the important role of biology education - from addressing critically socioscientific issues to environmental problems and other emerging topics where further research is needed.

The ERIDOB conference has been collaborating with the Journal of Biological Education, and three of the outstanding papers selected for this book have been also been selected for publication in the journal (Heemann \& Hammann; Lampert, Müllner, Pany, Scheuch \& Kiehn; and Mutanen $\&$ Uitto). These papers are currently in press in the JBE and are available as abstracts in this volume to avoid double publication.

We are thankful to all the reviewers who invested significant time and effort in the review process.

We hope that this volume will be of interest both to the biology education research community and to science teachers interested in the integration of new topics and challenges that biology education face, contributing to the development of biological education in Europe and around the world according to the needs of today's society. 
KEYNOTE CONFERENCE 



\title{
HOW TO GATHER AND ANALYSE QUALITY EVIDENCE ABOUT SUCCESSFUL BIOLOGY CLASSROOMS
}

\author{
María Pilar Jiménez-Aleixandre \\ Departamento de Didácticas Aplicadas, Facultad de Ciencias de la Educación, \\ Universidade de Santiago de Compostela (Santiago de Compostela-España) \\ marilarj.aleixandre@usc.es
}

\begin{abstract}
The paper discusses methodological issues related to classroom studies. Its focuses on examples of successful biology learning, with a double goal: 1) debriefing the processes leading to quality research studies; 2) providing teachers with models, rather than focusing on the problems of unsuccessful teaching. Our approach is grounded on a sociocultural perspective, drawing from discourse analysis and interactional ethnography (Kelly \& Green, 2019). Methodological issues are relevant, since most flaws in submitted manuscripts or research proposals relate to methods. The question we sought to answer is: What are warranted accounts and which is empirical evidence in qualitative studies? This is broken down in the examination of how to ask robust research questions; how to plan an appropriate design to gather data; how to elaborate specific tools to analyse learning gains and scientific practices; how to present results and conclusions grounded in evidence. These issues are discussed with examples from classroom studies in Early Childhood Education (Monteira \& Jiménez-Aleixandre, 2016), and about modelling genetics in high school (Puig, Ageitos \& Jiménez-Aleixandre, 2017). We suggest that in studies about practices and processes the evidence should be about participants' performances. Implications for research and school practice are discussed.
\end{abstract}

Keywords: methodological issues; classroom studies; biology education; qualitative studies; research evidence.

\section{Introduction: Goals of the paper}

The paper discusses methodological issues related to classroom studies, with attention to qualitative research. Methodological issues are relevant, since most flaws in submitted manuscripts or research proposals relate to problems 
with methods. The paper focuses on examples of successful biology teaching and learning, with a double goal:

1) Debriefing the processes leading to quality research studies and papers about biology education.

2) Providing researchers and teachers with models of exemplary practice, rather than focusing on the problems of unsuccessful teaching.

In the context of qualitative studies, the overarching question we sought to answer is:

Question: What are warranted accounts, and which is empirical quality evidence in qualitative studies?

This question is further broken down in the examination of:

(a) How to ask robust research questions.

(b) How to plan an appropriate design in order to gather data that constitutes quality evidence for the question examined.

(c) How to elaborate specific tools in order to analyse learning gains in biology and in scientific practices

(d) How to present results and conclusions grounded in evidence.

These issues are discussed and illustrated with two examples from longitudinal classroom studies, whose quality is evidenced by their publication in high impact journals indexed in the web of science. First, a study reporting learning about snails in Early Childhood Education (Monteira \& JiménezAleixandre, 2016); second, a study about modelling and argumentation in genetics in high school (Puig, Ageitos \& Jiménez-Aleixandre, 2017).

\section{Rationale: Framing methodological debates}

Methodological issues are relevant for biology education researchers, first because we, as a field, need to produce research that is rigorous. Second, in the process of publishing, major reasons for rejection are poor research design and flaws in methods. My argument is that methodology matters. However, biology education, and in general science education research, have tended to have a stronger focus either on theoretical approaches or on empirical findings about learning and teaching (Jiménez-Aleixandre, 2019). As a consequence, methodological issues specific of the science education field have been given less attention. A great deal of studies about biology education, and science education, draw from domain-general research methods. Certainly, we have much to learn from them, but they may be less suited to address some domain-specific issues.

As Heap (1995) claimed, in a seminal paper about qualitative research, the central issue in methodological debates "is the concept of science under which research is carried out and in terms of which is justified" (Heap, 1995, p. 271). A relevant question is the heuristic distinction between, on the one hand, natural sciences as is the case of biology research, and on the other hand, social and 
human sciences, which are concerned with inquiry into human actions and experiences, as is the case with biology education research. The background, for instance a bachelor degree, for a majority of researchers into biology education, is in biology, belonging to natural sciences, which influences our frameworks, how we think about or how we understand research. Nevertheless, the focus of our research is on education, not on biology. I contend that the biology background, the knowledge of the subject matter, is needed for a deep engagement with the subtleties of learning biology. However, it is also necessary an acknowledgement of the differences between natural and social sciences research, which entails or may entail different types of research questions, designs, evidence or claims.

Thus, for instance, Heap (1995) argues that, in qualitative educational research, claims are not necessarily the standard type of empirical claims. $\mathrm{He}$ discusses the relevance, for social and cultural inquiry employing observational methods, of two different, non-empirical, types of claims, logical and normative. Logical claims are defined in terms of the necessary conceptual relations in a proposition, for instance characterizing "appropriate participation" in a lesson as "actively interpreting the meaning being signaled". Normative claims are those related to contingent relations, what ought to be, or what should be related to what. For Heap an example of normative claim is the influence of the teacher's purpose for a lesson in the type of classroom discussion. This claim could be tested empirically or normatively, by considering that purpose and discussion are conceptually and normatively interlinked. Thus Heap introduces the notion of "rationally accountable, domain-oriented inquiry" (p. 271) in order to guide qualitative studies.

What does it mean "rationally accountable"? In their introductory chapter to the edited volume about theoretical and methodological issues in sociocultural research in science and engineering education, Greg Kelly and Judith Green (2019) take up this notion, characterizing research studies framed in a sociocultural perspective as "warranted accounts": "Our goal (...) is to make visible ways of developing and explaining processes involved in designing, conducting, and constructing research leading to warranted accounts of educational phenomena (Heap, 1995).” (Kelly \& Green, 2019, p. 1, my emphasis). Their volume brings a unique approach to methodological reviews about science -and engineering- education, by focusing on reflections about the process of research itself. It discusses, in each chapter, beyond the final form of research questions, rubrics or tools for analysis, the decisions made during the process. Thus, what Kelly and Green seek to make visible is how, for what purposes or with what outcomes, science is socially, discursively, and conceptually constructed in educational settings. The meaning of "warranted accounts" may be related to what Mitchell (1984) called telling cases, detailed presentations of ethnographic data which make visible previously obscured or unknown 
information. Likewise, Erickson (2012) states that in qualitative research "The emphasis is on discovering kinds of things that make a difference in social life; hence, an emphasis is placed on qualitas rather than on quantitas." (Erickson, 2012, p. 1451; author's emphasis).

It needs to be noted that qualitative and quantitative approaches are not discrete procedures, but should be viewed rather as different ends on a continuum, than as dichotomies or rigid categories (Creswell, 2014), with mixed methods residing in the middle. As Creswell points out, we may say that a study tends to be more qualitative or more quantitative. The differences are in the emphasis. For Erickson (2012) the priority of emphasis on quality "does not mean that information about frequency is irrelevant to qualitative inquiry" (Erickson, 2012, p. 1451).

Large-scale quantitative studies are appropriate to document products of learning, or what can be termed the "current state", seeking generalizability. However, as Kelly and Green (2019) suggest in their analysis about science and engineering education, they may lack the sensitivity to examine how access to knowledge and learning are constructed through social interaction. Therefore, they may fail to explain why or how that current state was constructed.

According to Creswell (2014), qualitative research seeks to explore and understand the meanings individuals or groups ascribe to social or human problems and issues. In education and science education, qualitative studies emphasize the socially constructed nature of events; seek to analyse processes of knowledge construction. Erickson (2012) claims that it is the responsibility of qualitative researchers to go beyond what the actors understand explicitly, identifying the meanings that are outside their awareness. However, as Kelly and Green (2019) point out, some qualitative studies do not make use of systematic and theoretically grounded approaches, and they suggest the importance of utilizing large-scale video data sets. Hence, my argument is that the study of educational events in biology -and science- classrooms needs systematic methodological approaches.

Be it qualitative, quantitative or mixed, a research approach involves, according to Creswell (2014) three interconnected components or framework elements:

(1) Philosophical assumptions, worldviews or epistemologies guiding action: thus for instance the studies discussed below are framed in a sociocultural perspective.

(2) Research design or strategies of inquiry: choice of a type of study within a given approach. The two studies analysed below make part of longitudinal studies.

(3) Specific research methods or procedures of research: detailed procedures for data collection, data analysis or interpretation. These specific research methods are the focus of this paper. 


\section{Warranted accounts and quality evidence in qualitative studies}

The specific research methods discussed in this section for qualitative and mixed methods studies may be of application, in many cases to quantitative studies. The two examples from longitudinal classroom studies from our research group analysed in this paper were chosen because its quality is evidenced by their publication in journals indexed in the Journal Citation Report of the Social Sciences Citation Index (JCR of SSCI).

- Monteira, S. F., \& Jiménez-Aleixandre, M. P. (2016). The practice of using evidence in kindergarten: The role of purposeful observation. Journal of Research in Science Teaching, 53(8), 1232-1258.

This paper is part of a longitudinal study examining kindergarteners' engagement in scientific practices during three years, from 3-4 to 5-6 years of age. Its focus is on generating and using evidence to support claims, and on learning about snails' biology during a 5-month project on snails in Early Childhood Education. The Journal of Research in Science Teaching (JRST) is one of the three science education journals with highest impact factor, over 3; currently 3.210; the other two being Studies in Science Education (3.455) and Science Education (3.035). This paper was also awarded the Research worth reading distinction in 2017, by a joint committee NARST / NSTA (National Association of Research in Science Teaching/ National Science Teachers Association), for its potential "to be most relevant and valuable for practicioners".

- Puig, B., Ageitos, N. \& Jiménez-Aleixandre, M. P. (2017). Learning gene expression through modelling and argumentation: A case study exploring connections between the worlds of knowledge. Science \& Education. 26(10), $1193-1122$.

This paper makes part of a longitudinal two-year study, examining the interactions between modelling and argumentation in the context of learning genetics in high school, $10^{\text {th }}$ and $11^{\text {th }}$ grades, $15-17$ years of age. Its focus is on learning gene expression in the context of diseases with a genetic component. The study is framed in Tiberghien's (2000) rationale about modelling involving two worlds of knowledge, the world of objects and events, which refers to observable aspects; and the world of theories, to which we propose the inclusion of a third world of external representations or expressed models. Science \& Education has an impact factor of 1.265. The paper was published in a special issue about genetics education.

\subsection{Asking and refining robust research questions}

Erickson (2012) sees doing research as paying unusually close attention and reflecting deliberately on what we have seen and heard. As the research report, be it doctoral dissertation or paper, consists of answers to the questions, Erickson 
considers that good questions are at the heart of inquiry. For Creswell (2014) a research problem is an issue of concern that needs to be addressed; it may come from a gap in the literature, from conflict in research results, or from topic previously ignored. Sometimes the research questions (RQs) need to be refined, revised or even changed. Erickson claims that in a qualitative study "(it) means that the post hoc analysis is working properly - discovering subtleties and contingencies that could not have been foreseen" (Erickson, 2012, p. 1462), and he further suggests that this is the goal of participant observational fieldwork, in order to discover what could not be anticipated.

Therefore the first step in research procedures is to ask robust research questions (RQ) that may be answered empirically, and not simply be answered yes or no.

In Monteira and Jiménez-Aleixandre the first formulations of the RQs were:

(1) To examine the meanings for what constitutes evidence constructed during the project.

(2) To examine how children use evidence to evaluate and revise knowledge, in other words the features of kindergarten children's engagement in the practice of using evidence.

The first was too general; it was developed into two more specific questions, in reference to the development of data into evidence, an original contribution of the study; the second was also refined and broken down into two, including in the new RQ2 the ways of gathering empirical evidence. Thus the new RQs in the published paper are:

RQ1 What meanings do kindergarteners construct for what constitutes evidence? How are those meanings reflected in the development of data into evidence?

RQ2 Which ways of gathering empirical evidence are jointly constructed by children and teacher during the project?

RQ3 How do children use evidence to revise their understandings?

In Puig et al. the first formulations of the RQs were:

(1) Which argumentation and modelling operations do students enact when building the model of gene expression?

(2) How are the interactions between these operations when modelling gene expression?

The first question a) was reworded to better fit the modelling practice studied, substituting it for "building the model", and b) was developed to address the connections among the three worlds of knowledge that frame the study. The second a) was reworded for the sake of clarity, and also developed to address those connections. The new RQs are:

RQ1 What argumentative and modelling operations do students enact in the process of modelling gene expression? Specifically, which operations allow connecting the three worlds of knowledge? 
RQ2 What are the interactions between modelling and argumentation in modelling gene expression? To what extent do these interactions help students connect the three worlds of knowledge and modelling gene expression?

These first versions of the RQs exemplify common problems in formulating questions, being too general, failing to capture the specificities of the issue studied, failing to adequately frame the issue in the rationale.

\subsection{Planning an appropriate research design and identifying relevant data sources}

For the purpose of planning a research design it is important to ascertain that it fits the problem. In other words, it is necessary to plan a design that is appropriate in order to gather data that constitutes quality evidence for the question examined. Erickson (2012) refers to it as where to be as a researcher, with whom, and how. For ethnographic studies in education Spindler and Spindler (1992) suggest that observation should be direct, prolonged and in situ. Direct because, besides using recording devices, the researcher should be in the setting where the action is occurring; prolonged and in situ because "the validity of ethnographic observation is based in observation in situ lasting long enough to permit the ethnographer to see things happening not once, but repeatedly." (Spindler \& Spindler, 1992, p. 65, authors' emphasis). The design involves identifying relevant data sources to answer the RQs, to warrant the claims that one would like to be able to make (Erickson, 2012).

Both studies had the purpose of identifying progression in the engagement in scientific practices along time, hence they were designed as longitudinal studies, lasting three school years in Early Childhood Education (ECE) -the full duration of ECE-, and two years in high school.

The ECE study reported in the paper, with 25 children (5-6 years of age) and her teacher, involved participant observation during the 5-months project. Data collection included video recording of 9 sessions (5 hours), field notes and children's drawings $(\mathrm{N}=190)$. Designing a range of data collection was needed to provide evidence of participants' performances, in other words actions and processes, thus for each RQ:

- For RQ1 data about the process of transformation of raw data into evidence: the sources are the pupil's conversations during the nine sessions, and their representations in the 190 drawings. Additionally it was necessary to develop criteria for what is "evidence" at this age.

- For RQ2 data about specific ways of how children gather empirical, or first hand evidence: the sources are the video-recordings and the field notes.

- For RQ3 about how children used evidence to revise and change their ideas: the sources are drawings about the same topic along the project, 
their revisions of the previous drawings, prompted by the teacher, and the recorded classroom discourse.

The genetics study is framed in design-based research (DBR) methods. It involved 20 high school students, who worked in five small groups of four students each, and their two biology teachers. The two teaching sequences were designed through collaboration of the researchers, the teachers and a genetics professor and went through two cycles of design, implementation, revision and further implementation. The two first authors, Puig and Ageitos, were participant observers. The data for the part of the study reported in the paper come from video recording of the eight sessions, field notes, and the artefacts, worksheets and reports produced by the students. Students were asked to build a physical model of gene expression to explain the sickle cell disease, for which they were provided with a kit. Then they were prompted to compare and revise their models and decide which one was better. For both research questions the data sources are: the physical models produced by the students, and their conversations during the construction of their own model and the comparison with those from other groups.

\subsection{Constructing specific analytical tools to analyse learning gains}

A delicate step in the research procedures is the elaboration of specific tools in order to analyse the questions under study, be them learning gains in biology or progression in engagement in scientific practices. For lack of space only analytical tools related to one question of each study are discussed, and we refer to the papers for more details.

In the ECE study, for RQ1, the development of data into evidence, data reduction was proceeding through discourse analysis (Gee, 2005) and the use of the constant comparative method (Glaser \& Strauss, 1967). The codes emerged from the interaction between the literature and data in successive iterations, and the construction of tools is extensively detailed in the paper and cannot be reproduced here. We will focus on how we established two levels and two sets of coding categories in the analysis: first, identifying the 276 argument components in the conversations, and distinguishing between claims (125), evidence (57) and justifications (9). It was necessary to create a new category that we called raw data (85), and defined it as a description unrelated to a claim or question. This is related to the finding that not all raw data develop into evidence. For the purposes of a study in the ECE context, we consider evidence data whose discursive role is to support a claim. The second level of analysis focused only on the 57 evidence statements, with the purpose of identifying levels of epistemic judgment, which would warrant the claims about how data are transformed into evidence. Within these 57 evidence statements two levels were identified, L1 ( $\mathrm{N}=36)$, closer to data, as in "(snails have) heart, brain", which supports the 
claim "they are almost like us"; and L2 (N21), involving evaluative judgments, such as to identify patterns, to connect data to claims, to compare or to evaluate alternatives.

In the genetics study, for RQ2 about the interactions between modelling and argumentation and to what extent do these interactions help students connect the three worlds of knowledge, the material models built by students were considered as external representations, while students' references to the processes of DNA transcription to RNA or RNA translation to proteins are categorized as belonging to the theories and models' world of knowledge. The analytical tool relates each of the modelling and argumentative operations with the connections established between two worlds of knowledge or among the three of them.

\subsection{Presenting results and conclusions grounded in evidence}

If one of the flaws causing rejection of manuscripts or of research proposals is poor methods, we may say that a frequent problem is the lack of coherence across the manuscript among research questions, data sources, reported findings and conclusions. Results and conclusions must be supported in data, grounded in evidence. The steps from data collection to data reduction to identifying patterns in data are complex; they require experience and guidance from experts. We discuss part of the results from only one RQ of each paper.

In the ECE study, results for RQ3, about how children use evidence to revise their understandings were derived, first from a thematic analysis of the 21 conceptual topics about snails emerging in the data; second, from these we identified 8 topics that were recurring through two, three or five sessions, including a) parts and features of a snail's body such as their two pairs of tentacles, their ribbon-like mouthpiece ("radula"), their feet and shell; b) snail's biology, such as what they eat, that they are hermaphrodite and lay eggs, how they are born, the function of slime, or how the shells grow with the snails. Third, from these eight, the question of mouthparts, discussed in five out of the six sessions, was selected to illustrate the process. For, as Spindler and Spindler (1992) point out, it is necessary to see things happening repeatedly. The study documents the revision of children's ideas about snails' mouthparts during the five months, from drawing anthropomorphic "teeth" and "tongue" to several cycles of revision based on three types of evidence, gathered respectively through purposeful observation, for instance of marks in food, experiments, and secondary sources such as watching videos or searching the Internet, resulting in a proposal about the radula's mechanism. The teacher's scaffolding, prompting reflection, thinking back about their observations and revision of previous models was crucial. An original theoretical contribution of the paper is the notion of purposeful observation: one that is prolonged, systematic, with a clear focus, discussed and used to test claims and compare initial ideas with later ones 
In the genetics study, results for RQ2, about the interactions between modelling and argumentation, show for instance how the engagement with producing an expressed model allowed students critique of the material model on the basis both of evidence -the presence of a foam piece representing a (condensed) chromosome, in a cell that was not dividing - and of the relevant theory about DNA configuration at different stages.

Lacking space to address the issue of the discussion section, it is important to recall that findings are descriptive and analytical, while the discussion is evaluative and interpretative.

\section{Concluding remarks}

The discussion about the research processes of formulating research questions, planning appropriate research design, constructing specific analytical tools and presenting results grounded in evidence is framed in concerns about what counts as valid research in biology education and science education. The analysis of research processes is illustrated through a reflection on the processes involved in two studies about biology topics in different ages and contexts. The reflection on the decisions highlights false starts, as initial research questions that needed revisions; in these two papers involving new questions much more specific, and breaking down themes. It shows that qualitative or mixed methods approaches can yield quality evidence to support claims. For both papers the suggestions of the anonymous referees and editors of the journals, Journal of Research in Science Teaching and Science \& Education, were of great help in sharpening the focus of each paper, directing us towards making data analysis more explicit and, in general, improving the quality of the paper. This points out to the role of referees -sometimes considered by beginning researchers as feared enemies - in supporting the community in publishing quality studies.

We suggest that long-term projects, as the ones reported in the papers, have specific affordances. In particular, for classroom studies about what students do, for instance about practices or processes, are appropriate data about performances of actions and discourse rather than responses to questionnaires. This would enable, as Kelly \& Green (2019) point out, bringing to light how different dimensions of the construction of science are accomplished.

\section{Acknowledgements}

Work supported by the Spanish Ministerio de Economía y Competitividad (MINECO), contract grant number: EDU2015-66643-C2-2-P. Thanks to the colleagues and co-authors of the studies, Blanca Puig, Sabela F. Monteira and Noa Ageitos. 


\section{References}

Creswell, J. W. (2014). Research design: Qualitative, quantitative and mixed methods approaches. Thousand Oaks, CA: Sage [1st Edition, 2003].

Creswell, J. W., \& Plano Clark, V.L. (2010). Designing and conducting mixed methods research. Thousand Oaks, CA: Sage.

Erickson, F. (2012). Qualitative research methods for science education. In B. Fraser, K. Tobin \& C. McRobbie (Eds.) Second international handbook for Science Education. Volume 2 (pp. 1451-1469). Dordrecht: Springer.

Gee, J. P. (2005). An introduction to discourse analysis: Theory and methods. London: Routledge.

Glaser, B. G., \& Strauss, A. L. (1967). The discovery of grounded theory: strategies for qualitative research. London: Weidenfeld and Nicholson.

Heap, J. L. (1995). The status of claims in "qualitative" educational research. Curriculum Inquiry, 25(3), 271-292.

Jiménez-Aleixandre, M. P. (2019). Foreword: Meeting methodological challenges. In G. J. Kelly \& J. Green (Eds.) Theory and methods for sociocultural research in science and engineering education (pp. xiv-xviii). New York: Routledge.

Kelly, G. J. \& Green, J. (2019). Framing issues of theory and methods for the study of science and engineering education. In G. J. Kelly \& J. Green (Eds.) Theory and methods for sociocultural research in science and engineering education (pp. 1-28). New York: Routledge.

Mitchell, J. (1984). Typicality and the case study. In R. F. Ellen (Ed.) Ethnographic research: A guide to general conduct. (pp. 238-241). Orlando, FL: Academic Press.

Monteira, S. F., \& Jiménez-Aleixandre, M. P. (2016). The practice of using evidence in kindergarten: The role of purposeful observation. Journal of Research in Science Teaching, 53(8), 1232-1258. DOI10.1002/tea.21259.

Puig, B., Ageitos, N. \& Jiménez-Aleixandre, M. P. (2017). Learning gene expression through modelling and argumentation: A case study exploring connections between the worlds of knowledge. Science \& Education. 26(10), 1193 - 1122.

Spindler, G., \& Spindler, L. (1992). Cultural process and ethnography: An anthropological perspective. In LeCompte, M.D., Millroy, W.L. \& Preissle, J. (Eds) The Handbook of Qualitative Research in Education (pp. 53-92). San Diego: Academic Press.

Tiberghien, A. (2000). Designing teaching situations in secondary school in R. Millar, J. Leach \& J. Osborne (Eds.) Improving science education: The contribution of research (pp. 27-47). Buckingham, PA. Open University Press. 

SECTION 1

RESEARCH METHODS 



\title{
CURRICULUM NARROWING IN UNIVERSITY ENTRANCE ASSESSMENT IN BIOLOGY
}

\author{
Francisco Luis Alda*, María José Gil Quílez* \\ and María Jesús Rodríguez Yoldi** \\ * Departamento de Didáctica de las Ciencias Experimentales, \\ Facultad de Educación, Universidad de Zaragoza (Zaragoza-España) \\ ** Departamento de Fisiología Animal, Facultad de Veterinaria, \\ Universidad de Zaragoza (Zaragoza - España) \\ fladab@gmail.com
}

\begin{abstract}
University entrance tests, especially those taken to gain admission onto high-demand degree courses, such as medicine or biotechnology, are a major milestone in students' educational processes. A test design that does not conform to the objectives established in the curriculum leads to undesirable effects on students' educational progress and fails to comply with validity, fairness and justice requirements. Our work has sought to examine whether university entrance assessments in the field of biology have adequately represented the official curriculum. To this end, we have studied curricular alignment (Anderson, 2002)which is used in some educational systems, such as the one in the United States, to review and test high-demand examinations (Webb, 2002). In Spain, however, no significant studies of this type have been conducted to date (Alda, 2016).
\end{abstract}

Keywords: biology, curriculum alignment, curriculum narrowing, assessment, curriculum analysis

\section{Introduction}

Every formal teaching activity attempts to put into practice a project or educational plan that has been designed in advance and is usually called a curriculum.As an educational plan evolves and interacts with reality, the original idea always changes in either a premeditated or unforeseen and potentially undesirable, way. Consequently, different 'versions' or 'representations' of this initial plan exist depending on the stage of the educational process in question. The most widespread name for curriculum representation is the didactic 
triangle'. This model shows us the difference between the intended curriculum (objectives), instruction and assessment (Anderson, 2002).

Assessment is a basic element in the educational process. This activity provides feedback that is essential to check whether the system is working, in other words, whether students are really learning what we are trying to teach, our intended curriculum. This means assessment is the only tool we have to discover whether educational goals have been achieved. Since assessment is no easy task, however, it is unfortunately usually only an indirect and partial indicator of a student's learning. It is indirect because it is impossible to obtain real proof of the knowledge students possess-we must restrict ourselves to mediated information provided by assessment instruments - and it is partial because no instrument can cover a student's entire educational experience.

The relationship between elements in the curriculum triangle is broadly called curricular alignment. In a more restricted sense, this term is used to name the necessary correspondence between the assessed curriculum and the intended curriculum (Anderson, 2002). Coherence between curriculum representations is a typical characteristic of functional educational systems. It can serve as a control variable since it is useful as a feedback tool to help adjust system operation(La Marca, Redfield, \& Winter, 2000). The relationship between the intended and the assessed curriculum is primarily important when the system uses high-stakes assessment tests as a basic element in the decision-making process, especially if these tests can affect learners' futures(Nitko, 1994).

In some countries, for example the United States, this concern has led to analysing the alignment between national examinations and official curricula. The results are considered by reviewing the test (accountability) and in the further design of new assessment tests (Webb, 2002).In Spain, the typical example of a high-stakes test is the university entrance exam. Initially a maturity test, it has now become a high-stakes test due to increased interestin gaining a place on some courses, especially in biology or the healthcare area.As a result, it is currently considered a highly selective test (Muñoz Vitoria, 1993). This role has been reinforced in recent years, when legal regulations have lent more weight to the exam mark in the admission decision. This work is part of broader research on the biology curriculum in Spain. Here, we have tried to analyse the relationship between the intended curriculum (Gobierno de Aragón, 2008) and the curriculum assessed by the biology entrance test at the University of Zaragoza(Universidad de Zaragoza, 2014). With this goal in mind, we have adapted the available methodology to verify whether the intended curriculum has been assessed properly. We also aim to confirm that the depth and structure of knowledge gleaned from the tests are congruent with those in the curriculum. The study period ranged from 2010 to September 2013.

The main goal of our research is to help discover whether university entrance exams meet suitable validity, fairness and justice requirements. 
University entrance tests are expected to reflect the intended curriculum. If this is not the case, then we are harming students and we fail to achieve the education system's objectives. The second goal of our work is to adapt methodologies developed in the USA and Canada to study the Spanish curriculum or, if possible, to generalise the analysis of curricula from several countries with the aim of using a common method to compare and understand curricula.

\section{Theoretical framework}

Alignment studies basically consist of comparing test activities with the intended objectives in the official curriculum. This comparison includes aspects that are the various dimensions of curricular alignment. Some methodologies were developed to conduct the analysis. The methods most used are the ones proposed by Webb (Webb 1997, 1999, 2002; Webb, Herman \& Webb, 2007), the survey method of the Education Consortium developed by Porter (Porter \& Smithson, 2001)and, to a lesser extent, the methodology used by Achieve, based on the work by Rothman et al.(Rothman, Slattery, Vranek \& Resnick, 2002).

Few studies have focused on curriculum alignment in Spain. We have found only two covering this issue. The first was performed by Muñoz-Repisoet al. (1997); these authors studied the content coverage of entrance tests in 1995. The second was conducted by Rebollo and Nieda (2005); they analysed entrance exams for Earth Science in Madrid. Llopis (cited in Muñoz-Repiso et al., 1997) also analysed entrance exams, and concluded that the contents of the official curriculum are not sufficiently represented in them. Our conclusion is that curricular alignment is an unexplored field of research in Spain. We hope our work will inspire these types of studies, whose pedagogical interest can be quite high.For curricular alignment studies, the Webb methodology (1999) uses a group of curriculum experts to analyse the documents that include educational objectives and standards. If the experts' opinions differ, the mean value is used to minimise the measurement error. The curricula analysed using this methodology have a hierarchical structure: each curriculum has a set of first level 'expectations' called standards that are subdivided into objectives. The set of objectives is assumed to cover all a standards'contents and capabilities. This structure is very different from the Spanish curriculum.

The analysis process starts when the evaluators assign a depth of knowledge level to each objective. This level indicates the greatest cognitive complexity needed to reach the intended objective. The result of this assessment is collected in a matrix whose rows represent the objectives (standards and objectives) and columns the items or activities in the evaluation test. Each matrix cell is occupied by one or several levels of cognitive demand when the evaluators consider that a certain item allows the student's performance to be measured in a certain objective. Each square occupied by the matrix is a hit.Each evaluator 
completes their own matrix and the results are shared. The evaluators can change their decisions after interacting with each other. The matrices are analysed with a spreadsheet to calculate the values for the four alignment dimensions:

- The categorical concurrence between assessment and curriculum provides a very general indication of alignment if both documents incorporate the same content. Estimates use the mean number of hits.

- The depth of knowledge consistency measures the complexity of knowledge required by each element. It is calculated using the frequency of aggregated hits per objective into each standard. This value is estimated by considering the proportion of hits that have a lower cognitive demand, equal to or higher than that expected for the corresponding standard. The reference values for the depth of knowledge consistency are the levels used by Bloom's taxonomy.

- The range-of-knowledge correspondence estimates whether the breadth of knowledge required on standards and assessments is comparable.

- Balance of representation is used to indicate the degree to which one objective is given more emphasis on the assessment than another. This criterion is calculated using a formula that considers the difference in the proportion of the standard represented by each objective and the proportion of hits assigned to the objective.

Porter and Smithson (2001) developed the survey method used by the Education Consortium to analyse the alignment between assessment and curriculum. In this case, the first step is coding the curriculum, assessments and teaching activities. The coding process uses a matrix defined by Porter as 'a bidimensional language to describe the curriculum'. The matrix columns represent the curriculum contents, whereas the rows include the cognitive demand established using Bloom's taxonomy (Anderson, Krathwohl, \& Bloom, 2001) as a reference.

Matrix cells are a measure of the emphasis of each coincidence (Figure 1). In the case of the assessment, values are calculated from the score assigned in the tests, and in the case of the curriculum, by estimating the time spent on each item. The resultant matrix is normalised by dividing the value of each cell by the sum of all the cells. Different matrices can be compared this way. The result can be graphically represented as a 'topographical profile' of the curriculum. The graphical representation provides a visual characterisation and a rapid method of comparison between several curricula (Figure 1). The marginal sum of columns in a matrix also provides a measure of the content coverage, and the marginal sum of rows estimate the depth of knowledge for the curriculum. Figure 1 shows the information that we can obtain from this method.

The data obtained up to this point describe the various curriculum versions, but they do not provide information on the degree of alignment between them. 


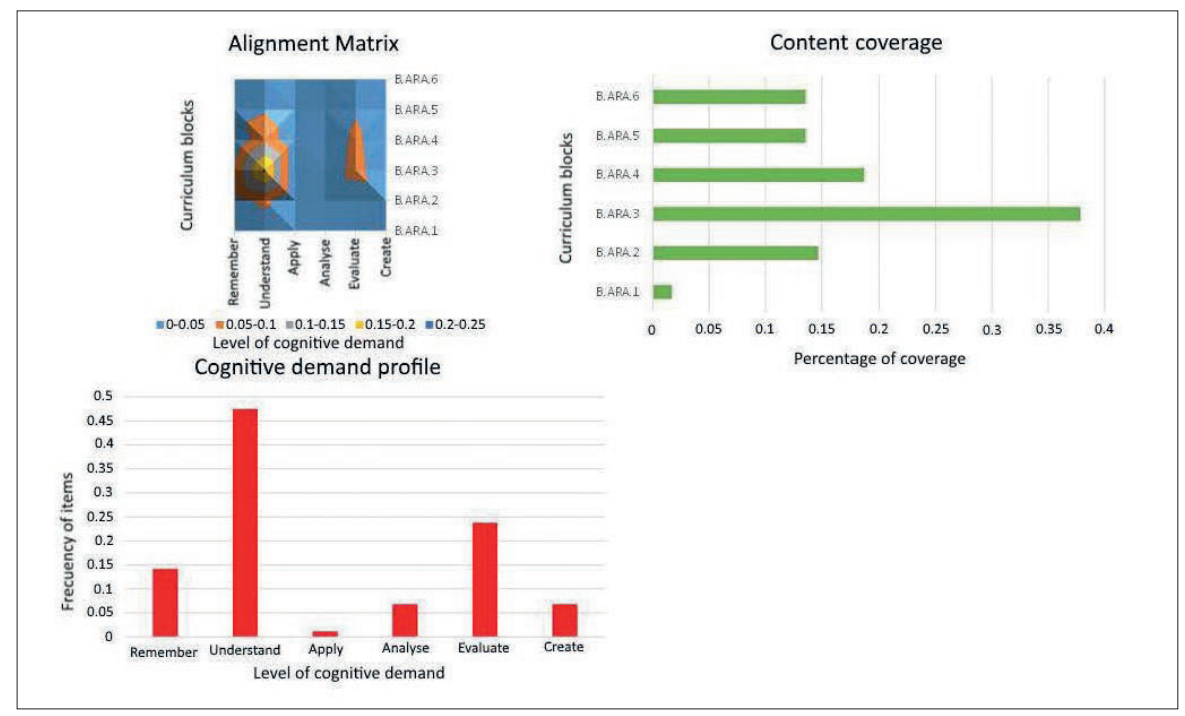

Figure 1 Alignment matrix and its marginal distributions obtained using the Porter's method. At the top left is the "topographic map" of the curriculum, which allows observing the relationship between the contents and the cognitive demand, while the vertical dimension corresponds to the emphasis. On the right, the degree of coverage, obtained from the marginal distribution that represents the sum within each block. On the bottom, the cognitive demand, deduced from the other marginal distribution.

To estimate the evaluation, Porter (2006) proposes calculatinga correlation index among the curricular matrices, using the following formula:

$$
\text { Alignment }=1-\Sigma|x-y|^{2}
$$

Where ' $x$ ' is the value of each cell in the first matrix and ' $y$ ' is the value of the corresponding cell in the second. This index varies between 0 and 1 . A zero value implies that the curricula are not related, whereas the value of one means that both curricula are identical and their elements are assessed with the same emphasis. This index can be used to compare both representations for a given curriculum or for several curricula if their contents are related. In fact, Neidorfet al. (2006)applied this method to compare American assessments (NAEP) and international assessment such as TIMSS or PISA.

\section{Method}

We considered that no previous methodology could be directly applied to the Spanish curriculum for two basic reasons: the differences in curriculum structure and the impossibility of finding an expert group to analyse the curriculum. For this reason, we decided to adapt both methods to our curricular framework. This adaptation should include some basic aspects: 
- Selecting alignment dimensions to consider

- Determining critical values on the basis of which the alignment can be considered meaningful. We need to establish these values for both individual tests and the whole set of analysed tests.

- Developing a procedure to assign the assessed items to the curricular categories (assessment criteria) without using an expert panel.

\subsection{Selection of alignment dimensions}

The elements of the Spanish curriculum (goals, assessment criteria, assessment standards) are quite different from those of the US curriculum. This poses a problem when trying to adapt the methodologies used by Webb or Porter directly to study their curricula. An initial analysis also showed a possible difference between two of those elements: goals and assessment criteria. Consequently, we decided to observe carefully the dimensions usually considered to measure the alignment, previously indicated above in the theoretical framework.Three areas enclose the alignment dimensions: content scope, cognitive demand and the emphasis on the curriculum parts. Content scope and emphasis are not problematic because we can study them in any curriculum element. However, cognitive demand needs the curricular element to use a verb to define it. This requirement is not met for contents that are defined as clauses without a verb. Consequently, it is impossible to estimate their cognitive demand.

Following Porter's observation (Porter, 2006) about the 'bi-dimensional languages' used to describe the curriculum, we considered that a code system could be produced to describe the biology curriculum. Assessment criteria propose a specific cognitive demand and can be related to one or some contents they assess. As a result, we can develop a 'curricular matrix' whose dimensions are the contents and the cognitive demand. The frequency of the coincidences allows us to measure the emphasis that the official curriculum gives to each curricular element. It is now possible to estimate the cognitive demand for this matrix.

\subsection{Alignment method}

The cognitive demand was measured using Bloom's Taxonomy (Anderson, Krathwohl, \& Bloom, 2001), which has been broadly employed in this area. There is a second dimension in this taxonomy called the knowledge structure. This category has been considered to estimate one of the dimensions proposed by Webb (1997), but not measured in his works: the knowledge structure. As this dimension describes the types of knowledge present in the curriculum characterising the subject, we have incorporated it into our research. 
We adaptedtwo curricular alignmentanalysis methods to the Spanish curriculum to conduct our study: the method proposed by Webb (Webb, 1997; Webb, Herman \& Webb, 2007), and the method developed by Porter for the Survey of Enacted Curriculum (Porter \& Smithson, 2001; Porter, 2002; Porter, 2006). We studied the following dimensions in our research:

- Content scope: measures the presence of curriculum test elements and their proper distribution using two indicators:

- Content coverage: applied to general objectives and content blocks, it determines the proportion that has been evaluated based on the evidence we considered.

- Balance of representation: seeks to establish whether the appearance frequency of objectives or contents in the assessment is asexpected according to the official curriculum.

- Cognitive demand: compares the depth of knowledge gained from the official curriculum with the knowledge gained from the proposed assessment tests. The assessment tests have been compared with the general objectives and the assessment criteria, given that the cognitive demands of both elements may differ.

- Knowledge structure: compares the knowledge dimensions characterising the official curriculum that are evaluated in different tests.

- Porter's alignment index (op. cit.): estimates the correlation between the curricular grids of assessment tests and the official curriculum grids. This value summarises the above-mentioned dimensionstaking into account the emphasis that assessment lays on element, and compares it with the emphasis gained from studying the curriculum.

\section{Results}

Our work shows significant differences between the evaluated and intended curriculum in most of the analysed dimensions. The content coverage analysis shows (Figure 2) that only half of the curriculum objectives have been evaluated during the analysed period.

Figure 2 shows the coverage of the content in the examinations analyzed. The horizontal blue line indicates the proportion of each objective in the curriculum, while each vertical line indicates the proportion of those same objectives in each of the examinations studied, represented in different colours. If the bars are below the blue line, the targets are underrepresented. If the bars are located above that line, the targets are overrepresented. Consequently, the tests have focused on core subject content (biochemistry, cell biology, genetics, immunology), but left out the dimensions that constitute scientific competence, as understood in the International PISA report (OECD, 2013)or in the Rocard report(European Union, 2007). The assessment criteria that have been assessed 


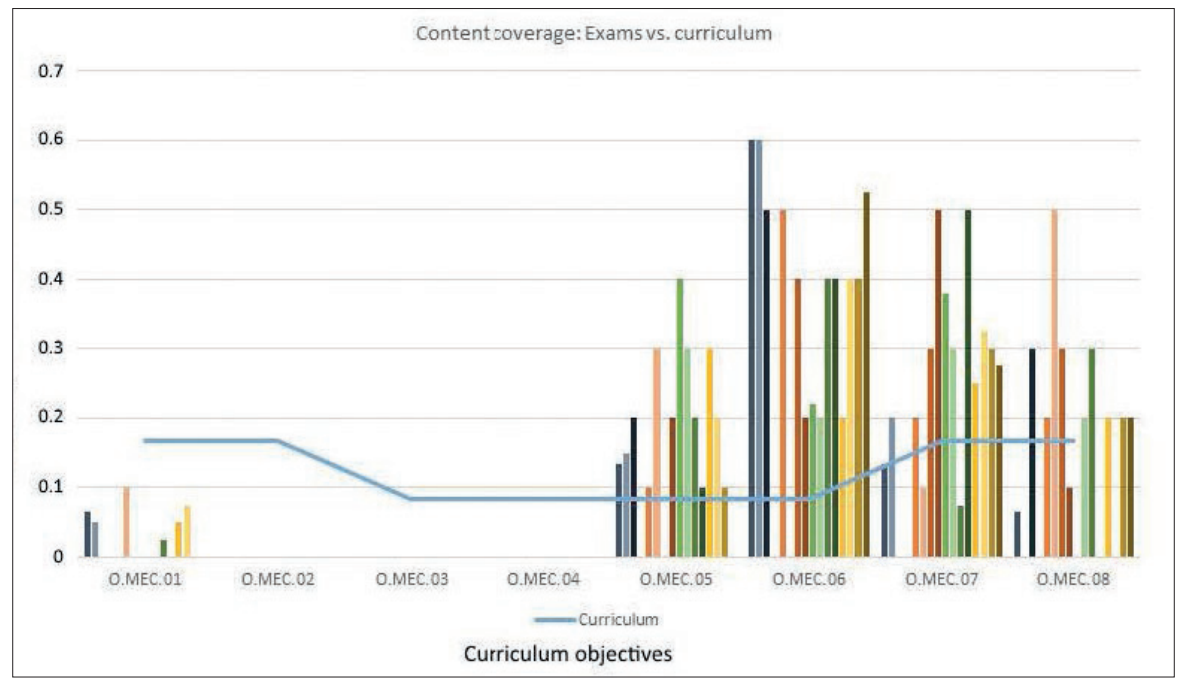

Figure 2 Relative emphasis on test objectives compared with curriculum objectives.

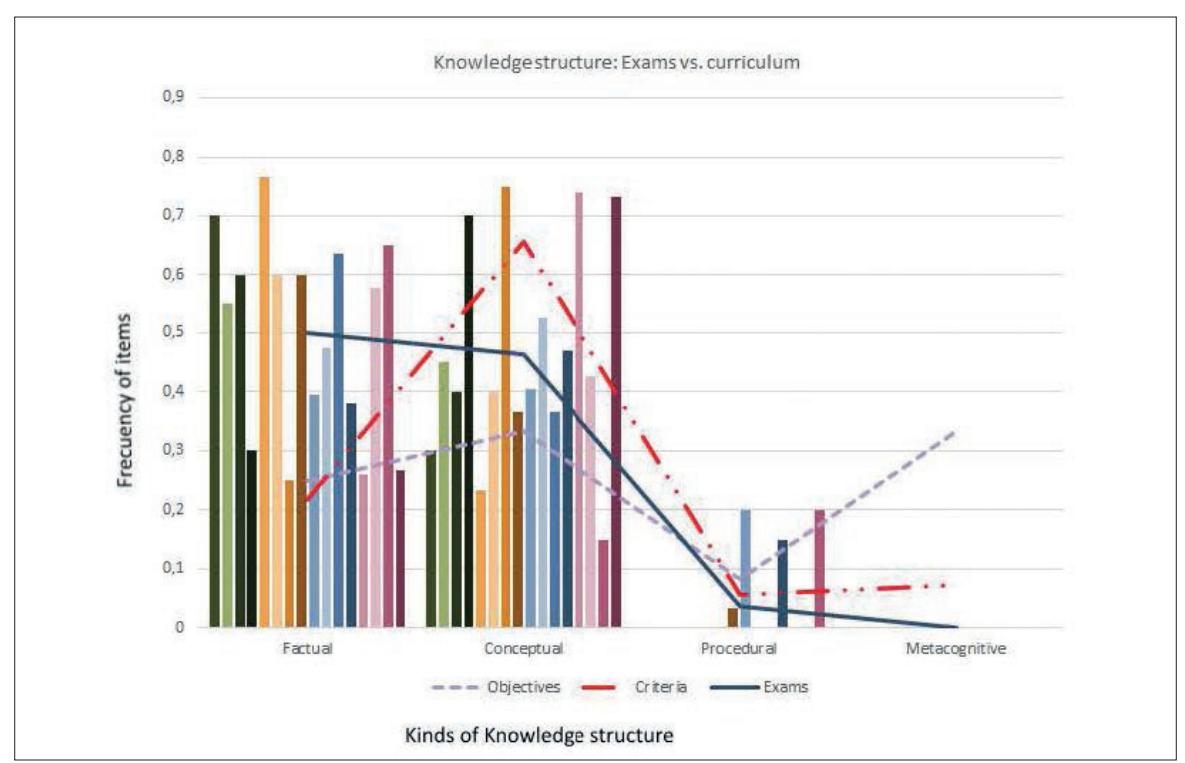

Figure 3 Comparison between the structure of knowledge tests and curriculum elements.

more frequently than expected relate to the fundamental concepts of matter (the structure and function of macromolecules and immune mechanisms); metacognitive criteria (nature of biology as a science) and the relationship between biology and society have been omitted. 
The cognitive demand of the tests is lower than the level established in the curriculum's objectives and assessmentcriteria. Most of the assessment items require students to recall information or, to a lesser extent, understand concepts, while application activities occur less frequently and no assessment activities have been posed.

The analysis of the knowledge structureshows that the assessment tests almost exclusively cover factual and conceptualcontents (Figure 3), with a low proportion of items on procedural knowledge, specifically solving Mendelian genetics problems, and none on metacognitive knowledge.

\section{Discussion}

By using the curricular alignment method, we have seen that biology evaluated in university entrance tests is a limited and impoverished version of the curriculum that should beimplemented in schools. We have identified a curriculum narrowing that affects the scope of the contents, but also the nature and depth of the curriculum and that completely omits social dimensions and science metacognitive aspects. It is likely that this impoverishment also affects students' learning, due to the 'washback effect'described below (Alderson \& Wall, 1993). Since the scope of our study is limited, no conclusions can be extrapolated beyond it. What we have observed is that a university entrance test does not fit the curriculum it supposedly evaluates. In our opinion, this can have negative effects on students: the results of the assessment could be misleading (Pellegrino, 2006), or even unfair (Nitko, 1994), which could reduce students' motivation (Nitko, 1994).The analysed tests focused especially oncell biology topics, which have been overassessed. Meanwhile, microbiology has almost been forgotten. In fact, the only topic from this block assessed during our study period was the lytic cycle of viruses.Furthermore, the contents related to a global view of biology; its historical referents and its relationships with society were not assessed in any test. This omission is quite remarkable considering the curriculum establishes the goal of making this relationship explicit (Gobierno de Aragón, 2008).

The results of our work show a clear phenomenon of curriculum narrowing. This problem restricts students' learning (Clarke, 1997; Pellegrino, 2006). Curriculum narrowing is a serious issue. When it affects content coverage, it implies that some basic aspects of biology are excluded from the learning process so that students can focus on the assessed contents. This situation is called a 'washback effect'(Alderson \& Wall, 1993). In Spain, the washback effect has been cited as a real situation in some cases (Contreras de la Fuente, Ordóñez Cañada, \& Wilhelmi, 2010). These authors describe the process as a 'sliding' of educational objectives.However, the problem of curriculum narrowing is ever greater when it affects the cognitive dimension of learning. A greater emphasis 
on remembering and understanding reduces the ability to apply the newly acquired knowledge, i.e. to develop 'scientific literacy' or 'scientific competency' that is the goal of a pre-university subject.

Our results show that the evaluated biology curriculum basically covers conceptual aspects. This situation coincides with the majority opinion of the teachers, who, in a study of the purposes of scientific education, mostly state that the Baccalaureate should prioritise the conceptual orientation of the teaching of sciences (Banet Hernández, 2010). However, the same study makes it clear that addressing dimensions related to preparing them as future student scientists is also essential.These dimensions include strategies for solving problems, knowledge of relationships between science, technology and society and understanding the nature of science. All these aspects are absent in the tests we analysed.Furthermore, as the tests focus on factual and conceptual issues, their value for assessing competencies is very limited because this kind of evaluation needs to prove that the student has procedural and metacognitive knowledge.High-cognitive-demand objectives or criteria (apply, create) can prove difficult, but are possible using open-ended or critical thinking questions or by asking students to design research processes. These types of assessment activities are real and have been used in university entrance tests in Catalonia (Generalitat de Catalunya, 2008).

Without data, we cannot confirm that curricular misalignment is a common situation in university entrance tests in Spain; however, a prospective, rough and non-systematic review of several entrance exams leads us to believe that it is quite frequent. Our research needs to be broadened to cover other universities and subjects to discover the extent of the problem. The main conclusion of our work is probably considering that curricular alignment can be used as a tool to identify weakness in the design of high-stakes assessment tests. In fact, in some advanced educational systems, such as the US system, curricular alignment is used as a tool for accountability.Assuming that highly demanding evaluation processes should be subject to a rigid control that guarantees their adequacy is logical. Consequently,besides the classic requirements of reliability and validity, evaluations, especially those certifying students' suitability for an academic degree or for continuing their studies at a higher level, should measure target objectives. This is the purpose of curricular alignment.

One of the possible future lines of research opened by this study is researching the effects that misalignment can have on classrooms. Faced with a test as demanding as university entrance, the activities actually taught and learned in the classroom (the implemented curriculum) most likely tend to adjust to evaluation demands and not, as expected, to the official curriculum;this situation would have negative impacts on student learning. We think the method we have adapted allows us to analyse any curriculum since all of them have some elements characterised by its content and cognitive demand. In addition, by 
analysing the subjectivity of a group of well-trained independent experts, it becomes easier to analyse and compare several curricular frameworks, which opens up interesting possibilities in comparative education. We also believe that curricular alignment studies can provide services of interest to educational research. For example, analysing the vertical dimension of the alignment, which has hardly been studied so far, could be a good tool for improving curricular designs, helping to detect and correct both redundancies and gaps or discontinuities in the curricula of every subject.

\section{Acknowledgements}

This research was partially supported by the Aragon Government (Grupo de Investigación Beagle S27_17R) and FEDER 2014 - 2020. We thank our colleagues from this group who also provided insight and expertise that greatly assisted the research.

\section{References}

Alda, F. L. (2016). La Biología en Enseñanzas Medias y primer curso de la Universidad: análisis de los curriculos oficiales mediante ontologias semánticas (Ph D dissertation). Zaragoza: Universidad de Zaragoza.

Alderson, J. C., \& Wall, D. (1993). Does washback exist? Applied linguistics, 14(2), 115-129. Anderson, L. W. (2002). Curricular alignment: A re-examination. Theory into Practice, 41(4), 255-260.

Anderson, L. W., Krathwohl, D. R., \& Bloom, B. S. (2001). A taxonomy for learning, teaching, and assessing: A revision of Bloom's taxonomy of educational objectives. Allyn $\&$ Bacon.

Banet Hernández, E. (2010). Banet Hernández, E. (2010). Finalidades de la educación científica en educación secundaria: aportaciones de la investigación educativa y opinión de los profesores. Enseñanza de las Ciencias, 28(2), 199-214.

Clarke, D. (1997). International handbook of mathematics education. En A. J. Bishop, M. K. Clements, C. Keitel, J. Kilpatrick, \& C. Laborde (Edits.). Springer.

Contreras de la Fuente, Á., Ordóńez Cañada, L., \& Wilhelmi, M. R. (2010). Influencia de las Pruebas de Acceso a la Universidad en la enseńanza de la integral definida en el bachillerato. Enseñanza de las Ciencias, 28(3), 367-384.

European Union. (2007). Science education now: A renewed pedagogy for the future of Europe. Office for Official Publications of the European Communities.

Generalitat de Catalunya. (julio de 2008). DECRETO 142/2008, de 15 de julio, por el que se establece la ordenación de las enseñanzas del bachillerato. DECRETO 142/2008, de 15 de julio, por el que se establece la ordenación de las enseñanzas del bachillerato.

Gobierno de Aragón. (julio de 2008). ORDEN de 1 de julio de 2008, del Departamento de Educación, Cultura y Deporte, por la que se aprueba el currículo del Bachi- 
llerato y se autoriza su aplicación en los centros docentes de la Comunidad autónoma de Aragón. B.O.A.

La Marca, P. M., Redfield, D., \& Winter, P. C. (2000). State Standards and State Assessment Systems: A Guide to Alignment. Series on Standards and Assessments. ERIC.

Muñoz-Repiso, M., Murillo, F., Arrimadas, I., Navarro, R., Díaz-Caneja, P., Martín, A., ... Fernández, E. (1997). El sistema de acceso a la universidad en España: tres estudios para aclarar el debate. Madrid: Ministerio de Educación.

Neidorf, T. S., Binkley, M., Gattis, K., \& Nohara, D. (2006). Comparing Mathematics Content in the National Assessment of Educational Progress (NAEP), Trends in International Mathematics and Science Study (TIMSS), and Program for International Student Assessment (PISA) 2003 Assessments. Technical Report. NCES 2006-029. National Center for Education Statistics.

Nitko, A. (1994). A model for developing curriculum-driven criterion-referenced and norm-referenced national examinations for certification and selection of students. Ponencia presentada en la Conferencia Internacional sobre Evaluación y Medición Educativas, de la Asociación para el Estudio de la Evaluación Educativa en Sudáfrica (ASSESA).

OECD. (marzo de 2013). PISA 2015. Draft Science Framework. PISA 2015. Draft Science Framework. Obtenido de http://www.oecd.org/pisa/pisaproducts/ Draft\%20PISA\%202015\%20Science\%20Framework\%20.pdf

Pellegrino, J. W. (2006). Rethinking and redesigning curriculum, instruction and assessment: What contemporary research and theory suggests. Retrieved Jan, 5, 2009.

Porter, A. C. (2002). Measuring the content of instruction: Uses in research and practice. Educational Researcher, 31(7), 3-14.

Porter, A. C. (2006). Curriculum assessment. Handbook of complementary methods in education research, 141-159.

Porter, A. C., \& Smithson, J. L. (2001). Defining, developing, and using curriculum indicators. Philadelphia, PA: University of Pennsylvania, Consortium for Policy Research in Education.

Rebollo Ferreiro, L. F., \& Nieda Oterino, J. (2005). Las pruebas de acceso a la universidad en la asignatura de Ciencias de la Tierra y del Medio Ambiente en la Comunidad de Madrid: análisis de las pruebas y evaluación de los resultados de los alumnos y su incidencia en la mejora de la práctica docente y el aprendizaje. Pulso(28), 25 -54 .

Rothman, R., Slattery, J. B., Vranek, J. L., \& Resnick, L. B. (2002). Benchmarking and alignment of standards and testing. Center for the Study of Evaluation, National Center for Research on Evaluation, Standards, and Student Testing, Graduate School of Education I\& Information Studies, University of California, Los Angeles. Universidad de Zaragoza. (20 de julio de 2014). Universidad de Zaragoza. Obtenido de Admisión a estudios de grado: http://wzar.unizar.es/servicios/acceso/admisgrado/ solici/donde.html

Webb, N. L. (1997). Criteria for alignment of expectations and assessments in mathematics and science education (Vol. 12 2). Madison: National Institute for Science Education. 
Webb, N. L. (2002). An analysis of the alignment between mathematics standards and assessments for three states. annual meeting of the American Educational Research Association, New Orleans, LA.

Webb, N. M., Herman, J. L., \& Webb, N. L. (2007). Alignment of mathematics statelevel standards and assessments: The role of reviewer agreement. Educational Measurement: Issues and Practice, 17-29. 



$$
\begin{gathered}
\text { SECTION } 2 \\
\text { STUDENTS' CONCEPTIONS }
\end{gathered}
$$





\title{
USING PROBLEMATIZED CONTEXTS TO INTRODUCE THE IDEA OF CLASSIFICATION CRITERIA IN TAXONOMY. CONTEXT-TRANSFERENCE AND RESISTANT IDEAS
}

\author{
Jordi Domènech-Casal \\ Departament de Didàctica de les Matemàtiques i les Ciències Experimentals, Universitat \\ Autònoma de Barcelona (Barcelona-España). \\ jdomen44@xtec.cat
}

\begin{abstract}
Taxonomy learning presents difficulties for students. Use of context, context-transference and situating taxonomy in problems has been proposed as a way to overcome these difficulties. We have developed, applied and tested a learning sequence promoting students to develop classification skills and transfer it to a living things context. Our results show that students present difficulties in transferring these abilities to the classification living things and that previous resistant ideas are interfering with their classification skills.
\end{abstract}

Keywords: Context, Taxonomy, Classification, Inquiry

\section{Introduction}

Situating learning in contexts is considered by several authors as a way to construct learning activities with deep understanding of key concepts and the development of competences (Hodson, 1994). Learning processes would be overcome when students are able to transfer their learning to new contexts (Gilbert, Bulte \& Pilot, 2011). It is complex to define "context", but several authors (Duranti \& Goodwin, 1992; Gilbert, 2006) consider that a context would include: a) a social, temporal and spatial scenario where events and ideas interact; b) a conductual frame; c) a specific language or code; and d) a link with the knowledge external to the context.

The presence of conflicts or problems to solve in context-situated learning promotes the exposure and correction of alternative concepts of students. In this 
sense, several authors consider that active methodologies, such as Inquiry-Based Science Education or Model-Based Inquiry can be of interest as learning strategies (Hodson, 1994, Llewellyn, 2005, Bybee, 2006, Windschitl, Thompson \& Braaten, 2008).

Taxonomy teaching is often seen as a "memory game" based on remembering strange names and their localization in a static classification tree. This representation of taxonomy fits badly with real science, for two reasons (Domènech-Casal, Espasa, \& Mestres, 2018):

1. taxonomy knowledge is based in scientific thinking skills as establishing classification criteria, connecting it to classification trees and classifying items in a given classification tree;

2. taxonomy is not static, but the result of successive steps of construction of a model along a timescale that is still in progress.

The first classification from Linné into two kingdoms (animals and plants) was further developed to five kingdoms from observable morphological and physiological characters: Bacteria, Protozoa, Fungi, Animals and Plants (Whittaker, 1969). This classification was further confirmed by phylogenetic data (Margulis \& Schwartz, 1985) and is the usual taxonomic frame proposed to students in textbooks. However, molecular phylogenetic rRNA analysis shows that living things should be classified into three domains (Bacteria, Archaea and Eucarya) (Woese, Kandler \& Wheelis, 1990), and that the current biological diversity is much more complex than expected. Symbiogenetic events (fusion or transmission of genome portions), may be at the origin of current Eucarya (Eukaryota), due to the fusion of a Eubacteria and an Archeobacteria, and Plants due to the result of the genomic fusion of a Protoctista and a Cyanobacteria. This leads to a complex net of genetic origins that makes it difficult to establish stable taxonomic groups even with phylogenetic approaches (Margulis and Sagan, 2003). Moreover, some taxonomic criteria refer to genetic or embriological elements (Ruiz-Trillo, Roger, Burger, Gray \& Lang, 2008), which are difficult to understand or manage by young students. As a result, developing inquiry or practical focus on taxonomy learning gets into conflict with the scientific criteria used in canonical taxonomies (Case, 2008).

When learning about taxonomy, students usually present difficulties in selecting and using appropriate classification criteria. Students often use "habitat" or "locomotion" criteria not suitable for taxonomy, classifying living things into terrestrial, aquatic or flying groups of living things (Kattman, 2001, Del Pozo \& Martín, 2012). Some authors consider that such difficulties could be due to the fact that classroom activities are in some cases oriented to the classification of living things with canonical criteria, rather than the classification criteria themselves (Trowbridge \& Mintzes, 1988, Rodríguez, de Las Heras, Romero \& Cañal, 2014), and to memorization approaches focused on taxonomic groups rather than the understanding of underlying criteria (De 
Manuel \& Grau, 1996, Galán \& Martín, 2013, Bermúdez, De Longhi, Díaz \& Catalán, 2014). Some authors consider that a good teaching strategy would be to use non-biological contexts - considering "contexts" as different topics not related to biological taxonomy- to develop classification abilities (Adey, Shayer \& Yates, 1989, Barker \& Philip, 2013). We consider that it might be of interest to study, if problematized activities were developed and classification abilities were transferred from non-biological to biological contexts.

\section{Objectives}

Our objective in this research is to apply and test the use of problematized contexts to teach taxonomy. In particular, we aim:

- To test the use of non-biological contexts to develop classification abilities.

- To test students' capabilities to transfer classification abilities to biological contexts.

\section{Methodology}

We have applied a taxonomy-learning activity with 98, 11 year-old students. In the first phase, students were given a set of 15 nails of different shapes and sizes and taught to:

1. Choose classification criteria relevant for the items.

2. Construct a classification tree derived from the classification criteria.

3. Classify new items in the classification tree.

In the second phase, students were given a set of 8 geometric figures of different shapes, sizes and colours and taught to transfer the same procedures to this new context.

Only 49 students (Near Transference) advanced to the third phase, where students were given a set of 15 figures of different living things and taught to transfer the same procedures to this new context. The rest of the students (Far Transference) worked only with contexts of nails and geometric figures.

At the end of the sequence, we gave all students of both groups (Far Transference and Near Transference) a test to measure their abilities to apply these 3 classification procedures to a new set of living things figures. They measured it at three levels, each associated with a numerical value in order to get mean values to compare between groups: 0 (failed), 5 (low performance), and 10 (high performance). For half (24) of students from the Near Transference group, the test was given with a delay of 6 weeks, to test the strength of the learned abilities (Delayed-Near-Transference). The mean was calculated for each of these groups and normalized to the academic level of the students, in order to compare differences between groups. 
At the end of the process, Near-Transference group students were asked to construct a general classification tree of a new set of 40 living things from different kingdoms. The resulting classifications were analysed to identify misconceptions.

\section{Results}

When comparing students' classification abilities (Figure 1), NearTransference group results were higher in all procedures. However, these abilities dropped to levels similar to Far-Transference when measured after a time delay from teaching to testing. This was observed in all 3 classification procedures, with a particular exception: students get better results in classifying living things when they have not been taught in a living things context rather than after a time of having been taught with living things.

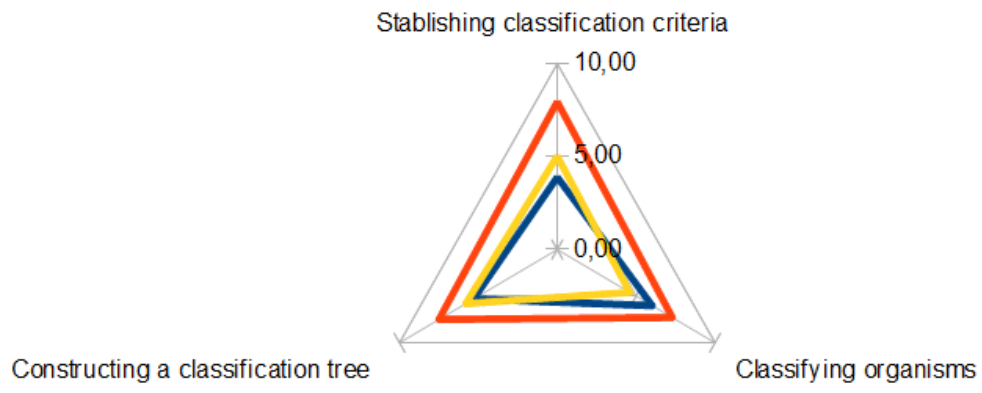

- Far- Transference

- Near-Transference

Delayed-Near-Transference

\begin{tabular}{lccc}
\hline & Far-Transference & Near-Transference & $\begin{array}{c}\text { Delayed- } \\
\text { Near-Transference }\end{array}$ \\
\hline Establishing classification criteria & 3.9 & 7.9 & 5.0 \\
Constructing a classification tree & 5.3 & 7.5 & 5.8 \\
Classifying organisms & 6.0 & 7.3 & 4.6 \\
\hline
\end{tabular}

Figure 1 Comparison of the mean level (measured from 0 to 10) in classification abilities of the different groups.

When students' final general classification trees of living things were analysed, some taxonomy misconceptions were detected mainly in those parts of the classification tree related to animal vertebrate/invertebrate phyla (Table 1). When working with nails and geometric figures or other phyla such misconceptions were not observed. 
TABLE 1

MAIN MISCONCEPTIONS DETECTED IN CLASSIFICATION TREES CONSTRUCTED BY 49 STUDENTS FROM THE NEAR-TRANSFERENCE GROUP

\begin{tabular}{lc}
\hline $\begin{array}{l}\text { Using a taxonomic group's name as classification criteria: "It is a bird / It is not a } \\
\text { bird". }\end{array}$ & $\begin{array}{l}83.7 \% \\
(41 / 49)\end{array}$ \\
\hline Using locomotion/habitat criteria: "It is terrestrial / aquatic". & $24.5 \%$ \\
& $(12 / 49)$ \\
\hline Using teleological / evolutionary criteria "It has not yet bones / It has not yet dif- & $\begin{array}{l}16.3 \% \\
(8 / 49)\end{array}$ \\
\hline
\end{tabular}

\section{Conclusions}

Our results show that students can develop classification abilities in nonbiological contexts, but they present strong difficulties in transferring it to living things, and inadequate taxonomy criteria from previous educational stages emerge when transferred to some parts of the classification tree, including locomotion and habitat criteria. This resistance of previous ideas on taxonomy has been observed by other authors (Kattman, 2001; Trowbridge \& Mintzes, 1988) and suggests taxonomy work in primary education should focus on morphological and physiological criteria, rather than consolidating inadequate classification groups. Moreover, some of the identified misconceptions in taxonomy, as using names of groups as classification criteria, or teleological ideas, might be due to previous memorization approaches and alternative ideas on evolution that should be a matter for consideration.

\section{Acknowledgements}

This research was funded by the Spanish Government (grant number EDU2015-66643-C2-1-P) and carried out within the ACELEC research group, acknowledged by the Catalan Government (grant number 2017SGR1399). The author also acknowledges the collaboration of the students and teachers participating in the study.

\section{References}

Adey, P. S., Shayer, M., \& Yates, C. (1989). Thinking science: Student and teachers' materials for the CASE intervention. London, Macmillan.

Barker, J. \& Philip, J. (2013). Phylogenetics of man-made objects: simulating evolution in the classroom. Science in School 27, 26-31.

Bermúdez. G. M. A., De Longhi, A. L., Díaz, S., \& Catalán, V.G. (2014). La transposición del concepto de diversidad biológica. Un estudio sobre los libros de texto de la educación secundaria española. Enseñanza de las Ciencias, 32(3), 285-302. 
Bybee, R. W. (2006). Scientific Inquiry and Science Teaching. En L. B. Flick \& N. G. Lederman (Eds.), Scientific Inquiry and Nature of Science. Implications for Teaching, Learning and Teacher Education (pp. 1-14). Dordrecht, The Netherlands: Springer.

Case, E. (2008). Teaching Taxonomy: How Many Kingdoms? The American Biology Teacher 70(8), 472-477.

De Manuel, J. \& Grau, R. (1996). Concepciones y dificultades comunes en la construcción del pensamiento biológico. Alambique, Didáctica de las Ciencias Experimentales, 7, 53-63.

Domènech-Casal, J., Espasa, L. \& Mestres, C. (2018). Poner orden en la biodiversidad. Clasificar para comprender. Alambique, Didáctica de la Ciencias Experimentales, 94, 13-19.

Del Pozo, R. \& Martín, P. (2012). Los criterios de clasificación de la materia inerte en la Educación Primaria: concepciones de los alumnos y niveles de competencia. Revista Eureka sobre Enseñanza y Divulgación de las Ciencias, 9(2), 213-230.

Duranti, A., \& Goodwin, C. (Eds). (1992). Rethinking context: Language as an interactive phenomenon. Cambridge: Cambridge, University Press.

Galán, P., \& Martín, R. (2013). La clasificación de la materia viva en Educación Primaria: Criterios del alumnado y niveles de competencia. Revista Electrónica de Enseñanza de las Ciencias, 12(3), 372-391.

Gilbert, J. K. (2006). On the nature of context in chemical education. International Journal of Science Education, 28(9), 957-976.

Gilbert, J. K., Bulte, A. M. W. \& Pilot, A. (2011). Concept development and transfer in context-based science education. International Journal of Science Education, 33(6), 817-837.

Hodson, D. (1994). Hacia un enfoque más crítico del trabajo de laboratorio. Enseñanza de las Ciencias, 12(3), 299-313.

Kattman, U. (2001). Aquatics, Flyers, Creepers and Terrestrials. Student's conceptions of animal classification. Journal of Biological Education 35 (3), 141-147.

Llewellyn, D. (2005) Teaching High School Science Through Inquiry. Thousand Oaks, CA: Corwin Press.

Margulis, L., \& Sagan, D. (2003). Captando Genomas. Una teoría sobre el origen de las especies. Barcelona: Editorial Kairós.

Margulis, L. \& Schwartz, K.V. (1985). Five Kingdoms: an illustrated guide to the phyla of life on Earth. Freeman and Company, New York.

Martínez-Losada, C., García-Barros, S. \& Garrido, M. (2014). How children characterise living beings and the activities in which they engage. Journal of Biological Education, 48(4), 201-210.

Rodríguez, F. P., De Las Heras, M. A., Romero, R., \& Cañal, P. (2014). El conocimiento escolar sobre los animales y las plantas en primaria: Un análisis del contenido específico en los libros de texto. Revista Electrónica de Enseñanza de las Ciencias, 13(1), 97-114.

Ruiz-Trillo, I., Roger, A. J., Burger, G., Gray, M. W., \& Lang, B. F. (2008) A phylogenomic investigation into the origin of Metazoa. Molecular Biology and Evolution, 25(4), 664-672. 
Trowbridge, J. \& Mintzes, J.J. (1988). Alternative Conceptions in Animal Classification: A Cross Age Study. Journal of Research in Science Teaching 26, 547-571.

Windschitl, M., Thompson, J. \& Braaten, M. (2008) Beyond the scientific method: Model-based inquiry as a new paradigm of preference for school science investigations. Science Education 92(5), 941-967.

Whittaker, R.H. (1969). New concepts of kingdoms of organisms. Science, 163, 150-160.

Woese, C.R., Kandler, O. \& Wheelis, M.L. (1990). Towards a Natural System of Organisms: Proposal for the domains Archaea, Bacteria, and Eucarya. Proc. Nati. Acad. Sci. USA, 87(12), 4576-4579. 



\title{
STUDENTS' CONCEPTIONS OF PLANT REPRODUCTION PROCESSES
}

\author{
Peter Lampert ${ }^{1}$, Bernhard Müllner ${ }^{1,2}$, \\ Peter Pany ${ }^{1,2}$, Martin Scheuch ${ }^{3}$, and Michael Kiehn ${ }^{1}$ \\ ${ }^{1}$ University of Vienna (Vienna - Austria), ${ }^{2}$ University College of Teacher \\ Education Vienna (Vienna - Austria), University College for Agricultural \\ and Environmental Education (Vienna - Austria) \\ peter.lampert@univie.ac.at
}

\begin{abstract}
Understanding plant reproduction is an important goal in biology education. Unfortunately, various studies show that students have difficulties in connecting the stages of plant reproduction. Students' conceptions of the processes of sexual reproduction (e.g. pollination and seed dispersal) remain unclear, although these conceptions appear crucial for understanding plant reproduction. Therefore, the current study focuses particularly on students' conceptions of the processes of plant reproduction. To assess students' conceptions, we used open-ended tasks and analyzed the answers through qualitative content analysis. In this contribution we present the results of the task "Open description of plant reproduction", which asked students to draw and describe their ideas of plant reproduction. The task was completed by 228 Austrian students from secondary school (age 10-18). The results show that students often describe only one of the processes involved in reproduction (either pollination or seed dispersal) but rarely describe the correct consecutive order of both processes. Moreover, many students from all age groups mix pollination and seed dispersal. This implies that it is necessary to address the confusion of these processes explicitly. The presented task can further help to easily assess students' conceptions in class and specifically address students' difficulties and needs.
\end{abstract}

Keywords: students' conceptions, plant reproduction, conceptual change, pollination, plant blindness

The full version of this paper is published in the Journal of Biological Education: Lampert, P., Müllner, B., Pany, P., Scheuch, M. \& Kiehn, M. (2020) Students' conceptions of plant reproduction processes. Journal of Biological Education.... 



\title{
SCHOOLGIRLS' UNDERSTANDING OF HIV/AIDS KNOWLEDGE PRESENTED IN LIFE SCIENCES TEXTBOOKS IN SOUTH AFRICA
}

\author{
Lindelani Mnguni \\ Department of Science \& Technology Education, College of Education, \\ University of South Africa, Pretoria, South Africa \\ mngunle@unisa.ac.za
}

\begin{abstract}
The prevalence of HIV/AIDS in South Africa remains high, particularly among women aged between 15 and 49, despite numerous educational interventions. There is also a high prevalence of HIV/AIDS among the youth. School curricula are therefore used to educate the youth about HIV/AIDS. There is, however, a dearth of research regarding learners' understanding of HIV/AIDS knowledge taught in schools and the effect of this knowledge on behavioral patterns. The present research sought to determine the extent to which schoolgirls have an understanding of academic and functional HIV/AIDS knowledge presented in the textbooks, as a proxy to determining the significance of textbooks in empowering schoolgirls for the prevention of HIV/AIDS infection. Results indicate that HIV/AIDS knowledge is not extensively integrated into the textbooks. Despite this, however, schoolgirls have a significantly higher functional HIV/AIDS knowledge than academic HIV/AIDS knowledge. Alternative sources of HIV/AIDS knowledge held by the participants were identified. These results suggest that the school curricula alone may not be effective in providing learners with functional HIV/AIDS knowledge. It is concluded that textbooks alone may not provide adequate knowledge of HIV/AIDS for empowering schoolgirls for the prevention of HIV/AIDS infection.
\end{abstract}

Keywords: HIV/AIDS knowledge; life sciences; schools; textbooks

\section{Introduction}

Recent research has shown that the prevalence of HIV/AIDS in South Africa remains high. Statistics South Africa (2018) estimates that in 2018, there were 7.52 million South Africans living with HIV/AIDS. This represents 
$13.06 \%$ of the population, which is highest since 2002. Statistics South Africa's (2018) data show that the prevalence has been increasing steadily over the last 17 years. Among the youth (aged between 15 and 24) the prevalence is estimated to be $5.45 \%$, which is the lowest since 2002 . However, among women aged between 15 and 49 , the prevalence is estimated to be $22.32 \%$, which is highest since 2002. This represents a 3.1\% increase from the 2008 estimates. Harrison et al. (2015) report that the incidence of new HIV infections among women aged between $15-24$ was $2.5 \%$ compared to $0.6 \%$ in men of the same age. This disproportionate risk of infection among women has been reported in the literature, which suggests that young women are a vulnerable group and a key target in efforts aimed at reducing the spread and prevalence of HIV/AIDS (Dellar et al., 2015). Consequently, the present research explored HIV/AIDS knowledge amongst schoolgirls as a preliminary effort to determine the extent to which formal education in general, and science education in particular, is useful in the fight against the spread of HIV/AIDS.

The high HIV/AIDS prevalence statistics in South Africa have been reported despite numerous programmes, which are aimed at reducing risk behaviour, eliminating stigma and promoting disclosure about HIV infections (e.g. Harrison et al., 2015). These programmes include the integration of HIV/ AIDS education in school curricula (Choi et al., 2011) where relevant content knowledge is taught in subjects such as Life Sciences as academic and functional HIV/AIDS knowledge. Wolff \& Mnguni (2015, p. 214) define functional knowledge as: "actionable scientific knowledge discovered through formal education and lived experiences, which could be used to transform social practices, norms and values in order to enhance human civilization"; and academic knowledge as: "scientific knowledge, in the form of didactic statements as part of scientific discourses to enhance scientific endeavors", which may not be applied directly in everyday life. In light of this, one wonders why the HIV/ AIDS prevalence remains significantly high among the youth, despite the various strategies being employed to reduce the spread of HIV/AIDS.

\subsection{HIV/AIDS education in school curricula}

One of the strategies used in the fight against HIV/AIDS among youth involves partnerships between education practitioners and healthcare practitioners. Healthcare practitioners generally adopt the biopsychosocial approach to understanding and managing human health and illness, including HIV/AIDS (Wade \& Halligan, 2017). Engel (1980), who developed this model, suggests that it systematically considers biological, psychological, and social factors and their complex interactions in understanding health, illness, and health care delivery. Consequently, Haberland (2015) suggests that effective attempts to reduce the spread and impact of HIV/AIDS should include both clinical services and 
curriculum-based approaches. Several countries, including South Africa, have now integrated both academic and functional HIV/AIDS education in their formal school curricula (Haberland, 2015; Wolff \& Mnguni, 2015).

Functional HIV/AIDS knowledge taught through formal curricula may involve the use of context-specific case studies to enhance the development of life skills as well as increased awareness of gender imbalances, human rights violations, stigma, and discrimination. This may be guided by theories such as social learning theory, behaviour transformation, and social influence ideology (Mahat et al., 2008; Maticka-Tyndale \& Barnett, 2010). The advantage of teaching functional HIV/AIDS knowledge is that it incorporates the socioeconomic and cultural dynamics of learners. Furthermore, people living with HIV can be involved as facilitators, who could share experience-based functional knowledge with learners concerning the treatment and management of HIV/ AIDS (e.g. Levy, 2009). To this end, research has shown that participating in programmes that teach functional HIV/AIDS knowledge improves participants' HIV/AIDS knowledge, self-efficacy and the adoption of safe behaviours (Kaponda et al., 2009; Mahat et al., 2008; Maticka-Tyndale \& Barnett, 2010).

Integration of academic HIV/AIDS knowledge in the curriculum is often aimed at correcting misconceptions and facilitate construction of scientifically correct knowledge about HIV/AIDS. This includes teaching about HIV/AIDS as part of science subjects where learners learn about human biology. In this instance, HIV/AIDS content could be taught as part of teaching about cell biology, virology, immunology, and haematology (Mnguni, 2017; Wolff \& Mnguni, 2015). The scope of this knowledge is dependent on the learning outcomes and related teaching resources available to teachers and learners. Previous research has shown that learners understanding of academic HIV/ AIDS knowledge could enhance the adoption of safe behavioural practices (Mnguni et al., 2016).

\subsection{Problem statement and rationale}

The effect of integration of HIV/AIDS knowledge in the curriculum on learners' behaviour has not been evaluated on a large scale. While considering the vast number of biopsychosocial factors that affect the spread of HIV/AIDS, there is an urgent need to investigate, whether female and male learners have the same conception of HIV/AIDS, given the disproportionate prevalence of HIV/AIDS between these groups. It is also necessary to determine the impact of specific schools subjects on learners' conception of HIV/AIDS and related behavioural patterns. While the current research is not addressing all these issues, it does, however, attempt to describe the extent to which schoolgirls have an understanding of functional and academic HIV/AIDS knowledge which is integrated into the biology curriculum. This is significant in the fight against HIV/AIDS as it will 
provide the scientific community with a view of the nature, depth and relevance of HIV/AIDS content taught in Life Sciences; and, identify gaps in schoolgirls' knowledge of HIV/AIDS. This knowledge can then be used to revise curriculumbased strategies in order to reduce the prevalence of HIV/AIDS.

\subsection{Aim and research question}

The aim of this research, therefore, was to explore the extent to which schoolgirls have an understanding of academic and functional HIV/AIDS knowledge presented in the textbooks, as a proxy to determining the significance of textbooks in empowering schoolgirls with the knowledge required for the prevention of HIV infection and management of AIDS. The research question framing the present research asked, "To what extent do schoolgirls have an understanding of HIV/AIDS content knowledge presented in the Life Sciences school textbooks?

\section{Methods}

\subsection{Research design}

A realism research paradigm was adopted in the present research. This is because unlike positivism and interpretivism, realism allows for the use of mixed-methods research design, which compensates for limitations of qualitative and quantitative methods when used in isolation. Realism as a research paradigm adopts epistemological relativism where empirical facts are used to describe and justify conclusions, even though these are understood to be relative and subjective to the researcher's context (Einheuser, 2008). To this end, data were collected through an explanatory concurrent mixed-methods approach.

\subsection{Sampling and sample description}

In conducting the present research, the researcher first identified the functional and academic HIV/AIDS knowledge presented in the Life Sciences textbooks. After that, schoolgirls' understanding of this knowledge was investigated. Two Life Sciences textbooks Focus on Life Sciences (Clitheroe et al., 2008) and Shuters Life Sciences Grade 11 Students Book (Ayerst et al., 2008) were purposively sampled for analysis. Purposive sampling meant only accredited textbooks that were used by the teachers in the schools studied were analyzed in the present research. The textbooks provide detailed content knowledge that is taught in line with the curriculum. The curriculum document itself was not investigated in the current research as this has been carried out previously (e.g. Wolff \& Mnguni, 2015). 
Purposive sampling was also used to select 180 schoolgirls aged between 15 and 18 to participate. These learners were all enrolled for Life Sciences in the eleventh grade in two rural/government schools, two urban/government schools, three urban/private schools, and two township/government schools. They had all been taught HIV/AIDS-related content, including basic cell structure and function, the circulatory system, immunology, and microorganisms, including viruses. The present research focused on girls only because of the significantly higher risk of HIV infection and prevalence among them compared with boys (e.g. Harrison et al., 2015). While research on both boys and girls is necessary, the present researcher decided to focus on girls only as an attempt to address the urgency to support girls in the fight against HIV/AIDS. Ethical clearance and permission to carry this research were granted by the KZN Department of Basic Education (Reference number 0046/2008) and the University of Pretoria (Reference number CS08/11/04).

\subsection{Data collection and analysis}

The textbooks were analyzed to determine how they integrate HIV/AIDS knowledge. The first step in this regard was curriculum mapping, using a document analysis protocol (Table 1 ) to guide the process, as suggested by Evans $\&$ Davies (2000) and Nicholls (2003). This protocol consisted of items which the researcher responded to by finding answers in the textbooks. It was developed and validated through an independent panel of experts, which consisted of two Life Sciences teachers, one healthcare practitioners, and four HIV/AIDS education researchers. The instrument was used to determine the context and extent to which HIV/AIDS content is presented in the textbooks. The focus in this regard was on both academic and functional HIV/AIDS knowledge. As defined by Wolff \& Mnguni (2015), academic HIV/AIDS knowledge in this regard related to microorganisms and their related human diseases, immunology

TABLE 1

A DOCUMENT ANALYSIS PROTOCOL USED FOR THE ANALYSIS OF TEXTBOOKS

\begin{tabular}{ll}
\hline Action & Details \\
\hline Sampling & Life Sciences textbooks authorized by the Department of Basic Education. \\
Analysis procedure & Deductively respond to the items below. \\
The instrument for & 1. Which concepts do the textbooks foreground for Grade 11 learners concerning \\
textbook analysis & HIV/AIDS? \\
& $\begin{array}{l}\text { 2. Which HIV/AIDS-related terms and concepts have the highest text page volu- } \\
\text { me in the textbooks? }\end{array}$ \\
& 3. What is the textbooks' approach to HIV/AIDS-related concepts? \\
& 5. What is the frequency of appearance for HIV/AIDS-related concepts? \\
& 6. What assumptions underlie the textual discourse?
\end{tabular}


(including immunity and vaccination), virology (including viruses and HIV/ AIDS), bacteriology (including bacteria and TB), and the circulatory system. Functional HIV/AIDS knowledge referred to HIV mode(s) of transmission between persons, the nature of, curability and treatability of AIDS as well as HIV/AIDS prevention strategies (Wolff \& Mnguni, 2015). The presentation of these concepts in the textbooks was therefore investigated using the document analysis instrument.

A non-experimental descriptive survey was carried out using a multiplechoice content knowledge test, which asked participants to select correct answers from a list of possible answers. The test was made up of twenty items spread equally in two sections, namely, academic HIV/AIDS knowledge and functional HIV/AIDS knowledge as defined above. This knowledge had been taught in Life Sciences in which the participants were enrolled. In addition to these, the test required participants to identify sources of knowledge from which they learn about HIV/AIDS. The test was developed by the researcher and validated through various stages of piloting and assessment by an independent panel of experts, which included two Life Sciences teachers, one healthcare practitioners and four HIV/AIDS education researchers. The test was administered by the researcher to the participants after which he marked the participants' answers against model answers. The participants' scores were then analysed quantitatively using SPSS Statistics 25.0 ink.

\section{Results}

\subsection{Presentation of HIV/AIDS content in the textbooks}

The analysis of the textbooks revealed that they both exclusively focus on presenting academic HIV/AIDS knowledge rather than functional knowledge. For example, the transmission of HIV/AIDS and related practical behavioural prevention strategies were not presented in Shuters Life Sciences, and insignificantly mentioned in Focus on Life Sciences (Tables 2 and 3). To this end, a word count of terms and concepts related to HIV/AIDS showed that terms describing HIV transmission and prevention, as well as treatment of AIDS, are mentioned negligibly in one textbook, and not mentioned in the other. For example, terms such as condom, safe sex, unprotected sexual intercourse, transfusion of infected blood, and vertical transmission were not mentioned in Shuters Life Sciences. Gaps were also identified in academic HIV/ AIDS knowledge, where terms and concepts that describe HIV/AIDS-specific behaviour in the body were not mentioned (Table 2). For example, Focus on Life Sciences made no mention of the terms glycoprotein, CD 4 receptors, Helper T lymphocytes, and CD 4 + T cells, which are central to how HIV binds onto host cells. 
TABLE 2

THE PRESENTATION OF TERMS AND CONCEPTS RELATED TO HIVIAIDS IN THE GRADE 11 TEXTBOOKS

\begin{tabular}{|c|c|c|c|}
\hline \multirow[t]{2}{*}{ Theme } & \multirow[t]{2}{*}{ Concepts } & \multicolumn{2}{|c|}{$\begin{array}{l}\text { Frequency of appearance } \\
\text { of concepts in textbooks }\end{array}$} \\
\hline & & $\begin{array}{l}\text { Focus on Life } \\
\text { Sciences }\end{array}$ & $\begin{array}{l}\text { Shuters Life } \\
\text { Sciences }\end{array}$ \\
\hline Definitions & Human Immunodeficiency Virus - HIV & 19 & 9 \\
\hline Types & HIV I, HIV II & 0 & 0 \\
\hline Domain & Virus & 49 & 27 \\
\hline Transmission & $\begin{array}{l}\text { Unprotected sexual intercourse } \\
\text { Transfusion of infected blood } \\
\text { Vertical transmission } \\
\text { Injection needles } \\
\text { Multiple infections }\end{array}$ & $\begin{array}{l}2 \\
0 \\
1 \\
1 \\
1\end{array}$ & $\begin{array}{l}0 \\
0 \\
0 \\
0 \\
0\end{array}$ \\
\hline Target cells & White blood cells & 5 & 6 \\
\hline Binding & $\begin{array}{l}\text { Antigen } \\
\text { Antibodies } \\
\text { Glycoprotein } \\
\text { CD 4 receptors } \\
\text { Helper T lymphocytes } \\
\text { Macrophages } \\
\text { CD4 + T cells }\end{array}$ & $\begin{array}{l}7 \\
9 \\
0 \\
0 \\
0 \\
1 \\
0\end{array}$ & $\begin{array}{r}17 \\
23 \\
0 \\
0 \\
4 \\
2 \\
0\end{array}$ \\
\hline Entry to cell & $\begin{array}{l}\text { Plasma membrane glycoproteins } \\
\text { Invasion } \\
\text { Infection }\end{array}$ & $\begin{array}{r}0 \\
4 \\
19 \\
\end{array}$ & $\begin{array}{l}0 \\
3 \\
4 \\
\end{array}$ \\
\hline Reproduction & $\begin{array}{l}\text { Reverse transcription } \\
\text { Host cell reproduction machinery }\end{array}$ & $\begin{array}{l}0 \\
3\end{array}$ & $\begin{array}{l}0 \\
7\end{array}$ \\
\hline Effects & $\begin{array}{l}\text { Non-specific flu-like symptoms } \\
\text { Increase of viral concentration } \\
\text { Viral spread } \\
\text { Organ infection } \\
\text { Asymptomatic phase } \\
\text { Drop in CD4 + T cell count } \\
\text { Symptomatic phase } \\
\text { Acquired Immune Deficiency Syndrome } \\
\text { - AIDS }\end{array}$ & $\begin{array}{r}0 \\
0 \\
0 \\
19 \\
0 \\
0 \\
0 \\
12\end{array}$ & $\begin{array}{r}0 \\
0 \\
0 \\
14 \\
0 \\
0 \\
0 \\
6\end{array}$ \\
\hline Treatment & $\begin{array}{l}\text { No cure } \\
\text { Antiretroviral drugs }\end{array}$ & $\begin{array}{l}3 \\
0\end{array}$ & $\begin{array}{l}1 \\
0\end{array}$ \\
\hline Prevention & $\begin{array}{l}\text { Condom } \\
\text { Safe sex }\end{array}$ & $\begin{array}{l}1 \\
0\end{array}$ & $\begin{array}{l}0 \\
0\end{array}$ \\
\hline
\end{tabular}

It was also observed that the textbooks present HIV/AIDS-related content knowledge to varying degrees (Table 3). For example, Shuters Life Sciences has significantly fewer pages than Focus on Life Sciences, presenting knowledge of the characteristics of bacteria, viruses, and the structure and function of the circulatory system. Shuters Life Sciences dedicates significant page space on the circulatory 
system and immunology. Interestingly, Focus on Life Sciences does not present content related to immunology. Furthermore, Focus on Life Sciences discusses AIDS using a case study, a diagram illustrating HIV as well as text (Clitheroe et al., 2008, p. 81). It also presents South African HIV/AIDS statistics, with particular emphasis on the youth. This textbook also presents content related to "what causes AIDS, how is AIDS spread, how do you know if you have AIDS, and what happens to someone with AIDS?” (Clitheroe et al., 2008, p. 161).

TABLE 3

A SUMMARY OF THE PRESENTATION OF HIVIAIDS CONTENT IN TWO LIFE SCIENCES TEXTBOOKS

\begin{tabular}{lcccc}
\hline \multirow{2}{*}{ Topic } & \multicolumn{2}{c}{ Shuters Life Sciences } & \multicolumn{2}{c}{ Focus on Life Sciences } \\
\cline { 2 - 5 } & $\begin{array}{c}\text { \% out of total } \\
\text { pages }(n=58)\end{array}$ & $\begin{array}{c}\text { Reference } \\
\text { Pages }\end{array}$ & $\begin{array}{c}\text { \% out of total } \\
\text { pages }(n=47)\end{array}$ & $\begin{array}{c}\text { Reference } \\
\text { Pages }\end{array}$ \\
\hline Characteristic of bacteria & 10 & $\begin{array}{c}180-182 \& \\
187-189\end{array}$ & 34 & $64-76$ \\
\hline $\begin{array}{l}\text { Characteristic of HIV/ } \\
\text { AIDS }\end{array}$ & 3 & $291 \& 221$ & 6 & $81-82 \& 161$ \\
\hline Characteristic of viruses & 7 & $175-177 \& 189$ & 13 & $78-83$ \\
\hline Immunology & 14 & $212-219$ & 0 & 77 \\
\hline Opportunistic infections & 3 & $188-189$ & 2 & $139-160$ \\
\hline $\begin{array}{l}\text { Structure and function of } \\
\text { the circulatory system }\end{array}$ & 31 & $270-272 \&$ & 45 & $84-85$ \\
\hline Vaccination & 5 & $275-290$ & & 4 \\
\hline
\end{tabular}

\subsection{Learners' knowledge of HIV/AIDS}

With regards to the participants' understanding of the HIV/AIDS knowledge taught in Life Sciences (i.e. Tables 2 and 3), data showed that the participants had a significantly higher functional HIV/AIDS knowledge $(M=$ $73.83 \%$, S.D. $=16.04 \%)$ than academic HIV/AIDS knowledge $(M=54.33 \%$, S.D. $=20.47 \%, p<.001)$. To this end, a large size effect was observed when academic HIV/AIDS knowledge was compared to functional HIV/AIDS knowledge (Cohen's $d=1.0604$, Gates' delta $=0.9526$, Hedges' $g=1.0604$ ). There was, however, a significant correlation (Pearson's correlation) between academic and functional HIV/AIDS knowledge $(r=.431, \mathrm{p}<.001)$. It was also found that the majority of participants did not know certain concepts related to HIV/AIDS. For example, some participants did not know the definitions of a virus, opportunistic diseases, antibodies and T-cells, immune defenses (Table 4). Over $73 \%$ of the participants did not know the meaning of 'immune deficiency.' Most of the participants, however, had significant knowledge of functional HIV/AIDS content (Table 4). 
TABLE 4

A SUMMARY OF LEARNER PERFORMANCE IN THE ACADEMIC AND FUNCTIONAL HIVIAIDS KNOWLEDGE ITEMS USED IN THE KNOWLEDGE TEST

\begin{tabular}{lcclcc}
\hline $\begin{array}{c}\text { Academic HIVIAIDS } \\
\text { knowledge topics }\end{array}$ & $\begin{array}{c}\text { Mean } \\
(\%)\end{array}$ & $\begin{array}{c}\text { Standard } \\
\text { deviation } \\
(\%)\end{array}$ & $\begin{array}{c}\text { Functional HIVIAIDS } \\
\text { knowledge topics }\end{array}$ & $\begin{array}{c}\text { Mean } \\
\text { (\%) }\end{array}$ & $\begin{array}{c}\text { Standard } \\
\text { deviation } \\
\text { (\%) }\end{array}$ \\
\hline What is a virus & 43.89 & 49.76 & Causes of AIDS & 81.11 & 39.25 \\
\hline Structure of viruses & 55.56 & 49.83 & Strains of HIV & 21.11 & 40.92 \\
\hline What are bacteria & 83.33 & 37.37 & HIV Transmission & 85.56 & 35.25 \\
\hline Opportunistic infections & 40.56 & 49.24 & HIV Infection & 80.56 & 39.69 \\
\hline Contaminated blood & 56.11 & 49.76 & Stages of AIDS & 85.56 & 35.25 \\
\hline Immune system & 83.33 & 37.37 & HIV mechanisms & 87.22 & 33.48 \\
\hline Antibodies and T-cell receptors & 48.89 & 50.13 & HIV re-infection & 77.78 & 41.69 \\
\hline Immune defense & 48.89 & 50.13 & Vaccination and HIV & 66.67 & 47.27 \\
\hline Immune deficiency & 26.67 & 44.35 & Antiretroviral drugs & 78.33 & 41.31 \\
\hline Antibiotics & 56.11 & 49.76 & AIDS curability & 73.42 & 30.14 \\
\hline
\end{tabular}

Results also showed that participants might rely on other extra-curricular resources as sources of HIV/AIDS knowledge. These include health facilities, newspapers, family, local radio stations, and television, which were identified by the participants as a significant source of information about HIV/AIDS for them $(76 \%<\mathrm{n}<92 \%)$. With regards to academic HIV/AIDS knowledge, data showed that the different sources of knowledge (i.e. Internet, TV, billboards, church, health facility, family, friends, school books, newspapers, teachers, radio) explain only $15.7 \%\left(R=.396, R^{2}=.157\right)$ of the participants' academic HIV/AIDS knowledge. The same was observed for functional HIV/AIDS knowledge where the sources of knowledge were shown to explain $15.0 \%$ of the participants' functional HIV/AIDS knowledge $\left(R=.387, R^{2}=.150\right)$.

\section{Discussion}

Textbooks play a critical role in presenting scientific knowledge about various phenomena which affect everyday life (Mnguni, 2018). As a potential source of HIV/AIDS knowledge, it is critical to ensure that knowledge presented in the textbooks is adequately transferred to learners, more so in instances where such knowledge could reduce the spread of HIV/AIDS. The present study, therefore, sought to determine the extent to which schoolgirls have an understanding of HIV/AIDS knowledge presented in the textbooks, as a proxy to determining the significance of textbooks in empowering schoolgirls with the knowledge required for the prevention of HIV infection and management of AIDS. 
The present research has found that some HIV/AIDS knowledge is integrated into the Life Sciences textbooks even though previous studies have shown that the Life Sciences curriculum does not recommend the integration of HIV/AIDS knowledge (e.g. Wolff \& Mnguni, 2015). This finding suggests that there may be a misalignment between the curriculum statements and the textbooks because the curriculum document (analyzed by Wolff \& Mnguni, 2019) informs what is integrated into the curriculum. Further research may be required to determine the alignment between the curriculum statements and the textbooks.

While some HIV/AIDS concepts are presented in the textbooks, there was also evidence which suggests that several critical HIV/AIDS concepts, both as functional and academic HIV/AIDS knowledge, are inadequately presented in the textbooks. These concepts are regarded as critical because, in previous studies (e.g. Mnguni et al., 2016), they were identified as significant for improving learners' content understanding of HIV/AIDS. Academic HIV/AIDS knowledge improves learners' understanding of HIV/AIDS by reducing misconceptions which could reduce stigma; while functional knowledge provides learners with actionable knowledge required for the adoption of safe behavioral practices (Mnguni et al., 2016). The minimal integration of related concepts, therefore, is also noteworthy given that in previous studies learners indicated that they "would like to see an in-depth look at the subject instead of a superficial general view" (Mnguni \& Abrie, 2012, p. 4). The present researcher argues, therefore, that the textbooks alone may not be a useful resource for teaching learners about HIV/AIDS. The impact of how textbooks present HIV/AIDS knowledge remains to be investigated. Further research is also required to investigate the role of textbooks on learners' knowledge and behavioural patterns related to HIV/AIDS.

The present research has also found critical information regarding schoolgirls' knowledge of HIV/AIDS. To this end, some studies (e.g. Agyemang et al., 2012; Kejela et al., 2015) have shown that youths, including girls, have a relatively high knowledge of HIV/AIDS, despite an increasing HIV/AIDS prevalence. What has not been established, however, is the nature of this knowledge primarily amongst female youths, who are most affected by HIV/AIDS, as is the case in South Africa. The present research has, however, found that the schoolgirls had a significantly higher understanding of functional HIV/AIDS knowledge than academic HIV/AIDS knowledge. This finding echoes previous studies that show that learners generally have higher functional HIV/AIDS knowledge than academic HIV/AIDS knowledge (Mnguni, 2017; Mnguni et al., 2016). The direct impact of this lower academic HIV/AIDS knowledge on the vulnerability and prevalence of HIV/ AIDS among schoolgirls requires investigation. However, previous research has shown that academic HIV/AIDS knowledge is positively correlated with 
self-reported safe behavioral preferences (Mnguni, 2017; Mnguni et al., 2016). Based on this, the present researcher argues that the high prevalence of HIV/AIDS among female youths in South African may be linked to a poor scientific understanding of HIV/AIDS. This deduction is supported by some scholars who argue that knowledge of socioscientific issues (such as HIV/ AIDS) promotes science literacy and the application of science in moral reasoning (e.g., Chang-Rundgren \& Rundgren, 2010). Context-specific science literacy has also been shown to be associated with decision-making (Marrero \& Mensah, 2010; Wallace \& Douden, 1998).

The research has also shown that schoolgirls may rely on other extracurricular sources to enhance their knowledge of HIV/AIDS. While their reasons for this were not explored in the present study, it is plausible that schoolgirls use these sources to compensate for knowledge gaps that may arise as a consequence of limited knowledge in the textbooks. This hypothesis may explain why schoolgirls have higher functional HIV/AIDS knowledge than academic HIV/AIDS knowledge. Further research is required, however, to determine how extra-curricular sources are used by learners to compensate for knowledge gaps, and what role is played by peers, teachers, and families in this compensation process. Additionally, to what extent learners validate this knowledge to ensure that they do not develop misconceptions.

\section{Conclusion}

Based on the findings of the present research, the researcher concludes that HIV/AIDS knowledge is not adequately integrated into the Life Sciences textbooks. To this end, learners may be using other sources of HIV/AIDS knowledge to compensate for knowledge gaps in the textbooks. The researcher argues, therefore, that curriculum designers need to reconsider the extent to which textbooks address HIV/AIDS if prevalence is to be adequately reduced. The researcher, therefore, posits that content in the curriculum and the textbooks should be applicable and relevant to those who learn it (Fraser, 1993). Given the findings of the present research, the researcher believes that the fight against HIV/AIDS requires urgent attention, more so given the steady increase in its prevalence among young women.

\section{Acknowledgments}

The author acknowledges all participating learners for their contribution to the success of this research. This research was funded by the South African National Research Foundation (NRF) (GUN 99210). 


\section{References}

Agyemang, S., Buor, D., \& Tagoe-Darko, E. (2012). The extent of knowledge about HIV/AIDS among young people in the Ejura-Sekyedumase district of Ghana. Journal of AIDS and HIV Research, 4(11), 241-247.

Ayerst, P., Langley, R., Majozi, P., Metherell, A., Raciborska, C., \& Smith, D. (2008). Shuters Life Sciences Grade 11 Learners Book. Cape Town: Shuter \& Shooter.

Broemmel, A. D., \& Lucas, K. K. (2010). Yellow Brick Roads and Emerald Cities: The Illusion of Intended Curricula in Education. Journal of Curriculum and Instruction, $4(2), 1-8$.

Chang Rundgren, S., \& Rundgren, C.J. (2010). SEE-SEP: From a separate to a holistic view of socioscientific issues. Asia-Pacific Forum on Science Learning and Teaching, 11(1), 1-24.

Choi, K., Lee, H., Shin, N., Kim, S. W., \& Krajcik, J. (2011). Re-conceptualization of scientific literacy in South Korea for the 21st century. Journal of Research in Science Teaching, 48(6), 670-697.

Clitheroe, F., Doidge, M., Marsden, S., van Aarde, I., Ashwell, A., Buckley, L., \& Dilley, L. (2008). Focus on Life Sciences. South Africa: Maskew Miller Longman.

Dellar, R. C., Dlamini, S., \& Karim, Q. A. (2015). Adolescent girls and young women: key populations for HIV epidemic control. Journal of the International AIDS Society, 18, 64-70.

Einheuser, I. (2008). Three forms of truth relativism. In M. García-Carpintero, \& M. Kölbel, (Eds.), Relative truth (pp. 187-203). London: Oxford University Press.

Engel, G. L. (1980). The clinical application of the biopsychosocial model. American Journal of Psychiatry, 137, 535-544.

Evans, L., \& Davies, K. (2000). No Sissy Boys Here, A Content Analysis of the Representation of Masculinity in Elementary School Reading Textbooks. Sex Role, 42(3/4), 255-270.

Fraser, W. J. (1993). The selection and ordering (arrangement) of learning content. In W. J. Fraser, C. P. Loubser, \& M. P. van Rooy (Eds.), Didactics for the undergraduate student, $2^{\text {nd }}$ ed. Durban: Butterworths.

Haberland, N. A. (2015). The case for addressing gender and power in sexuality and HIV education: A comprehensive review of evaluation studies. International Perspectives on Sexual and Reproductive Health, 41(1), 31-42.

Harrison, A., Colvin, C. J., Kuo, C., Swartz, A., \& Lurie, M. (2015). Sustained high HIV incidence in young women in Southern Africa: social, behavioral, and structural factors and emerging intervention approaches. Current HIVIAIDS Reports, 12(2), 207-215.

Kaponda, C. P. N., Jere, D. L., Chimango, J. L., Chimwaza, A. F., Crittenden, K. S. Kachingwe, S. I., McCreary, L. L., Norr, J. L., \& Norr, K. F. (2009). Impacts of a Peer-Group Intervention on HIV-related Knowledge, Attitudes, and Personal Behaviors for Urban Hospital Workers in Malawi. Journal of the Association of Nurses in AIDS Care, 20(3), 230-242. 
Kejela, G., Oljira, L., Dessie, Y., \& Misker, D. (2015). Comprehensive HIV/AIDS knowledge level among out-of-school youths in Wayu Tuka district, Western Ethiopia. European Journal of Preventive Medicine, 3(1), 11-16.

Levy, J. M. (2009). Women's expectations of treatment and care after an antenatal HIV diagnosis in Lilongwe, Malawi. Reproductive Health Matters, 17(33), 152-161.

Marrero, M. E., \& Mensah, F. M. M. (2010). Socioscientific decision making and the ocean: A case study of $7^{\text {th }}$ grade Life Science students. Electronic Journal of Science Education, 14(1), 1-27.

Maticka-Tyndale, E., \& Barnett, J. P. (2010). Peer-led interventions to reduce HIV risk of youth: A review. Evaluation and Program Planning, 33, 98-112.

Mnguni, L., \& Abrie, M. (2012). HIV/AIDS content knowledge and presentation strategies in biology for effective use in everyday life. Journal of Biological Education, 46(4), 226-233.

Mnguni, L., Abrie, M., \& Ebersohn, L. (2016). The relationship between scientific knowledge and behavior: An HIV/AIDS case. Journal of Biological Education, 50(2), 147-159.

Mnguni, L. (2017). The relationship between enrolment in biology, HIV/AIDS knowledge, and related behavior among South African schoolgirls. Journal of Baltic Science Education, 16(6), 898-907.

Mohammed, A. (2007, September). Challenging HIV/AIDS stigma and discrimination among students by incorporating HIV/AIDS into the curriculum, Paper presented at the Imagined Futures II: universities as incubators of change, University of Pretoria. Pretoria: Centre for the Study of AIDS

Nicholls, J. (2003). Methods in school textbook research. International Journal of Historical Learning, Teaching, and Research, 3(2), 11-26.

Saad, B. M., Subramaniam, G., \& Tan, P. L. (2013). Awareness and vulnerability to HIV/AIDS among young girls. Procedia-Social and Behavioural Sciences, 105, 195203.

Statistics South Africa. (2018). Mid-year population estimates 2018. Statistical Release P0302. Pretoria: Stats SA.

Wade, D. T., \& Halligan, P. W. (2017). The biopsychosocial model of illness: a model whose time has come. Clinical Rehabilitation, 31(8), 995-1004

Wallace, J., \& Douden, W. (1998). Curriculum change in science: Riding the waves of reform. In B. J. Fraser \& K. G. Tobin (Eds.), International Handbook of Science Education (pp. 471-485). Rotterdam: Kluwer.

Wolff, E., \& Mnguni, L. (2015). The Integration of HIV and AIDS as a Socio-scientific Issue in the Life Sciences Curriculum. African Journal of Research in Mathematics, Science and Technology Education, 19(3), 213-224.

Yaya, S., Bishwajit, G., Danhoundo, G., Shah, V., \& Ekholuenetale, M. (2016). Trends and determinants of HIV/AIDS knowledge among women in Bangladesh. BMC Public Health, 16(1), 812. 



\title{
NUTRITION AND REPRODUCTION STUDENTS' ALTERNATIVE CONCEPTIONS REGARDING ANIMAL CLASSIFICATION
}

\author{
Zghida Noureddine and Lamrani Zouhaire \\ Interdisciplinary Research Laboratory in Engineering Pedagogy, Normal Superior School \\ of Tetouan, University Abdelmalek Essaadi, Tetouan, Morocco \\ zghida100@gmail.com; zh.amrani@yahoo.fr
}

\begin{abstract}
Our study aims to complete Kattmann's work (2001) by highlighting other secondary school students' alternative conceptions of animal classification in Morocco. The data were collected by a test intended to probe secondary school students' understanding. This test was composed of a collection of 20 pictures of animals. This study showed that Moroccan secondary school students have serious problems with regard to animal classification. We found that some students had classified test animals according to taxonomic norms but the majority of them based their decisions on non-taxonomic criteria. The animals were classified in groups like: carnivorous, herbivorous, viviparous, oviparous, domestic and wild. These personal classifications are more interesting to us and allow us to improve the teaching-learning process of animal classification based on taxonomic criteria. Biology teachers need to take into account these alternative conceptions during the planning and management of their teaching in order to develop the understanding for using a biological classification based on accepted scientific criteria. The relative percentages of the answers of the high school students in this classification task were almost equal with those of junior high school students. Therefore, the students' alternative conceptions are almost similar and there is not a positive development between alternative conceptions at junior high school and high school.
\end{abstract}

Keywords: animal classification, alternative conceptions, non-taxonomic criteria, secondary school, conceptual change

\section{Introduction}

To highlight students' alternative interpretations regarding a scientific concept or natural phenomenon is an essential part of biological education. 
These alternative interpretations are also known as misconceptions, preconceptions or alternative conceptions (Gilbert \& Watts, 1983). Several studies showed that students develop alternative conceptions before and during their schooling (Driver, 1981; Bell, 1981; Bell and Barker, 1982). The alternative conceptions developed before and during the first school years persist relatively unchanged into adulthood; and have been named alternative stable conceptions (Arnaudin and Mintzes, 1985). Other misconceptions are progressive alternative conceptions and seem to respond to the formal teaching and/or to the scholar's experiences. In this sense, Markle and Tieman (1970) suggest that it is possible to define clearly concepts such as "insect" or "element" in terms of attributes which define them. A non-example is when things exclude one or several of these attributes and are considered by learners non-examples, and thus a misconception. The same argument was developed by (Herron and al., 1977) showing difficulties for students in perceiving the attributes.

Previous studies showed that students often develop poorly structured alternative conceptions coming from the outside world and sometimes from the school (Gilbert and al., 1982; Osborne and al., 1983). These are due to the inadequate construction of the concept, and the cognitive deficiency either of "bad" teaching. In fact, the individuals generate their own alternative conceptions from an essential, inevitable and desirable feature of the personal experience (Kelly,1955). This is immature, naive knowledge and less developed than a concept (Driver and Easley, 1978). In this sense, Hewson (1981) talked about preconceptions as being a reflection of the real status of the world for an individual person. Thus, these misconceptions are accessible both by verbal and non-verbal personal actions, often in answer to particular questions (Gilbert and Watts, 1983).

Identifying how students classify animals by applying their own criteria and categories is essential for teachers to be able to assist in developing their scientific understanding. These personal classifications are more interesting for biology teachers in order to take them into account during the planning and management of their teaching. Nevertheless, if teachers neglect these alternative conceptions, the student will be incapable in overcoming the difficulties to understand the biological classification. These difficulties cannot be caused by an over-generalization or a logical thought, but can be due to the conflict between the biological and the elementary and/or personal knowledge of students (Kattmann, 2001). For that purpose, the performance of the students to classify a collection of animals, based on taxonomic criteria (acceptable biological criteria by the scientific community), is poorly achieved (Braund, 1991). This indicates great difficulties met by the students who hold alternative conceptions as defined previously. Generally, students seem to classify animals in a very restricted way, often classifying only known ground vertebrates, in particular those who are at home, in zoos or at a farm (Trowbridge and Mintzes, 1988). 
The didactic stake in the biological classification problem is situated in the construction, by the students, of the taxonomic criteria, which are not a priori given. Indeed, they often know the definitions by heart, but cannot apply them due to an inadequate conceptualization. This leads to errors such as the thought that a snail was a reptile, even if they said that it does not possess vertebral features, by solely basing its classification decision on the mode of locomotion (Ryman, 1974b). In this sense, the students use non-taxonomic criteria (not defined by the scientific community) to establish a classification model of the animal kingdom. These classifications are often erroneous and not based on acceptable scientific attributes and criteria.

The classification of living things is an essential unity in the biology curriculum and an integral part of biological science. The study of the students' misconceptions concerning animal classification, in the Moroccan context, aims to highlight the difficulties met by secondary school students to name and classify the animal species studied in the school curriculum. Our study aims to identify secondary school students' conceptions regarding animal classification, and to know how alternative classification develops from middle school to high school.

Previous studies indicated that students, from primary school to the university, have significant problems in classifying several animals according to taxonomic criteria (Trowbridge \& Mintzes, 1985; Mintzes \& Trowbridge 1987; Braund, 1991; Kattmann, 2001). These problems cannot be caused by a deficit of the knowledge or by the adopted educational style, but can be due to the conflict between the biological criteria and elementary or personal criteria of students, with regard to habitat and locomotion, to classify several animals (Kattmann, 2001). Our study aims to complete the work of Kattmann (2001), focused only on some non-taxonomic criteria (habitat and locomotion), by highlighting other secondary school students' alternative conceptions relative to animal classification, and make a comparison between those of junior high school students (12-14 years) and high school students (15-17 years).

Our study aims to respond to the following questions:

How Moroccan's secondary school students classify animals? Have they other alternative conceptions regarding animal classification? Is there a development of alternative conceptions between middle school and high school students?

\section{Research design and methodology}

\subsection{Participants}

Our sample consisted of a group of 450 students of three educational delegations in the North of Morocco. 246 students from secondary high school (high school students) and the rest from secondary middle school (junior high 
school students). The choice of the two groups for our study is not arbitrary. It is for the objective of finding how alternative conceptions evolve between secondary middle school and secondary high school. The participants were not attending courses on the animal classification during our study, which was made at the beginning of 2016/2017 school year.

\subsection{Instrument}

The test allowed secondary school students' alternative conceptions to be highlighted and to reveal what they knew about animal classification. The data were collected by administering a test written for secondary school students. The survey allowed us to identify the students' alternative conceptions and indications about their knowledge level in order to develop a quantitative and qualitative study. Moreover, Javeau (1982) puts forward the relevance of the survey by questionnaire to collect this type of information. In the Moroccan secondary school biology curriculum, the teachers should be able to teach animal classification according to taxonomic criteria. The students are asked to classify animals into groups according to what they have learned about animal classification. Normally, students must classify animals according to biological classification and give the appropriate name to each group.

Our classification task will help to highlight how secondary school students classified animals. Did they use a biological classification or other types of classification? It does not judge student answers relative to taxonomic criteria, but it aims to know how students will classify animals. These personal classifications are not always erroneous; they are just according to an alternative conception relative to other types of classification.

The test was composed of a collection of 20 black and white pictures of animals. These pictures were the same size $(4 \mathrm{~cm} \times 5 \mathrm{~cm})$. The animals pictured were: seal, crocodile, snake, tiger, butterfly, goose, dog, bat, elephant, whale, hen, penguin, bee, crab, snail, frog, shark, monkey, mouse and spider. We tried to choose familiar animals for all students. The students were asked to classify these animals into groups and give an appropriate name for each group. They did not have to fit every animal into a group. The students used their knowledge about grouping and naming without teacher instructions in the classroom.

\section{Findings}

Some students classified the animals in the test according to taxonomic norms but the majority of them were based on non-taxonomic criteria such as diet, mode of reproduction and relationship between animal and human. The percentages of the answers of the high school students were almost equal with those of junior high school (Figures 1 and 2). 


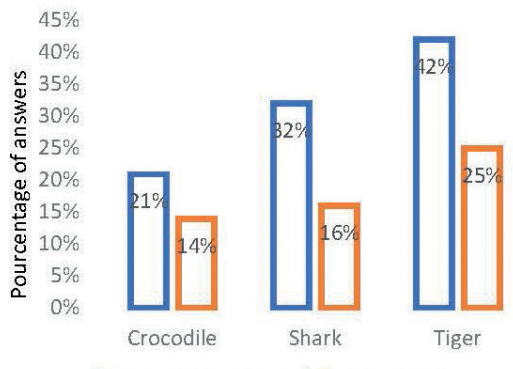

DJunior high school DHigh school

Figure 1 Animals classified as 'carnivorous'

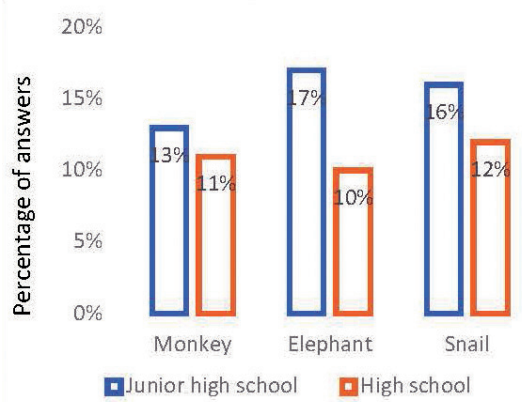

Figure 2 Animals classified as 'herbivorous'

We note that $21 \%$ of junior high school students and $14 \%$ of high school did not classify a crocodile as reptile. A substantial number of students used diet to classify animals (shark, tiger, monkey, elephant). The diet constitutes nontaxonomic criteria, which can hamper the understanding and the application of biological classification. The classification of the monkey and the snail as herbivores might seem a little strange, this might reflect the students' observations of snails attacking plants cultivated in gardens (or salad, crushed tomatoes, etc.) and monkeys eating bananas.

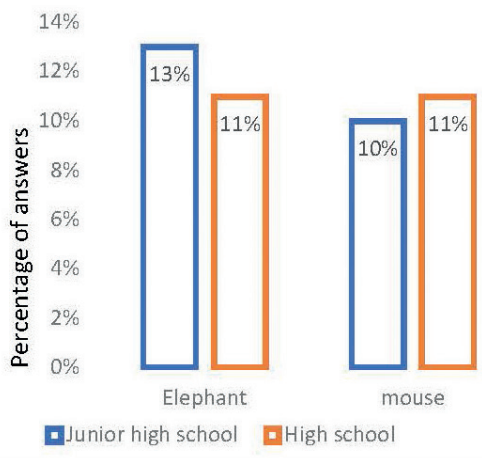

Figure 3 Animals classified as 'viviparous'

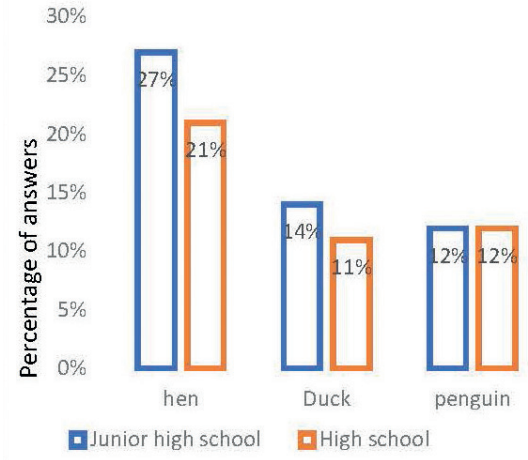

Figure 4 Animals classified as 'oviparous'

More than $10 \%$ of secondary school students could not classify an elephant or a mouse as a mammal. The students classified elephants and mice according to their mode of reproduction. They were classified as viviparous (Figure 3). The percentages of the high school students' answers were almost equal with those of junior high school. We found that $27 \%$ of junior high school students and $21 \%$ of high school students classified a hen as oviparous (figure 4). More than 10\% 


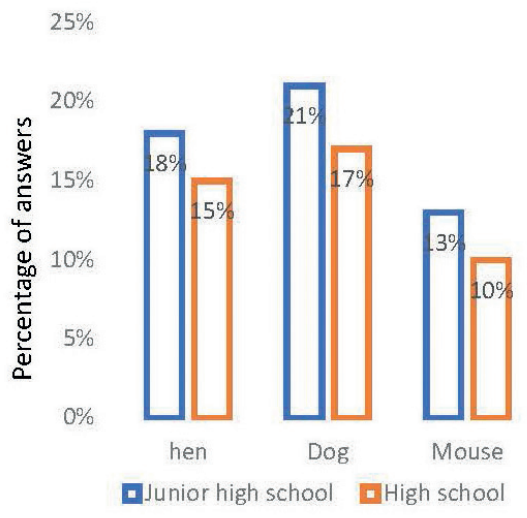

Figure 5 Animals classified as 'domestic'

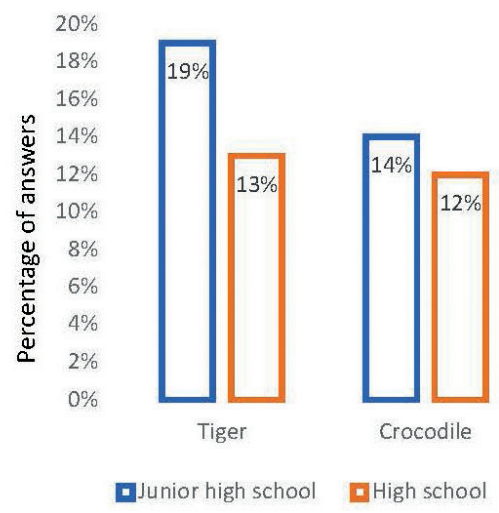

Figure 6 Animals classified as 'wild'

of secondary school students could not classify a duck or a penguin as a bird. The mode of reproduction was the most significant criterion used by students to classify animals.

Between $10 \%$ and $21 \%$ of secondary school students classified some animals with regard to the relationship between the animal and humans. Animals like dog, hen and mouse were classified as domestic because they live with humans. Other students classified tiger and crocodile as 'wild'. These 'domestic' and 'wild' relationships represented an alternative conception among the students to classify animals in groups. This alternative conception could constitute an obstacle for students and deter them from carrying out biological classification according to taxonomic criteria (Trowbridge \& Mintzes, 1985).

\section{Conclusions}

This study showed that these Moroccan secondary school students have a serious problem with animal classification. The results of this study support those of the previous works (e.g. Trowbridge \& Mintzes, 1985, 1988; Braund, 1991; Yen \& al, 2004, Kubiatko \& Prokop, 2007). We found that students prefer to use elementary and personal criteria, often non-taxonomic, to classify animals (Kattmann, 2001). These criteria represent students' alternative conceptions, which they substitute for the taxonomic criteria studied in the animal classification courses. These non-taxonomic criteria were: the mode of reproduction, animal diet, and their relationship with humans. Also, they used external morphological characters, the habitat and the mode of locomotion to classify animals (Kattmann, 2001). These alternative conceptions do not allow 
students to construct their scientific classifications based on taxonomic criteria. Therefore, it is essential to highlight how students classify animals by applying their own criteria and categories.

The high school students' responses in this classification task were almost the same as those by junior high school students. Therefore, the students' alternative conceptions do not development positively between junior high school and high school. Then, the secondary school students often hold erroneous alternative conceptions. It seems, therefore, that these conceptions are resistant to change and remain stable even after teaching-learning sequences (Taber, 2000; Vosniadou, 2002).

\section{Educational implications}

Biology teachers need to be aware of students' alternative conceptions regarding animal classification in order to overcome students' difficulties in using taxonomic criteria to classify living things. This task requires disciplinary, educational and didactic skills of teachers to take in account these alternative conceptions. They have to take them into consideration during their planning and for their teaching objectives to develop them positively and ensure that biological classification is based on acceptable scientific criteria.

Biology teachers need to develop strategies based on the concept of the prototype suggested by Trowbridge \& Mintzes (1985), that animal classification lessons should be distributed in three elements:

A. Introduction to the concept: definition of the concept (animal taxa); provide several examples of each taxon;

B. Visual presentation of animals belonging to the taxon: critical attributes of the class are mentioned; development of the concept prototype; demonstration of examples and non- examples which represent misconceptions relative to classification of the prototype; biology teachers describe the critical attributes which do not exist in the non- examples;

C. Practical work about classification and generalization of the concept prototype: students recognize several taxa based on critical attributes by acquiring more illustrations concerning the animal studied, and the others which can represent confusion and alternative conceptions.

\section{References}

Arnaudin, M. W., \& Mintzes, J. J. (1985). Students' alternative conceptions of the human circulatory system: A cross-age study. Science Education, 69(5), 721-733.

Bell, B. F. (1981). When is an animal, not an animal? Journal of Biological Education, 15(3), 213-218. https://doi.org/10.1080/00219266.1981.9654381 
Bell, B., \& Barker, M. (1982). Towards a scientific concept of 'animal'. Journal of Biological Education, 16(3), 197-200.

Braund, M. (1991). Children's ideas in classifying animals. Journal of Biological Education, 25(2), 103-110.

Driver, R. (1981). Pupils' alternative frameworks in science. European Journal of Science Education, 3(1), 93-101.

Driver, R., \& Easley, J. (1978). Pupils and paradigms: A review of literature related to concept development in adolescent science students. Studies in Science Education, 5(1), 61-84

Gilbert, J. K., \& Watts, D. M. (1983). Conceptions, Misconceptions, and Alternative Conceptions: Changing perspectives in science education. Studies in Science Education, 10(1), 61-98.

Gilbert, J. K., Osborne, R. J., \& Fensham, P. J. (1982). Children's science and its consequences for teaching. Science education, 66(4), 623-633.

Herron, J. D., Cantu, L. L., Ward, R., \& Srinivasan, V. (1977). Problems associated with concept analysis. Science Education, 61(2), 185-199.

Hewson, P. W. (1981). A conceptual change approach to learning science. European Journal of Science Education, 3(4), 383-396.

Javeau, C. (1982). L'enquête par questionnaire.

Kattmann, U. (2001). Aquatics, Flyers, Creepers and Terrestrials - students' conceptions of animal classification. Journal of Biological Education, 35(3), 141-147.

Kelly, J. L. (1955). General topology.

Kubiatko, M., \& Prokop, P. (2007). Pupils' misconceptions about mammals. Journal of Baltic Science Education, 6(1), 5-15.

Markle, S. M., \& Tiemann, P. W. (1970). Conceptual learning and instructional design. Journal of Educational Technology, 1, 52-62.

Mintzes, J. J., \& Trowbridge, J. E. (1987). Alternative frameworks in animal classification. In Proceedings of the 2. International Seminar" Misconceptions and Educational Strategies in Science and Mathematics (Vol. 2, pp. 338-347).

Osborne, R. J., Bell, B. F., \& Gilbert, J. K. (1983). Science teaching and children's views of the world. European Journal of Science Education, 5(1), 1-14.

Ryman, D. (1974). Children's' understanding of the classification of living organisms. Journal of Biological Education, 8(3), 140-144. https://doi.org/10.1080/00219266 .1974 .9653932

Ryman, D. (1974). The relative effectiveness of teaching methods on pupils' understanding of the classification of living organisms at two levels of intelligence. Journal of Biological Education, 8(4), 219-223. https://doi.org/10.1080/00219266.19 74.9653951

Taber, K. (2000) Multiple frameworks? evidence of manifold conceptions in individual cognitive structure. International Journal of Science Education, 22, 399-417.

Trowbridge, J. E., \& Mintzes, J. J. (1985). Students' Alternative Conceptions of Animals and Animal Classification. School Science and Mathematics, 85(4), 304-316. https://doi.org/10.1111/j.1949-8594.1985.tb09626.x 
Trowbridge, J. E., \& Mintzes, J. J. (1988). Alternative conceptions in animal classification: A cross-age study. Journal of Research in Science Teaching, 25(7), 547-571. https://doi.org/10.1002/tea.3660250704

Vosniadou S. (2002). On the Nature of Naive Physics. In M. Limon and L. Mason (éd), Reconsidering the Processes of Conceptual Change issues in theory and practice, Springer, p. 61-76.

Yen, C. F., Yao, T. W., \& Chiu, Y. C. (2004). Alternative conceptions in animal classification focusing on amphibians and reptiles: A cross-age study. International Journal of Science and Mathematics Education, 2(2), 159-174. https://doi.org/10.1007/ s10763-004-1951-z 



\title{
WHAT ARE STUDENTS' MENTAL REPRESENTATIONS OF CLIMATE CHANGE AND THE GREENHOUSE EFFECT?
}

\author{
Vanessa Sesto, Isabel García-Rodeja, Begoña Varela \\ Departamento de Didácticas Aplicadas, Universidade de Santiago de Compostela \\ (Santiago de Compostela - Spain) \\ vanessa.sesto@usc.es; isabel.garcia-rodeja@usc.es
}

\begin{abstract}
This paper investigates the students' mental representations of climate change and the greenhouse effect. Ninety-nine secondary education students (Grades 7, 9 and 11) in Spain, participated in this study. Data was obtained by means of an open-ended questionnaire which focused on the mechanisms, causes and actions that could slow down climate change. The students' conceptions and mental models were identified by means of an inductive and iterative analysis of their explanations. With regards to the participants' conceptions, the results have shown that students tend to mention generic actions to mitigate climate change, such as not polluting. With regards to the participants' mental models, the results indicate that when students have limited previous knowledge of climate change, they are able to easily reconstruct their models by assimilating new information into existing knowledge structures. However, the evolution of extremely coherent and functional models is difficult to achieve. As educational implications, we propose creating classroom situations that will allow students to make their mental representations explicit, giving them an opportunity to compare their validity through discussion.
\end{abstract}

Keywords: climate change; greenhouse effect; mental models; science education; secondary students.

\section{Introduction}

Within the field of science education, emphasis is placed on the mental models that are built by students to help explain specific scientific domains. A mental model refers to a mental representation which is created by a human 
being from their innate predispositions and their previous experiences, which enables them to generate predictions and explanations of the facts or phenomena that occur around them (Greca \& Moreira, 2000). Mental models are dynamic representations that can be expanded or improved as new information is incorporated (Johnson-Laird, 1983). From the perspective of change based on mental models, Márquez, Pujol \& Bonil (2005) pointed out that the science learning process can be understood as a construction process in which the students' mental models, far from the models of school science, are modified by new experiences, new information and, especially through discussion.

While alternative conceptions are conceived as isolated ideas, mental models are constituted by a generative structure of beliefs and images that allows individuals to explain and predict natural phenomena (Chi, 2008; Schwarz et al., 2009). If the individual's mental models involve many distortions, preconceptions and alternative conceptions, these might lead to inaccurate explanations (Reinfried \& Tempelmann, 2014). However, due to the dynamic nature of mental models, those that differ in content and structure from the scientific models can evolve if appropriate teaching strategies are implemented. According to Gutiérrez (2004), students will modify their mental models when the criteria of consistency, robustness and correspondence are broken. A model is consistent when it lacks internal contradictions; it is robust when it can be used in unforeseeable situations when the model was constructed; and correspondence exists when the model is able to describe with fidelity the system's real behaviour (Gutiérrez, 2004). From the perspective of mental models, Gadgil, Nokes-Malach \& Chi (2012) understand conceptual change to be the transformation of prior knowledge that conflicts with the learned concepts. Gadgil et al. (2012) establish that the cognitive processes associated with this change include inference generation and knowledge revision.

This paper discusses alternative ideas and describes the levels of sophistication of the students' mental models on climate change. Several studies have revealed that students tend to link climate change with other environmental problems, such as the destruction of the ozone layer (e. g. Boyes \& Stanisstreet, 1993; Dove, 1996; Pruneau et al., 2001; Punter et al., 2011; Rye et al., 1997). With regards to the causes of climate change, several studies have reported that students tend to identify carbon dioxide as a greenhouse gas, but they do not identify methane or chlorofluorocarbons as such (e. g. Fisher, 1998). With regards to the consequences of climate change, there was a common misconception among students that global warming increases the incidence of skin cancer (e. g. Boyes \& Stanisstreet, 1993). In general, these studies have identified the following trends (García-Rodeja \& Lima, 2012): the tendency to understand and interpret the greenhouse effect exclusively as an environmental problem; to ignore the fact that it is the result of a natural mechanism; to confuse the nature of environmental problems (climate change and ozone depletion) or 
attribute them a causal relationship, and to confuse the causes, effects, and possible strategies for mitigating these problems.

Schraw, Crippen \& Hartley (2006) considered that students must construct appropriate mental models in order to be able to integrate the functional and causal relationships of complex systems like global climate. Other authors went further by studying the students' understanding of climate change, inferring that these mental models are the means by which the students' conceptions of climate change are structured (e. g. Andersson \& Wallin, 2000; García-Rodeja \& Lima, 2012; Koulaidis \& Christidou, 1999; Reinfried \& Tempelmann, 2014; Shepardson, Niyogi, Choi \& Charusombat, 2011). What makes this particular study relevant is the fact that although the subject of climate change is one of today's most important social scientific issues, numerous studies have demonstrated that students' ideas and mental models about climate change remain inappropriate. Further research is therefore needed in order to gain a better understanding of students' ideas and mental models on climate change that will make it possible to plan the curriculum, and design teaching materials in order to enable these mental models to evolve towards those of school science (Shepardson et al., 2011).

\section{Research questions}

This study represents a new contribution to the area of Environmental Education given that it aims to describe the levels of sophistication of students' mental models on climate change before and after instruction. Moreover, this study compares the views of different aged students on climate change. The objectives of this study are summarised in the following research questions:

1 . What is the view of different aged students on climate change?

2. How do the mental models on climate change and the greenhouse effect of seventh grade students evolve after instruction?

\section{Research design and method}

\subsection{Sample}

The participants were 99 Spanish students from middle school and high school. The distribution of students by grade was as follows: 40 students from the seventh grade (12-13 years), 40 students from the ninth grade (14-15 years), and 19 students from the eleventh grade (16-17 years). Out of all of the participants in this study, only the seventh graders received specific instruction about climate change during their Biology and Geology lessons. The teaching unit consisted of five 50-minute sessions and included the following content: 
structure, composition and functions of the atmosphere; impact of human activities on the atmosphere; air pollution; the natural and the enhanced greenhouse effect. The pretest can be considered as a part of the sequence of instruction given that it allows students to activate and make explicit their previous ideas. In the second activity, participants watched a video and discussed several questions in a large group. The video dealt with the structure, composition and the major environmental problems in the atmosphere, identifying the causes, effects and possible solutions for climate change. The teacher also described the functions of the atmosphere. In addition to these explanations, she also showed students different diagrams of the mechanisms of the greenhouse effect, and addressed different actions aimed at slowing down climate change. The third activity was a negotiation table in which students prepared a series of arguments for or against the construction of a thermal power plant in their city. It is important to note that the teacher taught her class as normal, without implementing any of the patterns established in this research. The sequence of activities is included in Table 1 .

TABLE 1

DESCRIPTION OF THE SEQUENCE OF ACTIVITIES

\begin{tabular}{|c|c|c|c|}
\hline $\begin{array}{l}\text { No. of } \\
\text { activity }\end{array}$ & Activity & Educational purpose & Content \\
\hline 1 & $\begin{array}{l}\text { Pre-test } \\
\text { (1st session) }\end{array}$ & $\begin{array}{l}\text { Give students the opportunity } \\
\text { to express their initial ideas. }\end{array}$ & - \\
\hline 2 & $\begin{array}{l}\text { The atmosphere } \\
\text { and climate change. } \\
\text { (2nd and 3rd } \\
\text { sessions) }\end{array}$ & $\begin{array}{l}\text { Learn about the major envi- } \\
\text { ronmental problems in the } \\
\text { atmosphere and their causes. }\end{array}$ & $\begin{array}{l}\text { Students watched a video about the } \\
\text { structure, composition and the en- } \\
\text { vironmental problems in the atmos- } \\
\text { phere. It included several diagrams } \\
\text { about the mechanism of the green- } \\
\text { house effect in which a distinction } \\
\text { was made between infrared radiation, } \\
\text { ultraviolet radiation and visible light. }\end{array}$ \\
\hline 3 & $\begin{array}{l}\text { Negotiation table } \\
\text { (4th and } \\
5 \text { th sessions) }\end{array}$ & $\begin{array}{l}\text { Relate human activities to } \\
\text { their impact on the atmosphe- } \\
\text { re. Propose agreed solutions. }\end{array}$ & $\begin{array}{l}\text { Students had to propose arguments } \\
\text { for or against the construction of a } \\
\text { thermal power plant in their city. }\end{array}$ \\
\hline
\end{tabular}

\subsection{Data collection and analysis}

Data collection included the students' responses to an open-ended questionnaire (Figure 1). The questionnaire focused on the mechanism, causes and actions that could slow down climate change. The first question, which was taken from the Dawson's questionnaire (2015), aimed to make explicit the students' ideas regarding what climate change is. The second and fourth questions, which were adapted from García-Rodeja \& Lima's questionnaire (2012), aimed to indicate the causes of climate change and identify the actions 
that can be taken to slow down climate change. The purpose of the third question, which was taken from the Dove's questionnaire (1996), was for students to represent their ideas about the greenhouse effect. The seventh graders responded to the same questionnaire on an individual basis both before and after instruction. The ninth and eleventh grade students only completed the questionnaire once because these two groups were not given specific teaching on climate change and the greenhouse effect.

1 What is climate change?

2 What are the causes of climate change?

3 Try to illustrate the greenhouse effect using this diagram.

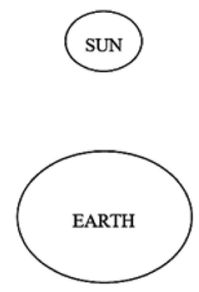

4 What actions do you suggest to slow down climate change?

Figure 1 Questionnaire items

The students' answers were analysed twice. The first analysis aimed to identify the conceptions held by students from all three grades. The second analysis aimed to identify the mental models of seventh grade students before and after instruction. During the first analysis, categories were generated in order to describe the elements of explanation, which students referred to in their answers (Fisher, 1998). In the second analysis, each questionnaire which had been completed by the seventh grade students was analysed carefully by reading the answers to each of the questions, and incorporating each student's conceptions into broader constructs, referred to as the students' mental models (García-Rodeja \& Lima, 2012; Shepardson et al., 2011). The pre-test was used to infer an initial model and the post-test was used to infer a final model. Additionally, since mental models are idiosyncratic in nature, different levels of sophistication were established making it possible to group together the mental models that share certain characteristics for each level.

\section{Results and discussion}

We will firstly describe the categorisation of each of the questions for all three grades. Each category is accompanied by a number that represents the 
frequency with which each of the explanatory elements appear in the participants' answers. Secondly, the levels established for the seventh grade students' mental models on the greenhouse effect are described, and the evolution of each participant after instruction is evaluated. For ethical reasons, each participant was identified by a code.

\subsection{Alternative conceptions}

Question 1. What is climate change?

When analysing the students' answers to this question, six main categories were identified (Table 2). This categorisation was inspired by previous studies (Dawson, 2015). From the group of seventh grade students, most of the answers, both before (40\%) and after (43\%) instruction, corresponded to the category that only mentions increases in temperature. One of the commonest explanations amongst the ninth and eleventh grade students was that climate change is the change in the Earth's average temperature. The fact that $30 \%$ of the ninth graders gave wrong answers and repeatedly associated climate change with the destruction of the ozone layer $(20 \%)$ was also significant. This idea has already been described at length by other authors (Andersson \& Wallin, 2000). For example, a ninth-grade student wrote: "It is the melting of the icecaps which is caused by the ozone layer breaking down" (Student 81, ninth grade).

TABLE 2

FREQUENCY OF REFERENCES TO THE DIFFERENT ELEMENTS OF EXPLANATION IN THE ANSWERS TO THE QUESTION: WHAT IS CLIMATE CHANGE?

\begin{tabular}{|c|c|c|c|c|c|}
\hline \multicolumn{2}{|l|}{ Categories } & $\begin{array}{c}\text { Seventh } \\
\text { grade } \\
(12-13 \\
\text { years }) \\
\text { Pre-test } \\
N=40\end{array}$ & $\begin{array}{c}\text { Seventh } \\
\text { grade } \\
(12-13 \\
\text { years }) \\
\text { Post-test } \\
N=40\end{array}$ & $\begin{array}{l}\text { Ninth } \\
\text { grade } \\
\text { (14-15 } \\
\text { years) } \\
N=40\end{array}$ & $\begin{array}{l}\text { Eleventh } \\
\text { grade } \\
\text { (16-17 } \\
\text { years) } \\
N=19\end{array}$ \\
\hline \multicolumn{2}{|c|}{$\begin{array}{l}\text { Climate change is associated with a change in } \\
\text { climate and/or an increase in temperature as a result } \\
\text { of the greenhouse effect or the accumulation of } \\
\text { greenhouse gases (right answer). }\end{array}$} & $3(8 \%)$ & $9(23 \%)$ & $1(3 \%)$ & $3(16 \%)$ \\
\hline \multicolumn{2}{|c|}{$\begin{array}{l}\text { Links climate change to an increase in temperature } \\
\text { with the associated consequences (partially right } \\
\text { answer). }\end{array}$} & $3(8 \%)$ & $0(0 \%)$ & $2(5 \%)$ & $2(11 \%)$ \\
\hline \multicolumn{2}{|c|}{$\begin{array}{l}\text { Links climate change to an increase in temperature } \\
\text { (partially right answer). }\end{array}$} & $16(40 \%)$ & $17(43 \%)$ & $\begin{array}{l}11 \\
(28 \%)\end{array}$ & $8(42 \%)$ \\
\hline \multicolumn{2}{|c|}{ Links climate change to a change in climate. } & $13(33 \%)$ & $10(25 \%)$ & $14(35 \%)$ & $3(16 \%)$ \\
\hline \multirow{2}{*}{$\begin{array}{l}\text { Incorrect } \\
\text { answer. }\end{array}$} & Links climate change to the ozone layer. & $0(0 \%)$ & $0(0 \%)$ & $8(20 \%)$ & $0(0 \%)$ \\
\hline & Others & $4(10 \%)$ & $1(3 \%)$ & $4(10 \%)$ & $3(16 \%)$ \\
\hline \multicolumn{2}{|c|}{ No answer. } & $1(3 \%)$ & $3(8 \%)$ & $0(0 \%)$ & $0(0 \%)$ \\
\hline
\end{tabular}


Question 2. What are the causes of climate change?

The categorisation of the answers to this question can be seen in Table 3 . In the pre-test, most of the seventh grade students claimed that pollution (50\%) and carbon dioxide (18\%) were the causes of climate change. After the intervention, the number of seventh grade students who referred to the increase in the greenhouse effect as a cause of climate change increased by $30 \%$.

TABLE 3

FREQUENCY OF REFERENCES TO DIFFERENT ELEMENTS OF EXPLANATION IN THE ANSWERS TO THE QUESTION: WHAT ARE THE CAUSES OF CLIMATE CHANGE?

\begin{tabular}{|c|c|c|c|c|c|}
\hline \multicolumn{2}{|l|}{ Categories } & $\begin{array}{l}\text { Seventh } \\
\text { grade } \\
(12-13 \\
\text { years) } \\
\text { Pre-test } \\
N=40\end{array}$ & $\begin{array}{l}\text { Seventh } \\
\text { grade } \\
\text { (12-13 } \\
\text { years) } \\
\text { Post-test } \\
N=40\end{array}$ & $\begin{array}{l}\text { Ninth } \\
\text { grade } \\
(14-15 \\
\text { years) } \\
N=40\end{array}$ & $\begin{array}{c}\text { Eleventh } \\
\text { grade } \\
(16-17 \\
\text { years) } \\
N=19\end{array}$ \\
\hline \multicolumn{2}{|c|}{ Increase in the greenhouse effect. } & $0(0 \%)$ & $12(30 \%)$ & $1(3 \%)$ & $6(32 \%)$ \\
\hline \multicolumn{2}{|c|}{ Greenhouse effect. } & $2(5 \%)$ & $3(10 \%)$ & $3(10 \%)$ & $2(11 \%)$ \\
\hline \multicolumn{2}{|l|}{ GHG emissions. } & $3(8 \%)$ & $8(20 \%)$ & $1(3 \%)$ & $0(0 \%)$ \\
\hline \multicolumn{2}{|l|}{$\mathrm{CO} 2$ emissions. } & $7(18 \%)$ & $1(3 \%)$ & $4(10 \%)$ & $1(5 \%)$ \\
\hline \multicolumn{2}{|l|}{ CFC emissions. } & $0(0 \%)$ & $1(3 \%)$ & $1(3 \%)$ & $0(0 \%)$ \\
\hline \multicolumn{2}{|l|}{ Aerosols. } & $0(0 \%)$ & $1(3 \%)$ & $1(3 \%)$ & $0(0 \%)$ \\
\hline \multicolumn{2}{|c|}{ Pollution or pollutant gases. } & $20(50 \%)$ & $12(30 \%)$ & $24(60 \%)$ & $8(42 \%)$ \\
\hline \multicolumn{2}{|l|}{ Human activities. } & $5(13 \%)$ & $8(20 \%)$ & $3(8 \%)$ & $3(16 \%)$ \\
\hline \multicolumn{2}{|l|}{ Natural causes. } & $0(0 \%)$ & $2(5 \%)$ & $1(3 \%)$ & $0(0 \%)$ \\
\hline \multicolumn{2}{|l|}{ Deforestation. } & $1(3 \%)$ & $0(0 \%)$ & $2(5 \%)$ & $0(0 \%)$ \\
\hline \multicolumn{2}{|c|}{ Overexploitation of natural resources. } & $2(5 \%)$ & $0(0 \%)$ & $0(0 \%)$ & $0(0 \%)$ \\
\hline \multirow[t]{2}{*}{ Effects } & Melting icecaps. & $3(8 \%)$ & $0(0 \%)$ & $2(5 \%)$ & $2(11 \%)$ \\
\hline & Rise in temperature & $3(8 \%)$ & $2(5 \%)$ & $2(5 \%)$ & $1(5 \%)$ \\
\hline \multirow[t]{2}{*}{ Other problems. } & Acid rain. & $0(0 \%)$ & $3(8 \%)$ & $0(0 \%)$ & $0(0 \%)$ \\
\hline & $\begin{array}{l}\text { Destruction of the ozone } \\
\text { layer. }\end{array}$ & $1(3 \%)$ & $7(18 \%)$ & $5(13 \%)$ & $1(5 \%)$ \\
\hline \multicolumn{2}{|c|}{ Don't know/no answer. } & $2(5 \%)$ & $2(5 \%)$ & $0(0 \%)$ & $2(11 \%)$ \\
\hline
\end{tabular}

When comparing the results of all participants, we are able to observe that the most commonly cited cause in all grades was pollution. This was interpreted as a generic answer because, although there are multiple pollutants, not all of them contribute to climate change. This finding is in line with results from previous studies (Pruneau et al., 2001). 
Question 3. Diagram of the greenhouse effect

Table 4 includes the elements of explanation used by students in their diagrams of the greenhouse effect. In the pre-test, $88 \%$ of seventh grade students included solar radiation in their drawings, $40 \%$ represented a layer of gases, $38 \%$ included retained heat and 38\% represented the radiation being emitted back towards the Earth. The idea of a layer of gases that traps solar radiation also appears in other papers (Anderson \& Wallin, 2000). In the post-test, 88\% of seventh grade students represented radiation being emitted back into space and $40 \%$ included infrared radiation. This great improvement after the intervention may be due to the video that the class watched in which a distinction was made between infrared radiation, ultraviolet radiation and visible light.

By comparing the results of the seventh grade students with those of the other two grades, we are able to observe that the ninth and eleventh grade students' drawings of the greenhouse effect included solar radiation and the radiation emitted back towards the planet; however, unlike some seventh grade students in the post-test, they did not include infrared radiation or greenhouse gases. In addition, $33 \%$ of ninth grade students drew the ozone layer, while $37 \%$ of eleventh grade students drew a layer without specifying further.

TABLE 4

FREQUENCY OF REFERENCES TO DIFFERENT ELEMENTS OF EXPLANATION IN THE ANSWERS TO THE QUESTION: TRY TO ILLUSTRATE THE GREENHOUSE EFFECT USING THIS DIAGRAM

\begin{tabular}{|c|c|c|c|c|}
\hline Categories & $\begin{array}{c}\text { Seventh } \\
\text { grade } \\
\text { (12-13 } \\
\text { years) } \\
\text { Pre-test } \\
N=40\end{array}$ & $\begin{array}{l}\text { Seventh } \\
\text { grade } \\
\text { (12-13 } \\
\text { years) } \\
\text { Post-test } \\
N=40\end{array}$ & $\begin{array}{l}\text { Ninth } \\
\text { grade } \\
(14-15 \\
\text { years) } \\
N=40\end{array}$ & $\begin{array}{c}\text { Eleventh } \\
\text { grade } \\
\text { (16-17 } \\
\text { years) } \\
N=19\end{array}$ \\
\hline No answer. & $2(5 \%)$ & $0(3 \%)$ & $5(13 \%)$ & $3(16 \%)$ \\
\hline Sun rays. & $35(88 \%)$ & $39(98 \%)$ & $33(83 \%)$ & $16(84 \%)$ \\
\hline Infrared radiation. & $0(0 \%)$ & $16(40 \%)$ & $0(0 \%)$ & $0(0 \%)$ \\
\hline Ultraviolet radiation. & $3(8 \%)$ & $2(5 \%)$ & $2(5 \%)$ & $2(11 \%)$ \\
\hline Radiation emitted back into space. & $9(23 \%)$ & $35(88 \%)$ & $14(35 \%)$ & $1(5 \%)$ \\
\hline Radiation emitted back towards the planet. & $15(38 \%)$ & $33(83 \%)$ & $16(40 \%)$ & $6(32 \%)$ \\
\hline Retained heat. & $15(38 \%)$ & $11(13 \%)$ & $5(13 \%)$ & $3(16 \%)$ \\
\hline Ozone layer & $4(10 \%)$ & $4(10 \%)$ & $13(33 \%)$ & $1(5 \%)$ \\
\hline Layer of gases. & $16(40 \%)$ & $6(15 \%)$ & $3(8 \%)$ & $5(26 \%)$ \\
\hline Layer. & $10(25 \%)$ & $17(43 \%)$ & $11(13 \%)$ & $7(37 \%)$ \\
\hline Pollution. & $0(0 \%)$ & $0(0 \%)$ & $3(8 \%)$ & $1(5 \%)$ \\
\hline Greenhouse gases (GHG). & $0(0 \%)$ & $7(18 \%)$ & $0(0 \%)$ & $1(5 \%)$ \\
\hline $\mathrm{CO} 2$ & $2(5 \%)$ & $2(5 \%)$ & $2(5 \%)$ & $1(5 \%)$ \\
\hline Water vapour. & $0(0 \%)$ & $2(5 \%)$ & $0(0 \%)$ & $0(0 \%)$ \\
\hline
\end{tabular}


Question 4. What actions do you suggest to slow down climate change?

The categorisation of the answers to this question can be seen in Table 5 . Consistent with the literature (Bodzin et al., 2014), almost half of the seventh grade students mentioned the idea of reducing the use of vehicles and increasing the use of public transport and cycling or walking short distances. After the intervention, we observed a significant increase in the number of references to energy-saving measures in the home and responsible energy consumption.

TABLE 5

FREQUENCY OF REFERENCES TO DIFFERENT ELEMENTS OF EXPLANATION IN THE ANSWERS TO THE QUESTION: WHAT ACTIONS DO YOU SUGGEST TO SLOW DOWN CLIMATE CHANGE?

\begin{tabular}{|c|c|c|c|c|c|}
\hline Categories & & $\begin{array}{l}\text { Seventh } \\
\text { grade } \\
(12-13 \\
\text { years) } \\
\text { Pre-test } \\
N=40\end{array}$ & $\begin{array}{l}\text { Seventh } \\
\text { grade } \\
(12-13 \\
\text { years) } \\
\text { Post-test } \\
N=40\end{array}$ & $\begin{array}{l}\text { Ninth } \\
\text { grade } \\
(14-15 \\
\text { years) } \\
N=40\end{array}$ & $\begin{array}{c}\text { Eleventh } \\
\text { grade } \\
\text { (16-17 } \\
\text { years) } \\
N=19\end{array}$ \\
\hline \multirow[t]{3}{*}{ No answer: } & & $2(5 \%)$ & $3(8 \%)$ & $1(3 \%)$ & $2(11 \%)$ \\
\hline & Reduce CO2 emissions. & $3(8 \%)$ & $3(8 \%)$ & $2(5 \%)$ & $2(11 \%)$ \\
\hline & Reduce GHG emissions. & $0(0 \%)$ & $1(3 \%)$ & $1(3 \%)$ & $2(11 \%)$ \\
\hline \multirow[t]{4}{*}{ Gases: } & Reduce gas emissions. & $5(13 \%)$ & $2(5 \%)$ & $3(8 \%)$ & $4(21 \%)$ \\
\hline & $\begin{array}{l}\text { Reduce CFC emissions and } \\
\text { aerosols. }\end{array}$ & $1(3 \%)$ & $8(20 \%)$ & $3(8 \%)$ & $0(0 \%)$ \\
\hline & $\begin{array}{l}\text { Reduce consumption of fos- } \\
\text { sil fuels. }\end{array}$ & $4(10 \%)$ & $0(0 \%)$ & $1(3 \%)$ & $0(0 \%)$ \\
\hline & $\begin{array}{l}\text { Increase consumption of re- } \\
\text { newable energy. }\end{array}$ & $3(8 \%)$ & $3(8 \%)$ & $1(3 \%)$ & $3(16 \%)$ \\
\hline \multirow[t]{2}{*}{ Energy: } & $\begin{array}{l}\text { Reduce the use of cars (using } \\
\text { public transport, bicycles, } \\
\text { electric cars, walking). }\end{array}$ & $18(45 \%)$ & $25(63 \%)$ & $14(35 \%)$ & $7(37 \%)$ \\
\hline & $\begin{array}{l}\text { Save energy, responsible and } \\
\text { efficient consumption. }\end{array}$ & $2(5 \%)$ & $20(50 \%)$ & $1(3 \%)$ & $1(5 \%)$ \\
\hline \multirow{7}{*}{ Others: } & $\begin{array}{l}\text { Generic actions, such as not } \\
\text { polluting the environment or } \\
\text { being more careful with the } \\
\text { environment. }\end{array}$ & $12(30 \%)$ & $4(10 \%)$ & $16(40 \%)$ & $4(21 \%)$ \\
\hline & $\begin{array}{l}\text { Not cutting down trees. } \\
\text { Planting trees. }\end{array}$ & $4(10 \%)$ & $6(15 \%)$ & $3(8 \%)$ & $2(11 \%)$ \\
\hline & $\begin{array}{l}\text { Not throwing rubbish into } \\
\text { rivers and seas. }\end{array}$ & $2(5 \%)$ & $1(3 \%)$ & $2(5 \%)$ & $0(0 \%)$ \\
\hline & Recycling. & $5(13 \%)$ & $5(13 \%)$ & $9(23 \%)$ & $5(26 \%)$ \\
\hline & $\begin{array}{l}\text { Reducing the use of, or not } \\
\text { using products that damage } \\
\text { the ozone layer. }\end{array}$ & $1(3 \%)$ & $0(0 \%)$ & $3(8 \%)$ & $0(0 \%)$ \\
\hline & $\begin{array}{l}\text { Reducing production in fac- } \\
\text { tories. }\end{array}$ & $3(8 \%)$ & $3(8 \%)$ & $4(10 \%)$ & $3(16 \%)$ \\
\hline & $\begin{array}{l}\text { Awareness campaign and le- } \\
\text { gislation. }\end{array}$ & $0(0 \%)$ & $0(0 \%)$ & $3(8 \%)$ & $1(5 \%)$ \\
\hline
\end{tabular}


When comparing the results of the three grades, we observed that the ninth grade students most frequently referred to strategies, such as reducing the use of products which are harmful to the ozone layer. The suggestion of this action is consistent with the results obtained from the other questions in the questionnaire, in which the ninth grade students often referred to the links between climate change and the destruction of the ozone layer. Likewise, it has been observed that ninth and eleventh grade students tended to suggest more generic actions, such as recycling and reusing materials. Furthermore, some of the older students mentioned actions aimed at increasing the surveillance and control of activities that produce pollution as well as the adoption of more restrictive laws and international treaties.

\subsection{Mental models}

We found that the seventh grade students' mental models regarding climate change and the greenhouse effect correspond to four levels of sophistication (Figure 2). These levels have been listed from 1 to 4 in increasing order of sophistication, attempting to show the progression in the students' learning about the greenhouse effect. The level 1 mental models are descriptive and similar to what Reinfried \& Tempelmann (2014) called "isolated pieces of knowledge". The level 2 mental models incorporated the idea that the destruction of the ozone layer allows more radiation to reach the Earth, or that the thickening of the ozone layer prevents solar radiation from being emitted back into space. This level is comparable to the mental model 2 identified by Shepardson et al. (2011). The level 3 mental model embraces the idea that there are greenhouse gases in the atmosphere that trap the sun's rays. This mental model also includes the idea of a layer of gases that surrounds the Earth. The level 4 mental models are the closest to the model taught in school science.

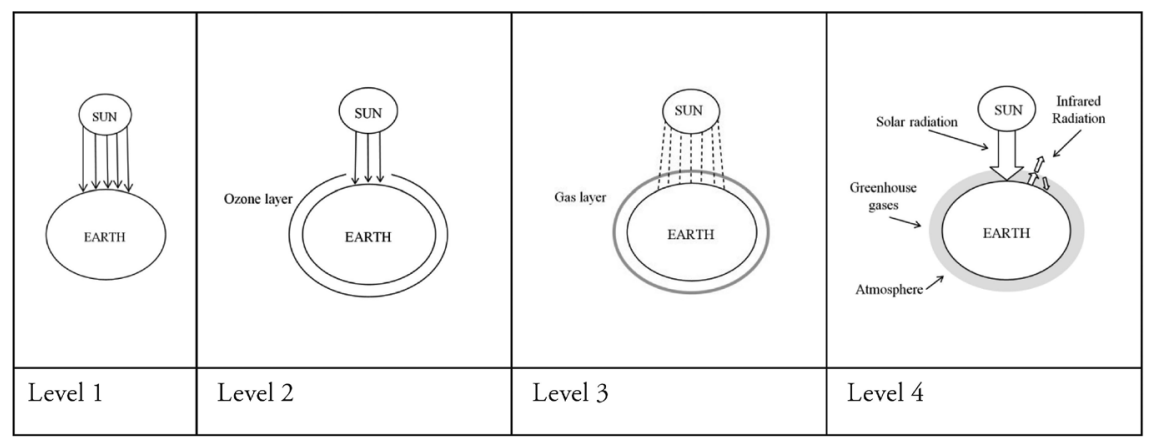

Figure 2 Diagrams of the levels in the seventh grade students' mental models on the greenhouse effect 
Table 6 shows the frequencies of each level of sophistication in the students' mental models in the pre-test and post-test. It also includes the level of the mental model demonstrated by each student, identified by a code in order to monitor the evolution of each participant. We observe that before instruction, the most frequent level was level $1(48 \%)$; whereas, after instruction, the most representative level was level $3(38 \%)$.

TABLE 6

RATIO OF SEVENTH GRADE STUDENTS ASSOCIATED WITH EACH LEVEL IN THE MENTAL MODELS AND FREQUENCY OF EACH LEVEL $(N=40)$

\begin{tabular}{|c|c|c|c|c|}
\hline Level & Pre-test student code & Post-test student code & $\begin{array}{c}\text { Number of students } \\
\text { (pre-test) }\end{array}$ & $\begin{array}{c}\text { Number of students } \\
\text { (post-test) }\end{array}$ \\
\hline 1 & $\begin{array}{l}2,3,4,7,8,11,14,16 \\
18,19,20,23,24,25 \\
29,30,38,39,40\end{array}$ & $\begin{array}{l}1,2,3,11,20,24,30 \\
39,40 .\end{array}$ & $19(48 \%)$ & $9(23 \%)$ \\
\hline 2 & $1,5,13,17,21,36,37$ & $5,13,16,17,23,36$ & $7(18 \%)$ & $6(15 \%)$ \\
\hline 3 & $\begin{array}{l}6,10,12,15,26,28 \\
32,34,35\end{array}$ & $\begin{array}{l}4,6,7,8,9,10,12, \\
14,21,25,26,29,32, \\
35,38 .\end{array}$ & $9(23 \%)$ & $15(38 \%)$ \\
\hline 4 & $9,22,27,31,33$ & $\begin{array}{l}15,18,19,22,27,28 \\
31,33,34,37 .\end{array}$ & $5(13 \%)$ & $10(25 \%)$ \\
\hline
\end{tabular}

Moreover, by comparing the students' codes in both columns of Table 6 we can see that 22 participants stayed on the same level before and after instruction. We attribute this finding to the fact that during instruction, insufficient emphasis was placed on the students becoming aware of their initial mental models and there were few opportunities to compare their mental models with the models taught in the school science curriculum. Seven students (codes 4, 7, 8, 14, 25, 29,38 ) changed their mental models from level 1 to level 3. Four students with level 1 models (codes 5, 13, 17, 36) did not change their models after instruction despite the fact that they were taught about alternative conceptions.

\section{Conclusions}

With regards to the conceptions of the seventh grade students, their responses to the questionnaire showed that some of them wrongly associated climate change with the reduction of the ozone layer, an idea already discussed in previous studies (Andersson \& Wallin, 2000; Boyes \& Stanisstreet, 1993). They generally provided generic answers with regards to the causes of this environmental problem, and they tended to use pollution as an element of explanation.

Furthermore, when comparing the results obtained from the students of all three grades, we observed no significant differences in relation to what they 
understand by climate change because, regardless of their age, most of them related this environmental problem to an increase in the average temperature of the planet and they failed to mention the increase in the greenhouse effect. The reason why the results obtained from the seventh grade students were similar to those obtained from students from higher grades, even before instruction, may be due to the fact that nowadays, attempts at raising awareness about climate change begin at an earlier age and this topic is considered to be more appropriate. This is important progress because it shows that existing training plans are beginning to yield positive results.

With regards to the seventh grade students' mental models of the greenhouse effect, we observed a general evolution in this group of students' mental models, moving towards more sophisticated mental models following instruction. The results reveal that descriptive models such as those included in level 1 can be easily modified and evolved towards models which are close to the model offered in the school science classroom. Students with level 1 mental models have limited prior knowledge of the greenhouse effect. As a consequence, they are able to easily reconstruct their mental models by assimilating new information into existing knowledge structures. On the contrary, the evolution of models in level 2 is difficult to achieve due to the fact that it implies the modification of a highly coherent and functional initial model. The differences between their previous ideas and the new information are so profound that students have to build a new mental model in order to be able to explain the mechanisms of the greenhouse effect (Reinfried \& Tempelmann, 2014).

As educational implications, we propose creating classroom situations that will allow students to make their mental representations explicit, giving them an opportunity to compare their validity through discussion. It must be made clear that this study does not seek to generalise results to other cases. However, it does allow for comparisons to be made with other studies of a similar nature, contributing to the knowledge of students' conceptions and mental models on climate change.

\section{Acknowledgment}

This study was funded by the Spanish Ministry of Economy and Competitiveness (EDU2015-66643-C2-2-P).

\section{References}

Andersson, B., \& Wallin, A. (2000). Students' understanding of the greenhouse effect, the societal consequences of reducing $\mathrm{CO}_{2}$ emissions and the problem of ozone layer depletion. Journal of Research in Science Teaching, 37(10), 1096-1111. 
Bodzin, A. M., Anastasio, D., Sahagian, D., Peffer, T., Dempsey, C., \& Steelman, R. (2014). Investigating climate change understandings of urban middle-level students. Journal of Geoscience Education, 62(3), 417-430.

Boyes, E., \& Stanisstreet, M. (1993). The greenhouse effect: children's perception of causes, consequences and cures. International Journal of Science Education, 15(5), 531-552.

Chi, M. T. H. (2008). Three types of conceptual change: Belief revision, mental models transformation, and categorical shift. In S. Vosniadou (Ed.), Handbook of research on conceptual change (pp. 61-82). Hillsdale: Erlbaum.

Dawson, V. (2015). Western Australian high school students' understandings about the socioscientific issue of climate change. International Journal of Science Education, 37(7), 1024-1043.

Dove, J. (1996). Student teacher understanding of the greenhouse effect, ozone layer Depletion and acid rain. Environmental Education Research 2 (1), 89-100.

Fisher, B. (1998). Australian students' appreciation of the greenhouse effect and the ozone hole. Australian Science Teachers Journal, 44(3), 46-55.

Gadgil, S., Nokes-Malach, T. J., \& Chi, M. T. H. (2012). Effectiveness of holistic mental model confrontation in driving conceptual change. Learning and Instruction, 22(1), 47-61.

García-Rodeja, I., \& Lima, G. (2012). Sobre el cambio climático y el cambio de los modelos de pensamiento de los alumnos [On climate change and the change of models of students' thinking]. Enseñanza de las Ciencias, 30(3), 195-218.

Greca, I. M., \& Moreira, M. A. (2000). Mental models, conceptual models, and modelling. International Journal of Science Education, 22(1), 1-11.

Gutiérrez, R. (2004). La modelización y los procesos de enseñanza/aprendizaje [Modelling and teaching/learning processes]. Alambique: Didáctica de las Ciencias Experimentales, 10(42), 8-18.

Johnson-Laird, P. N. (1983) Mental models. Towards a cognitive science of language, inference and consciousness. Cambridge: Cambridge University Press.

Koulaidis, V., \& Christidou, V. (1999). Models of students' thinking concerning the greenhouse effect and teaching implications. Science Education, 83(5), 559-576.

Márquez, C., Pujol R. M., \& Bonil J. (2005). Las preguntas mediadoras como recursos para favorecer la construcción de modelos científicos complejos [Mediating questions as resources to favor the construction of complex scientific models]. Enseñanza de las Ciencias, Extra, 1-5.

Pruneau, D., Liboiron, L., Vrain, E., Gravel, H., Bourque, W., \& Langis, J. (2001). People's ideas about climate change: A source of inspiration for the creation of educational programs. Canadian Journal of Environmental Education, 6, 121-138.

Punter, P., Ochando-Pardo, M., \& García, J. (2011). Spanish secondary students' notion on the causes and consequences of climate change. International Journal of Science Education, 33(3), 447-464.

Reinfried, S., \& Tempelmann, S. (2014). The impact of secondary school students' preconceptions on the evolution of their mental models of the greenhouse effect and global warming. International Journal of Science Education, 36(2), 304-333. 
Rye, J. A., Rubba, P. A., \& Wiesenmayer, R. L. (1997). An investigation of middle school students'alternative conceptions of global warming. International Journal of Science Education, 19 (5), 527-551.

Schraw, G., Crippen, K. J., \& Hartley, K. (2006). Promoting self-regulation in science education: Metacognition as part of a broader perspective on learning. Research in Science Education, 36(1-2), 111-139.

Schwarz, C. V., Reiser, B. J., Davis, E. A., Kenyon, L., Acher, A., Fortus, D., Shwartz, Y., Hug, B., \& Krajcik, J. (2009). Developing a learning progression for scientific modeling: Making scientific modeling accessible and meaningful for learners. Journal of Research in Science Teaching, 46(6), 632-654.

Shepardson, D. P., Choi, S., Niyogi, D., \& Charusombat, U. (2011). Seventh grade students' mental models of the greenhouse effect. Environmental Education Research, 17(1), 1-17. 
SECTION 3

STUDENTS' INTEREST AND MOTIVATION 



\title{
ENGAGING STUDENTS IN STUDYING HUMAN BIOLOGY THROUGH DIGITAL STORYTELLING
}

\author{
Maria Dokopoulou and Evangelia A. Pavlatou \\ School of Chemical Engineering - National and Technical University of Athens \\ mdokopoulou@gmail.com
}

\begin{abstract}
Our study focuses on exploring students' engagement in Human Biology using the construction of several digital stories (Digital Storytelling) in Human Anatomy and Physiology as a field of the Biology curriculum in the Greek upper secondary education system. 15 year old students used software to make digital stories about human organ systems and relevant health problems that were addressed by exploring possible causes and solutions. To gain an understanding of students' engagement, personal interviews were conducted. Students' responses were coded under three dimensions of students' engagement: behavioural, emotional and cognitive engagement. Our findings indicate the impact of Digital Storytelling in students' engagement in the biology content and the learning procedure. Both positive and negative perspectives are discussed to evaluate critically the strength and the weaknesses of implementing such an initiative in biology teaching.
\end{abstract}

Keywords: digital storytelling; engagement; secondary education

\section{Introduction}

The work in science education reform is to bring more engaged science activities into classrooms, given that the traditional methods fail the majority of students who leave introductory courses, viewing science, and especially biology, as a large collection of disconnected facts, which have little relevance to their daily lives and will soon be forgotten (Wood, 2009). To enable this, it is argued that students should be engaged in complex investigations since procedural and 
content understandings are both essential components of such practical investigations (Hodson, 1992). One of the most popular techniques that is proposed for achieving that goal is Digital Storytelling.

Digital stories allow opportunities for students' control of the learning process and self expression, fostering learning motivation. Each story challenges students to meticulously select and edit artifacts, from personal products to other multimedia resources that meaningfully support the story and learning goals, thereby developing technology and media skills (EDUCAUSE; Learning Initiative, 2007). The combination of text, images and audio motivates students to engage in deep learning (Pounsford, 2007). Since digital student- created stories demand a prerequisite level of understanding about the topic at hand, they prompt students to engage in reflective learning and deeper thought processes as they personalize their experience and communicate their ideas with peers (Sandars et al 2008; Dillard \& Reynolds, 2010).

Taking for granted that this pedagogical strategy is successful in engaging learners, our study focuses on exploring different types of students' engagement in Human Biology using the creation of several digital stories in Human Anatomy and Physiology as a field of the biology curriculum in the Greek upper secondary education system. We researched the three dimensions of students' engagement as proposed by Fredricks et al. (2004): cognitive, emotional and behavioral engagement, since a "fusion" of these categories is essential to get a deeper and more satisfying handle on students' engagement. The next step in our research is to explore students' engagement in the same content without using any of the digital storytelling tools in order to investigate if this approach is more engaging for students or not.

\section{Students' engagement}

Engagement is a key factor in successful learning (Hung, 2012). The application of technology improves students' engagement and performances in technology-rich classrooms (Jonassen, 2000). However, instructors need to design meaningful activities for enhancing students' interest and promoting active learning (Chang, 2005) in order to actively interpret and comprehend the knowledge (McLellan, 1993). Creating a digital story could be a meaningful activity for students as it provides them the chance to express their personal opinion on a subject or explore in their own way a physical phenomenon or procedure (Blocher, 2008). School engagement is a concept that has attracted growing interest as a way to explore students' academic achievement. Newman (1992) explored how classroom instruction and tasks can heighten intellectual engagement, and other studies examine how contexts interact with individual needs to promote or undermine engagement (Connel, 1990; Skinner \& Belmont, 1993). 
Student engagement, described as the tendency to be behaviourally, emotionally and cognitively involved in academic activities, is a basic construct in motivation research (Thijs \& Verkuyten, 2009) as highly motivated students make an effort to be engaged in the classroom. While engagement is viewed as a key factor for enhanced learning outcomes, focusing on what students do in the classroom, motivation is seen as a pre-requisite for student engagement in learning (Woolfolk \& Margetts, 2007) explaining why students get involved. Focusing on the role of Digital Storytelling as an educational tool, and taking under consideration that motivation is influenced by the social and the school context we examined what students do, feel and learn while using this educational approach, and not why they are doing it. This is why this research is looking for students' engagement and not motivation.

In our study we researched the following dimensions of students' engagement:

- Behavioral engagement draws on the idea of participation; it includes involvement in academic or extracurricular activities and is considered crucial for achieving positive academic outcomes. Participation could range from responding to the teachers directions to activities that require students' autonomy (Finn, 1989), reflecting on the level of commitment to the learning process.

- Emotional engagement encompasses positive and negative reactions to teachers, classmates and school, and is presumed to influence willingness to do the work. Students' involvement in academic tasks is one of the basic parameters of emotional engagement including behaviours such as effort, persistence, concentration, attention, asking questions and contributing to class discussion (Birch \& Ladd, 1997).

- Cognitive engagement incorporates thoughtfulness and willingness to exert the effort necessary to comprehend complex ideas and master difficult skills. The learning literature defines cognitive engagement in terms of being strategic or self-regulating, meaning that students use learning strategies such as rehearsal, summarizing and elaboration to remember and understand the material (Weinstein \& Mayer, 1986).

Digital storytelling uses the power of multimedia to engage students' visual and auditory senses, making abstract content more accessible and facilitating discussions about topics in the story, hence engaging a large group of students (Pounsford, 2007). This is possible since students are more willing to listen actively and relate the story to their own experiences and perspectives. As a result, the process attracts students to participate and be engaged (Miley, 2009). Taking into consideration these remarks in our study we developed and applied educational material that has two basic characteristics; firstly the use of several multimedia resources (e.g images, video) and secondly the connection of the educational content with everyday life problems. This material was used by the students to create their own digital stories. 


\section{Research design and method}

Our sample consists of 27 students in their first year ( 15 year olds) in upper secondary education. During the school year, the students used educational material (e.g. school books, extra texts, images, videos) and any other resources of their choice to produce their digital stories on Human Anatomy and Physiology, concerning Nervous, Sensory, Circulatory and Reproductive organ systems. The students used software (Microsoft Power Point, Windows Movie Maker and Windows Photo Story 3) to make digital stories about specific health problems that were addressed by exploring possible causes and solutions (Figure 1). The students that had no previous experience of group working worked individually to produce one digital story for each one of the above sections. Given that a list of all of these tasks had been handed to them at the beginning of the school year, they could choose if they would develop their digital stories as a revision of each section or as an add-on activity. None of these tasks was obligatory. Considering instruction, a teacher-centered teaching method was followed.

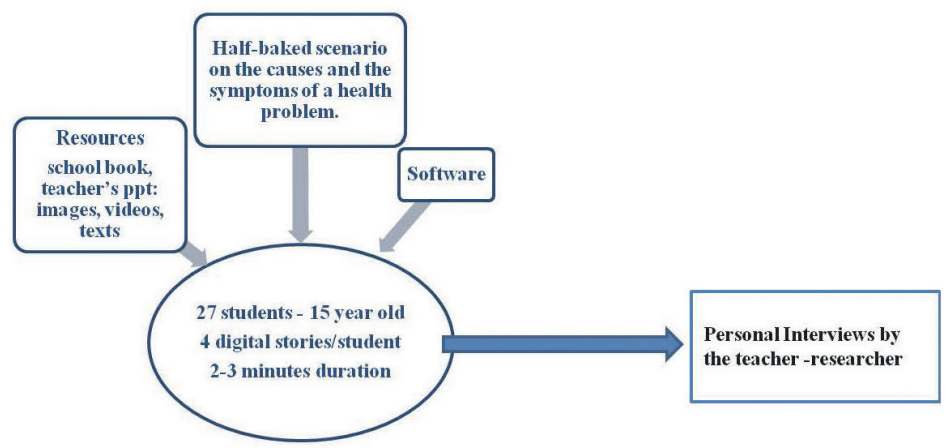

Figure 1 Research design

Table 1 presents the scenarios that were given to the students. Students had to make a two to three-minute digital story working on the given scenario, on which they could also make any changes they wanted in order to solve the problem that was proposed for every one of the organ systems.

Data collection began in November 2015 and was completed in September 2016. According to the Greek curriculum, Human Biology is a two-hour weekly lesson. Thus our study covered 40 teaching hours during the school year 2015-2016. Qualitative data were collected via interviews. Interviews were conducted at the end of school year both individually and in group discussions to investigate how students comment on their learning process. Table 2 indicates the way that the interview questions were organized to explore the three different types of engagement. 


\section{TABLE 1 \\ STUDENTS SCENARIOS AND TASKS}

\begin{tabular}{ll}
\hline Nervous system & An old couple visits the neurological clinic of a hospital. The main problem \\
is that in the last six months the old man forgets some things. Doctors ad- \\
vice him to have some tests like a brain MRI and special blood tests. Make \\
a digital story to answer to the following questions: \\
1. Why does the old man have to do these tests? \\
2. What is the possible cause of the symptoms? \\
3. Which is the part of the nervous system that is most affected? \\
4. Is there a treatment? \\
You are going to a music concert. The place is crowded, full of smoke and \\
it's dark. On the stage the light is very bright and the sound is very loud. \\
After some moments you feel very hot and dizzy and a friend of yours co- \\
llapses. Make a digital story to answer to the following questions: 1.Which \\
organs of your sensory system were affected during that concert? \\
2. What is the role of your brain in the function of these organs? \\
3. What may have caused your friend collapse? \\
A 45 years man visits his cardiologist because he suffers from chest pain. He \\
is a smoker, overweight and does no physical exercise. The doctor checks \\
his palms and his heart function. He asks him to have some blood tests and \\
explains to the patient how the blood circulation system works. Make a \\
digital story to answer to the following questions: \\
1. What is the basic role of the circulatory system? \\
2. Explain how the heart and blood vessels work? \\
3. What may be the man's problem? \\
4. What may be the doctor's advice in this case? \\
A young couple (35 years old) face problems in having a baby. They visit \\
a hospital to take medical advice. Make a digital story to answer to the \\
following questions: \\
1. Which are the organs of the reproductive system? \\
2. How do they work? \\
3. What may cause the couple's fertility problems? \\
4. Are there any possible solutions to this problem? \\
5. What should you do to keep your reproductive system healthy? \\
\hline Reproductive System
\end{tabular}

TABLE 2

INTERVIEW QUESTIONS

\begin{tabular}{|c|c|}
\hline Type of engagement & Questions \\
\hline Behavioural engagement & $\begin{array}{l}\text { How long did it take you to complete each of your digital stories? } \\
\text { How did you organize your work? }\end{array}$ \\
\hline Emotional engagement & $\begin{array}{l}\text { Would you like to make digital stories for Biology courses or other subjects } \\
\text { next year? } \\
\text { How did you feel when I first announced to you that you were going to } \\
\text { make digital stories in Biology courses? } \\
\text { What did you like less/more about your digital stories. }\end{array}$ \\
\hline Cognitive engagement & $\begin{array}{l}\text { How did you work? } \\
\text { Do you think that digital storytelling was helpful in studying Biology? }\end{array}$ \\
\hline
\end{tabular}


Student interviews were recorded and transcribed. A process of coding was used to interpret and categorize the three types of engagement: behavioural, emotional and cognitive engagement, to answer to the research question: how Digital Storytelling promotes students' engagement in Biology learning tasks. At the same time another group of 27 students (15 year olds - the control group) developed simple digital presentations (using Microsoft Power Point) on the same health problems without using any of the Digital Storytelling's tools (e.g. narration, music, pictures, scenario). These data will be analyzed in the next phase of our research to explore the extent to which Digital Storytelling promotes student engagement.

\section{Results}

Twenty-four out of twenty-seven students completed all the requested activities, producing 72 digital stories in total. Not one of the students had used digital storytelling before either in Biology lessons or other school subjects or activity, and they expressed their surprise at the beginning of the school year on using it in Biology courses, considering it more relevant to other subjects like History and Social Sciences.

\subsection{Behavioral engagement}

Students mentioned they spent two to three hours developing each of their digital story. Table 3 includes some of the students' feedback on the interview questions concerning behavioural engagement organized in different codes and themes. Positive and negative behaviours are presented in Table 3 ranging from willingness to complete the tasks to refusal to work with them.

TABLE 3

BEHAVIOURAL ENGAGEMENT - INTERVIEWS

\begin{tabular}{|c|c|c|}
\hline \multicolumn{3}{|l|}{ Behavioural engagement } \\
\hline \multirow{3}{*}{$\begin{array}{l}\text { Theme: involvement } \\
\text { in learning tasks }\end{array}$} & $\begin{array}{l}\text { Code: Time spent } \\
\text { on completing the } \\
\text { tasks }\end{array}$ & $\begin{array}{l}\text { DS15: "It took me } 4 \text { hours to complete my digital story on } \\
\text { nervous system but it worth it." DS26: "It took me two to } \\
\text { three hours to complete each of my stories." } \\
\text { DS17: "I didn't complete all the tasks because I had to study } \\
\text { hard for my English language tests." }\end{array}$ \\
\hline & $\begin{array}{l}\text { Code: effort/ } \\
\text { persistence }\end{array}$ & $\begin{array}{l}\text { DS7: "I completed all the tasks on time." } \\
\text { DS3: "I wanted to complete all the tasks but finally I didn't." } \\
\text { DS6: "I had to keep notes on every part of my narration." } \\
\text { DS22: "I worked really hard on my digital stories." } \\
\text { DS2: "I would like to work only on the sections I like most" }\end{array}$ \\
\hline & $\begin{array}{l}\text { Code: Help to } \\
\text { focus on the subject } \\
\text { / concentration }\end{array}$ & $\begin{array}{l}\text { DS7: "I wanted to be focused on this project because I wanted } \\
\text { to do my best." }\end{array}$ \\
\hline
\end{tabular}




\begin{tabular}{lll}
\hline & $\begin{array}{l}\text { Code: Using Digi- } \\
\text { tal Storytelling as a }\end{array}$ & $\begin{array}{l}\text { DS18: "I used Digital Storytelling technique to make a digi- } \\
\text { technique for other }\end{array}$ \\
Theme: partici- & $\begin{array}{l}\text { the theligion class." } \\
\text { pation in school } \\
\text { selated activities }\end{array}$ & \begin{tabular}{l} 
activities. \\
\cline { 2 - 3 }
\end{tabular} \\
\cline { 2 - 3 } & $\begin{array}{l}\text { Code: Participation } \\
\text { in class discussion }\end{array}$ & $\begin{array}{l}\text { DS5: "I had many questions to ask when I was working with } \\
\text { these activities." }\end{array}$ \\
\hline
\end{tabular}

\subsection{Emotional engagement}

Exploring students' positive or negative reactions twenty-five out of twentyseven students had positive reactions in studying Biology through using digital storytelling the next year, while two students (DS3, DS20) expressed their negative feelings. Table 4 includes some of the students' responses to the relevant questions.

TABLE 4

EMOTIONAL ENGAGEMENT - INTERVIEWS

\begin{tabular}{|c|c|c|}
\hline \multicolumn{3}{|c|}{ Emotional engagement } \\
\hline \multirow{4}{*}{$\begin{array}{l}\text { Theme: Students' } \\
\text { affective reactions } \\
\text { toward Biology }\end{array}$} & $\begin{array}{l}\text { Code: Interested in } \\
\text { the subject }\end{array}$ & $\begin{array}{l}\text { DS19: "Biology was more familiar to our lives this year" } \\
\text { DS26: "Learning about human brain is very interesting and } \\
\text { the digital story I made make me realize that." }\end{array}$ \\
\hline & Code: Boredom & $\begin{array}{l}\text { DS16: "I think that Biology could be boring if I had to study } \\
\text { the book and I would quit studying easily. But in this way I } \\
\text { had fun" }\end{array}$ \\
\hline & $\begin{array}{l}\text { Code : Personal } \\
\text { product }\end{array}$ & $\begin{array}{l}\text { DS14: "Using music makes it different. It is my choice and I } \\
\text { put my sign in the story. Other way all the products could be } \\
\text { the same." } \\
\text { DS5: "In my digital story on circulatory system I described my } \\
\text { grandfather's health problems because he had a heart attack } \\
\text { at that time." }\end{array}$ \\
\hline & $\begin{array}{l}\text { Code: Feeling } \\
\text { anxiety }\end{array}$ & DS3: "I didn't like listening to my voice" \\
\hline \multirow{2}{*}{$\begin{array}{l}\text { Theme: Students } \\
\text { orientation toward } \\
\text { Biology }\end{array}$} & Code: Difficulty & $\begin{array}{l}\text { DS24: In September I had ordered Biology to the difficult } \\
\text { school subjects. Now it is on the other side. I can study this } \\
\text { subject easily." }\end{array}$ \\
\hline & $\begin{array}{l}\text { Code: Future stud- } \\
\text { ies in Biology }\end{array}$ & $\begin{array}{l}\text { DS10: "I liked this way of work because I want to be a doctor } \\
\text { and these stories helped me understand how my job could be } \\
\text { in the future." }\end{array}$ \\
\hline
\end{tabular}

\subsection{Cognitive engagement}

Concerning students' effort to comprehend complex ideas, seventeen out of twenty-seven students described the way they worked and their thoughts on the 
way that digital stories helped them understand Biology content. Furthermore, four students gave detailed descriptions on the way digital stories helped them organize their study in Biology. Table 5 includes some examples of their responses.

TABLE 5

COGNITIVE ENGAGEMENT - INTERVIEWS

\begin{tabular}{|c|c|c|}
\hline \multicolumn{3}{|l|}{ Cognitive engagement } \\
\hline \multirow[b]{3}{*}{$\begin{array}{l}\text { Theme: Being } \\
\text { strategic }\end{array}$} & $\begin{array}{l}\text { Code: Summa- } \\
\text { rizing }\end{array}$ & $\begin{array}{l}\text { DS10 "I kept notes while I was studying a human organ sys- } \\
\text { tem because I usually used the most important topics for my } \\
\text { story." }\end{array}$ \\
\hline & $\begin{array}{l}\text { Code: Elaboration } \\
\text { to remember }\end{array}$ & $\begin{array}{l}\text { DS 18: "I had to repeat it many times while I was recording } \\
\text { my narration that I finally remember the whole lesson' }\end{array}$ \\
\hline & Code: Organizing & $\begin{array}{l}\text { DS2: "It helped me organize my research. At the beginning I } \\
\text { was searching based on the subject e.g. sensory system then I } \\
\text { searched to relevant images and finally I used images as the } \\
\text { background to narrate my story" } \\
\text { DS19: "I had to choose among the details of the textbook and } \\
\text { then I usually made a drawing of the organ system I had to } \\
\text { describe....") }\end{array}$ \\
\hline \multirow[b]{2}{*}{$\begin{array}{l}\text { Theme: Commit- } \\
\text { ment to understand } \\
\text { Biological concepts }\end{array}$} & $\begin{array}{l}\text { Code: Looking for } \\
\text { details and expla- } \\
\text { nations }\end{array}$ & $\begin{array}{l}\text { DS1O:"I couldn't understand the way that parotitis influences } \\
\text { human fertility, but I needed it for my story so I carry out a } \\
\text { small research" }\end{array}$ \\
\hline & $\begin{array}{l}\text { Code: comprehen- } \\
\text { sion of complex } \\
\text { ideas }\end{array}$ & $\begin{array}{l}\text { DS2: "The project on circulatory system was really difficult. } \\
\text { It took my one and a half week to write the texts and find the } \\
\text { relevant images and music." } \\
\text { DS2: "At the beginning I thought that I knew all about the } \\
\text { health problem I had to make the story but during my work } \\
\text { I understood that I didn't have all the necessary information } \\
\text { and I had to search it further." }\end{array}$ \\
\hline
\end{tabular}

\section{Discussion}

This study aimed to explore the three dimensions of students' engagement in Human Biology when Digital Storytelling is used as an educational tool. Behavioural engagement is indicated mostly by students' participation and involvement in conducting non-obligatory tasks. The majority of students (24 out of 27) completed four of the digital stories, spending two to three hours for a 3 -minute video. Both positive and negative behaviours were present in the results, mostly connected with the extra time students need to work on their tasks. Designing activities that fit the heavy school programme of students in upper secondary education, and the necessary time for their completion, are some of the factors that must be taken into consideration when using Digital Storytelling.

Emotional engagement is mostly expressed by students' effective reactions like interest, boredom or anxiety. Digital Storytelling gave the students the opportunity to express their own perspectives in their own way by expressing 
personal interests, opinions and choices. More specifically students had the chance to express their thoughts about Human Biology concepts such as infertility, neuron function and the human brain, medical innovations, diseaseprecaution measures, and the right uses of drugs. These subjects are rather interesting for the students at this age ( 15 years old) making it easier to become engaged in the proposed learning procedure. The students also expressed their talents (e.g. in music or drawing) using the Biology context. Some of the students made their own drawings of the organ systems and others searched and edited images or sounds to develop their stories. Most of the students expressed their enthusiasm for working with digital material instead of a text book. This finding must be explored further, bearing in mind that Greek students don't often use digital resources to create their own projects.

Cognitive engagement is described as students' commitment to the process and the content and the learning strategies students adopt to complete their digital stories. The students tend to organize their work in a different way because of the different tools they use (e.g. sound recorder, digital story software). They need to summarize and memorize some of the details to make a story, and finally they need to look for more information and explanations working with complex ideas.

Distinguishing the different types of engagement depends on qualitative differences that are not always clear. For instance, effort is an indicator for both behavioural and cognitive engagement. Furthermore, positive or negative feelings can lead to an increase in cognitive or behavioural engagement. Distinctions among these three dimensions of engagement and among the indicators within each type need to be further specified. Developing meaningful activities for the students that could give them the chance to explore problems and propose solutions is another crucial point in exploring students' engagement and their learning outcomes. Newmann (1992) proposed that engagement in the classroom is enhanced when the tasks are authentic; provide opportunities for students to assume ownership of their conception; permit diverse forms of talents, and provide opportunities of fun. Digital storytelling could be a useful tool for designing such meaningful activities in Human Biology.

During their reflection on this experience the students expressed positive thoughts for future similar tasks, especially working on everyday life problems using Biology terms and concepts. Individuals have a need for autonomy or a desire to do things for personal reasons, rather than doing things because their actions are controlled by others (Ryan \& Connel, 1989). Digital Storytelling could be an effective pedagogical tool to engage students in the learning process.

\section{Conclusion}

Our research is an initial study on exploring students' engagement in Human Biology using Digital Storytelling, to develop learning activities on 
Human Anatomy and Physiology. We have pointed out various types of student engagement and discussed the positive and negative reactions of students using this teaching method for a school year. Student interviews indicate that Digital Storytelling engages students in understanding several difficult and abstract topics in Human Anatomy and Physiology. Furthermore, Digital Storytelling facilitates the combination of an organ system structure and function and the correlation of causes and effects of an organ dysfunction, making it easier to connect biological concepts with real life problems and promote a healthier lifestyle to learners. The study of engagement as a multidimensional concept could help us to better understand the students' experiences in school, and to design more specifically targeted activities and interventions. While engagement alone does not ensure achievement, future research can examine the effectiveness of Digital Storytelling in students' engagement with Biological concepts.

\section{References}

Birch, S. H., \& Ladd, G. W. (1997). The teacher-child relationship and children's early school adjustment. Journal of school psychology, 35(1), 61-79.

Blocher, M. (2008, March). Digital storytelling and reflective assessment. In Society for Information Technology \& Teacher Education International Conference (pp. 892901). Association for the Advancement of Computing in Education (AACE).

Chang, H. H. (2005). The relationship between extrinsic/intrinsic motivation and language learning strategies among college students of English in Taiwan. Master of Arts. Taipei,Taiwan: Ming Chuan University.

Connell, J. P., Spencer, M. B., \& Aber, J. L. (1994). Educational risk and resilience in African-American youth: Context, self, action, and outcomes in school. Child development, 65(2), 493-506.

Dillard, J., \& Reynolds, M. A. (2010). Black swan and the corn maiden. Accounting Education: an international journal, 19(4), 393-401.

Finn, J. D. (1989). Withdrawing from school. Review of Educational Research, 59(2), 117-142.

Fredricks, J. A., Blumenfeld, P. C., \& Paris, A. H. (2004). School engagement: Potential of the concept, state of the evidence. Review of Educational Research, 74(1), 59-109.

Hodson, D. (1992). In search of a meaningful relationship: an exploration of some issues relating to integration in science and science education. International Journal of science Education, 14(5), 541-562.

Hung, J. L., Hsu, Y. C., \& Rice, K. (2012). Integrating data mining in program evaluation of K-12 online education. Journal of Educational Technology \& Society, 15(3).

EDUCAUSE Learning Initiative (ELI) (2007). The seven things you should know about. Retrieved January 15, 2008, from. http://www.educause.edu/7Things

Jonassen, D. H., \& Carr, C. S. (2000). Mindtools: Affording multiple knowledge representations for learning. Computers as cognitive tools, 2, 165-196. 
Lombardi, M. M. (2007). Authentic learning for the 21st century: An overview. Educause learning initiative, 1(2007), 1-12.

McLellan, H. (1993). Evaluation in a situated learning environment. Educational Technology, 33(3), 39-45.

Miley, F. (2009). The storytelling project: innovating to engage students in their learning. Higher Education Research \& Development, 28(4), 357-369.

Newmann, F. M. (1992).Student engagement and achievement in American secondary schools. Teachers College Press, 1234 Amsterdam Avenue, New York

Pounsford, M. (2007). Using storytelling, conversation and coaching to engage. Strategic Communication Management, 11(3), 32.

Ryan, R. M., \& Connell, J. P. (1989). Perceived locus of causality and internalization: examining reasons for acting in two domains. Journal of Personality and Social Psychology, 57(5), 749.

Sandars, J., Murray, C., \& Pellow, A. (2008). Twelve tips for using digital storytelling to promote reflective learning by medical students. Medical Teacher, 30(8), 774-777.

Skinner, E. A., \& Belmont, M. J. (1993). Motivation in the classroom: Reciprocal effects of teacher behavior and student engagement across the school year. Journal of Educational Psychology, 85(4), 571.

Thijs, J., \& Verkuyten, M. (2009). Students' anticipated situational engagement: The roles of teacher behavior, personal engagement, and gender. The Journal of Genetic Psychology, 170(3), 268-286.

Weinstein, C. E., \& Mayer, R. E. (1983, November). The Teaching of Learning Strategies. In Innovation Abstracts (Vol. 5, No. 32, p. n32).

Wood, W. B. (2009). Innovations in teaching undergraduate biology and why we need them. Annual Review of Cell and Developmental, 25, 93-112.

Woolfolk, A., \& Margetts, K. (2007). Educational psychology. NSW, Australia: Pearson. Prentice Hall. 



\title{
COLLABORATIVE CARE FOR ANIMALS IN \\ CLASS - EFFECTS ON STUDENTS' RELATEDNESS AND THEIR FLOW EXPERIENCE IN BIOLOGY LESSONS
}

\author{
Alexander Eckes ${ }^{1}$, Nadine Großmann ${ }^{2}$, \\ Annette Textor $^{3}$ and Matthias Wilde ${ }^{2}$ \\ 1 Osnabrück University, Germany, Didactics in Biology, 2 Bielefeld University, Germany, \\ Didactics in Biology, 3 Bielefeld University, Germany, Educational Sciences \\ Alexander.Eckes@Biologie.Uni-Osnabrueck.DE
}

\begin{abstract}
The need for relatedness, one of the basic psychological needs anchored in selfdetermination theory, can be satisfied by meaningful interactions and positive emotions. Since working with animals can evoke positive emotions, collaborative care for an animal together with the teacher might positively influence students' perceptions of relatedness towards their teacher. Students' flow experience as a positive quality of motivation may also be fostered. This study investigated the effect of collaborative animal care in biology lessons on students' feelings of relatedness towards their student teacher as well as students' flow experience. 613 fifth and sixth graders $\left(M_{\text {age }}=10.68 \pm 0.67\right.$ years) participated. Classes were randomly assigned to one experimental ('care') and two control groups ('mice' and 'laptop'). The groups differed with regard to the contact time with the animals (Micromys minutus). We found that students in the 'care' group perceived the highest relatedness towards their student teacher. Regarding students' flow experience, analysis showed significant effects of the treatment. The 'mice' and 'care' group had a significantly higher perception of flow than the 'laptop' group. Working with mice in biology lessons had a positive impact on students' relatedness as well as their flow experience.
\end{abstract}

\section{Introduction}

The subject of biology at secondary level in Germany is characterized by certain qualities. There is a change from primary to lower secondary school. Whereas in primary school biology is part of a more broad subject, "Sachunterricht" including science and part of the humanities (e.g. history and politics), in the secondary school there is usually a clearly defined subject, "biology", taught by highly specialized teachers. According to the PISA-study 2012 students at 
secondary level in Germany do not feel very "happy" at school. The mean value from Germany is slightly below the international average (PISA, 2012). The sense of belonging to the school is slightly above the PISA-average (Prenzel et al., 2012). Overall, lower secondary level might be a stressful time for students and various affective parameters develop unfavorably; this development includes students' interest and students' motivation (Gillet et al., 2012; Schiefele \& Schaffner, 2015). This is also true for biology classes (Löwe, 1987). A positive teacher-student relationship might have a positive effect on students' affective domain. The relationship between the biology teacher and the biology learner might have a substantially positive influence here (see Ryan et al., 1994). In biology classes, certain subject-specific methods might be used. In this article, three of these methods are compared: "use of laptops in biology class", "use of living animals in biology class" and "care of living animals in biology class".

\section{Theoretical and empirical background}

\subsection{Self-determination theory}

Self-determination theory (SDT) (Ryan \& Deci, 2017) states three basic psychological needs relatedness, autonomy and competence that are assumed to be inherent to every human being. The satisfaction of these three needs plays an essential role in fostering interest and self-determined types of motivation (Deci \& Ryan, 2000; Hofferber, Basten, Großmann, \& Wilde, 2016; Krapp \& Ryan, 2002). The current study focusses on the need for relatedness. The basic need for relatedness refers to the need for affiliation with social environments and the need to feel accepted and recognized by significant others (Krapp \& Ryan, 2002). Feeling related is important for an individual's social and emotional development (Solomon et al., 1997) and has an impact on relationship satisfaction, motivation and well-being (Ryan \& Deci, 2017). In SDT, motivation to act can be classified as extrinsic or intrinsic. One of the primary reasons why people perform extrinsically motivated actions is because they are prompted by external prods, pressures or rewards or modeled by behaviours, expectations or attitudes of significant others to whom they feel (or want to feel) attached or related to. The type of regulation that underlies an extrinsically motivated action depends on the individuals' perceived degree of selfdetermination (Vallerand \& Ratelle, 2002). That is, extrinsically motivated actions can be regulated in different ways (Vallerand \& Ratelle, 2002). This is reflected in the regulation types (extrinsic, introjected, identified and integrated) that range from low to high self-determination. In contrast to extrinsic motivation, intrinsically motivated behaviours occur spontaneously and are defined by curiosity, exploration, and interest in the task itself (Ryan \& Deci, 2017). This suggests that the type of regulation that underlies an extrinsically 
motivated action is dependent on an individual's feelings of relatedness (Reeve, 2002). In particular, the more heteronomous stages of extrinsic motivation were found to rely on the need for relatedness to a large extent (see Ryan \& Powelson, 1991; Ryan \& Stiller, 1991; Ryan et al., 1994).

Relatedness may support the internalization of behavioral patterns and the values of significant others (Krapp \& Ryan, 2002). For example, meaningful interactions between students and their teacher can improve the student's relatedness (Ryan \& Stiller, 1991; Ryan et al., 1994). Ryan et al. (1994) found that children who had fully internalized the regulation of positive, school-related behaviours were those who felt securely connected to their teachers as well as cared for by their teachers. Ryan und Deci (2002) point out that extrinsic motivation is an integral part of motivation in the school setting which makes relatedness an interesting candidate for investigation.

\subsection{Flow theory - Autotelic motivation}

In order to evaluate the effects of students' relatedness towards their teacher on students' motivation, the flow theory can offer additional insight and can be linked to SDT (Csikszentmihalyi \& Schiefele, 1993; Kowal \& Fortier, 1999). In comparison to SDT, which is focused on the process of an action and on the causes for human behaviour beyond a single point in time, flow focusses on the moment and the process of the action. Flow as a form of intrinsic motivation can be described as a state of excitement that is fulfilling, enjoyable and an experience that is rewarding in itself (Csikszentmihalyi, 2014; Nakamura \& Csikszentmihalyi, 2002). Individuals in a flow state are intertwined with the activity, are not reflective or self-conscious, and lose the sense of time (Nakamura \& Csikszentmihalyi, 2002). At the same time, individuals are focused and absorbed in a smooth-running activity, which feels well under control (Csikszentmihalyi, 1988; Rheinberg, Vollmeyer, \& Engeser, 2003). Flow experiences might be impeded by frequent interruptions, time pressure, or a bad social climate (see Rheinberg, 2008). Csikszentmihalyi (1990) differentiated between two types of flow experience: flow during a solitary activity and a collaborative activity. With regard to collaborative activities, Walker (2010) as well as Kiili et al. (2010) examined the social aspect of flow. Flow in a social context might be a qualitatively different phenomenon than flow experienced solitarily. Individuals may act and behave differently in group scenarios dependent on them being passive regarding one another, co-active or interdependent. In co-active situations, people perform side-by-side but do not interact with one another (jogging, hiking, playing golf, watching TV with others). In interdependent situations, people must cooperate and coordinate within established groups (playing a team sport, playing in a band). There is evidence that the most enjoyable flow experiences may occur during social interactions (see Froh et al., 1993; Walker, 2010). Csikszentmihalyi 
(1988) reported flow and the inherent joy to be present to a higher degree in social compared to solitary situations. Working as a group in class can be classified as co-active and interdependent. Yet, student groups are not always established groups in the sense of a band or sports team. Students do not always work in the same group constellation. The teacher is a constant factor during working processes in class. The relationship between students and teachers is important as it might influence these processes. Cooperating together with the teacher might therefore positively influence (social) flow.

\subsection{Living animals in biology lessons}

There is a growing body of evidence suggesting that interest and motivation for (Hidi \& Harackiewicz 2000; Krapp \& Prenzel 2011) as well as attitudes towards (Prokop et al., 2007) natural sciences deteriorate with students' age. Working with living animals may offer a possibility to create a cooperative learning environment (see Solomon et al., 1997) and use the authenticity that living animals provide (Gehlhaar, 2008) in the form of 'Primärerfahrungen' (Klingenberg, 2014), which are defined as direct interaction (first hand contact) with the original learning object (Klingenberg, 2014). 'Primärerfahrungen' offer learning that addresses multiple senses and makes affective objectives more accessible (see Gehlhaar, 2008; Kattmann, 2008; Killermann et al., 2013) through direct interaction, and can foster greater interest in the organism in question (Hummel \& Randler, 2012). Gehlhaar (2008) established working with animals as a biological working practice that can be anchored in biology education and that may foster motivation toward biological problems. By using living animals in their lessons, biology teachers may be able to access easily the four biological working practices (observation, examination, inquiry and experimentation) that are mentioned by Killermann et al. (2013). Taking care of animals may be exclusively anchored in biology education and could counteract the abovementioned decrease in interest and motivation through the support of students' relatedness (see Crosnoe, Johnson, \& Elder, 2004; Zimmer-Gembeck et al., 2006). Gest et al. (2005) reason that teachers' engagement on an emotional level may predict students' level of relatedness. As such, incorporating living animals in biology lessons may provide a possibility to foster relatedness between students and teachers and generate a cooperative climate in the classroom that offers the opportunity to experience social flow.

\section{Research Question}

Teachers are important attachment figures for students, and they are experts in their respective field that students can turn to. As such, they are significant 
others (Ryan \& Deci, 2017) that students want to be related to in the context of school. One way to improve the students' relatedness towards their teacher might be the design of collaborative learning environments. Collaborative activities may enable exchanges of thoughts, emotions, and ideas among learners (Childress \& Braswell, 2006). In turn, this might bond them with others participating in the same learning activity, for example the teacher. Since animals affect students' emotions, their use in such collaborations might be particularly beneficial for students' relatedness towards their teacher, as emotional engagement and feelings of relatedness are often correlated (see Gest et al., 2005). This leads to the first research question:

1) Does working and taking care of mice together with the biology teacher foster students' relatedness towards their teacher?

According to Rheinberg (2008), bad social climate interferes with an individual's flow experience. As relatedness presumably affects the climate in the classroom positively, the design of learning environments (e.g. collaborative contexts) that foster students' relatedness might as well foster students' flow experience. The emotional experiences while working with living animals, in groups of four or five students working interdependently on the same task, may foster an exciting and enjoyable experience for the students. This might affect students' flow experience by enabling social flow (Walker, 2010). These considerations lead to the second research question:

2) Does the use of living mice in biology lessons foster students' flow experience?

\section{Methods}

$616(50.4 \%$ female $)$ students from grade 5 and $6\left(M_{\text {age }}=10.68\right.$ years, $S D_{\text {age }}=0.67$ years $)$ participated in this study. Four male and five female student teachers conducted the treatments. All participating students received

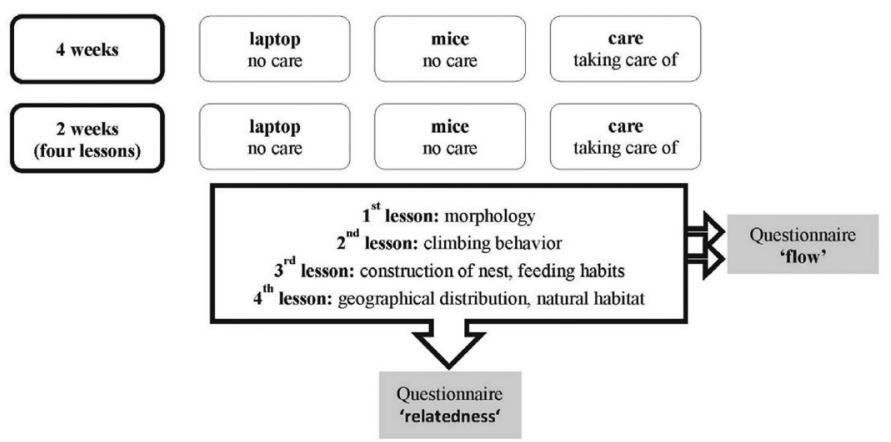

Figure 1 Study design 
the same four biology lessons regarding the life and adaptations of the Eurasian harvest mouse (Micromys minutus). Lessons were carried out by student teachers in advanced semesters. The design of the study is shown in Figure 1.

TABLE 1

NUMBER OF ITEMS, INTERNAL CONSISTENCIES (CRONBACHS ALPHA)

AS WELL AS THE ITEMS FOR THE IMI SUBSCALE RELATEDNESS (RYAN, 1982) AS WELL AS THE FLOW SHORT SCALE (RHEINBERG ET AL., 2003)

\begin{tabular}{|c|c|c|c|}
\hline Scale & $\begin{array}{l}\text { Number of } \\
\text { Items }\end{array}$ & $\begin{array}{l}\text { Cronbachs } \\
\text { alpha }\end{array}$ & Example Item \\
\hline \multirow{5}{*}{ Relatedness } & \multirow{5}{*}{5} & \multirow{5}{*}{$\alpha=.84$} & $\begin{array}{l}\text { 'It is likely that the teacher and I could become } \\
\text { friends if we interacted a lot.' }\end{array}$ \\
\hline & & & 'I feel close to this teacher.' \\
\hline & & & 'I felt like I could really trust this teacher.' \\
\hline & & & $\begin{array}{l}\text { 'I would really prefer not to interact with this } \\
\text { teacher in the future.' }\end{array}$ \\
\hline & & & $\begin{array}{l}\text { 'I would like a chance to interact with this } \\
\text { teacher more often.' }\end{array}$ \\
\hline \multirow{10}{*}{$\begin{array}{c}\text { FSS }\left(2^{\text {nd }} \text { and } 3^{\text {rd }}\right. \\
\text { lesson })\end{array}$} & \multirow{10}{*}{10} & \multirow{10}{*}{$\begin{array}{l}\alpha_{2 \text { nd }}=.85 \\
\alpha_{3 \mathrm{rd}}=.89\end{array}$} & 'I feel that I have everything under control.' \\
\hline & & & 'I am totally absorbed in what I'm doing.' \\
\hline & & & 'I know what I have to do each step of the way.' \\
\hline & & & 'The right thoughts occur of their own accord.' \\
\hline & & & 'My mind is completely clear.' \\
\hline & & & $\begin{array}{l}\text { 'I have no difficulty concentrating during the } \\
\text { experiments.' }\end{array}$ \\
\hline & & & 'I was not distracted by other things.' \\
\hline & & & 'I don't notice time passing.' \\
\hline & & & 'My activities run fluidly and smoothly.' \\
\hline & & & 'I feel just the right amount of challenge.' \\
\hline
\end{tabular}

Classes were randomly assigned to the three groups. The groups differed in the way that the students came into contact with the mice. Students in the 'laptop' group ( $n=278$ ) watched short video clips of the mice on laptops during the four biology lessons instead of working with the living mice. The video clips were specifically made with regard to the behaviour pattern that the students should analyze. In the group 'mice' $(n=167)$ students worked with the mice only during the four biology lessons. Students in the group 'care' $(n=171)$ worked with the living animals in the biology lessons, and additionally took care of the mice in their own classroom in a timeframe of four weeks prior to the four biology lessons, and participated in feeding the mice with mealworms. Pairs of students took care for the mice and rotated in their duty. Teachers fed the mice with mealworms together with a student group of five to seven 
students once a week, and visited the class to do so for approximately ten minutes. In this time, students' questions were also answered. Using an adapted, translated version of the subscale 'relatedness' of the Intrinsic Motivation Inventory (IMI) (Ryan, 1982), students' relatedness towards the student teacher was assessed in the post-test. An adapted version of the Flow Short Scale (FSS) (Rheinberg et al., 2003) was assessed in the first and third lesson to assess students' flow experience. Internal consistencies and examples for both questionnaires are shown in Table 1. In both questionnaires, a five-point rating scale ranging from 0 (not at all true) to 4 (very true) was used. The data was analyzed via Welch test and Games-Howell post-hoc tests due to unequal variances and sample sizes.

\section{Results}

The Welch test showed significant differences for students' relatedness towards their student teacher between the three groups (Table 2). Post-hocanalysis revealed significant differences in each of the comparisons of one group with one of the other groups. Students felt significantly more related towards their student teacher if they worked with living animals compared to working with laptops. Comparing the students who worked with the living animals with the students who additionally took care for the mice with the student teacher, a significant higher relatedness can be reported for the 'care' group. With regard to students' flow experience, the Welch test showed similar results (Table 2). In

TABLE 2

RESULTS OF WELCH TESTS (MAIN EFFECTS) AS WELL AS GAMES-HOWELL POST-HOC TESTS. THE COMPARED GROUPS, THE ABSOLUTE VALUE OF DIFFERENCES IN MEAN VALUES AS WELL AS SIGNIFICANCE AND EFFECT SIZE ARE SHOWN

\begin{tabular}{|c|c|c|c|c|c|c|}
\hline \multirow[b]{2}{*}{ Scale } & & \multirow[b]{2}{*}{$M( \pm S D)$} & \multirow[b]{2}{*}{ main effect } & \multicolumn{3}{|c|}{ Games-Howell } \\
\hline & & & & $\begin{array}{l}\text { group } \\
x \text { vs. } y\end{array}$ & $\left|M_{x}-M_{y}\right|$ & $\begin{array}{l}\text { effect size } \\
\text { (Cohen's d) }\end{array}$ \\
\hline \multirow{3}{*}{ Relatedness } & laptop & $2.13( \pm 0.99)$ & \multirow{3}{*}{$\begin{array}{l}F(2,349.78)=20.38, \\
p<.001 \\
\text { est. } \omega^{2}=.062\end{array}$} & laptop vs. mice & $0.26^{*}$ & $d=0.26$ \\
\hline & mice & $2.39( \pm 1.02)$ & & laptop vs. care & $0.57^{* * *}$ & $d=0.62$ \\
\hline & care & $2.70( \pm 0.84)$ & & mice vs. care & $0.31^{* *}$ & $d=0.33$ \\
\hline \multirow{3}{*}{$\begin{array}{l}\text { Flow (2 } 2^{\text {nd }} \\
\text { lesson) }\end{array}$} & laptop & $2.53( \pm 0.83)$ & \multirow{3}{*}{$\begin{array}{l}F(2,323.91)=35.64, \\
p<.001, \\
\text { est. } \omega^{2}=.119\end{array}$} & laptop vs. mice & $0.55^{* * *}$ & $d=0.81$ \\
\hline & mice & $3.08( \pm 0.49)$ & & laptop vs. care & $0.49^{* * *}$ & $d=0.62$ \\
\hline & care & $3.02( \pm 0.74)$ & & mice vs. care & 0.06 ns & - \\
\hline \multirow{3}{*}{$\begin{array}{l}\text { Flow }\left(3^{\text {rd }}\right. \\
\text { lesson) }\end{array}$} & laptop & $\begin{array}{l}2.57 \\
( \pm 0.92)\end{array}$ & \multirow{3}{*}{$\begin{array}{l}F(2,272.41)=37.96 \\
p<.001, \\
\text { est. } \omega^{2}=.136\end{array}$} & laptop vs. mice & $0.61^{* * *}$ & $d=0.78$ \\
\hline & mice & $3.18( \pm 0.58)$ & & laptop vs. care & $0.62^{* * *}$ & $d=0.81$ \\
\hline & care & $3.19( \pm 0.56)$ & & mice vs. care & $0.01 n s$ & - \\
\hline
\end{tabular}

$p<.001,{ }^{* * *} ; p<.01,{ }^{* *} ; p<.05, *$; and not significant (ns), $p>.05$ 
both lessons the FSS showed significant differences between the groups. Significant differences were found between the 'laptop' and 'mice' groups as well as between the 'laptop' and 'care' groups. The comparison of the 'mice' and 'care' groups showed no significant differences.

\section{Discussion}

Regarding the first research question, our results show that the 'Primärerfahrungen' (mice) in comparison to 'Sekundärerfahrungen' (laptops) led to a higher relatedness towards the respective student teacher in biology lessons. The group 'care' reported the highest relatedness when compared to the 'mice' and the 'laptop' groups. The heightened perception of relatedness towards the student teacher might be ascribed to the collaborative goal of taking care of the animal. In this case, the students can work together with the student teacher, a significant other in the context of school. Student teachers showed and explained how to take good care for the animals and worked together with the students during the care-taking process. This may lead to the formation of closer relationships between teacher and students and provide opportunities to establish links to students' interests in biology lessons and counteract the declining motivation and interest in natural sciences (Hidi \& Harackiewicz, 2000; Krapp \& Prenzel, 2011). The results indicate that the integration of living animals in biology classes can have a positive impact on the students' relatedness towards their teacher. This is particularly true when the students take care of the animals together with their student teacher. Living animals were effectively used in the care treatment and offered possibilities to use the biological working practices of observation, examination and inquiry while working on an authentic 'Primärerfahrung' and should be further examined as a working practice in biology lessons. The results of the flow assessment support the assumption that the students' perception of relatedness relates to the degree of flow that they experience. In the comparison between students who worked with living animals and students who worked with laptops, a higher flow can be reported for the groups with living animals. Yet, no effect could be shown between the 'mice' and the 'care' groups. Thus, taking care of the animals had no additional effect on students' flow experience. In this study, students worked in small teams (4-5 students) during the four biology lessons in all treatment groups.

Socially there was no difference between the 'laptop' and 'mice' groups. The 'care' group did not differ from the other two groups with regard to the work assignments, but they took care with the student teachers of the mice in the students' classroom for six weeks in total. Working together to take care of the mice was found to have a positive impact on students' perceived relatedness towards their student teacher. However, taking care of the mice in addition to working with them in class did not affect the students' flow experience during 
the lessons. The students in the 'care' group reported the same flow as the students in the 'mice' group. From the perspective of Walker's (2010) social flow, both the 'mice' and the 'care' group seem to be similar to one another. Students' perception of flow while working on the same task may be very similar or even identical to one another in the 'mice' and the 'care' group. The additional contact with the mice together with the student teacher in the 'care' group would suggest a better social climate (see Rheinberg, 2008) thus resulting in heightened perceptions of flow. Yet, the perception of flow does not seem to be influenced by the caretaking. As the assessment of flow is specific to the task at hand, it may not be surprising that the flow experience is not influenced by actions that happened up to four weeks prior to the lesson while taking care of the mice with the teacher (Meyer, Klingenberg, \& Wilde, 2015).

Collaborative learning environments (Solomon et al., 1997) may foster tutorial guidance (e.g. Bielaczyc \& Collins, 1999; Zumbach, 2003) and offer possibilities for students to work co-actively and/or interdependently. In such environments, social flow could be more prominent while working in groups or in an open learning environment. In this study, effects could not be shown. The reason might be that the tasks itself, although students were working in groups, did not support a large enough amount of co-active working or the need to coordinate one's performance with that of others was not necessary (see Walker, 2010).

\section{Limitations and conclusion}

Limitations regarding the teachers, the assessment of relatedness and the time spent with the students in the care treatment need to be addressed. With regard to the student teachers, it has to be kept in mind first that only nine student teachers participated in the study, which makes a generalization of the current results implausible. Replicating the study to establish a larger dataset for student teachers is needed to verify the findings. Especially between-subject effects among the teachers like instructional style, empathy (cf. Battistich et al., 1997; Katz \& Assor, 2007) as well as supportiveness, closeness and aggressiveness, may have an influence on the students' relatedness (Gest et al., 2005). These will need to be addressed in subsequent studies.

Second, relatedness was only assessed in the post-test, and as such cannot shed light on the relationship that students had to their biology teacher in their regular biology classes. This prior long-term relationship might moderate the formation of the relationships with the student teachers that are unknown before the lessons of this study took place. Additionally the newly formed relationships to the student teachers may have an influence on the existing relationship between students and their regular biology teacher. Further studies 
in the same vein need to investigate these dependencies using additional relationship measures in the pre-test as well as an added follow-up test. As these characteristics were not assessed, the results have to be interpreted with caution.

Third, as described in the methods section, students had an additional point of contact to the student teacher as they fed the mice with mealworms once a week for ten minutes during the overall six-week period. As five to seven students worked in one group, each student attended such a session at least once. This point of contact with the student teacher took place beside the normal lesson and can be characterized as informal. It is possible that this additional time spent did have an influence on students' relatedness beyond taking care of the animals in the classroom and during lessons. Yet, in comparison to the time spent with the student teachers and animals overall during the sixweek period, the ten minutes are only a small fraction.

Fourth, the flow assessment with the Flow Short Scale in this study may have not been inherently sufficient to assess changes in the perception of flow that may occur due to a change in the social climate between teacher student and students. Follow-up studies need to further classify the social interactions in student groups and might consider implementing social and solitary flow measurements to further classify similarities and differences between both forms of flow, and better highlight co-active and interdependent parts of the working processes.

In conclusion, taking care of animals in class together with the teacher can support students' relatedness towards these important attachment figures. Integrating living animals more often in learning environments could help to build interesting, motivating and authentic experiences for students and may help to establish better relationships through shared care of animals.

\section{Acknowledgments}

This project is part of the "Qualitätsoffensive Lehrerbildung", a joint initiative of the Federal Government and the Länder which aims to improve the quality of teacher training. The programme is funded by the Federal Ministry of Education and Research (funding code: 01JA1608). The authors are responsible for the content of this publication.

\section{References}

Battistich, V., Solomon, D., Watson, M., \& Schaps, E. (1997). Caring school communities. Educational Psychologist, 32, 137-151.

Bielaczyc, K., \& Collins, A. (1999). Learning communities in classrooms: a reconceptualization of educational practice. In C.M. Reigeluth (Ed.), Instructional design theories and models (Vol. II, pp. 269-292). Mahwah, NJ: Lawrence Erlbaum. 
Childress, M. D., \& Braswell, R. (2006). Using massively multiplayer online role-playing games for online learning. Distance Education, 27, 187-196.

Crosnoe, R., Johnson, M. K., \& Elder, G. H. (2004). Intergenerational bonding in school: The behavioral and contextual correlates of student-teacher relationships. Sociology of Education, 77(1), 60-81.

Csikszentmihalyi M. (1988). The flow experience and its significance for human psychology. In M. Csikszentmihalyi \& I.S. Csikszentmihalyi (Eds.), Optimal experience: Psychological studies of flow in consciousness. Cambridge, Great Britain: Cambridge University Press.

Csikszentmihalyi, M. (1990). Flow: The psychology of optimal experience. New York: Harper Perennial.

Csikszentmihalyi, M. (2014). Applications of flow in human development and education: The collected works of Mihaly Csikszentmihalyi. Clarement, CA: Springer.

Csikszentmihalyi, M., \& Schiefele, U. (1993). Die Qualität des Erlebens und der Prozess des Lernens [The quality of experience and the process of learning]. Zeitschrift für Pädagogik, 39(2), 207-221.

Deci, E. L., \& Ryan, R. M. (1993). Die Selbstbestimmungstheorie der Motivation und ihre Bedeutung für die Pädagogik [Self-determination theory of motivation and its significance for pedagogy]. Zeitschrift für Pädagogik, 39(2), 223-237.

Deci, E. L., \& Ryan, R. M. (2000). The "what" and "why" of goal pursuits: Human needs and the Self-Determination of behaviour. Psychological Inquiry, 11(4), 227268.

Froh, R. C., Menges, R. J., \& Walker, C. J. (1993). Revitalizing Faculty Work through Intrinsic Rewards. In R. Diamond, New Directions in Higher Education (Vol. 81). San Francisco, CA: Jossey-Bass.

Gehlhaar, K. H. (2008). Lebende Organismen [living organisms]. In H. Gropengießer \& U. Kattmann (Eds.), Fachdidaktik Biologie (pp. 298-311). Köln, Germany: Aulis Verlag Deubner.

Gest, S. D., Welsh, J. A., \& Domitrovich, C. E. (2005). Behavioral predictors of changes in social relatedness and liking school in elementary school. Journal of School Psychology, 43(4), 281-301.

Gillet, N., Vallerand, R. J., \& Lafrenière, M. A. K. (2012). Intrinsic and extrinsic school motivation as a function of age: The mediating role of autonomy support. Social Psychology of Education, 15(1), 77-95.

Hidi, S., \& Harackiewicz, I. M. (2000). Motivating the academically unmotivated: a critical issue for the $21^{\text {st }}$ century. Review of Educational Research, 70(2), 151-179.

Hofferber, N., Basten, M., Großmann, N., \& Wilde, M. (2016). The effects of autonomy-supportive and controlling teaching behaviour in biology lessons with primary and secondary experiences on students' intrinsic motivation and flow-experience. International Journal of Science Education, 38(13), 2114-2132

Hummel, E., \& Randler, C. (2010). Experiments with living animals-effects on learning success, experimental competency and emotions. Procedia-Social and Behavioral Sciences, 2, 3823-3830. 
Kattmann, U. (2018). Vielfalt und Funktionen von Unterrichtsmedien [Diversity and functions of media of instruction]. In H. Gropengießer, U. Harms \& U. Kattmann (Eds.), Fachdidaktik Biologie (pp. 344-349). Köln, G: Aulis.

Katz, I., \& Assor, A. (2007). When choice motivates and when it does not. Educational Psychology Review, 19(4), 429-442.

Kiili, K., Perttula, A., Tuomi, P., Suominen, M., \& Lindstedt, A. (2010). Designing mobile multiplayer exergames for physical education. In Proceedings of IADIS mobile learning. Porto, Portugal: IADIS Press.

Killermann, W., Hiering, P., \& Starosta, B. (2013). Biologieunterricht heute: Eine moderne Fachdidaktik (13., aktualisierte Aufl.) [Biology lessons today: modern didactics]. Donauwörth, Deutschland: Auer Verlag.

Klingenberg, K. (2014). 'Primärerfahrung' with living animals in contrast to educational videos: a comparative intervention study. Journal of Biological Education, 48(2), 105-112.

Kowal, J., \& Fortier, M. S. (1999). Motivational determinants of flow: Contributions from Self-Determination Theory. Journal of Social Psychology, 139, 355-368.

Krapp, A., \& Ryan, R. M. (2002). Selbstwirksamkeit und Lernmotivation. Eine kritische Betrachtung der Theorie von Bandura aus der Sicht der Selbstbestimmungstheorie und der pädagogisch-psychologischen Interessentheorie [Self-efficacy and learning motivation. A critical consideration of the theory of Bandura from the perspective of self-determination theory and the pedagogical-psychological theory of interests]. In D. Hopf \& M. Jerusalem (Hrsg.), Selbstwirksamkeit und Motivationsprozesse in Bildungsinstitutionen (S. 54-82). Weinheim, Deutschland: Beltz.

Krapp, A., \& Prenzel, M. (2011). Research on interest in science: theories, methods, and findings. International Journal of Science Education, 44, 27-50.

Löwe, B. (1987). Interessenverfall im Biologieunterricht [Loss of interest in biology lessons]. Unterricht Biologie, 124, 62-65.

Meyer, A., Klingenberg, K., \& Wilde, M. (2015). The benefits of mouse keeping - an empirical study on students' flow and intrinsic motivation in biology lessons. Research in Science Education, 46(1), 79-90.

Nakamura, J., \& Csikszentmihalyi, M. (2002). The concept of flow. In C. R. Snyder \& S. J. Lopez (Eds.), Handbook of positive psychology (pp. 89-105). Oxford, Great Britain: Oxford University Press.

PISA (2012). Fortschritte und Herausforderungen in Deutschland. [Progress and challenges in Germany] URL: http://www.pisa.tum.de/fileadmin/w00bgi/www/Berichtsbaende_und_Zusammenfassungungen/PISA_2012_EBook_ISBN3001.pdf, [24.06.2019].

Prenzel, M., Sälzer, C., Klieme, E., \& Köller, O. (2012). Fortschritte und Herausforderungen in Deutschland. Zusammenfassung. [Progress and challenges in Germany. Summary].

URL: dttp://www.pisa.tum.de/fileadmin/w00bgi/www/Berichtsbaende_und_Zusammen fassungungen/PISA_2012_Zusammenfassung_online.pdf, [24.06.2019].

Prokop, P., Tuncer, G., \& Chudá, J. (2007). Slovakian students' attitudes toward biology. Eurasia Journal of Mathematics, Science \& Technology Education, 3(4), 287-295. 
Reeve, J. (2002). Self-determination theory applied to educational settings. In R. M. Ryan \& E. L. Deci (Eds.), Handbook of self-determination research (pp. 183-203). Rochester, NY: University of Rochester Press.

Rheinberg, F. (2008). Intrinsic motivation and flow. In J. Heckhausen \& H. Heckhausen (Eds.), Motivation and action (pp. 323-348). Cambridge, Great Britain: Cambridge University Press.

Rheinberg, F., Vollmeyer, R., \& Engeser, S. (2003). The recording of Flow experience. In J. Stiensmeier-Pelster \& F. Rheinberg (Eds.), Diagnostics of motivation and self-conception (pp. 261-279). Göttingen, Germany: Hogrefe.

Ryan, R. M. (1982). Control and information in the intrapersonal sphere: An extension of cognitive evaluation theory. Journal of Personality and Social Psychology, 43, 450461.

Ryan, R. M., \& Deci, E. L. (2002). An overview of self-determination theory. In E. L. Deci \& R. M. Ryan (Eds.), Handbook of self-determination research (pp. 3-33). Rochester, NY: University of Rochester Press.

Ryan, R. M., \& Deci, E. L. (2017). Self-Determination Theory. Basic psychological needs in motivation, development, and wellness. New York, NY: Guilford Press.

Ryan, R. M., \& Powelson, C. L. (1991). Autonomy and relatedness as fundamental to motivation and education. The Journal of Experimental Education, 60(1), 49-66.

Ryan, R. M., \& Stiller, J. (1991). The social contexts of internalization: Parent and teacher influences on autonomy, motivation, and learning. Advances in Motivation and Achievement, 7, 115-149.

Ryan, R. M., Stiller, J., \& Lynch, J. H. (1994). Representations of relationships to teachers, parents, and friends as predictors of academic motivation and self-esteem. The Journal of Early Adolescence, 14(2), 226-249.

Schiefele, U., \& Schaffner, E. (2015). Motivation. In E. Wild \& J. Möller (Hrsg.), Pädagogische Psychologie (2. Aufl.; S. 153-175). Berlin, Germany: Springer.

Solomon, D., Battistich, V. Kim, D. I., \& Watson, M. (1997). Teachers' practices associated with students' sense of the classroom as a community. Social Psychology of Education, 1(3), 235-267.

Vallerand, R. J., \& Ratelle, C. F. (2002). Intrinsic and extrinsic motivation: A hierarchical model. In E. L. Deci \& R. M. Ryan (Eds.), Handbook of self-determination research (pp. 37-63). Rochester, NY: University of Rochester Press.

Walker, C. J. (2010) Experiencing flow: Is doing it together better than doing it alone?, The Journal of Positive Psychology, 5(1), 3-11.

Zimmer-Gembeck, M. J., Chipuer, H. M., Hanisch, M., Creed, P. A., \& McGregor, L. (2006). Relationships at school and stage-environment fit as resources for adolescent engagement and achievement. Journal of Adolescence, 29(6), 911-933.

Zumbach, J. (2003). Problembasiertes Lernen [Problem-based learning]. Münster, Germany: Waxmann. 



\title{
TRAINING PRE-SERVICE TEACHERS TO APPROACH MICROORGANISMS THROUGH AN ACTIVE PRACTICE BASED ON HOMEMADE CULTURE: ROLE OF STUDENTS’ EMOTIONS
}

\author{
José María Marcos-Merino, Rocío Esteban Gallego \\ and Jesús A. G. Ochoa de Alda \\ Science and Mathematics Education Department, Faculty of Education, \\ University of Extremadura (Badajoz, Spain) \\ jmmarcos@unex.es
}

\begin{abstract}
Primary school students, as well as their teachers, hold several misconceptions related to microorganisms. In addition, Microbiology is an area that generates negative emotions, a fact that hinders its learning. Due to this situation, it has been recommend to carry out active practical activities with which to improve both learning and emotions about microorganisms. These activities should also be implemented in initial teacher training, since emotions experienced by teachers, as well as their misconceptions, can be transferred to their students. In this contribution a practical based on homemade microorganism culture, carried out with a sample of 134 future primary school teachers (students of the Degree in Primary Education, University of Extremadura, Spain) is described. The objective is to ascertain the interaction between the learning outcomes of a designed practical, and participants' values and emotions relating to this activity. Results reveal that this activity is effective in relation to Microbiology learning, motivating and highly valued by participants in relation to their professional future; observing significant correlations between these phenomena. Results suggest that students who learn more Microbiology are those who experienced, during the implementation of the practice, more trust, satisfaction, fun, pride, gratitude and awe; and less nervousness and disgust; and those participants also better value the practice for their future as Biology teachers.
\end{abstract}

Keywords: microbiology education, emotions, guided research, primary education, initial teacher training

\section{Introduction}

Microbiology teaching faces the difficulty of approaching living beings which are not observable by the naked human eye, and usually related to 
different kinds of diseases. As a result, core microbiological concepts are related to many misconceptions. Recently, Ballesteros et al. (2018) have revealed that primary school students hold an incomplete and limited view of microorganisms, usually focused on their role as pathogens, and obviating their importance in health, environment or industry. Some widespread misconceptions detected in this and other research performed with students at this educational stage (Byrne, 2011; Harms, 2002; Karandon and Sahin, 2010; Simonneaux, 2010) are:

- Lack of knowledge of ubiquity of microorganisms, placing them mainly in dirty places (such as the floor, in rubbish, etc.).

- Lack of knowledge of diversity of microorganisms, identifying all microorganisms as bacteria.

- Lack of recognition of microorganisms as living beings, ignoring that they are made up of cells and that they perform the three vital functions.

- Identification of viruses as living beings.

- Unfamiliarity with methods of sterilization and asepsis.

- Impossibility of seeing microorganisms with the naked eye, even if millions are joined together.

These misconceptions have been also detected with in-service primary teachers (Jones \& Rua, 2006) as well as with pre-service teachers (MarcosMerino \& Esteban, 2018). Given that research has pointed out that teachers' misconceptions are one of the main origins of students' misconceptions (Kikas, 2004), it is necessary to develop effective teaching-learning sequences in microbiology and address them in Biology Education courses within initial teacher training. Raised educational interventions must be motivating, since research has shown that positive emotions experienced by students promote learning, whereas negative ones limit it (Marcos-Merino et al., 2016; Pekrun, 2014). This circumstance is very relevant regarding microbiology teaching, since microorganisms generate negative emotions in the majority of primary school students, who feel bad when they hear about microorganisms and relate them to terms such as "aggressiveness", "badness" or "danger" (Karandon \& Sahin, 2010). Given this situation, and considering that emotions experienced by teachers can be transferred to their students (Frenzel et al., 2009), it is necessary to reduce in future teachers, negative emotions towards microorganisms, as well as promoting positive ones (Pekrun, 2014). According to current research in Biology Education some ways to encourage motivation are:

- Highlighting the applicability of contents (Hulleman \& Harackiewicz, 2009), raising activities in which they are related to students' daily lives and to their current and future goals.

- Using practical approaches (Hofstein \& Lunetta, 2004), especially those that follow an inquiry-based teaching model (Marcos-Merino et al., 2016; Gormally et al., 2009; Retana-Alvarado et al., 2018). 
In addition, practical activities are more effective than lectures in relation to microbiology learning (Faccio et al., 2013; Redfern et al., 2013). However, in-service primary school teachers implement few practical activities in their biology lessons (García-Barros \& Martínez-Losada, 2001), particularly in microbiology, arguing lack of knowledge, technical difficulty and fear in the light of health and safety problems (Redfern et al., 2013). Against this background, it is necessary to train future teachers in the practical teaching of microbiology. According to Harms (2002), microorganism culture is a basic procedure to include in the practical teaching of microbiology. In this paper, a practical based on microorganism culture, carried out with a sample of students of the Degree in Primary Education, is described. This intervention includes a discussion under guided research about how to prepare a culture medium using daily materials, in order to connect microbiology contents to the future professional performance of participants.

\section{Research objectives}

The main objective is to establish (with a sample of pre-service primary school teachers at the University of Extremadura), the interaction between the cognitive learning outcomes of a teacher training microbiology practical, and participants' values and emotions relating to this activity. Several specific objectives are set:

- test the effectiveness, in relation to learning of microbiological core contents, of a microbiology practical;

- ascertain the intensity with which participants felt some positive and negative emotions during the implementation of a microbiology practical;

- determine the value assigned by participants to a microbiology practical for their future as biology teachers in primary school;

- establish the interactions of microbiology learning outcomes with students' emotions and values.

\section{Methodology}

\subsection{Sample}

The sample consists of 134 future teachers (21 years old on average, $66 \%$ females) belonging to three groups of students, enrolled in a Biology Education subject, of the sixth semester of the Degree in Primary Education at the University of Extremadura (eight semesters in all). Regarding their studies at Upper-Secondary School, only a $30.1 \%$ of them took an itinerary of Science. 


\subsection{Description of the intervention}

The intervention is based on a laboratory practice and consists of two phases. In the first phase, microbial culture is used to address some core microbiological concepts such as ubiquity and diversity of microorganisms, colony, asepsis and sterilization. First of all, the teacher explains briefly how to prepare a culture medium for microorganisms in a laboratory, introducing the materials (Petri dish, nutrient agar, distilled water, autoclave, Bunsen burners...) and explains the procedure. During this process, the teacher enumerates the nutrient agar's elements (yeast extract, meat extract, agar, peptone and sodium chloride), explains why it is dissolved in distilled water, illustrates the autoclave's operation and how it is used to sterilize the culture medium, approaches working in aseptic conditions such as introducing the culture medium in sterilized Petri dishes, cleaning the working surface with ethanol, lighting several Bunsen burners around the working area, closing doors and windows to avoid air flow, handwashing before this process, not to talk during the process, and an explanation about storage conditions. After these explanations, three Petri dishes with culture medium are distributed to pairs of students who perform a sequence of experiments related to microbiological concepts (Figure 1).
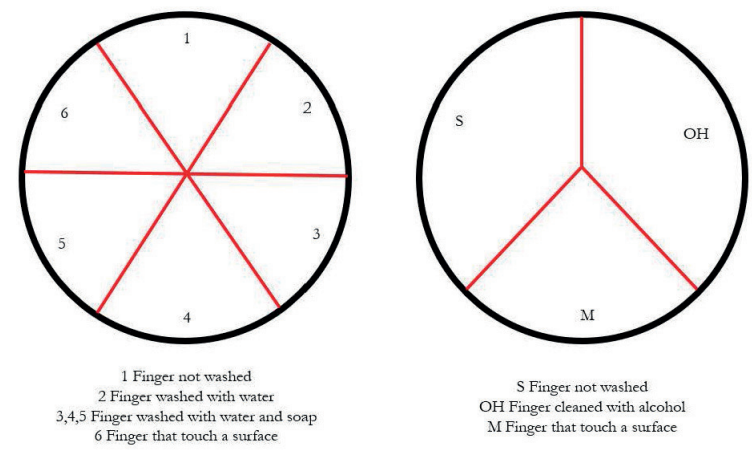

Figure 1 Steps for asepsis and sterilization experiments

In order to show microorganisms' ubiquity and diversity, students leave opened Petri dish in different places of the Faculty (such as the cafeteria, library, events hall, classrooms, baths, parking, garden, etc.) for 20 minutes. Afterwards, they test the effectiveness of methods of sterilization (with ethanol) and asepsis (handwashing). For these two experiments they create sections on the Petri dish using a marker pen. A week later, they come to another session in which analyse the main results (Figure 2). In this lesson (the second phase of the practice), students discuss, guided by teachers, how to prepare a culture medium for microorganisms in a homemade way (e.g. daily materials and instruments to use 

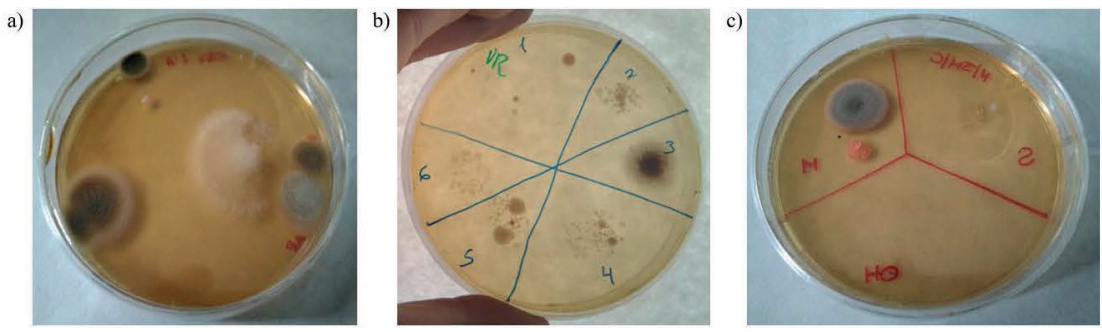

Figure 2 Examples of results by students in experiments of ubiquity and diversity (a), asepsis (b) and sterilization (c).

and how to maintain asepsis and sterility) to be able to perform this activity in a primary school classroom.

This lesson is based on an enquiry-based teaching model (Gormally et al., 2009). The teacher raises several problems through open questions (Table 1), whose answers provide students with the necessary information to elaborate a culture medium using daily materials. Students solve these problems through debates guided by the teacher, in which they use their previous knowledge as well as all the concepts they have learnt in the first phase of the intervention. Moreover, they research about these topics, carrying out bibliographic research using their smartphones. The teacher has to redirect students' answers (endorsing, rejecting or qualifying them), until the group agree on one answer for every question (Table 1). Using them, students prepare a protocol with which to elaborate a homemade culture medium for microorganisms.

TABLE 1

RAISED QUESTIONS TO INITIATE DISCUSSIONS AND ANSWERS PROVIDED BY STUDENTS AT THE END OF AN ENQUIRY-BASED PROCESS

\begin{tabular}{ll}
\hline Initial question raised by the teacher & Answer agreed by the students \\
\hline What daily container would you use instead of a Petri dish? & Box of chocolates, swabs, needles, candies... \\
\hline $\begin{array}{l}\text { What homemade products would you use to elaborate a cul- } \\
\text { ture medium? }\end{array}$ & $\begin{array}{l}\text { Beef stock cubes and agar for confectionary } \\
\text { (instead of nutrient agar). } \\
\text { Ironing water as distilled water. }\end{array}$ \\
\hline How would you sterilize the culture medium? & $\begin{array}{l}\text { In a pressure cooker, through bain-marie pro- } \\
\text { cedure (the culture medium has to be in a jar } \\
\text { covered but not closed). }\end{array}$ \\
\hline How would you sterilize the selected container? & Boiling it or cleaning it with ethanol. \\
\hline $\begin{array}{ll}\text { What aseptic measures would you perform when introdu- } \\
\text { cing the medium in the containers? }\end{array}$ & $\begin{array}{l}\text { Handwashing before the process, cleaning } \\
\text { the working surface with ethanol, work near } \\
\text { flames (stove or candles), closing doors and }\end{array}$ \\
windows, not to talk during the process, to \\
work few people...
\end{tabular}




\subsection{Determination of the intervention's effectiveness}

The effectiveness of this educational intervention is estimated by using pretest and posttest, completed by participants before the intervention and 15 days later. These tests are comprised of 15 one choice questions, and were validated as indicated by Smith et al. (2008). Their questions are based on:

- Common misconceptions of microbiology among secondary school students as well as pre-service and in-service primary teachers (Jones \& Rua, 2006; Marcos-Merino \& Esteban, 2018).

- Basic microbiological contents of secondary education, higher level in science of the majority of the sample. These contents were assessed by using TIMSS questions for $8^{\text {th }}$ grade (Foy et al., 2013).

\subsection{Estimation of students' emotions and subjective value towards the intervention}

In posttest, in addition to the content questions, students reported their emotions associated with this educational intervention, and the subjective value or utility they give to it in relation to their future professional performance as primary teachers.

In order to determine students' emotions towards the implemented practice, we use a simple and fast quantitative self-reporting questionnaire measuring 16 academic emotions (Appendix 1), validated in previous research through factorial analysis with samples of pre-service primary teachers (MarcosMerino et al., 2016). Nowadays, measurement of self-reported emotions is among the most commonly used method, since it is easy to implement and it is a fast instrument that hardly affects the development of educational activities. In addition, it provides measures of subjective and verbalized emotional experiences (Mauss \& Robinson, 2009). In line with recent works (Gogol et al., 2014), academic emotions were assessed using single items since, compared to longer multi-item statement measures, it provides enough validity, requires less time and is less intrusive on emotional responses of participants. On the basis of all the above, students self-report, following a Likert scale (ranging from 1 "not experienced" to 5 "intensely experienced") about the intensity with which they have experienced emotions, during the implementation of the practice: 8 positive emotions (joy, trust, satisfaction, enthusiasm, fun, gratitude, pride and awe), and 8 negative ones (worry, frustration, uncertainty, nervousness, boredom, disgust, shame and fear). The selection of these emotions is based on the following principles: these emotions have been previously described in samples of teachers in initial training (Mellado et al., 2014, Retana-Alvarado et al., 2018) and they have an impact on learning outcomes (Pekrun, 2014). 
Regarding the utility of the practice for a primary school teacher, in order to ascertain the value given by students to the implemented practice, it was included the next question: "If learning to add has a value of 100 for your daily life, what value do you give from 0 to 100 to this practice for your future professional performance?". As with emotions, a simple-item question is used since, compared to longer instruments, single-item measures are a better tool to assess motivational-affective constructs (Gogol et al., 2014).

\subsection{Statistical analysis}

Data do not fit a normal distribution, so nonparametric statistics were used. Data of different groups of students were grouped into a single data set, after verifying the absence of significant differences between them. The test used to compare groups (Wilcoxon test) and linear regression analyses were performed with Kaleidagraph program (Synergy software). Normality tests (KolmogoroSmirnov and Shapiro-Wilk) and correlation analysis (Spearman) were carried out with SPSS program (IBM software). Data obtained during this study are available to anyone who requests it.

\section{Results and discussion}

\subsection{Analysis of the effectiveness of the intervention}

Learning results analysis, based on the comparison of marks that participants got in pretest and posttest, shows that designed intervention is effective, since a significant increase in test marks is observed (from a median of 4.67 in pretest to a median of 6 in posttest, $\mathrm{p}$-value $<.001$, Wilcoxon test). In addition, when every single question is analysed, a significant increase is observed (p-value $<.05$, Wilcoxon test) in the percentage of success of questions related to core microbiological concepts such as: microorganisms as living things that perform the three vital functions (from $50 \%$ to $71.94 \%$, p-value $=.027$ ); bacteria and fungi as microorganisms that are living things (from $18.04 \%$ to $48.20 \%$, p-value $=.013)$; pathogenicity as a characteristic of only some microorganisms (from $37.79 \%$ to $52 \%$, p-value $<.001$ ); sterilization (from $23.84 \%$ to $63.31 \%$, p-value<.001); asepsis (from $46.60 \%$ to $68.35 \%$, p-value<.001); as well as water as the basic nutritional requirement of all microorganisms (from $12.79 \%$ to $29.50 \%$, p-value $=.004$ ).

These results show that implemented intervention is effective in relation to microbiology learning. This circumstance may be due to its potential characteristics, as supported by previous research. Thus, it has been described that practical activities of microbiology are more effective than lectures (Faccio et al., 2013; Redfern et al., 2013). Regarding the implemented teaching model, 
it has been shown that practical activities developed under an inquiry-based approach provide better learning outcomes (Gormally et al., 2009). Moreover, social learning processes, carried out through raised debates guided by the teacher, improves comprehension (Smith et al., 2009) and memory (Edelson et al., 2011). Considering these results, it is suggested to incorporate, in future primary teacher training, practical activities developed under and inquiry-based approach and in which peer learning is promoted. This fact is relevant to improve microbiology qualifications of pre-service primary school teachers, which could be key to avoiding the transmission of misconceptions regarding microorganisms in their future teaching action (Ballesteros et al., 2018; MarcosMerino \& Esteban, 2018).

\subsection{Students' emotions and subjective value towards the intervention}

Participants describe with different intensity their positive and negative emotions towards the implemented practice (Table 2).

TABLE 2

DESCRIPTIVE STATISTICS, MEAN AND STANDARD DEVIATION (SD), REGARDING THE INTENSITY OF POSITIVE AND NEGATIVE EMOTIONS FELT BY STUDENTS DURING THE PRACTICE.

\begin{tabular}{lclr}
\hline Positive emotions & Mean $(S D)$ & Negative emotions & Mean (SD) \\
\hline Joyful & $3.91(.83)$ & Nervousness & $1.86(1.09)$ \\
Trust & $3.73(.94)$ & Boredom & $1.31(.71)$ \\
Satisfaction & $4.26(.72)$ & Frustration & $1.30(.64)$ \\
Enthusiasm & $3.82(.93)$ & Worry & $1.60(.91)$ \\
Fun & $4.07(.79)$ & Uncertainty & $3.01(1.42)$ \\
Pride & $3.51(1.14)$ & Fear & $1.31(.67)$ \\
Gratitude & $3.75(1.01)$ & Shame & $1.25(.64)$ \\
Awe & $4.25(.92)$ & Disgust & $2.11(1.31)$ \\
\hline
\end{tabular}

Positive emotions are always above a mean of 3.50, and several of them (satisfaction and fun) above a mean of 4; whereas the majority of negative ones are below a median of 2 (excepting uncertainty with a median of 3.01). These results indicate that intervention was motivating for participants, due to it causing a high intensity of positive emotions as well as a low intensity of negative ones. This observation agrees with previous studies that have shown the motivating role of practical activities (Hofstein \& Lunetta, 2004), especially of those developed under an inquiry-based approach (Marcos-Merino et al., 2016; Retana-Alvarado et al., 2018). The separate behaviour of uncertainty is also in agreement with these research studies, that have revealed that this methodology generate higher intensities of this emotion with regard to other negative emotions. 
Regarding the value conferred by participants to the practical, in relation to its utility for their future as biology teachers, a mean of 78.23 is obtained (standard deviation of 20.87). This score suggests that the majority of the participants consider this practice as useful for their future professional performance. Given that emotions felt by teachers can be transferred to their students (Frenzel et al., 2009), it could be relevant to include, in initial training processes, this sort of active practice, highly-valued by pre-service teachers, as strategies for microbiology teaching. In this way, by generating positive emotions towards microorganisms in future primary school teachers, they will be able to promote them among their future students (Pekrun, 2014); as well as contributing to reducing negative emotions, so widespread among these biological contents (Ballesteros et al., 2018; Karandon \& Sahin, 2010). This circumstance is relevant in relation to prospective primary school teachers, since research has revealed that their memory of emotions towards science in elementary education (the stage in which students describe an emotional depression towards microbiology), is transferred to the emotions they think are going to feel in their future teaching action, as well as coinciding with the emotions they feel during their teaching practices (Mellado et al., 2014).

\subsection{Analysis of the interactions between learning outcomes, emotions and subjective value}

Correlation analyses reveal significant associations between the intensity of several emotions felt by students during the practice, particularly positive emotions, and learning outcomes, measured through posttest mark (Table 3). Namely, positive correlations (Spearman, p-value<.05) have been detected between the posttest mark and the intensities of trust ( $\mathrm{p}$-value=.023), satisfaction

TABLE 3

SPEARMAN CORRELATIONS $\left({ }^{* *} P\right.$-VALUE $\left.<.01,{ }^{*} P-V A L U E<.05\right)$

BETWEEN MICROBIOLOGY LEARNING OUTCOMES AND EMOTIONS EXPERIENCED BY STUDENTS. BOLD TYPE HIGHLIGHTS SIGNIFICANT CORRELATIONS

\begin{tabular}{|c|c|c|c|}
\hline Positive emotions & $\begin{array}{l}\text { Correlation with } \\
\text { microbiology test }\end{array}$ & Negative emotions & $\begin{array}{l}\text { Correlation with } \\
\text { microbiology test }\end{array}$ \\
\hline Joyful & .151 & Nervousness & $-.200^{*}$ \\
\hline Trust & $.249^{* *}$ & Boredom & -.094 \\
\hline Satisfaction & $.201^{*}$ & Frustration & -.116 \\
\hline Enthusiasm & .082 & Worry & -.116 \\
\hline Fun & $.207^{*}$ & Uncertainty & -.070 \\
\hline Pride & $.207^{*}$ & Fear & -.156 \\
\hline Gratitude & $.238^{* *}$ & Shame & -.082 \\
\hline Awe & $.296^{* *}$ & Disgust & $-.193^{*}$ \\
\hline
\end{tabular}


( $\mathrm{p}$-value $=.02)$, fun ( $\mathrm{p}$-value $=.006)$, pride $(\mathrm{p}$-value $=.001)$, gratitude $(\mathrm{p}$-value $=.006)$ and awe ( $\mathrm{p}$-value<.001); as well as negative associations between learning outcomes and the intensities of nervousness ( $\mathrm{p}$-value $=.028)$ and disgust ( $\mathrm{p}$-value $=.026$ ).

These results suggest that students who got a better mark in microbiology tests are those that experienced, during the implementation of the practice, more trust, satisfaction, fun, pride, gratitude and awe; and less nervousness and disgust. These observations coincide with previous studies (Pekrun et al., 2011) that have pointed out that learning is both a cognitive and an affective process: emotions experienced during teaching processes affect learning outcomes (positive emotions are positively associated with them while negative ones are negatively associated). Specifically, the correlations between learning outcomes and the intensity of positive emotions have been previously detected with the implementation of an active practice of Cell Biology performed with teachers in initial training (Marcos-Merino et al., 2016). Similarly, results agree with several studies that have shown that information related to some emotional stimuli is better remembered than neutral information (Dunsmoor et al., 2015). Most of the significant correlations between emotions and learning are detected for positive emotions. These interactions are in accord with previous research that have revealed that an activation, during the learning processes, of positive emotions can trigger better learning outcomes (Kensinger \& Corkin, 2004), since they cause in the amygdala an excitation that improves memory.

These associations detected between emotions and learning do not allow us to establish a causality; but suggest that emotions improve learning, and learning stimulates emotions or both processes at once. Learning could have been triggered either through the influence of emotions in memory (Kensinger \& Corkin, 2004) and attention (Aydogan et al., 2015), or through the role of positive emotions in the regulation of the motivation (Bradley, 2000). Therefore, future studies are required to deepen these interactions. Even so, current results reveal that there is an association between both cognitive and affective variables, since people are motivated to remember details of emotional events, due to this information being useful for controlling future events (Dunsmoor et al., 2015). The correlations revealed suggest that microbiology learning could be encouraged through raising practical activities with which to increase positive emotions (above all, trust, satisfaction, fun, pride, gratitude and awe) and which generate lower intensities of nervousness and disgust.

A positive correlation (Spearman correlation coefficient of .211, $\mathrm{p}$-value $=.0014)$ is found regarding the interaction between learning outcomes and the value given by students to the practice. This interaction indicates, as linear regression reflects (Figure 3), that students who got a better mark in posttest are those who value better this practice for their future as primary school 


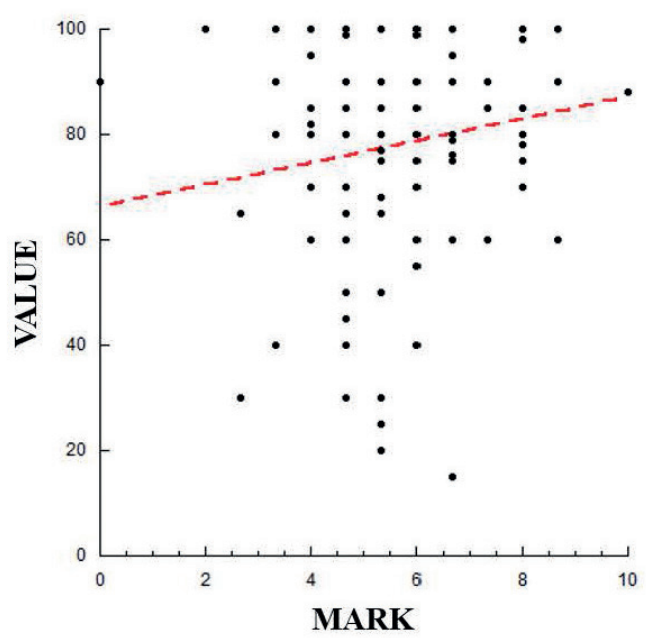

Figure $\mathbf{3}$ Linear regression between the value given by students and posttest mark.

teachers of biology. This association is in agreement with previous studies that indicate that carrying out activities, in which the applicability of contents is highlighted, encourages students' performance (Hulleman \& Harackiewicz, 2009). Taking this relation into consideration, it is necessary to implement, in biology education subjects of initial training, interventions perceived by students as useful for their future professional performance.

\section{Conclusions}

Results of this paper reveal that a practical of microbiology based on microorganism culture is effective in relation to microbiology learning, motivating (generating positive emotions towards microbiology and reducing negative ones), and highly-valued by participants in relation to their professional future as primary school biology teachers. Moreover, some significant interactions between these variables are detected: those participants who felt more positive emotions and less negative ones during the implementation of the practical, as well as those who valued it better for their career, are those who obtained better learning outcomes. These results reinforce the need to implement this kind of motivating intervention in order to improve pre-service primary school teachers' qualifications and their future teaching action. Thus, future teachers may avoid the development of microbiology misconceptions and negative emotions towards microorganisms at primary schools, and they could reinforce the relevance of microorganisms in primary school students' daily lives, generating positive emotions to them. 


\section{Acknowledgements}

This study has been funded by the Research Project EDU2016-77007R of the Ministry of Economy and Competitiveness of Spain and by the Project GR18004 of the Government of Extremadura and FEDER. José María MarcosMerino is a beneficiary of a FPU grant from Spanish Ministry of Education, Culture and Sports.

\section{References}

Aydogan, H., Bozkurt, F., \& Coskun, H. (2015). An Assessment of Brain Electrical Activities of Students toward Teacher's Specific Emotions. International Journal of Social, Behaviors, Educational, Economic, Business and industrial Engineering, 9(6), 1977-2000.

Ballesteros, M. I., Pańos, E., \& Ruiz, J. R. (2018). Los microorganismos en la educación primaria: ideas de los alumnos de 8 a 11 ańos e influencia de los libros de texto. Enseñanza de las ciencias, 36(1), 79-98.

Bradley, M. (2000). Emotion and motivation. Handbook of Psychophysiology, 2, 602642.

Byrne, J. (2011). Models of Micro-Organisms: Children's knowledge and understanding of micro-organisms from 7 to 14 years old. International Journal of Science Education, 33(14), 1927-1961.

Dunsmoor, J., Murty, V., Davachi, L., \& Phelps, E. (2015). Emotional learning selectively and retroactively strengthens memories for related events. Nature, 520, 345348.

Edelson, M., Sharot, T., Dolan, R., \& Dudai, Y. (2011). Following the crowd: brain substrates of long-term memory conformity. Science, 333(6038), 108-111.

Faccio, E., Costa,N., Losasso, C., Cappa, V., Mantovani, C., Cibin, V., Andrighetto, I. \& Ricci, A. (2013). What programs work to promote health for children? Exploring beliefs on microorganisms and on food safety control behavior in primary schools. Food Control, 33(2), 320-329.

Foy, P., Arora, A., \& Stanco, G. M. (2013). TIMSS 2011 User Guide for the International Database. Supplement 1: International Version of the TIMSS 2011 Background and Curriculum Questionnaires. Amsterdam, HO: International Association for the Evaluation of Educational Achievement

Frenzel, A., Goetz, T., Lüdtke, O., Pekrun, R. \& Sutton R. (2009). Emotional transmission in the classroom: exploring the relationship between teacher and student enjoyment. Journal of Educational Psychology, 101(3), 705-716.

García-Barros, S., \& Martínez-Losada, C. (2001). Qué actividades y qué procedimientos utiliza y valora el profesorado de educación primaria. Enseñanza de las Ciencias, 19(3), 433-452.

Gogol, K., Brunner, M., Goetz, T., Martin, R., Ugen, S., Keller, U., Fischbach, A. \& Preckel, F. (2014). "My questionnaire is too long!" The assessments of motivation- 
al-affective constructs with three-item and single-item measures. Contemporary Educational Psychology, 39(3), 188-205.

Gormally, C., Brickman, P., Hallar, B. \& Armstrong, N. (2009). Effects of inquiry-based learning on students' science literacy skills and confidence. International Journal for the Scholarship of Teaching and Learning, 3(2), 16-22.

Harms, U. (2002). Biotechnology education in schools. Electronic Journal of Biotechnology, 5(3), 5-6.

Hofstein, A., \& Lunetta, V. N. (2004). The laboratory in science education: Foundations for the twenty-first century. Science Education, 88(1), 28-54.

Hulleman, C., \& Harackiewicz, J. (2009). Promoting interest and performance in high school science classes. Science, 326(5958), 1410-1412.

Jones, M., \& Rua, M. (2006). Conceptions of germs: Expert to novice understandings of microorganisms. Electronic Journal of Science Education, 10(3), 1-40.

Karadon, H. D., \& Şahin, N. (2010). Primary school students' basic knowledge, opinions and risk perceptions about microorganisms. Procedia-Social and Behavioral Sciences, 2(2), 4398-4401.

Kensinger, E., \& Corkin, S. (2004). Two routes to emotional memory: Distinct neural processes for valence and arousal. Proceedings of the National Academy of Sciences of the United States of America, 101(9), 3310-3315.

Kikas, E. (2004). Teachers' conceptions and misconceptions concerning three natural phenomena. Journal of Research in Science Teaching, 41(5), 432-448.

Marcos-Merino, J. M., \& Esteban, R. (2018). Ideas alternativas sobre Biología de los maestros en formación: implicaciones de su presencia. Campo Abierto. Revista de Educación, 36(2), 167-179.

Marcos-Merino, J. M., Esteban, R., \& Ochoa de Alda, J. (2016). Efecto de una práctica docente diseńada partiendo de las emociones de maestros en formación bajo el enfoque Ciencia, Tecnología y Sociedad. Indagatio Didactica, 8(1), 143-157.

Mauss, I., \& Robinson, M. (2009). Measures of emotion: A review. Cognition and Emotion, 23(2), 209-237.

Mellado, V., Borrachero, A., Dávila, M., Melo, L., \& Brígido, M. (2014). Las emociones en la enseñanza de las ciencias. Enseñanza de las ciencias, 32, 11-36.

Pekrun, R. (2014). Emotions and Learning. Educational Practices Series-24. Belley, FR: UNESCO International Bureau of Education

Pekrun, R., Goetz, T., Frenzel, A., Barchfeld, P., \& Perry, R. (2011). Measuring emotions in students' learning and performance: The Achievement Emotions Questionnaire (AEQ). Contemporary Educational Psychology, 36(1), 36-48.

Redfern, J., Burdass, D., \& Verran, J. (2013). Practical microbiology in schools: a survey of UK teachers. Trends in Microbiology, 21(11), 557-559.

Retana, D. A., De las Heras-Pérez, M. Á., Vázquez-Bernal, B., \& Jiménez-Pérez, R. (2018) El cambio en las emociones de maestros en formación inicial hacia el clima de aula en una intervención basada en investigación escolar. Revista Eureka sobre Enseñanza y Divulgación de las Ciencias, 15(2), 1-16.

Simonneaux, L. (2000). A study of pupils' conceptions and reasoning in connection with 'microbes', as a contribution to research in biotechnology education. International Journal of Science Education, 22(6), 619-644. 
Smith, M., Wood, W., Adams, W., Wieman, C., Knight, J., Guild, N., \& Su, T. (2009). Why peer discussion improves student performance on in-class concept questions. Science, 323(5910), 122-124.

Smith, M., Wood, W., \& Knight, J. (2008). The genetics concept assessment: a new concept inventory for gauging student understanding of genetics. CBE- Life sciences Education, 7(4), 422-430.

\section{Appendix 1. Self-reported test about academic emotions}

What emotions did you feel during the implementation of the microbiology lesson? Please, indicate intensity from 1 "nothing" to 5 "much or intensely"

\begin{tabular}{|l|l|l|l|l|l|}
\hline & \multicolumn{5}{|c|}{$\begin{array}{c}\text { Emotions felt during } \\
\text { the microbiology activity }\end{array}$} \\
\hline & 1 & 2 & 3 & 4 & 5 \\
\hline Joy & & & & & \\
\hline Worry & & & & & \\
\hline Trust & & & & & \\
\hline Frustration & & & & & \\
\hline Satisfaction & & & & & \\
\hline Uncertainty & & & & & \\
\hline Enthusiasm & & & & & \\
\hline Nervousness & & & & & \\
\hline Fun & & & & & \\
\hline Boredom & & & & & \\
\hline Gratitude & & & & & \\
\hline Disgust & & & & & \\
\hline Pride & & & & & \\
\hline Shame & & & & & \\
\hline Awe & & & & & \\
\hline Fear & & & & & \\
\hline
\end{tabular}




\title{
I WON'T BELIEVE IT UNTIL I SEE IT? AN INQUIRY-BASED SEQUENCE ON "MICROORGANISMS" FOR SECONDARY SCHOOL
}

\author{
María Martínez-Chico, Farida Abou Akl, M. Rut Jiménez-Liso \\ University of Almeria (Almería, Spain) \\ mmartinez@ual.es
}

\begin{abstract}
In response to reform efforts recommending students' engagement in scientific practices and the lack of the enactment of such practices in science classrooms, we explored the use of scientific practices with special emphasis on Inquiry-Based Science Education. In biology classes, difficulties in teaching and learning of biological phenomena relating to organisms that at first sight, are invisible to student's eyes are addressed. Students have misconceptions about microorganisms such as relating them only with diseases, locating them only into contaminated areas, or overlooking processes that are advantageous to humans, such as the bacterial use for fermentation. This paper focuses on the designing of an inquiry-based activity sequence (nine activities) which has been implemented with a group of secondary school students (12-13 years old) in southern Spain. Preliminary results show the sequence encourages students to carry out scientific practices (improving their understanding of the scientific activity), and achieve learning about microorganisms by working from different aspects linked to daily life. The participants experienced positive emotions throughout their engagement in the sequence and perceived that they developed adequate understanding about scientific practices and key ideas relating to microorganisms.
\end{abstract}

Keywords: inquiry-based activity sequence, microorganism, secondary school

\section{Introduction}

The emphasis on scientific practices is especially important in primary and secondary education when students' lack of interest in science has become a major concern among science educators, researchers, and policy makers (NRC, 2012). Being involved in scientific practices, is not only linked to promoting 
students' motivation, but mainly connected to the fact that science learning implies participating in the epistemic goals of scientific work - objectives related to the construction of knowledge (Duschl et al., 2011). Promoting students' understanding of the epistemic basis of science - how we know what we know requires students to engage in the practices of science (Duschl \& Bybee, 2014). Although science education research has highlighted that inquiry-oriented science education can produce positive results, classroom practice often tends to be a passive act of transmitting ideas from teacher to student, and focuses on a set of products rather than on the processes of science (Duschl \& Grandy, 2013), with the lack of student interest that this entails. This "change" in the teaching approach requires deep reforms in classroom practice (Hazelkorn \& Ryan, 2015) that usually focuses on a set of products rather than on the processes of science.

This reality implies the need to question the science teaching usually developed, in order to promote an appropriate way to construct knowledge, which means considering the multiple goals of science education. These are to develop understanding of a set of 'big ideas' in science which include ideas about science and its role in society, scientific capabilities concerned with gathering and using evidence, and scientific attitudes (Harlen, 2010). If we focus on the educational aspect, the difference between development and achievements in the field of microbiology, and advances in the teaching of microbiology is striking. Indeed, microorganisms participate in many processes that are present in human daily life, but difficulties in learning about biological phenomena at first sight, which are invisible to student's eyes, have been reported (Barberán et al., 2016).

As with many other natural phenomena, students' misconceptions about microorganisms have been reported in different works (Teodoro \& Chambel, 2013; Pivatto, 2014; Garrido, 2007; Byrne et al., 2009), and include:

- lack of identification of microorganisms as living things and confusion in relation to the microscopic size of the microorganisms (similar to atomic level) considering they can never be seen with the naked eye, even if there are many of them joined together;

- ignorance of the diversity of microorganisms (bacteria, viruses, protoctists, fungi) and equating the concept of microorganism to bacteria (Teodoro \& Chambel, 2013);

- relating microorganisms only with diseases and locating microorganisms only in wet and contaminated areas (Jones et al., 2013; Teodoro \& Chambel, 2013);

- ignorance of the presence of beneficial or harmless bacteria in the human body (Byrne et al, 2009; Teodoro and Chambel, 2013);

- lack of recognition of the importance of microorganisms in beneficial processes and useful for human beings, such as food transformations (Díaz et al., 1996; Simonneaux, 2010), or for the environment (Jones et al., 2013). 
These misconceptions are of special importance, not only to improve the lack of knowledge of the appropriate scientific content, but also, they may pose a risk to health, in the sense of contamination by pathogenic infection. Furthermore, we cannot forget the lack of awareness that microbial life often represents an important gap in our worldview of nature. Microbes are, by definition, invisible to the naked eye, which hampers an appreciation of their enormous diversity and key ecological roles (Barberán et al. al., 2016).

\section{Rationale and research questions}

Designing, implementing and evaluating effective proposals is essential to reach a real understanding of usual microbiology processes in contexts meaningful to students. The purpose of this paper therefore, is to present a teaching sequence for secondary school with an emphasis on scientific practices, with the aim of making significant a concept that is minimally perceptible throughout a set of minds on and hands on activities. This work attempts to address the issue of the lack of scientific practices in schools and the existence of misconceptions related to microorganisms, by addressing the following research questions:

- Which activities could promote learning introductory microbiology from everyday real experiences through scientific practices?

- What is the effect of this activity sequence on students' thoughts? Specifically, - What do (12-13 years old) secondary school students perceive they have learned along the sequence?

- Which emotions do they feel?

In order to promote scientific practices in schools, and to provide reassuring examples available for other teachers, a teaching sequence has been designed and implemented, with the aim of making significant a concept that is minimally perceptible throughout Inquiry-Based Science Education (IBSE). The sequence was designed with the dual aim of improving students' knowledge on microorganisms and inquiry practices. Each decision on the design is justified by the referenced ideas and principles included in the theoretical framework below, and then the different activities are described to facilitate its implementation by teachers. Some results of its implementation with secondary school students have been analyzed to show the sequence's effect on students' scientific knowledge and emotions.

\section{Theoretical Framework}

Scientific practices engage students in use of critical thinking skills, asking questions, planning and carrying out investigations, grappling with data, building and using models, using evidence to justify explanations, and engaging in argumentation with peers to make sense of the natural [and material] world, 
with the expert guidance of a teacher (Crawford, 2014; NRC, 2012). In short, these practices allow students to construct scientific knowledge, address questions and obtain conclusions based on evidence, activities that agree with the IBSE approach (Minner et al., 2009). However, science practical activities, usually developed in schools, have been strongly criticised for exposing learners to phenomena disconnected from the theoretical knowledge needed to understand them. Such activities can be successful in the 'domain of observables' but not the 'domain of ideas' (Philip \& Taber, 2016). As few teaching sequences have focused on improving the effectiveness of science activities in the domain of ideas, this work incorporates the developed and implemented design of a sequence to engage students in scientific practices combining both, hands on and minds on activities.

Due to the confusion surrounding the meaning of inquiry in science classrooms (Osborne, 2014), we use the phrase "teaching science as inquiry" to include both the pedagogy and the learning outcomes of inquiry. The pedagogy is the method of engaging students in designing and carrying out investigations, and the learning outcomes refer to learning science subject matter by engaging in these investigations, in addition to learning "about" the nature of scientific inquiry (Crawford, 2014). In Europe, the current emphasis in innovation in science education has been placed on promoting Inquiry-Based Science Education (IBSE) approaches, a complex process of sense-making and constructing new understanding such as coherent conceptual models, by engaging students in: i) authentic, problem-based learning activities where there may not be one correct answer; ii) experimental procedures, experiments and "hands on" activities, including searching for information; iii) self-regulated learning sequences where student autonomy is emphasized; and iv) discursive argumentation and communication with peers ("talking science"). This is how IBSE is defined in the Report to the European Commission of the expert group on science education 'Science Education for Responsible Citizenship' (Expert group on Science Education, 2015), where the need to close the gap between what we have learned from science education research and classroom practice to obtain positive results is emphasized.

Nevertheless, this recommendation is in contrast with a reality into which outcomes of science education research are not embedded. In most schools, science is taught through lectures, and focused on teacher's lectures and book contents, memorizing, and presenting in this way to give a naïve picture of scientific activity. Both European and national educational laws and reforms establish a science education oriented to promote scientific literacy through inquiry-based approaches, but there is a scarcity of teaching sequences oriented by these purposes.

We adopted a student-centred approach, which has antecedents in constructivism, as IBSE moves learners to participate actively in personal or 
authentic experiences to make meaning from it, starting from their own ideas. The structure of a proper activity sequence should respond to fundamentals or principles of didactic research that must guide our decisions in design. The existence of conceptions and ideas makes it impossible to support effective science teaching based on information transmission. In the case of learning biology, students have misconceptions related to microorganisms, which must be made explicit to construct knowledge from themselves, something that IBSE facilitates by incorporating scientific questions to engage students and help their conceptions emerge. Another key aspect that should be considered is the fact that students build knowledge by testing their ideas, discussing their explanations with teachers and peers, and through interaction with the phenomena (Jasmin et al., 2010), i.e. learning processes need an active interaction with the surrounding world and social interaction - something promoted by IBSE.

On the other hand, as research has shown, sustained learning is a complex phenomenon involving a myriad of processes, such as those involved in perceptual-cognitive appraisals, affective responses, fulfilling motivational goals, striving future goals and self-regulation (Phye et al., 2011). The importance of emotions in both cognitive and affective processes is one of the key aspects of conceptual change (Thagard, 2008). Despite research evidence pointing to the prominent role of emotions in learning, researchers examining scientific practices have largely focused on the cognitive aspects of learning. However, there is much to be learned about how students enter into and sustain their engagement in these practices (Jaber \& Hammer, 2016). Thus, a relevant intervention is not synonymous with success if emotions experienced are not identified, and it may be that, as it happens with knowledge, different emotions can go unnoticed, leading to negative attitudes even to rejection of science (Mellado et al., 2014). We should not forget that as science-based learning processes, scientific practices are not merely cognitive, but are highly charged with feelings and self-regulation they should not be reduced to metacognitive aspects, but also be extended to the affective dimensions (Costillo et al., 2013). All these considerations have guided the design process presented below.

\section{Methodology}

\subsection{Process design of the sequence}

The sequence designed is result of Design Based Research which blends empirical educational research with the theory-driven design of learning environments, important for understanding how, when and why educational innovations work in practice (Baumgartner et al., 2002, Easterday et al., 2016; Juuti \& Lavonen, 2006). After reviewing literature to identify the key ideas and 


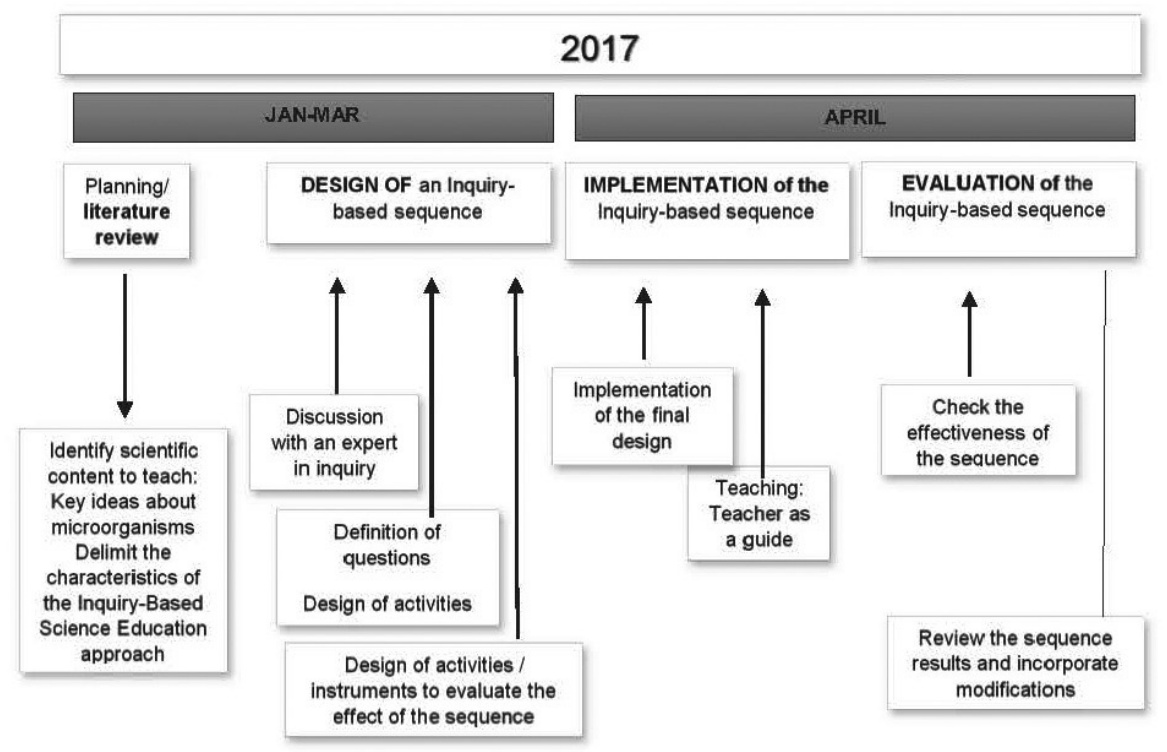

Figure 1 Process of sequence development

misconceptions related to microorganisms, the design process began with an activity whose effect suggested the need to continue with a sequence. Its purpose was making students express their ideas on microorganisms. In the different parts of the sequence, we tried to adopt a structure that responded to a teaching approach based on inquiry (as defined above). Therefore, we decided to transform the key learning ideas into activities with their own entity that made the process of inquiry explicit, thus responding to the demands of educational reports and regulations to initiate students in scientific activity. In Figure 1, below, we present the design process, conducted during 2017.

In the context of this study, we begin the sequence from the 'Real World' because our students are engaged in the main question of the sequence: Which living things can be found at the school? Do you think living things could be right here but we cannot see them? Would they be all over the place in equal quantities or predominantly somewhere? Why? Once the students have answered by considering what they think, so that they are really involved in looking for a response, we orient the teaching towards the realization of predictions ('Prediction') about what they think will happen with the different locations, by using pictures (school bathroom, canteen and classroom). Once we have discussed, argued and justified this (relying on the model or not), more complex answers are elicited, so then we can move to the observation of the phenomena after thinking of the experiments to collect the necessary 'data' that allow us to check their predictions 
and revise the stated explanations. Following that, students perform 'Activities' (mainly hands-on) with bacterial culture and obtain results that compare with what they thought initially. Then we rely on that data, to try to answer the question that initiated the sequence. The data obtained encourage the students to reason, and a new and more completed knowledge on microorganisms' existence and location emerges through reformulating their previous ideas. After obtaining conclusions on microorganisms' existence and location, we move to another daily life situation with the aim of considering the possibility of finding other kinds of microorganisms. To do this, we used for example, a little story in a common context such as the supermarket is used (entitled "Be careful! It may die"); making bread dough and enabling students to question the possible causes of finding different results; and observing food in poor condition.

\subsection{Context and participants}

The resulting sequence was implemented by the second author, a preservice secondary school teacher who was enrolled in a Master's degree where the other two authors teach and supervise final dissertations. This sequence design is a product of a 4-month training process in the Master's degree, in which preservice teachers follow the next training structure to improve their didactic knowledge: Teachers as learners, teachers as thinkers, teachers as designers and teachers as practitioners. The secondary school participants were 12-13 year old students with low achievement and high absenteeism at a public secondary school in a southern Mediterranean European country. They take part in a group within a programme focused on improving learning and performance, where the usual way of working consists of reading and transcribing contents of textbooks individually, and carrying out activities.

\subsection{Data collection}

Throughout the implementation of the sequence, information of a different nature was collected. Part of the analyzed data corresponds to student productions, made in response to the activities proposed in the sequence, specifically, the activities: $1,2.1$, and 4 . In order to achieve the goal of supporting secondary school students to recognize what they have learned, how they have learned it, and their emotions that the IBSE approach produces in them, a questionnaire (Figure 2) was used that includes a KPSI (Knowledge Previous Students Inventory) (Tamir \& Amir, 1981). This is a post-experimental design and its purpose is to generate outcomes that can later be tested with more systematic designs (Bisquerra et al., 2012). The questionnaire design responds to the structure of a KPSI to self-reflect on learning, considering the participants' knowledge before and after experiencing the sequence about specific ideas and 


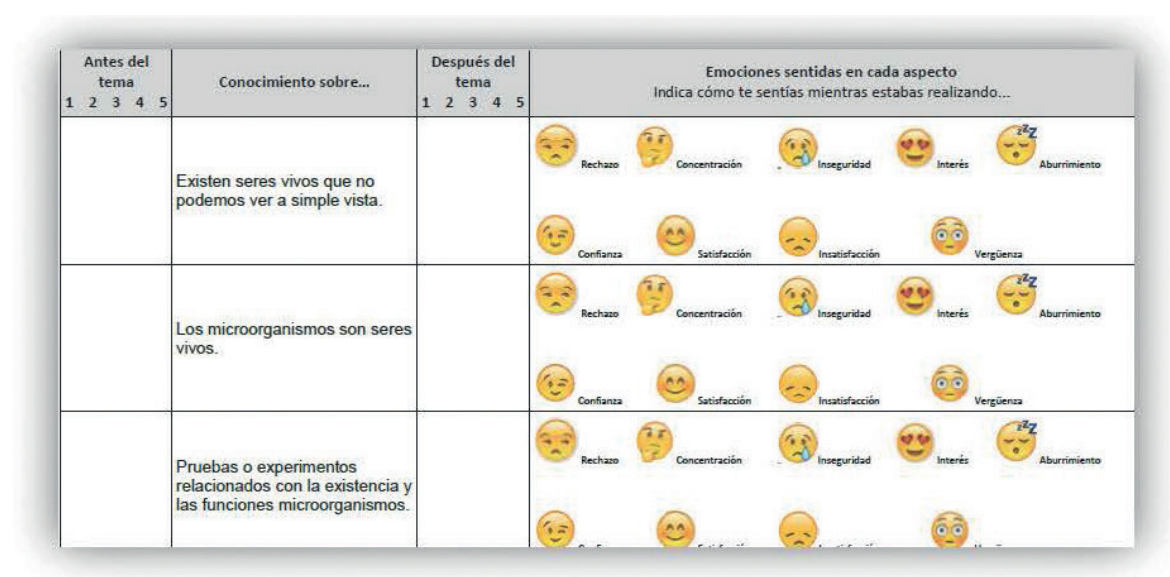

Figure 2 View of the self-refection on knowledge and emotions questionnaire.

procedures, through Likert scale responses (from 1 to 5 points). The instrument has two parts. The first is designed to know the students' self-perception of what they have learned about the basic contents of the sequence, expressing in each of them what they knew before and after, using an ordinal scale of 1 to 5 , which means: 1: I do not know anything, 2: I know a little, 3: I know it well, 4: I know it very well, 5: I can explain it to a friend. The second part is intended to assess the emotions experienced in the activities of the sequence related to each of the basic contents, indicating which emotions they have felt among the nine that are presented; students are also asked to point out those emotions. The emotions considered (i.e., Rejection, Concentration, Insecurity, Interest, Boredom, Confidence, Satisfaction, Dissatisfaction, and Shame), were chosen using an adapted version of the Borrachero et al. (2015), selecting only those more understandable and clearly different from the others, avoiding overlapping, and excluding those emotions not directly related to science activities.

\section{Results}

\subsection{The inquiry-based sequence on "microorganisms"}

In this section we describe each step of the sequence by itself (Figure 3). The sequence is composed of nine activities (indicative duration: 6 hours) divided into three two-hour sessions, held on non-consecutive days. The materials used are laboratory instruments (Petri dish, microorganism culture medium, etc.), school supplies and other elements (flour, yeast, sugar, bottle). The main ideas addressed are: the existence of microscopic living things (microorganisms), the abundance of microorganisms in a large variety of places, 


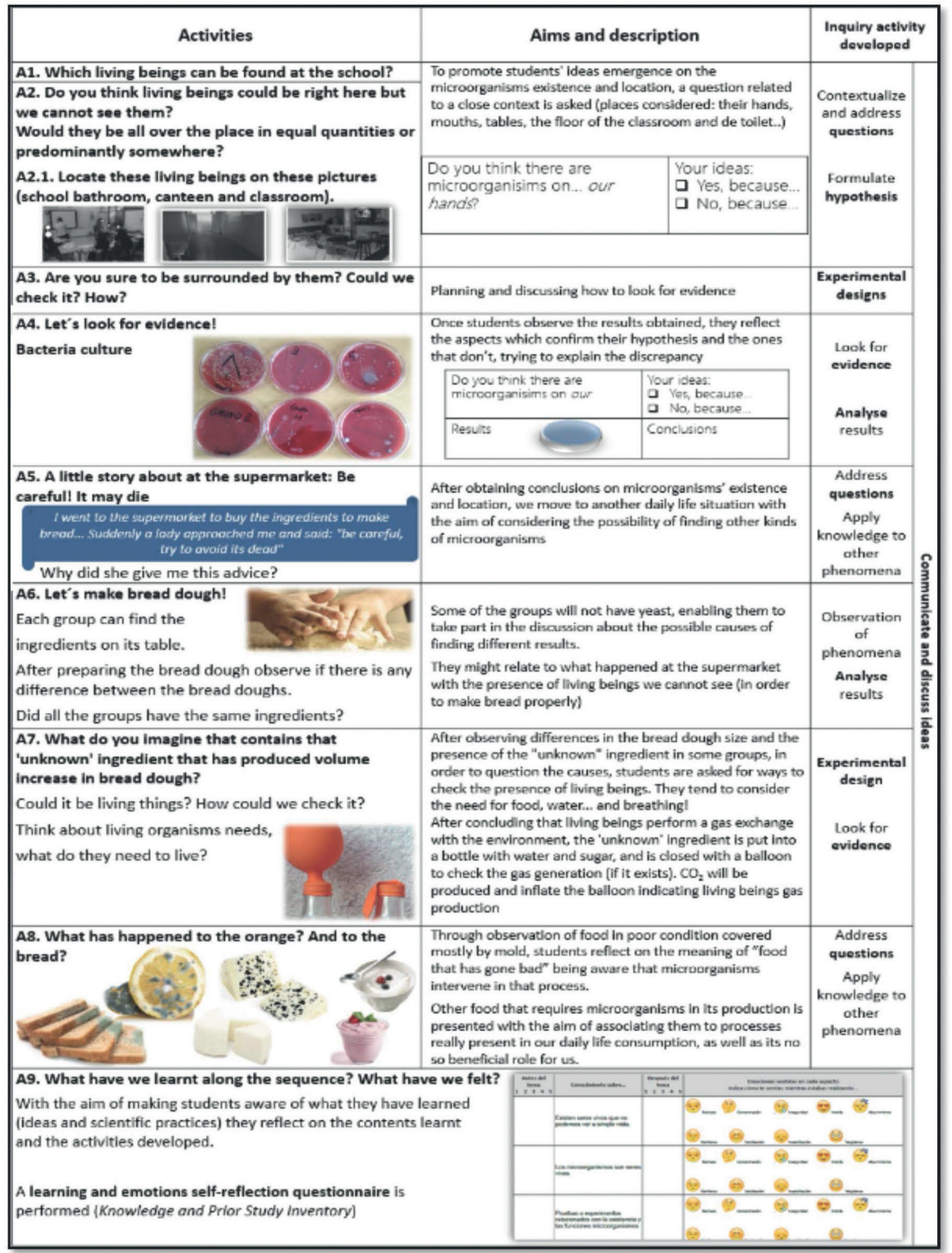

Figure 3 Activity sequence

and the many functions of microorganisms and their relation to daily life (uses, utilities). For most of the activities, the participants were expected to work in small groups, and they are provided with a script with the scheme of the sequence where they write their answers to the various activities. 


\subsection{Preliminary results to evaluate the sequence effectiveness}

Below we present some results from the responses of the students that can provide interesting information for the sequence evaluation. Preliminary results show the activity sequence encourages students to do scientific practices (improving their understanding of the scientific activity), and achieve learning about microorganisms by working from different aspects linked to daily life. The data analyzed correspond to the responses given to activities 1, 2.1 and 4 and students' responses to the questionnaire. Figure 4 shows the great variety of answers provided by the students to Activity 1 that included the question: "Which living things can be found at the school?"

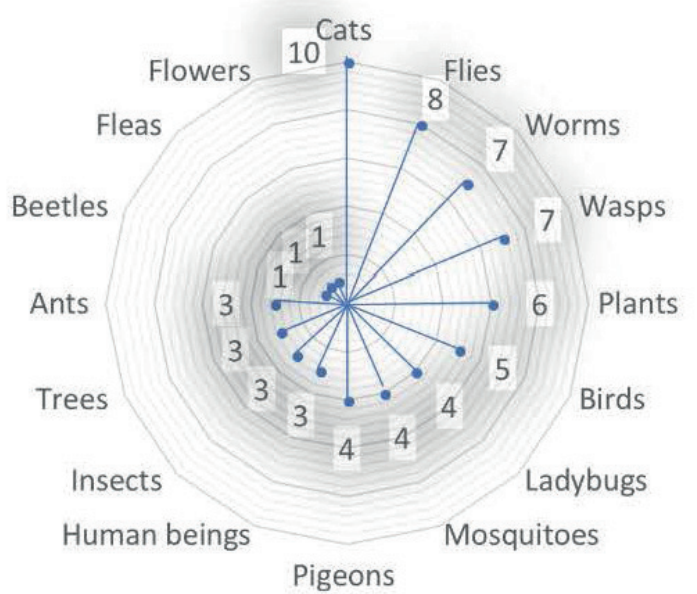

Figure 4 Students' responses to activity 1: "Which living things can be found at the school?"

Regarding Activity 2.1, which focused on promoting students' emerging ideas about microorganisms' existence and location, more than half of the students located the microorganisms in wastepaper baskets, washbasins, floors, blackboards and stairs.

The responses of the students to activities A3 and A4 were collected on a large piece of construction paper drawn up by the groups, which included different sections (Figure 5).

The conclusion obtained by one of the groups (Figure 5) indicates that students concluded that the microorganisms exist in many places, although we are not aware of it. The differences between students' perception of what they have learned (Figure 6) shows that the sequence made sense to them. This is observed in that their answers on previous knowledge in almost all the items are above 2.5. They show a perception of having learned that microorganisms are not only "bad", and evidence about the presence of microorganisms. 


\begin{tabular}{|l|r}
\hline $\begin{array}{l}\text { Do you think there are } \\
\text { microorganisms on } \\
\text { your hands? }\end{array}$ & $\begin{array}{r}\text { Your ideas: } \\
\square \text { Yes, because... } \\
\square \text { No, because... }\end{array}$ \\
\hline Drawing of the results & Conclusions \\
\hline
\end{tabular}

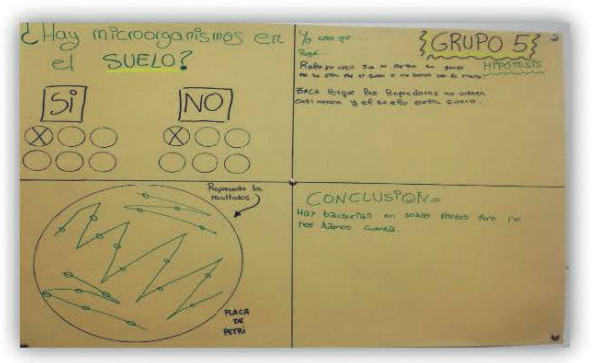

Figure 5.Template to include the responses and example of the one from a group.

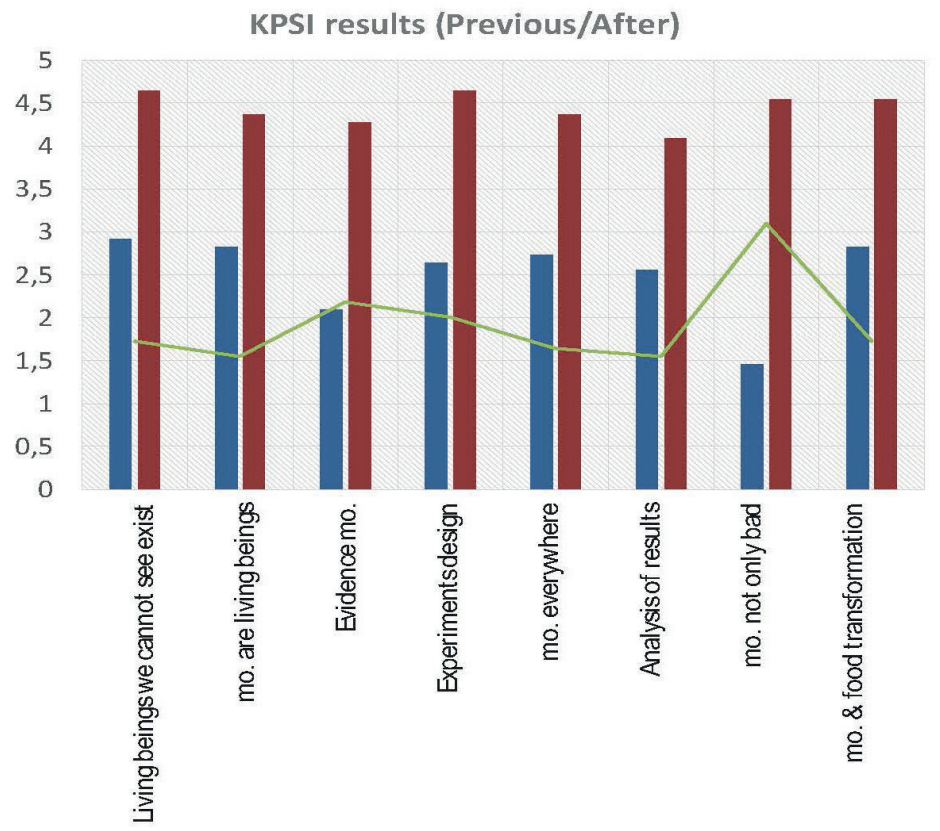

Figure 6 Students' perceptions on contents learned

Regarding emotions, in general the students recognized having felt positive emotions such as concentration or interest in most of the activities carried out. We can also notice that several emotions are more remarkable than others because of the high percentages obtained; this is the case of Interest, Confidence, Concentration, Satisfaction, and Insecurity. In the case of negative emotions, the most commonly experienced one is Insecurity, when facing some of the questions in which they had to express their own ideas. If we analyse temporal moments throughout the teaching sequence we find that, at the beginning, some participants experienced insecurity and, as the sequence progresses, fewer 
students indicate feeling it, which seems to show that as the sequence makes sense for them, it makes them feel more confidence and satisfaction (the emotions which in fact increase).

\section{Conclusions}

Given the need to promote the implementation of teaching proposals that incorporate scientific practices in science education, a teaching sequence on microorganisms that follows an IBSE approach has been presented. This design promotes students doing scientific practices to have a better understanding of the scientific inquiry process, as well as achieving meaningful learning by understanding different aspects linked to daily life. The implementation of the sequence has enabled us to check the benefits of engaging students in inquirybased activities on their motivation. The results of the KPSI questionnaire where students recognize the greater perception of what they learned in the item about the idea that microorganisms should not be considered only as something harmful, show that living scientific practices produces "conceptual content" learning (minds on activities). This is important because usually the students tend to ignore it and it seems that scientific practices only serve to motivate and to learn manipulative skills (Johnstone \& Al-Shuaili, 2001). Probably that learning would never have occurred without the evidence obtained about the existence of microorganisms, the other item where they recognize having learned more. The fact of recognizing having felt emotions in all the activities, most of them positive, can also be understood as proof of their engagement in the scientific practices developed. These results have an added value when considering the fact that the students belonged to a group of limited performance with a high absenteeism that, generally, are separated from any attempt to learn concepts and that, nevertheless, is what they have most emphasized having learned. Therefore, we could reconsider the title used in this article and transform it into: "if I do not look for evidence, I do not learn it".

\section{Acknowledgement}

SensoCiencia: P11-SEJ7385 (Andalusian government) \& EDU201569701-P (Spanish government).

\section{References}

Barberán, A., Hammer, T.J., Madden, A.A and Fierer, N. (2016). Microbes should be central to Ecological Education and outreach. Journal of Microbiology \& Biology Education, 17 (1), 23-28. 
Baumgartner, E., Bell, P., Brophy, S., Hoadley, C., Hsi, S., Joseph, D., Orrill, C., Puntambekar, S., Sandoval, W., \& Tabak, I. (2002). Design-based research: An emerging paradigm for educational inquiry. Educational Researcher, 32(1), 5-8.

Bisquerra Alzina, R., and Pérez Escoda, N. (2007). Las competencias emocionales. Educación XX1, 10(0), 61-82. http://doi.org/10.5944/educxx1.1.10.297

Borrachero Cortés, A. B., Mellado Jiménez, V., Bermejo García, M. L., \& Costillo Borrego, E. (2015). Las Emociones en la Enseñanza y el Aprendizaje de las Ciencias en Educación Secundaria. Enseñanza de Las Ciencias, 33(3), 199-200. https://doi. org/http://dx.doi.org/10.5565/rev/ensciencias. 1823

Byrne, J., Grace, M., \& Hanley, P. (2009). Children's anthropomorphic and anthropocentric ideas about micro-organisms. Journal of biological education, 44(1), 3743.

Crawford, B. A. (2014). From Inquiry to Scientific Practices in the Science Classroom. In N. G. Lederman \& S. K. Abell (Eds.), Handbook of research on science education volume II (pp. 515-541). New York, NY: Routledge.

Díaz, R., López, R., García, A., Abuín S, G., Nogueira, E y García, J.A. (1996). ¿Son los alumnos capaces de atribuir a los microorganismos algunas transformaciones de los alimentos? Enseñanza de las Ciencias, 14 (2), 143-153.

Duschl, R. A., Maeng, S., \& Sezen, A. (2011). Learning progressions and teaching sequences: a review and analysis. Studies in Science Education, 47(2), 123-182.

Duschl, R. A., \& Grandy, R. (2013). Two views about explicitly teaching nature of science. Science \& Education, 22(9), 2109-2139.

Duschl, R. A., \& Bybee, R. W. (2014). Planning and carrying out investigations: An entry to learning and to teacher professional development around NGSS science and engineering practices. International Journal of STEM education, 1(1), 12.

Easterday, M. W., Rees Lewis, D. G., \& Gerber, E. M. (2016). The logic of the theoretical and practical products of design research. Australasian Journal of Educational Technology, 32(4), 125-144. http://doi.org/10.14742/ajet.2464

Harlen, W. (Ed.). (2010). Principles and big ideas of science education. Association for Science Education.

Garrido Portela, M. (2007). La evolución de la idea de los niños sobre los seres vivos (Doctoral thesis. Universidad de Coruña, A Coruña). Retrieved from: http://ruc.udc.es/ dspace/handle/2183/7330

Hazelkorn, E. \& Ryan, C. (2015). Science education for responsible citizenship, Brussels, European Commission.

Jasmin, D., Baptist, P., Artigue, M., Dillon, J., Harlen, W. \& Léna, P. (2010). Fibonacci Starting Package: Scientific background. Fibonacci Scientific Committee.

Jaber, L. Z., and Hammer, D. (2016). Learning to Feel Like a Scientist. Science Education, 100(2), 189-220. DOI:10.1002/sce.21202

Johnstone, A. H., \& Al-Shuaili, A. (2001). Learning in the laboratory; some thoughts from the literature. University Chemistry Education, 5, 42-51

Jones, G., Gardner, G., Lee, T., Poland, K., \& Robert, S. (2013). The Impact of Microbiology instruction on students' perceptions of risks related to microbial illness. International Journal of Science Education, 3(3), 199-213. 
Juuti, K., \& Lavonen, J. (2006). Design-Based Research in Science Education: One Step Towards Methodology. NorDiNa: Nordic Studies in Science Education, (4), 54-68.

Mellado, V., Borrachero, A. B., Brígido, M., Melo, L. V., Dávila, M. A., \& Cañada, F. (2014). Las emociones en la enseñanza de las ciencias. [Emotions in science teaching]. Enseñanza de Las Ciencias, 32(3), 11-36.

Minner, D.D., Levy, A.J \& Century, J. (2009). Inquiry-Based Science InstructionWhat Is It and Does It Matter? Results from a Research Synthesis Years 1984 to 2002. Journal of Research in Science Teaching.

National Research Council. (2012). A framework for K-12 science education: Practices, crosscutting concepts, and core ideas. Washington, DC.: National Academy Press.

Osborne, J. (2014). Tecahing Scientific Practices: Meeting the Challenge of Change. Journal Science Teacher Education, 25, 177-196.

Philip, J. M., \& Taber, K. S. (2016). Separating 'inquiry questions' and 'techniques' to help learners move between the how and the why of biology practical work. Journal of Biological Education, 50(2), 207-226.

Phye, G. D., Schutz, P., \& Pekrun, R. (2011). Emotion in education. Elsevier.

Pivatto, W. (2014). Bactérias, vírus ou febre: Os conhecimentos prévios dos alunos sobre saúde e combate a doenças. Revista de Educação, Ciências e Matemática, 4(3).

Redelman, C.V., Marrs, K. \& Anderson, G.G. (2012). Inquiry-based examination of chemical disruption of bacterial biofilms. The American Biology Teacher, 71(5), 305-309.

Simonneaux, L. (2000). A study of pupils' conceptions and reasoning in connection with 'microbes', as a contribution to research in biotechnology education. International Journal of Science Education, 22(6), 619-644.

Tamir, P., \& Amir, R. (1981). Retrospective Curriculum Evaluation: An Approach to the Evaluation of Long-Term Effects. Curriculum Inquiry, 11(3), 259-278. https:// doi.org/10.1080/03626784.1981.11075259

Teodoro, A., \& Chambel, L. (2013). The role of teachers in students' education for antibiotic use. A. Mendez-Vilas (coords), Microbial pathogens and strategies for combating them: science, technology and educations, 1957-1968.

Thagard, P. (2008). Conceptual change in the history of science: life, mind and disease. In $S$.

Vosniadou (Ed.), International Handbook of Research on Conceptual Change (pp. 374387). NY, New York: Routledge. 


$$
\begin{gathered}
\text { SECTION } 4 \\
\text { SCIENTIFIC THINKING, NATURE } \\
\text { OF SCIENCE AND ARGUMENTATION }
\end{gathered}
$$





\title{
CONTINGENCY IN PEER SCAFFOLDING WHEN ADDRESSING SOCIO-SCIENTIFIC ISSUES IN BIOTECHNOLOGY
}

\author{
Birgitta Berne \\ Lindaskolan (Sweden) \\ birgitta.berne@telia.com
}

\begin{abstract}
Although policy and research in science education suggests that students learn best when engaged in discussions about socially relevant issues, less is known about how this actually happens in the classroom. This paper reports on a research project in a secondary school in Sweden, which examined the processes taking place in a peer-group discussion during a unit focussed on the desirability of universal DNA registers. Prior to the students' (14-15 years old) discussions, varied prompts were used to highlight different aspects of the issue. In addition, students were given time to search further information themselves. Data were collected through students' own video recordings of the discussions. The results suggest that the notion of scaffolding is relevant for analysing students' dialogical argumentation and for understanding the interactions in a group where no student appears to be more knowledgeable than the others. This study shows that students collectively may contingently scaffold each other to make more reflective arguments. Students support each other in affect, metacognition and cognition with the result that students start to structure their arguments by connecting scientific data and qualifiers to their claims. Furthermore, students begin to consider alternative perspectives and recognise challenges to their own position.
\end{abstract}

Keywords: socio-scientific issues, peer-group discussions, biotechnology, scaffolding.

\section{Introduction}

Scientific issues connected to society are the authentic dilemmas that many researchers in science education highlight as interesting and motivating for students to discuss, for students to learn science and acquire higher argumentation skills (e.g. Sadler, 2011; Simonneaux, 2008). Socio-scientific issues (SSIs) are 
controversial, include conceptual and/or procedural connections to science and have social significance (Sadler, 2009). These issues could not be answered just by connecting scientific data to claims, but moral and ethical values must also be considered (Evagorou et al., 2012; Nielsen, 2012).

However most classroom talk is asymmetrical, with the teacher in a more authoritative role than learners (Mercer \& Dawes, 2008). But if students get the opportunity to discuss with peers, they can get access to different aspects of the issues and evidence that could be used for different views (Duschl \& Osborne, 2002). By challenging each other's thinking in the discussion they can develop their own understanding. From a constructivist view Smith et al. (2009) argue that students get valuable opportunities to develop communicative and metacognitive skills while explaining and justifying their own claims, and while examining peers' explanations. Vygotsky (1935/1978) describes students' discussions as students being in their 'zone of proximal development' where they benefit from being assisted. The assistance he is referring to is talk, as he regards talk as a tool for thinking, arguing that by being engaged in talk about shared problems individuals can develop and construct knowledge and understanding. According to Vygotsky, knowledge from the social context passes on to the individual understanding as individuals restructure their thoughts. This interaction between the learner and the teacher or more knowledgeable peer, was called scaffolding by Wood et al. (1976).

To decide whether a teaching strategy could be characterised as scaffolding or if it should be characterised as mere help however, Van de Pol et al. (2010) have identified three key characteristics essential for identifying a strategy as scaffolding. These three strategies are: contingency, fading and transfer of responsibility. The first and most important of the key characteristic, contingency, is defined as responsiveness or tailored, adjusted or calibrated support for fading and transfer of responsibility to happen. However we still lack empirical evidence for how students in peer groups can support each other. As argued by Evagorou \& Osborne (2013), we still need more research to understand how this learning takes place on the micro-level within the classroom.

The research questions were:

- What kind of support could peers give each other when discussing an SSI - here a universal DNA-register - in groups?

- How does this peer support affect students' arguments?

\section{Method}

In order to know how students could support each other to gain higher argumentation skills, empirical evidence from the implementation and outcomes of a classroom-based study of SSI was collected (Sadler, 2012). An intervention was designed based on previous research in argumentation in science education 
(e.g. Jiménez-Aleixandre \& Erduran, 2008; Sadler \& Zeidler, 2005). The aim of the intervention was to help students use scientific knowledge and reasoning, as well as ethical considerations, as a basis for forming their views on SSIs. A further aim was that students should develop a critical and constructive attitude towards their own and others' arguments, showing sensitivity and respect for the reasoning of others and acquiring an ability to see issues from different perspectives, as prescribed in the Swedish curriculum (National Agency of Education, 2000). The first part of the intervention is presented in more detail below. To get empirical evidence of how students interact, a teacher-researcher design was chosen, a design that according to Roth (2007) gives the researcher a unique position: "Teacher - researcher is an ideal position for gathering evidence not available to university-based researchers who are not based at the site in the same permanent way as we are" (p. 83).

In this study, this gathering of evidence could be related to the fact that all 20 students in the class, 9 boys and 11 girls in grade 9 (14-15 years of age) signed a form consenting to their participation in the study. The form explained the aims of the study and how the study was integrated into the ordinary teaching. The institution approved for the execution of the study and so did the students' parents. The students attended a small school located outside Gothenburg on the west coast of Sweden. Including all the students was of importance to the study, since the goal was to examine each individual student's contribution to collaborative argumentation. The theoretical lens was that learning involves a passage from the social context to individual understanding, which means that new ideas must be rehearsed between people and talked through (Vygotsky, 1935/1978). Students in collaboration can share risks in the presentation of new ideas, give constructive criticism, and by that create a safe zone of proximal development for each other "where intellect and affect are fused in a unified whole" (Vygotsky, 1934/1987, in Mahl \& John-Steiner, 2002, p. 373).

Hence the intervention was based on students discussing four different SSIs in connection to biotechnology in peer groups. The students were divided up with five students in each group, resulting in a total of four groups. To nurture discussions, students known to be enthusiastic about discussing were placed in each group, which consisted of both female and male students. The following section presents how the teaching was framed and formulated.

\subsection{Teaching strategy}

The first issue in the intervention was the issue of whether we should have a universal DNA-register or not. This issue was chosen to support student affect by the means of modelling a multifaceted and interesting issue that according to Wood et al. (1976) is the prerequisite for recruiting students as tutoring partners. The teacher knew the students and their neighbourhood well, and by that she 
could choose an issue that had the possibility to motivate students by involving them personally and by relating school science to real problems.

From the start, she scaffolded students' cognitive activities by explaining the concept of DNA and how it can be used for a universal register, and by modelling different aspects of the issue via films and texts. In previous science lessons students had practiced how to connect scientific content knowledge to arguments and how to analyse data and values behind an argument. Furthermore, she scaffolded students' metacognitive activities by instructing them to prepare for the discussion and by instructing them to write down their arguments for or against a register before discussing with peers. At this point in the intervention she reduced her role as the scaffolding teacher and handed over the responsibility for the actual discussion to the students. Drawing on her personal experience, student peers have a unique capacity to support each other in learning and they feel freer to discuss without teacher control.

The goal, as explained to the students, was not that the students should get to a final decision, but to understand the complexity of the issue, develop analytical skills and through that experience make more reflective arguments. Six months prior to the peer discussions, the students were taught genetics, and a month before the discussions, they saw the science fiction film Gattacca (1997), where a genetically inferior man assumes the identity of a superior one in order to pursue his lifelong dream of space travel.

Lesson 1: In the first lesson about a DNA register, the students were introduced to the issue by means of a local case. Fifteen years ago, an 8-year old girl was raped close to their school and the week the intervention started it was taken up as a cold case on the front page of the local newspaper. The students' teacher read some excerpts from the article and handed out copies. The article described what had happened and highlighted the fact that nobody had been caught although they had searched for 15 years. The article described how today you identify a person from DNA in saliva and what restrictions there are in Sweden, permitting only suspected persons to be tested. After this introduction, the students watched a newly produced film about genetic technology and the teacher helped them to connect the message in the film to the genetic knowledge they had been given before.

Homework: Students were instructed to prepare themselves for a discussion with peers where they would discuss whether we should have a DNA register or not. To do so, students had to read for homework a short piece of text in their biology textbook, and a more advanced short piece of text in a book by Brändén (2002). Furthermore, the students were asked to search for more information from the internet. The students also had to write down their own arguments for or against a DNA register before discussing with peers in groups.

Lesson 2: The second lesson started with the students' teacher presenting the new Nobel Prize winners in medicine and chemistry, both with connections to 
biotechnology, taking the opportunity to connect school science to science in society, exemplifying the importance of biotechnology knowledge. The students were given some time to ask questions and some extra time was given for the students who had not written down their own arguments. Thereafter the students were divided into peer groups for having their discussions. In case the groups needed more triggers to start the discussions, they were given articles from the internet presenting different perspectives on the issue. However, the group analysed in this study never used these triggers.

\section{Data collection}

Each group discussion was video-recorded by the students themselves. The students were given the film and the camera so they could feel that they were the owners of the recordings. They were told that they could choose how to record as long as it was possible to capture the process of their discussion, and in case someone did not want to be seen on the film the teacher would still be able to recognise their voices. To become familiar with the recording and to feel relaxed when being recorded, the students had used the cameras in many different situations in science lessons the year prior to the intervention. There were intense discussions in three of the four groups. However, to be able to present students' interactions on a micro-level, just one groups is presented in this article. In the group, two of the girls, who seldom said anything in whole class situations, fought for the floor. What processes in the peer discussions made such a big difference in the students' engagement? The group consisted of three girls, Fanny, Emma and Anna and two boys, Carl and Edward. The students spoke in Swedish and their discussions have been translated into English. The translation was made as close to the students' words as possible with only small corrections to be able to understand what the students said.

\section{Data Analysis}

The teacher-researcher watched the video-recordings repeatedly. This initial inductive analysis indicated that all students supported each other to pose more reflective arguments in a very fine-tuned way. It seemed as if students had taken over the responsibility to scaffold each other when the teacher had reduced her role as the scaffolding teacher. Hence to be able to analyse students' support, the framework for describing scaffolding strategies constructed by Van de Pol et al. (2010) was tried out. The framework was originally constructed for analysing teacher-student scaffolding. However, after having tried out the framework and modified it for the purpose of analysing students' interaction in argumentation about SSIs, it turned out to be useful also for analysing the appearance of 
student-student scaffolding. This integrative framework made it possible to capture the contingency, the responsiveness or tailored, adjusted or calibrated support that Van de Pol et al. (2010) view as the most important of the three key characteristics for naming support as scaffolding.

The framework describes three different scaffolding intentions and six scaffolding means, and van de Pol et al. (2010) conclude that: "Any combination of scaffolding means with scaffolding intentions can be construed as a scaffolding strategy" (p. 277). The intentions, or goals, for scaffolding are classified under the activities of affect, metacognition and cognition. The focus of the present study was on students' scaffolding strategies to support peers to pose more reflective arguments, hence the intentions for support of cognitive activities are here specified for argumentation:

— by students' supporting each other to structure arguments as described by Toulmin (1958);

- by students' supporting each other to use advanced ethical reasoning as described by Jones et al. (2007);

- by students' supporting each other to examine the issue, important practices as described by Sadler et al. (2007).

The scaffolding means to support the learning activities of the students are by Van de Pol et al. (2010) distinguished as feeding back, giving hints, giving instruction, explaining, modelling and questioning.

\section{Results}

The results are presented and analysed under the headlines of the different activities: support of student affect, support of students' metacognitive activities, and support of students' cognitive activities. Students' interactions are categorized

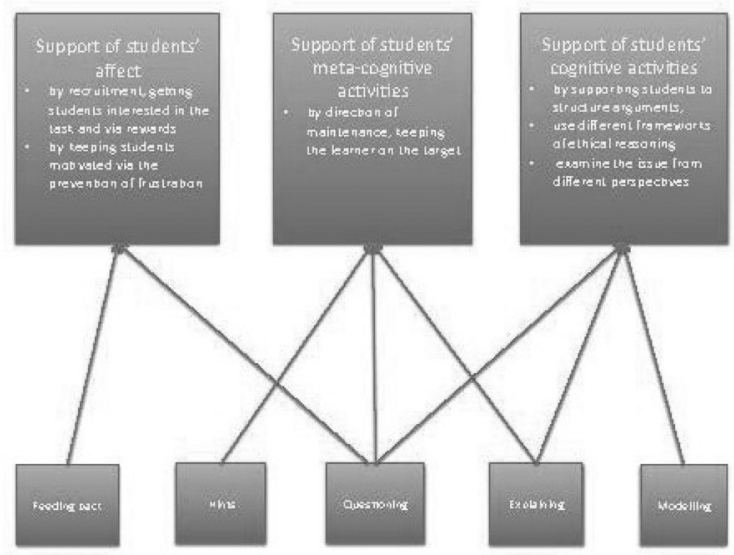

Figure 1 Modified framework for analysis of scaffolding strategies, adopted from van de Pol et al. (2010). 
by the teacher-researcher in collaboration with several doctoral students in science didactics. Students' names are pseudonyms. Figure 1 shows that the students did not use all the different means to support every activity, and they did not use the means of instruction at all. However, they used the means of questioning more frequently than the others and they used questioning as a means to scaffold all the three activities.

\subsection{Support of student affect}

In this study, this is illustrated by the means of feeding back and questioning. In the following discussion, Fanny and Anna contingently feed back when Emma asks for the floor by talking about the PKU register.

Emma: Now it's like this that I think one should have a PKU register.

(Cannot hear who): You have!

Fanny: Ssh, yes but listen now!

Anna: No, DNA register.

Emma: No, DNA register for that then, then so to say if you use it then you ... catch criminals faster.

Anna: $\mathrm{Mmmm}$.

Emma: Then they don't have time to commit so many crimes at the same time. Do you get it?

Anna: Yes.

Fanny: No, and I totally agree with you.

In this excerpt, it is clear that Fanny, by asking the others to listen, directly gives Emma the floor and encourages her to continue to give her argument. Furthermore, Anna feeds back on Emma's argument by contingently, correcting Emma when mentioning the PKU register instead of the DNA-register. The Phenylketonurea (PKU) register already exists, but it is for medical care and not for the police, and Emma directly takes up the corrections, indicating a positive atmosphere even during corrections. Anna is feeding back on Emma's explanation of possible consequences of a register and her small utterance: " $m m m$ " provides Emma with the information that Anna agrees with her argument, encouraging her to explain even more possible consequences. In this excerpt, Emma demonstrates the importance of approvals by saying: "Do you get $i t$ ?". Even if she has already been given the floor by Fanny and has been approved by Anna she asks for more approvals. Her question results in more approval from Anna and a strong approval from Fanny saying: "I totally agree". This encouraging start sets the stage for the rest of the discussion.

\subsection{Support of students' metacognitive activities}

In this study, thinking about one's thinking is illustrated by the means of asking peers questions, explaining and giving hints. In the next discussion, 
whether the man guilty of rape is free or not, Edward contingently explains, asks questions and gives hints for Emma to realize that we do not know, making Emma reflect on her own argument.

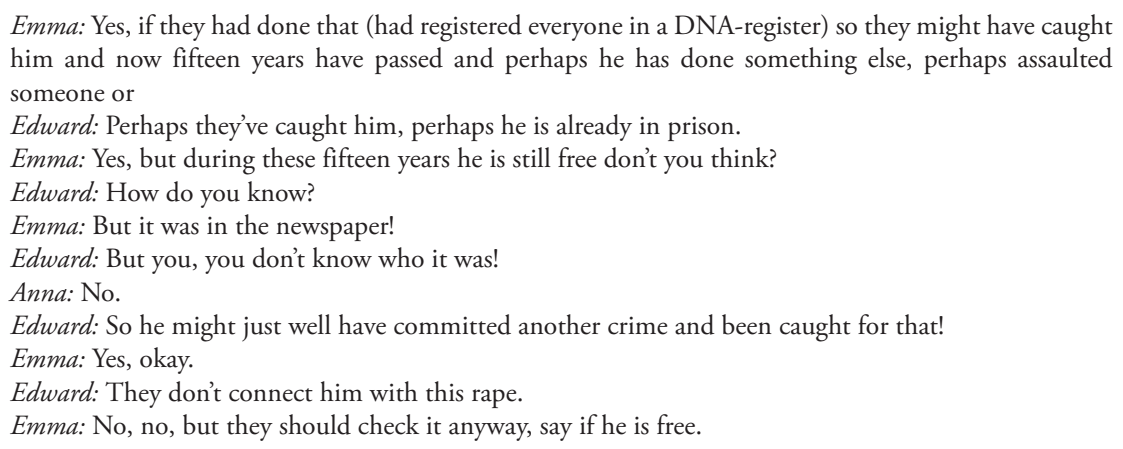

When externalizing their thoughts in the argumentation process, students can be supported in learning more about their own thinking, which is one of the most important aspects of scaffolding and evident in this excerpt. Discussing with peers makes it possible for students to test their own arguments at the same time as they come in contact with different perspectives presented by their peers, and where their arguments can be widened or questioned, encouraging their reasoning ability. In this discussion, Emma assumes that the man guilty of rape still is free, but Edward, in a contingent way, argues that we do not know. From the beginning, Emma does not understand Edward's argument, but by giving hints, asking questions and explaining, Edward scaffolds Emma until she is able to understand his meta-perspective. Emma realizes that Edward has a strong argument, as she could not really know that the man is free, but his argument does not say anything about not using the register, so Emma makes a qualifier to her argument by adding: "if he is free".

\subsection{Support of students' cognitive activities}

In this study, this was done by the means of asking questions, explaining and modelling. In this excerpt, Fanny and Carl question the fact that the PKU register was actually used to solve the murder of Anna Lindh, (the Swedish Foreign Minister at that time).

Fanny: Yes, but it's also special when they used it for Anna Lindh, if it should be a society of equal rights, that all people are worth the same!

Carl: I also think that,

Anna: Why should they go into it just for her? 
Carl: Because yesterday I read on the Internet that they have only used the register a few times and one of the times was for her then, just because they surely thought that she was a more important person. Emma: But that's wrong!

Fanny: All people are worth the same and still they used it for her!

Carl: But there are rapes and outrages several times a year!

Fanny: But still we are not worth as much as she was because she had a special job!

Edward: Supposedly it was because they didn't want to have bad publicity for the country. The situation was an emergency where they had to go into the PKU register to catch this guy, otherwise it would have been bad for Sweden, bad publicity for the country.

Swedish students have been taught about their rights in a democratic society, and the fact that the PKU register was opened to solve the murder of Anna Lindh and not to solve any other crimes upset the students at this time, more than the fact that the register was opened. In a previous discussion (not presented in the results) the students approached the issue from a rights and duties aspect, arguing that using the PKU-register was to break the law. Now the students approach the issue from a virtue ethics perspective, focusing on who should have the possibility to use the DNA-register, and discuss the potential benefits of using the register to solve crimes committed against ordinary people as well. In the discussion, Carl and Edward explain possible reasons for using the register and by that model how regulations and laws could be set aside supposedly in order to save the Swedish nation from bad publicity.

\section{Discussion}

This article explored what kind of support peers can give each other and what affect the support can have on students' arguments, focusing on contingency, the most important characteristic of scaffolding. Hence, this study is in line with the request from by van de Pol et al. (2010) to document the effectiveness of the use of specific scaffolding strategies under particular circumstances empirically. The results suggest that the notion of scaffolding is relevant also to understand the interactions in a group, in which no student appears more knowledgeable than the others. However, in peer scaffolding different students can take on more responsibility for scaffolding one or more of the three activities. Findings indicate that students have a unique possibility to contingently support each other, contingency that according to van de Pol et al. (2010) is the most important of the key characteristics of scaffolding. Being contingent is not easy for a teacher to achieve, even if there are just 20 students in the class. However, peers, as shown in this study, are not just more available, but they can take on roles seldom taken on by teachers, and thus offer further possibilities for discussion and exploration when they consider and challenge each other's perspectives. Students can be more fine-tuned having the ability to scaffold their peers contingently by adapting to the current 
level of their peers' performance. As argued by Rogoff (1990), young people feel freer to examine the logic of arguments when interacting with peers rather than with adults.

In this study, the choice of an SSI as the context of instruction was based on previous studies that suggested that SSI could engage students in argumentation (e.g. Sadler, 2011; Simonneaux, 2008). However, even if students in this study engaged in the discussion directly from the start, and after the discussion reported that the issue had been interesting and motivating, support in affect during the discussion seemed to be as important. It seems that the students in this study, by attending to the scaffolding activities of affect, cognition and metacognition, and by using the means of questions, explorations, feedback, hints and models, could scaffold reflection and construction of knowledge amongst their peers. However, although the students used all the means described by van de Pol et al. (2010), except for the means of instruction, they used the means of questioning more frequently than the others, and they used questioning as a means to scaffold all the three activities. This result is in alignment with the argument from Osborne (2014) highlighting that “... questioning has the potential to promote critical thinking and to foster reflection, deep thinking and construction of knowledge" (p. 55).

Furthermore, it seems that the students did not use the means of instruction for any of the activities, a means that would probably be used by a teacher scaffolding a student. The explanation might be found in the argumentation from Wertsch (1979/2008) who describes the mismatches between the adult's and the child's definition of the task situation as they are participating in different language-games. He posits that when an adult instructs a student, the coherence between action and speech can not be assumed but must be created, while the coherence when an adult directs another adult already exists. Hence, when a student direct another student she/he might also understand what is being requested because she/he understands the speech and the situation and hence might not find the means of instruction appropriate.

These findings challenge the usually accepted description of the tutor as a more knowledgeable peer (Wood et al., 1976). On the contrary, this classroombased qualitative study shows that all the participant students scaffolded each other to present more reflective arguments. Scaffolding that sometimes seems to be intended and sometimes seems to be unintended. These results are in line with the results from Smith et al. (2009) in which they argue that peer discussion enhanced students' understanding through discussion and debate, even if none of the students in a discussion group knew the correct answer. From a constructivist viewpoint, Smith et al. (2009) argue that students get valuable opportunities to develop communicative and metacognitive skills, while explaining and justifying their own claims and while examining peers' explanations. They further argue that: "...previous explanations for the value of 
peer instruction have maintained the 'transmissionist' view that during discussion, student who know the right answer are explaining the correct reasoning to their less knowledgeable peers...", while their study suggests a more constructivist explanation that: "...these students are arriving at conceptual understanding on their own, through the process of group discussion and debate" (p. 3).

\section{Conclusion and implications}

From one practitioner's study, it is not possible to make generalizations. However, on an enquiry methods level, it is important to show that a modified framework from van de Pol et al. (2010) makes it possible to capture the dialectical features of students' argumentation. Contingent scaffolding was shown to be most beneficial for helping students make more reflective arguments. Students supported each other in affect, metacognition and cognition with the result that students started to choose amongst conflicting perspectives before deciding what argument to pose. Students reflected both on social and scientific aspects of the issue and they considered consequences, rights and duties and virtue ethics aspects. Furthermore, they became aware of counterarguments and started to use qualifiers for their arguments. It seems that teachers, by motivating and framing SSI discussions in science education, can reduce their authoritative presence, hence the work has implications for the classroom and thus for continuing profession development and teacher education.

\section{References}

Bränden, H. (2002). Genteknik, kloning och stamceller. Stockholm. Kungl. Ingenjörsvetenskapsakademien.

Duschl, R., \& Osborne, J. (2002). Supporting and Promoting Argumentation Discourse in Science Education. Studies in Science Education, 38 (1), 39-72.

Evagorou, M., Jiménez-Aleixandre, M., \& Osborne, J. (2012). 'Should We Kill the Grey Squirrels?' A Study Exploring Students' Justifications and Decision-Making. International Journal of Science Education, 34(3) 401-428.

Evagorou, M., \& Osborne, J. (2013). Exploring Young Students' Collaborative Argumentation Within a Socioscientific Issue. Journal of research in Science teaching, 50(2) 209-237.

Jones, A., Mckim, A., Reiss, M., Ryan, B., Buntting, C., Saunders, K., et al. (2007). Research and development of classroom-based resources for bioethics education in New Zealand. Hamilton, NZ: Wilf Malcolm Institute of Educational Research, School of education, University of Waikato.

Mahl, H., \& John-Steiner, V. (2002). The gift of confidence: A Vygotskian view of emotions. In C. G. Wells \& G. Claxton (Eds). Learning for life in the $21^{\text {st century. }}$ Oxford, UK; Cambridge, MA: Blackwell. 
Mercer, N. \& Dawes, L. (2008). The value of Explorative Talk. In Mercer, N., \& Hodgkinson, S. (Eds) Exploring Talk in Schools. Los Angeles, London, New Delhi, Singapore, Washington DC: SAGE 55-71.

Nielsen, J. A. (2012). Science in discussions: An analysis of the use of science content in socio-scientific discussions. Science Education, 96(3), 428-456.

Osborne, J. (2014). Teaching critical thinking? New directions in science education. Schools Science Review, 95 (352)

Osborne, J., \& Dillon, J. (2008). Science Education in Europe: Critical Reflections. London. King's College. A report to the Nuffield Foundation.

Rogoff, B. (1990). Apprenticeship in thinking. New York, Oxford University Press.

Roth, W-M. (2007). Doing Teacher-Research A Handbook for Perplexed Practitioners. Rotterdam: Sense Publishers.

Sadler, T. D. (2009). Situated learning in science education: socio-scientific issues as contexts for practice. Studies in Science Education, 45 (1), 1-42.

Sadler, T. D. (2011). Situating Socio-scientific Issues in Classrooms as a Means of Achieving Goals of Science Education. In: Sadler, T. D. (Ed) Socio-scientific Issues in the Classroom - Teaching, Learning and Research. Dordrecht Heidelberg London New York: Springer, 1-10.

Sadler, T. D., Barab, S. A, \& Scott, B. (2007). What Do Students Gain by Engaging in Socioscientific Inquiry? Research in Science Education, 37: 371-391.

Sadler, T. D., \& Zeidler, D. L. (2005). The significance of content knowledge for informal reasoning regarding socioscientific issues: Applying genetics knowledge to genetics engineering issues. Science Education, 89, 71-93.

Simonneaux, L. (2008). Argumentation in Socio-Scientific Contexts. In Erduran, S., \& Jimenez-Aleixandre, M. P. (Eds.) Argumentation in Science Education: Perspectives from Classroom-Based Research. Dordrecht: Springer, 179-199.

Skolverket (The national agency for education). (2000). Natural Science Programme. Programme Goal, Structure and Syllabuses. Retrieved July 20, 2009, from: http:// www3.skolverket.se/ki/eng/nv_eng.pdf_.

Smith, M. K., Wood, W. B., Adams, W. K., Wieman, C., Knight, J. K., Guild, N., \& $\mathrm{Su}, \mathrm{T}$. T. (2009). Why peer discussion improves student performance on in-class concept questions. Science, 323, 122-124.

Toulmin, S. (1958). The uses of argument. Cambridge: Cambridge University Press.

Van de Pol, J., Volman, M., \& Beishuizen, J. (2010). Scaffolding in Teacher-Student Interaction: A Decade of Research. Educational Psychology Review, 22: 271-296.

Vygotsky, L., S. (1935/1978). Mind in society: The development of higher psychological processes. Cambridge, MA: Harvard University Press.

Wertsch, J. V. (1979/2008). From Social Interaction to Higher Psychological Processes. A Clarification and Application of Vygotsky's Theory. Human Development, 22(1), 1-22 / 51:66-79

Wood, D., Bruner, J., \& Ross, G. (1976). The role of tutoring in problem solving. Journal of Child Psychology and Psychiatry, 17, 89-100. 


\title{
DIALOGUE AND LINGUISTIC SCAFFOLDS \\ AS TOOLS TO HELP STUDENTS CONSTRUCT INVESTIGABLE QUESTIONS
}

\author{
Concepció Ferrés-Gurt and Jordi Domènech-Casal \\ Departament de Didàctica de les Matemàtiques i les Ciències Experimentals, Universitat \\ Autònoma de Barcelona (Barcelona-España). \\ cferres@hotmail.com,jdomen44@xtec.cat
}

\begin{abstract}
The development of scientific competence implies specific scientific thinking skills linked to the procedural dimension of scientific competence. Posing investigable questions is one of these scientific thinking skills that, together with experiments, design or data analysing, are essential in Inquiry-Based Science Education. Students have difficulties with identifying and constructing investigable questions. We have developed two scaffolding strategies centred on dialogue and linguistic supports to help students construct investigable questions. Our results show that these strategies enhance students' scientific thinking skills and connect the construction of questions with experimental design.
\end{abstract}

Keywords: inquiry, investigable questions, linguistic scaffolds, designing experiments

\section{Introduction}

The development of scientific competence implies working on three dimensions (OECD, 2013). The conceptual dimension includes mastering scientific models (e.g. the water cycle, cell models, etc.), and being able to apply it to the understanding of real contexts. The procedural dimension makes reference to scientific thinking skills as constructing questions, designing experiments, inducing explanations and making predictions. The epistemic dimension refers to the comprehension of the logic and social frames of the construction of scientific knowledge, including social dynamics of argumentation and means to validate scientific knowledge. 
Inquiry-Based Science Education (IBSE) has been proposed as an appropriate methodology to deliver this, as it implies deepening in the comprehension of scientific models, scientific argumentation and the nature of science (Llewellyn, 2005, Osborne \& Dillon, 2008). In such approaches, students are proposed to construct scientific models and concepts by applying the scientific methodology as a learning methodology, following standard steps: 1) construct investigable questions; 2) make observations and design experiments; 3) analyse the evidences; 4) construct an explanation based on evidences; 5) connect the explanation with existing scientific knowledge; 6) communicate and justify the explanation; 7) reflect on the process. This methodological frame has been suggested as a good approach to work on the procedural dimension of scientific competence, and the development of key scientific skills for designing experiments, to get conclusions from data, or make predictions based on evidence. Some authors reduce the key scientific skills to two main abilities: creating investigable questions and analysing data to answer them (Bell et al., 2010, National Research Council, 2012).

When getting into practice for the development of the procedural dimension of scientific competence in inquiry-based activities, students usually depart from questions proposed by teachers and rarely make their own investigable questions (Fay et al., 2007). This can be at the same time the cause and consequence of the difficulties students present to make investigable questions (Kelsey \& Steel, 2001). Making investigable questions is a high order cognitive skill (Zoller \& Tsaparlis, 1997) hard to develop by students, as it implies abilities as identifying open problems, decision-making, and analyzing and assessing data. In fact, these cognitive processes can be related to the three dimensions of scientific competence: connecting phenomena with scientific models (conceptual), designing experiments (procedural) and assessing scientific research (epistemic). Regarding the procedural dimension, when asked to, students usually propose "information questions" that are not investigable, referring directly the scientific models behind a phenomena with complex questions (Why?... How...?). These questions are non-investigable, as its answers are constructs, not data, so it can hardly entail data-obtaining processes as designing experiments. Instead, questions making reference to the factors underpinning a phenomenon (What is the difference between...? What if...?) are investigable, and can be immediately connected to an effective research studies (Domènech-Casal, 2014; 2019). Other authors point out students' present difficulties to identify and control variables and design experiments (Grunwald \& Hartman, 2010; D’Costa \& Schlueter, 2013).

Some authors, such as Windschitl et al. (2008), propose that establishing linguistic frames could help students to connect their research questions to the construction/validation of scientific models or concepts, as: "If we think that (scientific model or concept), when (conditions of the independent variable), we will 
observe that (results in the dependent variable)". Such kinds of scaffolds have been successfully used to improve students' abilities to design experiments and structure their reasoning in the frame of the scientific research approaches (D'Costa \& Schlueter, 2013; Domènech-Casal, 2013). Other authors suggest that students' difficulties in generating investigable questions can be overcome and assessed with appropriate scaffolding, and an initial, basic comprehension of the scientific models depicting the phenomena (Abell \& Lederman, 2007, Windschitl et al., 2008; Marbà et al., 2015), and that the process of learning to generate investigable questions is a dialogic, iterative process between teachers and students (Lombard \& Schneider, 2013). In this research, we aim to propose and analyse the effectiveness of different linguistic scaffolds to improve students' abilities to construct questions investigable through experimental design.

\section{Objectives}

- To develop and test scaffolding strategies to support students in their transition from non-investigable to investigable questions.

- To describe students' difficulties in constructing investigable questions at different ages in compulsory and not compulsory education.

\section{Methodology}

We performed two experiences in compulsory and non-compulsory education to promote students' transition from non-investigable to investigable questions. In both cases, different linguistic scaffolding was used, in two approaches: in Case 1, linguistic written scaffolding consisted of phrase initiators, and in Case 2, scaffolding was not based on written scaffolds, but on oral conversation.

Case 1. 25 students (11 years old) were told the main concepts of cell biology and asked to construct investigable questions to develop laboratory experimental investigations on cellular biology using microscopy. They were given several samples (e.g. yogurt, plant tissue, animal tissue, fungal culture on bread, etc.) to be used in their experiments. In the first session, no scaffolding was used, but results were analysed together. In the second session, Investigable Questions for Research (IQR) linguistic scaffolding (Table 1) was modelled and given to the students. This scaffold aims to help students transform noninvestigable questions into investigable questions and design meaningful experiments from investigable questions. Students worked in pairs for two 10-minute sessions. At the end of both sessions, resulting questions and experiments proposed by students were collected and analysed together with students. 
TABLE 1

INVESTIGABLE QUESTIONS FOR RESEARCH (IQR) SCAFFOLD.

EXAMPLES OF THE FILLING PROCESS ENTAILING THINKING SKILLS IS SHOWN IN GREY

\begin{tabular}{|c|c|c|}
\hline \multicolumn{3}{|c|}{ As we know that...photosynthesis depends on light } \\
\hline \multicolumn{3}{|c|}{ Does it make a difference if (think on factors)... we change the wavelength? } \\
\hline \multicolumn{3}{|c|}{ This would allow us to test if... different wavelengths has different photosynthetic power } \\
\hline \multicolumn{3}{|c|}{ We would measure (dependent variable)... plant growing (weight) } \\
\hline $\begin{array}{l}\text { Treatment A } \\
\text { Red light }\end{array}$ & $\begin{array}{l}\text { Treatment B } \\
\text { White light }\end{array}$ & Conclusion expectation \\
\hline If...plant grows & And...plant does not grow & $\begin{array}{l}\text { That would mean...other colours than red } \\
\text { decrease photosynthesis. }\end{array}$ \\
\hline If...plant does not grow & And...plant grows & $\begin{array}{l}\text { That would mean...photosynthesis uses } \\
\text { mainly other colours than red }\end{array}$ \\
\hline If...plant grows & And...plant grows & $\begin{array}{l}\text { That would mean...photosynthesis does } \\
\text { not need other colours than red }\end{array}$ \\
\hline If...plant does not grow & And...plant does not grow & $\begin{array}{l}\text { That would mean...something else is } \\
\text { wrong with the experiment. }\end{array}$ \\
\hline
\end{tabular}

Case 2. 38 students (17 years old) where asked to undertake a research project. They were prompted to propose an investigable question about a biology topic and to develop first steps or theoretical information. Three 20-minute sessions were performed. In the first session, students were asked to write their questions, with no further explanation. In the second, students received explanations about investigable questions and were guided through dialogue to improve their questions. The guided dialogue aimed to connect students' questions to key concepts or models of science. In the third session, guided-dialogue was applied again, to help students improve their questions and research designs, and final proposals were collected. For both cases, resulting questions at the initial (pre-test) and final steps (post-test) were analysed, using a rubric modified from Möller \& Mayer (2010). The resulting rubric, described in previous publications (Ferrés-Gurt, 2015) developed on 5 levels, as shown in Table 2.

TABLE 2

RUBRIC FOR THE ASSESSMENT OF CONSTRUCTED RESEARCH QUESTIONS

\begin{tabular}{cl}
\hline Level & \\
\hline 1 & Does not identify research questions \\
2 & Unapproachable research questions \\
3 & Questions are formulated ambiguously \\
4 & Identifies research questions but does not suggest a suitable methodology \\
5 & Identifies research questions that suggest a suitable methodological design \\
\hline
\end{tabular}




\section{Results}

Students' questions showed progression through different levels of research questions (see examples in Table 3).

TABLE 3

EXAMPLES OF PRE-TEST AND POST-TEST QUESTIONS CONSTRUCTED BY STUDENTS FROM CASES 1 AND 2

\begin{tabular}{|c|c|c|}
\hline $\begin{array}{l}\text { Student } \\
\text { and Case }\end{array}$ & & $\begin{array}{c}\text { Rubric } \\
\text { Level }\end{array}$ \\
\hline \multirow{2}{*}{$\begin{array}{l}\text { Student } 3 \text {, } \\
\text { Case } 2\end{array}$} & Pre-test: What is cancer? What triggers it? & 1 \\
\hline & Post-test: Are there any differences between families in their cancer frequencies? & 4 \\
\hline \multirow{2}{*}{$\begin{array}{l}\text { Student } 5 \text {, } \\
\text { Case } 2\end{array}$} & Pre-test: Why are some plants better adapted to different climates? & 1 \\
\hline & $\begin{array}{l}\text { Post-test: Are there any differences in germination when different kinds of peas } \\
\text { are exposed to hydric and thermic stress? }\end{array}$ & 5 \\
\hline \multirow{2}{*}{$\begin{array}{l}\text { Student } 8 \\
\text { Case } 1\end{array}$} & Pre-test: Why are some microorganisms harmful? & 1 \\
\hline & $\begin{array}{l}\text { Post-test: Do harmful microorganisms share common structures when observed } \\
\text { through a microscope? }\end{array}$ & 5 \\
\hline \multirow{2}{*}{$\begin{array}{l}\text { Student } 14, \\
\text { Case } 1\end{array}$} & Pre-test: How do fungi eat? & 1 \\
\hline & Post-test: Are there differences between fungi depending on what they eat? & 4 \\
\hline
\end{tabular}

Dialogue strategies applied in Case 2 evidenced the difficulties among students to make the difference between non-investigable and investigable questions. In some cases, as a part of the dialogue strategy, the teacher proposed to students a research context, and undertook a dialogue asking students to identify the investigable question driving the proposed research context. Such dialogue strategy (example in Table 4) was helpful to identify students' difficulties.

TABLE 4

DIALOGUE BETWEEN A STUDENT (S3) IN CASE 2 AND THE TEACHER, TO DEEPEN ON THE CONCEPT OF AN INVESTIGABLE QUESTION

S3. The investigable question was: why do parasites disappear when we put fishes in high saline concentration?

T. Do you think this question can be answered from the data collected?

S3. No...in fact what I am proposing as a question is what allows to explain the disappearance of parasites when salt concentration increases. It's an “information” question.

T. Don't you think researchers did know previously that parasites would decrease from osmosis reaction? What was their question when they designed this methodology?

S3. Yes, of course, they knew that osmosis would play a role, this is why they designed the experiment as they did.

T. So...what would be their question?

S3.They wanted to know what the salt concentration was that...this is a question that can be answered from the data, an investigable question. 
T. So...what would this investigable question be?

S3. Will parasites decrease if we expose the fishes to high salt concentration?

T. But you said before that they already knew that salt and osmosis would play a role. Why did they test different concentrations if this was the goal?

S3. OK...I see. I have to observe the resulting data. That's it! They were asking what the best salt concentration was to eliminate the parasites.

Both scaffolding strategies applied in Case 1 and Case 2 (linguistic scaffolding and guided dialogue) improved students' abilities to pose investigable questions and design experiments (Figures 1 and 2).

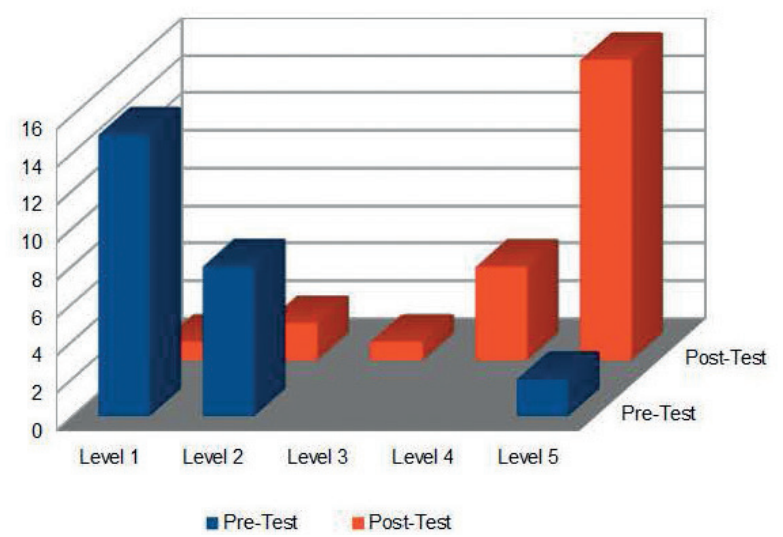

Figure 1 Number of questions of each level developed by students before (pre-test) and after (post-test) linguistic scaffolding intervention (Case 1).

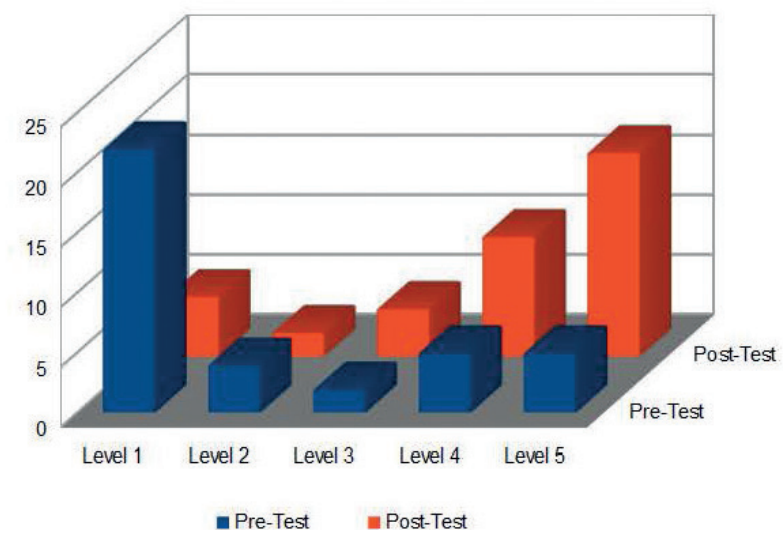

Figure 2. Number of questions of each level developed by students before (pre-test) and after (post-test) dialogue intervention (Case 2). 
In Case 1 (Figure 1) students' abilities are less distributed than in Case 2 (Figure 2). It might be related to two facts: 1 ) the lower student's age makes the initial level lower than older students; 2 ) the proposal is less open in Case 1 (the topic, samples and tools are determined), this being an additional scaffolding that allows better improvement of students' abilities. In both cases, some students design incorrect experiments even after posing a good investigable question, suggesting that designing experiments requires specific thinking skills that are not solved by the proposed scaffolds.

\section{Conclusions}

Our data show that students present remarkable difficulties in onstructing investigable questions, and these difficulties can be overcome by appropriate scaffolding through linguistic and dialogue scaffolding. This ability is a key point in the procedural dimension of scientific competence, that is an essential part of the PISA 2015 framework (OECD, 2013): "Identify the question explored in a given scientific study and distinguish questions that are possible to investigate scientifically". From dialogues with students and observed errors, we conclude that the main difficulties among students are: 1) their concept of "research", linked to information searches; 2) their lack of basic knowledge on the topic they are constructing questions about. As stated before, constructing research questions includes not only the procedural dimension (i.e. experimental design), but also cognitive processes related to the conceptual and epistemic dimensions of scientific competence. In particular, and regarding the second identified difficulty, we consider that more effort has to be done to scaffold the connection between phenomena and scientific models to construct questions that are scientific questions besides experimental investigable questions. Efforts to improve students' abilities to initiate and conduct inquiry activities should take into account these two initial difficulties, and propose some kind of specific scaffolding. This communication refers mainly to improving and assessing students' procedural abilities to construct investigable questions. This is part of a global inquiry process that can be assessed with other proposed tools, as in NPTAI (Tamir et al., 1982, Ferrés-Gurt et al., 2015).

\section{Acknowledgements}

This research was funded by the Spanish Government (grant number EDU2015-66643-C2-1-P) and carried out within the ACELEC research group, acknowledged by the Catalan Government (grant number 2017SGR1399). The authors acknowledge and thank the students and teachers who participated in the study for their collaboration. 


\section{References}

Abell, S.K. \& Lederman, N. G. (2007) Handbook of Research on Science Education. New York: Routledge.

Bell R., Maeng, J. \& Peters, E. (2010) Teaching About Scientific Inquiry and the Nature of Science. Task Force Report. Virginia: Virginia Mathematics and Science Coalition.

D'Costa, A. \& Schlueter, M. (2013). Scaffolded Instruction Improves Student Understanding

of the Scientific Method and Experimental Design. The American Biology Teacher, 75, $18-28$.

Domènech-Casal, J. (2013). Secuencias de apertura experimental y escritura de artículos en el laboratorio: un itinerario de mejora de los trabajos prácticos en el laboratorio. Enseñanza de las Ciencias, 31 (3), 249-262.

Domènech-Casal, J. (2014). Indagación en el aula mediante actividades manipulativas y mediadas por ordenador. Alambique, Didáctica de las Ciencias Experimentales, 76, $17-27$.

Domènech-Casal, J. (2019). Aprenentatge Basat en Projectes, Treballs pràctics i Controvèrsies. 28 experiències i reflexions per a ensenyar ciències. Rosa Sensat: Barcelona.

Fay, E., Grove, N., Towns, M.H. \& Bretz, S. L. (2007) A rubric to characterize inquiry in the undergraduate chemistry laboratory. Chemistry Education Research and Practice, 8(2), 212-219.

Ferrés-Gurt, C. (2015). El reto de plantear preguntas científicas investigables. Revista Eureka sobre Enseñanza y divulgación de las Ciencias, 14(2), 410-426.

Ferrés-Gurt, C., Marbá-Tallada, A. \& Sanmartí, N. (2015). Trabajos de indagación de los alumnos: instrumentos de evaluación y detección de dificultades. Revista Eureka de Enseñanza y Divulgación de las Ciencias 12(1), 22-37,

Grunwald, S. \& Hartman, A. (2010). A Case-Based approach improves science students' experimental variables identification skills. Journal of College Science Teaching, 2010, 28-33.

Kelsey, K. \& Steel, A. (2001) The Truth about Science. Arlington, Virginia: NSTA Press.

Llewellyn, D. (2005) Teaching High School Science Through Inquiry. Thousand Oaks, CA: Corwin Press.

Lombard, F. \& Schneider, D. (2013) Good student questions in inquiry learning. Journal of Biological Education, 47(3), 166-174.

Marbà-Tallada, A., Ferres, C. \& Sanmartí, N. (2015). Students' scientific inquiry ability: Rubric to evaluate it. ESERA Conference 2015. Helsinki (Finland).

Möller, A. \& Mayer, J. (2010) Learning progressions in biological inquiry skills. In: Bernholt et al. Learning Progressions -German and Swiss Studies on Models of Competence Development (pp. 17-20).

National Research Council. (2012) A framework for K-12 Science Education: Practices, Crosscutting Concepts, and Core Ideas. Washington DC: The National Academies Press.

OECD (2013). PISA 2015. Draft Science Framework. [http://www.oecd.org/pisa/pisaproducts/Draft PI-SA 2015 Science Framework .pdf] 
Osborne, J. \& Dillon, J. (2008). Science Education in Europe: Critical Reflections. Report to the Nuffield Foundation.

Tamir, P., Nussinovitz, R., \& Friedler, Y. (1982). The development and use of a Practical Test Assessment Inventory. Journal of Biological Education, 16, 42-50.

Windschitl, M., Thompson, J. \& Braaten, M. (2008) Beyond the scientific method: Model-based inquiry as a new paradigm of preference for school science investigations. Science Education 92(5), 941-967.

Zoller, U. \& Tsaparlis, G. (1997) Higher and lower-order cognitive skills: The case of chemistry. Research in Science Education 27(1), 117-130. 



\title{
IS TEACHING BIOLOGY THROUGH SOCIO- SCIENTIFIC ISSUES ENOUGH FOR THE DEVELOPMENT OF ARGUMENTATION SKILLS?
}

\author{
Georgiou Martha ${ }^{1}$, Mavrikaki Evangelia ${ }^{1}$, Constantinos Constantinou ${ }^{2}$ \\ ${ }^{1}$ Faculty of Primary Education, National \& Kapodistrian University of Athens \\ ${ }^{2}$ Department of Education, University of Cyprus \\ marthagio@primedu.uoa.gr,emavrikaki@primedu.uoa.gr,c.p.constantinou@ucy.ac.cy
}

\begin{abstract}
The purpose of this research was to identify to what extent teaching Biology only through socio-scientific issues (SSIs) for a long period of time contributes to the development of students' argumentation skills, even when they lack the cognitive background about the subject. We worked on a random sample of 20 Cypriot students who were asked to write their opinions on various SSIs on Biotechnology. These students had previously been taught Biology only through SSIs for two years, but they had never been taught Biotechnology. Their answers were assessed by Toulmin's Argumentation Pattern combined with Dawson and Venville's level scale. Results revealed that students could not formulate high-level arguments. However, in many answers students expressed the need to be provided with more information about the issue under negotiation, and/or an expert's opinion, in order to finalize their own viewpoint and make a decision. Therefore, it was obvious that although the lack of knowledge limited students to low-level arguments, they took a critical stance on how they should work when lacking the relevant knowledge. We believe that both an appropriate teaching framework and the cognitive background would better enhance students' argumentation skills, bringing them one step closer to scientific literacy.
\end{abstract}

Keywords: argumentation; socio-scientific issues (SSI); biology; biotechnology; scientific literacy

\section{Introduction}

\subsection{Argumentation and Socio-scientific Issues (SSIs)}

According to many researchers, argumentation is at the heart of an effective teaching in science education (Newton et al., 1999). It is even considered as 
scientific literacy's indicator (Dawson \& Venville, 2009) and promotes the development of active citizenship skills. That is why much research has been conducted (Dawson \& Venville, 2009; Evagorou \& Osborne, 2013; Georgiou \& Mavrikaki, 2017; Iordanou \& Constantinou, 2015; Osborne et al., 2004; Zohar \& Nemet, 2002) focusing on different elements such as students' argumentative ability (Dawson \& Venville, 2009; Evagorou, Jimenez-Aleixandre \& Osborne, 2012; Georgiou \& Mavrikaki, 2013) or teachers' role concerning their students' development of this ability (Dawson \& Venville, 2010; Iordanou \& Constantinou, 2014; Simon, Erduran, \& Osborne 2006). However, students have been proven to have difficulties when expressing arguments (Erduran et al., 2004; Osborne et al., 2004). Thus, it is suggested that these argumentation skills could be improved either by explicit teaching of argumentation techniques (Zohar \& Nemet, 2002) or by creating appropriate teaching frameworks, where students could have the opportunity to shape their informed point of view (Duschl \& Osborne, 2002).

Socio-scientific issues (SSIs) could be considered as such frameworks (Zohar \& Nemet, 2002). Their controversial character, which means that they do not have unique and uniformly applied solutions (Sadler, 2004), is ideal so that students can express their arguments. Cloning, genetically modified organisms or food, laboratory animals, transgenic animals and plants are some examples of SSIs. Moreover,

it is commonplace in science education that the study of SSI by students constitutes a prime avenue for fostering scientific literacy of a kind that will prompt young people to familiarize themselves with science in action, to develop their capacity for evaluating the information made available to them on a daily basis, to make decisions concerning controversial sociotechnical issues, and to take part in debates and discussion on sociotechnical controversies of concern to them (Pouliot, 2008, cited in Zeidler \& Nichols, 2009, p.51).

Content knowledge and conceptual understanding play a central role in developing arguments (von Aufschnaiter et al., 2008) and it is important that students have the proper information about the issue on which they are asked to express their opinion. But Zohar (1996) found that students were able to transfer their newly acquired reasoning strategies, which were learned within one biology problem, to another, new biology problem. Khishfe (2014) had similar findings in her research trying to verify if Nature of Science (NOS) understanding and argumentation ability could be transferred even in totally unfamiliar contexts for students (familiar: water fluoridation; unfamiliar: genetically modified food). However, other researchers doubt this kind of transfer (Brown et al., 1989). In any case, research about the transfer of argumentation skills is underdeveloped (Khishfe, 2014) and it would be interesting to see if teaching SSIs could help students develop argumentation skills even in subjects, they are unfamiliar with. 


\subsection{New Biology curricula and textbooks in Cyprus}

In recent years (since 2012) in Cyprus, Biology curricula and textbooks of the $7^{\text {th }}-9^{\text {th }}$ grade (12-15 age, Gymnasium years or Lower Secondary Education) have been replaced by new ones. These new curricula and teaching materials follow a different pattern from the older ones. In old textbooks, various biological concepts were presented to students but outside a context, without obvious applications in everyday life. Through the new textbooks, students are involved in socio-scientific issues in which they are asked to take sides. So in order to be able to express their opinion and make decisions, they gradually unfold various necessary concepts. At the end of each module, the students, according to what they have learned earlier, must finally express their opinion about the SSI under discussion.

Hadjichambis et al. (2013) described this framework and more specifically they gave the example of the Reproduction unit, which is taught in $7^{\text {th }}$ grade. Based on their textbook's instructions, students participated in a SSI in order to make a substantiated decision and advise a young couple seeking medical advice for childbearing whether to go through in vitro fertilization (IVF) or not. The module includes the following 6 subsections:

1. presentation of the scenario and the mission of the students;

2. male reproductive system and male germ cell;

3. female reproductive system and female germ cell;

4. fertilization - stages of embryo development;

5. in vitro fertilization - advantages and disadvantages;

6. completion of mission and decision-making.

In contrast to a 'traditional' lesson, where students are provided with information and then asked comprehension questions but without having any mission, this section follows a problem-centered approach through which students have to shape their informed viewpoint on a SSI. In the beginning, students gather all the information they need from both print sources and audiovisual material (video, animation, PowerPoint presentations, etc.) in order to respond to structured worksheets. The goal is to make a substantiated decision, advising the couple appropriately. This module attempts to promote implementation and impact of biological knowledge on everyday life and society, in order to make its study more enjoyable and meaningful. In addition, it incorporates the bioethical dilemmas accompanying biological applications in everyday life, in particular the dilemmas resulting from in vitro fertilization (Hadjichambis et al., 2013).

All biological concepts are introduced in a similar way. Hence, the muscular system, nervous system, microorganisms and various Biology modules are taught to students through SSIs, in which they are engaged and they are asked to develop argumentation about their decision. 
Based on the above-mentioned literature that a) an appropriate teaching framework could improve argumentation skills, b) a conceptual background is necessary for the development of arguments, and c) a transfer could be possible even in unfamiliar contexts, we decided to ask the following research question:

Is teaching Biology through SSIs an appropriate framework to improve students' argumentation skills, even when they lack the necessary knowledge about the issue being considered?

The present research is a part of a wider research project, which has been granted by the Greece National Scholarships Foundation.

\section{Research Methodology}

\subsection{Participants}

Our sample was randomly collected and consisted of twenty 15-year old Cypriot students, with a roughly equal distribution across genders. They were all of middle socioeconomic status and were attending public schools in Nicosia. According to their teachers they were average achievers. Moreover, all of them had been taught Biology only through SSIs for two years, without having ever been taught Biotechnology.

\subsection{Research tool - Data collection}

At the end of the school year 2014-2015, students were asked to answer anonymously a questionnaire of eight open-ended questions on various SSIs from the field of Biotechnology. We chose this area of Biology as it is rich in SSIs. The questions were structured around specific axes derived from the 2010 Eurobarometer (Gaskell at al. 2010), a EU-wide survey conducted by the European Union approximately every 4 years, mainly to highlight the attitudes of European citizens on issues about Biotechnology. The axes that the questionnaire was based on were Health, Environment, Food and the effect of Biotechnology on them. For instance, students were asked questions such as:

"In your area the Mayor approved the operation of a factory that produces genetically modified microorganisms that help in the cleaning of oil spills. Some of the residents are up in arms against the operation, while others support it. What is your opinion and why?" or

"Your parents entrust you to buy vegetables that are necessary for your family for a week. You need potatoes, tomatoes, eggplants and lettuce. Going to the grocery store you see that there are many options for all four types of vegetables. Specifically, there are three crates of tomatoes: one with the inscription "biological", one with the inscription "genetically modified", and one with the inscription "conventional crop" (crop in a traditional way). Which one would you prefer if all of them have the same cost and why?". 
We ensured face validity for the questionnaire (two science educators, three biologists and two high school biology teachers) making the suggested modifications. Finally, we distributed it to students emphasizing that they could freely express their opinion answering the questions but accompanying them with the appropriate arguments. In total, we collected 160 answers (all of the students answered all the questions).

\subsection{Analysis}

In order to achieve high reliability, all the answers were analyzed by two researchers regarding their argumentation ability, using Toulmin's Argumentation Pattern - TAP (Toulmin, 2003) in combination with Dawson \& Venville's (2009) level scale. Toulmin's model is focused on the pattern of an argument paying attention especially to its structural elements rather than in its context. The TAP model consists of the following components: claim, data, warrant, backing, qualifier, rebuttal. According to Toulmin (2003), the 'claim' is the position of the individual asked, based on specific data. The way that data are associated with the claim, in other words the path followed from the data to the claim, is the 'warrant'. Of course, the warrant may be supported by further data, the 'backing', that have the effect of further strengthening the warrant. On the other hand, the 'qualifier' testifies the confidence level of the claim and finally, the conditions under which this claim is not valid are covered by 'rebuttals'.

Toulmin's model, places emphasis on the generic features of an argument, fitting better with our interest in argumentation in general, and at the same time it is a prime model according to several researchers (Dawson \& Venville, 2009; Jimenez-Aleixandre, Rodriguez \& Duschl 2000; Osborne et al., 2004; von Aufschnaiter et al., 2008). Furthermore, the use of TAP was appropriate as our next step was to make comparisons between the sample of this research and samples of similar researches (Georgiou \& Mavrikaki, 2013; 2017), which were examining the argumentation level of students with different engaging opportunities in SSIs.

Therefore, we used the TAP in combination with the scale of Dawson and Venville (2009), which is essentially a modification of the scale proposed by Osborne et al. (2004). This scale includes four levels. The first level includes arguments that simply consist of a claim. In the second level we find arguments that, besides the claim, they also include some data and/or warrants, explaining how the data are connected to the claim. At the third level, the arguments that contain claim, data, warrant and backing or qualifier are ranked, while at the fourth level we find arguments with claim, data, warrant and backing and qualifier. Examples are given in findings and Table 1. 


\section{Findings}

Based on the analysis of the students' answers we verified that most of the students did not give high-level arguments. More precisely, we noted that the majority of arguments consisted of only a claim and some data:

"I prefer the biological ones [tomatoes]"

"She should try [gene therapy], repeated transfusions are exhausting."

In other words, students managed to reach only second level arguments, which means poor arguments without solid grounds based on scientific knowledge and connected to the claim. More specifically more than $70 \%$ of the answers were classified as second level arguments followed by above $20 \%$ belonging to the first level, that is, in this kind of answer we captured only a single claim. Only a few answers $(7.5 \%)$ were constructed providing stronger arguments with more elements such as backings or qualifiers, reaching the third level. And finally, very few answers (1.9\%) contained well shaped arguments of the fourth level. In any case we did not identify rebuttals in the students' written answers. Hence, 147 of 160 responses were weak depending on their structure elements, but at the same time as these elements represent only claims and little data or warrants, it was shown that the responses were weak in structure and content. However, evaluating the written records in order to classify them according to the argument level, we did not come often upon inaccurate scientific data, but we found many answers like:

"I am not sure. I think I need an expert's opinion to make my own." first."

"The biological ones tomatoes] probably, but I prefer to ask for some information

In these kinds of answers, it is obvious that students, even if they did not have the cognitive skills to formulate their opinion, it is important that they

TABLE 1

EXAMPLES OF ARGUMENT LEVELS PROVIDED BY STUDENTS

\begin{tabular}{|c|c|}
\hline Argument Level & Example \\
\hline $\begin{array}{l}\mathbf{1} \\
\text { claim }\end{array}$ & "I prefer the biological ones [tomatoes]". \\
\hline $\begin{array}{l}2 \\
\text { claim, data and/or } \\
\text { warrant }\end{array}$ & "She should try [gene therapy], repeated transfusions are exhausting". \\
\hline $\begin{array}{l}3 \\
\text { claim, data, warrant, } \\
\text { backing or qualifier }\end{array}$ & $\begin{array}{l}\text { "Oil spills are especially harmful for marine life because many fish are killed and } \\
\text { some of them are endangered species. I support the operation of the industry only } \\
\text { if in its turn it doesn't pollute the environment". }\end{array}$ \\
\hline $\begin{array}{l}4 \\
\text { claim, data, warrant, } \\
\text { backing and qualifier }\end{array}$ & $\begin{array}{l}\text { "Treating diseases is for a good purpose as people don't die even if it sacrifices } \\
\text { some animal lives. I would consider it [selling the goats for experiments] as a } \\
\text { perspective for the future and I would sell the herd so as to counter the disease". }\end{array}$ \\
\hline
\end{tabular}


recognized their lack of the necessary knowledge and expressed it indicating the need for having further information on the requested issue, or an expert's viewpoint on it. What was even more impressive was the fact that these kinds of answers were captured in all students' written records, and usually more than once in the same questionnaire. In particular, we identified 38 responses of this form, in response to different questions. Of course, they do not count as strong arguments, as their structure elements were limited, not even their content was rich, but we found that students' expression of the need for additional material or an expert's opinion before they reach a conclusion was very interesting.

\section{Discussion and conclusions}

As already mentioned, students of our sample did not achieve high-level arguments when making their own decisions on various SSIs in the field of Biotechnology. Particularly, most of them expressed just a claim and/or little data - more than $90 \%$ of their answers - and only around $8 \%$ surpassed the third level, which means that we scarcely located backings and/or qualifiers additionally with the claims, data and warrants. In other words, most of them did not construct strong arguments of the third level or higher. Content knowledge and conceptual understanding are dominant elements in formulating arguments (von Aufschnaiter et al., 2008). However, several studies (Albe, 2008; Dawson \& Venville, 2010; Kolstø, 2006; Sadler, 2004; Sadler \& Zeidler, 2005) showed that a SSI framework could effectively engage students in argumentation when they are asked to provide their documented viewpoint making a decision on each issue. They improved their argumentation ability in this way according to several researchers, but in all these studies students had already gained the cognitive supplies, or they had been provided with them during the argumentative process (Albe, 2008; Dawson \& Venville, 2010; Kolstø, 2006; Sadler, 2004; Sadler \& Zeidler, 2005). The fact, that in this research students did not formulate high-level arguments, was more or less expected as they lack knowledge on Biotechnology. The lack of knowledge limited the argumentation development of the students, therefore, an essential factor of students' argumentation level is the cognitive background, and the teaching framework on its own cannot effectively affect arguments' robustness.

However, we recorded enough answers, which included arguments with no great structure elements, therefore not ranked as high-level, but with great expression of awareness. These responses clearly indicated students' need for expert opinion or better/more information concerning the issue. This finding was very encouraging as it showed that students who have been taught Biology through SSIs have become aware of the way they should base their decisions on issues they have no knowledge about. Even if they could give answers based on intuitive or empirical arguments, they preferred to follow another way of 
thinking and acting. They pointed out their disadvantaged position and they admitted that they could make a decision only after relevant help. Thus, their attitude showed that perhaps the way that they had been taught Biology, namely the SSI framework, led them to think in a more scientific direction. Students gained through this way of teaching the ability to recognize the way they have to work to make decisions based on proper arguments. Of course, this is clearly hopeful, but not enough, since ultimately the strong argumentation sought was not achieved - although it is one of the elements of a scientific literate citizen (Dawson \& Venville, 2009), and one literate citizen's skill is to take part in debates and discussions on everyday life's issues, expressing their opinion based on scientific data with concern for social implications (Zeidler \& Nichols, 2009).

Comparing these results to the results of our previous studies (Georgiou \& Mavrikaki, 2013, 2017) we find that students who had been taught Biology traditionally for two years but not based on SSIs, but had not been taught Biotechnology, also showed low argumentation ability. We could interpret this finding by the lack of knowledge as well. Furthermore, we concluded that it is necessary for students to have all the proper information to express their opinion in a documented way. However, the results of this previous research differed qualitatively from the results of the present one, mostly in that they did not contain any consciousness elements about the way to work on the decisionmaking based on arguments when lacking knowledge (Georgiou \& Mavrikaki, 2013, 2017). Thus, even students of both studies presented the same argumentative pattern concerning the percentages of the four-level arguments. They did not appear equally aware about the appropriate working manner in case they are not equipped with the necessary knowledge. The arguments developed by our previous sample were mostly based on inadequate or even incorrect data, and no phrases expressing the need of more information or an expert's viewpoint were formulated. It is this point that leads us to believe that the teaching framework (SSIs) of the present research played a central role.

Argumentation skills still need to be enhanced as they were found to be low, but students acted in a more rational way of thinking and not in an intuitive one. It seems that some kind of transfer had been achieved, not in terms of transferring argumentation skills (students had never been taught argumentation explicitly), but in terms of the appropriate working pattern when dealing with SSIs lacking basic related concepts. Hence, we could concur with Khishfe (2014) who supported transfer of argumentation skills even in unfamiliar contexts for students.

In conclusion, we believe that a combination of both conceptual background and teaching framework would be even more effective on improving argumentation skills. In any case, it is a question of finding ways for education to contribute efficiently to the creation of future active citizens, who should be 
competent in arguing. Besides, as scientific literacy is promoted through argumentation skills, and argumentation is considered to be an indicator of scientific literacy (Dawson \& Venville, 2009), this field requires more research.

\section{References}

Albe, V. (2008). When scientific knowledge, daily life experience, epistemological and social considerations intersect: Students' argumentation in group discussions on a socio-scientific issue. Research in Science Education, 38(1), 67-90.

Brown, J. S., Collins, A., \& Duguid, P. (1989). Situated cognition and the culture of learning. Educational Researcher, 18(1), 32-42.

Dawson, V., \& Venville, G. J. (2009). High-school Students' Informal Reasoning and Argumentation about Biotechnology: An indicator of scientific literacy? International Journal of Science Education, 31(11), 1421-1445.

Dawson, V. M., \& Venville, G. (2010). Teaching strategies for developing students' argumentation skills about socioscientific issues in high school genetics. Research in Science Education, 40(2), 133-148.

Duschl, R. A., \& Osborne, J. (2002). Supporting and promoting argumentation discourse in science education. Studies in Science Education, 38, 39-72.

Erduran, S., Simon, S., \& Osborne, J. (2004). TAPping into argumentation: Developments in the application of Toulmin's argument pattern for studying science discourse. Science Education, 88(6), 915-933.

Evagorou, M., Jimenez-Aleixandre, M. P., \& Osborne, J. (2012). 'Should we kill the grey squirrels?'A study exploring students' justifications and decision-making. International Journal of Science Education, 34(3), 401-428.

Evagorou, M., \& Osborne, J. (2013). Exploring young students' collaborative argumentation within a socioscientific issue. Journal of Research in Science Teaching, 50(2), 209-237.

Gaskell, G., Stares, S., Allansdottir, A., Allum, N., Castro, P., Esmer, Y., Fischler,

Jackson, J., Kronberger, N., Hampel, J., Mejlgaard, N., Quintanilha, A., Rammer, A., Revuelta, G., Stoneman, P., Torgersen, H. \& Wagner, W. (2010). EUR 24537 - Europeans and Biotechnology in 2010 Winds of change? Luxembourg: Publications Office of the European Union. doi 10.2777/23393

Georgiou, M., \& Mavrikaki, E. (2013). Greek students' ability in argumentation and informal reasoning about socioscientific issues related to biotechnology. In C.P. Constantinou, N. Papadouris \& A. Hadjigeogiou (ed.), Proceedings of the 10th Conference of the European Science Education Research Association (ESERA) (pp. 1158-1166). Nicosia, Cyprus.

Georgiou, M., \& Mavrikaki, E. (2017). Do Greek adolescents argue? The case of socioscientific issues of biotechnology. Themes in Science and Technology Education, 9(3), 137-149. In greek.

Hadjichambis A., Georgiou G., Paraskeva-Hadjichambi D., Kyza E., Mappouras D. (2013). Human Reproduction by Inquiry: conceptual understanding and motivation 
of students of the $7^{\text {th }}$ grade of Cyprus, In E. Mavrikaki, P. Stasinakis, C. Zahopoulos (ed.), Proceedings of the $2^{\text {nd }}$ Conference of Panhellenic Bioscientists Association, Biology in Education (pp 21-28). Athens, Greece. In Greek.

Iordanou, K., \& Constantinou, C. P. (2014). Developing pre-service teachers' evidencebased argumentation skills on socio-scientific issues. Learning and Instruction, 34, 42-57.

Iordanou, K., \& Constantinou, C. P. (2015). Supporting use of evidence in argumentation through practice in argumentation and reflection in the context of SOCRATES learning environment. Science Education, 99(2), 282-311.

Jiménez-Aleixandre, M. P., Rodriguez, A. B., and Duschl, R. A. (2000). "Doing the lesson" or" doing science": Argument in high school genetics. Science Education, 84(6), 757-792.

Khishfe, R. (2014). Explicit nature of science and argumentation instruction in the context of socioscientific issues: An effect on student learning and transfer. International Journal of Science Education, 36(6), 974-1016.

Kolstø, S. D. (2006). Patterns in students' argumentation confronted with a risk-focused socio-scientific issue. International Journal of Science Education, 28(14), 16891716.

Newton, P., Driver, R., \& Osborne, J. (1999). The place of argumentation in the pedagogy of school science. International Journal of Science Education, 21(5), 553-576.

Osborne, J., Erduran, S., \& Simon, S. (2004). Enhancing the quality of argumentation in school science. Journal of Research in Science Teaching, 41(10), 994-1020.

Sadler, T. D. (2004). Informal reasoning regarding socioscientific issues: A critical review of research. Journal of Research in Science Teaching, 41(5), 513-536.

Sadler, T. D., and Zeidler, D. L. (2005). The significance of content knowledge for informal reasoning regarding socioscientific issues: Applying genetics knowledge to genetic engineering issues. Science Education, 89(1), 71-93.

Simon, S., Erduran, S., \& Osborne, J. (2006). Learning to teach argumentation: Research and development in the science classroom. International Journal of Science Education, 28(2-3), 235-260.

Von Aufschnaiter, C., Erduran, S., Osborne, J., \& Simon, S. (2008). Arguing to learn and learning to argue: Case studies of how students' argumentation relates to their scientific knowledge. Journal of Research in Science Teaching, 45(1), 101-131.

Walton, D. (1996). Argumentation Schemes for Presumptive Reasoning. New York: Routledge.

Zeidler, D. L., \& Nichols, B. H. (2009). Socioscientific issues: Theory and practice. Journal of Elementary Science Education, 21(2), 49.

Zohar, A. (1996). Transfer and retention of reasoning strategies taught in biological contexts. Research in Science \& Technological Education, 14(2), 205-219.

Zohar, A., \& Nemet, F. (2002). Fostering students' knowledge and argumentation skills through dilemmas in human genetics. Journal of Research in Science Teaching, 39(1), 35-62. 


\title{
ECOSYSTEMS IN SCIENCE EDUCATION RESEARCH IN THE LAST 20 YEARS: A RESEARCH SYNTHESIS
}

\author{
Pedro Lucha and María José Sáez \\ Departamento de Didáctica de las Ciencias Experimentales. \\ Universidad de Zaragoza (Zaragoza-Spain) \\ plucha@unizar.es,msaezbo@unizar.es
}

\begin{abstract}
Ecosystems constitute a central topic in biology education and research syntheses can be useful to identify central issues in a particular research field. The present work aims to identify the characteristics of ecosystem-related investigations published by European researchers in science education journals for the last 20 years, as well as their numbers. It is remarkable that there is a scarcity of articles about ecosystems contextualized in preschool, and a high number of them in high school. The amount of papers devoted to evaluate students' ideas and learnings is similar to that of articles focused on the investigation of teaching and learning strategies and tools. On the other hand, attitudes are a less-evaluated aspect of learning, and biogeochemical cycles are the most scarcely considered ecosystem elements in the analysed articles. Finally, there seems to be some kind of relationship between the ecosystem elements explicitly mentioned in the papers and the educational level where they are contextualized. Thus, complex ideas and relations of ecosystems are scarcely represented in papers dealing with elementary or preschool learners, and they concentrate in studies contextualized in high school and higher educational levels. In our opinion, this result reinforces the systems thinking approach.
\end{abstract} Keywords: ecosystems, ecology education, systematic analysis, systems thinking

\section{Introduction}

Ecosystems constitute a core idea of biology education as they function at the interface of several other aspects of biology (National Research Council, NRC, 2012). As with other natural systems (e.g. the water cycle, Earth-SunMoon system, etc.) they are formed by elements linked by complex cause-effect relationships which change through time (daily, seasonally or lower-frequency 
cycles). These characteristics make them hard to understand and so, their comprehension is challenging for most of the students (Leach et al., 1996; Çokadar \& Yilmaz, 2010). However, ecosystems are present in the curricula at many educational levels in different countries. Although there are comprehensive literature reviews on the effects of environmental education (O'Flaherty \& Liddy, 2018) and about the educative treatment of particular relationships within ecosystems (Hayes et al., 2017), there are not research syntheses dealing with ecosystems as a whole. Research syntheses allow integrating investigations conducted in a particular time span and identifying central issues and gaps, which can motivate future research (Cooper et al., 2009).

Thus, given the importance of ecosystems in biology education, the present work aims to identify the characteristics of ecosystem-related investigations published by European researchers in science education journals over the last 20 years. A research synthesis was carried out to answer the following research questions:

(1) Is there any trend in the number of papers dealing with ecosystems, published in science education journals in the last 20 years?

(2) How is research about ecosystems published in those journals?-

(3) What are the educational levels more often surveyed?

(4) What kind of student learning do the selected articles focus on?

(5) What are the ecosystem components more frequently included in the analysed articles?

(6) Is there any relationship between the considered categories?

\section{Theoretical framework}

Several papers remark on students' difficulties in explaining everyday natural processes and phenomena using biological concepts and models (e.g. Grotzer \& Bell-Basca, 2003; Eilam, 2012; Jordan et al., 2013). There are many recommendations to overcome these problems. One of them consists of designing biology school programmes where the curricular elements to be learned are grouped within a few number of core ideas (NRC, 2012; Zangori \& Koontz, 2017). Ecosystems are complex open systems, which constitute one of the disciplinary core ideas in life sciences teaching. Other examples are: 'heredity' or 'biological evolution' (NRC, 2012). For instance, students' inquiry about a particular ecosystem allows them to acquire much biological knowledge such as: morphological characteristics of different plants and animals, trophic chain comprehension, or recording descriptions and drawings in their field notebook. The learning and teaching process is fairly linear in time and thus, once we have a meaningful core idea to link the biological learning to be achieved, deciding what to do, how and when is not an easy question to solve. The systems thinking approach might be useful during this down-to-the-praxis step. According to 
several authors 'systems thinking' is a cognitive macro-skill, which allows understanding of complex biological processes (Ben Zvi Assaraf \& Orion, 2005; Riess \& Mischo, 2010; Verhoeff et al., 2018). That is to say:

"a conceptual framework of knowledge, principles, and tools that enable observing within the interrelationship and the mutual connections necessary in order to determine changeable patterns and repeated phenomena" (Assaraf \& Orion, 2005, p. 520).

Systems thinking could be summarized in eight characteristics, hierarchically ordered, that go from the ability to identify the components of a system and processes within it, to thinking temporally (see Assaraf \& Orion, 2005). Besides this theoretical framework, there is a large set of teaching strategies and tools to help the practitioner about the ecosystems learning and teaching practice, published in science education journals (Doberski, 1998; Wilensky \& Reisman, 2006; Jussila \& Virtanen, 2014; Yücel \& Özkan, 2015; Allen, 2017). Identifying and characterizing research based on these strategies and tools, is relevant to both the research and educative communities.

\section{Method}

\subsection{Bibliographic search and selection criteria}

A bibliographic search was conducted in November 2017. According to Cooper et al. (2009), research syntheses have to consider inclusion criteria. In this study, we have considered:

- Only journal articles from Web of Science that includes "ecosystems", in the research areas of "education and educational research" ( $\mathrm{n}=530)$

- Temporal criteria: since 1997, and geographical criteria: European authors $(\mathrm{Au})(\mathrm{n}=129,24.3 \%)$

- Only related to biological ecosystems (not learning ecosystems) ( $\mathrm{n}=72$, $13.58 \%)$

\subsection{Data coding}

After conducting the bibliographic search, the chosen papers were quickly reviewed and classified based on their publication year, journal title and educational context of the researched learners. All the papers were included in one or more of the following levels: pre-school, elementary school, high school, teacher training (pre- and in-service), or others. Papers included under "others" dealt with university students (different form pre-service teachers) and nonformal learners. Literature reviews and those papers where the educational level is not explicit were also included in this category. This preliminary review of the articles allowed the construction of the system of categories displayed on Table 1. 
TABLE 1

SYSTEM OF CATEGORIES CONSIDERED FOR THE ANALYSIS

\begin{tabular}{|c|c|c|}
\hline $\begin{array}{l}\text { Category } \\
\text { (code) }\end{array}$ & $\begin{array}{l}\text { Sub-category } \\
\text { (code) }\end{array}$ & Definition and examples \\
\hline \multirow{2}{*}{$\begin{array}{l}\text { Type of } \\
\text { Investigation } \\
\text { (TI) }\end{array}$} & $\begin{array}{l}\text { Assessment } \\
\text { of Students' } \\
\text { Learning (SL) }\end{array}$ & $\begin{array}{l}\text { Include "one-dimensional" researches whose goal is to diagnose stu- } \\
\text { dents' competence (concepts, skills or attitudes) in relation to ecosys- } \\
\text { tems. It implies only one evaluation of learning. Examples of research- } \\
\text { es within this category would be: a study made to evaluate attitudes } \\
\text { towards certain organisms among a students' population or a research } \\
\text { conducted to evaluate students' use of evidences when planning a } \\
\text { management plan to rule a protected area. }\end{array}$ \\
\hline & $\begin{array}{l}\text { Assessment } \\
\text { of teaching } \\
\text { and learning } \\
\text { strategies and } \\
\text { tools (St\&T) }\end{array}$ & $\begin{array}{l}\text { Include "two-dimensional" investigations where certain tools or teach- } \\
\text { ing strategies are evaluated "measuring" the increase in students' com- } \\
\text { petence, after conducting a tool or strategy-based learning sequence. It } \\
\text { includes more than one learning "measurement". A typical example of } \\
\text { research that would fit within this category includes an investigation } \\
\text { where an experimental group and a control group are surveyed before } \\
\text { and after conducting an ecosystem-related learning sequence. }\end{array}$ \\
\hline \multirow{8}{*}{$\begin{array}{l}\text { Ecosystem } \\
\text { Elements } \\
(\mathrm{EE})\end{array}$} & Organism (O) & $\begin{array}{l}\text { The research is focused on students' ideas about certain organisms. } \\
\text { For example, a study carried out to know children's perceptions of } \\
\text { animals with a bad image (shark, mouse...) }\end{array}$ \\
\hline & Population (P) & $\begin{array}{l}\text { Investigations related to comprehension of populations within ecosys- } \\
\text { tems. For example, a paper dealing with students scientific attitudes } \\
\text { after working with ants. }\end{array}$ \\
\hline & $\begin{array}{l}\text { Community } \\
\text { (C) }\end{array}$ & $\begin{array}{l}\text { Papers dealing with student's ideas about ecological communities, but } \\
\text { not paying much attention to the Energy Flow (EF) within the ecosys- } \\
\text { tem. An example would be a paper evaluating attitudes towards and } \\
\text { knowledge about water birds, among children. Papers dealing with } \\
\text { food webs, where explicit consideration to energy flow is not made, } \\
\text { have also been included in this sub-category. }\end{array}$ \\
\hline & $\begin{array}{l}\text { Biocoeno- } \\
\text { sis-Biotope } \\
\text { (BB) }\end{array}$ & $\begin{array}{l}\text { Articles where the biotope is explicitly considered within the ecosys- } \\
\text { tem-related educative-research. For example, a study to evaluate pu- } \\
\text { pils' learning about living things' adaptations to habitat. }\end{array}$ \\
\hline & $\begin{array}{l}\text { Sustainability } \\
(\mathrm{S})\end{array}$ & $\begin{array}{l}\text { Research is focused on students' understanding of factors threatening } \\
\text { ecosystems stability. For example, a study to diagnose weather the stu- } \\
\text { dents identify non-sustainable courses of action or not. }\end{array}$ \\
\hline & $\begin{array}{l}\text { Succession } \\
(\mathrm{Su})\end{array}$ & $\begin{array}{l}\text { Investigations where students forecast changes in ecosystems through } \\
\text { time. For example, a paper dealing with students' use of evidence } \\
\text { when designing a regeneration plan for a forest area damaged by fire. }\end{array}$ \\
\hline & $\begin{array}{l}\text { Energy Flow } \\
\text { (EF) }\end{array}$ & $\begin{array}{l}\text { Papers considering students understanding of how energy flows with- } \\
\text { in ecosystems. For example, a research evaluating students' use of evi- } \\
\text { dences when justifying the limited number of levels in a trophic chain. } \\
\text { Papers dealing with food webs where explicit consideration to energy } \\
\text { flow is made have been included in this sub-category. }\end{array}$ \\
\hline & $\begin{array}{l}\text { Matter Cycle } \\
(\mathrm{MC})\end{array}$ & $\begin{array}{l}\text { Articles explicitly considering the cycling of matter in an ecosystem. } \\
\text { For example, a paper presenting software, which allows students to } \\
\text { "holistically" learn about ecosystems. }\end{array}$ \\
\hline
\end{tabular}




\begin{tabular}{lll}
\hline & Concepts (C) & $\begin{array}{l}\text { Research included in the paper evaluates pupils' achievement of eco- } \\
\text { system-related concepts. For example, an article evaluating the num- } \\
\text { ber of different animals known by students, for a particular ecosystem. }\end{array}$ \\
\cline { 2 - 3 } $\begin{array}{l}\text { Evaluated } \\
\text { Learning }\end{array}$ & Skills (S) & $\begin{array}{l}\text { The investigation evaluates students' scientific skills. For example, } \\
\text { student's use of evidences, argumentative or decision-making skills. }\end{array}$ \\
\cline { 2 - 3 } & Attitudes (A) & $\begin{array}{l}\text { Research evaluates attitudes of students towards the natural environ- } \\
\text { ment or scientific attitudes. For example, students tolerance to frogs } \\
\text { or autonomous keeping of ants during an "ants-based" learning se- } \\
\text { quence. }\end{array}$ \\
\hline
\end{tabular}

Then, during a second thorough revision, the papers were codified according to defined sub-categories. Sub-categories "SL" and "St\&T" within type of investigation (TI) are exclusive and thus, none of the articles were assigned to both of them. These sub-categories inform about the elements of the didactic system considered in the research, as well as about the research design. A similar coding was considered in the research synthesis conducted by O'Flaherty \& Liddy (2018). For the rest of the sub-categories, a single paper could have been associated with more than one of them.

To answer the $6^{\text {th }}$ research question, cross-tables between pairs of categories were created. In order to calculate the relationship between variables (sub-categories) we conducted likelihood-ratio analysis instead of Pearson chi-square analysis because there were several codes present in less than five papers (García, 1995).

\section{Results}

\subsection{Is there any trend in the number of papers published in the last 20 years?}

Regarding the first research question, although there has been a general increase in the number of ecosystem-related papers published per year lately, so also has the total number of papers published in science education journals. Thus, considering the relative number of papers about ecosystems, published in science education journals in the last 20 years, no trend is visible (Figure 1).

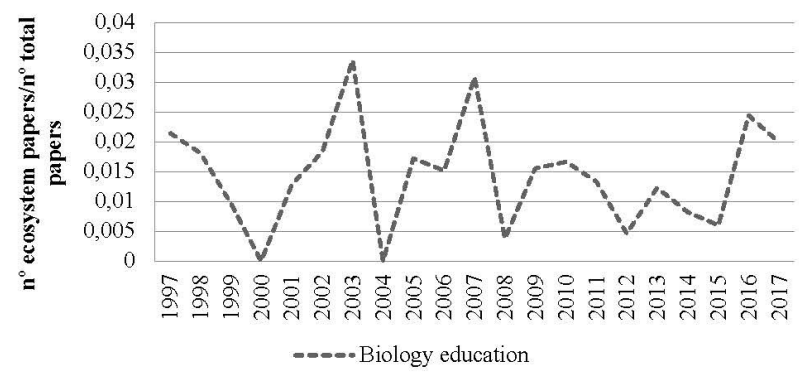

Figure 1 Temporal evolution of the number of ecosystem-related papers published since 1997. 
4.2. How is research about ecosystems published in those journals?

As researchers, we are interested on the goals and scope of the published investigations or the elements of the didactic systems more thoroughly researched. These characteristics of the investigations are independent from the chosen method (qualitative or quantitative). As previously depicted, these are the reasons why we used the SL and St\&T codes instead. The analysis indicates that the number of papers evaluating teaching and learning strategies, or the effect of specific tools (St\&T), is higher than the number of papers devoted to elucidate students' ideas and learning (SL) (Table 2). In addition, 2 out of the 72 analysed articles include research syntheses, and another one consists of a content analysis of middle and high school textbooks (paper number 7).

TABLE 2

DISTRIBUTION OF ANALYSED ARTICLES ACCORDING

TO THE TYPE OF INVESTIGATION (TI)

\begin{tabular}{|c|c|c|}
\hline Type of investigation & $\begin{array}{l}\text { Total number } \\
\text { of papers (\% total } \\
\text { of papers) }\end{array}$ & Paper included (see Appendix 1) \\
\hline $\begin{array}{l}\text { Assessment of Students' } \\
\text { Learning (SL) }\end{array}$ & $29(40.2 \%)$ & $\begin{array}{l}1,2,4,5,9,10,11,12,18,19,20,22,23,24,25,28, \\
29,30,35,45,48,49,54,60,63,65,69,70 \text { and } 72\end{array}$ \\
\hline $\begin{array}{l}\text { Assessment of teaching } \\
\text { and learning strategies } \\
\text { and tools }(\mathrm{St} \& \mathrm{~T})\end{array}$ & $40(55.6 \%)$ & $\begin{array}{l}3,6,8,13,14,15,16,17,21,26,27,31,32,33,36, \\
37,38,39,40,41,42,43,44,46,47,51,52,53,55, \\
56,57,58,59,61,62,64,66,67,68 \text { and } 71\end{array}$ \\
\hline Others (synthesis studies) & $3(4.2 \%)$ & 7,34 and 50 \\
\hline
\end{tabular}

\subsection{What are the educational levels more often surveyed?}

As previously mentioned, the educational context is not an exclusive category. However, only two papers included research conducted with students of more than one educational level (papers 22 and 70). On the other hand, most of the articles are focused on high school, with pre-school being the least studied

TABLE 3

EDUCATIONAL LEVEL (EL) WHERE THE PAPERS ARE CONTEXTUALIZED

\begin{tabular}{lcl}
\hline Educational level & $\begin{array}{c}\text { Total number of } \\
\text { papers (\% total } \\
\text { of papers) }\end{array}$ & Paper included (see Appendix 1) \\
\hline Pre-school & $3(4.1 \%)$ & 2,20 and 47 \\
\hline Elementary & $14(18.9 \%)$ & $3,14,21,22,26,29,30,31,36,40,42,51,58,66$ and 67 \\
\hline High School & $29(39.2 \%)$ & $7,9,10,13,17,18,22,25,28,32,33,35,41,43,44,45,49$, \\
\hline Teacher training & $10(13.1 \%)$ & $1,5,11,12,19,39,46,60,64$ and 70 \\
\hline Others & $18(24.3 \%)$ & $4,6,8,15,16,23,24,27,34,37,38,48,50,53,62,65,68$ and 69 \\
\hline
\end{tabular}


educational level (Table 3). Furthermore, 2 out of the 3 articles related to kindergarten are very recent (from 2017), and the other one was published in 2010. We have also noticed that the frequency of the code 'others' (synthesis studies, university students different from pre-service teachers and non-formal education) has increased over time.

\subsection{What kind of student learning do the selected articles focus on?}

Since many national curricula in Europe are based on the achievement of learning competences, much overlapping among sub-categories was expected for this category. Thus, most of the articles deal with more than one kind of student learning. For example, paper number 3 analyses attitudes towards water birds and concepts acquisition about these animals. As depicted in Table 4, ecosystem concepts are considered in more than half of the analysed papers (65.3\%). However, attitudes are evaluated only in $23.6 \%$ of them. In addition, most of the evaluated attitudes have to do with sustainability and ecosystem preservation, and scientific attitudes are scarcely surveyed. Literature reviews have been included under 'others'.

TABLE 4

LEARNING EVALUATED AMONG STUDENTS (EL)

\begin{tabular}{lcl}
\hline $\begin{array}{l}\text { Student } \\
\text { learning }\end{array}$ & $\begin{array}{c}\text { Total num- } \\
\text { ber of papers } \\
\text { (\% total of } \\
\text { paper) }\end{array}$ & Paper included (see Appendix 1) \\
\hline Concepts & $47(65.3 \%)$ & $\begin{array}{l}1,2,3,5,6,9,10,12,13,15,16,17,19,20,24,26,28,29,30,31,32, \\
66,67,68,69,42,46,71 \text { and } 72\end{array}$ \\
\hline Skills & $33(45.8 \%)$ & $\begin{array}{l}8,9,10,11,14,16,17,19,20,21,24,25,26,27,28,33,36,37,39,40, \\
41,44,47,51,56,57,58,62,63,64,66,68 \text { and } 69\end{array}$ \\
\hline Attitudes & $17(23.6 \%)$ & $3,4,13,18,22,23,35,43,44,45,53,54,59,61,64,67$ and 71 \\
\hline Others & $3(4.2 \%)$ & 7,34 and 50 \\
\hline
\end{tabular}

4.5. What are the ecosystem components more frequently included in the analysed articles?

As previously noted, analysed research could deal with more than one ecosystem element. For instance, a single paper can include the students' inquiry about any particular species within a community, which is also researched. Thus, codes within this category are not exclusive. 'Others' includes articles with no explicit reference to any ecosystem element. As shown in Table 5, codes within this category are evenly distributed among the selected papers. However, there is a prevalence of articles centred on biological communities, either about 
a particular community, or in relation to energy flow, or biogeochemical cycles within the ecosystem. The considered sub-categories could be grouped into: ecosystem processes (succession, energy flow and cycling of matter (34\% of the papers); ecosystem functions (sustainability 12\%); relationships among ecosystem elements (between biotic and abiotic factors, relationships intra- and inter-species ( $55 \%$ of the papers)), and sub-categories related to a single ecosystem element (14\%). Thus, the number of papers related to comprehension of relationships among ecosystem elements (55\%) is higher than the number of papers devoted to ecosystem process understanding.

TABLE 5

ECOSYSTEM ELEMENTS (EE) IN THE REVIEWED PAPERS

\begin{tabular}{lcl}
\hline Student learning & $\begin{array}{c}\text { Total number of papers } \\
\text { (\% total of papers) }\end{array}$ & Paper included (see Appendix I) \\
\hline Organism & $10(13.9 \%)$ & $1,3,33,37,38,45,49,54,59$ and 68 \\
\hline Population & $11(15.3 \%)$ & $16,20,22,30,31,36,48,59,63,65$ and 66 \\
\hline Community & $15(20.8 \%)$ & $\begin{array}{l}2,5,9,14,20,26,35,42,46,51,53,64,67,70 \\
\text { and } 72\end{array}$ \\
\hline Biocoenosis-Biotope & $14(19.4 \%)$ & $7,8,13,21,24,26,34,40,41,43,44,52,62$ and 72 \\
\hline Sustainability & $9(12.5 \%)$ & $4,6,18,25,50,55,56,58$ and 61 \\
\hline Succession & $6(8.3 \%)$ & $16,19,24,28,57$ and 60 \\
\hline Energy Flow & $13(18.1 \%)$ & $1,2,7,9,10,11,12,15,31,46,49,64$ and 65 \\
\hline Matter Cycle & $6(8.3 \%)$ & $1,7,13,15,31$ and 46 \\
\hline Others & $9(12.5 \%)$ & $17,23,27,29,32,39,47,69$ and 71 \\
\hline
\end{tabular}

4.6. Is there any relationship between the considered categories?

After creating six cross-tables between pairs of variables to combine the four categories (TI, el, EL and EE), and performing likelihood-ratio analyses, no significant relationships between variables have been found $(\mathrm{p}<0.05)$. However, considered relatively, there are relationships between variables stronger than others. The two strongest relationships involve the educational level (el), the first one with respect to the type of investigation (TI) $(\mathrm{p}=0.128)$ and the second one with the ecosystem elements (EE) $(p=0.157)$. Most of the papers including investigations with pre-school children are focused on assessing pupils' learning (SL), while the vast majority of investigations involving elementary school students are "two dimensional" (St\&T 11/14). On the other hand, complex ideas of the ecosystem model such as energy flow (EF), matter cycle $\mathrm{MC}$ ) and ecological successions $(\mathrm{Su})$ are scarcely represented in papers dealing with elementary or pre-school learners, and they concentrate on studies contextualized in high school and higher educational levels. Table 6 consists of a contingency table recording how many times sub-categories show up in the 
articles. Literature reviews or articles including content analyses have been excluded from this table (papers: 7, 34 and 50).

TABLE 6

NUMBER OF TIMES SUB-CATEGORIES SHOW UP IN THE ANALYSED ARTICLES (SQUARES). THE COLOUR OF THE SQUARES DENOTES EDUCATIONAL LEVEL. THE NUMBERS WITHIN THE SQUARES REFER TO THE NUMBERS OF THE ANALYSED ARTICLES DISPLAYED IN APPENDIX 1

\begin{tabular}{|c|c|c|c|c|c|c|c|c|c|c|c|c|c|c|c|c|}
\hline \multirow{10}{*}{ 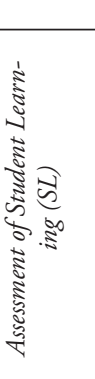 } & \multirow{3}{*}{\begin{tabular}{|l|}
$\mathrm{O}$ \\
$\mathrm{P}$ \\
\end{tabular}} & \multicolumn{6}{|c|}{ Concepts } & \multicolumn{6}{|c|}{ Skills } & \multicolumn{3}{|c|}{ Attitudes } \\
\hline & & \multirow{2}{*}{$\frac{35}{20}$} & \multicolumn{2}{|c|}{49} & \multirow[b]{2}{*}{65} & \multirow[b]{3}{*}{72} & & \multirow[b]{2}{*}{20} & \multirow[b]{2}{*}{63} & & & & & \multirow{2}{*}{\begin{tabular}{|l|}
35 \\
22 \\
\end{tabular}} & \multirow{2}{*}{$\frac{45}{22}$} & \multirow{2}{*}{54} \\
\hline & & & 30 & 48 & & & & & & & & & & & & \\
\hline & $\mathrm{C}$ & 2 & 20 & 3 & 70 & & 70 & 20 & 9 & & & & & & & \\
\hline & BB & 72 & 24 & & & & & 24 & & & & & & & & \\
\hline & S & & & & & & & 25 & & & & & & 18 & 4 & \\
\hline & SU & 28 & 19 & 60 & 24 & & & 28 & 19 & 24 & & & & & & \\
\hline & FE & 2 & 9 & 10 & 49 & 1 & \begin{tabular}{l|l}
12 & 65 \\
\end{tabular} & 9 & 10 & 11 & & & & & & \\
\hline & $\mathrm{MC}$ & & & & & & & & & & & & & & & \\
\hline & Ot & 69 & 29 & & & & & 69 & & & & & & 23 & & \\
\hline & $\mathrm{O}$ & 3 & 38 & 68 & & & & 33 & 37 & 68 & & & & 3 & 59 & \\
\hline ฐః & $\mathrm{P}$ & 31 & 36 & 66 & 16 & & & 36 & 66 & 16 & & & & 59 & & \\
\hline 30 & $\mathrm{C}$ & 26 & 42 & 67 & 46 & 64 & 53 & 14 & 26 & 51 & 64 & & & 67 & 64 & 53 \\
\hline 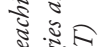 & BB & 26 & 40 & 52 & 55 & 96 & & 21 & 26 & 40 & 13 & \begin{tabular}{l|l|l}
41 & 44 & 8 \\
\end{tabular} & 96 & 13 & 43 & 44 \\
\hline$\frac{5}{5} 5$ & $S$ & 58 & 56 & 61 & 6 & & & 58 & 56 & & & & & 61 & & \\
\hline 芯运 & \begin{tabular}{|l|}
$S U$ \\
\end{tabular} & 16 & & & & & & 57 & 16 & & & & & & & \\
\hline हี้ & FE & 31 & 46 & 64 & 15 & & & 64 & & & & & & 64 & & \\
\hline$\frac{7}{3}$ & MC & 31 & 46 & 15 & & & & 13 & & & & & & 13 & & \\
\hline & Ot & 47 & 17 & 32 & 71 & & & 47 & 17 & 39 & 27 & & & 71 & & \\
\hline Pre & -school & & & & Ele & nent: & Iry levels & & & & High s & school levels & & & & \\
\hline Tea & cher tr & ining & & & Otl & & & & & & & & & & & \\
\hline
\end{tabular}

\section{Discussion}

This paper summarises a research synthesis conducted with articles included in the WOS database, published in science education journals over the last 20 years. The results can be useful for those interested on knowing what, how and at which educational level, has been investigated in Europe, in relation to ecosystems, since 1997. Although not foreseen originally, after conducting the bibliographic search we realized that $40.3 \%$ of the selected papers were not related to ecosystems in biology classrooms but with learning environments. The terms 'classroom ecosystems' or 'learning ecosystems' have spread across science didactics literature in the last 4 years. This fact indicates how fast certain terms spread through the scientific community and reveals that some of them may cause some interference when conducting bibliographic queries. On the 
other hand, the relative quantity of papers about biological ecosystems published in science education journals has remained steady.

The number of analysed papers devoted to evaluate students' ideas and learning (SL) is similar to the number of those focused on the investigation of teaching and learning strategies, or the learning effects of specific tools (ST\&T). However, just 2 out of the 72 selected articles are research syntheses. The oldest one is from 2010 and both of them are related to environmental education. This reveals the historical deficit of literature reviews in this field and their convenience in order to identify central issues for future research in biology education (Cooper et al., 2009). However, we wish to highlight the originality and convenience of sub-categories SL and ST\&T defined within the type of investigation (TI).

Regarding the educational level, it is remarkable how there is a low number of articles about ecosystems contextualized in pre-school, and there is a high number of them in high school. Since biology education stretches from preschool to university, we would expect an even distribution in the number of papers along the educative levels comprised between these two endpoints. These research distribution has also been noticed for other science education topics (Monteira \& Jiménez-Aleixandre, 2016). These results may drive some researchers to migrate their investigations to lower educational levels. Attitudes are the less evaluated learning in the analysed articles (about 25\% of the considered learning among the analysed papers). Since scientific attitudes are essential components of scientific literacy we wonder what the relative weight of attitudes in science literacy should be. The ecosystem elements considered in this research synthesis are homogeneously distributed among the selected papers. It might be worthy to note the lower number of papers paying attention to biogeochemical cycles, taking into account the potential of these cycles to link elements within the system, and to contextualize the learning process (Leach et al., 1996; Çokador \& Yilmaz, 2010).

Statistically, no significant relationships between pairs of categories have arisen. However, considering relatively, there seems to be some relationship between the ecosystem elements explicitly mentioned in the analysed papers and the educational level where they are contextualized. Thus, complex ideas and relations such as energy flow, cycling of matter or ecological succession are scarcely represented in papers dealing with elementary or pre-school learners, and they concentrate on studies contextualized in high school and higher educational levels. In our opinion, these results reinforce the systems thinking approach (Ben Zvi Assaraf \& Orion, 2005), which postulates that, in order for students to systems think, they have previously had to achieve other skills, such as the ability to identify the components of a system and processes within it, which can be related to the description of populations $(\mathrm{P})$ within ecosystems; or the ability to identify relationships among the systems' components, which can be linked to the comprehension of ecosystems at the community (C) level. 
As previously reported, research related to ecosystems contextualized in preschool are scarce and fairly recent (2010 and later). On the other hand, we assume that SL research prevails during the first stages of any educative research field, while ST\&T research is characteristic of more consolidated knowledge areas. This could explain why there are few articles from pre-school focused on analysing teaching and learning strategies, and why most of them evaluate learners' ideas and learning. Similarly, as research around ecosystems in elementary school has got an older tradition, it could explain why the evaluation of teaching and learning strategies or the effect of specific tools, prevail among papers contextualized at this educational level. Finally, we hope the results displayed in the present research synthesis contribute to the clarification of the characteristics of investigations related with ecosystems, conducted by science-education researchers over the last 20 years, and to guide them with their future research projects.

\section{References}

Allen, M. (2017). Early understandings of simple food chains: A learning progression for the preschool years. International Journal of Science Education, 39(11), 14851510 .

Ben-Zvi Assaraf, O. \& Orion, N. (2005). Development of system thinking skills in the context of earth system education. Journal of Research in Science Teaching, 42(5), $518-560$.

Çokadar, H. \& Yilmaz, G. C. (2010). Teaching ecosystems and matter cycles with creative drama activities. Journal of Science Education and Technology, 19, 80-89

Cooper, H., Hedges, L. V. \& Valentine, J. C. (Eds.). (2009). The handbook of research synthesis and meta-analysis. Russell Sage Foundation.

Doberski, J. (1998). Teaching ecosystem ecology through studying sewage treatment. Journal of Biological Education, 32(3), 216-225.

Eilam, B. (2012). System thinking and feeding relations: Learning with a live ecosystem model. Instructional Science, 40(2), 213-239.

García, R. M. (1995). Contraste Chi-cuadrado. UADE: Buenos Aires

Grotzer, T. A. \& Bell-Basca, B. (2003). How does grasping the underlying causal structures of ecosystems impact students' understanding? Journal of Biological Education, 38(1), 16-29.

Hayes, M. L., Plumley, C. L., Smith, P. S. \& Esch, R. K. (2017). A Review of the Research Literature on Teaching about Interdependent Relationships in Ecosystems to Elementary Students. Chapel Hill, NC: Horizon Research, Inc.

Hokayem, H., \& Gotwals, A. W. (2016). Early elementary students' understanding of complex ecosystems: A learning progression approach. Journal of Research in Science Teaching, 53(10), 1524-1545.

O'Flaherty, J. \& Liddy, M. (2018). The impact of development education and education for sustainable development interventions: a synthesis of the research. Environmental Education Research, 24 (7), 1031-1049. 
Jordan, R. C., Gray, S. A., Brooks, W. R., Honwad, S. \& Hmelo-Silver, C. E. (2013). Process-based thinking in ecosystem education. Natural Sciences Education, 42(1), 68-74.

Jussila, T. \& Virtanen, V. (2014). Learning in Virtual Forest: a forest ecosystem in the web-based learning environment. Journal of Biological Education, 48(4), 196-200.

Leach, J., Driver, R., Scott, P. \& Wood-Robinson, C. (1996). Children's ideas about ecology 2: ideas found in children aged 5-16 about the cycling of matter. International Journal of Science Education, 18(1), 19-34

Moreira, S. F. \& Jiménez-Aleixandre, M. P. (2016). The practice of using evidence in kindergarten: the role of purposeful observation. Journal of Research in Science Teaching, 53(8), 1232-1258

NRC (2012). A framework for K-12 Science Education: Practices, Crosscutting Concepts and Core Ideas. The National Academies Press. Washington D.C.

Riess, W. \& Mischo, C. (2010). Promoting Systems Thinking through Biology Lessons. International Journal of Science Education, 32, 705-725.

Verhoeff, R., Gilissen, M.G.R. \& Knippels, M.C. (2018). Systems thinking and the theoretical natures of seeing coherence. Paper presented in XII Conference of European Researchers in Didactics of Biology (ERIDOB), Zaragoza (Spain).

Wilensky, U. \& Reisman, K. (2006). Thinking like a wolf, sheep, or firefly: Learning biology through constructing and testing computational theories-an embodied modelling approach. Cognition and Instruction, 24(2), 171-210.

Yücel, E. Ö. \& Özkan, M. (2015). Development and Implementation of an Instructional Design for Effective Teaching of Ecosystem, Biodiversity, and Environmental Issues. Educational Sciences: Theory and Practice, 15(4), 1051-1068.

Zangori, L. \& Koontz, J. A. (2017). Supporting upper-level undergraduate students in building a systems perspective in a botany course, Journal of Biological Education, 51(4), 399-411.

\section{Appendix 1 Reference list of analysed papers}

1. Akçay, S. (2017). DOI: https://doi.org/10.1080/002119266.2016.1170067

2. Allen, M. (2017). DOI: https://doi.org/10.1080/09500693.2017.1336809

3. Almeida, A., Fernández, B. G. \& Silva, T. (2017). Changing negative perceptions of animals through teaching practice: A research in primary education. Journal of Baltic Science Education, 16, 446-458.

4. Almers, E. (2013). DOI: 10.1080/00958964.2012.719939

5. Azul, A. M., Ramos, V., Pato, A., Azenha, M. \& Freitas, H. (2008). DOI: https://doi.org/10.1080/00219266.2008.9656126

6. Barbalios, N., Ioannidou, I., Tzionas, P. \& Paraskeuopoulos, S. (2013). DOI: https://doi.org/10.1016/j.compedu.2012.10.029

7. Bemúdez, G., De Longhi, A. L. \& Gavidia, V. (2016). DOI: 10.10498/18495

8. Billington, H. L. (1997). DOI: https://doi.org/10.1080/00219266.1997.9655566

9. Bravo-Torija, B. \& Jiménez-Aleixandre, M. P. (2012). DOI: https://doi. org/10.1007/s11165-011-9254-1 
10. Bravo-Torija, B. \& Jimenez Aleixandre, M. P. (2014). DOI: https://doi. org/10.5565/rev/ensciencias. 1281

11. Carlsson, B. (2002a). DOI: https://doi.org/10.1080/09500690110098868

12. Carlsson, B. (2002b). DOI: https://doi.org/10.1080/095006901198877

13. Çokadar, H. \& Yilmaz, G. C. (2010). DOI: https://doi.org/10.1007/s10956-0099181-3

14. Demetriou, D., Korfiatis, K. \& Constantinou, C. (2009).

DOI: https://doi.org/10.1080/00219266.2009.9656180

15. Doberski, J. (1998). DOI: https://doi.org/10.1080/00219266.1998.9655623

16. Dove, J. (1997). DOI: https://doi.org/10.1080/00219266.1997.9655565

17. Eckhardt, M., Urhahne, D., Conrad, O. \& Harms, U. (2013). DOI: https://doi. org/10.1007/s11251-012-9220-y

18. Erbilen, S. Ü. (2013). The Participation in Ecological Activities and Its Influence on High School Pupils' Attitude towards The Environment: Famagusta Case. Egistim arastirmalari-Euroasian Journal of Educational Research. 13 (53A), 107-118.

19. Ergazaki, M. \& Ampatzidis, G. (2012). DOI: https://doi.org/10.1007/s11165011-9208-7

20. Ergazaki, M. \& Andriotou, E. (2010). DOI: https://doi.org/10.1007/s11165-0089109-6

21. Evagorou, M., Korfiatis, K., Nicolaou, C. \& Constantinou, C. (2009).

DOI: https://doi.org/10.1080/09500690701749313

22. Fančovičová, J. \& Prokop, P. (2010). DOI: https://doi.org/10.1007/s10956-0109207-x

23. Garavito-Bermúdez, D. \& Lundholm, C. (2017). DOI: https://doi.org/10.1080/1 3504622.2016.114662

24. Garavito-Bermúdez, D., Lundholm, C. \& Crona, B. (2016). DOI: https://doi.org/10.1080/13504622.2014.936307

25. Gresch, H. \& Bögeholz, S. (2013). DOI: https://doi.org/10.1007/s11165-012-9287-0

26. Guilherme, E., Faria, C. \& Boaventura, D. (2016). DOI: https://doi.org/10.1080 /03004279.2015.1007884

27. Hill, J. L. \& Nelson, A. (2011). DOI: https://doi.org/10.1080/13504622.2010.5 45873

28. Ibarra Murillo, J. \& Gil Quilez, M. J. (2009). Use of ecological concepts by secondary school students: The prediction of changes in ecosystems. Enseñanza De Las Ciencias, 27(1), 19-31.

29. Janssen, R. \& Crauwels, M. (2011). DOI: https://doi.org/10.1080/00219266.201 1.537836

30. Jiménez-Tejada, M. P., Sánchez-Monsalve, C. \& González-García, F. (2013). DOI: https://doi.org/10.1080/00219266.2013.799081

31. Jussila, T. \& Virtanen, V. (2014). DOI: https://doi.org/10.1080/00219266.2013. 863794

32. Karaca, T. \& Koray, O. (2017). DOI: https://doi.org/10.14689/EJER.2017.67.12

33. Komis, V., Ergazaki, M. \& Zogza, V. (2007). DOI: https://doi.org/10.1016/j. compedu.2005.12.007 
34. Krasny, M. E., Lundholm, C. \& Plummer, R. (2010).

DOI: https://doi.org/10.1080/13504622.2010.505445

35. Kubiatko, M. \& Balatova, K. (2017). DOI: https://doi.org/10.12973/ eurasia.2017.00665a.

36. Kyza, E. A., Constantinou, C. P. \& Spanoudis, G. (2011).

DOI: https://doi.org/10.1080/09500693.2010.550951

37. Linde, A. R. \& Garcia-Vazquez, E. (2006).DOI: https://doi.org/10.1002/ bmb.2006.494034052653

38. Linde, A. R. \& Garcia-Vazquez, E. (2009). DOI: https://doi.org/10.1080/002192 66.2009 .9656157

39. Magntorn, O. \& Helldén, G. (2005). DOI: https://doi.org/10.1080/ 095069500102706

40. Magntorn, O. \& Helldén, G. (2007a). DOI: https://doi.org/10.1080/00219266.2 007.9656065

41. Magntorn, O. \& Helldén, G. (2007b). DOI: https://doi.org/10.1080/ 09500690600708543

42. Malinverni, L. Schaper, M. M., \& Pares, N. (2016). DOI: https://doi.org/10.1007/ s11423-016-9468-z

43. Manzanal, R. F., Rodríguez Barreiro, L. M. \& Casal Jiménez, M. (1999). DOI: https:// doi.org/10.1002/(SICI) 1098-2736(199904)36:4<493::AID-TEA6>3.0.CO;2-P

44. Martínez Hernández, C., Ibarra Marinas, A. D., Pérez Resina, J. P. \& Figueres Cuesta, C. (2016). DOI: https://doi.org/10.7203/DCES.304584

45. Mazas Gil, B. \& Fernandez Manzanal, R. (2016). DOI: https://doi. org/10498/18290

46. Mutlu, M. (2013). Effect of using Roundhouse diagrams on preservice teachers' understanding of ecosystem. Journal of Baltic Science Education, 12(2), 205-218.

47. Nazaruk, S. K. \& Klim-Klimaszewska, A. (2017). Direct learning about nature in 6-year-old children living in urban and rural environments and the level of their knowledge and skills. Journal of Baltic Science Education, 16(4), 524-532.

48. Neves, J. P. C. D. \& Monteiro, R. C. R. (2014). DOI: https://doi.org/10.1080/13 504622.2013 .780586

49. Özay, E. \& Öztaş, H. (2003). DOI: https://doi.org/10.1080/00219266.2003.9655853

50. Özdemir, O. (2007). A New Environmental Education Perspective:" Education For Sustainable Development". Egitim ve Bilim, 32(145), 23-38.

51. Papaevripidou, M., Constantinou, C. P. \& Zacharia, Z. C. (2007). DOI: https:// doi.org/10.1111/j.1365-2729.2006.00217.x

52. Papapanagou, E., Tiniakou, A. \& Georgiadis, T. (2005).

DOI: https://doi.org/10.1080/00219266.2005.9656005

53. Prokop, P., Majerčíková, D. \& Vyoralová, Z. (2016). The use of REALIA versus powerpoint presentations on botany lessons. Journal of Baltic Science Education, 15(1), 18-27.

54. Prokop, P., Medina-Jerez, W., Coleman, J., Fančovičová, J., Özel, M. \& Fedor, P. (2016).

DOI: https://doi.org/10.12973/eurasia.2016.1241a 
55. Randler, C. \& Bogner, F. X. (2009). DOI: https://doi.org/10.1007/s10763-0079117-4

56. Riess, W. \&Mischo,C.(2010).DOI:https://doi.org/10.1080/09500690902769946

57. Rodellar, G. \& Bravo-Torija, B. (2016). DOI: https://doi.org/10.7203/ DCES.30.5152

58. Roesch, F., Nerb, J. \& Riess, W. (2015). DOI: https://doi.org/10.1080/09500693 .2014 .1000427

59. Sammet, R. \& Dreesmann, D. (2015). DOI: https://doi.org/10.1525/ abt.2015.77.7.6

60. Sander, E., Jelemenská, P. A. \& Kattmann, U. (2006). DOI:10.1080/00219266.2 006.9656028

61. Sattler, S. \& Bogner, F. X. (2017). DOI: https://doi.org/10.1080/13504622.2016 .1144173

62. Schultz, L. \& Lundholm, C. (2010). DOI: https://doi.org/10.1080/13504622.20 10.505442

63. Tomkins, S. P. \& Tunnicliffe, S. D. (2001). DOI: https://doi.org/10.1080/ 09500690119322

64. Tsivitanidou, O. E. \& Constantinou, C. P. (2016). DOI: https://doi.org/10.1016/J. IHEDUC.2015.11.002

65. Urmeneta, J. \& Duró, A. (2011). DOI: https://doi.org/10.1525/abt.2001.73.5.4

66. Vergnoux, A., Allari, E., Sassi, M., Thimonier, J., Hammond, C., \& Clouzot, L. (2011). DOI: https://doi.org/10.1080/00219266.2011.537839

67. Von Albedyll, A., Fritsch, A., \& Dreesmann, D. (2017). DOI: https://doi. org/10.1525/abt.2017.79.5.351

68. Walker, M., Read, L., Jackson, K., \& McFarlane, P. (1998). DOI: https://doi.org/10.1080/00219266.1998.9655624

69. Walpole, S. C., Pearson, D., Coad, J., \& Barna, S. (2016). DOI: https://doi.org/10.3109/0142159X.2015.1112897

70. Yli-Panula, E., \& Matikainen, E. (2014). Students and student teachers'ability to name animals in ecosystems: a perspective of animal knowledge and biodiversity. Journal of Baltic Science Education, 13(4), 559-572.

71. Yücel, E. Ö., \& Özkan, M. (2015a). DOI: https://doi.org/10.12738/ estp. 2015.4.2579

72. Yücel, E. Ö., \& Özkan, M. (2015b). DOI: https://doi.org/10.15390/EB.2015.4326 



\title{
PROMOTING THE ROLE OF DATA AND SCIENTIFIC MODELS IN STUDENTS' ARGUMENTATION ON SOCIO-SCIENTIFIC ISSUES THROUGH COMMUNICATION SCAFFOLDS
}

\author{
Anna Marbà-Tallada and Jordi Domènech-Casal \\ Departament de Didàctica de les Matemàtiques i les Ciències Experimentals, \\ Universitat Autònoma de Barcelona (Barcelona-España). \\ anna.marba@uab.cat
}

\begin{abstract}
Learning science in context implies learning to transfer scientific models to real scenarios and make decisions. In science education, this aspect is well represented by science learning activities around controversial socio-scientific issues (SSIs). Several scaffolds to write and assess scientific essays on SSIs are proposed to 15-year old students. We analyse students' essays for several items regarding scientific competence (use of scientific models and data, argumentation), and collate students' perceptions on the usefulness of such scaffolds.
\end{abstract}

Keywords: socio-scientific issues; assessment, linguistic scaffolds, context.

\section{Introduction}

The development of scientific competence implies not only mastering scientific models (e.g. the water cycle, heredity, etc.), but also being able to transfer it to take decisions in real contexts and situations (Gilbert, 2006; Sadler, 2011). However, science classrooms keep developing practices where context doesn't play a relevant role (Gilbert, 2006). Socio-Scientific Issues (SSIs) are social dilemmas underpinned by scientific concepts and models, but also by personal or cultural values and social, political or ethical concerns that have open and complex answers (Sadler, 2004). SSIs can link to several topics: sustainability, health, security, biotechnology, etc., and present different levels: individual ("Which car should I buy?") or social ("Should we forbid diesel?") (Domènech et al., 2015; Domènech-Casal, 2019). 
Teaching sciences by using SSIs as a context have been promoted by several authors as a method for:

1) deepening an understanding of scientific models and concepts: SSI situates scientific concepts, models and vocabulary in conflictive scenarios that promote its analysis and meaning-construction in context (Sadler, 2009a, 2011);

2) developing students' abilities to participate as citizens in decision-making on complex problems with impact on global questions (Sadler et al., 2007), as taking part in debates, using ethics frameworks, connecting with values such as democracy, sustainability and justice;

3) promoting scientific skills as argumentation and data analysis, including critical analysis, identifying epistemic concerns on proposals, and use of evidences (Kolsto, 2001; Sadler, 2009b; Sadler, 2011).

When applying SSIs to science education, students have difficulties in assessing different aspects of the dilemmas (Sadler \& Zeidler, 2009), in particular about integrating social and scientific aspects in a SSI (Ryder, 2002; Sadler et al., 2004). When students construct oral or written argumentations from SSIs, they experience difficulties in connecting ideas and use evidence for argumentation. Their ideas often focus on the 'social' part of the controversial issue, neglecting the key scientific concepts. Writing essays on SSIs is a didactic space to work on these difficulties, but students are not used to such linguistic practices or argumentation. Linguistic scaffolding has been proposed by several authors as a way to improve and assess high-order cognitive skills as comparison, justification and argumentation (Lemke, 1989). Other authors have claimed that specific attention to scientific vocabulary linked to a dilemma is a key aspect to an adequate deepening in scientific concepts and models, and proposed the specific work on scientific vocabulary in an SSI framework as a way to develop it (Lawrence et al., 2010; 2011). These authors have proposed Word Generation, a standard framework to work with short-sequences of SSIs, structured in 4 steps (Snow et al., 2009): 1) proposing a dilemma; 2) reading texts from different sources and sustaining positions on the dilemma and extract the key vocabulary terms; 3) debate on the dilemma; 4) writing an essay with a personal argumentation on the dilemma.

Teachers find difficulties to relate SSIs with curriculum items, and connect them appropriately scientific concepts and models (Evagorou et al., 2014). Moreover, they experience a lack of classroom strategies to apply SSIs effectively in the classroom and assess students' learning (McNeill \& Knight, 2013). We consider that the structure proposed by Snow et al. (2009), together with linguistic scaffolds, could be an adequate way to undertake the work with SSIs in the classrooms. Our objectives in this research are:

- Testing students' abilities to use data and scientific models to construct argumentation in SSIs related to genetics.

- Testing scaffolds to address SSI activities in the classrooms. 


\section{Research design and method}

We developed two SSI dilemmas related to genetics: the use of transgenics and genetic engineering. The dilemmas were situated in Genetics topics, as the new technical possibilities in this field entail complex questions such as access to genetic data, genetic manipulation, etc., relevant for the scientific competences of citizenship (Kampourakis et al., 2014). The proposed dilemmas (Table 1) were developed ad hoc for this experience, proposing hypothetic situations with the following terms:

- The scientific concepts should be necessary, but not enough, to solve the dilemma.

- Different positions or answers should be admitted.

TABLE 1

DILEMMAS, MODELS AND VOCABULARY OF THE TWO SSIS PROPOSED

\begin{tabular}{lll}
\hline Dilemma & Scientific Models & Vocabulary \\
\hline $\begin{array}{l}\text { 1."Should police applicants pass genetic tests about } \\
\text { their genetic inclination to violence?" }\end{array}$ & Genetic determinism & Genotype \\
& & Phenotype \\
& & Genetic linkage \\
\hline 2."Should we authorize growing medical transgenic & Transgenics & Multifactorial characters \\
maize, displacing a local traditional crop?" & & Transgenic \\
& & Ecologic farming \\
& & Endemic species \\
& Metabolic diseases \\
\hline
\end{tabular}

These dilemmas were developed as SSIs following a sequence as proposed by Snow et al. (2009). For each dilemma, after presenting the dilemma, students were given 3-4 readings. After cooperative reading, students engaged in debates in the classroom where key vocabulary was remarked and analysed. At the end of each activity, students were asked to write a 400 -word essay, which included their argumentation on the dilemma. 30 students 15 years old participated in the study. They followed the whole process for two dilemmas, as shown in Figure 1.

To assess students' abilities to use data and scientific models to construct argumentation in SSIs related to genetics, the resulting essays were assessed

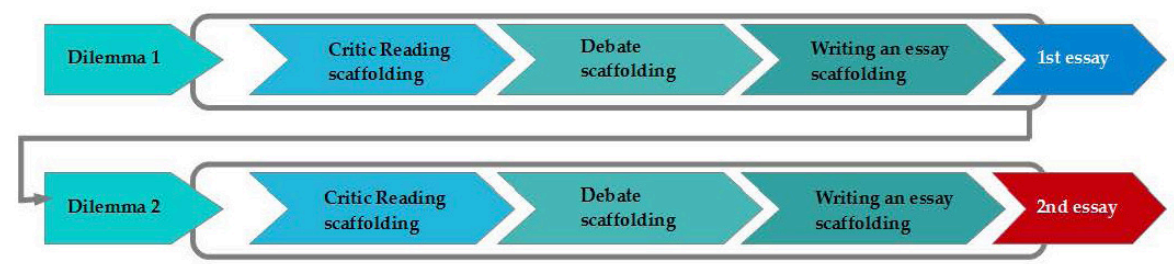

Figure 1 Outline of the SSI sequence proposed to students. 
through a rubric developed ad hoc, called McLeares Rubric (Table 2). This rubric separately assesses five items: 1) using scientific concepts and models for argumentation; 2) using contexts and data for argumentation; 3) using appropriately scientific vocabulary; 4) using grammar particles in argumentation; 5) developing the discourse structure for scientific essays - context, data, argumentation, conclusions. After the first essay, students were assessed and received feedback from the rubric. Two months later, students worked on the second dilemma. For both dilemmas, students' essays were assessed. Each item of the rubric was assessed from 0 (not attained) to 10 (excellent).

TABLE 2

MCLEARES RUBRIC TO ASSESS ESSAYS ON SOCIO-SCIENTIFIC ISSUES SEPARATELY FOR 5 DIMENSIONS: KEY VOCABULARY, SCIENTIFIC MODELS, DATA AND CONTEXT, ARGUMENTATION, DISCOURSE STRUCTURE

\begin{tabular}{|c|c|c|c|}
\hline & 10 & 5 & 0 \\
\hline Key Vocabulary & $\begin{array}{l}\text { 4-5 specific scientific vo- } \\
\text { cabulary terms are used } \\
\text { in pertinent ways and } \\
\text { help to make the essay } \\
\text { understandable. Vocabu- } \\
\text { lary is clarified through } \\
\text { periphrasis or establis- } \\
\text { hing relationships with } \\
\text { other terms. }\end{array}$ & $\begin{array}{l}2-3 \text { specific scientific vo- } \\
\text { cabulary terms related to } \\
\text { the topic are used. } \\
\text { Rest of specific terms are } \\
\text { not present or their relati- } \\
\text { onship with the argument } \\
\text { remains unclear. }\end{array}$ & $\begin{array}{l}\text { Only one or none of the } \\
\text { specific vocabulary terms } \\
\text { are used in the essay. }\end{array}$ \\
\hline Scientific Models & $\begin{array}{l}\text { The Scientific Model is } \\
\text { well connected to the di- } \\
\text { lemma and used to give } \\
\text { sense to the data. }\end{array}$ & $\begin{array}{l}\text { The Scientific Model is } \\
\text { mentioned but not used } \\
\text { in argumentation, which } \\
\text { is based mainly in other } \\
\text { aspects of the dilemma. }\end{array}$ & $\begin{array}{l}\text { The Scientific Model is } \\
\text { not mentioned in any } \\
\text { way. }\end{array}$ \\
\hline Data and Context & $\begin{array}{l}\text { At least two data (num- } \\
\text { bers, statistics, etc.) and } \\
\text { some examples are used } \\
\text { in the argumentation. }\end{array}$ & $\begin{array}{l}\text { Some examples from real } \\
\text { life (not data) are used to } \\
\text { make clear some ideas. }\end{array}$ & $\begin{array}{l}\text { No examples nor data } \\
\text { participate in the text, }\end{array}$ \\
\hline Argumentation & $\begin{array}{l}\text { Grammar Connectors } \\
\text { (so, as a consequence, } \\
\text { however, because, etc.) } \\
\text { are used, and ideas are } \\
\text { coherent. Uses emphasis } \\
\text { and puntuation to re- } \\
\text { mark ideas. Includes and } \\
\text { neutralizes opposite argu- } \\
\text { ments. }\end{array}$ & $\begin{array}{l}\text { Some Grammar Connec- } \\
\text { tors used, but the text is } \\
\text { mainly a description. }\end{array}$ & $\begin{array}{l}\text { No Grammar Connectors } \\
\text { for Argumentation. The } \\
\text { text is a description. }\end{array}$ \\
\hline $\begin{array}{l}\text { Discourse } \\
\text { Structure }\end{array}$ & $\begin{array}{l}\text { Global structure is cor- } \\
\text { rect (Tittle, Sub-Tittle, } \\
\text { Data, Argumentation, } \\
\text { Conclusions) and each } \\
\text { section develops its func- } \\
\text { tion in the text. No inter- } \\
\text { nal contradictions. }\end{array}$ & $\begin{array}{l}\text { Some sections include } \\
\text { ideas that should be pla- } \\
\text { ced elsewhere. Some ideas } \\
\text { are not well aligned with } \\
\text { the position the text pro- } \\
\text { motes. }\end{array}$ & $\begin{array}{l}\text { Text completely discon- } \\
\text { nected. It is difficult to } \\
\text { identify a direction in the } \\
\text { text. There are internal } \\
\text { contradictions. }\end{array}$ \\
\hline
\end{tabular}


Several linguistic scaffolds were proposed. Scaffolds are available at https:// sites.google.com/site/cscframe/recursos (Domènech-Casal, 2017) and include:

1) a template and a step-guide for writing essays with phrase initiators;

2) examples of scientific essays on other topics;

3) the McLeares rubric as an auto-assessment tool;

4) using the McLeares rubric to co-assess other students' essays;

5) the teacher's assessment using the McLeares rubric.

To assess its usefulness, students' preferences on the proposed scaffolds were registered through a survey. In the survey, students selected which of the proposed scaffolds were useful to them to learn how to construct arguments on a SSI, and the percentage of students supporting each scaffold was calculated.

\section{Results}

Students' abilities to use models or data at the initial step were very low (Figure 2), in particular regarding the use of Scientific Models, Key Vocabulary and Argumentation. Students' productions included several kinds of errors, as citing opinions as facts, or constructing argumentations without references to the scientific aspects of the SSI (Table 3). In the second essay, after feedback with the rubric, students increased mainly their abilities on these aspects, with very slight increases in Discourse Structure and the use of Data and Contexts.

TABLE 3

EXAMPLES OF THE MOST USUAL ERRORS REGARDING THE USE OF SCIENTIFIC MODELS AND DATA AND CONTEXT FOUND IN STUDENTS' ESSAYS.

\begin{tabular}{|c|c|}
\hline Usual Errors (Item) & Examples \\
\hline $\begin{array}{l}\text { Citing opinions as facts. } \\
\text { (Data and Context) }\end{array}$ & $\begin{array}{l}\text { "As a doctor Vallmitjana says, ecologic breeding is being challenged by } \\
\text { transgenics". Student } 2 \text {. Dilemma } 2 .\end{array}$ \\
\hline $\begin{array}{l}\text { Argumentation without refer- } \\
\text { ences to the scientific models } \\
\text { (Scientific Models) }\end{array}$ & $\begin{array}{l}\text { "Genetic markers would not have effect on people security, as being a } \\
\text { police doesn't give you the right to kill people". Student 5, Dilemma } 1 .\end{array}$ \\
\hline $\begin{array}{l}\text { Wrong use of scientific models } \\
\text { (Scientific Models) }\end{array}$ & $\begin{array}{l}\text { "Because if you detect a genetic marker, it will be transmitted to the } \\
\text { descendants of the policeman". Student 9, Dilemma } 1 .\end{array}$ \\
\hline
\end{tabular}

The main argumentation errors among students were: using opinions; incorrect use of scientific models; building argumentations only from personal motivations and values; not using scientific models or data. Students' results are not likely to arise strictly from linguistic communicative abilities. Individual students' results on items Scientific Models, Data and Context and Key Vocabulary (those we consider more related specifically to scientific abilities), were compared with students' individual academic results of the current course. As a result, a higher correlation (0.43) was obtained for science disciplines rather than language disciplines (0.33), indicating that the proposed activity of writing 


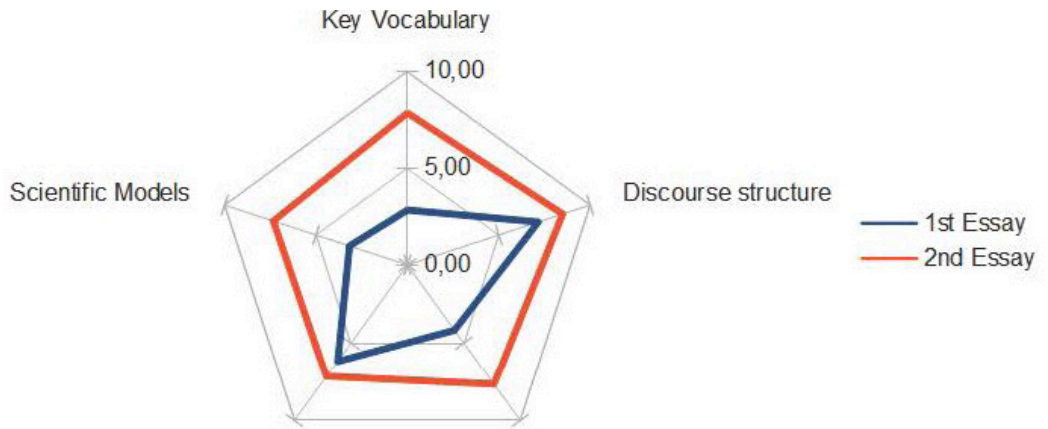

Data and Context

Argumentation

\begin{tabular}{llllll}
\hline & Key Vocabulary & Scientific Models & Data and Context & Argumentation & $\begin{array}{c}\text { Discourse } \\
\text { structure }\end{array}$ \\
\hline 1st Essay & 2.8 & 3.2 & 6.2 & 4.2 & 7.2 \\
\hline 2nd Essay & 7.8 & 7.3 & 7.2 & 7.7 & 8.5 \\
\hline
\end{tabular}

Figure 2. Comparison of the different McLeares items between the first and the second essays.

essays on SSIs and its assessment through McLeares rubric would affect scientific thinking abilities.

Students' preferences on scaffolds for constructing argumentation on a SSI were positive for several scaffolds (Figure 3). The scaffolding strategies most valued by students were those regarding the application of the McLeares rubric to their own work, by themselves or by the teacher. Step-guides and templates were also valued, and lower levels were obtained by scaffolding strategies based on reading other essays, or other students' essays.

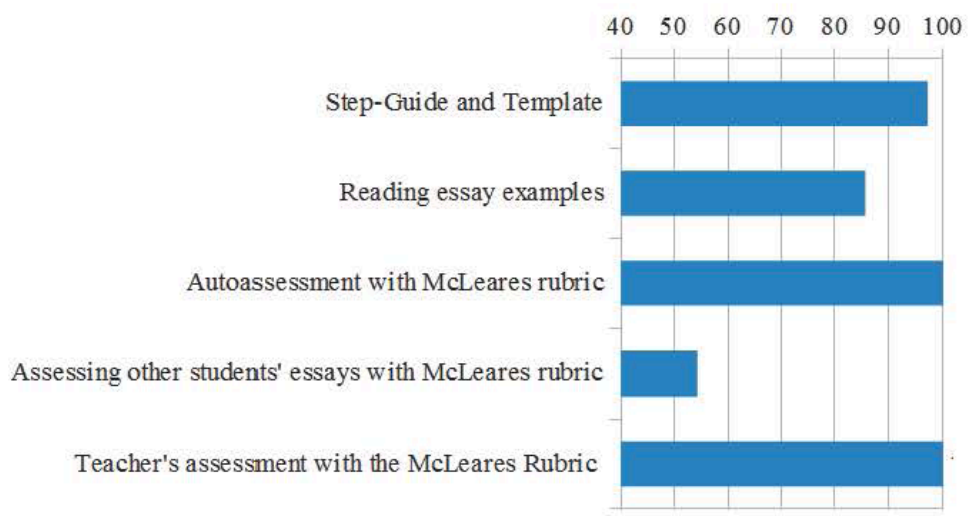

Figure 3 Percentage of students supporting each of the scaffolding strategies used to learn how to argue about a SSI. 


\section{Discussion and conclusions}

Students' arguments on SSIs show difficulties mainly on using scientific models and key vocabulary. These difficulties can be assessed and addressed through the proposed scaffolding strategies. It also helps to improve some of the students' difficulties identified in the literature, such as their lack of skills to build structured argumentations on SSIs (Ryder, 2002; Sadler et al., 2004). All the linguistic scaffolds, but especially those related with the use of the McLeares rubric on students' work, were valued by students. The proposed sequence and linguistic scaffolds to work with SSIs were also applied in in-service teachertraining activities. Assessing separately "Scientific" items (using data and scientific concepts, argumentation, vocabulary) and "Linguistic" items (essay structure) was considered by the participating teachers as a way to communicate, expose and identify key science curricular elements developed when working with SSIs in the classrooms, and thus, facilitating its use as a science education methodology.

\section{Acknowledgements}

This research was funded by the Spanish Government (grant number EDU2015-66643-C2-1-P) and carried out within the ACELEC research group, acknowledged by the Catalan Government (grant number 2017SGR1399). The authors acknowledge and thank the students and teachers participating in the study for their collaboration.

\section{References}

Domènech-Casal, J. (2017) Propuesta de un marco para la secuenciación didáctica de Controversias Socio-Científicas. Estudio con dos actividades alrededor de la genética. Revista Eureka sobre Enseñanza y Divulgación de las Ciencias, 14(3), 601-620.

Domènech-Casal, J. (2019). Aprenentatge Basat en Projectes, Treballs Pràctics i Controvèrsies. 28 experiències i reflexions per a ensenyar ciències. Rosa Sensat: Barcelona.

Domènech, A.M., Márquez, C., Roca, M. \& Marbà, A. (2015) La medicalización de la sociedad, un contexto para promover el desarrollo y uso de conocimientos científicos sobre el cuerpo humano. Enseñanza de las ciencias, 33(1), 101-125.

Evagorou M., Guven D. \& Mugaloglu E. (2014). Preparing Elementary and Secondary Pre-Service Teachers for Everyday Science. Science Education International, 25(1), 68-78.

Gilbert, J.K. (2006). On the nature of "context" in chemical education. International Journal of Science Education, 28(9), 957-976.

Kampourakis K., Reydon T. A. C., Patrinos G.P. \& Strasser B.J. (2014). Genetics and Society. Educating Scientifically Literate Citizens. Science \& Education 23, 251-258. 
Kolstø, S. D. (2001). Scientific Literacy for Citizenship: Tools for Dealing with the Science Dimension of Controversial Socioscientific Issues. Science Education, 85(3), 291-310.

Lawrence, J., White C. \& Snow C. (2010). The words students need. Educational Leadership 68 (2), 22-26.

Lawrence J., White C. \& Snow C. (2011). Improving Reading Across Subject Areas With Word Generation. CREATE Briefs, September 2011, 1-5. Center for Research on the Educational Achievement and Teaching of English Language Learners, U.S. Department of Education.

Lemke, J. L. (1989). Using Language in the Classroom. Oxford: Oxford University Press. [First appeared in Geelong, VIC (Australia): Deakin University Press 1985].

McNeill, K. L. \& Knight A. M. (2013). Teachers' Pedagogical Content Knowledge of Scientific Argumentation: The Impact of Professional Development on K-12 Teachers. Science Education 97 (6), 936-972.

Ryder, J. (2002). School science education for citizenship: strategies for teaching about the epistemology of science. Journal of Curriculum Studies, 34(6), 637-658.

Sadler, T.D. (2004). Informal reasoning regarding socioscientific issues: A critical review of the literature. Journal of Research in Science Teaching, 41(4), 513-536.

Sadler, T.D. (2009a). Situated learning in science education: socioscientific issues as contexts for practice. Studies in Science Education, 45(1), 1-42.

Sadler, T. D. (2009b). Socioscientific issues in science education: labels, reasoning, and transfer. Cultural Studies in Science Education, 4, 697-703.

Sadler, T. D. (2011). Situating Socio-scientific Issues in Classrooms as a Means of Achieving Goals of Science Education, in Sadler, T. D. (Ed.) Socio-scientific Issues in the Classroom: Teaching, learning and research (pp. 1-9). Netherlands: Springer.

Sadler, T. D., Barab S. A. \& Scott B. (2007). What do students gain by engaging in socioscientific inquiry? Research in Science Education, 37(4), 371-391.

Sadler, T.D., Chambers, W.F., \& Zeidler, D. (2004). Student conceptualizations of the nature of science in response to a socio-scientific issue. International Journal of Science Education, 26(4), 387.

Sadler, T.D., \& Zeidler, D.L. (2009). Scientific literacy, PISA and socio-scientific discourse: Assessment for progressive aims of science education. Journal of Research in Science Teaching, 46 (8), 909-921.

Snow C., Lawrence J., \& White C. (2009). Generating knowledge of academic language among urban middle school students. Journal of Research on Educational Effectiveness, 2(4), 325-344. 


\author{
SECTION 5 \\ TEACHING STRATEGIES \\ AND TEACHING ENVIRONMENTS
}





\title{
THE FLORAL DIAGRAM AS A DIDACTIC RESOURCE FOR DEGREE STUDENTS IN EARLY CHILDHOOD EDUCATION
}

\author{
Beatriz Carrasquer Álvarez ${ }^{1}$ and Adrián Ponz Miranda ${ }^{1,2}$ \\ ${ }^{1}$ Dpto. de Didáctica de las Ciencias Experimentales. Universidad de Zaragoza. \\ Email: becarras@unizar.es; ${ }^{2}$ Grupo Beagle. Instituto Universitario de Investigación en Ciencias \\ Ambientales de Aragón. Universidad de Zaragoza. Email: adrian.ponz@unizar.es
}

\begin{abstract}
This paper presents a study on how the flower concept and its components are taught in pre-university education, and analyses the didactic value of the diagram and the floral formula to learn about the flower concept. A floral formula is a representation of the structure of a flower by symbols, letters and numbers. During five academic courses, the floral diagram with real flowers and its formula was used with more than 440 students doing a degree in Early Childhood and Primary Education. During two academic years, some of them were asked how they had learned that biological term in previous educational stages, and how they valued their learning using the manipulative resource presented here. $94 \%$ of the students stated that they had never used a real flower before to learn the concept, and agreed to use the floral diagram as a resource with their own students. $97 \%$ of the students correctly identified the parts of the plant organ. All the students perceived that this knowledge is better acquired through this manipulative methodology, than with the traditional method of images of the traditional texts provided by publishers. As expected, learning through manipulative research experiences is more effective and motivating than through traditional master classes. We recommend using these didactic techniques in the learning of biological concepts by the teachers in formation, to facilitate their future application in the classroom.
\end{abstract}

Keywords: botany, flowers, teacher training, early childhood education, Spain

\section{Introduction}

According to Cabello (2011), during early childhood education it is necessary to experiment with the objects and materials in the children's 
environment. Continuously in the playground or outside the school, they find ants, worms, plants, flowers or objects that attract their attention, and it is difficult to know how to channel these interests systematically (Almagro, 1992). Children construct knowledge about biological phenomena, and when this knowledge is based on scientific knowledge, it will promote the elaboration of a broad vision of the natural world, that can influence the construction of an awareness linked to the conservation and care of the environment (Villarroel, 2013; Villarroel \& Infante, 2014). The preschool period is precisely when children start the early phases of abstract knowledge, and a biologically organised framework will eventually lead them to grasp the concept of living things, including the notion of plants as animate entities (Margett \& Witherington 2011). The understanding of plants as living things is a significant conceptual step that young children must overcome in their development of an understanding of biological concepts (Villarroel \& Infante, 2014). When children make drawings about plant life, they intentionally select, from among the elements that make up their collection of ideas and concepts, those that correspond to their specific area of knowledge (Villaroelet al., 2016). Plants readily engage pupil interest and they tend to focus on striking anatomical features (Tunnicliffe $\&$ Reiss, 2000). These authors suggest that the teachers (whether formal science teachers, botanic gardens educators, or parents) can help pupils to learn by encouraging them to describe and comment on less obvious anatomical features. At primary level, teachers need to be encouraged to find ways to engage their attention on living organisms and especially plants, it may be something as simple as naming classrooms after trees or keeping a wild flower diary (Bebbington, 2005). In Malta, for example, children's knowledge of plant species is mainly due to their families, leaving behind the influence of teaching (Gatt et al., 2007).

Van Aalderen-Smeets et al. (2012) state that only when teachers believe that science content is necessary and important, and when they themselves feel sure that their own students are able to learn these contents, without relying on too many context factors (training, time, materials, etc.), will they change and improve their teaching. Hoban (1997) suggests that the confidence of teachers in training does not increase by giving them more content in science, but by facilitating activities of metacognition, reflecting on the teaching practice of specific scientific contents. Floral diagrams are used as a graphic representation of the organized formation of floral pieces (sepals, petals, stamens and carpels), in a cross-section of a flower, and are useful for flower identification or can help in understanding angiosperm evolution (Ronse, 2010). For this author the merits of floral diagrams in the classroom are obvious, because used together with floral formulae, they convey information in a rigorous and clear way.

Villaroel (2015) suggests a significant connection between young children's colour preferences when depicting plant life and their comprehension of the vegetable world. In addition, previous research emphasises a close relationship 
between the content of young children's drawings and their understanding of biological and science-related concepts. Then, to draw the natural world could assist pupils in constructing further understanding of living organisms (Katz, 2017). The mental models that children and lay adults construct have predictive and explanatory power, and can be used as mediating mechanisms for the revision of existing theories and the construction of new ones; for that reason they are important in conceptual development and conceptual change (Vosniadou, 1999). Modelling provides opportunities for students to interpret the natural world and generate their own models of how it works. This includes building, discussing and contrasting them to establish a final consensus model (Acher et al., 2007), recognizing its potential to generate new questions to investigate, make explanations and predictions (Chamizo, 2013), and allowing thinking, speaking and acting for students (García, 2005). Aduriz-Bravo \& Izquierdo-Aymerich (2009) consider the scientific model as a representation, in any symbolic means, that allows us to think, speak and act with rigor and depth on the system that is being studied. These authors consider a model as being not only more elaborate abstract models, but also other types of representations, such as images or analogies, provided they enable the user to describe, explain or predict that system.

Doménech \& Viñas (1997) consider that in the educational development of children in early childhood education, the materials we use in the teachinglearning process play a very important role, being the mediating elements between the educator and the surrounding environment. To understand the definition of a word properly, children must act physically on a concept in which the word was used, because when children have tested a concept by exploration and manipulation, then it has meaning (Brown, 2004). Actions such as manipulating, touching, dragging, doing, undoing, building, looking, contribute to children knowing the properties and qualities of objects. Furthermore, the childhood education school must encourage the progress of these methods of knowledge of reality, manipulation and observation, so that they become more systematic and thus more useful (Gassó, 2005). In this work, floral diagrams with real floral pieces, and its formulae are used with the Education degree students as a didactic resource for learning the flower concept, by modelling and manipulation. The didactic methodology used in schools to teach it is also analyzed.

\section{Methodology}

A floral diagram (a representation of the structure of a flower by symbols, letters and numbers) was used in different ways as a didactic resource with students doing the Degree of Teaching in Early Childhood Education (DTECE), during five academic courses (2012-2017). The main goals were: 
- to use floral diagrams with real pieces and its formula to teach the flower concept;

- to review changes in ideas by using real flowers;

- to study how degree students learned such biological terms in previous educational stages, and how they valued their learning through the use of this resource.

First, the floral diagram with real pieces and its formula was used to teach the flower concept (total students $=444$ ) in the course 'The Science of Nature in Early Childhood Education'. For many plant families and genera, students annotated a simplified formula, in which they gave the number for each floral whorl from the periphery to the centre of the flower; e.g., $5 \mathrm{~S}+5 \mathrm{P}+$ many $\mathrm{E}+$ many $\mathrm{C}(\mathrm{S}=$ sepals, $\mathrm{P}=$ petals, $\mathrm{E}=$ stamens, $\mathrm{C}=$ carpels) (Prenner, Bateman $\&$ Rudall, 2010). The learning evaluation was done through the correction of individual work (with grades in the range from 0 to 10) during the courses 2012-16. Additionally, to review the ideas change produced by the use of the floral diagram, in the 2016-2017 academic year, pre- and post-tests were carried out with 73 students DTECE students. For the application and assessment of the resource, the next steps were followed:

i) Detection of previous ideas. It is necessary to detect what ideas students have about the contents that will be taught and make them explicit. To this end, a new questionnaire was designed, where, in addition to including questions from the previous course, it presented a drawing where the parts of the flower should be pointed out and named (Appendix 1). The students completed the questionnaire before implementing the floral diagram in the laboratory.

ii) Application of floral diagram and formula. The students were asked to bring a couple of flowers of angiosperm plants to the laboratory per person for their study (one of them, for replacement of floral pieces, in case of breakage in the manipulation), that had the typical floral elements, thus avoiding other types of flowers that do not fit the model to work in class (inflorescences, incomplete flowers, gymnosperms, etc.), separating their components and distributing them according to the diagram of floral diagram shown in class by their teacher. Once finished, they had to count the different pieces and write their floral formula. Afterwards, to finish the activity they had to compare their diagram with those of the rest of their classmates, to express their doubts and conclusions to the whole class, as a scientific discussion. All these data were recorded in class by the teachers. The diagram and the formula had to be photographed, incorporating the image into their portfolio of practices. 
iii) Evaluation of ideas change. In this process, the students' previous ideas about their initial flower model are compared with their mental model constructed after the work with the diagram and floral formula, verified through the filling in of a questionnaire the same as the previous one (Appendix 1), but containing only the last two questions: "Do you think that the construction of a floral diagram, together with its formula, can be a good method for your future students to learn the flower parts?", and "Write the name of each floral part and, on the right, the letter of the corresponding drawing."

Two more innovations were introduced in 2015-16 and 2016-17. During these academic years, 144 of these DTECE students were asked, through a small survey about how they learned such biological terms in previous educational stages, and how they valued their learning through the use of this resource. These questions were: "How did you learn the flower elements in your pre-university education?"; "How do you think your future students would learn the flower parts better?"; and "Do you think that the construction of a floral diagram, together with its formula, can be a good method for your future students to learn the flower parts?" (Appendix 1). This questionnaire was also handed out in 2015-16, to 57 students in the third year of the Degree of Teaching in Primary Education (DTPE).

\section{Results}

A small number of students (not quantified) brought a type of flower that did not fulfil the specified requirements (described in section 2). It also allowed their classmates to know about other types of floral structures. $94 \%$ of the students stated that they had never used a real flower to learn about its components and functions before. They always studied them with the help of drawings, photographs and texts (80\% DTECE and 92\% DTPE) and agreed to use the diagram and floral formula, when they are teachers. Students pointed out the manipulation as one of the most positive didactic aspects of this resource. A word cloud built on the answers to question "How do you think your future students would learn the flower parts better?" (Figure 1; Question 3, Appendix 1). It is considered that a word cloud is the best representation option when there are many different answers. With other kinds of representation (bars for example), it would not be possible to represent the totality of answers, and it would be necessary to limit or categorize the answers given by the students. DTECE students rated the floral formula negatively because it was complex for the children of that stage, in DTPE students considered it positive by encouraging the counting and relationship between the components of the flower. 
A)

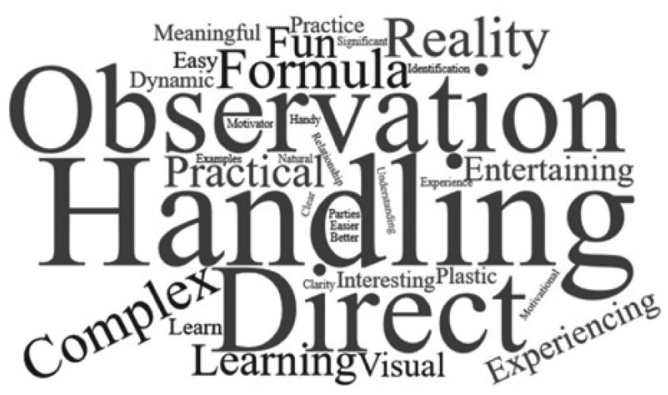

B)

Figure 1 Word cloud with terms used by students on teaching degrees in questionnaires. (A) Early Childhood

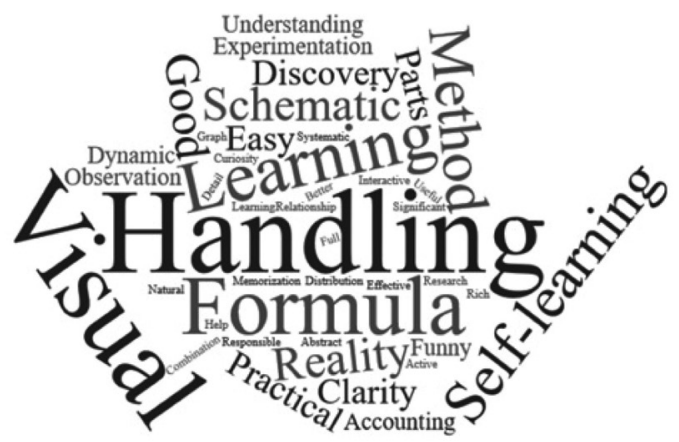
Education; (B) Primary Education.

The mean percentage of success (rate of the denomination and location with respect to the total number of floral elements in the drawing and table of question 4 in the questionnaires), obtained by the students in the previous questionnaire was $36 \%(s d=23, n=73$; Figure 2). However, in the final questionnaire, the success is notably greater, with a mean percentage of $72 \%(s d=23, n=70)$. When comparing individually the percentages obtained in the two questionnaires $(n=70)$, it is observed that $17 \%$ of the students had the same result $(100 \%$ success) in the two questionnaires, and only one obtained less success in the final.

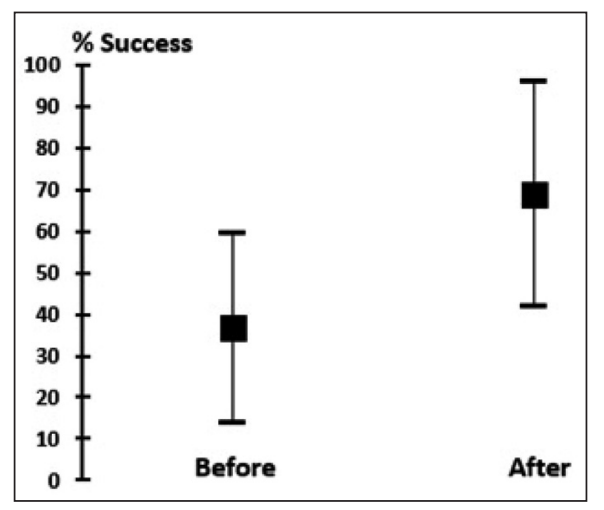

Figure 2 Success rate of the denomination and location with respect to the total number of floral elements in the drawing and table of question 4 in the questionnaires (before and after of diagram implementation; Appendix 1). It shows the mean values \pm the standard deviation. 
When evaluating the diagram and floral formula in students' portfolios, we observed that $97 \%$ of these correctly identified the parts of the plant organ (Figure 3). The average grade obtained by students in the work presented through the portfolio of practices was 9.51 (d.t. $=1.52 ; \mathrm{n}=321$ ). The only errors found were: incorrect location of floral pieces $(2 \%)$, and to obviate some of them, or incorrect writing of the floral formula (1\%).
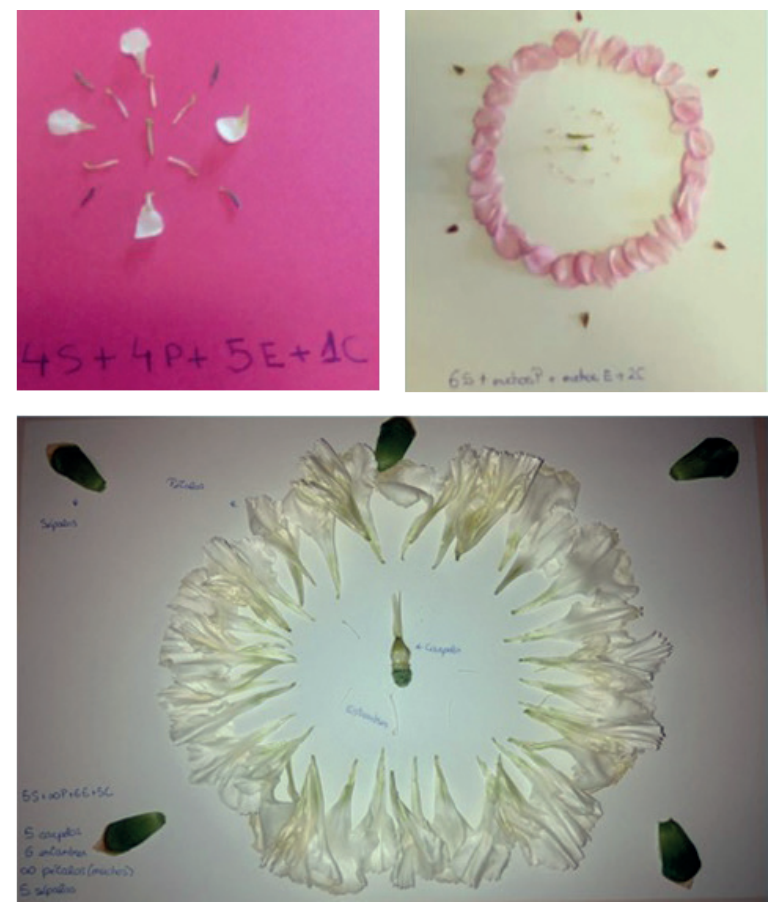

Figure 3 Examples of diagrams and floral formulas made by students.

\section{Discussion}

Results obtained show the floral diagram as a valid resource for learning the floral structure, as suggested by Ronse (2010). On the one hand, it allows for learning through the manipulation of natural objects, a recommended action for learning in Childhood Education, where the teachers in training must apply it, a matter indicated by most of the students surveyed. On the other hand, the diagram supposes a graphic representation that facilitates the construction of the mental model of a flower, very close to natural reality. The number of questionnaires completed was greater than the number of floral diagrams presented in the portfolio, due to some students who did not present their work. If one does a search on the internet about images related to the flower concept 
in Early Childhood Education, it is surprising to see that, in most cases, an inflorescence is used in the form of a chapter, which characterizes the family Compositae, as a model or example of a flower. It is evident, therefore, that the treatment of the concept at this stage is not the most appropriate for the correct learning of the same by the students of this educational level. It is also common to observe how the plant organism's name is mistakenly used instead of the word 'flower', or vice versa, to use of the term 'plant' to refer to a flower represented in an image. The conversation about these errors arose in the discussion carried out in the laboratory after finishing the construction of the floral diagrams. In this way, the training teachers will be able to avoid these errors when they carry out their teaching work.

This experience has helped students to identify properly and more intuitively the parts of the flower. Students also learn to detect differences in the characteristics of the flowers depending on the species (shape, number), differences of real flowers with respect to usual graphic representations. As seen in many studies of didactics of experimental sciences, learning through practical research experiences is more motivating than doing it through the traditional master classes. Nevertheless, despite efforts made in recent years by European institutions (Osborne \& Dillon, 2008; Rocard, 2007; Ryan, 2015), the teaching of science in schools does not seem to have been noticeably improved in recent years. Ryan (2015) suggests that better ways of nurturing the curiosity and cognitive resources of children should be found. For that proposal, the educational process must be improved by better training of future researchers and other actors, with the necessary knowledge, motivation and sense of responsibility of society to participate actively in innovation processes. That is the reason why we decided to perform our study. Our results reveal it as well in a specific field (students of science subjects in teaching degrees) with a broad sample of study.

When our students observed the floral diagrams of their classmates in the laboratory, they were surprised at seeing very different pieces among different vegetal species. Also, when checking the absence of some of them in some taxa, the existence of other types of structures (tepals, etc.) and that, therefore, they do not resemble the models which are shown in the images of educational books, which helps to build the concept of diversity. The use of the floral diagram as a model is recommended at any educational stage, because, as seen, it facilitates the understanding of different floral models among classmates (Justi, 2006). It also stimulates the negotiation of ideas among students, creating the necessary conditions for interesting ideas to develop (Halloun, 2004), and it encourages situations in which students can test their models, promoting the development of students' ideas about their models in other contexts - or simply making the problem in question evident to those students who have not yet perceived it (Vosniadou, 1999). It encourages interest in the use of these tools in 
their future work as teachers, giving value to biological diversity and to the use of practical activities. If students learn only to memorize and reproduce knowledge, they run the risk of being educated only for jobs that require those skills, which are currently on the way to disappearing (Bybee, 2010). Initiatives are needed to engage the interest of primary school children and to provide more opportunities for fieldwork at secondary level, including time to teach students to recognise organisms (Bebbington, 2005).

\section{Acknowledgments}

This study was supported by Project PIIDUZ_17_146 (Universidad de Zaragoza) and Project EDU2016-76743-P (MINECO). A. Ponz is member of Group for Applied Research "Beagle" (IUCA, Universidad de Zaragoza) financed by the Department of Science, Technology and University of the Government of Aragon and the European Social Fund.

\section{References}

Almagro, M. (1992). Tenemos caracoles. Aula de Innovación Educativa, 4, 60-62.

Acher, A., Arcá, M. y Sanmartí, N. (2007). Modeling as a teaching learning process for understanding materials: a case study in primary education. Science Education, 91, 398-418. DOI: 10.1002/sce.20196

Aduriz-Bravo, A. \& Izquierdo-Aymerich, M. (2009). Un modelo científico para la enseñanza de las ciencias naturales. Revista Electrónica de Investigación en Educación en Ciencias, 4(3), 40-49.

Bebbington, A. (2005). The ability of A-level students to name plants. Journal of Biological Education, 39:2, 63-67. DOI: 10.1080/00219266.2005.9655963

Brown, S E. (2004). Bubbles, Rainbows \& Worms: Science Experiments For Preschool Children. Revised Edition. Lewisville: Gryphon House.

Bybee R. W. (2010). The Teaching of Science: 21st Century Perspectives. Arlington, VA: NSTA Press.

Cabello, M. J. (2011). Ciencia en educación infantil: La importancia de un "rincón de observación y experimentación" o "de los experimentos" en nuestras aulas. Pedagogía Magna, 10, 58-63.

Chamizo, J. A. (2003). A new definition of models and modeling in chemistry's teaching. Science \& Education, 22(10), 1613-1632.

Doménech, J. \& Viñas, J. (1997). La organización del espacio y del tiempo en el centro educativo. Barcelona: Grao.

García, M. P. (2005). Los modelos como organizadores del currículo en biología. Enseñanza de las Ciencias, núm. extra, 1-6.

Gassó, A. (2005). La educación infantil. Métodos, técnicas y organización. Barcelona: Ed. CEAC. 
Gatt, S., Tunnicliffe, S., Borg, K. \& Lautier, K. (2007). Young Maltese Children's Ideas About Plants. Journal of Biological Education, 41 (3), 117-121.

Halloun, I. A. (2004). Modeling Theory in Science Education. Dordrecht: Kluwer.

Hoban, G. (1997). Learning about learning in the context of a science methods course. In J. Loughran and T. Russell (Eds.), Teaching about teaching: Purpose, passion and pedagogy in teacher education (pp. 133-149). London: Falmer Press.

Justi, R. (2006). La enseñanza de ciencias basada en la elaboración de modelos. Enseñanza de las Ciencias, 24 (2), 173-184.

Katz, P. (2017). Drawing for Science Education. An International Perspective. Rotterdam: Sense Publishers.

Margett, T. E. \& Witherington, D. C. (2011). The Nature of Preschoolers' Concept of Living and Artificial Objects. Child Development, 82 (6), 2067-2082.

Osborne, J. \& Dillon, J. (2008). Science education in Europe: Critical reflections (a report to the Nuffield Foundation). London: The Nuffield Foundation, In: https://www. nuffieldfoundation.org/sites/default/files/Sci_Ed_in_Europe_Report_Final.pdf

Rocard, M. (2007). Science Education Now: A Renewed Pedagogy for the Future of Europe. European Commission. In: http://ec.europa.eu/research/science-society/document_library/pdf_06/report-rocardon-science-education_en.pdf

Ronse, L. P. (2010). Floral diagrams: An Aid to Understanding Flower Morphology and Evolution. New York: Cambridge University Press.

Ryan, C. (2015). Science Education for Responsible Citizenship. European Commission. In: http://ec.europa.eu/research/swafs/pdf/pub_science_education/KI-NA-26893-EN-N.pdf

Tunnicliffe, S.D. \& Reiss, M.J. (2000). Building a model of the environment: how do children see plants? Journal of Biological Education, 34 (4), 172-177. DOI: 10.1080/00219266.2000.9655714

Van Aalderen-Smeets, S. I., Walma Van Der Molen, J.H. \& Asma, L. J. F. (2012). Primary Teachers' Attitudes Toward Science: A New Theoretical Framework. Science Education, 96 (1), 158-182.

Villarroel, J. D. (2013). Environmental judgment in early childhood and its relationship with the understanding of the concept of living beings. Springer Plus, 2(1), 1-13.

Villarroel, J.D. (2015). Young Children's Drawings of Plant Life: A Study Concerning the Use of Colours and Its Relationship with Age. Journal of Biological Education. DOI: 10.1080/00219266.2014.1002519

Villarroel, J.D. \& Infante, G. (2014). Early understanding of the concept of living things: An examination of young children's drawings of plant life. Journal of Biological Education, 48(3), 119-126.

Vosniadou, S. (1999). Mental Models in Conceptual Development. In Magnani, L., Nersessian, N.J. \& Thagard, P. (Eds.). Model-based Reasoning in Scientific Discovery (pp.353-368. Nueva York: Kluwer and Plenum Publishers 
Appendix 1 Example of questionnaire carried out by training teachers before of the floral diagram implementation

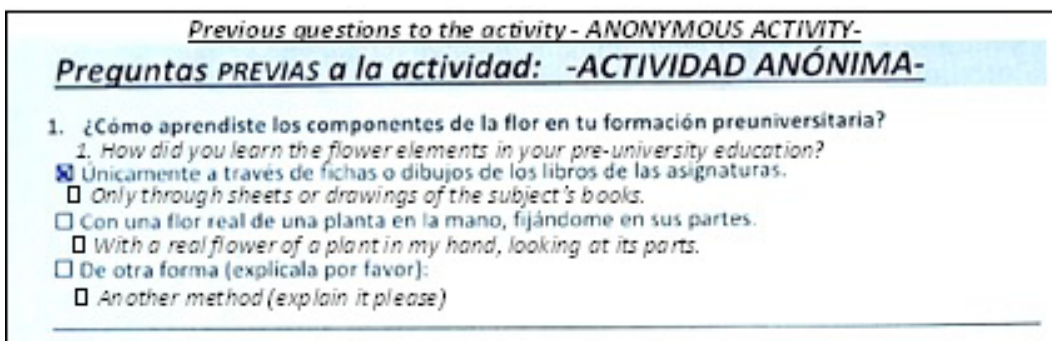

2. ¿Como piensas que aprenderian mejor tus futuros/as alumnos/as las partes de una flor? 2. How do you think your future studen ts would leorn the fower ports better?

口 Unicamente a traves de fichas o dibujos de los libros de las asignaturas

Q Only through sheets ordrawings of the subject's books.

$\otimes$ Con una flor real de una planta en la mano, fijändome en sus partes.

$\square$ with a real flower of a plant in my hand, looling ot its ports.

$\square$ De otra forma (explicala por iavor):

$\square$ Another method (exploin it pleose)

3. ¿Piensas que la construcción de un diagrama floral, junto con su fórmula, puede ser un buen método para que tus futuros/as alumnos/as aprendan las partes de una flor?
通
$\square$ Yes
3. Do you think that the construction of a floral diagram, together with its formula, ¿Por quê? Why?
Es una buen metodo para qe apaedan los avmos las partes de wa yer, por la fórmila cree que es vaeceisana
it is a goodmethod for students to leom the flower ports, but the formula i think is unnecessory

4. Escribe el nombre de cada pieza floral y, a la derecha, la letra del dibujo que le corresponde. 4. Write the nome of eoch floral port and, on the right, the letter of the comesponding drowing.

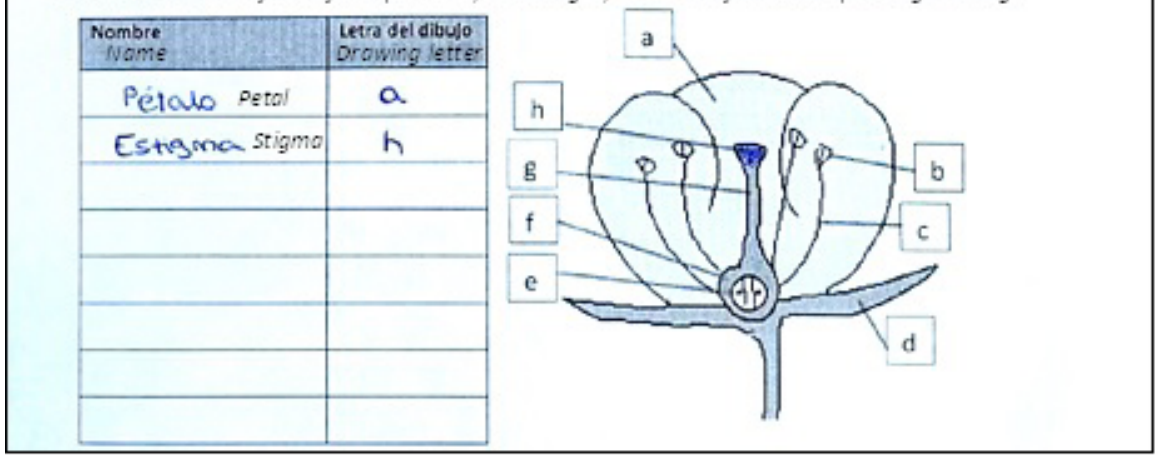





\title{
REPRESENTATIONS OF GENE MODELS IN GREEK SECONDARY SCHOOL BIOLOGY TEXTBOOKS
}

\author{
Akrivi Christidou and Pinelopi Papadopoulou \\ University of Western Macedonia (Greece) \\ achristidou@uowm.gr
}

\begin{abstract}
Textbooks play a crucial role in teaching biology as the quality of didactic transformation and the scientific accuracy of the content determines their pedagogical effectiveness when implemented. There is a development of a methodology using epistemological features for the categorization of the representations of the gene and its functions in biology textbooks, into five historical models: Mendelian model, Classical model, Biochemical model, Neoclassical model and Modern model. The purpose of this study is to explore which gene models are represented in the biology textbooks being used in secondary education in Greece, for 12 to 18-year-old students, that is the basis for understanding more complex genetic concepts at university. Using content analysis, we found that in Greek biology textbooks the epistemological characteristics of the Biochemical model dominates, while those of the Modern model are limited. The content orientation seems to affect the presence of the epistemological characteristics of the historical gene models. However, the textbooks include all historical gene models in parallel so this conceptual diversity in describing the gene function results in lack of conceptual coherence and can be a potential source of alternative or deterministic conceptions for students.
\end{abstract}

Keywords: textbooks, biology, secondary school, historical gene models, gene function.

\section{Introduction}

Textbooks are important teaching aids for biology education and mainly the only printed source of information available for students and teachers (Santos et al., 2012). Provided that the textbooks implement the curriculum or even sometimes determine it, they usually transform and pass the scientific 
knowledge to the students (Gericke et al., 2014). It has been estimated that $40 \%$ of teaching time is used by teachers teaching from textbooks (Liu, 2015). Therefore, textbooks can strongly influence students' learning and understanding and can be a potential source of alternative conceptions.

A number of international studies have dealt with how genetics are presented in biology, geology, and chemistry textbooks of upper education or even in research articles, and how this can affect the learning process. It has been shown that in some cases there is absence of conceptual linking of complex genetic terms with simple concepts of basic genetics (Martínez-Gracia et al., 2003, 2006). The relative position of particular genetic concepts differs in biology textbooks (Wernick et al., 2014). Furthermore, information on modern genetic issues is inadequate and genetic counseling is missing from university textbooks (Kim \& Han, 2010). It has been recorded that the use of the gene concept attributes to the gene different functions that are mixed in textbooks, confusing students' conceptions, but this also occurs in research articles (Flodin, 2009, 2017). Moreover, the classical molecular concept of the gene is still often used, although new discoveries question it (Albuquerque et al., 2008).

Besides the general research on genetics mentioned above, there is other research exploring the gene concept and its functions, presented in textbooks by developing analysis tools and grouping the gene concepts into five historical gene models. These models are: the Mendelian model, the Classical model, the Biochemical model, the Neoclassical model and the Modern model, depending on how scientists understood the gene concept at different historical periods of biology development (Albuquerque et al., 2008; Gericke \& Hagberg, 2007). The gene concept has evolved and has been described as: 1) a trait with physical place (locus), in the Mendelian model and used in Mendelian genetics; 2) a nucleotide sequence that provides instructions, is expressed and regulated in the Classical model, and used in molecular biology; 3) a factor or DNA that interacts, moves or duplicates in the Biochemical model and encountered in genomics; 4) a regulator, thus DNA controls, directs and defines patterns in the Neoclassical model and used in developmental biology; 5) a marker that can be fixed or added, in the Modern model and is encountered in population genetics (Aivelo \& Uitto 2015; Gericke \& Hagberg 2010a). Briefly, the gene was considered as a hypothetical construct in the beginning, then it acquired a more active role and finally recently it exists in frequencies. The genotype gradually separated from phenotype, and the environmental factors were progressively taken into account. Analysis by the use of historical gene models was implemented by researchers in secondary and university science textbooks from different countries, to identify the types of gene models used as well as the way they can affect students' learning (Aivelo \& Uitto 2015; Gericke \& Hagberg 2010a \& b; Santos et al., 2012). 
In Greece, the educational research on biology textbooks is limited to environmental-related fields (Lemoni et al., 2013), and there is no previous approach to genetics similar to ours. The present study focuses not only on compulsory education, hence education for all citizens, but also on higher school grades aiming to meet university entry requirements. The aim of this study is to examine how the first representations of gene concept are formed in biology textbooks. These representations are fundamental for understanding the more complex genetic concepts presented later at university and for coping with crucial genetic or biotechnological issues of society and personal life. Thus, it will be possible to understand and predict the alternative concepts formed by students as well as the difficulties they face in learning. The results are expected to provide guidance for remodeling genetics in Greek secondary school biology textbooks. The research questions guiding our study are:

a) Which of the epistemological features of historical gene models are found in biology textbooks used in Greek secondary schools?

b) What is the frequency of these epistemological features?

c) Do any of the historical models dominate?

\section{Methodology}

In this study, the material of content analysis includes all six unique and compulsory biology textbooks of Greek secondary education, though one more textbook from primary school was added, in which there are mentions of gene concepts and this will be referred to as T1. The rest of the biology textbooks from junior high school to high school successively, will be referred to as T2 to T6. In the last grade of high school, there are two biology courses that are taught. In particular, there is one general biology course, the textbook of which is mentioned as T6, and another biology course which prepares students for their entry to the university in departments of Life Sciences, and its textbook will be referred to as T7. The analysis of Textbook 3 was conducted previously (Christidou \& Papadopoulou, 2017a \& b) and afterwards the same methodology was applied to the rest of the biology textbooks. Firstly, the whole texts of the books were broken down into units of analysis where there was either implicit or explicit mention of the gene concept. The unit of analysis was a continuous, coherent daily lesson, 2-4 pages. All chapters were examined including those placed at the end of the textbooks and are optional according to the curriculum: Chronology of Biology and the Vocabulary of Terms. Figures were not analyzed. The number of the units of analysis for each textbook separately and in total, is presented in Table 1 . T7 has the greatest number of units of analysis. 
TABLE 1

THE NUMBER OF THE UNITS OF ANALYSIS A

ND THE NUMBER OF THE EPISTEMOLOGICAL

FEATURES IN GREEK BIOLOGY TEXTBOOKS

\begin{tabular}{lcc}
\hline Textbooks & Units of analysis & Number of epistemological features \\
\hline $6^{\text {th }}$ Grade Of Primary School (T1) & 1 & 10 \\
$1^{\text {st }}$ Grade Of Junior High School (T2) & 5 & 25 \\
$2^{\text {nd }} 3^{\text {rd }}$ Grades Of Junior High School (T3) & 13 & 147 \\
$1^{\text {st }}$ Grade Of High School (T4) & 11 & 52 \\
$2^{\text {nd }}$ Grade Of High School (T5) & 11 & 104 \\
$3^{\text {rd }}$ Grade Of High School-general (T6) & 9 & 73 \\
$3^{\text {rd }}$ Grade Of High School-orientation (T7) & 33 & 455 \\
\hline Total & 83 & 866 \\
\hline
\end{tabular}

We used the historical gene model's classification and its epistemological features developed by Gericke \& Hagberg (2007, 2010a \& b), with some additions of epistemological feature-variants from Santos et al., (2012). Also, three feature-variants emerged from our analysis and they are presented in Table 2 (in italics). We excluded the epistemological feature-variant number 5 , the idealistic versus naturalistic relationships in the models, which concerns figure analysis. Each epistemological feature corresponds to one or more historical models (Gericke \& Hagberg 2010a \& b; Santos et al., 2012), although there are some unclassified features called non-historical, as shown in Table 3. Thereafter, the feature-variants were ascribed to certain sentences or paragraphs from the texts, and the number of the epistemological featurevariants was calculated for each textbook and it is presented in Table 1. Therefore, methodological limitations arise in the calculation of the occurrence of historical models. This means that either the epistemological features corresponding to more models should have been excluded and some analysis units should have been removed, or we should have attributed each epistemological feature to only one model based on an arbitrary criterion, or attributed it equally to all the matching models, forming non-mutually excluded categories, by creating virtually multiple units of analysis. We chose the third case. For the reliability of the results, content analysis was carried out independently by two researchers, and in case of disagreement they discussed it until they reached an agreement.

Finally, to determine the extent of hybridization within the textbooks, we defined the frequency of the unclassified non-historical feature-variants, and those epistemological features not belonging to the prevalent historical model of every textbook. 
TABLE 2

DESCRIPTION OF THE EPISTEMOLOGICAL FEATURE-VARIANTS

USED (ADAPTED FROM GERICKE \& HAGBERG 2010B; SANTOS ET AL., 2012)

AND THEIR FREQUENCY FOUND IN GREEK BIOLOGY TEXTBOOKS. ('THE VARIANTS EMERGED FROM OUR ANALYSIS ARE SHOWN IN ITALICS)

Feature-variants

Frequency

(\%)

The relationship between the structure and function of the gene.

1a The gene is an abstract entity and has no structure. $3 \%$

$1 \mathrm{~b}$ The gene is a particle on the chromosome. $30 \%$

1c The gene is a DNA segment. $30 \%$

Icx The gene and its functions are related to DNA. * $6 \%$

1d The gene consists of one or several DNA segments with various purposes. $\quad 1 \%$

le The gene is a carrier, bearer and/or unit of information. $28 \%$

If The gene is present in frequencies. * $2 \%$

The relationship between organizational level and definition of gene function.

2Ia The model has entities at the macro- and symbolic levels. 2\%

2Ib The model has entities at the macro- and cell levels. 24\%

2Ibx The model has entities at the macro-, cell- and molecular levels. $\quad 43 \%$

2Ic The model has entities at the molecular level. 3\%

2Icx The model has entities at the cell- and molecular levels. $17 \%$

2Icy The model has entities at the phenotypic and molecular levels. $12 \%$

2IIa The correspondence between the gene and its function is one-to-one. 93\%

2IIb The correspondence between the gene and its function is many-to-many.

\begin{tabular}{|c|c|c|}
\hline \multicolumn{3}{|c|}{ The "real" approach to defining the function of the gene. } \\
\hline $3 a$ & The function of the gene is defined top-down. & $43 \%$ \\
\hline $3 b$ & The function of the gene is defined bottom-up. & $55 \%$ \\
\hline $3 c$ & The function of the gene is defined by a process. & $3 \%$ \\
\hline \multicolumn{3}{|c|}{ The relationship between genotype and phenotype. } \\
\hline $4 \mathrm{a}$ & There is no separation between genotype and phenotype. & $3 \%$ \\
\hline $4 \mathrm{~b}$ & There is a separation, without explanation, between genotype and phenotype. & $47 \%$ \\
\hline $4 \mathrm{c}$ & $\begin{array}{l}\text { There is a separation between genotype and phenotype, with an enzyme as the } \\
\text { intermediary. }\end{array}$ & $19 \%$ \\
\hline $4 \mathrm{~d}$ & $\begin{array}{l}\text { There is a separation between genotype and phenotype with a biochemical process } \\
\text { explanation. }\end{array}$ & $15 \%$ \\
\hline $4 e$ & There is a distinction between genotype and phenotype, with chromosomal explanation. * & $15 \%$ \\
\hline \multicolumn{3}{|c|}{ The explanatory reduction problem. } \\
\hline $6 \mathrm{a}$ & There is explanatory reduction from the macro level to the symbolic level. & $0 \%$ \\
\hline $6 b$ & There is explanatory reduction from the macro level to the cell level. & $28 \%$ \\
\hline
\end{tabular}




\begin{tabular}{|c|c|c|}
\hline $6 b x$ & There is explanatory reduction from the macro to the molecular level. & $24 \%$ \\
\hline $6 c$ & There is no explanatory reduction. & $47 \%$ \\
\hline \multicolumn{3}{|c|}{ The relationship between genetic and environmental factors. } \\
\hline $7 \mathrm{a}$ & Environmental entities are not considered. & $65 \%$ \\
\hline $7 \mathrm{ax}$ & Environmental- and genetic entities result in a trait/product/function. & $24 \%$ \\
\hline $7 \mathrm{~b}$ & Environmental entities are implied by the developmental system. & $2 \%$ \\
\hline $7 \mathrm{c}$ & Environmental entities are shown as part of a process. & $9 \%$ \\
\hline
\end{tabular}

TABLE 3

THE HISTORICAL MODEL-CATEGORIES OF GENE FUNCTION AS DESCRIBED BY THE EPISTEMOLOGICAL FEATURE-VARIANTS (ADAPTED FROM GERICKE \& HAGBERG 2010B, SANTOS ET AL., 2012)

\begin{tabular}{|c|c|c|c|c|c|c|c|}
\hline \multirow{2}{*}{ Historical model-category } & \multicolumn{7}{|c|}{ Epistemological feature-variants } \\
\hline & 1 & $2 I$ & $2 I I$ & 3 & 4 & 6 & 7 \\
\hline Mendelian model & $1 \mathrm{a}$ & 2Ia & 2IIa & $3 \mathrm{a}$ & $4 a$ & $6 a$ & $7 \mathrm{a}$ \\
\hline Classical model & $1 \mathrm{~b}$ & $2 \mathrm{Ib}$ & $2 \mathrm{IIb}$ & $3 a$ & $\begin{array}{c}4 \mathrm{~b} \& \\
4 e\end{array}$ & $6 \mathrm{~b}$ & $7 \mathrm{a}$ \\
\hline Biochemical model & $1 \mathrm{~b}$ & $2 \mathrm{Ib}$ & $\begin{array}{c}\text { 2IIa \& } \\
\text { 2IIb }\end{array}$ & $\begin{array}{c}3 \mathrm{a} \& \\
3 \mathrm{~b}\end{array}$ & $4 \mathrm{c}$ & $6 b$ & $7 \mathrm{a}$ \\
\hline Neoclassical model & $\begin{array}{c}1 \mathrm{c}, 1 c x \\
\& 1 \mathrm{e}\end{array}$ & $2 \mathrm{Ic}$ & 2IIa & $3 b$ & $4 \mathrm{~d}$ & $6 c$ & $7 \mathrm{~b}$ \\
\hline Modern model & $1 \mathrm{~d} \& 1 f$ & 2Ic & 2IIa & $3 c$ & $4 \mathrm{~d}$ & $6 c$ & $7 \mathrm{c}$ \\
\hline Non-historical features & & $\begin{array}{l}\text { 2Ibx, } \\
\text { 2Icx \& } \\
\text { 2Icy }\end{array}$ & & & & 6bx & $7 \mathrm{ax}$ \\
\hline
\end{tabular}

\section{Results}

The analysis of the seven Greek biology textbooks showed that direct or indirect reference to gene concept is found in some chapters. In Table 4, the chapters marked with the green colour indicate where the gene concept is present. Light green colour indicates the implicit mentions, while dark green colour indicates the explicit mentions. In the last grade of high school, almost in all chapters of textbooks T6 and T7, there are references to gene concepts.

The percentage of the occurrence of historical gene models comes from the proportion of the epistemological features recorded in each biology textbook after having been ascribed to the models that they describe. The data in Figure 1 shows that the Classical model dominates in T1 from the $6^{\text {th }}$ grade of primary school. T1 includes a chapter for reproduction that deals with the genetic factor inherited from parents by children. The Mendelian model prevails in the textbook of the $1^{\text {st }}$ grade of junior high school, namely $\mathrm{T} 2$, which focuses on 
human biology, specifically the functions of the human organism. Moving forward to the higher grades, the most prevalent model is the Biochemical model in textbooks T3, T4, T5 and T7. Specifically, it is in T3 that we encounter separate topics regarding genetics, biotechnology and evolution, for the first time. However, in the $1^{\text {st }}$ grade of high school, T4 includes again human physiology issues, like in T2, but in more detail, using more complex terminology. We observe how the way of presenting the human physiology in two different textbooks (T2, T4), thus school grades, changes from the Mendelian model (T2) to the Biochemical model (T4). In the grade between, students are exposed to the gene concept and its functions presented in T3, where the Biochemical model is more common. T7, the textbook that particularly deals with genetics and biotechnology preparing students for university, presents the gene function mostly through the epistemological characteristics of the Biochemical model. In all the above cases, the epistemological characteristics of the Modern model are the most limited. Moreover, in the general biology textbook of the last grade of high school, T6, of which the one third of its material concerns evolution topics, the Neoclassical model is more prevalent and the Modern model has its highest percentage.

TABLE 4

THE STRUCTURE AND THE CONTENT OF THE GREEK BIOLOGY TEXTBOOKS. IMPLICIT MENTIONS OF THE GENE CONCEPT ARE FOUND IN CHAPTERS MARKED IN LIGHT GREEN COLOUR, WHILE THE EXPLICIT MENTIONS ARE MARKED IN DARK GREEN COLOUR

\begin{tabular}{|c|c|c|c|c|c|c|c|c|c|c|c|c|c|c|c|}
\hline \multirow{2}{*}{$\begin{array}{l}\text { Cirades } \\
6^{\text {th }} \text { grade } \\
\text { of } \\
\text { primary } \\
\text { school }\end{array}$} & \multirow{2}{*}{$\begin{array}{l}\text { Texibeo } \\
\text { ks } \\
\text { T1 }\end{array}$} & \multicolumn{14}{|l|}{ Chapters } \\
\hline & & Energy & $\begin{array}{l}\text { Tempera } \\
\text { ture- } \\
\text { heat }\end{array}$ & $\begin{array}{l}\text { Living- } \\
\text { non } \\
\text { living }\end{array}$ & Plants & Animals & $\begin{array}{l}\text { Eoosyst } \\
\text { ems }\end{array}$ & $\begin{array}{l}\text { Respirat } \\
\text { ory } \\
\text { system }\end{array}$ & $\begin{array}{l}\text { Circulat } \\
\text { ory } \\
\text { system }\end{array}$ & $\begin{array}{l}\text { Electro } \\
\text { magneti } \\
\text { sm }\end{array}$ & Light & $\begin{array}{l}\text { Acids- } \\
\text { bases- } \\
\text { salts }\end{array}$ & $\begin{array}{l}\text { Infectio } \\
\text { us } \\
\text { diseases }\end{array}$ & $\begin{array}{l}\text { Reprodu } \\
\text { ctive } \\
\text { system }\end{array}$ & \\
\hline $\begin{array}{l}\text { 1" grade } \\
\text { of junior } \\
\text { high } \\
\text { school }\end{array}$ & $\mathbf{T 2}$ & $\begin{array}{l}\text { The } \\
\text { organiza } \\
\text { tion of } \\
\text { life }\end{array}$ & $\begin{array}{l}\text { Recruit } \\
\text { ment of } \\
\text { substane } \\
\text { es }\end{array}$ & $\begin{array}{l}\text { Transfer } \\
\text { and } \\
\text { disposal } \\
\text { of } \\
\text { substanc } \\
\text { es }\end{array}$ & $\begin{array}{l}\text { Respirat } \\
\text { ion }\end{array}$ & $\begin{array}{l}\text { Support } \\
\text { and } \\
\text { moveme } \\
\mathrm{nt}\end{array}$ & $\begin{array}{l}\text { Reprodu } \\
\text { ction }\end{array}$ & $\begin{array}{l}\text { Inceptio } \\
\text { n }\end{array}$ & $\begin{array}{l}\text { Chronol } \\
\text { ogy of } \\
\text { biology }\end{array}$ & $\begin{array}{l}\text { Vocabul } \\
\text { ary of } \\
\text { terms }\end{array}$ & & & & & \\
\hline $\begin{array}{l}2^{\text {ud }}-3^{\text {rd }} \\
\text { grades of } \\
\text { junior } \\
\text { high } \\
\text { school }\end{array}$ & T3 & $\begin{array}{l}\text { The } \\
\text { organiza } \\
\text { tion of } \\
\text { life }\end{array}$ & $\begin{array}{l}\text { Organis } \\
\text { ms in } \\
\text { their } \\
\text { environ } \\
\text { ment }\end{array}$ & $\begin{array}{l}\text { Metabol } \\
\text { ism }\end{array}$ & Discases & $\begin{array}{l}\text { Conserv } \\
\text { ation } \\
\text { and } \\
\text { continui } \\
\text { ty of life }\end{array}$ & $\begin{array}{l}\text { Genetic } \\
\text { engineer } \\
\text { ing and } \\
\text { biotechn } \\
\text { ology }\end{array}$ & $\begin{array}{l}\text { Evolutio } \\
\text { n }\end{array}$ & $\begin{array}{l}\text { Chronol } \\
\text { ogy of } \\
\text { biology }\end{array}$ & $\begin{array}{l}\text { Vocabul } \\
\text { ary of } \\
\text { terms }\end{array}$ & & & & & \\
\hline $\begin{array}{l}\text { It grade } \\
\text { of high } \\
\text { school }\end{array}$ & T4 & $\begin{array}{l}\text { From } \\
\text { cell to } \\
\text { organiza } \\
\text { tion }\end{array}$ & $\begin{array}{l}\text { Digestiv } \\
\text { e system }\end{array}$ & $\begin{array}{l}\text { Circulat } \\
\text { ory } \\
\text { system }\end{array}$ & $\begin{array}{l}\text { Lympho } \\
\text { id } \\
\text { system }\end{array}$ & $\begin{array}{l}\text { Respirat } \\
\text { ion }\end{array}$ & $\begin{array}{l}\text { Excretio } \\
\mathrm{n} \text { and } \\
\text { osmoreg } \\
\text { ulation }\end{array}$ & Skeleton & $\begin{array}{l}\text { Muscle } \\
\text { system }\end{array}$ & $\begin{array}{l}\text { Nervous } \\
\text { system }\end{array}$ & $\begin{array}{l}\text { Sensor } \\
\text { organs- } \\
\text { senses }\end{array}$ & $\begin{array}{l}\text { Endocri } \\
\text { ne } \\
\text { glands }\end{array}$ & $\begin{array}{l}\text { Reprodu } \\
\text { ction- } \\
\text { develop } \\
\text { ment }\end{array}$ & $\begin{array}{l}\text { Vocabul } \\
\text { ary }\end{array}$ & \\
\hline $\begin{array}{l}2^{\text {od }} \text { grade } \\
\text { of high } \\
\text { school }\end{array}$ & T5 & $\begin{array}{l}\text { Chemic } \\
\text { al } \\
\text { composi } \\
\text { tion of } \\
\text { eell }\end{array}$ & $\begin{array}{l}\text { Cell: the } \\
\text { fundame } \\
\text { ntal unit } \\
\text { of life }\end{array}$ & $\begin{array}{l}\text { Metabol } \\
\text { ism }\end{array}$ & Genetics & $\begin{array}{l}\text { Vocabul } \\
\text { ary of } \\
\text { terms }\end{array}$ & & & & & & & & & \\
\hline $\begin{array}{l}3^{\text {rd }} \text { grade } \\
\text { of high } \\
\text { school- } \\
\text { general } \\
\text { course }\end{array}$ & T6 & $\begin{array}{l}\text { Human } \\
\text { and } \\
\text { health }\end{array}$ & $\begin{array}{l}\text { Human } \\
\text { and } \\
\text { environ } \\
\text { ment }\end{array}$ & $\begin{array}{l}\text { Evolutio } \\
\mathrm{n}\end{array}$ & & & & & & & & & & & \\
\hline $\begin{array}{l}3^{\text {rd }} \text { grade } \\
\text { of high } \\
\text { school- } \\
\text { orientatio } \\
\text { n course }\end{array}$ & 17 & $\begin{array}{l}\text { The } \\
\text { genetic } \\
\text { material }\end{array}$ & $\begin{array}{l}\text { Copying } \\
\text { expressi } \\
\text { on and } \\
\text { regulati } \\
\text { on of } \\
\text { genetic } \\
\text { informat } \\
\text { ion }\end{array}$ & Viruses & $\begin{array}{l}\text { Technol } \\
\text { ogy of } \\
\text { recombi } \\
\text { nant } \\
\text { DNA }\end{array}$ & $\begin{array}{l}\text { Mendeli } \\
\text { an } \\
\text { inherita } \\
\text { nee }\end{array}$ & $\begin{array}{l}\text { Mutatio } \\
\text { ns }\end{array}$ & $\begin{array}{l}\text { Principl } \\
\text { es and } \\
\text { methodo } \\
\text { logy of } \\
\text { biotechn } \\
\text { ology }\end{array}$ & $\begin{array}{l}\text { Applicat } \\
\text { ions of } \\
\text { biotechn } \\
\text { ology in } \\
\text { medicin } \\
\text { c }\end{array}$ & $\begin{array}{l}\text { Applicat } \\
\text { ions of } \\
\text { biotechn } \\
\text { ology in } \\
\text { agricult } \\
\text { ure and } \\
\text { federati } \\
\text { on }\end{array}$ & $\begin{array}{l}\text { Applicat } \\
\text { ions of } \\
\text { biotechn } \\
\text { ology in } \\
\text { industry }\end{array}$ & $\begin{array}{l}\text { Applicat } \\
\text { ions of } \\
\text { biotechn } \\
\text { ology in } \\
\text { environ } \\
\text { mental } \\
\text { protecti } \\
\text { on }\end{array}$ & $\begin{array}{l}\text { Biocthic } \\
\mathrm{s}\end{array}$ & $\begin{array}{l}\text { Techniq } \\
\text { ues used } \\
\text { in } \\
\text { biology }\end{array}$ & $\begin{array}{l}\text { Glossar } \\
\mathbf{y}\end{array}$ \\
\hline
\end{tabular}




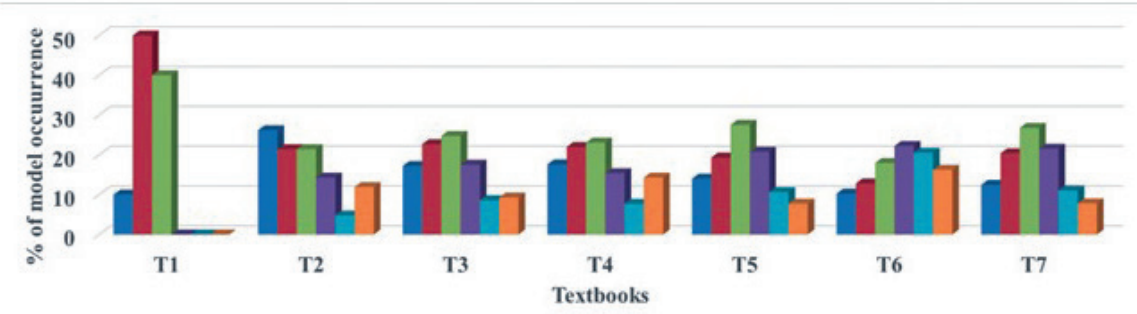

= Mendelian model $=$ Classical model $\equiv$ Biochemical-classical model $\|$ Neoclassical model $\equiv$ Modern model $\equiv$ Other

Figure 1 Occurrence of historical gene models separately for each Greek biology textbook.

In total, the gene models found in the seven Greek biology textbooks include all historical models, in parallel. The epistemological feature-variants of Biochemical model are the most common (25.9\% on average) in all of our analysis material, except in T1 and T2 for the younger grades and in T6 for the last grade. They are followed by those of the Classical model (24.1\%), Neoclassical model (15.9\%) and Mendelian model (15.5\%). Besides, the epistemological feature-variants of the Modern model are rare (9\%) and even the unclassified non-historical features exceed their presence $(9.6 \%)$. Additional to the results presented in Figure 1, data analysis revealed that, only in 4 out of total 83 units of analysis, the models adhered completely to the historical versions of the models. Particularly, in one unit of analysis of T5 the Biochemical model is represented by all of its epistemological features (1b, 2Ib, 2IIa, 2IIb, 3a, 3b, 4c, 6b, 7a), in one unit of analysis of T7 the Classical model is constituted by all of its epistemological features (1 b, 2Ib, 2IIb, 3a, 4b, 4e, 6b, 7a) and in two units of analysis of the same textbook the Biochemical model adhered completely to its historical version. Moreover, the hybridization frequency of the historical models within the textbooks has been estimated for each prevalent historical model. We found that the level of hybridization for the Mendelian model is $56 \%$, for the Biochemical model the level of hybridization is $52 \%$ and for the Neoclassical model the level of hybridization is $64 \%$. The Classical model that dominates only in $\mathrm{T} 1$ did not show hybridization (0\%). The level of hybridization regarding the Modern model, which did not prevail in any textbook, could not be estimated.

Concerning the content, the distribution of the epistemological characteristics depends on the topic, which is depicted in Figure 2; particularly, in four major topics: 'General introduction', 'Human physiology/ health', 'Genetics/molecular biology' and 'Biotechnology/ bioethics'. The gene concept is presented mostly through the characteristics of the Biochemical model, those of the Classical and Neoclassical models come second, followed by those of the Mendelian model, and finally the Modern elements are very few. On the contrary, as it was expected and preferred, in 'Evolution and Ecology' chapters, 


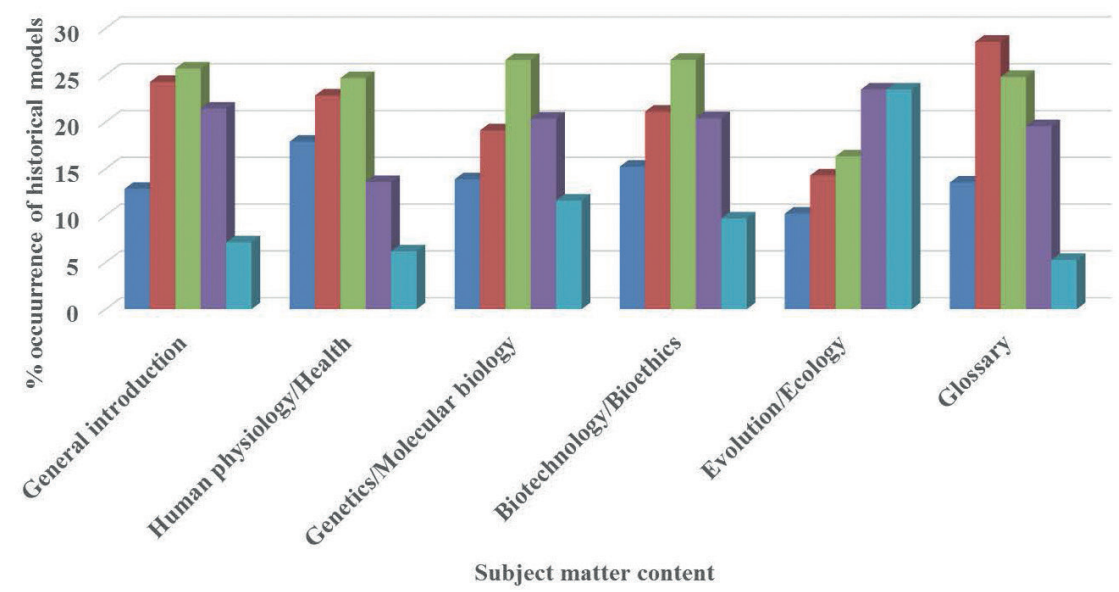

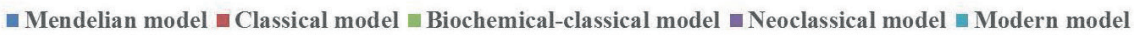

Figure 2 Occurrence of historical gene models in different topics of the Greek biology textbooks.

the Neoclassical model and the Modern model are prevalent for describing the gene functions. Moreover, in the Glossary that contains definitions, the Classical model prevails.

\section{Discussion and conclusions}

This study of the Greek biology textbooks revealed that there is conceptual variation of the representation of the gene concept, and its functions with the simultaneous implicit coexistence of the five historical gene models. Comparing our research to previous ones, the main difference is that the current study takes into account not only textbooks used in secondary education in Greece but also the textbook written for the last grade of primary school that refers to the genetic factor and addresses 12-year-old students. Concerning the results, we differentiated from the findings of previous research, finding that the Biochemical model dominates in Greek biology textbooks. It has been reported that in Swedish and Brazilian biology textbooks the Neoclassical model prevails, while in Finnish biology textbooks the Mendelian model is the most common (Aivelo \& Uitto 2015; Gericke \& Hagberg 2010a \& b; Santos et al., 2012). Furthermore, we found that the elements of the Modern model are limited in the topics which are presented in Greek biology textbooks, as also found in other studies.

As recognized in the literature, the Biochemical model has some internal inconsistencies concerning the gene function and the explanatory reduction (Gericke \& Hagberg, 2007). The main purpose of this historical model is to explain the processes of the gene function like the Classical model, providing, 
though, a biochemical aspect within the cell. In the Biochemical model, although one gene produces one enzyme, it does not have molecular structure but it is considered as a particle on the chromosome. Moreover, the connection of the gene to the trait at the macro level, and reverse, has a "bottom up" approach, as well as a "top down" approach at the same time (Gericke \& Hagberg, 2007). Since the Biochemical model predominates in Greek biology textbooks, the above inconsistencies encountered within the textbooks can provoke not only problems in students' understanding of the gene function but also alternative conceptions.

We mostly analyzed general biology textbooks which means that different biological fields are covered, such as human physiology and health, genetics and molecular biology, biotechnology and bioethics, evolution and ecology. Only the textbook for the $3^{\text {rd }}$ grade of high school, the biology course required for further studies in biology at university (T7), is oriented to the genetics field. The simultaneous presence of multiple historical gene models found in all Greek biology textbooks could be attributed to the diverse topics that were included in the content analysis. It has been reported that conceptual diversity in textbooks itself is not a problem when it is obvious to the reader, as it is a useful tool for scientists (Flodin, 2017). Therefore, the conceptual diversity in describing the gene function that was found, can be a useful tool not only for the teachers but also for the students. The prerequisite is that it should be obviously indicated and clearly explained that the gene concept might differentiate according to the historical model used in each topic of the textbooks in order to transform and convey the scientific information. The use of multiple definitions of the gene within the defined fields of the textbooks could be explicitly implemented (Albuquerque et al., 2008). Our findings could be taken into consideration by the authors of biology textbooks.

Although the presence of the Modern model is limited in Greek biology textbooks, its highest percentage is encountered in the textbook of the general biology course of the last grade of high school, which devotes a great part of its material to the topic of evolution. In this topic, the epistemological featurevariants from the Modern model mainly found are that the gene is present in frequencies (1f) and that the environmental entities are shown as part of a process (7c). We strongly suggest the integration of the epistemological characteristics of the Modern model into all Greek biology textbooks in order to avoid the formation of alternative conceptions by students. Deterministic misconceptions can arise from the lack of epigenetic and environmental factors that influence the gene function and the phenotype. This epistemological characteristic of the environmental entities not being considered (7a) describes the Mendelian model, the Classical model and the Biochemical model, the last two being dominant in Greek biology textbooks.

In conclusion, we suggest that the incorporation of a description of the historical evolution of the gene concept, through the biological developments 
and scientific achievements, especially in genetic and biotechnological topics, would be beneficial to the readers of the biology textbooks. This could explain the differentiations of the gene concept and its functions among the five historical gene models that are being used. In addition to this, the introduction of modern views of the gene concept in all topics, could help the more integrated acquisition of gene functions. All the above could provide the future citizens with knowing how to thoroughly understand and manage the constantly emerging biotechnological issues along with their political and socio-economic effects.

\section{Acknowledgements}

This research is part of a PhD being funded by the Greek General Secretariat for Research and Technology (GSRT) and the Hellenic Foundation for Research and Innovation (HFRI).

\section{References}

Aivelo, T., \& Uitto, A. (2015). Genetic determinism in the Finnish upper secondary school biology textbooks. Nordic Studies in Science Education, 11(2), 139-152.

Albuquerque, P. M., de Almeida, A. M. R., El-Hani, N. C. (2008). Gene Concepts in Higher Education Cell and Molecular Biology Textbooks. Science Education International, 19(2), 219-234.

Christidou A., \& Papadopoulou P. (2017a). Representations of historical gene models in Greek biology school textbooks: The case of textbook of the $3^{\text {rd }}$ grade of junior high school. In D. Stavrou, A. Michailidi, A. Kokolaki (Eds.), Proceedings of the $10^{\text {th }}$ Pan-Hellenic Conference on Science Education and New Technologies in Education: Bridging the Gap between Natural Sciences, Society and Educational Practice (pp. 446-454). Rethimno: Pedagogical Department of Primary Education, Laboratory of Teaching Science, University of Crete.

Christidou A., \& Papadopoulou P. (2017b). Representations of historical gene models in Greek biology secondary school textbooks: A Comparison. In A. Polyzos \& L. Anthis (Eds.), Proceedings of the $4^{\text {th }}$ Pan-Hellenic Conference on Biology Education (pp. 133-142). Athens: Panhellenic Association of Bioscientists.

Flodin, V. S. (2009). The necessity of making visible concepts with multiple meanings in science education: The use of the gene concept in a biology textbook. Science and Education, 18(1), 73-94.

Flodin, V. S. (2017). Characterization of the Context-Dependence of the Gene Concept in Research Articles. Science and Education, 26, 141-170.

Gericke, N. M., Hagberg, M., dos Santos, V. C., Joaquim, L. M., \& El-Hani, C. N. (2014). Conceptual Variation or Incoherence? Textbook Discourse on Genes in Six Countries. Science and Education, 23(2), 381-416. 
Gericke, N. M., \& Hagberg, M. (2010). Conceptual incoherence as a result of the use of multiple historical models in school textbooks. Research in Science Education, 40(4), 605-623. a

Gericke, N. M., \& Hagberg, M. (2010). Conceptual Variation in the Depiction of Gene Function in Upper Secondary School Textbooks. Science and Education, 19(10), 963-994. b

Gericke, N. M., \& Hagberg, M. (2007). Definition of historical models of gene function and their relation to students' understanding of genetics. Science and Education 16, 849-881.

Kim, M., \& Han, J. (2010). Genetic content in Korean nursing textbooks. Nursing \& Health Sciences, 12(1), 135-141.

Lemoni R. Lefkaditou A., Stamou A.G., Schizas D., Stamou G.P. (2013). Views of nature and the human-nature relations: An analysis of the visual syntax of images about the environment in Greek primary school textbooks-Diachronic considerations. Research in Science Education 43(1), 117-140.

Liu, Y., Khine, M. S. (2016). Content Analysis of The Diagrammatic Representations of Primary Science Textbooks. Eurasia Journal of Mathematics, Science and Technology Education, 12(8), 1937-1951.

Martínez-Gracia, M. V, Gil-Quílez, M. J., \& Osada, J. (2003). Genetic engineering: a matter that requires further refinement in Spanish secondary school textbooks. International Journal of Science Education, 25(9), 1148-1168.

Martínez-Gracia, M. V, Gil-Quílez, M. J., \& Osada, J. (2006). Analysis of molecular genetics content in Spanish secondary school textbooks. Journal of Biological Education, 40(2), 53-62.

Santos, V. C., Joaquim, L. M., \& El-Hani, C. N. (2012). Hybrid Deterministic Views about Genes in Biology Textbooks: A Key Problem in Genetics Teaching. Science and Education, 21(4), 543-578.

Wernick, N. L., Ndung'u, E., Haughton, D., \& Ledley, F. D. (2014). Positioning genomics in biology education: content mapping of undergraduate biology textbooks. Journal of microbiology \& biology education, 15(2), 268-76. 


\title{
TOWARD TEACHING FOR AN INTEGRATED UNDERSTANDING OF TRAIT FORMATION: AN ANALYSIS OF GENETICS TASKS IN HIGH SCHOOL BIOLOGY TEXTBOOKS
}

\author{
Tim Heemann and Marcus Hammann \\ Centre for Biology Education, Westfälische Wilhelms-Universität (Münster-Germany) \\ hammann.m@uni-muenster.de
}

\begin{abstract}
This paper reports on findings from an analysis of trait-formation tasks in the genetic sections of high school biology textbooks. Drawing on studies exploring a range of problems in students' explanations of trait formation, we investigated trait-formation tasks and analyzed their potential for knowledge integration by addressing the relationships between genes, proteins, traits and environmental factors. The rationale for this research interest is that such tasks may help students build integrated knowledge networks enabling multi-level mechanistic reasoning. Among the 216 trait-formation tasks, 39 tasks (18\%) were classified as integrative tasks addressing the relationships between genes, proteins and traits. The remaining 177 tasks (82\%) were non-integrative tasks addressing selected aspects of the relationship between genes and proteins alone, respectively the relationship between proteins and traits alone. Among the nonintegrative tasks, $64 \%$ addressed the molecular level alone and thus did not encourage students to address the higher levels of biological organization. 13\% of the nonintegrative tasks $(n=23)$ and $5 \%$ of the integrative tasks $(n=2)$ addressed the role of the environment in trait formation. The findings are related to three main arguments from the genetics literature, concerning knowledge integration, the levels of biological organization and environmental factors. As educational implications, we recommend that biology educators make use of integrative tasks to foster students' understanding of trait formation from an integrated model connecting genes, proteins, environmental factors and traits to overcome gene-centered and gene-deterministic beliefs.
\end{abstract}

\section{The full version of this paper is published in the Journal of Biological Education:}

Tim Heemann, T. \& Hammann, M. (2020) Toward teaching for an integrated understanding of trait formation: An analysis of genetics tasks in high school biology textbooks, Journal of Biological Education 2020, in press. 



\title{
PROCESSES OF PROFESSIONALIZATION: OUTDOOR TEACHING AND ASSESSMENT OF PCK
}

\author{
${ }^{1}$ Lissy Jäkel, ${ }^{1}$ Ulrike Kiehne, ${ }^{1}$ Sabrina Frieß, \\ ${ }^{1}$ David Hergesell and ${ }^{2}$ Benjamin Tempel \\ ${ }^{1}$ University of Education Heidelberg, ${ }^{2}$ PH Ludwigsburg \\ jaekel@ph-heidelberg.de; kiehne@ph-heidelberg.de; \\ friess@ph-heidelberg.de; hergeselld@ph-heidelberg.de
}

\begin{abstract}
When biology teachers use the local environment to teach curriculum areas, for instance in school gardens, it is a highly demanding situation. Do the teachers need special competencies for this? We extended the model of pedagogical content knowledge (PCK) by adding the component of outdoor teaching and Education for Sustainable Development (ESD). Therefore, our questionnaire measures different aspects: attitudes towards nature, self-assessment of one's knowledge in biological topics and gardening, didactical competence with regard to one's capacity for fieldwork and organizational skills, ESD competence, and the advantages as well as limits of fieldwork during lessons. With a confirmatory factor analysis (CFA), we checked that our PCK model with a specific extension concerning outdoor learning is valid. Most of our pre-service teachers in Biology at our university were tested ( $n=200$ in 2018). Outdoor-PCK and PCK connected to teaching ESD were shown to be separate parameters. As expected, the attitudes on nature were relatively positive, in contrast to low gardening skills. Our further aim is to measure to what extent educational treatments at university are effective to develop the competencies of biology pre-service teachers for outdoor teaching.
\end{abstract}

\section{Introduction}

High expectations are set for outdoor teaching in biology or crossdisciplinary lessons by experienced didactics (e.g. Gade \& von Au 2017; Bentsen 2012) for regular lessons, regardless of the type of school. Outdoor education refers to teachers making use of the local environment when teaching specific subjects and curriculum areas (Gade \& von Au 2016), for instance in school gardens (Weusmann 2015). There is a long list of publications that strongly 
indicate advantages of outdoor education compared to regular in-classroomeducation (Benkowitz 2014). For example, the work of Hethke et al. (2010) as well as Hergesell \& Jäkel (2014) shows the benefits of outdoor education especially in terms of motivation for pupils as well as pre-service teachers (Jäkel 2014). However, outdoor teaching is a highly demanding situation - notably for pre-service teachers and teachers in their early professional life. These challenges consist in the simultaneous lack of previous knowledge of learners (see Glackin, 2017), of routines in the planning of lessons, as well as uncertainty in unfamiliar space outside the classroom. At the Department of Biology at the University of Education Heidelberg, further teachers are trained for different types of schools. In didactic of biology, one focus is outdoor education. This kind of training combines theoretical concepts and active teaching with pupils in the ecological garden of the university (e.g. with so-called 'outdoor classes'). We conduct a lot of courses and lectures with different biological subjects. Our research aims to measure if educational treatments are effective to develop the competences of pre-service teachers for outdoor teaching in a pre-post-design. Therefore, we assess and model the development of pedagogical content knowledge (PCK) for outdoor teaching of biology. This setting leads to an interface between measuring instruments based on valid theoretical concepts and providing a deeper insight in academic outdoor education learning situations for future teachers.

\section{Theoretical background and state of research}

Since Shulman's paper in 1987, different areas of professional knowledge are well known: subject matter knowledge (CK), pedagogical content knowledge related to the subject (PCK), and general pedagogical knowledge (PK). Therefore, we extend the highly topical model of Baumert \& Kunter (2006) for the professionalism of teacher action by adding the component outdoor learning (see Hellberg-Rode \& Schrüfer, 2016). Until now, PCK has been a great topic of further research (e.g. Großschedl et al. 2015), but some studies question whether these three constructions can be assessed independently from one another. Examples in this framework are 'Measuring the professional knowledge of preservice mathematics and science teachers' (KiL-Project), the ProjectCOACTIV, and the project 'professional knowledge of science teachers' (ProwiN) (Großschedl et al. 2015).

Outdoor education in our opinion is an expansion of indoor education and both are closely connected. Learning through personal experience should take place in conjunction with a lot of physical activity, which is also advisable from a medical point of view (Gade \& von Au 2016; Bentsen 2012). Previous work defined outdoor education as teaching subject matter outdoors on a regular basis - as opposed to the concept of having short-term outdoor trips (Jäkel 2016). 
In our previous research, we found that the didactical challenge of working outside with children influences the attitude to outside teaching, but does not lead to a strengthening of practical horticultural competence. Previous research about teaching modules at outdoor 'Nature Education Spots' showed that activity supported the motivation of students, no matter if this was offered with modern digital media or as a conventional activity (Hergesell \& Jäkel 2014). In addition, it could be shown by extensive and repeated (over seven years) measurements of the interest of students, that the motivation of pre-service teachers concerning their studies increases measurably when they come in early contact with pupils that means with later professional requirements. Such practical aspects spur on the participants to enlarge their personal knowledge of the subject matter. For this purpose, a short questionnaire of intrinsic motivation was used, and knowledge tests too (Jäkel, 2014).

\section{Scientific issue}

If outdoor learning means receiving lessons, it is important to provide preservice teachers with a variety of positive experiences and competences to support future outdoor education activities in their professional development. Wüsten et al. (2008) classified teaching with the use of real objects to be a strong factor for quality teaching, specifically in biology. Our research analyses theoretical concepts that relate to outdoor education and out of school learning. References to Education for Sustainable Development (ESD) arise consequentially. A sustainable development has to combine social, technological, economic and ecological sustainability. Biological knowledge turns into a bottleneck for conservation of biodiversity (Rädiker \& Kuckartz, 2012). For the structural anchorage of ESD in a school context, it is important to offer the possibility of practicing skills and develop the competency to shape the future (De Haan 2008; Rost 2002).

Therefore, we extend the highly topical model of Baumert \& Kunter (2006) for the professionalism of teacher action by adding the component of outdoor learning. Professional knowledge is domain specific and training dependent. Professional expertise integrates contexts and allows a varied behavior (Baumert $\&$ Kunter 2006). In our opinion, the first and second phase of teacher training should be more closely interlaced. Pre-service teachers should focus on professional requirements already while studying. For this purpose, pre-service teachers at our university are given opportunities to learn how to teach subject matter to children in authentic settings and to reflect on their actions.

One key component is the versatile use of the Ecologic Garden, which is located near the University of Education Heidelberg. The Ecologic Garden has now been in place for three decades, and was recently honoured as a UNESCO role model project in the world action programme for sustainability. In this garden, 
there is a variety of plant and animal species as well as a set of specific learning modules designed by university personnel and students. Approximately eight hundred pupils visit the Ecologic Garden every year and make use of the previous mentioned learning modules. Whilst pupils find themselves learning in nature and reflecting on ecological, biological and sustainability topics, pre-service teachers of our university conduct courses and are gathering experience in outdoor teaching.

\section{Methods and research design}

\subsection{Modelling and questionnaire design}

In the process of the assessments, we built a theoretical construct based on Baumert \& Kunter (2006), declaring outdoor PCK being a part of the PCK model. Furthermore, we classified different aspects of attitudes on nature to be separate factors. We intended to separate attitudes in social context, in a private gardening context and in general. The separation of limits and advantages of outdoor education was derived from Weusmann (2015). Großschedl (2013) discusses the absence of suitable tests to find out whether the university training of future teachers is progressing successfully. Our team is working to improve tests in this context. The instrument developed and used by Weusmann (2015) with standardized items is domain-specific for nature-based, out-of-school learning places and for school gardening. We improved the scale quality as well as cleared away less selective items. The test (as adapted by Weusmann, 2015) was divided into three complexes: attitudes towards nature, self-assessment of one's knowledge, and didactical competence regarding one's capacity for field work, as well as advantages and limits of fieldwork during lessons.

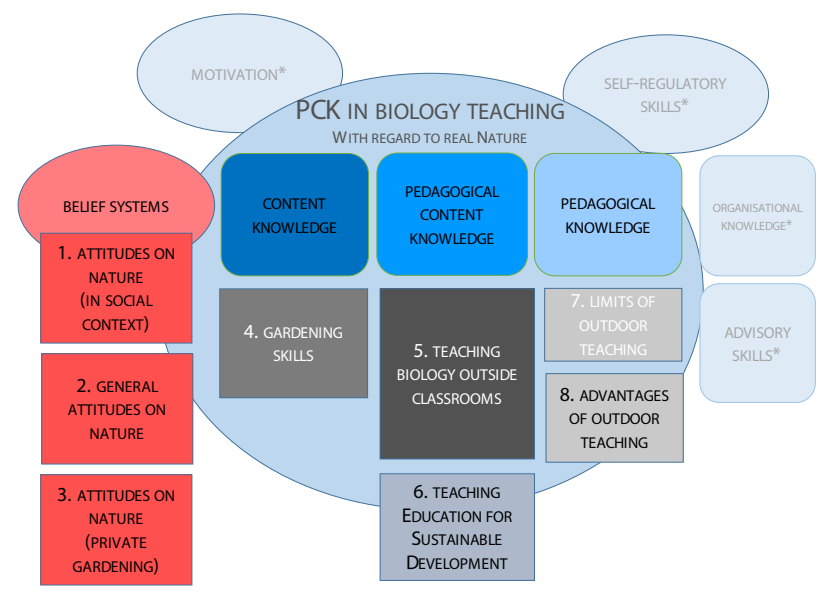

Figure 1 Model of Professional Competence and outdoor teaching, changed according to Baumert \& Kunter (2006) ( ${ }^{*}$ not evaluated in this research). 
We improved the breadth of the previously mentioned assessment instrument. We added items in the field of Education for Sustainable Development (ESD) and separated items for specialized outdoor PCK. All scales ranged from 1 (= I don't agree) to 7 (= I completely agree). The original PCK model by Baumert \& Kunter (2006) is described to have further elements in place, that are also influencing the pedagogical performance of teaching persons. These aspects include motivation, self-regulatory skills, organizational knowledge and advisory skills. We did not measure advisory skills, motivation and self-regulatory skills.

\subsection{Participants and interventions}

All pre-service teachers in biology of our university were tested (2017 pilot testing $n=195 ; n=200$ in 2018). These seminars had (depending on the choice of participants) the following topics: basics of botany, outdoor teaching, gardening seminars, and seminars on ecology and environmental education, and included 14 weeks during the summer semester. It was set as a pretestposttest design to determine whether or not the lectures and seminars at the department had influence on students' cognitive development - especially the development of PCK or on their attitudes on nature. The pre-service teachers attended a variety of academic lectures and courses. The syllabus consists of courses with regard to content knowledge (for example botany, gardening and excursions), and also didactical experience with pupils in class and in outdoor settings. The exact seminar design was the responsibility of the lecturers.

\section{Findings and conclusions - model validation and conclusion regarding PCK-assessment}

After the earlier research conclusions at our department (Jäkel et al., 2016) and conclusions on PCK in outdoor situations, we validated our new theoretical construct with a confirmatory factor analysis (Mplus) (Muthén \& Muthén 19982011). The results of the analysis of pretest-data 2018 ( $n=200)$ showed eight consistent factors. First, there are three factors in the framework of beliefs. This topic consists of attitudes on nature in social context, general attitudes on nature and attitudes on nature in a private gardening context. Second, there is a CK-factor named gardening skills. The third cluster is located in the area of PCK. It consists of two factors. These are teaching biology outside classrooms and teaching ESD. The last cluster, named pedagogical knowledge, is also divided into two factors. Those are limits and advantages of outdoor teaching. Table 1 gives an overview of all factors with relevance to teaching outdoor biology and shows examples of items for every factor.

The results of confirmatory factor analysis (CFA) showed that PCK connected to outdoor teaching, as well as PCK connected to teaching Education 
TABLE 1

OVERVIEW OF THE FACTORS WITH RELEVANCE TO TEACHING

OUTDOOR BIOLOGY (SUMMER 2018)

\begin{tabular}{|c|c|c|c|c|}
\hline Factors & $\begin{array}{l}\text { Cronbach's } \alpha \\
\text { Pretest } \\
\text { Posttest }\end{array}$ & $\begin{array}{l}\text { Arithmetic } \\
\text { Mean/SD } \\
1=I \text { don't } \\
\text { agree. } 7=I \\
\text { completely } \\
\quad \text { agree. }\end{array}$ & Examples of items & $\begin{array}{l}\text { Cohens d } \\
\text { Effect } \\
\text { size }\end{array}$ \\
\hline $\begin{array}{l}\text { 1. attitudes on } \\
\text { nature in social } \\
\text { context }\end{array}$ & $\begin{array}{l}.783 \\
.773 \\
3 \text { items both }\end{array}$ & $\begin{array}{l}4.75(.92) \\
4.86(.993)\end{array}$ & $\begin{array}{l}\text { It is important to me to support environ- } \\
\text { mental protection groups. }\end{array}$ & 0.115 \\
\hline $\begin{array}{l}\text { 2. general } \\
\text { attitudes on } \\
\text { nature }\end{array}$ & $\begin{array}{l}.850 \\
.857 \\
10 \text { items both } \\
\end{array}$ & $\begin{array}{l}5.39(.73) \\
5.58(.738)\end{array}$ & $\begin{array}{l}\text { I like to find out which animals inhabit } \\
\text { meadows. } \\
\text { Nature protection is very important for me. }\end{array}$ & 0.259 \\
\hline $\begin{array}{l}\text { 3. attitudes on } \\
\text { nature in pri- } \\
\text { vate context }\end{array}$ & $\begin{array}{l}.646 \\
.629 \\
3 \text { items } \\
\text { both }\end{array}$ & $\begin{array}{l}5.48(1.055) \\
6.15(4.77)\end{array}$ & $\begin{array}{l}\text { I wouldn't use pesticides in my own garden. } \\
\text { I would offer domestic animals refuge spots } \\
\text { in my own garden. }\end{array}$ & 0.165 \\
\hline $\begin{array}{l}\text { 4. biological } \\
\text { knowledge and } \\
\text { gardening skills } \\
\text { self-perception }\end{array}$ & $\begin{array}{l}.917 \\
.850 \\
19 \text { items both }\end{array}$ & $\begin{array}{l}3.79(.94) \\
4.36(.947)\end{array}$ & $\begin{array}{l}\text { I know how to care for a fruit tree. } \\
\text { I know many domestic types of insects. } \\
\text { I know to which family meadow plants can } \\
\text { be assigned to. }\end{array}$ & 0.604 \\
\hline 5. PCK outside & $\begin{array}{l}.850 \\
.875 \\
11 \text { items }\end{array}$ & $\begin{array}{l}5.155(.714) \\
5.4(.763)\end{array}$ & $\begin{array}{l}\text { I know how to motivate pupils to deter- } \\
\text { mine plants. } \\
\text { I know how to deal with the phobia pupils } \\
\text { have of animals. } \\
\text { I can carry out growth experiments with } \\
\text { plants. }\end{array}$ & 0.084 \\
\hline 6. ESD & $\begin{array}{l}.722 \\
.841 \\
3 \text { items } \\
\text { both }\end{array}$ & $\begin{array}{l}4.71(.867) \\
5.17(.926)\end{array}$ & $\begin{array}{l}\text { I am able to create connections between } \\
\text { gardening and responsibility for a sustain- } \\
\text { able economy. }\end{array}$ & 0.513 \\
\hline 7. limits & $\begin{array}{l}.801 \\
.810 \\
7 \text { items } \\
\text { both }\end{array}$ & $\begin{array}{l}2.98(.86) \\
3.02(.947)\end{array}$ & $\begin{array}{l}\text { Fieldwork takes too much time. What I } \\
\text { don't like about fieldwork teaching is that it } \\
\text { is difficult to plan. }\end{array}$ & 0.044 \\
\hline 8. advantages & $\begin{array}{l}.862 \\
.889 \\
12 \text { items }\end{array}$ & $\begin{array}{l}5.87(.578) \\
5.98(.663)\end{array}$ & $\begin{array}{l}\text { Fieldwork strengthens the team spirit. } \\
\text { Self-reliant fieldwork is important for the } \\
\text { understanding of the subject matter. } \\
\text { Pupils understand natural phenomena bet- } \\
\text { ter after having been taught in the field. }\end{array}$ & 0.177 \\
\hline $\begin{array}{l}\text { 9. organization- } \\
\text { al skills }\end{array}$ & $\begin{array}{l}.592 \\
2 \text { items }\end{array}$ & $\begin{array}{l}6.21(.87) \\
6.27(.9934)\end{array}$ & I'm able to coordinate teamwork outside. & 0.064 \\
\hline
\end{tabular}

for Sustainable Development (ESD), were shown to be separate parameters. In our observations, the earlier mentioned eight factors could be distinguished. The model-fit-parameters are acceptable (RMSEA $=0,044 ;$ TLI=0,871; $\mathrm{CFI}=0,876$ ). A confirmatory factor analysis (CFA) after the posttest 2018, 
showed organizational skills as a single factor, in addition to the eight factors detected by the CFA of the data of the pretest. The model-fit-parameters show a slight increase of the values from pretest to posttest $(\mathrm{RMSEA}=0.045 ; \mathrm{TLI}=$ 0.901; CFI $=0.905$ ).

Detailed data from autumn 2018 have been published in Jäkel et al. (2019). Because of the sample size we decided on the effect size d Cohen.

The data showed results on multiple levels. Speaking generally, we concluded that our courses over one semester are effective. Some factors did not show a significant change (for example PCK in general) over one single semester. However, we could see that the arithmetic means of most of our item responses changed measurably, in particular expertise in ESD and biological knowledge. Furthermore, we found a significant difference between regular courses on the one hand and academic excursions on the other hand (for examples, see Table 2 ). The participants of excursions showed more achievement of both curricular content knowledge and outdoor PCK - in some items significantly (t-tests). For instance, in the beliefs column there is significance in item responses with regard to being in nature, financing nature reserve groups, and the attitude towards living things in meadows. A typical item was "It is important for me to recognize connections in nature." As expected, the attitudes to nature were relatively positive. On the other hand, we found low gardening skills (see Table 1).

TABLE 2

EXAMPLES OF SINGLE ITEMS ON ATTITUDES TO NATURE OR COMPETENCIES IN COMPARISON BETWEEN PARTICIPANTS ON FIELDTRIPS AND OTHER STUDENTS IN SUMMER 2018, WITH SIGNIFICANT DIFFERENCES (T-TEST)

\begin{tabular}{lccc}
\hline \multicolumn{1}{c}{ Example Items } & $\begin{array}{c}\text { Arithmetic Mean/SD } \\
1=I \text { don't agree. } \\
7=I \text { completely agree. } \\
n=12 \text { participants } \\
\text { of field trips }\end{array}$ & $\begin{array}{c}\text { Arithmetic Mean/SD } \\
1=I \text { don't agree. } \\
7=I \text { completely agree. } \\
n=200 \text { participants of } \\
\text { seminars in general }\end{array}$ & $\begin{array}{c}\text { Cohens d } \\
\text { Effect size }\end{array}$ \\
\hline $\begin{array}{l}\text { It is important for me to understand } \\
\text { ecological connections in nature. }\end{array}$ & $6.08(.669)$ & $5.43(1.01)$ & 0.759 \\
\hline $\begin{array}{l}\text { It is important to me to support envi- } \\
\text { ronmental protection. }\end{array}$ & $6.25(.866)$ & $5.60(1.003)$ & 0.694 \\
\hline I am able to assign plants to their family. & $4.67(1.557)$ & $2.96(1.437)$ & 1.141 \\
\hline
\end{tabular}

\section{Discussion}

Our questionnaire seems to be a valid instrument in research of biology teaching in outdoor contexts. However, we wish to add more items in the ESD cluster and the organizational knowledge cluster. Now these clusters consist of three items (ESD) and two items (organizational skills). That way we intend to improve the statistical foundation. 
Unfortunately, the mean values obscure differences of individual seminars. Looking deeper into the data, it is seen that certain seminars promoted biological knowledge and gardening skills, others didactic knowledge. This confirms measurements from 2016 (Jäkel et al., 2016).

Future research may be able to create assessment strategies that observe and describe all subcategories of PCK.

In the long run, it would be promising to conduct mid-term and long-term studies to determine whether the effects accumulate over a longer period. This would also offer the opportunity to observe individuals that take part in more than one course in their academic education. This could provide insights not only in effectiveness, but also into efficiency of academic teacher education courses. Nevertheless, a wider outreach of the specific research appears necessary. With reference to studies of the German Federal Agency for nature conservation (2017), it must be assumed that even observable improvements in beliefs regarding nature conservation do not provide evidence for the prediction of sustainable behaviour schemes. Rädiker \& Kuckartz (2012) determine specific content knowledge with regard to biodiversity as a bottleneck-phenomenon for the promotion of sustainable actions.

It is urgently necessary to train patterns of sustainable handling of organisms and nature.

\section{Summary}

The results showed that required professional knowledge is domain specific for biology and gardening as well as for the didactic of outdoor biology teaching, and training dependent. School gardens are valuable places for teacher training, as well as academic excursions. Teaching biology outside had to be implemented within the established model of PCK. Therefore, we adapted methods of assessment and evaluated a variety of courses. PCK connected to outdoor teaching, as well as PCK connected to teaching Education for Sustainable Development (ESD), were shown to be separate parameters (CFA). Our results indicate that the theoretical expansion seems to be valid as well as the adapted questionnaire.

Taking into account the rapid developments in education for sustainable development, data become obsolete quickly (Hellberg-Rode \& Schrüfer 2016). Importantly, a result of our study is that facets of PCK are not developed side by side and by themselves. Future research should aim to further improve the item syllabus in some of the item clusters as well as the number and variety of participants. We recommend using the expanded model of PCK in future approaches in outdoor education research and in the field of pedagogical content knowledge in biology. We further recommend the application of the model and the methods in assessments of pre-service teachers at higher education institutions, as well as for in-service teachers at schools. 


\section{References}

Baumert, J. \& Kunter, M. (2006). Stichwort: Professionelle Kompetenz von Lehrkräften. Zeitschrift für Erziehungswissenschaft, 9, 4, 469-520.

Benkowitz, D. (2014). Wirkung von Schulgartenerfahrung auf die Wahrnehmung pflanzlicher Biodiversität durch Grundschulkinder. Baltmannsweiler: Schneider Hohengehren.

Bentsen, P. (2012). The concept of udeskole in Danish schools, University of Copenhagen, Denmark; pbe@life.ku.dk February 2012.

De Haan, G. (2008). Gestaltungskompetenz als Kompetenzkonzept der Bildung für nachhaltige Entwicklung. In I. Bormann \& G. de Haan, Hrsg., Kompetenzen der Bildung für nachhaltige Entwicklung. Operationalisierung, Messung, Rahmenbedingungen, Befunde. (23-43). Wiesbaden.

Federal Agency for Nature Conservation Germany (2017). Nature Awareness Study. https://www.bmu.de/fileadmin/Daten_BMU/Pools/Broschueren/naturbewusstseinsstudie_2017_de_bf.pdf July 31, 2018.

Gade, U. \& von Au, J. (Hrsg.). (2016). Raus aus dem Klassenzimmer. Outdoor Education als Unterrichtskonzept. Weinheim und Basel: Beltz.

Glackin, M. (2017). 'Control must be maintained': exploring teachers' pedagogical practice outside the classroom. British Journal of Sociology of Education, 39 (1). 61-76.

Großschedl, J. (2013). Universitäre Biologielehrerausbildung auf dem Prüfstand. BiuZ 3, 43, 147-149.

Großschedl J., Harms U., Kleickmann T. \& Glowinski I. (2015). Preservice biology teachers' professional knowledge: Structure and learning opportunities. Journal of Science Teacher Education, 26, 291-318.

Hellberg-Rode, G. \& Schrüfer, G. (2016). Which specific professional action competencies do teachers need in order to implement education for sustainable development in schools? Findings of an exploratory study. ZDB 20, 1-29.

Hergesell, D., Jäkel. L. u. a. (2014). Helfen moderne Geomedien (GPS, GIS), die Interessiertheit Jugendlicher für Naturbegegnung und Umweltschutz zu steigern? In M. Müller, I. Hemmer \& M Trappe, Hrsg., Nachhaltigkeit neu denken Rio+X: Impulse für Bildung und Wissenschaft, München: oecom, S. 243-249.

Hethke, M.; Menzel, S. \& Overwien, B. (2010). Das Potenzial von botanischen Gärten als Lernorte zum Globalen Lernen. In: Zeitschrift für internationale Bildungsforschung und Entwicklungspädagogik 33, 2, S. 16-20.

Jäkel, L. (2014). Interest and Learning in Botanics, as Influenced by Teaching Contexts, In C.P. Constantinou, N. Papadouris \& Hadjigeorgius (Eds.), E-Book Proceedings of the ESERA 2013 Conference: Science Education Research for Evidence-based Teaching and Coherence in Learning. Part 13 (co-ed. L. Avraamidou \& M. Michelini), (pp.12) Nicosia, Cyprus: ESERA.

Jäkel, L. (2016). Garten und Schulumfeld als Lerngelände und Handlungsraum. Innovative Lernorte außerhalb des Schulgebäudes. In J. v. Au \& U. Gade, Hrsg., Raus aus dem Klassenzimmer. Outdoor Education als Unterrichtskonzept, Weinheim und Basel: Beltz, f. 183-198. 
Jäkel, L., Kiehne, U., Frieß, S. (2016). The effect of school garden activities on pre-service student teachers' attitudes to teaching biology outside the classroom. E-Book Proceedings of the ERIDOB 2016 conference. Karlstad: SMEER.

Jäkel, L. in cooperation with Frieß, S., Kiehne, U. \& Tempel, B. (2019). Heimische Vielfalt kennen, schützen, erhalten - Outdoor Teaching Kompetenzen fördern + messen. In S. Schumann, P. Favre \& A. Mollenkopf (Eds.), "Green, Outdoor and Environmental Education", Shaker, 109-141.

Kunter, M., Baumert, J., Blum, W., Klusmann, U., Krauss, S. \& Neubrand, M. (Hrsg.). (2011). Professionelle Kompetenz von Lehrkräften - Ergebnisse des Forschungsprogramms COACTIV. Münster: Waxmann Verlag.

Lenhard, W. \& Lenhard, A. (2016). Berechnung von Effektstärken. accessed under: https://www.psychometrica.de/effektstaerke.html. Dettelbach: Psychometrica.

Muthén, L. K., \& Muthén, B. O. (1998-2011). Mplus User's Guide. Sixth Edition. Los Angeles, CA: Muthén \& Muthén.

Rost, J. (2002). Umweltbildung - Bildung für nachhaltige Entwicklung. Was macht den Unterschied? Zeitschrift für internationale Bildungsforschung und Entwicklungspädagogik 25, 1, 7-12.

Rädiker, S., Kuckartz, U. (2012). Das Bewusstsein über biologische Vielfalt in Deutschland: Wissen, Einstellung und Verhalten. Natur und Landschaft 87, 3, 109-113.

Shulman, L. (1987). Knowledge and teaching: foundations of the new reform. Harvard Educational Review, 57, 1-22.

Weusmann, B. (2015). Biologie- und Sachunterricht im Freiland: Überzeugungen zu einer wenig genutzten Unterrichtsform. Baltmannsweiler: Schneider.

Wüsten, S., Schmelzing, S., Sandmann, A. \& Neuhaus, B. (2008). Unterrichtsqualitätsmerkmale im Fach Biologie - Identifizierung und Quantifizierung von Qualitätsmerkmalen im Biologieunterricht. In D. Krüger, A. Upmeier zu Belzen, T. Riemeier \& K. Niebert, Hrsg., Erkenntnisweg Biologiedidaktik 7, 145-158. Hannover. 


\title{
THE BIODIVER PROJECT: DEVELOPMENT OF OUTDOOR INQUIRY SKILLS IN UNDERGRADUATE ELEMENTARY TEACHERS' COURSES
}

\author{
Isabel Jiménez-Bargalló, Arnau Amat \\ and Jordi Martí-Feixas \\ Universitat de Vic-Universitat Central de Catalunya \\ (Barcelona, Spain) \\ isabel.jimenez@uvic.cat
}

\begin{abstract}
We present features and results from a study investigating undergraduate elementary school student teachers' development of outdoor inquiry skills required to perform field investigations. Our study was driven by the following research question: what kind of outdoor inquiry skills do undergraduate elementary school student teachers develop, and what challenges do they face when support is given to perform field investigations related to animal biodiversity? Research was done within the framework of BIOdiver, a project that seeks to promote school scientific inquiries of the local biodiversity in school environments. We describe specific pedagogical approaches used to guide preservice teachers to develop an understanding of the experimental skills required to perform field investigations related to animal biodiversity. We expose results from the qualitative content analysis of 70 outputs of 21 preservice teacher groups, made when undergraduate students were writing scientific posters reporting their own outdoor investigations. Results provide evidence, for example, of students developing capabilities for posing investigable questions or identifying variables. It also gives insights into challenges or incomplete understandings regarding outdoor inquiry skills, such as using evidence to draw conclusions. The utility of the development of field investigations in undergraduate elementary teachers' science courses for the enhancement of outdoor inquiry skills is discussed.
\end{abstract}

Keywords: biodiversity, inquiry skills, field investigations, undergraduate teacher education, scientific posters. 


\section{Introduction}

The BIOdiver project, starting in 2008 and with the participation of more than 50 elementary schools, seeks to promote school scientific research of the local biodiversity in school environments. The project can be identified with broader, international initiatives of the last decades, for example 'inquiry-based science' (Minner et al., 2010), 'problem-based learning' in science (Krajcik \& Blumenfeld, 2006) and 'authentic science' (Roth, 1995). These approaches have in common the desire to improve cognitive and procedural outcomes for students through encouraging them to engage in activities that follow the approaches scientists take when they are trying to solve problems and aspiring also to have affective benefits for them. Furthermore, BIOdiver can be also framed in the Education for Sustainable Development movement, because it supposes a learning process that empowers people to participate critically and act for the benefit of the community, after understanding complex phenomena (Mogensen \& Mayer, 2005).

In particular, BIOdiver provides elementary school students with the opportunity to increase knowledge and awareness about biodiversity in a tangible and available environment, their own schoolyard. It builds upon what we will call students' 'outdoor inquiry skills' (henceforth referred as 'OIS'), which refers to students' scientific inquiry skills required to perform field investigations. It becomes, therefore, a clear environment both: i) to foster learning of scientific processes and nature of science; and (ii) to promote education for sustainable environment by helping students become well-informed, critical and competent, and in consequence, able to act in favour of biodiversity.

In 2017, BIOdiver was implemented as a pilot test in undergraduate science elementary school teacher courses being seen as an opportunity to enhance preservice teachers' OIS, and to prepare them to implement effective Education for Sustainable Development and inquiry-based learning experiences in school settings. In this study, our attention is on preservice teachers' OIS development. If teachers are expected to motivate and support their students to conduct field inquiries, the need and urgency to enhance the development of solid OIS during their preservice training is evident. Furthermore, it appears interesting and complex to understand how this knowledge is acquired and how it can be fostered and assessed.

Specifically, we focus in scientific posters developed by undergraduate students while performing their own outdoor inquiries. The development of posters was a prominent activity during the project. According to the characteristics described by Bell \& Cowie (2001), this practice was conceived as a formative assessment strategy where teachers and students could recognize and respond to the learning process regarding OIS. In this article we report findings from the evaluation of different outputs from undergraduate elementary school 
teachers, while doing their scientific posters, to give light to the effectiveness of using such formative assessment strategies for promoting and measuring the progressive understanding of OIS.

\section{Aim of the study}

The aim of this study is to interpret the development of undergraduate elementary school student teachers' understandings of outdoor inquiry skills, when support is given to perform field investigations related to animal biodiversity. To be precise, we report results regarding the ability of undergraduate teachers to pose investigable questions, design an outdoor inquiry, and draw conclusions and interpretations from results.

\section{Scientific inquiry skills, outdoor inquiry and teacher education}

Helping students develop informed understandings, scientific inquiry has been a perennial focus of new ways of thinking about science education in general, and of biology education in particular (Kremer et al., 2014). Scientific inquiry refers to the processes of how scientists do their work, how it is validated and the utility of scientific knowledge. Although there is not a specific definition or meaning of what inquiry means for science education (Bybee, 2000), it is seen as an integral component of scientific literacy, with identified central skills and practices such as posing questions, forming hypotheses, planning investigations, interpreting data or reaching conclusions, among others (Lederman et al., 2014).

However, many science educators agree that members of diverse scientific disciplines have unique philosophical perspectives and assumptions, engage in a great variety of enterprises and struggle to design unique methods to answer the questions they pose (Duschl \& Grandy, 2008; Windschitl et al., 2007; Ault \& Dodick, 2010; Kloser, 2012). Educational approaches to inquiry that pay careful attention to the diversity of different scientific disciplines and value these plural epistemologies, elements of practice, specialized language, use of specific tools and methodologies, patterns of discourse, representations, etc., can contribute to build a more informed, representative and flexible idea of science (Duschl et al., 2007; Windschitl et al., 2007; Kloser, 2012). Clearly acknowledging the plurality of methods across subjects and the myth of 'the' scientific method would contribute to a better understanding of the Nature of Science, which is central to scientific literacy (Crowther et al., 2005).

\subsection{Outdoor inquiry}

From our point of view, designing outdoor inquiries and constructing conclusions and interpretations from their results requires a different sort of 
knowledge than other kinds of inquiries. In outdoor biodiversity studies, the systems being analyzed are complex and variables often interact in probabilistic ways. Thus, the paradigm of investigations predominant in school science (characterized by randomized and manipulated control group experiments) is not useful in this context Windschitl et al., 2007. Therefore, it is necessary to enhance OIS and engage young learners in representative forms of such current outdoor scientific practice, in order to provide adequate understanding of the Nature of Science. In the biological sciences, many studies and programme descriptions of field experiences outline positive impacts on students' knowledge of ecological content, specific inquiry skills, environmental attitude and motivation (Brune, 2002; Dillon et al., 2006; Scott \& Boyd, 2016). These experiences result in memorable, comprehensive, and long-term learning (Waite, 2007). Furthermore, they appear to be a potential framework for a convergence of environmental and science education (Wals et al., 2014).

Giving students the opportunity to study biodiversity in a natural environment enables the acquisition of the new knowledge necessary for decision-making about biodiversity conservation issues (Wals et al., 2014; Grace \& Byrne, 2010). It also allows articulating and learning OIS (i.e. identifying questions, planning data collection, drawing conclusions from results, etc.) as it supposes a meaningful framework to introduce and guide them to the methodologies and practices used for scientific field research (Ryken et al., 2007). Furthermore, extending teaching beyond the classroom walls has been known for its potential effects on outcomes for students and to promote inquirybased learning in various disciplinary domains (Dillon et al., 2006). Properly conceived, adequately planned, well taught and effectively followed up outdoor experiences, offer learners opportunities to develop their motivation, knowledge, skills and problem solving abilities, thereby increasing academic achievement across disciplines (Ryken et al., 2007).

\subsection{Teacher education}

Even if teachers are aware of the vast potential of field experiences and outdoor inquiry to support students' inquiry-based learning and environmental education, implementing outdoor inquiry as a pedagogical strategy appears to be quite challenging (Borsos et al., 2018). Preservice teachers are newcomers to science teaching, but they are not newcomers as science learners (Abell et al., 2006). How they experienced science as students is really important in determining how they will teach science as teachers. Furthermore, most of them have no in depth understanding of how to solve biological problems successfully, facing many challenges to design successfully and implement scientific inquiry experiences in school settings (Windschitl et al., 2008). 
To help them, studies suggest the importance that teachers experience the sort of teaching we are expecting of them in the context of teacher education programmes (Abd-El-Khalick, 2013). Furthermore, reflection-orientation methods in science education courses would facilitate changes in pre-service teachers' perception of how science should be taught (Abell et al., 2010). Finally, new visions of assessment, being conceived as part of an integrated, collaborative learning experience, would involve providing feedback to students (and teachers) about the learning which is occurring during (and not after) the teaching and learning process (Bell \& Cowie, 2001).

\section{Research design and methodology}

Our research is framed in an interpretative paradigm, because our aim is to understand and reconstruct how knowledge regarding OIS is acquired and how it can be fostered and assessed (Guba \& Lincoln, 1994). In this study, data was obtained from 70 outputs of undergraduate elementary school student teachers in the subject of Science Education. These products were made when students were writing scientific posters reporting their own outdoor investigations within the framework of the course (which was designed according the general ideas exposed in the theoretical framework). Students were asked to design an outdoor inquiry on changes in the communities and the populations of animals living in the university garden over the spring (March-June). To conduct their inquiry, the 64 student teachers worked into 21 small groups. All but 13 had not studied science subjects since the age of sixteen at high school. Only one had graduate studies in Biology, and none of them had other graduate scientific degrees.

During the course, the small garden (which is one of the university facilities and an open space for all students) was conceived as a school playground in order to help preservice teachers to promote outdoor inquiries for their future elementary school students. They were given specific guidance to help them to become more familiar with OIS and what field investigations and inquiryoriented pedagogies. For example, they were given specific instruments/ methodologies to engage the formulation of investigable questions, or how to do a line transect. Specific information about most common species of birds and insects in the garden were also provided. A model of an ecological network (visualizing complex direct/ indirect interactions between species in ecosystems), was also presented and debated in order to facilitate the interpretation of the obtained data.

Scientific posters were conceived as a formative assessment strategy (Bell \& Cowie, 2001), where teachers and students could recognize and respond to the learning process regarding OIS. While doing the posters, students had to deliver their own outputs in two different phases: 
i. Design of the inquiry: in a virtual forum, students delivered a first assignment with a proposal of an outdoor inquiry including question and description. Following feedback provided by the professor, students delivered a second assignment refining required items. This phase took place at the very beginning of the Didactics of Science subject, when no specific content about the inquiry process had been taught.

ii. Communication of the study: students had to deliver a poster prototype as a third assignment, where not only the question and the design had to be described, but also the results, the empirical conclusions and the interpretation of the results had to be presented.

Using a rubric with the main quality criteria, each group of students had to evaluate the poster of two other groups and use the rubric to make a brief report to help their peers to improve their poster. Students doing the fourth assignment had to deliver a final poster taking into account the feedback from their peers. This final poster contributed to the final mark in the Didactics of Science subject and was evaluated using the same rubric as in the third assignment. Data from these productions was analyzed from a qualitative content analysis approach. The aim of qualitative content analysis is to keep the strengths of the quantitative approach but, at the same time, keep the advantages of systematic qualitative oriented text analysis following the hermeneutical circle structure. In this respect, categories emerge as qualitative steps, while category frequency is calculated as a quantitative step. Students' productions were analyzed using a mixture of inductive and deductive ways of categorizing (Mayring, 2014).

Analysis focused on two critical features of OIS. On one hand, how inquiry was designed by undergraduate teachers, paying special attention to question formulation and experimental design (see tables 1 to 3 ). On the other hand, how conclusions and interpretations were built from results, as explained below. Regarding question formulation and experimental design, after defining the aims of our study, an analysis of the data allowed us to create a first proposal of code families. This proposal was evaluated and restructured to create a final system of code families checking both the data and the theoretical framework. Then, data was analyzed separately by the authors of the research through the lens of this final proposal. This last analysis gave some incoherencies that allow us to sophisticate the code families as presented below (tables 1 to 3 ).

Concerning how conclusions and interpretations were built from results, three items were considered:

i) coherence between conclusions and results. Considering whether or not conclusions were based on the patterns obtained in the results, therefore establishing a fact.

ii) ability to distinguish between conclusions and interpretations. Considering whether in posters there was no confusion between conclusions 
TABLE 1

CODES FROM INVESTIGABILITY AND ADEQUACY OF QUESTION FORMULATION CATEGORY INSPIRED ON CATEGORIES DESCRIBED IN CUCCIO®SCHIRRIPA \& STEINER (2000)

\begin{tabular}{ll}
\hline $\begin{array}{l}\text { Non-investiga- } \\
\text { ble questions: }\end{array}$ & $\begin{array}{l}\text { Students post one or more questions. All or some of these questions pertain to factual } \\
\text { information or simple "yes" or "no" responses. E.g. Do we find the same kind of insects } \\
\text { in bushes as in trees? }\end{array}$ \\
\hline $\begin{array}{l}\text { Low-level } \\
\text { investigable } \\
\text { questions: }\end{array}$ & $\begin{array}{l}\text { Students post only one descriptive question that only requires choosing the measura- } \\
\text { ble or observable variable. E.g. Where in the garden is the greatest diversity to be found? }\end{array}$ \\
\hline $\begin{array}{l}\text { Middle-level } \\
\text { investigable }\end{array}$ & $\begin{array}{l}\text { Students post only one question. This question leads to students' outdoor compara- } \\
\text { tive/correlative investigation and requires experimental design. Formulation of ques- } \\
\text { tion is deficient. Question shows deficit in the identification of variables. E.g. How } \\
\text { does the community of swallows evolve at the garden? }\end{array}$ \\
\hline $\begin{array}{l}\text { High-level } \\
\text { investigable } \\
\text { questions I: }\end{array}$ & $\begin{array}{l}\text { Students post only one question. This question leads to students' outdoor comparati- } \\
\text { ve/correlative investigation and requires experimental design. Question shows deficit } \\
\text { in the identification of variables. The question is well-formulated: variables are spe- } \\
\text { cific, well identified within the question and measurable. E.g. How does temperature } \\
\text { affect to the appearance of insects in the central part of the garden? }\end{array}$ \\
\hline $\begin{array}{l}\text { High-level } \\
\text { investigable } \\
\text { questions II: }\end{array}$ & $\begin{array}{l}\text { Students post only one question. This question leads to outdoor investigations that } \\
\text { focus on animal behavior under natural conditions. E.g. Which are the birds' behaviors } \\
\text { at the garden? }\end{array}$ \\
\hline
\end{tabular}

TABLE 2

CODES FROM ADEQUACY OF QUESTION IN RELATION TO EXPERIMENTAL DESIGN CATEGORY

\begin{tabular}{ll}
\hline Non-adequacy: & coherence between question and proposed research methodology does not exist \\
\hline Adequacy: & coherence between question and proposed research methodology exists \\
\hline
\end{tabular}

TABLE 3

CODES FROM QUALITY OF EXPERIMENTAL DESIGN CATEGORY

\begin{tabular}{ll}
\hline Low-level: & $\begin{array}{l}\text { General description without clearly choosing measurable/observable variables, ways } \\
\text { to measure/observe them, how to control or manipulate them. }\end{array}$ \\
\hline Middle-level & $\begin{array}{l}\text { Detailed experimental design description that includes some deficiencies when choo- } \\
\text { sing measurable/observable variables and/or when defining how to manipulate them/ } \\
\text { control them (when necessary). }\end{array}$ \\
\hline High level: & $\begin{array}{l}\text { Detailed and correct description of experimental design including observable/mea- } \\
\text { surable variables and how to proceed. }\end{array}$ \\
\hline
\end{tabular}

(that established facts derived from results) and the interpretations of these facts/evidences.

iii) how the model of the ecosystem network discussed in class was used to explain those conclusions. Contemplating if the given model was being used and to what extend and how it was being used to interpret facts/evidences. 


\section{Results}

Deep analysis and combination of code families in tables 1 to 3 allowed us to identify five different profiles of preservice elementary school teachers regarding their OIS performance (see Table 4). As it can be seen, these profiles can be identified with different sophistication levels of OIS performance - profile 1 being the less sophisticated level and profile 5 the most sophisticated one.

TABLE 4

PROFILES OF PRESERVICE ELEMENTARY STUDENTS REGARDING OIS PERFORMANCE. PROFILES AROSE FROM COMBINATION OF CODES IN TABLES 1 TO 3

\begin{tabular}{ll}
\hline Profile 1: & $\begin{array}{l}\text { Students pose low to middle-level investigable questions; there is not adequacy of } \\
\text { question in relation to experimental design and experimental design is considered } \\
\text { low-level. }\end{array}$ \\
\hline Profile 2: & $\begin{array}{l}\text { Students pose high-level investigable questions I and II; there is not adequacy of } \\
\text { question in relation to experimental design and experimental design is considered } \\
\text { low-level. }\end{array}$ \\
\hline Profile 3: & $\begin{array}{l}\text { Students pose high-level investigable questions I and II; there is not adequacy of } \\
\text { question in relation to experimental design and experimental design is considered } \\
\text { high-level. }\end{array}$ \\
\hline Profile 4: & $\begin{array}{l}\text { Students pose high-level investigable questions I and II; there is adequacy of ques- } \\
\text { tion in relation to experimental design and experimental design is considered } \\
\text { middle-level. }\end{array}$ \\
\hline Profile 5: & $\begin{array}{l}\text { Students pose high-level investigable questions I and II; there is adequacy of ques- } \\
\text { tion in relation to experimental design and experimental design is considered high- } \\
\text { level. }\end{array}$ \\
\hline
\end{tabular}

The profiles in Table 4 allowed us to study the temporal evolution of levels of OIS performance both at individual group and collective/average levels (see figures 1 and 2, respectively), which defines trajectories that depict the changes on OSI performance along the studied period.

To explain results at a collective level, we clustered groups of students according OIS performance levels (see Table 4 for description of profiles/ performance levels and Figure 2 for collective trajectories).

General clear increasing trajectories can be both recognized at individual and collective levels (see figures 1 and 2), resulting in more sophisticated OIS over time. In general terms, throughout outdoor inquiry, students moved from profiles of performance 1-2 to profiles of performance 4-5 (see Figure 2). However, two different trends in trajectories can be identified: a minority one, which comprises those groups starting at profiles 4 and moving to 5 over time (9.45\% of groups); and those starting at lower levels (1-2) and moving to higher levels (4-5) over time (see figures 1 and 2). Furthermore, a clear jump in OIS 


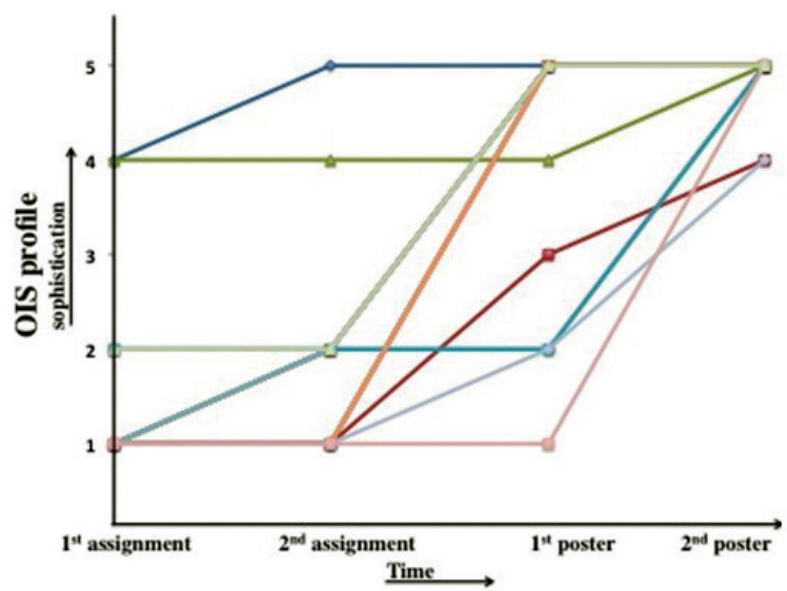

Figure 1. Temporal evolution of individual groups OIS performance. Each colour represents one preservice students' group. Note that some of the group trajectories overlap and, therefore, not all 21 trajectories are visible. Profiles of OIS performance in Table 4 (axis $Y$ ) have been identified with sophistication levels of performance.

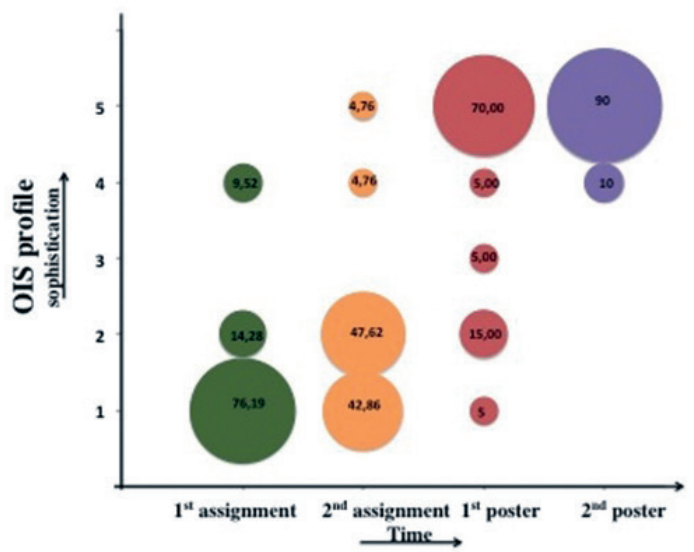

Figure 2 Temporal evolution of the collective OIS performance. Size and numbers within spheres indicate $\%$ of students included in a specific profile/level of performance (Note that profiles of OIS performance in table 4 -axis $\mathrm{Y}$ - have been identified with sophistication levels of performance). Colors correspond to preservice students' productions given at a certain point of time.

performance can be found between the delivery of the $2^{\text {nd }}$ assignment and the delivery of the $1^{\text {st }}$ poster in both cases (see Figure 2). A close look at profiles in Table 4 enables us to see that this is due to enhancement of adequacy between question and experimental design and enhancement of experimental design. Profile 3 appears to be really rare, with a single presence $(5 \%$ in Figure 2$)$ at the delivery of the $1^{\text {st }}$ version of the complete poster. 
Initial questions were mostly non-investigable questions. Nevertheless, professor and peer feedback helped preservice students to move to high-quality questions I and II in all cases (e.g. initial stage non-investigable question: "Are ladybugs affected by climate change?", changes, after feedback, to: "How is the population of ladybugs affected by sunny/cloudy days?'). In the majority of the cases, and in accordance to Windschitl et al. (2007), these questions lead to comparative and correlative studies. Only in one case, animal behaviour studies were purposed and performed. At initial stages, some questions leading to descriptive studies were also found. In general, these questions were not even well posed, as they contained unspecific terms (e.g. "Where in the garden is the greatest diversity to be found?"). Note that here 'biodiversity' appears as a too wide/unspecific term to be investigated. In all cases but one, reformulation of descriptive questions was accompanied by reformulation of a kind of design study (comparative/correlative ones).

First descriptions of experimental designs were vague in almost all cases and failed to identify variables correctly (e.g. "We want to observe the distribution of blackbirds in the garden at a specific time"). Over time, all groups succeeded in identifying variables and/or in describing procedures to obtain data. However, most final descriptions lack the rigour of real scientific contexts. The definition of control variables represented a significant constraint (e.g. “...during April and May, every Wednesday between 9:30 and 10:30, we measured the temperature and counted the number of blackbirds"). Students also indicate that they have taken into accout weather conditions but not, for example, presence of human beings. Weaknesses in posing investigable questions and making experimental designs made question-experimental design adequacy difficult at the first stages. Feedback and instruction provided during the course succeeded in enhancing both scientific skills, thus improving overall adequacy.

Coherence between conclusions and evidence was general. However, 8 out of 18 initial posters submitted contained conclusions that either: i) failed to show differences between conclusions from inferences and/or limitations; ii) presented conclusions that included data that did not refer to the question being investigated; iii) confused conclusions with a graph legend. Peer review sessions only helped to overcome this problem in two cases. Only 17 initial posters contained interpretations, and only 7 from them used the model of ecological network discussed during the course to interpret results. In 4 cases the incorporation of the model was done after peers' feedback. All final posters included interpretations, but 7 of them still did not use the presented/discussed model. However, in all cases, explanations failed to reflect real complexity of the model.

Consider the following excerpt from the 'interpretations section' of a final poster investigating the correlation between temperature and abundance of insects: "The first day we did not observe wasps or bumblebees...temperatures have 
been lower this spring, delaying flowering and blossom development. As the butterflies, wasps and bumblebees are pollinators, this has not favoured its appearance. However, we have seen wasps and bumble bees as these are not affected by the temperature while butterflies do so." Although it should only refer to the interpretations of the facts ("temperatures have been lower this spring, delaying flowering and blossom development. As the butterflies, wasps and bumblebees are pollinators, this has not favoured its appearance"), it also contains results ("the first day we did not observe wasps or bumblebees") and conclusions ("we have seen wasps and bumble bees as these are not affected by the temperature while butterflies do so"). In addition, as it can be seen, the model is used very poorly giving a single linear argument for the presence/ absence of insects.

\section{Discussion and conclusions}

This study provides valuable evidence about elementary school preservice teachers' developing capabilities as well as insights into challenges or incomplete understandings regarding OIS. Deep content analysis of different OIS let us define four different profiles regarding their OIS performance. In turn, these profiles allowed us to explore collective and individual group temporal trajectories of OIS performance.

Analysis of the data, and the displayed profiles and temporal trajectories revealed that, at the beginning of the study, the participants in general, showed weak OIS (Windschitl et al., 2008). Giving them the opportunity to design and perform a field investigation as it would happen in a school science environment, as well as an adequate formative assessment, rapidly increased their OIS (AbdEl-Khalick, 2013; Bell \& Cowie, 2001). Enhancement of investigable questions and experimental design was easily achieved at initial stages, after teacher feedback. This reflected positively the global enhancement of adequacy between question and experimental design. Minor problems regarding posing question or designing experiments were solved after feedback from peers. Data shows that the construction of an investigable question is a critical point to improve students' OIS performance. In this respect, the lack of groups in profile 3 may be explained because students can only construct a good experimental design if they have a deeper understanding of what they are investigating. Using a given model to interpret data, differentiating between empirical conclusions and explanatory interpretations appear to be major difficulties for preservice elementary teachers. Their own limitations regarding these specific inquiry skills may limit their contribution when assessing their peers.

Conclusions also suggest implications for teaching courses. Providing elementary school student teachers with real contexts to promote field investigations, and reflecting on them while doing scientific posters, appears to be an interesting tool to explicit OIS. Therefore, it seems compelling to promote 
such practices as an effective formative assessment tool in undergraduate contexts. It would be interesting to analyze which pieces of knowledge discussed in class were meaningful for undergraduate students to enhance their OIS. Further research would be needed to gain a deeper understanding of how OIS knowledge is constructed, to improve undergraduate courses.

\section{References}

Abd-El-Khalick, F. (2013). Teaching with and about nature of science, and science teacher knowledge domains. Science \& Education, 22(9), 2087-2107.

Abell, S. K. (2006). Challenges and opportunities for field experiences in elementary science teacher preparation. In K. Appleton (Ed.) Elementary science teacher education: International perspectives on contemporary issues and practice (pp. 7-89). Mahwah: Erlbaum

Abell, S. K., Appleton, K., \& Hanuscin, D. L. (2010). Designing and teaching the elementary science methods course. Routledge.

Ault Jr, C.R., \& Dodick, J. (2010). Tracking the Footprints Puzzle: The problematic persistence of science-as-process in teaching the nature and culture of science. Science Education, 94(6), 1092-1122.

Bell, B., \& Cowie, B. (2001). The characteristics of formative assessment in science education. Science education, 85(5), 536-553.

Brune, J. (2002). Take it outside!. Science and Children, 39(7), 29-33

Borsos, E., Patocskai, M., \& Boric, E. (2018). Teaching in nature? Naturally!. Journal of Biological Education, 1-11.

Bybee, R. (2000). Teaching science as inquiry. In: Minstrell J.\& van Zee E. (Eds.), Inquiring into inquiry learning and teaching in science. Washington, DC: American Association for the Advancement of Science.

Crowther, D. T., Lederman, N. G., \& Lederman, J. S. (2005). Understanding the true meaning of nature of science. Science and Children, 43(2), 50-52.

Cuccio-Schirripa, S., \& Steiner, H. E. (2000). Enhancement and analysis of science question level for middle school students. Journal of Research in Science Teaching, 37(2), 210-224.

Dillon, J., Rickinson, M., Teamey, K., Morris, M., Choi, M. Y., Sanders, D., \& Benefield, P. (2006). The value of outdoor learning: evidence from research in the UK and elsewhere. School science review, 87(320), 107.

Duschl, R. A., \& Grandy, R. E. (2008). Consensus: Expanding the scientific method and school science. In R. A. Duschl \& R. E. Grandy (Eds.), Teaching scientific inquiry (pp. 304 - 325). Rotterdam, The Netherlands: SensePublishers.

Duschl, R . A., Schweingruber, H. A., \& Shouse, A. W. (Eds.). (2007). Taking science to school: Learning and teaching in grades K-8. Washington, DC: National Academy Press.

Grace, M. and Byrne, J. (2010) Engaging pupils in decision-making about biodiversity conservation issues. School Science Review, 91 (336), 73-80 
Guba, E. G., \& Lincoln, Y. S. (1994). Competing paradigms in qualitative research. In N.K. Denzin \& Y. S. Lincoln (Eds.), Handbook of qualitative research, (pp.105 117). London: Sage.

Kloser, M. J. (2012). A Place for the Nature of Biology in Biology Education. Electronic Journal of Science Education 16 (1): 1-18.

Krajcik, J. S., \& Blumenfeld, P. (2006). Project-based learning. In R. K. Sawyer (Ed.), The Cambridge handbook of the learning sciences (pp. 317-333). Cambridge: Cambridge University Press.

Kremer, K., Specht, C., Urhahne, D., \& Mayer, J. (2014). The relationship in biology between the nature of science and scientific inquiry. Journal of Biological Education, 48(1), 1-8.

Lederman, J. S., et al. (2014). Meaningful assessment of learners' understandings about scientific inquiry-The views about scientific inquiry (VASI) questionnaire. Journal of Research in Science Teaching, 51(1), 65-83.

Mayring, Ph. (2014). Qualitative content analysis: theoretical foundation, basic procedures and software solution. Retrieved October 19, from: http://nbn-resolving.de/ urn:nbn:de:0168-ssoar-395173

Minner, D., Levy, A., \& Century, J. (2010). Inquiry-Based science instruction-what Is It and does It matter? Results from a research synthesis years 1984 to 2002. Journal of Research in Science Teaching, 47(4), 474-496.

Mogensen, F., Mayer, M., (2005). Eco-schools - trends and divergences: A comparative Study on ECO-school development processes in 13 conutries. Vienna: Austrian Federal Ministry of Education, Science and Culture. Retreived October 19, from: https:// ensi.org/global/downloads/Publications/173/ComparativeStudy1.pdf

Ryken, A. E., Otto, P., Pritchard, K., \& Owens, K. (2007). Field investigations: Using outdoor environments to foster student learning of scientific processes. Olympia, WA: Pacific Education Institute.

Roth, W. M. (1995). Authentic school science knowing and learning in open-inquiry science laboratories. The Netherlands: Kluwer Academic Publishers.

Scott, G. W., \& Boyd, M. (2016). Getting more from getting out: increasing achievement in literacy and science through ecological fieldwork. Education 3-13, 44(6), 661-670.

Waite, S. 2007. Memories are made of this: Some reflections on Outdoor Learning and Recall. Education 3-13 35(4): 333-347

Wals, A. E., Brody, M., Dillon, J., \& Stevenson, R. B. (2014). Convergence between science and environmental education. Science, 344(6184), 583-584.

Windschitl, M., Dvornich, K., Ryken, A. E., Tudor, M., \& Koehler, G. (2007). A comparative model of field investigations: Aligning school science inquiry with the practices of contemporary science. School Science and Mathematics, 107(1), 382390

Windschitl, M., Thompson, J., \& Braaten, M. (2008). Beyond the scientific method: Model-based inquiry as a new paradigm of preference for school science investigations. Science education, 92(5), 941-967. 



\title{
STORYTELLING AS AN EDUCATIONAL TOOL IN BIOLOGY TEACHING: A PILOT STUDY
}

\author{
Nausica Kapsala and Evangelia Mavrikaki \\ Department of Primary Education, National and Kapodistrian University of Athens \\ nkapsala@gmail.com
}

\begin{abstract}
Storytelling is a core human characteristic that describes the way we think, dream, construct our knowledge of the world, communicate, and learn. In science and in biology teaching, it may facilitate the introduction of history and philosophy of science in the teaching context, promoting cultural content knowledge and Nature of Science (NOS) understanding. We present a case study concerning an experimental teaching strategy that involves storytelling followed by conversation, which was applied to teach the concept of bio-accumulation to 10th grade Greek students. The story told is "The silenced robins" about the incident of an increased number of dying robins in 1955, and George Wallace's research that led to the ascertainment that DDT had poisoned them. We followed a quasi-experimental design and looked into the way students evaluate storytelling as a teaching-learning method. Students were positive towards the method and praised the storytelling biology lesson more than a lesson without it. They found it more interesting, participatory and engaging, and considered storytelling as helpful for them in achieving cognitive goals, and understanding core ideas of science. Furthermore, a positive change to the classroom's climate was noted. We propose that storytelling can contribute to an active and meaningful learning.
\end{abstract}

Keywords: storytelling, student engagement, history of science, nature of science, classroom climate

\section{Introduction}

Storytelling is a core human characteristic that describes the way we think, dream, construct our knowledge of the world, communicate, and learn (Bruner, 1991; Egan, 1989; Pace-Schott, 2013). Storytelling is considered as an 
evolutionary characteristic of our species (Boyd, 2009; Gottschall, 2012; Mayr, 2001), a suggestion that is supported by neurobiological and biochemical findings (Cheetham et al., 2014; Zak, 2015), and explains why although storytelling is such a big part of our everyday lives we barely notice - just like fish are unaware of the existence of water (Bruner, 2003).

Storytelling has long been the educational method of oral societies, yet it retains its position in our literal technological world. It provides us with a strong mnemonic tool: stories. Due to their form as well as the fact that they provoke feelings, their incorporated information can pass to the long-term memory (Bruner, 2003; Egan, 1989; Klassen, 2010). Moreover, in educational contexts it has been proposed that storytelling can reinforce class cohesion, and studentteacher relationships (Abrahamson, 1998; Wills, 1992). These last two attributes, relate to the mean of storytelling, which is orality. Oral communication is special, as the transmitter is also a receiver simultaneously (Ong, 2013). That way, successful communication is achieved both through speech and non-verbal forms of communication, such as gestures and eye contact. The story told is being formed by the storyteller / teacher as well as by the listeners / students, whose reactions to the story affect it. During storytelling, the teacher and the students share a common experience of co-creation that reinforces their relationships.

In science and in biology teaching, storytelling may facilitate the introduction of history and philosophy of science in the teaching context. Such an approach promotes cultural content knowledge, puts science in context and results in meaningful learning (Galili, 2015). Science gets humanized and students are inspired and motivated (Kokkotas et al., 2010) as science gets connected to more personal, moral, cultural and political worries (Mathews, 1992). Moreover, examples/stories from the History of Science (HOS) can serve to introduce the nature of science (NOS) aspects (McComas \& Kampourakis, 2015), especially when, as we have previously proposed (Kapsala \& Mavrikaki, in press), those examples are delivered through storytelling followed by a discussion of the respective sociocultural aspects of science. Such an approach can promote students' critical thinking (Kokkotas, et al., 2010), as the subjects are being presented in the context of doubt and questioning, and in a way that promotes problematisation and dialogue.

Storytelling is an art and its implementation may serve STEAM (Science, Technology, Engineering, Arts and Maths) educational goals. But not any story is suitable for a science storytelling intervention. The story should be both amusing and conveying a message so as to be a good story that will attract interest and engage students. Moreover, since it is a scientific story, it should facilitate teaching and learning science and make scientific ideas understandable. Finally, as we are working with the history of science stories, the story should be historically accurate, and it should approach facts and concepts with consideration of the thinking, morals and beliefs which existed in historical times (Abd-Khalick \& Lederman 
2000; Klassen, 2009). Considering the above, we came up with the following research questions:

- How do secondary school students evaluate the storytelling (based on the History of Science) teaching method?

- Do they consider it helpful for achieving science learning goals?

- How do they evaluate it in terms of emotional concepts?

- How do they evaluate it in terms of their engagement with the lesson?

- How do they consider that it affects the classroom climate?

- Do they consider it as helpful for learning about the Nature of Science?

- Do boys and girls evaluate storytelling differently, and does the grade matter?

- How do students evaluate the biology lesson with and without storytelling?

\section{Research design and Method}

This study is part of a broader research project, for the purposes of which we have developed and written stories derived from the History of Biology, which are presented in Kapsala \& Mavrikaki (in press). The stories have been written based on the structure of traditional folktales (Propp, 1991), and they were elaborated with several storytelling tools, like the narrative pyramid (Ellery $\&$ Rosenboom, 2011). The pyramid presented in Figure 1 was constructed by the authors in order to organize the story information in a clear and memorable way. The story we used in our case is 'The silenced robins' (Carson, 2002). During our pre-studies, which followed a qualitative research design (and included nonparticipatory observation of the interventions, students' interviews, and teachers' interviews), storytelling was found to be equally effective with the traditional teaching method in achieving learning goals. Moreover, we came up with several interesting findings about how students evaluate the storytelling (based on HOS) teaching method. Students' comments could be grouped into the following categories: emotional dimensions, cognitive dimensions, engaging dimensions, NOS implications, effect on the classroom climate (Kapsala et al., 2015; Kapsala \& Mavrikaki, unpublished results). Based on those findings, we developed the questionnaire described later on, aiming to see if those findings will be confirmed by a bigger number of students. The study presented here, is about the first application of the questionnaire with a small number of students.

\subsection{Method, Sample and Research instrument}

We followed a quasi-experimental design (White \& Sabarwal, 2014) and the research was conducted in the $2^{\text {nd }}$ Experimental Lyceum of Athens in the A' Lyceum (grade $10^{\text {th }}$ ). The experimental teaching was delivered by one of the authors who is a well-trained, experienced storyteller, and at that time she was a teacher in that school. She was the biology teacher of all the classes that 
participated in the research, so the students were familiar with her. Therefore, we used convenience sampling. The experimental group consisted of two classes, 45 students in total (19 girls and 26 boys), and the control group consisted of one class, 24 students (15 girls and 9 boys). The students of both groups throughout the school year were taught biology in the traditional way (teachercentered). An experimental intervention was implemented once with the experimental group. The intervention lasted for one teaching hour ( 45 minutes) and it included storytelling and discussion. At first the students were informed about what would follow. Then the teacher told them orally, by heart, in her own words the story. During the storytelling the students were carefully listening, and at some points they would interject with comments or questions about the story, which were welcomed by the teacher. When the story ended, students were asked about what had impressed them the most about the story, and a discussion followed about the story and some sociocultural and NOS aspects that came up, such as how politics and economics affect science, etc.

Two weeks after the storytelling, a questionnaire was distributed to the students of both groups, and they had about 20 minutes to complete it. The questionnaire was built in order to collect data about how students evaluated the biology lesson with and without storytelling. Of course students in the control group completed only half of the questionnaire (not the part that was about storytelling). The questionnaire consisted of six demographic questions, two open- ended questions, two multiple choice questions with multiple answers, three multiple choice questions with single answers, and two attitude scales. One attitude scale consisted of 34 items with a 5-point Likert scale, to be answered twice by each student (expressing his/her opinion about the biology lesson with and without storytelling); the other attitude scale consisted of 17 items with a 5-point Likert scale, where students expressed their opinion about storytelling as a teaching method (where 1 refers to "totally disagree" and 5 to "totally agree"). Five items of the first scale and five items of the second one were negatively phrased, and they were later on reversed for the statistical analysis.

For the construction of the two scales (with the 5-point Likert items) we drew on other researchers' findings (Kokkotas et al., 2010; Frisch \& Saunders, 2008) as well as the findings of our own pre-studies (Kapsala et al., 2015), which were conducted with 14, 15 and 17 year old students. During the prestudies: i) a story derived from the History of Biology that matched students' curriculum was told during the lesson, and in the meanwhile a researcher/nonparticipatory observer filled an observation tool; ii) two months later the researcher interviewed the students about the storytelling lesson in focus groups; and iii) students' quotes retrieved from those interviews were included in the questionnaire as Likert-scaled questions. Examples of such students' quotes were: "The story is the equivalent of the experiment; like an experiment stays in your mind and gives you a better understanding, so does the story ... it ... basically plays a 
little inside your head", "Our teacher was more relaxed, not like the other times that she scolds us all the time" (Kapsala et al., 2015).

The variables that guided us to the construction of the questionnaire were:

- independent variables: a) group (control or experimental); b) gender; c) last year's average grade; d) biology grade; e) having a family member who is a scientist; f) storytelling during other courses; g) having read books about science and scientists; and h) having watched movies about science and scientists.

- dependent variables: a) how the students claim to learn information better; b) how students evaluate the biology lesson without storytelling; c) how they evaluate it with storytelling; and d) how they evaluate the storytelling as a teaching method.

\subsection{The story}

The story we told was 'The silenced robins'. It is about the incident of dying robins in 1955 in the Michigan State University campus, and George Wallace's research that led to the ascertainment that DDT had poisoned them. George Wallace, a professor of ornithology, along with his student John Mehner connected the reduction in the size of the robin population with the use of the insecticide DDT. Combining their findings with another researcher's publication, and a strange incident in a wildlife laboratory, Wallace published the paper 'Insecticides and Birds' that caused a huge reaction from the agricultural industry and even put his tenure in danger. After the positive intervention of a politician, the communication with Rachel Carson, and the findings of another doctoral student of his, Richard Bernard, Wallace was finally proven correct (Carson, 2002; Morgan, 2012; Wallace, 1959; Wallace \& Bernard, 1963). The story was chosen as it concerns an environmental issue, and can lead to the discussion of several sociocultural and Nature of Science (NOS) topics.

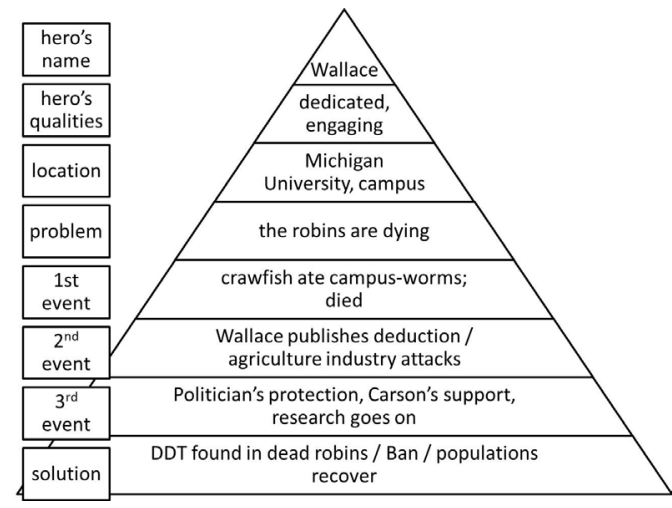

Figure 1 The narrative pyramid for "the silenced robins" story. 


\subsection{Data analysis}

Data were analyzed with the @IBM SPSS22. Descriptive statistics were performed, independent samples t-test, two-tailed Pearson correlation between variables, and chi-square tests were applied. The frequencies of the positive answers and the means for each subscale were estimated. Paired samples t-test was used in order to look for differences in students' attitudes as a whole and for each statement $(\alpha=0.05)$. Both researchers analyzed students' answers to the open-ended questions following the principles of classic thematic analysis (Braun \& Clarke, 2006). They coded the answers independently and they reached an agreement of $97 \%$.

\section{Results}

\subsection{How students evaluated storytelling as a teaching method}

The students of the experimental group filled in an attitude scale evaluating storytelling as a teaching method. The scale's reliability was high (Cronbach's alpha $=0.88$ ). Students evaluated positively the storytelling lesson, with a mean value of $4.02 \pm 0.52$. In Figure 2 we present the distribution of students' answers.

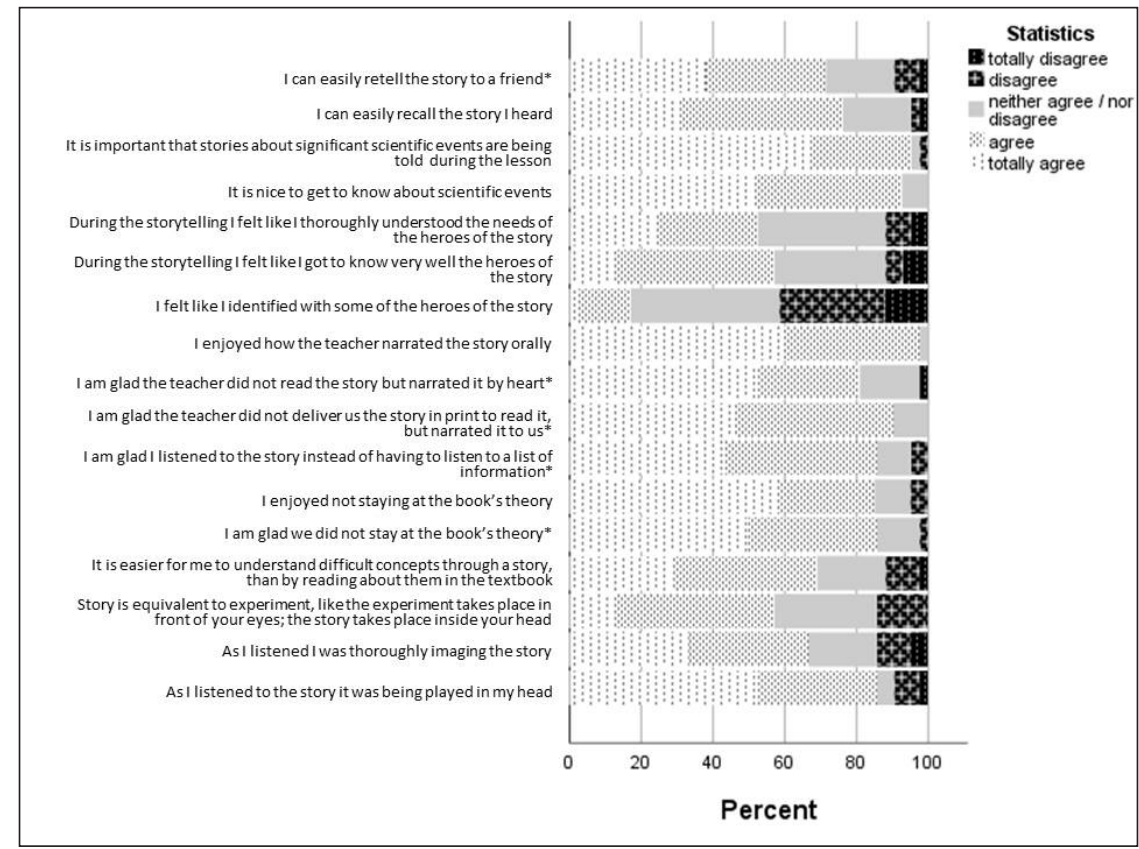

Figure 2 Stack bar chart of the frequencies of students' ideas (evaluation) regarding the storytelling as a teaching method. Items marked with an asterisk $\left(^{*}\right)$ were originally negatively phrased, and reversed for the statistical analysis. 
An independent samples' t-test revealed that there are no statistically significant differences between the way girls and boys evaluate the storytelling lesson $(\mathrm{t}=-1.23, \mathrm{df}=38.8, \mathrm{p}=0.225>0.05)$. Moreover, we found that there is no correlation between the way the students evaluated the storytelling lesson and the previous year's overall grade $(\mathrm{R}=-0.026, \mathrm{p}=0.87>0.05)$, nor their grade in biology especially $(\mathrm{R}=-0.095, \mathrm{p}=0.57>0.05)$.

\subsection{Working on with the experimental group}

As previously mentioned, the students in the control group filled in only the subscale that was about evaluating the biology lesson in general (without storytelling). The students in the experimental group filled in this subscale as well. We performed a paired samples t-test, finding no statistically significant difference between the two groups (experimental and control) $(\mathrm{t}=0.720, \mathrm{df}=67$, $\mathrm{p}=0.474>0.05)$. So since the students in the experimental group evaluated the biology lesson in the same way as the students in the control group, for the following analyses and comparisons between the biology lesson with and without storytelling, we only used the data derived from the experimental group ( $\mathrm{N}=45$ students / 19 girls and 26 boys).

\subsection{How students evaluate the biology lesson with and without storytelling}

The reliability of the questionnaire was checked, and it was found that both scales (evaluating the lesson with and without storytelling) had a high Cronbach's alpha (Table 1). We also computed the mean value for each scale (with and without storytelling), and performed a paired samples t-test. We found that there are statistically significant differences between how students evaluate the biology lesson with and without storytelling, $(t=7.67, \mathrm{df}=44, \mathrm{p}=0<0.05)$ with students being in favour of the lesson with storytelling.

TABLE 1

RELIABILITY (CRONBACH'S ALPHA) AND MEAN VALUES FOR THE LIKERT SCALED QUESTIONS EVALUATING THE LESSON OF BIOLOGY WITH AND WITHOUT STORYTELLING

\begin{tabular}{lll}
\hline & with storytelling & without storytelling \\
\hline Cronbach's alpha & 0.90 & 0.92 \\
\hline mean value & $3.87 \pm 0.55$ & $2.80 \pm 0.65$ \\
\hline
\end{tabular}

We performed a paired samples t-test for each of the statements of the attitude scale, comparing how students answer for the biology lesson with and without storytelling. The statements for which there is a statistically significant difference $(\mathrm{p}<0.05)$ are presented in Table 2. 
TABLE 2

STATEMENTS FOR WHICH STUDENTS EXPRESSED A DIFFERENT EVALUATION BETWEEN THE BIOLOGY LESSON WITH AND WITHOUT STORYTELLING. ITEMS MARKED WITH AN ASTERISK (*) WERE ORIGINALLY NEGATIVELY PHRASED, AND REVERSED FOR THE STATISTICAL ANALYSIS

\begin{tabular}{|c|c|c|c|c|c|c|}
\hline$A A$ & Statement & $\begin{array}{l}\text { Mean with } \\
\text { Storytelling }\end{array}$ & $\begin{array}{c}\text { Mean } \\
\text { without } \\
\text { Storytelling } \\
\end{array}$ & $t$ & $d f$ & $p$ \\
\hline 1 & it helps me understand difficult concepts & $3.95 \pm 0.94$ & $3.16 \pm 1.4$ & 3.374 & 43 & 0.002 \\
\hline 2 & it helps bear the theory to mind & $4.23 \pm 1.04$ & $3.28 \pm 1.02$ & 3.476 & 42 & 0.001 \\
\hline 3 & it helps remember textbook's theory & $3.78 \pm 1.20$ & $3.05 \pm 1.34$ & 7.644 & 42 & 0.000 \\
\hline 4 & I use it as an example when I study & $3.67 \pm 1.43$ & $2.45 \pm 1.27$ & 3.745 & 41 & 0.001 \\
\hline 5 & I like it & $4.60 \pm 0.79$ & $2.81 \pm 1.45$ & 6.803 & 42 & 0.000 \\
\hline 6 & I can participate in it & $3.33 \pm 1.43$ & $3.48 \pm 1.42$ & 9.439 & 42 & 0.000 \\
\hline 7 & it is interactive & $4.09 \pm 1.12$ & $2.32 \pm 1.22$ & 5.720 & 43 & 0.000 \\
\hline 8 & it is done in a way that makes me attend & $4.49 \pm 0.81$ & $3.17 \pm 1.20$ & 6.006 & 40 & 0.000 \\
\hline 9 & most of my classmates attend it & $4.42 \pm 0.79$ & $2.40 \pm 1.09$ & 8.530 & 43 & 0.000 \\
\hline 10 & it is not boring* & $4.36 \pm 0.81$ & $2.89 \pm 1.37$ & 6.155 & 43 & 0.000 \\
\hline 11 & it interests $\mathrm{me}^{*}$ & $4.68 \pm 0.62$ & $3.98 \pm 1.19$ & 3.557 & 39 & 0.001 \\
\hline 12 & it is very interesting & $4.27 \pm 0.73$ & $2.84 \pm 1.33$ & 6.397 & 43 & 0.000 \\
\hline 13 & it is imagerial / vivid & $4.33 \pm 1.93$ & $2.21 \pm 1.00$ & 10.48 & 41 & 0.000 \\
\hline 14 & it revives my imagination & $3.95 \pm 1.18$ & $1.77 \pm 1.10$ & 4.346 & 42 & 0.000 \\
\hline 15 & I feel strong feelings during it & $2.86 \pm 1.39$ & $1.84 \pm 1.10$ & -5.871 & 42 & 0.000 \\
\hline 16 & it is relaxing & $4.20 \pm 1.21$ & $2.05 \pm 1.05$ & 4.770 & 43 & 0.000 \\
\hline 17 & teacher is relaxed during it & $4.60 \pm 0.62$ & $2.91 \pm 1.34$ & 6.457 & 42 & 0.000 \\
\hline 18 & teacher does not scold during it* & $4.21 \pm 0.99$ & $2.53 \pm 1.40$ & 10.321 & 43 & 0.000 \\
\hline 19 & teacher is approachable during it & $4.11 \pm 1.02$ & $3.45 \pm 1.15$ & 3.710 & 43 & 0.001 \\
\hline 20 & it helps me understand how science works & $3.59 \pm 1.35$ & $2.61 \pm 1.33$ & 6.256 & 42 & 0.000 \\
\hline 21 & it helps me understand about scientists & $3.74 \pm 1.24$ & $2.21 \pm 1.17$ & 3.130 & 43 & 0.003 \\
\hline 22 & $\begin{array}{l}\text { it motivates me to research and study more } \\
\text { aspects of its scientific subject }\end{array}$ & $3.07 \pm 1.45$ & $2.35 \pm 1.19$ & 3.606 & 43 & 0.001 \\
\hline 23 & $\begin{array}{l}\text { it makes me curious about science and } \\
\text { scientists }\end{array}$ & $3.77 \pm 1.16$ & $2.73 \pm 1.45$ & 9.534 & 40 & 0.000 \\
\hline 24 & we have interesting conversations during it & $4.23 \pm 1.05$ & $3.11 \pm 1.43$ & 3.817 & 43 & 0.000 \\
\hline
\end{tabular}

Aspects which showed no statistical significance in the way students evaluated the biology lesson with storytelling were: gender; last year's average grade; biology grade; having a family member who is a scientist; storytelling during other courses; having read books about science and scientists; and having watched movies about science and scientists. However, the way students evaluated the biology lesson without storytelling (i.e. the 'traditional' one) presents a 
positive correlation with their average grades $(\mathrm{R}=0.389, \mathrm{p}=0.01)$ as well as their biology grades $(\mathrm{R}=0.371, \mathrm{p}=0.18)$. Students with a higher grade expressed a better attitude for the biology lesson without storytelling. Therefore, the positive attitude of all students towards the lesson based on the storytelling signifies that a lesson like that would attract all students, regardless of their school achievements.

\subsection{Students' opinions about the teaching method that helps them remember scientific information better}

Students from both groups (experimental and control) were asked in a multiple-choice question with multiple answers how they get to remember scientific information better (Table 3).

TABLE 3

STUDENTS' ANSWERS ABOUT THE WAYS THROUGH WHICH THEY REMEMBER SCIENTIFIC INFORMATION BETTER

\begin{tabular}{lcc}
\hline Preferable way & Frequency & Frequency (\%) \\
\hline Through a story & 29 & 45.3 \\
When their teacher has explained it & 27 & 42.2 \\
Through an experiment & 26 & 40.6 \\
When they read about it & 19 & 29.7 \\
\hline
\end{tabular}

No statistical significances were found between students' answers in the control and the experimental group ( $p>0.05)$. An open ended question followed, asking students to support their choices. The answers of students who chose the story were content-analyzed and the thematic categories that emerged are presented in Table 4.

TABLE 4

THEMATIC CATEGORIES OF STUDENTS' ANSWERS SUPPORTING THE CHOICE: "I REMEMBER SCIENTIFIC INFORMATION BETTER WHEN IT IS DELIVERED THROUGH A STORY"

\begin{tabular}{lcc}
\hline Because that way it is... & Frequency & Frequency \% \\
\hline understandable & 5 & 17.2 \\
bared to mind & 5 & 17.2 \\
interesting & 4 & 13.8 \\
easier & 3 & 10.3 \\
imagerial & 3 & 10.3 \\
participatory & 3 & 10.3 \\
practical/experiential & 2 & 06.9 \\
about everyday life & 2 & 06.9 \\
fun & 2 & 06.9 \\
\hline Total & 29 & 100.0 \\
\hline
\end{tabular}




\section{Discussion}

\subsection{Students evaluating the emotional dimensions of the storytelling method}

According to the data derived from the questionnaires, students enjoyed the biology lesson with the storytelling, in fact they liked it more than the usual biology lesson, and they evaluated positively the storytelling as a teaching method. Neither students' gender nor their grades affected the way students evaluated the storytelling lesson and this is considered quite important as the method appeals to all students, boys and girls, regardless of their performance. Students claimed that they were engaged with the story. Storytelling is a lot about reviving the listeners' imagination and letting them create their own mental images as they listen to the story; according to the students' answers, this was achieved, as $85.7 \%$ of them agreed that as they listened to the story it was being played in their minds, and $66.7 \%$ that they were thoroughly imaging the story. In comparison to the usual biology lesson, they claimed that storytelling revived their imagination more. Commenting on the story they were told, a student wrote: "I liked it very much, because it gave a new shape to biology, like a movie".

The students seem to have appreciated and enjoyed the storytelling method, as $97.6 \%$ of them claimed that they enjoyed how the teacher narrated orally, $81 \%$ claimed that they preferred that the teacher told the story in a lively way and by heart, rather than reading it, and $90.2 \%$ rather than distributing it in script form. It seems that students appreciated the live, oral storytelling and the deep connection and communication that direct oral speech can offer (Ong, 2013; Stephens et al., 2010).

\subsection{Students evaluating the cognitive dimensions of the storytelling method}

Students claimed that the story made difficult scientific concepts understandable $(69.1 \%)$, in fact more than the usual biology lesson. They claimed that the story helped them remember the textbook's theory better, and that they bring it to mind as an example when studying at home more often than the usual instruction. Similar findings have come up from studies with older students (biology majors) (Frisch \& Saunders, 2008). Students also claimed that they can recall $(76.2 \%)$ and retell $(71.4 \%)$ the story, which has also been a finding in other studies, where a month after the intervention, high school students, during interviews, were able to concisely tell the story they had been told (Kapsala et al., 2015). The findings from the students' attitude scale towards the storytelling lesson are confirmed by the students' answers to the open-ended questions, asking them for their preferred choice of method to 
memorize information. Among the students, $44.7 \%$ referred to the cognitive gains from storytelling, such as: "the story helps me to understand better", and: "usually when I listen to a story I then remember it, so I also remember the scientific information included'. Along with these comments we can draw the conclusion that students consider the stories to be useful for them as educational tools.

\subsection{Students evaluating the engaging dimensions of the storytelling method}

Students evaluated the biology lesson that implemented storytelling as more interesting, more participatory and more interactive than the usual biology lesson. Among the students' answers to support their choice of storytelling, $41.3 \%$ of them supported it focusing on how interesting and participatory storytelling was (e.g. "it is more interactive that way and attracts more interest", "through the story I can see everything in practice"). This may seem surprising but it agrees with literature that supports that listening to a story is an active process of collecting facts, forming hypotheses, testing them and correlating new information to the known one (Kokkotas et al., 2010; Clair, 2008). Moreover, neurobiological findings also indicate that when listening to a story the brain reacts as if it is living the story (Cheetham et al., 2014; Speer et al., 2009). So listening to a story is an active process that can lead to active learning.

\subsection{NOS implications in students' evaluation}

Students enjoyed the fact that they had a chance to 'evade' the textbook (85.7\%), as one student noted commenting on the story: "it was nice that we did something different". It seems that the students had the feeling that the story was important; one student wrote: "He saved the robins' species, as well as ours". Students considered that such scientific stories should be told during courses (95.3\%). They considered it important to get to know about scientific events that led to discoveries (95.3\%). This acknowledgement can be considered as a necessary basis for the introduction of NOS aspects; it is encouraging that students seem to be interested in NOS.

Students also claimed that the storytelling lesson helped them, more than the usual biology lesson, to understand about how science works, as well as about the scientists' work. As one student wrote: "that way we get in the shoes of the scientist and learn through his/her experiences". Students also claimed that storytelling motivated them a lot to delve into some aspects of a scientific topic, and that it made them more curious about science and scientists than the usual biology lesson. These findings are in accordance with the findings of other studies with younger students (Kokkotas et al., 2010). Students also claimed that more, interesting conversations come up during the storytelling biology lesson than the 
usual one; this is very important, as it is through conversation that the sociocultural issues that concern the story can be speculated about, NOS aspects can be explicitly investigated, students' questions can be answered, and critical thinking can be reinforced. Since students are engaged with the appropriate guidance from the teacher, a better NOS understanding can be achieved. As we have previously proposed, following a story, as long as it is based on reliable historical sources, the myth of positivism is broken, as there is no straight path leading to knowledge, and through the story social and political obstacles or benefits are revealed, while scientists are seen as humans not 'superheros', and science as a human endeavour with flaws and high achievements. Plenty of motives for negotiation emerge, giving room for fruitful dialogues with the students that can sharpen their critical thinking skills (Kapsala et al., 2017).

\subsection{Students evaluating the classroom climate during the storytelling intervention}

Students found that the biology lesson with storytelling was more relaxing than the usual one, that their teacher was more relaxed during it, and that she made fewer remarks than during the usual lesson. What these answers imply is that storytelling improves the classroom climate, and cultivates a more relaxing atmosphere. Either it is that the teacher is more content and calmer or that the students are more engaged, and thus more concentrated and cooperative, or both. This comes in accordance with findings reported in the literature. According to Tigner (1993), through storytelling, both students and teachers are inspired and satisfied, and as information is mixed with inspiration, encouragement, satisfaction and charm, that will have an effect on the person's life and the society with which he/she interacts.

In addition, students found their teacher more approachable during the storytelling lesson than the usual ones. This can be explained by the fact that, as mentioned before, storytelling may importantly contribute to successful communication. Apart from that, it seems that storytelling can contribute to the repositioning of teachers' and students' roles and the cultivation of a classroom climate of trustfulness and collaboration (Kapsala, et al., 2017), encouraging democratic, honest dialogue, so that students can co-modify the teaching and learning process with their teacher, and freely work on ideas about science and its historical, moral and cultural dimensions (Skordoulis, 2009).

\section{Conclusions}

The students that participated in the research enjoyed the storytelling during their biology lesson, and they found that lesson more interesting than their typical ones. They also appreciated storytelling as a tool that can help them 
understand difficult concepts and remember scientific information. Students were engaged with the story, finding the lesson with the storytelling interactive and pleasant to attend. They followed the story, creating mental images in their minds and reported that interesting conversations followed the storytelling. They claimed that the story helped them understand about science and scientists, and they also said that the story motivated them and made them curious to learn more about science and scientists. It seems that storytelling can be an effective way to engage students, introduce NOS to them, and motivate them about science.

Finally, there was a change in the teacher-student relationship, as students found the teacher more approachable and calmer the day of the storytelling. Such a repositioning of the teacher's role may help towards the cultivation of trustfulness between teacher and student, which is an important perquisite for fruitful and honest conversations that can lead to meaningful learning.

\section{Acknowledgements}

We heartily thank all the students who took part to the research.

\section{References}

Abd-El-Khalick, F., \& Lederman, N. G. (2000). Improving science teachers' conceptions of nature of science: a critical review of the literature. International Journal of Science Education, 22(7), 665-701.

Abrahamson, C. E. (1998). Storytelling as a pedagogical tool in higher education. Education, 118(3), 440-452.

Boyd, B. (2009). On the Origin of Stories. Cambridge, MA: Harvard University Press.

Braun, V., \& Clarke, V. (2006). Using thematic analysis in psychology. Qualitative Research in Psychology, 3, 77-101.

Bruner, J. (1991). The narrative construction of reality. Critical Inquiry, 18(1), 1-21.

Bruner, J. (2003). Making Stories: Law, Literature, Life. Cambridge, MA: Harvard University Press.

Carson, R. (2002). Silent Spring. Boston, NY: Houghton Mifflin Harcourt.

Cheetham, M., Hänggi, J., \& Jancke, L. (2014). Identifying with fictive characters: Structural brain correlates of the personality trait "fantasy." Social Cognitive and Affective Neuroscience, 9(11), 1836-1844.

Clair, K. L. S. (2008). Storytelling Facilitates Natural Learning: A Teaching Strategy. NEFDC EXCHANGE, 19(2), 11.

Ellery, V., \& Rosenboom, J. (2011). Sustaining strategic readers: Techniques for supporting content literacy in grades $6-12$. Newark: DE: International Reading Asssociation.

Egan, K. (1989). Memory, Imagination, and Learning: Connected by the Story. Phi Delta Kappan, 70(6), 455-459. 
Frisch, J. K., \& Saunders, G. (2008). Using stories in an introductory college biology course. Journal of Biological Education, 42(4), 164-169.

Galili, I. (2015). On the involvement of History and Philosophy of Science in teaching Science - an approach promoting cultural content knowledge. Review of science. Mathematics and ICT Education, 9(1), 7-17.

Gottschall, J. (2012). The Storytelling Animal: How Stories Make Us Human. Boston, NY: Houghton Mifflin Harcourt.

Kapsala, N., Mpalampekou, E., Mavrikaki, E., \& Skordoulis, K. (2015). Storytelling in Biology Teaching - A case study in the range of Critical Education: The story of John Snow and the disease's transmission. In D. Psyllos, A. Molochidis, \& M. Kalleri (Eds.), Proceedings of the 9th Panhellenic Conference in Science Teaching and Technology in Education - Teaching and Learning in Natural Sciences and Technology: Research, Innovation, and Practice (pp. 262-270). Thessaloniki: Faculty of Education, AUTH

Kapsala N., Mpalampekou M. \& Mavrikaki E. (2017) Repositioning Science Teacher's Role in The Context of Critical Education with History of Science Storytelling. VII. International Conference on Critical Education "Rethinking alternatives to neoliberalism in education", 28 June - 2 July, Athens

Kapsala N. \& Mavrikaki E. (in press) Storytelling as a pedagogical tool in teaching NOS aspects. In McComas (ed.), Second Edition of The Nature of Science in Science Education: Rationales and Strategies, Springer

Klassen, S. (2009). The construction and analysis of a science story: A proposed methodology. Science \& Education, 18(3-4), 401-423.

Klassen, S. (2010). The Relation of Story Structure to a Model of Conceptual Change in Science Learning. Science \& Education, 19(3), 305-317.

Kokkotas, P., Rizaki, A., \& Malamitsa, K. (2010). Storytelling as a Strategy for Understanding Concepts of Electricity and Electromagnetism. Interchange, 41(4), 379-405.

Mathews, M. R. (1992). History, philosophy, and science teaching: The present rapprochement. Science \& Education, 1(1), 11-47.

Mayr, E. (2001). What evolution is. London: Weidenfeld \& Nicolson.

McComas, W. F., \& Kampourakis, K. (2015). Using the history of biology, chemistry, geology, and physics to illustrate general aspects of nature of science. Review of Science, Mathematics and ICT Education, 9(1), 47-76.

Morgan, G. (2012). The Robins of MSU, George Wallace and Rachel Carson's Silent Spring. Retrieved 26 January 2017, from http://alumni.msu.edu/newsarticle. cfm?id=314

Ong, W. J. (2013). Orality and literacy. New York, NY: Routledge.

Pace-Schott, E. F. (2013). Dreaming as a story-telling instinct. Frontiers in Psychology, 4, 159. Prop, V. (1991). Morphology of the Tale. Athens: Kardamitsa.

Skordoulis, C. D. (2009). A Philosophy for Critical Science Education. Kritiki: Critical Science and Education, 9, 81-92.

Speer, N. K., Reynolds, J. R., Swallow, K. M., \& Zacks, J. M. (2009). Reading stories activates neural representations of visual and motor experiences. Psychological Science, 20(8), 989-999. 
Stephens, G. J., Silbert, L. J., \& Hasson, U. (2010). Speaker-listener neural coupling underlies successful communication. Proceedings of the National Academy of Sciences, 107(32), 14425-14430.

Tigner, S. S. (1993). Homer, teacher of teachers. Journal of Education, 175(3), 43-64.

Wallace, G. J. (1959). Insecticides and Birds. Audubon Magazine, 61(10): 147-151.

Wallace, G. J., \& Bernard, R. F. (1963). Tests show 40 species of birds poisoned by DDT. Audubon Magazine, 65(4):198-202.

White, H., \& S. Sabarwal (2014). Quasi-experimental Design and Methods, Methodological Briefs: Impact Evaluation 8. Florence: UNICEF Office of Research.

Wills, J. E. (1992). Lives and Other Stories: Neglected Aspects of the Teacher's Art. The History Teacher, 26(1), 33-49.

Zak, P. J. (2015, January). Why inspiring stories make us react: The neuroscience of narrative. In Cerebrum: the Dana forum on brain science (Vol. 2015). Dana Foundation. 



\title{
STUDENT TEACHERS ON THE WAY TO ACCURATE DIAGNOSIS: DEVELOPMENT, TESTING AND ASSESSMENT OF DIAGNOSTIC TASKS BY TEACHER TRAINING STUDENTS
}

\author{
Bianca Kuhlemann and Corinna Hößle \\ Carl von Ossietzky University of Oldenburg (Germany) \\ bianca.kublemann@uni-oldenburg.de
}

\begin{abstract}
The diagnosis of learning conditions is a significant competence of teachers. This includes, among others, the recognition of pupils' conceptions. With the help of diagnosis, for example, lesson planning can be optimally adapted for the pupils. For this reason, the presented study examines to what extent prospective teachers succeed in developing written instruments for diagnosis. In order to enable the student teachers to assess the quality of their developed tools, they are tested in the teaching-learning laboratory. The instruments are written tasks, which are processed by the pupils. While constructing, testing and reflecting, and optimization of the diagnostic tasks, the student teachers of various semesters $(\mathrm{N}=36)$ have to fill out qualitative research instruments (evaluation sheets). The outcome of the evaluation of these indicates that the student teachers are pursuing different approaches for the development of diagnostic tasks. Following the testing, optimizations of the task were carried out, which also proved to be diverse. The study detects challenges that indicate a need for greater involvement of diagnostic-enhancing learning sequences in teacher training. This will help student teachers to find a way to become professionally diagnosing teachers.
\end{abstract}

Keywords: diagnostic competence, diagnostic instruments, pupils' conceptions and competency structure model

\section{Introduction}

The diagnosis of student characteristics has an outstanding meaning and is both anchored in national and international requirements for future teachers (National Academy of Sciences, 1996). This comprises a performance diagnosis 
and the determination of different learning conditions. The latter includes, for example, the collection of learners' conceptions. This is a major step in the construction of knowledge. Morrison \& Lederman (2003, p. 850) underline that "...all knowledge must be individually and socially constructed and based on the learner's existing knowledge and experiences." The purpose of diagnosis is to identify student characteristics and to use this information for the preparation of lesson content (Hußmann et al., 2007). Uncovering and working with pupils' ideas is particularly important for biology lessons, as pupils often use their everyday ideas to describe new content (Hammann \& Asshoff, 2015). In addition, the recognition of pupils' perceptions for the preparation of lesson content constitutes a major role, as described in Didactic Reconstruction by Kattmann et al. (1997).

\section{Theoretical background}

\subsection{Diagnosis}

Diagnosis, also known as summative and formative assessment, is the basis of teaching and preparing content. Bell \& Cowie (2001) summarize the differences of purposes of both forms of assessment. Summative assessment is used "[... to monitor educational progress or improvement" (Bell \& Cowie, 2001, p. 538). In contrast, assessment is formative when the information gathered from the pupils is used "...to revise their classroom practices, and the students can use the feedback to monitor their own learning." The OECD (2005, p. 21) underline that "[in] schools, the most visible assessments are summative." Hesse \& Latzko (2017, p. 60) describe diagnosis as "the ability to make use of the competences of recognizing and distinguishing as well as the ability to use suitable ways and methods for this."

According to Schrader (2013), the purpose of diagnosis is to obtain knowledge about learners. For this, Hußmann et al. (2007) find a supplement regarding the use of this information to adapt the lessons for the pupils. In gaining information about different aspects of the learner, a distinction is made between explicit and implicit approaches (Hesse \& Latzko, 2017). In contrast to the implicit diagnosis, also referred to as informal, methods for the identification of information are used in explicit approaches (Hesse \& Latzko, 2017). Schrader (2014) describes the diagnostic competence as a combination of many skills to determine the knowledge and abilities of the students. In the standards of teacher education (Kultusministerkonferenz, 2004, p. 11), the following is stated under diagnostic competence: "The graduates ...

— know how different learning conditions influence teaching and learning and how they are taken into account in the classroom.

- recognize development status, learning potential, obstacles to learning and learning progress. 
- recognize initial learning situations and use special funding opportunities."

In the sub-competence "recognize initial learning situations" (ibid, p. 11), there is a connection to the areas of competence described by von Aufschnaiter et al. (2015). These are various sub-competences, such as the ability to choose a suitable set of diagnostic methods (von Aufschnaiter et al., 2015). This aspect of diagnostic competence is the focus of the study presented. Tomanek et al. (2008, p. 1115) state that "[during] planning, a teacher who practices teaching-forunderstanding carefully considers what an assessment task has the potential to reveal about her students' knowledge or understanding."

\subsection{Diagnostic instruments}

As shown before, the diagnostic ability includes various sub-competences. An important competence is the ability to develop and select suitable diagnostic tools (von Aufschnaiter et al., 2015). Diagnostic instruments can be described as a key to access student traits. Numerous tools for diagnosis are cited in literature (Hößle, 2014; Hamann \& Asshoff, 2015), e.g. conversations, oral participations, observations and interviews that can be used as part of a lesson sequence (ibid). Also often cited are written tasks such as tests, learning reports and diagnostic tasks. In terms of diagnosis, tasks turn out to be a rich source of information (Christiansen, 2007). Figure 1 gives an example of a written diagnostic task.

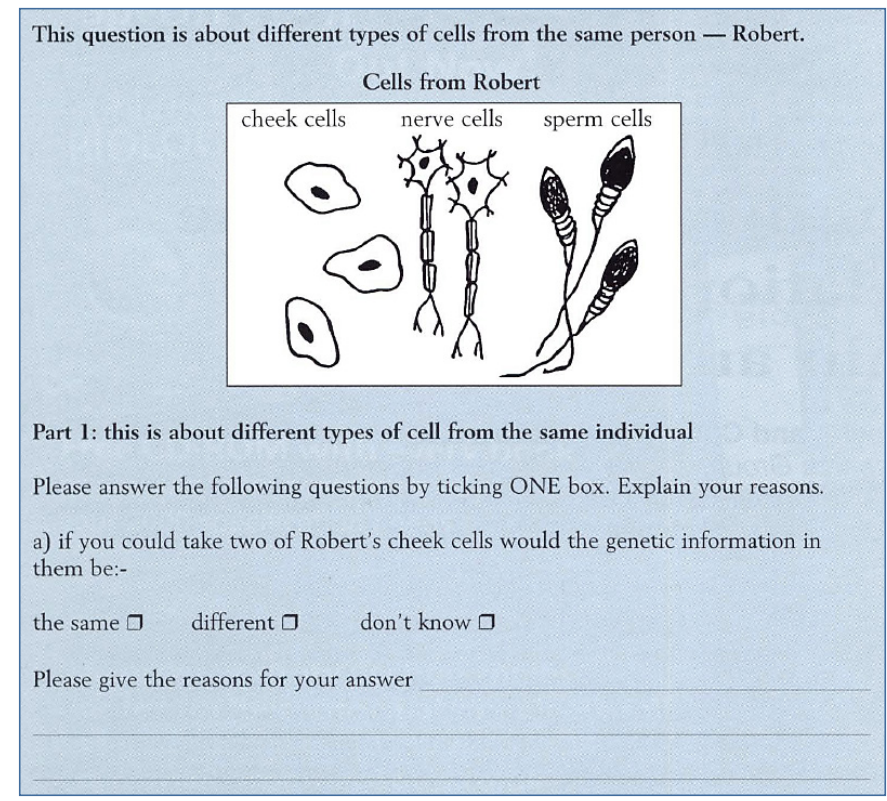

Figure 1 Example of a written diagnostic task (taken from Lewis et al. 2000, p. 130) 
The preparation of the instrument (written tasks) for pupils also represents a decisive element (Hößle, 2014). One possible way to an accurate diagnosis is seen in the development of writing diagnostic tasks. Written diagnostic tasks can be properly prepared and followed up and are suitable tools for student teachers. And as they are diagnostic tasks, the development and testing of written diagnostic tools in particular can be integrated in an excellent way in a teacher training course. Hußmann et al. (2007) give a detailed insight into the characteristics of the construction of diagnostic tasks. At first, they describe focussing on preassigned areas of competence (ibid.). In addition, a task should help to gain as many insights from individual pupils as possible and, therefore, should contain different processing levels (ibid.). With the third element, the authors state that a diagnostic task should stimulate a detailed examination of the task in order to gain as much information as possible about the pupils (ibid.).

\subsection{The teaching-learning laboratory as a rehearsal room for diagnostic tasks}

An important element for the evaluation of one's own diagnostic task is to test it with actual learning groups in the student laboratory. For this reason, in the present study, student laboratories are used as 'rehearsal rooms' in teacher training programmes, in order to enable student teachers to assess the suitability of their developed diagnostic tools. This form of student laboratory, used as a space for learning and as support of learning processes by student teachers, can also be described as a teaching-learning laboratory (Hößle, 2014). The embedding of the diagnosis in courses often takes place with the aid of diagnostic processes in which teacher training students go through various steps in a structured manner. According to Hesse \& Latzko (2017), this process begins with a question or definition of a background to be diagnosed. After you have formulated your own possible answers in the second step, you choose a suitable tool. The use of this diagnostic tool is listed as the next step. With the information gained, it is now possible to check one's own answers given in the second step. In the final step, the information is used to assess the situation (Hesse \& Latzko, 2017).

\section{Research design and method}

In the context of the examination of the diagnostic competence of teachers, there are various research projects in particular in the subject didactics of mathematics (COACTIV project according to Kunter et al., 2013). Also, in current research, mathematics student teachers were examined regarding their diagnostic abilities (Heinrich, 2017). Biology didactic research on the diagnostic skills of future teachers, such as Dübbelde (2013), refers to the acquisition of 
scientific knowledge. Morrison \& Lederman (2003, p.855) observed lessons with the focus on diagnostic strategies. They found out that "[none] of the four teachers observed used any type of instrument to identify students' preconceptions." Furthermore, they discovered that the teachers used implicit diagnosis with classroom discussions (Morrison \& Lederman, 2003).

That is why it is just as important to examine the ability of student teachers to develop their own diagnostic tools.

The survey focuses on the following questions:

1. Which features do the developed diagnostic tasks have?

2. How do student teachers assess the tasks with regard to defined criteria before and after the test?

3. How does the ability to create and assess diagnostic tasks change through field testing?

4. How do student teachers describe testing their own tasks?

\subsection{Structure of the study}

Qualitative questionnaires are used to survey the ability to develop and assess the tasks. These questionnaires support the student teachers during didactic seminars when going through pre-determined steps. Figure 2 illustrates these steps in research design, which are based on general task analyses, as described by Blömeke et al. (2006).

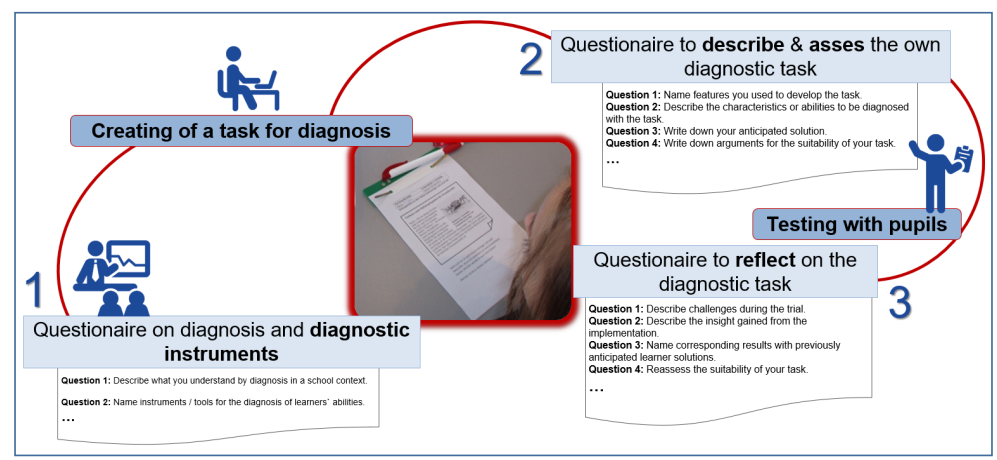

Figure 2 Structure of the study

During the seminar, the student teachers have to plan and execute a lesson sequence on different topics. Thus, the diagnostic tasks can be formulated based on the respective topic. In the first questionnaire (1), which is processed by the student teachers prior to the development of the diagnostic tasks, general questions are asked about the diagnosis and diagnostic tasks. These provide an insight into the previous knowledge and experience in these areas. This questionnaire includes the following items: 
- Describe what you mean by diagnosis in a school context.

- Name instruments / tools for diagnosis in the classroom.

After the student teachers have developed a written exercise to diagnose students' conceptions and to raise learning outcomes, they are asked to provide a first description and assessment of this task by using the second questionnaire (2). This includes, for example, the mention of student characteristics to be recorded, anticipated student responses, and a justification for the suitability of the task type to survey student characteristics. In the questionnaire, these three items can be found:

- Name the characteristics you used to develop the tasks.

- Describe the feature to be diagnosed with the task.

- Name possible pupils' solutions.

Likewise, features should be mentioned that are in focus during the development of the task. Following the testing of the diagnostic task with real school pupils, the student teachers have to reflect on the diagnostic task (step 3) with the help of a final questionnaire. With these questions, the re-evaluation and further development of the task can be highlighted. The mentioned steps are embedded in various (altogether four) didactic seminars, which include the testing of learning sequences in the teaching-learning laboratory. In two courses there is the possibility that a further developed task from the first test can be optimized and worked on once again by pupils. The openly formulated questionnaires are evaluated by qualitative content analysis according to Mayring (2015). This method allows a comprehensive consideration of the pre-defined deductive criteria chosen by student teachers, which are presented in the second chapter. In addition, inductively obtained criteria supplement the method. Through this broad spectrum, a competency structure model can be described, which considers future assessments as well as assistance for competence development of future teachers.

\subsection{Sample}

In order to obtain information on the development of the students' abilities to conceive tasks, both student teachers of the Bachelor's as well as of the Master's programme are included in the study. This selection is based on the maximal variation sampling (Creswell, 2014). The sample therefore comprises 20 Bachelor's and 16 Master's student teachers of Biology.

\section{Findings}

We would like to concentrate on questions one and two of the survey. The first results of the surveys show that student teachers construct tasks in very different ways. The characteristics listed by the subjects for task development are very similar to the hints formulated by Hussmann et al. (2007). The greatest 
similarities were found in the points 'Openness of the task' and 'Suggestion to work on a task'. In addition to the similarities, differences were seen in the theoretical description of the tasks and the formulations of the tasks. Based on the example of student teachers from the third Bachelor's semester, this result becomes particularly clear.

Task a) "Which organs are involved in the smelling process?" (student teacher T6) Task b) "Can people who are blind play memory? If so, why? If not, why not?" (student teacher $\mathrm{H} 5$ )

A critical comparison of the tasks developed by the student teachers T6 and H5 shows that the first task (student teacher T6) is rather closed, while the second task is rather openly formulated. The first task allows only a few answers compared to the second. Consequently, the student teacher $\mathrm{H} 5$ succeeds better to consider the task feature 'openness' in the development of diagnostic tasks. For student teacher $\mathrm{T} 6$ the testing of the tasks leads to a further development of the diagnostic abilities. After a practical test of the task, T6 noticed that the task can be optimized by an additional description by the pupils. This description allows, according to the student teacher, a better insight into pupils' conceptions. After the practical testing of the tasks, the optimization measures features adapted formulations. In the reformulation of the tasks the focus is on increasing the proportion of selfemployed activities of pupils (student teacher T6, Questionnaire 3, Item 8). Both the reformulation of the task and the call for more self-employment, as described by Büchter (2006), can lead to more insights into students' conceptions. In many tasks, a clear and address-oriented formulation can be identified.

As part of the further development of the task, it is also described for the second example of the task that detailed processing on the part of the pupils is necessary for a detailed diagnosis (student teacher H5, Questionnaire 3). Based on the results, various aspects of the development and optimization of diagnostic tools by students can be examined and used for a more detailed description of the abilities. In the illustrated example a), it can be stated that a mention of task characteristics takes place, but discrepancies occur in the student teacher's task formulation. However, there is a successful optimization of the task with regard to the aforementioned task characteristics. The student teacher $\mathrm{H} 5$ of the second diagnostic task is able to improve her ability to implement the previously recorded features of her diagnostic task. She shows knowledge regarding the naming of task characteristics and considers them in the development of their own diagnostic task. A further aspect for the optimization of diagnostic tools can be seen in the following example (student teacher C7). The student teacher used the findings of the testing to open the task to gain an insight into pupils' conceptions. The optimization of the task includes a clear instruction. Task before optimization: "What do you think, why can you smell spices?" Task after optimization: "Describe how smelling works. Why can we smell with our nose?" 
One feature that is missing in many tasks is a clear and appropriate formulation. This issue is often detected and corrected thanks to testing in the teaching-learning laboratory. For example, terms were used in the tasks that the learners were unfamiliar with. The significant challenge of task formulation was provided to the student teachers through written editing of the students. The student teachers learned that formulations that are not appropriate for the target group mean that the task cannot be dealt with. However, this does not mean that the students did not have a concept for the phenomenon they were inquiring about, but only had a different vocabulary.

The rating serves as a first guide to the skills of future teachers to develop diagnostic tasks. It also forms the basis for the further promotion of competences. In particular, joint reflection on the practical testing of diagnostic tasks plays a key role in the seminar. The individual task formulations can be checked and optimized with regard to their suitability in this phase. As a further element of the seminar, students gain insight into further theoretical features of diagnostic tasks, which they can take into account during their own task development and then are able to test them out practically. At the same time, student teachers are encouraged to independently identify characteristics that they use to develop their tasks. In the course of an evaluated Master's seminar, the seminar participants formulated task features for written diagnostic tools. These are, for example, the adaption of complexity, choosing the widest possible range of answers, and adaption to the learning group.

\section{Discussion}

As part of the study presented, which is embedded in the project "Qualitätsoffensive Lehrerbildung", student teachers are guided through various steps of an explicit diagnosis (according to Hesse \& Latzko, 2017; Hößle et al., 2017). It was recognized that some student teachers are already well able to develop diagnostic tools. This emphasizes a good thematic embedding of the diagnostic tasks in the context of the learning sequence of the teaching-learning laboratory. Also, individual tasks have a high degree of openness. The openness of a diagnostic tool is also listed as a relevant feature by Hußmann et al. (2007). The assessment of the openness of the diagnostic task can be identified as a challenge in some subjects (example task a)). Here, one can draw a parallel to the research of Ostermann et al. (2015) on difficulty assessments of tasks by aspiring and already active teachers. The study found that the teacher's own perspective is very important in assessing tasks. The ability to take on the pupil's perspective is also reflected in the anticipated task processing presented by some student teachers. Likewise, in relation to the criteria of diagnostic tasks established by Hußmann et al. (2007), in the case of the features to be diagnosed 
by the students, sometimes too many or too broad features are cited. It is important in the conception of diagnostic tasks to focus on one specific diagnostic feature (ibid.).

It is also recognized that students who have difficulties in describing the technical basis of their task also face challenges in developing written diagnostic tools. Hößle et al. (2017) describe that a diagnosis requires knowledge of the subject matter, the steps required to access the content, and knowledge of appropriate contexts. This difficulty, which was proven in the study, can be understood as an argument for a stronger integration of subject-specific, didactic and pedagogical contents in the teaching degree program. Not only a stronger networking of the main areas of teacher training, but also the embedding of learning opportunities to promote diagnostic skills can contribute to optimizing teacher education. In doing so, in response to the findings of this study, the following points should be noted:

- By jointly processing the developed tasks with fellow student teachers in advance of a trial with pupils, a more accurate assessment of task characteristics can be made possible.

- By determining the backgrounds or characteristics, which will be diagnosed, the lecturers can counteract a loss of focus. This would, for example, relate to the assessment of the degree of openness of the task.

- Already in the preparation of the accompanying seminars, product vignettes (like tasks and the pupils products demonstrated in the findings) can be used to address both the characteristics of diagnostic tasks as well as, for example, thereof derived pupil conceptions.

- Accurate documentation in the design and execution of diagnostic tasks is essential for sound reflection. As they accompany the task development and its optimization, the subjects are persuaded to compare their findings with the own estimates described above. This view of one's own knowledge belongs to the metacognitive learning theory (Sander \& Igelbrink, 2015).

An interpretation of the results of the diagnosis is also important as Jones \& Moreland (2005, p. 196) state: "Effective formative interactions are thus dependent on informed assessors who are able to interpret observations and student outcomes, and consequently act upon the interpretation to enhance student learning." A well-developed ability to use diagnostic tools forms a small part of the diagnostic competence. Buholzer \& Zulliger (2013) emphasize that mere knowledge of diagnostic instruments is insufficient and that an accurate selection and assessment of instruments is required. The goal of diagnostic expertise can be achieved via the promotion of certain keys. This path leads to a didactic understanding of diagnosis, good knowledge of subject matter content, and the design of diagnostic tools to diagnose accurately pupil traits (Hößle et al., 2017). 


\section{Outlook}

As diagnostic tasks are developed by student teachers and tested in practice as well as processed by the pupils, written vignettes are generated that can be used in teacher training. Authentic vignettes can be used to sharpen the view on the formulation of diagnostic tasks. The written material of the students is a medium for the collection of pupils' conceptions in didactic seminars. The generation of authentic vignettes, which serve both the development and the acquisition of competences of prospective teachers, has been carried out by various research activities. The work of Brovelli et al. (2013) can be highlighted here. Thus, there is a stronger integration of theoretical and practical references in the study, which can benefit the development of competences of future teachers. The diagnostic tasks developed by the student teachers are currently in the phase of objective validation by experts. Accompanying student teachers while they gain diagnostic experiences, can already be integrated in the early stages of the teacher training programme. This requirement is highlighted in literature, such as Buck \& Trauth-Nare (2009, p. 490): "[we] suggest that selfreflection and exploration of teacher's formative assessment practices should not occur only at the end of professional development programs".

\section{Acknowledgments}

This project is part of the "Qualitätsoffensive Lehrerbildung", a joint initiative of the Federal Government and the Federal States, which aims to improve the quality of teacher training. The programme is funded by the Federal Ministry of Education and Research. The authors are responsible for the content of this publication.

\section{References}

Artelt, C., \& Gräsel, C. (2009). Diagnostische Kompetenz von Lehrkräften. Zeitschrift für Pädagogische Psychologie, 23(34), 157-160.

Aufschnaiter, C. von, Cappell, J., Dübbelde, M., Ennemoser, J., Mayer, J., StiensmeierPelster, R., \& Sträßer A. (2015). Diagnostische Kompetenz. Zeitschrift für Pädagogik, 61(5), 738-758.

Bell, B., \& Cowie, B. (2001). The characteristics of formative assessment in science education. Science Education, 85(5), 536-553.

Blömeke, S., Risse, J., Müller, C., Eichler, D., \& Schulz, W. (2006). Analyse der Qualität von Aufgaben aus didaktischer und fachlicher Sicht. Unterrichtswissenschaft, 34(4), 330-357

Brovelli, D., Bölsterli, K., Rehm, M., \& Wilhelm, M. (2013). Erfassen professioneller Kompetenzen für den naturwissenschaftlichen Unterricht: Ein Vignettentest mit 
authentisch komplexen Unterrichtssituationen und offenem Antwortformat. Unterrichtswissenschaft, 41, 306-329.

Buck, G. A., \& Trauth-Nare, A. E. (2009). Preparing Teachers to Make the Formative Assessment Process Integral to Science Teaching and Learning. Journal of Science Teacher Education, 20, 475-494.

Buholzer, A., \& Zulliger, S. (2013). Die Entwicklung von diagnostischen Fähigkeiten bei Studierenden der pädagogischen Hochschulen im Laufe ihrer Ausbildung. Beiträge zur Lehrerbildung, 31, 186-197.

Büchter, A. (2006). Kompetenzorientierte Diagnose im Mathematikunterricht. In Gesellschaft für Didaktik der Mathematik (Ed.), Beiträge zum Mathematikunterricht 2006. Berichtband von der 40. Tagung für Didaktik der Mathematik vom 6.3.-10.3.2006 an der Universität Osnabrück (p. 155-158). Hildesheim/Berlin: Franzbecker.

Christiansen, D. (2007). Entwicklung und Erprobung von Aufgaben zur Erfassung zentraler Kompetenzen im Chemieunterricht am Beispiel Säuren und Basen. Retrieved from https://d-nb.info/1019669578/34 (May, 2018)

Creswell, J. W. (2014). Educational Research: Planning, Conducting and Evaluating Quantitative and Qualitative Research. Harlow, England: Pearson Education Limited.

Dübbelde, G. (2013). Diagnostische Kompetenzen angehender Biologie-Lehrkräfte im Bereich der naturwissenschaftlichen Erkenntnisgewinnung. Dissertation University of Kassel. Retrieved from https://kobra.bibliothek.uni-kassel.de/bitstream/urn:nbn:de: hebis:34-2013122044701/3/DissertationGabiDuebbelde.pdf (September, 2018)

Hammann, M., \& Asshoff, R. (2015). Schülervorstellungen im Biologieunterricht-Ursachen für Lernschwierigkeiten. Seelze: Kallmeyer in Verbindung mit Klett.

Heinrich, M. (2017). Diagnosebasierte Adaptionen von Mathematikunterricht: Angehende Lehrpersonen im fachbezogenen Schulpraktikum. Baltmannsweiler: Schneider Verlag Hohengehren.

Hesse, I. \& Latzko, B. (2017) Diagnostik für Lehrkräfte. Opladen \& Toronto: Barbara Budrich Verlag

Hößle, C. (2014). Lernprozesse im Lehr-Lern-Labor Wattenmeer diagnostizieren und fördern, In A. Fischer, C. Hößle, S. Jahnke-Klein, H. Kiper, M. Komorek, J. Michaelis, V. Niesel \& J. Sjuts (Eds.), Diagnostik für lernwirksamen Unterricht (pp. 144-155). Baltmannsweiler: Schneider-Verlag Hohengehren.

Hößle, C., Hußmann, S., Michaelis, J., Niesel, V., \& Nührenbörger, M. (2017). Fachdidaktische Perspektiven auf die Entwicklung von Schlüsselkenntnissen einer förder-orientierten Diagnostik, In C. Selter, S. Hußmann, C. Hößle, C. Knipping, K. Lengnink, \& J. Michaelis (Eds.), Diagnose und Förderung heterogener Lerngruppen -Theorien, Konzepte und Beispiele aus der MINT-Lehrerbildung (pp. 19-37). Münster, New York: Wachsmann Verlag.

Hußmann, S., Leuders, T., \& Prediger, S. (2007). Schülerleistungen verstehen -Diagnose im Alltag. Praxis der Mathematik in der Schule, 15, 1-8.

Jones, A., \& Moreland, J. (2005). The importance of pedagogical content knowledge in assessment for learning practices: a case-study of a whole-school approach. The Curriculum Journal, 16(2), 193-206 
Kattmann, U., Duit, R., Gropengießer, H., \& Komorek, M. (1997). Das Modell der Didaktischen Rekonstruktion - Ein Rahmen für naturwissenschaftsdidaktische Forschung und Entwicklung. Zeitschrift für Didaktik der Naturwissenschaften, 3(3), $3-18$.

Kultusministerkonferenz (2004). Standards für die Lehrerbildung: Bildungswissenschaften. Retrieved from http://www.kmk.org/fileadmin/Dateien/veroeffentlichungen_ beschluesse/2004/2004_12_16-Standards-Lehrerbildung.pdf (May, 2018)

Kunter, M., Baumert, J., Blum, W., Klusmann, U., Krauss, S., Neubrand, M. (Eds.) (2013) Cognitiv Activation in the Mathematics Classroom and Professional Competence of Teachers. New York, Heidelberg, Dordrecht, London: Springer Verlag

Lewis, J., Leach, J., \& Wood-Robinson, C. (2000). What's in a cell? -young people's understanding of the genetic relationship between cells, within an individual. Journal of Biological Education 34, 129-132.

Mayring, P. (2015). Qualitative Inhaltsanalyse. Grundlagen und Techniken (12. Aufl.). Weinheim and Basel: Beltz Verlag.

Morrison, J. A., \& Lederman, N. G. (2003). Science teachers' diagnosis and understanding of students' preconceptions. Science Education, 87, 849-867.

National Academy of Sciences (1996). National Science Education Standards. Retrieved from https://www.csun.edu/science/ref/curriculum/reforms/nses/nses-complete. pdf [October, 2017]

Organisation for Economic CO-Operation and Development (OECD) (Ed.) (2005). Formative Assessment -Improving Learning In Secondary Classrooms. Paris: OECD Publishing.

Ostermann, A., Leuders, T., \& Nückles, M. (2015). Wissen, was Schülerinnen und Schülern schwer fällt. Welche Faktoren beeinflussen die Schwierigkeitseinschätzung von Mathematikaufgaben? Journal für Mathematik-Didaktik, 2015, 36(1), 45-76

Sander, W., \& Igelbrink, C. (2015). Wie Lernen gelingt: individuelle Förderung und Selbstbestimmung. Weinheim: Beltz.

Schrader, F.-W. (2013). Diagnostische Kompetenz von Lehrpersonen. Beiträge zur Lehrerinnen- und Lehrerbildung 31 2, 154-165.

Schrader, F.-W. (2014). Lehrer als Diagnostiker. In E. Terhart, H. Bennewitz, M. Rothland (Eds.), Handbuch der Forschung zum Lehrerberuf. Münster, New York: Waxmann,

Tomanek, D., Talanquer, V., \& Novodvorsky, I. (2008). What Do Science Teachers Consider When Selecting Formative Assessment Tasks? Journal Of Research In Science Education, 45(10), 1113-1130. 


\title{
MAKE BIOLOGY RELEVANT AGAIN! PRE-SERVICE TEACHERS' VIEWS ON THE RELEVANCE OF BIOLOGY EDUCATION
}

\author{
Justus Mutanen and Anna Uitto \\ University of Helsinki \\ justus.mutanen@helsinki.fi
}

\begin{abstract}
Biology education should be relevant to young students so that they can become interested in biology and understand biological topics in their everyday and vocational lives. We conducted interviews and collected mind maps to examine Finnish pre-service biology teachers' $(\mathrm{N}=16)$ views on the relevance of biology education. Furthermore, we analyzed Finnish secondary school biology curricula, which were compared with the pre-service teachers' answers. We classified the views on relevance into nine main categories using grounded theory as the methodological frame of reference. Pre-service teachers emphasized the relevance of biology to the student's own life, whereas scientific practices and the nature of science were expressed in secondary school curricula more often. Novice pre-service teachers put more value on general knowledge, while more experienced pre-service teachers were more likely to mention sustainable futures and societal aspects in their reasoning. Based on the results, we identified two stages in the development of the views. This study suggests that pedagogical studies, teaching experience and teacher training have an impact on the pre-service teachers' views about the relevance of biology education. Moreover, we could find differences between curricula and pre-service teachers' views, especially regarding scientific practices and the role of the nature of science in biology education.
\end{abstract}

Keywords: biology teacher education, relevance, professional development, curriculum, scientific literacy

The full version of this paper is published in the Journal of Biological Education: Mutanen, J. \& Uitto, A. (2020) Make biology relevant again! Pre-service teachers' views on the relevance of biology education, Journal of Biological Education 2020. 



\title{
PROPOSAL OF A MODEL FOR PROFESSIONAL DEVELOPMENT: PERSPECTIVES AND STAGES THAT CONTRIBUTE TO THE IMPROVEMENT OF THE PRACTICE OF BIOLOGY TEACHING
}

\author{
Eduardo Ravanal Moreno', Édgar Valbuena Ussa², \\ Elias Amórtegui Cedeño ${ }^{3}$ \\ ${ }^{1}$ Universidad Bernardo O'Higgins (Santiago de Chile-Chile), ${ }^{2}$ Universidad Pedagógica Nacional \\ (Bogotá-Colombia), ${ }^{3}$ Universidad Surcolombiana (Neiva-Colombia) \\ luis.ravanal@ubo.cl
}

\begin{abstract}
The practice of teaching, because of its contextual nature and particular form of implementation, can promote or limit learning among students. That is why any initiative for professional development aimed at improving teachers' performance must acknowledge its complexity. The data that support the proposal of this model for professional development (MPD) were collected among 92 biology teachers working in Chile through multi-method research that included surveys, individual interviews, discussion groups, class observation and analysis. The proposed MDP acknowledges four stages of development: professional concerns, teaching difficulties, teaching problems and formalization of professional knowledge. Operationalization of MPD is achieved through a methodology focused on a reflection about situations that commonly occur during the teacher's professional activity. Preliminary results make it possible to state that the initial stage, professional concerns (stage 1) consists of the spontaneous thinking that invigorates the initial reflection of the participants; in turn, it represents a scaffold to achieve an increasing complexity in the process of organizing the teacher's thought patterns when formalizing his/her professional knowledge (stage 4). The latter is the most erratic stage of the teacher's reflection.
\end{abstract}

Keywords: model for professional development, teaching practice, professional knowledge, biology teachers.

\section{Introduction}

One of the major challenges faced by the 'Chilean educational reform' is to create students being able to understand new knowledge, and to develop skills for 
the 21 st century (Reimers \& Chung, 2016). In this context, education aims to generate multidisciplinary knowledge that transcends the school (Porlan, 2018), acknowledging that citizens' formation seeks a more fair society, which appreciates and respects others and their diversity (Mansour \& Wegerif, 2013). Therefore, it is necessary to recognize the value of biology teaching in schools, in order to abandon the prevailing transmissionist conceptions of knowledge that focus on propaedeutic purposes, hindering the achievement of the aforementioned interests and the whole-person development. Thus, there is a need for spaces for reflection contributing to understanding the teaching complexity for decisionmaking when planning and implementing the educational practice. For the training of biology teachers, teaching practices are a key element, particularly because of their contextual and set nature, on which the teacher thinks, decides and acts (Saariaho et al., 2016). For active teachers, they constitute an instance of professional knowledge building (Päuler-Kuppinger \& Jucks, 2017) and an input for permanent reflection on their work, in pursuit of their professional development. The last constitutes an uncommon activity in the teachers' community (Fernández et al., 2011). Hence there is a need to design a Model of Professional Development (MPD) for teachers that contributes in that direction.

Professional development is a continuous process of reflection (Fraser et al., 2007) about the teacher, and his/her learning and teaching (Hewson, 2007; San Antonio et al., 2011), to improve the quality of the schools (Desimone, 2011) and teaching practice (Clarke \& Fournillier, 2012). The aims of professional development are achieved through delving into professional knowledge (Antoniou \& Kyriakides, 2011; Kang et al., 2013) and understanding the complexity of teaching (Krell \& Krüger, 2015), so as to improve the students' learning results (Kang et al., 2013). However, initiatives for professional development tend to be disconnected from the problems of the practice of teaching (Zhang et al., 2015), showing low efficiency in the learning process of teachers and students alike (Jiménez, 2018). Therefore, initiatives are needed for professional development that would allow teachers to take control of their own learning (Meijer et al., 2011) based on teaching problems. It is also necessary to develop the professional capacity to notice how teachers can build opportunities for learning for their students (Bolhuis, 2003). Professional development should not only delve into understanding the actual knowledge of the subject that is taught and how to teach it; it should also try to understand the thought patterns of the teacher regarding his/her planning of pertinent interventions that contribute to the adequate learning outcome of each student.

Teaching is complex (Loucks-Horsley et al., 2010), it requires understanding teacher knowledge and to develop, in context, specific skills (Gess-Newsome, 2015) to recognize and handle the situations that are relevant for teaching and for the students' learning, with selective attention (Stürmer \& Seidel, 2017). In this framework, understanding the practice of teaching helps to make sense of 
these situations considering that they are thus acknowledged as an authentic part of the professional activity and as an encouragement for teachers' learning. Thus, a more perceptive 'phronesis', rather than conceptual approach (Kessel \& Korthagen, 1996), would be helpful to recognize the characteristics of these relevant situations, and 'selective attention' to learn to reason and act upon them separately, so as to learn from all of them (Hennisen et al., 2017). An approach centered on the perception of experience makes that experience valuable in the eyes of the teacher (Rusell, 2014); it also acts as catalyst to demand professional development in that particular area. Reflection in and on action is one of the evident strategies to attend to this, especially as this approach explains changes in human activities after reflection about the interactions of the teacher within the specific situations he/she conducts; as well as through the dialogue he/she sustains with others about these situations (Schön, 1983). Reflection can reveal the complexity of teaching through observation of the thought processes of the teacher (Guzman-Valenzuela \& Cabello, 2016), in a scale of development that begins with signifying the concerns that arise from the characterization of situations that are relevant for teaching and learning. It involves understanding reflection and metacognition as a meta-disciplinary component of teachers, that shapes it and makes it possible to structure and restructure their own teaching practice (Amórtegui et al., 2017). The challenge is to guide the teacher's thought patterns towards a greater understanding of teaching and professional knowledge. In our research, we conceived the professional development of teaching as a process of systematic reflection of the professional experiences that promote a progress in the thought patterns the teacher has on teaching and the actions that structure it in relation to the students' learning.

\subsection{Experiences of professional development}

Although the professional development of teaching makes it possible to improve the knowledge and practice of the teacher's teaching (Kang et al., 2013), some authors state that not all programmes are effective for improving the quality of the teacher (Soine \& Lumpe, 2014). Some state that professional development should focus on content (Kang et al., 2013) and be linked to what happens in the classroom (Soine \& Lumpe, 2014), so it isn't taken out of context. San Antonio et al. (2011) state that professional development contributes to strengthen the teacher's knowledge and the development of his/ her teaching skills that are necessary for the progress of the students. Therefore, according to Zhang et al. (2013) a programme for development should be backed up by a theory of learning, be intense and constant, focused towards content, give opportunities to enrich learning and be connected to the daily practice of the teacher. Some experiences of professional development have been focused on the promotion of professional knowledge through the module-based 
professional development of teachers with mathematics teachers in the Philippines (San Antonio et al., 2011). This experience has shown that professional experience is important in an activity of professional development, and that a traditional development model has a low effectiveness among teachers, in particular because of its fragmentation, scarce link with the classroom and irrelevance regarding the teacher's problems (Zhang et al., 2015).

In England, Adey (1999) describes the programme for professional development Cognitive Acceleration through the Science Education (CASE), based on the theories of Piaget and Vigotsky (Simon \& Campbell, 2012), and which promotes cognitive conflict. CASE is organized on five foundations: concrete preparation, cognitive conflict, meta-cognition, reasoning and construction. Other initiatives of professional development have been focused on collaborative development and learning (Kuusisaari, 2013) through discussion groups, which has revealed that there is a distance between the level of actual development of the teacher and the potential level that is possible to attain when discussing teaching and the theories of learning. In a programme for development focused on argumentation, Crippen (2012) showed the effect this has on the beliefs of 42 teachers about science. According to Kang et al. (2013) the Cognitive Guided Instruction (CGI) series of books is an effective programme. In Spain, the group Investigación y Renovación Escolar (IRES, School Investigation and Renovation) has developed the model Formación de Profesores para Investigar la Práctica (FOPIP, Training of Teachers for Research in Practice), focused on addressing the study of didactic and epistemological conceptions of teachers, the characterization of Practical Professional Knowledge, and implementation of formative proposals with a constructivist orientation (Porlán et al., 2011). Later on, Rivero et al., (2017) included the focus of Reflection Orientation as an aspect of professional development, which allows teachers to address teaching situations in which their own knowledge is evaluated and reformulated based on powerful feedback between teacher and students. We think that a programme for professional development should consider: i) identification of professional concerns and difficulties; ii) construction of practical teaching problems, iii) significant reflection on teaching problems, to identify and evaluate their own professional needs (Van den Bergh et al., 2015), and iv) theorization of the relation between practice and theory considering stages of development of teachers (Ravanal et al., 2017). In Chile, activities for development are frequently held, like courses, workshops, conferences, seminars and research - the latter is preferred by a third of the teachers (Bordón et al., 2017). The questions that arise are:

- do these kinds of activities broaden the teacher's knowledge for practical use?

- do they develop their skills for teaching?

- do they encourage an understanding of professional experiences and of the reasons to change them? 


\subsection{Research objective}

The objective of this research is to propose a Model for Professional Development (MPD) that makes it possible to notice the complexity of teaching through reflection on professional experiences, to broaden the professional knowledge of the biology teacher and improve understanding of the practice of teaching biology.

\section{Research design and method}

We chose a mixed prospective longitudinal design comprised between the years 2015-2017. To identify the entities of the development model we used: a questionnaire with Likert scales, discussion groups, individual and group interviews, and observation and participant analysis of a biology class. A descriptive and inferential analysis of the questionnaire with Likert scale (Ravanal et al., 2018) allowed us to identify the epistemological beliefs about the preparation and teaching of biology, therefore, the qualitative analysis of the content made it possible to identify the thought patterns of the teacher and the entities of the developmental model.

\subsection{Participants}

In this study, 92 working biology teachers participated, who were contacted through e-mail to take part independently on a seminar about Teacher Professional Development. Convening was done gradually in three regions of Chile: Coquimbo (32), Bio-Bio (15) and Metropolitan Region (45). In Table 1 we show the sociodemographic background of the participants.

TABLE 1

SOCIODEMOGRAPHIC BACKGROUND OF THE PARTICIPATING WORKING BIOLOGY TEACHERS

\begin{tabular}{|c|c|c|c|c|c|c|c|}
\hline Background & \multicolumn{7}{|c|}{ Distribution (\%) } \\
\hline Age & \multicolumn{3}{|c|}{$\begin{array}{l}25 \text { to } 35 \text { years old } \\
(46.5 \%)\end{array}$} & \multicolumn{2}{|c|}{$\begin{array}{l}36 \text { to } 45 \text { years old } \\
(33.7 \%)\end{array}$} & \multicolumn{2}{|c|}{$\begin{array}{l}46 \text { or more years } \\
\text { old }(19.8 \%)\end{array}$} \\
\hline $\begin{array}{l}\text { Teaching } \\
\text { experience }\end{array}$ & \multicolumn{2}{|l|}{$\begin{array}{l}0 \text { to } 5 \text { years } \\
(36.5 \%)\end{array}$} & $\begin{array}{l}6 \text { to } 15 \text { years } \\
(40.0 \%)\end{array}$ & $\begin{array}{l}16 \text { to } 25 y \\
(14.1 \%)\end{array}$ & & \multicolumn{2}{|c|}{$\begin{array}{l}26 \text { or more years } \\
(9.4 \%)\end{array}$} \\
\hline $\begin{array}{l}\text { Gender of } \\
\text { participants }\end{array}$ & \multicolumn{3}{|c|}{ Male $(25.3 \%)$} & \multicolumn{4}{|c|}{ Female $(74,7 \%)$} \\
\hline $\begin{array}{l}\text { Educational } \\
\text { level taught }\end{array}$ & $\begin{array}{l}\text { Complete } \\
\text { primary } \\
\text { school } \\
(1.2 \%)\end{array}$ & $\begin{array}{l}\text { Partial } \\
\text { primary } \\
\text { school } \\
(4.7 \%)\end{array}$ & $\begin{array}{l}\text { Partial } \\
\text { primary } \\
\text { and } \\
\text { secondary } \\
\text { school } \\
(8.2 \%)\end{array}$ & $\begin{array}{l}\text { Complete } \\
\text { primary } \\
\text { and } \\
\text { secondary } \\
\text { school } \\
(10.6 \%)\end{array}$ & $\begin{array}{l}\text { Com } \\
\text { seco } \\
\text { scho } \\
(30 .\end{array}$ & $\begin{array}{l}\text { lete } \\
\text { dary } \\
1 \\
0)\end{array}$ & $\begin{array}{l}\text { Partial } \\
\text { secondary } \\
\text { school } \\
(44.7 \%)\end{array}$ \\
\hline
\end{tabular}


Information gathering and the techniques associated to it were done based on the perspective of deductive analysis. First the questionnaire with Likert scale was submitted to 92 teachers and, later on, the teachers made an assessment about their teaching of biology (Table 2).

TABLE 2

TECHNIQUES FOR INFORMATION GATHERING AND NUMBER OF PARTICIPANTS PER YEAR

\begin{tabular}{lcc}
\hline Technique for information gathering & Year & Number of participants \\
\hline Questionnaire with Likert scale & 2015 & 92 \\
Discussion group & 2015 & 8 \\
Discussion group & 2016 & 5 \\
Episodic interview & 2016 & 15 \\
Group interview & 2016 & 4 \\
Class obervation & 2017 & 20 \\
Class observation and participant analysis & 2017 & 1 \\
\hline
\end{tabular}

\subsection{Information gathering}

Questionnaire. Based on the contributions of Contreras (2010), we designed and validated the questionnaire 'Thought and action on the preparation and teaching of biology' in the context of two dimensions: Preparation and Teaching of Biology. Each dimension represents two spheres for exploration: Thought and Action. In turn, each sphere serves a particular epistemological vision, Traditional (T) or Constructivist (C). The purpose of the appliance was to explore epistemological beliefs about the preparation and teaching of biology, so as to develop the discussion groups later on.

Discussion group. With the purpose of going further into the teachers' representations about the Preparation and Teaching of Biology, we designed a discussion group (DG). The first group (during 2015) was focused on the purpose of teaching biology and how to prepare adequately for this. The participants of DG1 were 8 working biology teachers ( 5 males and 3 females). The DGs are organized as learning communities and as such, their main objective is to discuss problem areas in the practice of the profession. To this end, we designed cases we submitted to the participants for analysis and discussion. DG1 takes place during 7 sessions. Each session is recorded on video and transcribed. During DG2 discussion is steered towards the teaching of biology. Here, fragments of real classes were used as topics for discussion; this awoke the teachers' interest in problematizing the structure and sequencing the biology contents of the syllabus. This second group was formed by 5 teachers, only 3 of whom worked during the 7 planned sessions. The purpose of the DG was to go into the teachers' representations about the preparation and teaching of biology and, in turn, have input to design cases that could lead to discussions. 
Episodic interview. In this type of interview the participant gathers knowledge of his experiences (Flick, 2007). Meanwhile, the idea was to centre the teacher's attention on his most relevant teaching experiences. The participants, 15 teachers in all, were chosen by grounded theory; 4 participated in DG1 and the others were selected based on an analysis of the questionnaire. The aim was to identify indicators of effective teaching. To complement the information, there were 4 focus group interviews about the teaching of biology and the handling of the classroom.

Observation and analysis of classes. The last stage is aimed at the observation and analysis of classes (20 in all), the main purpose was to identify real situations experienced by the teacher during his/her professional practice. Afterwards, there was a deeper analysis together with one of the teachers who voluntarily made a personal and individual analysis of one of his biology classes. This stage of research was organized into 5 work sessions, all conducted by one of the authors of this article. The first consisted of recording one of his biology classes on video. The next 4 sessions combined participant observations and focused interviews. Through a qualitative analysis of the information, we identified three relevant categories: concerns of the teacher, acts of teaching, and difficulties in teaching about the cell membrane. The reduction of data is the result of a qualitative analysis of the content; this is done firstly through open codification and a selection of frequent codes, so as to identify the entities of the model based on the representations made by the participants during the different stages of research.

\section{Model for Professional Development (MPD)}

We understand professional development as a process that promotes the teacher's learning so as to give new meaning to his/her professional knowledge, to broaden the understanding of the teaching of his subject area, with a systematic method based on personal and professional interests in a framework of reflection and collaborative work, to improve the process of teaching and learning. The model for development should: i) be active and be interwoven with the teacher's learning (Soine \& Lumpe, 2014); ii) consider that professional development encompasses spheres of the Personal, External, Practical and Consequences (Clarke \& Hollingsworth, 2002); iii) acknowledge that development implies a cognitive and situated perspective (Borko, 2004) of the experiences of professional learning; iv) focus on the professional requirements for teaching specific knowledge (Desimone, 2009; Van Driel \& Berry, 2012; Rozenszajn \& Yarden, 2014); and v) allow for a bi-directional relation between theory and practice through selective attention and reasoning about what happens in the classroom. Thus, the model of professional vision is a relevant axis for a Model for Professional Development underpinned by reflection on action. 


\subsection{Premises of the Model for Professional Development}

1) Development is influenced by the stage of development of the teacher, and it can be focused on the student, the content, or the teacher; the latter is the stage of initial development we see in the teacher during his/ her teaching (Kugel, 1993).

2) Development is influenced by the spaces for reflection; we recognize concrete and abstract spaces based on the teacher's thinking. Professional concerns are the initial expression and main way to access reflection on action. The construction of problems in teaching is the way of terminal access, given the higher degree of complexity for the teacher.

3) Development should make it possible to identify what the teacher needs to learn (Vaillant \& Marcelo, 2015), and answer how to address a teaching problem with this learning.

\subsection{Spheres of the Model for Professional Development}

The MPD is based on cognitive science and on the way the teacher can build his/her professional knowledge individually and collectively, based on the reflection about his/her action. In this sense, we recognize four spaces of professional development (Figure 1), which are described below:

1) The sphere of professional concerns addresses the teachers' worries regarding the preparation of teaching or its implementation. A 'Professional Concern' is an intrapersonal representation derived from a teaching experience that makes the teacher uneasy, because it negatively affects his students' learning or his/her own performance. Concerns represent the personal domain of the teacher and are influenced by the beliefs and experiences related to teaching and learning of a subject specifically in science - in our case, biology.

2) The sphere of difficulties in teaching-learning refers to the teacher's reflection on his/her actions, with the purpose of becoming aware of those teaching actions that restrict the students' learning. In this framework, 'Difficulties in Teaching' is the construction the teacher makes based on the analysis of this teaching action, and discovering how he/she may be limiting students' learning. Reflection on specific actions is key in this sphere.

3) The sphere of practical problems in teaching is conceived as difficulties in teaching that require reflexivity, which implies the relation between 'Theory and Practice'. Theory acquires meaning when it is used in accordance with practical problems, otherwise the teacher does not perceive them as helpful to improve practice (Klein, 1992).

4) Formalization of practical knowledge. In this stage the teacher formalizes his/her professional knowledge and materializes it in the practice of 
teaching. Here the teacher reaches greater autonomy to think about how to tackle problems. This sphere aims to favour integration of action and theory on different levels - epistemological, psychological and educational - to conform schemes of rational-practical thought - not so much causal as more complex.

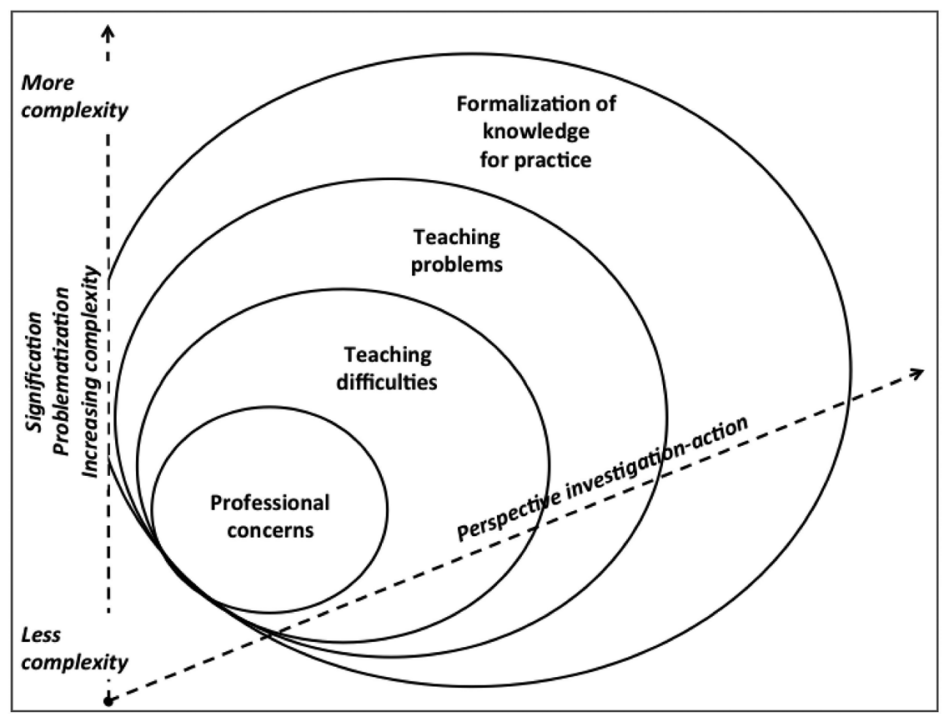

Figure 1 Stages of professional development for learning about teaching.

The model adopts a research-action perspective, recognizing that teachers question, analyze, propose and share ideas, experiences and knowledge in the community. At the same time, it promotes the reflection for conscious decisionmaking, with the aim of gradually transforming the participant when the interaction occurs within and between entities of the model.

\subsection{Operationalization of the Model for Professional Development:} methodological strategy for reflection, interpretation and decision-taking with conscience of the value of professional knowledge (RINDE con-Ciencia)

To put MPD into practice, we designed a methodological strategy for the teachers' reflection regarding the spheres of the model. It begins with a revision of the Framework for Good Teaching (FGT), a public tool that guides the good performance of teachers in the classroom. Based on the observations and analysis of classes in which they don't participate, the team designs a series of situations in the classroom related to some indicator of the Chilean FGT. With the purpose 
of guiding the participants' reflection, the strategy is supported by a work pane and instruction cards for the teachers. Finally, the strategy of Reflection, Interpretation and Decision (RINDE con-Ciencia) makes it possible for the participants to have a mental exchange and declarations regarding situations in the classroom in the different stages of the strategy (Figure 2).

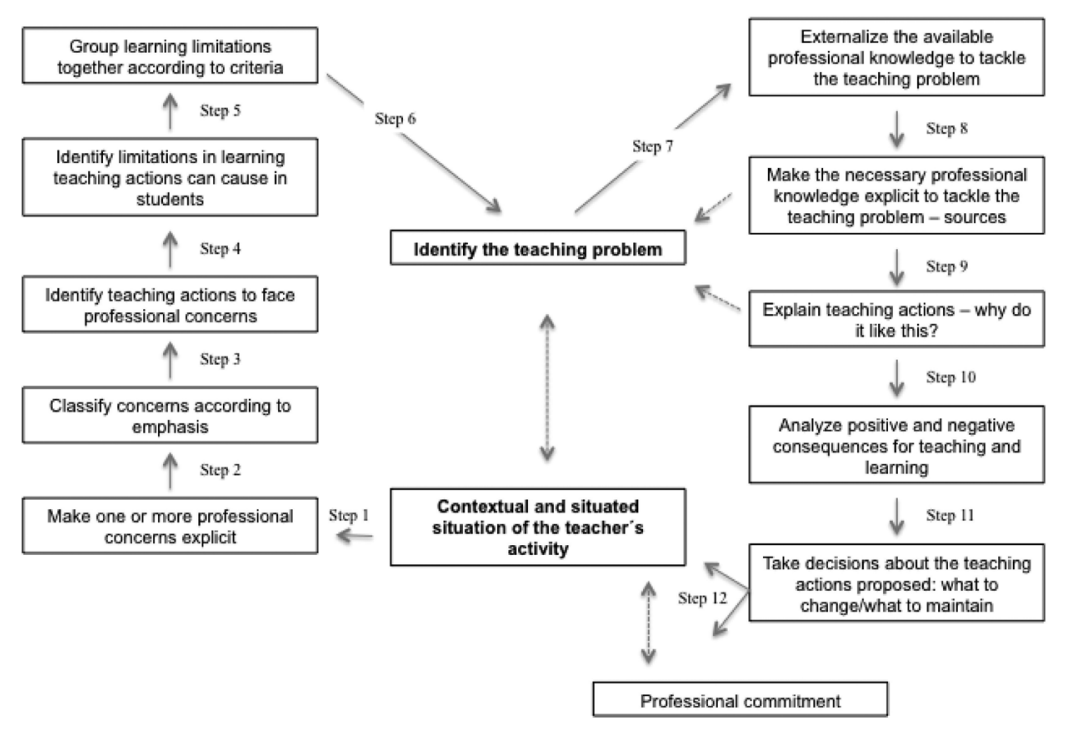

Figure 2 Stages of the methodological strategy for professional development - RINDE con-Ciencia

\subsection{Perception of the participating teachers}

We examined the perception of the RINDE con-Ciencia methodology with an online questionnaire about two aspects: i) the strategy is perceived to be conducive to reflection, and ii) the strategy is perceived to be conducive to professional learning. For this purpose, a qualitative analysis of the open coding content is carried out. Then, the code frequency is estimated to express them in a cloud of words (Figure 3).

"The exchange of experiences with other colleagues, the collective reflection and teamwork" (P8).

"I value the instance of discussion and reflection that allow identifying problems" (P18). "Teachers realize that students not always constitute the problem. Being able to recognize the problem and provide a solution is part of our professional vision" (P20).

First aspect. A strategy designed for personal reflection and reflection among peers. For a group of 20 biology teachers, the strategy promotes personal reflection and reflection among peers $(90 \%)$ and makes it possible to focus on the problems in the classroom while recognizing if these are related to the teacher or the student 
(stage 1 and 3 of MPD). Additionally, teachers perceive the strategy as an invitation to a dialogue about a shared problem that is the result of the analysis of concrete cases. Some teachers state that the strategy favours questioning, analysis of the practice of teaching itself, group discussion and reaching agreements about a problem. A group of primary school teachers specialized in science $(\mathrm{n}=4)$ perceived the strategy as conducive to reflection (100\%) as it allows to dig deeper into the problems of teaching linked to the teacher's practice.

Second aspect. A strategy designed for professional learning. The biology teachers perceive that their learning entailed increasing their capacity to systematize the information, valuing the progression of their learning and that the 'problem' of learning doesn't always revolve around the student. They acknowledge that learning is favoured when reflection begins with identifying the professional concerns and teaching problems; that is to say, the evolution of professional development is valued, from concerns to teaching problems. Together with this, it contributes to stimulate the teacher's meta-analysis in pursuit of revealing what aspects of a situation are professionally approachable by him/her, or which ones are still too confusing to explore.

A)

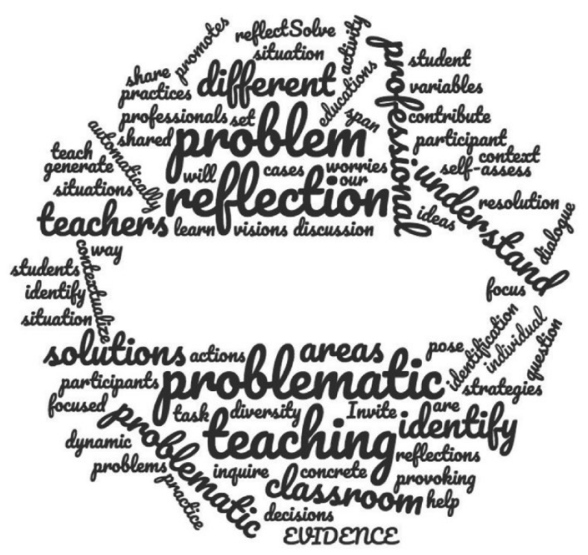

B)

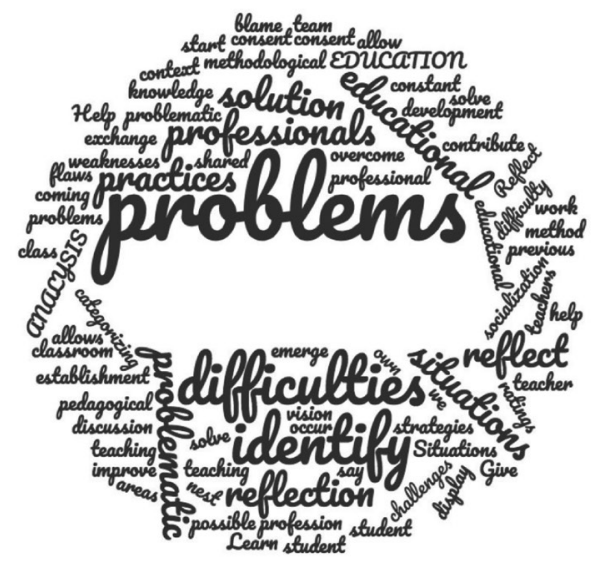

Figure 3 Perception of the teachers on the RINDE con Ciencia strategy as conducive to reflection and professional learning within the framework of the MPD. A) Strategy that promotes reflection. B) Strategy that promotes learning.

\section{Final reflection}

The Model for Professional Development (MPD) acknowledges the teacher as a professional of education (Marcelo, 2009); we acknowledge that teaching should facilitate students' learning and requires a specialized knowledge (LoucksHorsley et al., 2010). We propose a MPD that favours a reflection by teachers 
about the practice of teaching, that is contextual (spatially and temporarily) and situated, that acknowledges the value of the situations in which the teacher puts his/her beliefs, knowledge and experiences in practice to promote learning. The MPD recognizes personal theory as a construction derived from processes of personal examination and research, that respond to a progression of learning that goes from less (professional concerns) to more complexity (formalization of knowledge), and that is useful for the construction of teaching problems and of professional knowledge. The MPD is defined as functional and explanatory, as it allows for a transition towards levels of higher development, stressing the role of reflection in the development of the declaratory sphere of teachers' representations on certain situations. Thus, the MPD aims to guide teachers to reconstruct their personal theory about teaching, improve their understanding of teaching biology and increase appraisal of professional knowledge through the acknowledgement of concerns, difficulties and teaching problems. The teacher needs opportunities to develop his/her knowledge from the mastery of practice (what he/she does/how he/she does it), and from the mastery of results (consequences of what the teacher does/students' learning/teachers' acting), and identify what he/she masters and uses to analyze, critically, the actions of teaching. The proposed MPD seeks to serve this process.

The MDP favours the work in learning communities over particular focuses of interest, but at the same time, it stresses or conflicts with the legitimacy of opinions and views of the biology professor. This is because the pedagogical situations under discussion - the ones that are reflected upon demand the use of academic knowledge, or the knowledge based in teaching experience. In this perspective, the model's challenge is to answer the following question:

To what extent does the MDP represent a path of authentic development that favours the building or rethinking of the professional knowledge aiming to better teaching practice?

\section{Acknowledgements}

To Fondecyt project 11140297 directed by the first author of the article (ERM).

\section{References}

Adey, P. (1999). The science of thinking, and science for thinking: A descriptive of cognitive acceleration through science education (CASE). Switzerland: International Bureau of Education.

Álvarez, C. (2013). Enseñanza y desarrollo profesional docente. Pensar y vivir la educación. La Muralla: Madrid. 
Amórtegui, E., Mosquera, J., Bernal, J., Dussán, N., Quiroga, A., \& Dussàn, C. (2017). La construcción del conocimiento del profesor de ciencias naturales: un estudio de caso en el marco de la práctica pedagógica de la Universidad Surcolombiana, Enseñanza de las Ciencias (no extraordinario), 2275-2280.

Antoniou, P \& Kyriakides, L. (2011). The impact of a dynamic approach to professional development on teacher instruction and student learning: results from an experimental study. School Effectiveness and School Improvement, 22(3), 291-311. doi:1 $0.1080 / 09243453.2011 .577078$

Bolhius, S. (2003). Towards process-oriented teaching for self-directed lifelong learning: a multidimensional perspective. Learning and Instruction, 13, 327-347.

Bordón, P., Canals, C., Rojas, S. \& Serra, C. (2017). Desarrollo profesional de los docentes. En Centro de Estudios (MINEDUC). Contextualización de la enseñanza en Chile. Resultados de la encuesta internacional TALIS 2013 (pp. 49-88). Santiago, Chile: Ministerio de Educación.

Borko, H. (2004). Professional development and teacher learning: Mapping the terrain. Educational Researcher, 33(8), 3-15.

Clarke, P. A., \& Fournillier, J. B. (2012). Action research, pedagogy, and activity theory: Tools facilitating two instructors' interpretations of the professional development of four preservice teachers. Teaching and Teacher Education, 28(5), 649-660. doi:10.1016/j.tate.2012.01.013

Clarke, D. \&Hollingsworth, H. (2002). Elaborating a model of teacher professional growth. Teaching and Teacher Education, 18(8), 947-967.

Contreras (2010). Las creencias y actuaciones curriculares de los profesores de ciencias de secundaria de Chile. (Tesis doctorado, Universidad Complutense de Madrid). Recuperada de http://eprints.ucm.es/11624/1/T32362.pdf.

Crippen, K. (2012). Argument as Professional Development: Impacting Teacher Knowledge and Beliefs About Science. Journal Science Teacher Education, 23, 847 -866.

Desimone, L. M. (2009). Improving impact studies of teachers' professional development: Toward better conceptualizations and measures. Educational Researcher, 38(3), 181-199.

Desimone, L. M. (2011). A Primer on Effective Professional Development. Phi Delta Kappan, 92(6), 68-71. doi:10.1177/003172171109200616

Fernández, Nistal, M., Pérez Ibarra, R., Peña Boone, S., Ibarra, M., y Magdalena, S. (2011). Concepciones sobre la enseńanza del profesorado y sus actuaciones en clases de ciencias naturales de educación secundaria. Revista Mexicana de Investigación Educativa, 16(49), 571-596.

Flick, U. (2014). La gestión de la calidad en investigación cualitativa. Madrid, España: Morata.

Fraser, C., Kennedy, A., Reid, L., \& Mckinney, S. (2007). Teachers'continuing profesional development: contested concepts, understandings and models. Journal of In-Service Education, 33(2), 153- 169. doi: 10.1080/13674580701292913

Gess-Newsome J. (2015). A model of teacher professional knowledge and skill including PCK: Results of the thinking from the PCK Summit. En A. Berry, P. Friedrichsen, P. \& J. Loughran (Eds) Re-examining Pedagogical Content Knowledge in Science Education (pp. 28-42). New York: Routledge. 
Guzmán-Valenzuela, C. \& Cabello, V. (2016). Enhancing reflective practices in professional adult education. In Fehring, H. \& Rodrigues, S. Teaching, Coaching and Mentoring Adult Learners: Lessons for Professionalism and Partnership. p.p. 35-44. London: Routledge.

Hennissen, P., Beckers, H., and Moerkerke, G. (2017). Linking practice to theory in teacher education: A growth in cognitive structures. Teaching and Teacher Education, 63, 314-325. doi: 10.1016/j.tate.2017.01.008

Hewson, P. (2007). Teacher professional development in science. In S. Abell y N. Lederman (Eds,). Handbook of research on science education (pp. 1179-1203). New York, EEUU: Routledge.

Jiménez, M. (2018). Y llega uno y se estrella con un montón de cosas. La inserción profesional de profesores de ciencias naturales. Medellín: Editorial Universidad de Antioquia.

Kang, H., Cha, J. \& Ha, B. (2013). What Should We Consi- der in Teachers Professional Development Impact Studies? Based on the Conceptual Framework of Desimone. Creative Education, 4(4A), 11-18. doi: 10.4236/ce.2013.44A003

Kessels, J., \& Korthagen, F. (1996). The relationship between theory and practice: Back to the classics. Educational Researcher, 25(3), 17-22. doi: 10.2307/1176664

Klein, F. (1992). A perspective on the gap between curriculum theory and practice. Theory into Practice, 31(1), 191-197.

Krell, M. \& Krüger, D. (2015). Testing models: A key aspect to promote teaching activities related to models and modeling in biology lessons? Journal of Biological Education, 50(2), 160-173. doi: 10.1080/00219266.2015.1028570

Kugel, P. (1993). How professors develop as teachers. Studies in Higher Education, 18(3), 315-328.

Kuusisaari, H. (2013). Teachers' collaborative learning - development of teaching in Group discussions. Teachers and Teaching: Theory and Practice, 19, 1, $50-62$.

Loucks-Horsley, S., Stiles, K., Mundry, S., Love, N. \& Hewson, P. (2010). Designing professional development for teachers of Science and Mathematics, California, Corwin Press.

Marcelo, C. (2009). La evaluación del desarrollo profesional docente: de la cantidad a la calidad. Revista Brasileira de Formação de professores, 1(1), 43-70.

Mansour N. \& Wegerif R. (2013) Why science educatoon for diversity? En N, Mansour y R. Wegerif (Eds.), Science Education for Diversity. Theory and Practice (pp. ix-xx). Cultural Studies of Science Education: Springer.

Meijer, P., de Graaf, G., \& Meirink,J. (2011). Key experiences in student teachers'development. Teachers and Teaching: Theory and Practice, 17(1), 115-129. doi: 10.1080/13540602.2011.538502

Päuler-Kuppinger, L. y Jucks, R. (2017). Perspectives on teaching: Conceptions of teaching and epistemological beliefs of university academics and students in different domains. Active Learning in Higher Education, 18(1), 63-76. doi:10.1177/ 1469787417693507

Porlán, R., Martín Del Pozo, R., Rivero, A., Harres, J., Azcárate, P., \& Pizzato, M. (2011). El cambio del profesorado de ciencias II: itinerarios de progresión y obstáculos en estudiantes de magisterio. Enseñanza de las Ciencias, 29(3), 413-426.

Porlán, R. (2018). Didáctica de las ciencias con conciencia. Enseñanza de las Ciencias, 36(3), 5-22. doi: 10.5565/rev/ensciencias. 2795 
Ravanal, E., López-Cortés, F. \& Rodríguez, L. (2017). Elaboración y validación de un cuestionario de preocupaciones profesionales sobre la enseńanza de la biología (PPEB). Bio-Grafía - Escritos sobre la biología y su enseñanza, 10(18), 111-123.

Ravanal, E., López-Cortés, F. \& Rodríguez, L. (2018). Creencias de profesores de biología chilenos sobre la Preparación de la enseñanza. Revista Eureka sobre divulgación y enseñanza de la ciencia, 15(3), 3601.

Reimers, F. \& Chung, C. (Eds.)(2016). Enseñanza y aprendizaje en el Siglo XXI. Metas, politicas educativas y curriculo en seis paises. Ciudad de México, México: Fondo de Cultura Económica.

Rivero, A., Martín del Pozo, R., Solís, E., Azcárate, P., \& Porlán, R. (2017). Cambio del conocimiento sobre la enseñanza de las ciencias de futuros maestros. Enseñanza de las Ciencias, 35(1), 29-52.

Rosenzajn, R. \& Yarden, A. (2014). Expansion of biology teachers' pedagogical content knowledge (PCK) during a long-term professional development program. Research in Science Education, 44(1), 189-213. doi: 10.1007/s11165-013-9378-6

Rusell, T (2014). La práctica en la formación de profesores: tensiones y posibilidades en la experiencia de aprender a enseñar. Estudios Pedagógicos, XI (Número especial 1), 223-238.

Saariaho, E., Pyhältö, K., Toom, A., Pietarinen, J. \& Soini, T. (2016). Student teachers` self- and Co-regulation of learning during teacher education. Learning: Research and Practice, 2(1), 44-63. doi:10.1080/23735082.2015.1081395

San Antonio, D.; Morales, N. \& Moral, L. (2011). Module-based professional development for teachers: a cost-effective Philippine experiment. Teacher Development, 15, 2, $157-169$.

Schön, D. (1983). The reflective practitioner: How professionals think in action. New York: Basic Books.

Simon, S. \& Campbell, S. (2012). Teacher Learning and Professional Development in Science Education. En Fraser, B.; Tobin, K. y Campbell, M. (eds). Second International Handbook of Science Education (307-321). New York.

Soine, K. M. \& Lumpe, A. (2014). Measuring characteristics of teacher professional development. Teacher Development, 18(3), 303-333.

Stürmer, K. \& Seidel, T. (2017). A standardized approach for measuring teachers professional vision: The observer research tool. En E, Schack, Fisher, M. y J. Wilhelm (Eds.), Teacher Noticing: Bridging and braodening perspectives, contexts, and frameworks (pp. 359-380). Springer.

Vaillant, D \& Marcelo, C. (2015). El ABC y D de la formación docente. Madrid, España: Narcea.

Van den Bergh, L., Ros, A. and Beijaard, D. (2015). Teacher learning in context of a continuing professional development programme: A case study. Teaching and Teacher Education, 47, 142-150. doi: 10.1016/j. tate.2015.01.002.

Van Driel, J \& Berry, A. (2012). Teacher profesional development focusing on pedagogical contentknowledge.EducationalResearcher,41(1),26-28.doi:10.3102/0013189X11431010

Zhang, M., Parker, J., Koehler, M., \& Eberhardt, J. (2015). Understanding inservice science teachers' needs for profesional development. Journal Science Teacher Education, 26(5), 471-496. doi: 10.1007/s10972-015-9433-4 



\title{
TEACHING \& LEARNING LABORATORIES IN BIOLOGY TEACHER EDUCATION: ANALYSIS OF TEACHING REFLECTIONS
}

\author{
Antje Saathoff and Corinna Hößle \\ Carl von Ossietzky University Oldenburg, Germany \\ antje.saathoff@uni-oldenburg.de
}

\begin{abstract}
One possibility to integrate more practical work into biology teacher education is the implementation of 'teaching \& learning laboratories'. Here, students are given the opportunity to plan and then repeatedly test, reflect, and optimize a biology teaching sequence in the context of teaching \& learning laboratories and accompanying seminars. This is done in order to expand their pedagogical content knowledge. Therefore, the step of reflection is a basis for an increase in competence and proficiency. The main objective of this study is to analyse how biology student teachers reflect on their own teaching experiences in a teaching $\&$ learning laboratory. A qualitative approach was chosen for this. As part of the data collection, group discussions $(N=10)$ were conducted. The sampling includes biology student teachers during their Bachelor's and Master's degrees. Data were evaluated using a grounded theory approach. In the results, a central axial category is presented by way of example. This category is called 'professional teaching while still being a student', and conveys a conflict in which students find themselves while teaching in a teaching \& learning laboratory. From the results, implications are derived to optimize the use of teaching \& learning laboratories in biology teacher education.
\end{abstract}

Keywords: biology teacher education, teaching \& learning laboratories, teaching reflection, group discussions, grounded theory

\section{Introduction}

During their studies, biology student teachers should expand their professional competencies. In this regard, in its requirements for the subject of 
Biology, the German Conference of Education Ministers (KMK) demands that, at the end of their studies, biology student teachers should have gained profound biological expertise, biology-based methodological competencies in form of working and knowledge acquisition methods, knowledge of biology-related teaching and learning research, and reflected experiences in competenceoriented planning and implementation of biology lessons (KMK, 2008). Additionally, current discourses call for a higher degree of practice within teacher education (Allen \& Wright, 2014). One possibility to provide the required study contents in a highly practical way is the integration of 'teaching \& learning laboratories' in biology teacher education. The concept of teaching \& learning laboratories has gained popularity especially in the field of biology teacher education because for biology teacher students the training of experimental skills is of particular importance. Teaching \& learning laboratories represent a special form of classical school laboratories. Besides the learners' learning process, the focus lies especially on the teaching of pre-service biology teachers (Hößle, 2014). Within the framework of teaching \& learning laboratories and the accompanying seminars, students are given the opportunity to plan and then repeatedly test, reflect and optimize a biology teaching unit. This supports the expansion of students' professional teaching competencies (Hößle, 2014; Brauer \& Hößle, 2018).

The present research project focuses on this concept. The reflection phases within the teaching \& learning laboratories are ascribed a central role in the further development of the students' professional competencies. Therefore, this study examines how biology student teachers reflect on their experiences in a teaching $\&$ learning laboratory. Thus, the reflection practice is taken into focus. For data collection, group discussions were conducted with biology student teachers, in which they reflected on their teaching experiences in a teaching $\&$ learning laboratory. Above all, opportunities and challenges in the implementation of teaching \& learning laboratories into biology teacher education will be discussed.

\section{Teaching \& Learning Laboratories in biology teacher education}

\subsection{Developing professional competencies by reflecting on teaching activities}

A central goal of the teacher training programme is the development of professional competencies (KMK, 2004). Here, the focus lies especially on the development of the pedagogical content knowledge (PCK), as this area plays an important role in successful teaching (Baumert \& Kunter, 2013; Großschedl et al., 2015; Tamir, 1988). Often, however, the students get a so-called 'reality shock' after their academic studies in teacher education (Herzog \& von Felten, 
2001; Komorek, 2015). In this case, students find it difficult to apply the contents of their studies in their teaching activities. In order to close this gap between theory and practice, both students and the institutional side demand an integration of more practical elements into the teacher training programme (Allen \& Wright, 2014; KMK, 2008).

By means of practical experiences and related reflection processes, students can develop professional competencies, and above all, their pedagogical content knowledge (PCK). Park \& Oliver (2008, p. 278) comment on this as follows: "Teachers develop PCK through a relationship found amid the dynamics of knowledge acquisition, new applications of knowledge, and reflection on the uses embedded in practice. This assertion also supports the knowledge that others are learning to teach. Although teachers' knowledge can be improved and learned by receptive learning, the most powerful changes result from experiences in practice."

Thus, reflexivity is also characterized as a prerequisite for the professionalization of teachers (Korthagen, 2001; Postholm, 2008), even calls reflection a key activity for professional teacher action. This relevance was also recognized by the KMK and recorded in the standards for teacher education. Students should reflect on their personal occupational values and attitudes in their theoretical teacher training (KMK, 2004). In addition, the subject-specific requirements for biology require that graduates have first reflected on experiences of competence-oriented planning and implementation of biology lessons (KMK, 2008). In general, it is postulated that the development of competencies can be promoted through personal testing and subsequent reflection of a theoretical concept in extracurricular learning places (KMK, 2004). The use of teaching $\&$ learning laboratories in biology teacher education can be located in this field.

\subsection{Concept of teaching \& learning laboratories}

The initiators of school laboratories have set themselves the overriding goal of arousing learners' interest in scientific topics and promoting their scientific understanding. If a school laboratory is additionally used to build up professional knowledge of student teachers in a practice-oriented manner at an early stage, it is called a 'teaching \& learning laboratory'. Already during their studies, students can gain experiences for their own teaching. In doing so, they develop teaching competencies and patterns of action by repeatedly planning, implementing and reflecting on learning units (Hößle, 2014; Hößle et al., 2017). These practical experiences from a teaching $\&$ learning laboratory differ from the experiences gained in a regular school internship. There is a reduction in complexity as students work with small groups of learners. In addition, they can plan and design their learning units more freely than in the framework of a school internship (Komorek, 2015). Through these aspects, the combination of theory and practice should be facilitated. This forms a basis for facilitating the transition 
between the different phases of teacher education and encountering 'reality shock' (Allen \& Wright, 2014; Hößle, 2014; Komorek, 2015).

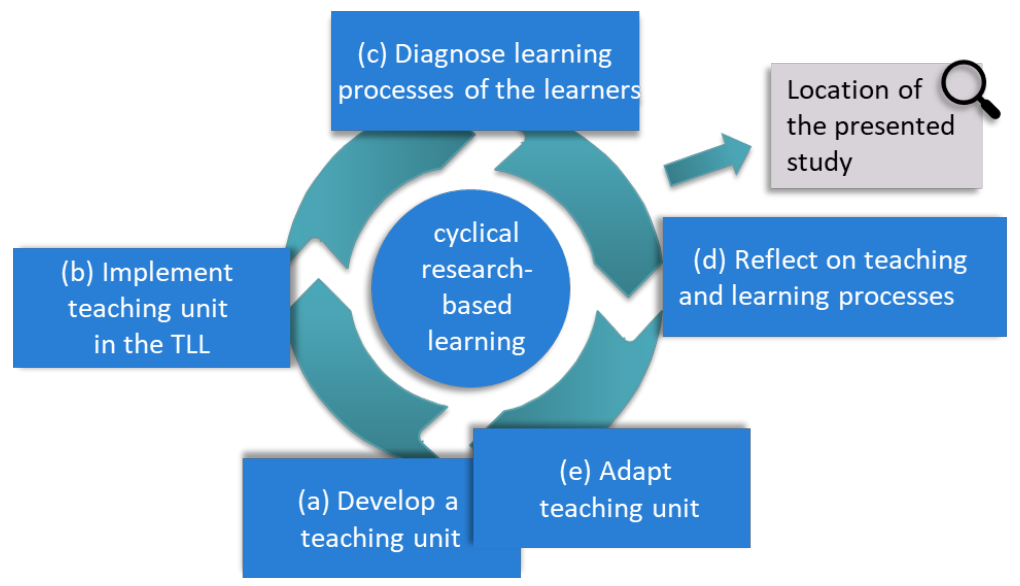

Figure 1 The process model of cyclical and research-based learning

In the Oldenburg biology teacher training, teaching \& learning laboratories are well-established concepts for a theory-practice integration since they are anchored in the module concepts and training curricula. The integration of teaching \& learning laboratories into different didactical seminars follows the process model of cyclical and research-based learning (Figure 1). The steps of the model are repeated several times in order to build up the didactic knowledge of the students (Hößle et al., 2017).

\subsection{Reflection of teaching experiences in the teaching \& learning laboratory}

In the process model of cyclical and research-based learning, the step of teaching reflection (step d) plays a central role in the students' professionalization processes (Saathoff \& Hößle, 2017). In the implementation of more practical elements, however, knowledge does not follow directly from experience. (Hascher \& Hagenauer, 2016; Weyland, 2014). Rather, it may happen that scientific theories are poorly integrated or even ignored. Instead, biographical knowledge of a pedagogical and didactic nature can be established. This knowledge tends to be very stable and shapes the teaching style of a teacher substantially (Herzog \& von Felten, 2001). Herzog \& von Felten (ibid.) speak in this context of an overfamiliarity with the institution school, which may affect the professional development of student teachers. This kind of knowledge cannot easily be replaced by other contents within the course of studies but must be scrutinized and explicated. In this context, internships should not be understood as places of 
gaining experiences, but as an opportunity to reflect on hidden educational and didactic knowledge, and to connect it with scientific knowledge (Herzog \& von Felten, 2001). In this context, Combe \& Kolbe (2008) also claim that there must be facilities in teacher education in which these conventional patterns can be put to the test and be worked through. The reflection of practical experiences is, therefore, of particular importance. Through this process, the experiences can be linked with existing academic knowledge, which contributes to the professionalization of the students (Korthagen, 2001).

\subsection{State of research}

So far, the concept of teaching reflection has only been studied in few biology didactical studies. In a questionnaire study with pre-service and experienced biology teachers, Schmelzing et al. (2010) observed that an increase in reflectivity takes place along the different stages of teacher education. In addition, they were able to establish a connection between explicit reflectivity and pedagogical content knowledge. In their interpretation, declarative pedagogical content knowledge must be present in order to be able to describe special teaching situations, as well as analyze these situations explicitly and with reference to theoretical knowledge (ibid.).

Wischmann (2015) examined teaching reflections in the context of biology didactical school internships with a focus on ongoing mentoring processes. She was able to determine that the potential of reflection for the professionalization of students differed depending on the reflection partner, but complemented each other in a meaningful way. In reflection sessions with university mentors, students set up references to pedagogical content knowledge and often elaborated alternative options for action. Above all, reflections in peer-groups included an integration of pedagogical knowledge and a reference to one's own attitudes and convictions. Since the work in peer-groups was rated as very profitable by students, the peer reflection should, according to Wischmann's (ibid.) recommendation, also be an integral part of school-practical elements.

More and more, the professionalization processes of students within the framework of teaching \& learning laboratories have come into the focus of current research in didactical studies. Constructs have already been studied which are similar to the process of teaching reflection. From this, first insights can be derived. The study by Brauer \& Hößle (2018) focuses on the diagnostic skills, which include the ability to describe and assess specific learner characteristics in order to adapt the lesson to the learners (Bell \& Cowie, 2001). Brauer and Hößle (2018) found that participation in a seminar involving a teaching \& learning laboratory has positive effects on the diagnostic skills of biology student teachers. Through the activity in the teaching \& learning laboratory, students were able to improve their ability to recognize teaching situations that are relevant for learning. 
The ability to recognize learning-relevant situations is also of high importance for the process of teaching reflection (Schmelzing et al., 2010).

The concept of professional vision includes the steps of noticing and interpreting such learning-relevant situations (van Es, 2012) and thus represents a prerequisite for productive reflection (Meschede, 2014). Treisch (2018) found in this context that the students' ability of professional vision in a teaching $\&$ learning laboratory could only be improved in combination with video analysis and theory-based teaching reflections. Without these additional aspects, no development could be achieved. This can be explained as the oral reflection processes that take place are often not used effectively because only a small amount of theory is used. In addition, it is difficult for students to recognize relevant teaching situations at all. Treisch (2018), therefore, recommends investigating the reflection processes in teaching \& learning laboratories in further studies in order to optimize them. At this point, the present study starts.

\section{Key objective}

This study takes a closer look at the step of teaching reflection in teaching $\&$ learning laboratories as a basis for professionalization. From this, the focus of the research interest lies in the concrete reflection practice of biology student teachers. This is done to gain deeper insights into the steps and processes involved in reflecting on teaching experiences. From the results, optimizations for the reflection phases in the teaching \& learning laboratory should be derived. Therefore, the following central research question arises:

- How do biology student teachers reflect on their teaching experiences in a teaching $\&$ learning laboratory?

\section{Research design and methodology}

The study focuses on biology student teachers who have previously taught in a teaching $\&$ learning laboratory. The Oldenburg biology didactics has three teaching \& learning laboratories: 'The Wadden Sea Learning Laboratory' (http://www.lernlabor-wattenmeer.de), which deals with topics relating to the Wadden Sea ecosystem; the 'Green School' in the botanical garden (http://www. grueneschule.uni-oldenburg.de), where learners can study topics of botany and ecology close to nature; and the 'School of Senses' (http://www.sinnesschule. uni-oldenburg.de), where experiments on the human senses are conducted.

The conceptual integration of all laboratories follows a similar principle in that the students work together as partners or small groups and prepare their teaching units within the accompanying seminars. The students then implement their teaching units in the form of team teaching in the teaching \& learning laboratory. After that, experiences are reflected in the accompanying seminar 
with the aim of deriving implications for subsequent lessons and adapting the teaching units (Hößle et al., 2017).

For this explorative study, a qualitative approach was chosen. For data collection, group discussions were conducted with students. Group discussions are characterized by a very open procedure, which is supposed to enable the participants to work on relevant topics in a self-contained discourse. This openness and spontaneity is achieved above all by the fact that the discussion moderator has the lowest possible influence on the discourse (Bohnsack, 2010). The aim of the discussions is that the students reflect on their teaching experiences in a selfcontained discourse. For this purpose, the following entry impulse was provided and pilot testing developed (Saathoff \& Hößle, 2017): "Tell me how you experienced the day and the lessons with the learners. Please reflect the experiences you had today."

The group discussions were conducted directly after a completed learning unit in a teaching \& learning laboratory. The groups consisted of two or three small student teams each, which were prepared in the same accompanying seminar and which had taught together in team teaching. A total of ten discussions were held with students. The sampling includes pre-service biology teachers in their Bachelor's $(\mathrm{N}=29)$ and Master's $(\mathrm{N}=43)$ degree. The sample is presented in more detail in Table 1. All discussions were audio-recorded, prepared and transcribed according to the guidelines of Bohnsack (2010). The data were analyzed using a grounded theory methodology according to Strauss \& Corbin (1990). This involves three coding processes: In the step of open coding, all data are conceptualized and the concepts are named with codes. In the step of axial coding, the codes are recombined by using the coding paradigm. Therefore, one creates axial categories. In the last step, selective coding, the axial categories are combined at a higher level of abstraction into the central core category. The aim of the study is the development of a grounded theory of medium reach.

TABLE 1

SAMPLE OF THE PRESENTED STUDY

\begin{tabular}{|c|c|c|c|c|c|}
\hline Group & Degree & Teaching \& learning laboratory & \multicolumn{2}{|c|}{ Composition } & Duration \\
\hline 01 & Bachelor & Green School & 4 우 & & $0 \mathrm{~h} 46 \mathrm{~min}$ \\
\hline 02 & Bachelor & Green School & 6 우 & & $0 \mathrm{~h} 37 \mathrm{~min}$ \\
\hline 03 & Master & Green School & 2 우 & $3 \sigma^{\lambda}$ & $0 \mathrm{~h} 52 \mathrm{~min}$ \\
\hline 04 & Bachelor & Wadden Sea Laboratory & 2 우 & $2 \widehat{\jmath}$ & $1 \mathrm{~h} 01 \mathrm{~min}$ \\
\hline 05 & Master & Wadden Sea Laboratory & 4 우 & $2 \hat{\sigma}$ & $0 \mathrm{~h} 50 \mathrm{~min}$ \\
\hline 06 & Master & Wadden Sea Laboratory & 4 우 & & $0 \mathrm{~h} 30 \mathrm{~min}$ \\
\hline 07 & Master & Wadden Sea Laboratory & 4 ㅇ & $1 \hat{\jmath}$ & $1 \mathrm{~h} 08 \mathrm{~min}$ \\
\hline 08 & Master & Wadden Sea Laboratory & 4 우 & & $0 \mathrm{~h} 38 \mathrm{~min}$ \\
\hline 09 & Master & Wadden Sea Laboratory & 5 우 & & $0 \mathrm{~h} 46 \mathrm{~min}$ \\
\hline 10 & Bachelor & School of Senses & 4 우 & $1 \hat{0}$ & $1 \mathrm{~h} 00 \mathrm{~min}$ \\
\hline
\end{tabular}




\section{Findings}

This section gives an insight into selected results. For this purpose, a central axial category is shown as the result of open and axial coding (Figure 2 ), and illustrated with exemplary quotes from the group discussions. The data point to a central axial category, which was conceptualized as the phenomenon 'professional teaching while still being a student'. The reflection is characterized primarily by the fact that the students try to overcome the conflict, on the one hand, of acting professionally in their teaching role and, on the other hand, of still being in the role of learners with little experience in professional teaching. They work on this conflict within their teaching reflections, which is influenced by different conditions and leads to different consequences and strategies.

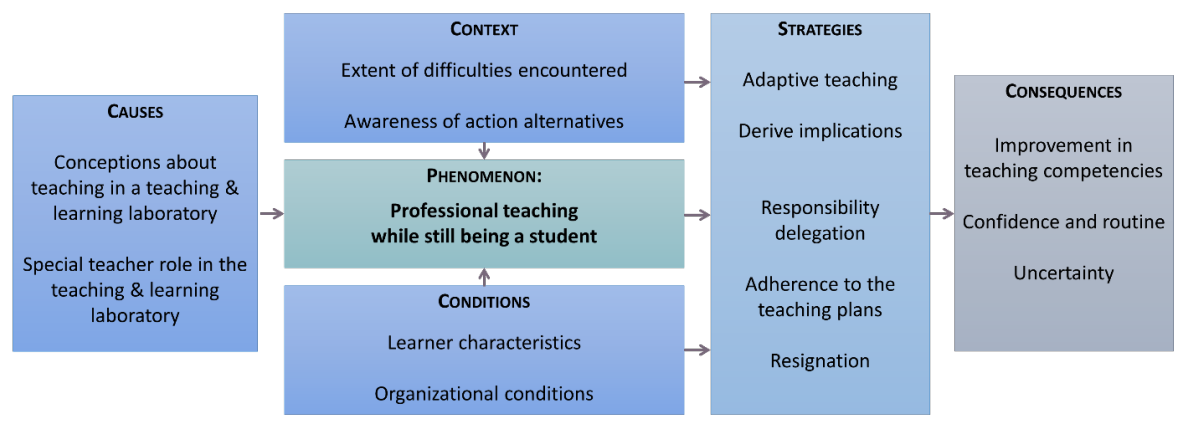

Figure 2 Axial category 'professional teaching while still being a student' represented using the coding paradigm (Strauss \& Corbin, 1990).

\subsection{Causes}

The reason for the phenomenon is, for one, the special teacher role, in which the students are in the teaching \& learning laboratory. This is characterized by a dual role because the students are both in the teacher and in the student position. As can be seen in the following quote, some students do not even classify themselves as teachers, but completely as students. "Actually, we are only students and the learners know that too." Furthermore, the students have specific ideas about teaching in the teaching \& learning laboratory, which differ from the ideas for teaching in a school context. In the following example, a student describes fun as the primary goal of teaching in the laboratory instead of learning success. "The main thing is that they learn something at all. So this is really more about having fun and being a bit more relaxed. So there's no pressure and no stress for the children." 


\subsection{Context}

The contextual conditions describe the properties of the phenomenon. The strength of the conflict is characterized by the extent of the difficulties encountered while teaching. The following quotes describe typical difficulties that students encountered while teaching. "I basically did the experiment and chose the highest requirement level. Then the learners were overwhelmed by this."; "They did not know that there is a swim bladder and then they said that the gill is responsible for storing the air and pumping up." In addition, the scope of alternative action strategies that students are aware of, in order to respond adequately to such difficulties, influences the strength of the conflict. As shown in the following example, in some situations students were not able to respond adequately to difficulties. "And I did not want to take anything away from their learning process by just telling them how it really is, because you really want them to understand it on their own. But at some point, I did not know how I could get them there."

\subsection{Conditions}

The phenomenon is influenced by different conditions. Thus, the characteristics of the learners play a central role in the students' teaching reflection and are often included, as in the following examples: "The learners were not interested in biology."; "Everyone in our group was very bright and very interested and it was really fun to work out the stations with them." In addition, the organizational aspects of the seminar influence teaching activities and teaching reflection. In some cases, students justify difficulties with organizational factors and do not relate them to their own teaching activities. "What I found difficult about the situation was that we were three students, who were responsible for only five learners. It was almost a one on one attention."

\subsection{Strategies}

To overcome the conflict, students use different strategies of action that they discuss in their teaching reflections. With the strategies of adaptive teaching and the derivation of implications for subsequent lessons, the students react to difficulties encountered and can, thus, master them. "I have solved this by first collecting the statements of the students. We then discussed this, so that the learners themselves realize that the gills cannot save anything or inflate. But I had to provide the impulse that there is a swim bladder."; "I noticed that next time I have to take some time to explain the task exactly. Because as soon as they start experimenting, they stop listening to me."

In other cases, they delegate responsibility for their own teaching activities. "The teaching in the teaching \& learning laboratory is too superficial."; "We had too little time." 
"It was too warm and too stuffy in the room." In addition, they frequently adhered to their teaching plans in this case:

Em: "I think that is justifiable with the teaching situation".

Em:" I am satisfied with myself".

Bm: "I have to say I think I would not have done much differently in the end."

In this case, they may even resign. "But then I felt a bit lost as a teacher because I just did not know how to motivate them anymore." With the latter strategies, they cannot adequately respond to emerging difficulties.

\subsection{Consequences}

Depending on the applied strategy, there are different consequences for the self-perception of the students. Responsibility delegation, adherence to teaching plans and resignation, often lead to uncertainties and doubts about their own teaching competencies. This can be seen in the following quotation. "And now I know what's behind it all while teaching. And now I have so many questions in my head and no answers to everything." However, through the strategies of adaptive teaching and the derivation of implications, students often perceive an improvement in their teaching competencies. They also develop confidence and routine in their teaching activities in these cases.

Af: "But I found it interesting this morning, as I often noticed directly that I could have said it otherwise. So, if you have asked a question and then saw the blank looks. Then you thought, yes you have"

Cm: "You completely missed it."; "A few things went better. And it really helped that we did it the last time before. I just knew what to expect. "

\section{Discussion and conclusions}

The results can now be discussed in terms of the implementation of teaching \& learning laboratories in biology didactical seminars. For this purpose, concrete implications for the use of teaching $\&$ learning laboratories in the context of the process model of cyclical and research-based learning (Figure 1) were derived (Table 2). Overall, the study confirms the assumption made by Treisch (2018) that oral reflection processes are often not used effectively. This can be counteracted by the identified causes of this phenomenon and the resulting developments. 
TABLE 2

IMPLICATIONS FOR THE USE OF TEACHING \& LEARNING

LABORATORIES IN BIOLOGY TEACHER EDUCATION

\begin{tabular}{|c|c|}
\hline Findings & Implications \\
\hline $\begin{array}{l}\text { Special teacher role and spe- } \\
\text { cific conceptions about teach- } \\
\text { ing in a teaching \& learning } \\
\text { laboratory }\end{array}$ & $\begin{array}{l}\text { Convey the structure of the teaching \& learning laboratory } \\
\text { For planning the teaching unit, it is crucial to discuss not only the teach- } \\
\text { ing goals but also the goals of the teaching \& learning laboratory. In } \\
\text { the presented case, the teaching \& learning laboratory serves as an 'un- } \\
\text { graded practical experience', within which students can gain first teach- } \\
\text { ing experiences without performance pressure. In addition, they will be } \\
\text { encouraged to self-critically reflect on their lessons. This seems to be a } \\
\text { specific difference to the internship in the school, with which students } \\
\text { often already connect a concrete performance expectation, which has to } \\
\text { be fulfilled. }\end{array}$ \\
\hline $\begin{array}{l}\text { Characteristics of the learners } \\
\text { are unknown to the students } \\
\text { but central to teaching }\end{array}$ & $\begin{array}{l}\text { Enable learner orientation } \\
\text { As a frequently occurring challenge in the teaching \& learning laborato- } \\
\text { ries, the planning of the teaching unit is difficult without first getting to } \\
\text { know the learners. The early development of diagnostic tasks can coun- } \\
\text { teract this. The tasks are given to the learners before they visit the labo- } \\
\text { ratory so that they can work on them before. The results provide insights } \\
\text { into the conceptions and skills of the learners and can be used for further } \\
\text { diagnostic tasks used in the teaching \& learning laboratories. This also } \\
\text { supports the later reflection, because the learning increase of the learners } \\
\text { can be considered process-oriented (Kuhlemann \& Hößle, 2019). }\end{array}$ \\
\hline
\end{tabular}

Delegation of responsibility Delegate organization to the students

The challenge is that students tend to delegate the responsibility for their own teaching within their reflections and justify any difficulties that encountered with organizational factors. This can be counteracted by giving students more responsibility in the organization of the lab day. For example, they could autonomously contact the class and the teacher beforehand to clarify teaching goals and to discuss the organization of the lab day.

Adherence to teaching plans Develop action alternatives

Another challenge is that students are not aware of sufficient action alternatives during teaching. This can be counteracted by a more comprehensive lesson plan, which shows action alternatives at specific points. These can be discussed in the reflection phase in terms of their suitability.

\section{Focus reflection}

In order to best prepare the students for the step of reflection, the topic of reflection should be theoretically and practically trained in the accompanying seminar. This should clarify which goals and which contents a reflection contains. In addition, the reflection should be practically tested, e.g. by working with teaching vignettes. Apart from this, it makes sense to develop a list of questions for teaching reflection that supports productive reflection.

\section{Acknowledgements}

The participation at the XIIth ERIDOB conference was supported by the University Society Oldenburg e.V. 


\section{References}

Allen, J. M., \& Wright, S. E. (2014). Integrating theory and practice in the pre-service teacher education practicum. Teachers and Teaching: Theory and Practice, 20 (2), 136-151.Baumert, J., \& Kunter, M. (2013). The COACTIV Model of Teachers' Professional Competence. In M. Kunter, J. Baumert, W. Blum, U. Klusmann, S. Krauss, \& M. Neubrand (Eds.), Cognitive Activation in the Mathematics Classroom and Professional Competence of Teachers. Results from the COACTIV Project (pp. 2548). New York: Springer.

Bell, B., \& Cowie, B. (2001). The characteristics of formative assessment in science education. Science Education, 85(5), 536-553.

Bohnsack, R. (2010). Documentary Method and Group Discussions. In R. Bohnsack, N. Pfaff, \& W. Weller (Eds.), Qualitative analysis and documentary method in international educational research (pp. 99-124). Opladen: Budrich.

Brauer, L., \& Hößle, C. (2018). Acquiring diagnostic skills in the field of experimentation in the Wadden Sea's Teaching \& Learning Laboratory. In N. Gericke \& M. Grace (Eds.), Challenges in Biology Education Research (pp. 256-272). Karlstad: University Printing Office.

Combe, A., \& Kolbe, F.-U. (2008). Lehrerprofessionalität: Wissen, Können, Handeln. In W. Helsper \& J. Böhme (Eds.), Handbuch der Schulforschung (pp. 857-875). Wiesbaden: VS, Verlag für Sozialwissenschaften.

Großschedl, J., Harms, U., Kleickmann, T., \& Glowinski, I. (2015). Preservice Biology Teachers' Professional Knowledge: Structure and Learning Opportunities. Journal of Science Teacher Education, 26(3), 291-318.

Hascher, T., \& Hagenauer, G. (2016). Openness to theory and its importance for pre-service teachers' self-efficacy, emotions, and classroom behavior in the teaching practicum. International Journal of Educational Research, 77, 15-25.

Herzog, W., \& von Felten, R. (2001). Erfahrung und Reflexion. Zur Professionalisierung der Praktikumsausbildung von Lehrerinnen und Lehrern. Beiträge zur Lehrerbildung, 19(1), 17-28.

Hößle, C. (2014). Lernprozesse im Lehr-Lern-Labor Wattenmeer diagnostizieren und fördern. In A. Fischer, C. Hößle, S. Jahnke-Klein, V. Niesel, H. Kiper, M. Komorek, \& J. Sjuts (Eds.), Diagnostik für lernwirksamen Unterricht (pp. 144-156). Baltmannsweiler: Schneider Verlag.

Hößle, C., Hußmann, S., Michaelis, J., Niesel, V., \& Nührenbörger, M. (2017). Fachdidaktische Perspektiven auf die Entwicklung von Schlüsselkenntnissen einer förderorientierten Diagnostik. In C. Selter, S. Hußmann, C. Hößle, C. Knipping, K. Lengnink, \& J. Michaelis (Eds.), Diagnose und Förderung heterogener Lerngruppen. Münster, New York: Waxmann.

KMK. (2004). Standards für die Lehrerbildung: Bildungswissenschaften. Retrieved from http://www.kmk.org/fileadmin/Dateien/veroeffentlichungen_beschluesse/ 2004/2004_12_16-Standards-Lehrerbildung.pdf [08.10.2018].

KMK. (2008). Ländergemeinsame inhaltliche Anforderungen für die Fachwissenschaften und Fachdidaktiken in der Lehrerbildung. Retrieved from http://www.kmk. 
org/fileadmin/Dateien/veroeffentlichungen_beschluesse/2008/2008_10_16-Fachprofile-Lehrerbildung.pdf [08.10.2018].

Komorek, M. (2015). Schülerlabore als dynamischer Lernort einer praxisnahen Lehrerbildung. In LernortLabor (Ed.), 10 Jahre LeLa-Jahrestagung - Festschrift (pp. 2226). Berlin: Eigenverlag LernortLabor.

Korthagen, F. A. J. (2001). A Reflection on Reflection. In F. A. J. Korthagen (Ed.), Linking Practice and Theory: The Pedagogy of Realistic Teacher Education (pp. 5168). Mahwah, New Jersey: Erlbaum.

Kuhlemann, B., \& Hößle, C. (2019). Angehende Lehrpersonen auf dem Weg zur akkuraten Diagnose. In E. Christophel, M. Hemmer, F. Korneck, T. Leuders, \& P. Labudde (Eds.), Fachdidaktische Forschung zur Lehrerbildung (pp- 147-156). Münster, New York: Waxmann.

Park, S., \& Oliver, J. S. (2008). Revisiting the Conceptualisation of Pedagogical Content Knowledge (PCK): PCK as a Conceptual Tool to Understand Teachers as Professionals. Research in Science Education, 38, 261-284.

Postholm, M. B. (2008). Teachers developing practice: Reflection as key activity. Teaching and Teacher Education, 24(7), 1717-1728.

Saathoff, A., \& Hößle, C. (2017). Wie reflektieren Biologielehramtsstudierende ihre Unterrichtserfahrungen im Lehr-Lern-Labor? Eine qualitativ-rekonstruktive Analyse. In D. Krüger, P. Schmiemann, A. Möller, \& A. Dittmer (Eds.), Erkenntnisweg Biologiedidaktik 16 (pp. 25-39). Rostock: Universität Rostock.

Schmelzing, S., Wüsten, S., Sandmann, A., \& Neuhaus, B. (2010). Fachdidaktisches Wissen und Reflektieren im Querschnitt der Biologielehrerbildung. Zeitschrift für Didaktik der Naturwissenschaften, 16, 189-207.

Smoor, S., \& Komorek, M. (2017). Einfluss epistemischer Überzeugung auf Planungsprozesse im Lern-Labor. In C. Maurer (Ed.), Implementation fachdidaktischer Innovation im Spiegel von Forschung und Praxis. GDCP-Jahrestagung Zürich 2016 (pp. 260-263). Regensburg: Universität Regensburg.

Strauss, A. L., \& Corbin, J. (1990). Basics of Qualitative Research. Newbury Park, CA: Sage.

Tamir, P. (1988). Subject matter and related pedagogical knowledge in teacher education. Teaching and Teacher Education, 4, 99-110.

van Es, A. (2012). Examining the developement of a teacher learning community: The case of a video club. Teaching and Teacher Education, 28(2), 182-192.

Weyland, U. (2014). Schulische Praxisphasen im Studium: Professionalisierende oder deprofessionalisierende Wirkung? bwp@ Berufs- und Wirtschaftspädagogik - online, Profil 3, 1-24. Retrieved from http://www.bwpat.de/profil3/weyland_profil3. pdf [08.10.2018].

Wischmann, F. (2015). Mentoring im fachbezogenen Schulpraktikum: Analyse von Reflexionsgesprächen. Retrieved from http://elib.suub.uni-bremen.de/edocs/0010 4792-1.pdf [08.10.2018]. 



\title{
TEACHING TO TEACH THE MODEL OF EVOLUTION IN PRIMARY EDUCATION: AN EXPERIENCE WITH PRE-SERVICE TEACHERS AT A SPANISH UNIVERSITY
}

\author{
Lucía Vázquez-Ben and Ánxela Bugallo-Rodríguez \\ Universidade da Coruña (UDC, Spain) \\ lucia.vben@udc.es
}

\begin{abstract}
Numerous experts consider it necessary to start building the model of evolution as soon as possible, in primary or even infant education. Nevertheless, to promote a successful and progressive construction of this scientific model, we must first provide our teachers with the appropriate knowledge and skills to deal with such complex contents. Therefore, we designed a specific intervention on evolution education for our primary school preservice teachers. After working on the model of evolution itself, they were introduced to a set of real primary school activities they first had to solve and then assess from a didactic viewpoint. Following a qualitative approach, data was collected on participant observation as well as the material produced by the students, that is, an activity booklet and an assessment worksheet filled in during the task. Results have shown that, even when our pre-service teachers found the intervention useful for their future career, more time would be needed to develop not only their Pedagogical Content Knowledge, but also their understanding of the model of evolution itself. Limitations to this study and implications for future research are discussed.
\end{abstract}

Keywords: model of evolution, primary education, pre-service teachers, teaching strategies, didactics of biology

\section{Introduction}

Bishop and Anderson (1990, p.415) said that "an understanding of modern biology is incomplete without an understanding of evolution". After all, the model of evolution should be considered one of the four basic - and deeply interrelated - models in Biology, next to the model of cell, the model of an organism and the 
model of an ecosystem (García Rovira, 2005). Nowadays such understanding is even more essential. Following Emmons et al. (2016, p.1205), this knowledge has grown to be "more than academic", since a thorough understanding of evolution has become necessary today, not just for those dedicated to Life Sciences careers, but for any citizen to be able to make informed decisions about societal and bioethical issues.

Unfortunately, in Spain the theory of evolution - not the model - is taught for the first time at the end of secondary education, as part of an optional subject. As a result, many students finish their compulsory education having learnt very little about this content. But such is the case of plenty of our primary school preservice teachers, who will have to deal with topics like 'living things', 'biodiversity', 'adaptation' and 'extinction' in their future careers. For that reason, at the University of A Coruña (Spain), we decided to design and implement a specific intervention on the model of evolution and how to teach it in primary school with our $3^{\text {rd }}$ grade students from the Degree in Primary Education.

\section{Theoretical background and rationale}

\subsection{The model of evolution in primary education}

Numerous studies have shown how many students from secondary education and above struggle to understand evolution, mainly because of their way of reasoning, too often driven by essentialism, empiricism, common sense, teleology and anthropocentrism (Banet \& Ayuso, 2003; Grau \& De Manuel, 2002; González Galli, 2011; Gregory, 2009; among others). For example, from an essentialist perspective, variation within individuals in a population is not perceived as an ordinary event, but as a failure. Still, assuming intraspecific variation is crucial for comprehending the mechanism of natural selection. Similarly, common sense and teleology might lead students to justify the appearance or disappearance of particular traits in terms of 'use' and 'disuse', while 'adaptation' is too often conceived in anthropocentric terms, that is, as an intrinsic ability that living things consciously put into action when needed to avoid perishing.

However, as Gregory (2009) points out, most of these naïve, intuitive and biased explanations, are constructed during early childhood. In addition, they tend to remain even after instruction (Yates \& Marek, 2015). Consequently, many experts have suggested starting to work on the model of evolution as soon as possible, that is, in primary or even infant education (Cañal et al., 2016; Jewers, 2011; Nadelson et al., 2009). In fact, this content has recently been included in the curriculum for primary education in different countries, such as France and England. What is more, states like New York and California in the United States of America, have been working on key ideas such as inheritance, adaptation or natural selection at elementary levels for decades. Now they have 
adapted - or adopted - the new Framework for K-12 Science Education (NCR, 2012) and its Next Generation Science Standards (NCR, 2013), which not only incorporate evolution as one of the four Disciplinary Core Ideas of Life Sciences, but also give recommendations about what content must be addressed at each stage (Vázquez-Ben \& Bugallo-Rodríguez, 2018). Then again, there are also many countries and states which are not following these recommendations, but still limiting the presence of the model of evolution within their curriculum, like Arizona or Texas in the USA (Vazquez, 2017), or even completely removing it, just as Turkey has recently done (Altuntaş, 2017). Such a decision becomes particularly alarming in a time when the Theory of Evolution is yet being discredited and openly rejected all around the globe due to political and religious reasons, among other factors (Heddy \& Nadelson, 2012).

\subsection{Teaching to teach evolution}

If we are to introduce the model of evolution in primary education, we must accordingly incorporate it to our primary school teachers training programmes, either initial or ongoing. That is, we must find the most appropriate strategies to enable our teachers to teach this content in their - future or current - classrooms. What is their starting point though? According to literature, both pre-service and in-service teachers from primary school seem to lack the content knowledge as well as the specific pedagogical skills needed to deal with this scientific model. From not being sure whether or not dinosaurs coexisted with humans (Prinou et al., 2011) or reducing natural selection to a fight for being the strongest (Nadelson, 2009), to having no strategies to work from an evolutionary perspective (Ashgard et al., 2007) and handle the controversy (Thagard \& Findlay, 2010), teachers recognise themselves as incapable of teaching this content in the classroom (Akyol et al. 2012; Vázquez-Ben \& Bugallo-Rodríguez, 2017).

The solution appears to be to implement such content in their education programmes, for both pre-service and in-service teachers, as initial or ongoing training respectively. However, this training must be carefully thought through, if it is to have an impact in the long-term, as Ha et al. (2015) insist. Sickel \& Friedrichsen (2013) recommend covering five major themes: the content knowledge, the acceptance of evolution, the Nature of Science, how to handle the controversy and, finally, the pedagogical content knowledge, that is, knowledge of the learners, instructional strategies, assessment and curriculum associated with this particular topic. Likewise, this training should include the use of models and modelling, given the important role they play in Science (Gilbert \& Justi, 2016). Moreover, their argumentation skills should also be developed, so that they become able to not only justify their position but also refute others' positions using evidence (Jiménez \& Puig, 2013). 


\section{Key objectives and research questions}

The main purpose of this study is to design, implement and assess an intervention on evolution education aimed to prepare our pre-service teachers to teach the model of evolution in primary schools. This training shall provide them with both the content knowledge and the pedagogical content knowledge needed to deal with this important, yet complex, scientific model. To be more specific, our research questions are:

- What strategies could be used to successfully develop pre-service teachers' pedagogical skills for the model of evolution?

- Are pre-service teachers able to identify what content of the model of evolution is being dealt with in each activity proposed during the intervention?

- What criteria do pre-service teachers use to decide whether a particular activity should be applied in a classroom setting?

- How do pre-service teachers' difficulties affect their ability to solve the activities suggested?

\section{Research design and methodology}

The research consisted of introducing our undergraduate students from the 3rd year of a Degree in Primary Education to a set of activities regarding the model of evolution and its teaching, as part of the annual subject Science Teaching and Learning II, which focuses on Biology and Geology Didactics. There were 44 participants in total, from 3 different class groups, and organised into 10 small groups.

\subsection{Design and application of the intervention}

1. In order to develop not only our pre-service teachers' understanding of the model of evolution but also, and above all, their Pedagogical Content Knowledge, we designed an intervention structured into 3 different parts: Evolution and Primary Education (a 90-minute session): after having collected our students' previous ideas about evolution in an earlier session, we worked on the model of evolution and explained some of the most common misconceptions and difficulties children show when learning about this topic. For example, evolution as an analogy of progress, adaptation as a conscious and controllable ability of living things, appearance of new species as a result of combining another two, appearance or disappearance of traits in terms of need as well as use or disuse, only the strongest survives., etc.

2. Performance and assessment of real activities (a 90-minute session): each small group was given an activity they had to first solve and later assess from 
a didactic point of view. To assist them with both tasks, they were given an activity booklet, which contained the instructions needed to carry out the activity, and an assessment worksheet, which included different aspects to be considered when analysing didactic materials. These included: the goal of the activity, the content being dealt with, the age targeted, the adequacy of the methodology and resources employed, the previous knowledge required to understand the activity, and any obstacles that might appear while performing it. While the booklets for each activity and the assessment worksheet were specifically designed by the authors for this task, most of the activities were selected and adapted from real primary school activities, taken from literature and/or pre-existing curricular materials. This way we expected to make the experience for our students as practical, useful and motivating as possible. Specifically, we adapted Armour's (2011) activity about human evolution (1); Sá-Pinto and Campos' (2012) activities on natural selection, (2), genetic drift (3) and inheritance (4); and Teachit's (2014) activity "Getting to know Charles Darwin" - to work on Nature of Science - (5), and "What is adaptation? Plant perspective" (6), from their Evolution and Inheritance Curriculum Pack. Additionally, we designed a seventh (7) activity where students would play the role of a palaeontologist. They would first have to dig for fossils, then identify (name and date) those fossils using the books provided by the professor, and finally discuss: 1) how natural conditions must have been at that particular time and place according to the characteristics of the fossils given, and 2) whether (and how) these fossils could be related to any modern organism.

3. Therefore, each activity dealt with different contents (fossils, inheritance, natural selection, adaptation, etc.), introduced a different type of task (searching for information, table-games, role-playing, etc.), and made use of different materials (worksheets, books, internet, recycled stuff, etc.). Please note that, as students were from three different class groups, some activities were done within the three groups, while others were performed in just one or two of the groups, or even not performed, depending on the number of students present that day. Sharing and discussion. In the third and last session (a 90-minute session), each group would have 10 minutes to present their activity to the other groups and discuss their didactic assessment together.

\subsection{Collection and analysis of data}

Regarding the methodology, we decided to adopt a qualitative approach (Flick, 2004). Data was collected through the material produced by the students during the intervention, that is, the aforementioned activity booklets and their assessment worksheets, as well as the participant observation carried out by the researchers. For the analysis, we combined Miles \& Huberman's (1994) phases and design of matrices with Saldaña's (2009) cycle coding. In the first cycle, we 
used Structural Coding, to find out which content they were able to put into practice, which criteria they were applying when assessing the different activities, as well as what the main difficulties were that they had to face. In the second cycle, we employed Pattern Coding, in order to identify any similarity or difference within the groups.

\section{Findings}

\subsection{Pre-service teachers' Content Knowledge}

As illustrated in Table 1, most groups were able to identify correctly the content that was actually involved in their activity. However, they also tended to 'over-identify' content, that is, to tick concepts that were not addressed at all in that particular activity. For example, up to seven groups decided they were working about 'Evidence for evolution' in their activity, but only the ones solving activity 7 did so. The same happened with 'Sexual reproduction', which appeared just in activity 4, where students had to analyse a family tree and reflect on how traits are randomly inherited and combined within individuals over generations. In addition, it took them a lot of time and effort to complete this part of the assessment worksheet, which suggests a limited grasp of the model of evolution.

\subsection{Pre-service teachers' Pedagogical Content Knowledge}

When asked which grade our pre-service teachers would use the activities presented, all the groups ranged them between $2^{\text {nd }}(7-8$ years old $)$ and $5^{\text {th }}$ grade (10-11 years old), focusing most of them in $4^{\text {th }}$ grade ( $9-10$ years old), as Table 2 shows. Since they had been informed from the beginning that the activities had been adapted from real primary school activities, it was not a surprise to obtain these results. Nevertheless, what is really interesting to note is that, by indicating these periods of age, they are agreeing not only with applying these activities in a primary school, but also, and above all, to the possibility of developing this content during this stage. For example, Group 5, working on activity 3 (genetic drift), stated that "Even when we know how difficult to explain Genetics at this ages is, students might be able to understand some of its factors through hands-on activities".

Methodology was in fact the main criteria considered when deciding whether to use these activities in a primary school setting. The more manipulative, visual and innovative the activity was, the more they approved it: "Yes, [we would use this activity] because we think it is a good activity to work about this topic [inheritance] in a practical and visual way, but we would introduce some more manipulative work" (G7, Activity 4). If we look again at 
TABLE 1

KEY CONCEPTS ACTUALLY INVOLVED IN EACH ACTIVITY (IN RED) VS KEY CONCEPTS IDENTIFIED BY EACH GROUP (A DIFFERENT COLOUR PER GROUP)

\begin{tabular}{|c|c|c|c|c|c|}
\hline Key Concepts & $\begin{array}{c}\text { Activity } 2 \\
\text { Natural } \\
\text { selection }\end{array}$ & $\begin{array}{c}\text { Activity } 3 \\
\text { Genetic } \\
\text { Drift }\end{array}$ & $\begin{array}{l}\text { Activity } 4 \\
\text { Inheritance }\end{array}$ & $\begin{array}{c}\text { Activity } 6 \\
\text { Adaptation } \\
\text { in plants }\end{array}$ & $\begin{array}{l}\text { Activ.7 } \\
\text { Fossils }\end{array}$ \\
\hline Inheritance & & & & & \\
\hline Variation within an organism & & & & & \\
\hline $\begin{array}{l}\text { Variation within a popu- } \\
\text { lation }\end{array}$ & & & & & \\
\hline $\begin{array}{l}\text { Mechanisms for variation: } \\
\text { Sexual reproduction }\end{array}$ & & & & & \\
\hline $\begin{array}{l}\text { Mechanisms for variation: } \\
\text { Mutation }\end{array}$ & & & & & \\
\hline Common ancestors: Fossils & & & & & \\
\hline $\begin{array}{l}\text { Common ancestors: Phy- } \\
\text { logeny }\end{array}$ & & & & & \\
\hline $\begin{array}{l}\text { Mechanisms for evolution: } \\
\text { Natural selection }\end{array}$ & & & & & \\
\hline $\begin{array}{l}\text { Mechanisms for evolution: } \\
\text { Artificial selection }\end{array}$ & & & & & \\
\hline $\begin{array}{l}\text { Mechanisms for evolution: } \\
\text { Genetic Drift }\end{array}$ & & & & & \\
\hline $\begin{array}{l}\text { Mechanisms for evolution: } \\
\text { Migration }\end{array}$ & & & & & \\
\hline Adaptation & & & & & \\
\hline Biodiversity & & & & & \\
\hline Extinction & & & & & \\
\hline Evidence for evolution & & & & & \\
\hline
\end{tabular}


Table 2, other aspects they took into account were: the level of difficulty of both the content and the task; students' cognitive and even motor development; and how accessible and attractive the resources were: "We would use plastic beads instead of confetti. We would use it [the activity], since it is very visual and easy to understand [the content] while having fun. (G1, Activity 2).

TABLE 2

CRITERIA PRE-SERVICE TEACHERS USE TO DECIDE WHEN AND WHY AN ACTIVITY COULD BE APPLIED

\begin{tabular}{|c|c|c|c|c|c|}
\hline & $\begin{array}{l}\text { Activity } 2 \text { Natu- } \\
\text { ral selection }\end{array}$ & $\begin{array}{c}\text { Activity } 3 \\
\text { Genetic Drift }\end{array}$ & $\begin{array}{l}\text { Activity } 4 \\
\text { Inheritance }\end{array}$ & $\begin{array}{c}\text { Activity } 6 \\
\text { Adaptation in } \\
\text { plants }\end{array}$ & $\begin{array}{l}\text { Activity7 } \\
\text { Fossils }\end{array}$ \\
\hline Age & $2 n d, 3 r d$ or $4 t h$ & $3 r d, 4$ th or 5 th & $3 r d$ & 4 th & $4 t h$ \\
\hline Criteria & $\begin{array}{l}\text { - Level of diffi- } \\
\text { culty (content } \\
\text { \& task) } \\
\text { - Methodolo- } \\
\text { gy: Visual \& } \\
\text { Hands-on } \\
\text { - Previous } \\
\text { knowledge } \\
\text { required } \\
\text { - Motivation } \\
\text { - Easy to grasp } \\
\text { - Students' cog- } \\
\text { nitive \& motor } \\
\text { development }\end{array}$ & $\begin{array}{l}\text { - Level of diffi- } \\
\text { culty (content } \\
\text { \& task) } \\
\text { - Methodo- } \\
\text { logy: active, } \\
\text { hands-on, } \\
\text { innovative, } \\
\text { motivating. } \\
\text { - Previous } \\
\text { knowledge } \\
\text { required } \\
\text { - First time } \\
\text { dealing with } \\
\text { this content. }\end{array}$ & $\begin{array}{l}\text { - Methodolo- } \\
\text { gy: Visual \& } \\
\text { practical } \\
\text { - First time } \\
\text { dealing with } \\
\text { this content. }\end{array}$ & $\begin{array}{l}\text { - Methodolo- } \\
\text { gy: passive vs } \\
\text { active } \\
\text { - Previous } \\
\text { knowledge } \\
\text { required } \\
\text { - Easy to grasp }\end{array}$ & $\begin{array}{l}\text { - Level of } \\
\text { difficulty } \\
\text { (content) } \\
\text { - Motivation } \\
\text { - Significant } \\
\text { learning }\end{array}$ \\
\hline
\end{tabular}

Finally, when asked about what knowledge children would need to solve the activity as well as what difficulties might appear, there was no reference to any misconceptions, except for Group 4 (see Table 3), even though we had discussed many of them during the first part of the intervention. Instead, they tended to include the very same content they were supposed to introduce with their activity (natural selection, genetic drift, inheritance, adaptation, evolution, etc.) in the list of 'Previous knowledge needed'. That was the case of Groups 2 and 3 ('Natural selection'); G7, ('Genetics'); or G9 ('What a fossil and palaeontology are').

However, they demonstrated themselves to be pretty sensible about what obstacles children might have to face in each activity, probably because they experience those same difficulties while performing the activities. For instance, G1, G4, G5 and G6 mentioned the difficulty to understand and follow the instructions provided. G3 and G10 alluded to lack of knowledge. G4, G5, G7 and G8 added struggling to interpret results, differentiate terms, confront viewpoints or search for information. G9 and G10 talked about dealing with the concept of time. In this sense, our intervention has proved to be very effective. 
TABLE 3

PREVIOUS KNOWLEDGE NEEDED AND POSSIBLE DIFFICULTIES PRE-SERVICE TEACHERS IDENTIFIED

\begin{tabular}{|c|c|c|c|c|c|}
\hline & $\begin{array}{l}\text { Activity } 2 \mathrm{Na}- \\
\text { tural selection }\end{array}$ & $\begin{array}{c}\text { Activity } 3 \\
\text { Genetic Drift }\end{array}$ & $\begin{array}{l}\text { Activity } 4 \\
\text { Inheritance }\end{array}$ & $\begin{array}{c}\text { Activity } 6 \\
\text { Adaptation in } \\
\text { plants } \\
\end{array}$ & $\begin{array}{l}\text { Activity } 7 \\
\text { Fossils }\end{array}$ \\
\hline $\begin{array}{l}\text { Previous } \\
\text { knowledge }\end{array}$ & $\begin{array}{l}\text { (G1) } \\
\text { - None; activi- } \\
\text { ty explains } \\
\text { (G2) } \\
\text { - Habitat } \\
\text { - Biodiversity } \\
\text { - Population } \\
\text { - Natural } \\
\text { selection } \\
\text { - Reproduc- } \\
\text { tion } \\
\text { (G3) } \\
\text { - Chain foods } \\
\text { - Evolution } \\
\text { - Adaptation } \\
\text { - Natural } \\
\text { selection }\end{array}$ & $\begin{array}{l}\text { (G4) } \\
\text { - Maths ope- } \\
\text { rations } \\
\text { - Species } \\
\text { - Variation } \\
\text { - Habitat } \\
\text { - Natural } \\
\text { selection } \\
\text { - Evolution } \\
\text { (G5) } \\
\text { - Genetics \& } \\
\text { Evolution } \\
\text { - Variation } \\
\text { within a } \\
\text { species } \\
\text { (G6) } \\
\text { - Natural } \\
\text { selection } \\
\text { - Basic notions } \\
\text { of evolution } \\
\end{array}$ & $\begin{array}{l}\text { (G7) } \\
\text { - Reproduc- } \\
\text { tion } \\
\text { - Genetics }\end{array}$ & $\begin{array}{l}\text { (G8) } \\
\text { - Plant } \\
\text { characteristics } \\
\text { - Skills to } \\
\text { search for } \\
\text { information }\end{array}$ & $\begin{array}{l}\text { (G9) } \\
\text { - What a fossil is } \\
\text { - What palaeon- } \\
\text { tology is } \\
\text { (G10) } \\
\text { - Evolution } \\
\text { - Inheritance } \\
\text { - Living things }\end{array}$ \\
\hline Difficulties & $\begin{array}{l}\text { (G1) } \\
\text { - Understand } \\
\text { instructions. } \\
\text { - Grabbing } \\
\text { confetti; } \\
\text { better plastic } \\
\text { beads. } \\
\text { (G2) ------- } \\
\text { (G3) } \\
\text { - Add \& } \\
\text { subtract } \\
\text { correctly. } \\
\text { - Lack of } \\
\text { previous } \\
\text { knowledge } \\
\text { required. }\end{array}$ & $\begin{array}{l}\text { (G4) } \\
\text { - Understand } \\
\text { instructions. } \\
\text { - Wrong } \\
\text { previous } \\
\text { knowledge. } \\
\text { - Wrong inter- } \\
\text { pretation of } \\
\text { results. } \\
\text { (G5) } \\
\text { - Understand } \\
\text { instructions. } \\
\text { - Distinguish } \\
\text { "variety" vs } \\
\text { "species". } \\
\text { (G6) } \\
\text { - Follow steps } \\
\text { correctly. }\end{array}$ & $\begin{array}{l}\text { (G7) } \\
\text { - Confront } \\
\text { different } \\
\text { viewpoints } \\
\text { - Under-stand } \\
\text { why we } \\
\text { resem-ble } \\
\text { to our rel- } \\
\text { atives from } \\
\text { previous } \\
\text { generations. }\end{array}$ & $\begin{array}{l}\text { (G8) } \\
\text { - Struggle } \\
\text { to identify } \\
\text { advantages } \\
\text { \& disadvan- } \\
\text { tages [for } \\
\text { each plant } \\
\text { adaptation]; } \\
\text { search \& } \\
\text { select infor- } \\
\text { mation }\end{array}$ & $\begin{array}{l}\text { (G9) } \\
\text { - Find \& } \\
\text { identify the } \\
\text { species given } \\
\text { [fossils] in a } \\
\text { chronological } \\
\text { order. } \\
\text { (G10) } \\
\text { - Identify \& } \\
\text { classify the } \\
\text { fossils in } \\
\text { periods. } \\
\text { - Lack of } \\
\text { previous } \\
\text { knowledge } \\
\text { required. }\end{array}$ \\
\hline
\end{tabular}

\section{Conclusions, limitations and future research}

Even when our findings are tentative and further research is needed, the intervention proposed in this paper appears to be effective in introducing 
elementary pre-service teachers to the content and abilities required to assist their future pupils in the construction of their model of evolution.

First, it made it possible, not only for us, but also for our pre-service teachers, to (self-) assess their content knowledge about the model of evolution. How much they struggle (or not) to solve each activity and identify its content were good indicators of their level of understanding of the model of evolution. Actually, this limited knowledge has become one of the flaws in our study, since a better domain of this scientific model, and modelling itself, would have probably allowed our pre-service teachers to perform even better. Secondly, by being 'forced' to describe the methodology that was being used, to decide in which grade each activity could be applied, or to indicate some difficulties and previous ideas that might appear on the way, they have started to consciously develop their PCK. Working in small groups with just one activity at a time was especially relevant, as it encouraged debate and a deeper analysis. In addition, most of the groups showed willingness to use these same activities in their future careers, either directly or with minor changes, due to considering them innovative and motivating for the children. Therefore, the assignment itself, as well as the activities presented, was perceived as useful for their training.

Unfortunately, there were some limitations to this research that we would like to overcome in future projects, such as: analysing its long-term impact (if any); extending the study, so we get more groups to do all the different activities planned within the intervention; and also to gather all the groups in a last session to discuss their work, making the experience more enriching. In conclusion, more time is definitely needed to work on evolution education, but also on the model of evolution itself, due to the absence of a progressive and effective learning during compulsory education.

\section{Acknowledgements}

Project funded by Ministerio de Economía y Competitividad EDU20156643-C2-2-P and Programa de Axudas Predoutorais da Xunta de Galicia ED48A-2016/291. We would also like to thank all the participant pre-service teachers for taking part in this research.

\section{References}

Akyol, G.; Tekkaya, C.; Sungur, S. \& Traynor, A. (2012). Modeling the Interrelations among pre-service Science teachers' understanding and acceptance of Evolution, their views on Nature of Science and self-efficacy beliefs regarding teaching Evolution. Journal of Science Teacher Education, 23, 937-957.

Altuntaş, Ö. (2017, September 19). Turkey's new school year: Jihad in, evolution out. BBC News. Retrieved from https://www.bbc.com/news/world-europe-41296714 
Armour, L. (2011). Darwin, Evolution and the Origins of Life. Avaliable at: https://www. studymode.com/essays/Darvin-And-Evolution-Lesson-Plan-55899741.html

Asghar, A.; Wiles, J. R. \& Alters, B. (2007). Canadian pre-service elementary teachers conceptions of biological evolution and evolution education. McGill Journal of Education, 42 (2), 189-210.

Banet, E. \& Ayuso, G. E. (2003) Teaching of biological inheritance and evolution of living beings in secondary school. International Journal of Science Education, 25 (3), 373-407, DOI: 10.1080/09500690210145716

Bishop, B. A. \& Anderson, C. W. (1990). Student conceptions of Natural Selection and its role in Evolution. Journal of Research in Science Teaching, 27 (5), 415-427.

Cañal, P. (Coord.); García-Carmona, A. \& Cruz-Guzmán, M. (2016). Didáctica de las Ciencias Experimentales en Educación Primaria. Madrid: Ediciones Paraninfo.

Emmons, N.; Smith, H. \& Kelemen, D. (2016). Changing minds with the story of adaptation: strategies for teaching young children about natural selection. Early Education and Development, 27 (8), 1205-1221. DOI: 10.1080/10409289. 2016.1169823

Flick, U. (2004). Introducción a la investigación cualitativa. Madrid: Morata.

García Rovira, M.P. (2005). Los modelos como organizadores del curriculum de biología. Enseñanza de las Ciencias, extra VII International Conference, 1-6.

Gilbert, J.K \& Justi, R. (2016). Modelling-based Teaching in Science Education. In Models and Modeling in Science Education, vol. 9, 17-40. Springer Int. Publ.

González Galli, L. M. (2011). Obstáculos para el aprendizaje del modelo de evolución por selección natural (Doctoral Thesis). Biblioteca Digital de la Facultad de Ciencias Exactas y Naturales. Universidad de Buenos Aires. Buenos Aires (Argentina).

Grau, R. \& De Manuel, J. (2002). Enseńar y aprender evolución: una apasionante carrera de obstáculos. Alambique, 32, 56-64.

Gregory, T. R. (2009). Understanding Natural Selection: essential concepts and common misconceptions. Evolution: Education and Outreach, 2, 156-175.

Ha, M; Baldwin, B. C. \& Nehm, R. (2015). The Long-Term Impacts of Short-Term Professional Development: Science Teachers and Evolution. Evolution: Education and Outreach, 8, 11. DOI 10.1186/s12052-015-0040-9.

Heddy, B. C. \& Nadelson, L.S. (2012). A Global Perspective of the Variables Associated with Acceptance of Evolution. Evolution: Education and Outreach, 5, 412-418. DOI 10.1007/s12052-012-0423-0

Jewers, W. M. (2011). Next steps in evolution education: A literature review and suggestions for the future (Doctoral Thesis). Library and Archives Canada. McGill University. Montreal (Canada).

Jiménez, M. P. \& Puig, B. (2013). El papel de la argumentación en la clase de ciencias. Llevando a cabo prácticas científicas. Alambique, 75, 85-90.

Miles, M. B. \& Huberman, A. M. (1994). Qualitative Data Analysis: An expanded sourcebook. Thousand Oaks, CA: Sage.

Nadelson, L. S. (2009). Preservice Teacher Understanding and Vision of how to Teach Biological Evolution. Evolution: Education and Outreach, 2, 490-504. DOI 10.1007/s12052-008-0106-z 
Nadelson, L. S.; Culp, R.; Bunn, S.; Burkhart, R.; Shetlar, R.; Nixon, K. \& Waldron, J. (2009). Teaching Evolution concepts to early elementary school students. Evolution: Education and Outreach, 2, 458-473. DOI 10.1007/s12052-009-0148-x

National Research Council (NRC) (2012) A Framework for K-12 Science Education: Practices, Crosscutting Concepts, and Core Ideas. Committee on a Conceptual Framework for New K-12 Science Education Standards. Board on Science Education, Division of Behavioral and Social Sciences and Education. Washington, DC: Nat. Ac. Press.

National Research Council, National Science Teachers Association, American Association for the Advancement of Science and Achieve (2013) Next Generation Science Standards. Washington, DC. Nat. Ac. Press. Retrieved from: http://www.nextgenscience.org/

Prinou, L.; Halkia, L. \& Skordoulis, C. (2011). The Inability of Primary School to Introduce Children to the Theory of Biological Evolution. Evolution: Education and Outreach, 4, 275-285. DOI 10.1007/s12052-011-0323-8

Sá Pinto, X. \& Campos, R. (2012). As borboletas da floresta amarela. Porto, Portugal: CIBIO (Centro de Investigação em Biodiversidade e Recursos Genéticos).

Saldaña, J. (2009). The coding manual for qualitative researchers. London: SAGE.

Sickel, A. J. \& Friedrichsen, P. (2013). Examining the evolution education literature with a focus on teachers: major findings, goals for teacher preparation, and directions for future research. Evolution: Education and Outreach, 6, 23. https://doi. org/10.1186/1936-6434-6-23

Teachit (2014). Evolution and Inheritance Curriculum Pack. Manchester (UK): AQA Education. www.teachitprimary.co.uk

Thagard, P. \& Findlay, S. (2010). Getting to Darwin: Obstacles to Accepting Evolution by Natural Selection. Science \& Education, 19, 625-636. DOI 10.1007/s11191009-9204-8

Vázquez, B. (2017). A state-by-state comparison of middle school science standards on evolution in the United States. Evolution: Education and Outreach, 10, 5. https:// doi.org/10.1186/s12052-017-0066-2

Vázquez-Ben, L. \& Bugallo-Rodríguez, Á. (2017). El modelo de evolución en educación primaria: desafíos identificados por expertas y expertos. Enseñanza de las ciencias, Extra, 4293-4298.

Vázquez-Ben, L. \& Bugallo-Rodríguez, Á. (2018). El modelo de evolución biológica en el curriculum de Educación Primaria: Un análisis comparativo a nivel internacional. Revista Eureka sobre Enseñanza y Divulgación de las Ciencias, 15(3), 3101. DOI: 10.25267/Rev_Eureka_ensen_divulg_cienc.2018.v15.i3.3101

Yates, T. B., \& Marek, E. A. (2015). A Study Identifying Biological Evolution-Related Misconceptions Held by Prebiology High School Students. Creative Education, 6, 811-834. DOI: 10.4236/ce.2015.68085 


\title{
COMBINING BIOLOGY EDUCATION AND EDUCATION FOR SUSTAINABILITY IN PRESCHOOL: INSIGHTS FROM THE $2^{\mathrm{ND}}$ CYCLE OF A DESIGN RESEARCH
}

\author{
Maria-Christina Kasimati and Marida Ergazaki \\ University of Patras, Greece \\ kasimatimx@gmail.com; rergazaki@upatras.gr
}

\begin{abstract}
This paper provides insights from a design research, addressing the question of whether it is feasible to design a learning environment that could help preschoolers enhance both their conceptual understanding about nature and their socio-environmental awareness. More specifically, we report on a case study we performed in the $2^{\text {nd }}$ research cycle to test the 'forest-part' of the $2^{\text {nd }}$ version of our learning environment ('LE2-forest'). Our objective is to identify whether and how preschoolers' understanding about target ecological ideas (e.g. 'forest impact on abiotic environment and human life'), and socioenvironmental ones (e.g. 'present-future' or 'individual-collective'), has changed within 'LE2-forest'. There were 15 participants in the case study, conveniently selected preschoolers (aged 4.5-5.5). They were divided in three five-member mixed age/mixed level groups, and took part separately in five, 20-30 minute sessions over a three-week period. Activities of several types (e.g. storytelling, scaffolded-dialogue, puppet-show, or role-playing) were attached to a central scenario so that all target ideas would be introduced. Children gave pre/post, individual, semi-structured, 20-minute interviews, which were audio-recorded and transcribed. The analysis in NVivo showed shifts from lower-level to higher-level responses for all the ecological, and most of the socioenvironmental target ideas. Results are thoroughly discussed in the paper.
\end{abstract}

Keywords: early childhood; education for sustainability; early biology education; 'possible futures' approach; design research

\section{Introduction}

Humanity is currently faced with serious environmental, economic and social problems, which undermine a sustainable future. This highlights an 
urgent need to make 'education for sustainability' (EfS) a high priority, even at kindergarten. An early beginning that would give young children the opportunity to get familiar with the contemporary socio-environmental issues, and the idea of shared responsibility for their solution, might help them develop the socioenvironmental awareness that will be required from them as modern adults (Davis, 2009; Iliopoulou, 2016). However, research on 'Early Childhood Education for Sustainability' (ECEfS) is rather limited and still of a theoretical nature (Ärlemalm-Hagsér, 2013; Cutter-Mackenzie \& Edwards, 2013; Duhn, 2012; Smidt, 2018). That is, it mainly provides theoretical suggestions about the ways through which young children could possibly grow their responsibility to both environment and fellow humans.

Such a suggestion is, for instance, to put children in the positions of 'problem seekers', 'problem solvers' and 'action takers' (Davis, 2009; Arlemalm-Hagser, 2013). In other words, to involve them in educational activities that could give them the chance to a) locate socio-environmental problems that may be important to them in some way, b) look for possible solutions, and c) plan their implementation - or even perform it. Another interesting suggestion is the 'possible futures'-approach (Hicks \& Holden, 2007). According to this, children should have the chance to a) examine how their current actions may affect the future of environment and humans, b) decide whether or not they like this future they are heading for, and if not, c) examine what they should change today so that a more desirable future would be possible (Hicks \& Holden, 2007). This way, children might be facilitated in understanding that their current actions can have environmental and socio-economic impact on the future of the world, as well as them having both the power and responsibility to adjust these actions in order to ensure a sustainable future (Rogers \& Tough, 1996).

Besides offering theoretical suggestions that might serve as 'principles' or 'criteria' for the design of learning environments in the context of ECEfS, previous research can also contribute in locating 'target ideas' that might be integrated in such learning environments. Biology Didactics can actually pinpoint concepts that a) are important for children's understanding about nature, and at the same time, b) they may fit in a context where the inter-connectedness of 'nature-society-individual' needs to be highlighted for young children (Ergazaki \& Andriotou, 2010; Palmer \& Suggate, 1996). For instance, the ecological concepts of 'habitat' or 'food chain', which are within young children's potential, could be linked, at least theoretically, with the socio-environmental problem of deforestation and land use. Combining biology education and ECEfS seems to be possible; but whether it can really work, needs to be empirically tested.

Thus, we decided to perform a design research approach addressing the question of whether it is feasible to design a learning environment that could help preschoolers enhance both their conceptual understanding about nature and their socio-environmental awareness. In this paper we provide insights from 
the $2^{\text {nd }}$ research cycle, and our objective is to identify whether and how preschoolers' understanding about our target ecological and socio-environmental ideas has changed within the 'forest-part' of the $2^{\text {nd }}$ version of our learning environment ('LE2-forest'). So, our research question here is:

How do young children reason about specific ecological and socioenvironmental ideas before and after their participation in'LE2-forest?

\section{Methods}

\subsection{An overview of the study}

Our study focuses on the design of a learning environment which combines Biology Education and ECEfS. We follow a design research methodology (McKenney \& Reeves, 2012), and so we are engaged in three research cycles that include one or two case studies each. In the case study of the $1^{\text {st }}$ research cycle, we tested the $1^{\text {st }}$ version of the learning environment. The findings were used for arriving at an elaborated, new version with two parts. The 'forest-part' of the $2^{\text {nd }}$ version was tested in the case study of the $2^{\text {nd }}$ research cycle, which we present here, whereas the 'decomposition/ recycling-part' was tested in another case study of the same cycle. The whole study was performed in Patras, which is located in the Peloponnese peninsular in the southwest of Greece. Patras is a large seaside city built at the foothills of a mountain, which suffers from human disturbances, and not far from a national park of great ecological, aesthetic and economical value. Due to the city's geography, there is rather easy access to both aquatic and land ecosystems of several types.

\subsection{The participants}

The participants of the case study $(\mathrm{N}=15,9$ girls and 6 boys, age 4.5-5.5) were pupils of a public kindergarten in a semi-urban area of Patras with medium/ high socio-economic status. Children were selected conveniently, due to their teachers' wish to facilitate our study. Before taking the pre-interviews, the first author visited the children's school in order to give them the chance to get familiar with her and give their assent for participating in the study. Parents were also informed about this and no objections were raised. Moreover, children were already familiar with educational interactions since they were attending kindergarten for several months, and according to their teachers they had not been engaged in formal activities about our target ideas up to that point. During the implementation of 'LE2-forest' the fifteen participants were divided in three groups of five. Each group consisted of mixed age and mixed level children and took part separately in five, 20-30 minute sessions, led by the first author in a three-week period. Finally, the participants were interviewed once more. 


\subsection{The learning environment ('LE2-forest')}

The learning environment was informed by a 'possible futures' approach (Hicks \& Holden, 2007) and constructivism (Driver et al., 1994). The focus was set on a series of ecological and socio-environmental target ideas, which are actually our learning objectives (Table1).

TABLE 1

AN OVERVIEW OF THE LEARNING OBJECTIVES OF 'LE2-FOREST'

\begin{tabular}{lll}
\hline Learning Objectives (LO) & & \\
\hline & LO1 & Future is what is coming later in time \\
\cline { 2 - 3 } & LO2 & Present actions have future effects \\
\cline { 2 - 3 } $\begin{array}{l}\text { Socio-environmental } \\
\text { ideas }\end{array}$ & $\begin{array}{l}\text { Humans-Nature respect/equality } \\
\text { (humans have no right to decide against nature) }\end{array}$ \\
\cline { 2 - 3 } & LO4 & $\begin{array}{l}\text { Humans-Humans respect/equality } \\
\text { (humans have no right to decide against fellow humans) }\end{array}$ \\
\cline { 2 - 3 } & LO5 & Local environmental problems have global effects \\
\cline { 2 - 3 } & Ho7 & $\begin{array}{l}\text { Everyone needs to act for the environment; individual action is an } \\
\text { important part of the collective one }\end{array}$ \\
\hline LO8 & $\begin{array}{l}\text { Forests have beneficial impact on the abiotic environment and hu- } \\
\text { man life; their function is anti-heat, anti-flood, anti-wind, anti- } \\
\text { noise, pro-air }\end{array}$ \\
\hline $\begin{array}{l}\text { Ecological } \\
\text { ideas }\end{array}$ & $\begin{array}{l}\text { A forest is a home to many animals (habitat) } \\
\text { LO10 }\end{array}$ & $\begin{array}{l}\text { Living things are connected in food chains (FCs); when one relation- } \\
\text { ship in a FC breaks, the others are affected too }\end{array}$ \\
\hline
\end{tabular}

All target ideas were integrated in a modified version of a scenario suggested by Hadzigeorgiou et al. (2011) about the people of a city, their financial problem and the nearby forest. The scenario starts with the local problem: 'Nice-city' suffers from unemployment and decides to cut down its huge forest so that people who lost their jobs could be employed as wood-cutters or wood-sellers (Session 1 is: 'Nice-City now' - present solutions/future effects). At the beginning, this local solution seems appealing. But later, it proves to be a rather global disaster. Not only people of 'Nice-city', but also people of other cities as well as animals of the ex-forest, have to suffer severe consequences, although they were not necessarily part of the initial problem or its solution (Session 2 is: 'Nice-City in the future' - nearby cities protest; sessions 3 and 4 are: 'Nice-City in the future' - animals protest for loosing home and food). So, recovery and prevention plans need to be implemented with the contribution of everyone (Session 5 is: 'Possible solutions': current collective plans for future recovery and prevention). The sessions included educational activities of several types, such as card-based storytelling, guided dialogue (questions \& answers), brainstorming, 
interactive puppet show (questions $\&$ answers) and role-playing. The activities, which are presented in Table 2 along with their learning objectives, were in line with children's age and were meant to promote active participation, so that the target ideas could be introduced more effectively.

TABLE 2

AN OVERVIEW OF 'LE2-FOREST'

\begin{tabular}{|c|c|c|}
\hline Sessions & Educational Activities & $L O$ \\
\hline $\begin{array}{l}\text { 1. Nice-city now': } \\
\text { Present solu- } \\
\text { tions \& future } \\
\text { effects }\end{array}$ & $\begin{array}{l}\text { - Card-based story (scenario's introduction) } \\
\text { - Problem: unemployment } \\
\text { - Solution: forest cut down to create jobs } \\
\text { - Scaffolded dialogue } \\
\text { - The idea of the 'future' (examples, Qs/As) } \\
\text { - Brainstorming } \\
\text { - Asking for the solution's future effects } \\
\text { - Card-based story } \\
\text { - Discussing the solution's future effects }\end{array}$ & LO1-2 \\
\hline $\begin{array}{l}\text { 2. 'Nice-City in } \\
\text { the future': } \\
\text { nearby cities } \\
\text { protest }\end{array}$ & $\begin{array}{l}\text { - Interactive puppet show (Qs/As) } \\
\text { - Representatives of other cities protest to the city-council for } \\
\text { what they suffer because of the city's decision to cut down the } \\
\text { forest for creating jobs } \\
\text { - They explain how the 'local forest' cut down triggered these } \\
\text { 'global' effects }\end{array}$ & $\begin{array}{c}\mathrm{LO} 2-5 \\
\mathrm{LO} 8\end{array}$ \\
\hline $\begin{array}{l}\text { 3. 'Nice-City in } \\
\text { the future': } \\
\text { forest animals } \\
\text { protest for } \\
\text { losing home }\end{array}$ & $\begin{array}{l}\text { - Interactive puppet show (Qs/As) } \\
\text { - Mr. Squirrel represents the ex-forest's animals to protest for lo- } \\
\text { sing their home because of the city's decision to cut down the } \\
\text { forest for creating jobs } \\
\text { - Storytelling } \\
\text { - The tree: who else lives here? } \\
\text { - Interactive card-based story }\end{array}$ & $\begin{array}{c}\mathrm{LO} 2-4 \\
\text { LO9 }\end{array}$ \\
\hline $\begin{array}{l}\text { 4. 'Nice-City in } \\
\text { the future': } \\
\text { forest animals } \\
\text { protest for } \\
\text { losing food }\end{array}$ & $\begin{array}{l}\text { - Interactive puppet show (Qs/As) } \\
\text { - Mr. Squirrel represents the ex-forest's animals to protest for lo- } \\
\text { sing their food because of the city's decision to cut down the } \\
\text { forest for creating jobs } \\
\text { - Scaffolded dialogue } \\
\text { - The idea of the 'food chain' (examples, Qs/As) } \\
\text { - Role playing } \\
\text { - Children participate in a role play to experience disturbances in } \\
\text { simple food chains }\end{array}$ & $\begin{array}{c}\mathrm{LO} 2-3 \\
\mathrm{LO} 10\end{array}$ \\
\hline $\begin{array}{l}\text { 5. 'Possible Solu- } \\
\text { tions': current } \\
\text { collective plans } \\
\text { for future } \\
\text { recovery and } \\
\text { prevention }\end{array}$ & $\begin{array}{l}\text { - Interactive puppet show (Qs/As) } \\
\text { - The city council and all the stakeholders resume what has been } \\
\text { 'globally' caused by a bad 'local decision' and how, and they ex- } \\
\text { plore what needs to be done and how }\end{array}$ & LO2-8 \\
\hline
\end{tabular}

\subsection{The interview protocol}

Children were interviewed before and after the implementation of the 'forest-part' of LE2 at a quiet place in their school. The interviews were semi- 
structured and lasted approximately 20 minutes each. The interview protocol consisted of ten open-ended questions with the aim of testing children's reasoning about our target ideas or learning objectives. The questions, which are briefly presented in Table 3, along with the learning objectives they probe, were all integrated in a scenario similar to that of 'LE2-forest'.

TABLE 3

AN OVERVIEW OF THE INTERVIEW PROTOCOL.

\begin{tabular}{|c|c|c|}
\hline Question & What does it require? & What does it probe? \\
\hline Q1 & Explaining what 'future' means & LO1 \\
\hline Q2 & $\begin{array}{l}\text { Explaining in the context of the deforestation protocol-scenario } \\
\text { that present actions have future effects }\end{array}$ & $\mathrm{LO} 2$ \\
\hline Q3 & $\begin{array}{l}\text { Reasoning about whether and how other people who live elsewhere } \\
\text { will also suffer the bad effects of the cut down of a forest that is } \\
\text { distant to them }\end{array}$ & LO5 \\
\hline Q4 & $\begin{array}{l}\text { Reasoning about if people should care about whether other people } \\
\text { will suffer from the effects of their bad decisions or not, when they } \\
\text { are making up their minds }\end{array}$ & $\mathrm{LO} 4$ \\
\hline Q5 & Reasoning about why preserving forests is important for animals & LO9 \\
\hline Q6 & $\begin{array}{l}\text { Reasoning about if people should care about whether animals will } \\
\text { suffer from the effects of their bad decisions or not, when they are } \\
\text { making up their minds }\end{array}$ & $\mathrm{LO} 3$ \\
\hline Q7 & $\begin{array}{l}\text { Reasoning about whether and how people could eliminate the bad } \\
\text { effects of the forest cut down and prevent re-appearance }\end{array}$ & LO6 \\
\hline Q8 & Reasoning about how forest function benefits human life & LO8 \\
\hline Q9 & $\begin{array}{l}\text { Reasoning about the importance of individual action as part of the } \\
\text { collective one for helping nature recover or keep it protected }\end{array}$ & LO7 \\
\hline Q10 & $\begin{array}{l}\text { Reasoning about how food chains work; i.e. following the effects of } \\
\text { a food relationship's break, throughout the whole FC }\end{array}$ & LO10 \\
\hline
\end{tabular}

According to the protocol scenario, a city faces a serious problem of overpopulation, which makes it very difficult for people to find a house to live in. The city council decides to cut down the city's forest, in order to use the land for building more houses for the people. What follows are some examples of how protocol questions were addressed to the children.

- "So, now they cut down the trees of the forest to build more houses for the people. Does this thing they do to the forest now have any importance for how life in the city will be after some time? Can it bring any changes for the people of the city after some time or not? Would you like to explain to me a little bit what you think about this?" (Q2).

And later on:

- "So, you think that if the city cuts down the city forest, the air of the city would be dirty after some time. In fact, cutting down the city forest would 
result in dirty air for other cities as well. If this is true, do you think that people of the city should mind about it? Should they mind that other people would also have dirty air because of them? Or should they just mind about their own air? Would you like to explain to me a little bit what you think about this?" (Q4).

\subsection{The data analysis}

The audio-recorded interviews were transcribed and prepared for coding in NVivo, a 'qualitative data analysis' software. Children's responses were coded as a) 'naïve', when wrong or stating ignorance ('don't know'), b) 'transitional', when correct but incomplete, and finally c) 'informed, when correct and complete at the same time. For instance, Q4 (presented above) gathered responses of all three categories as follows:

- 'naïve': "I think that they should just mind about their own air, but I don't know why";

- 'transitional': "They should care about other people's air, because what they do is bad and other people want to have clean air too";

- 'informed': "They should care that other people will breathe dirty air, because they don't have the right to create problems for them, they're equal".

The coding was performed by both the authors and cases of disagreement were discussed until consensus was reached. Finally, the frequency of the 3 categories was identified per question.

\section{Findings}

In this section, we present our findings by comparing children's pro/postresponses for each question of the interview protocol. So, starting with the first question about what 'future' means (Q1), we note that children did make progress. Most of their post-responses were coded as 'informed' (12/15), whereas most of the pre-ones as 'naïve' (12/15). The number of 'transitional' responses didn't actually change (2/15 vs.2/15) (Figure 1$)$. In children's own words: "The future is the moon" ('naïve' pre-response); "The future is what comes later in time. Tomorrow is in the future." ('informed' post-response).

The same seems to be true for the second question (Q2), which concerns the 'present-future' relationship. In the post-test almost all responses were coded as 'informed (13/15), whereas in the pre-test there were no 'informed' responses at all $(0 / 15)$. The number of 'transitional' responses remained almost the same (1/15 vs. 2/15) (Figure 2). In children's words, "They can cut down the forest to build houses. Nothing can happen after time because they cut down the forest." ('naïve' pre-response); "If they cut down the forest, they will have many problems in the future. This thing will cause problems." ('informed' post-response). 


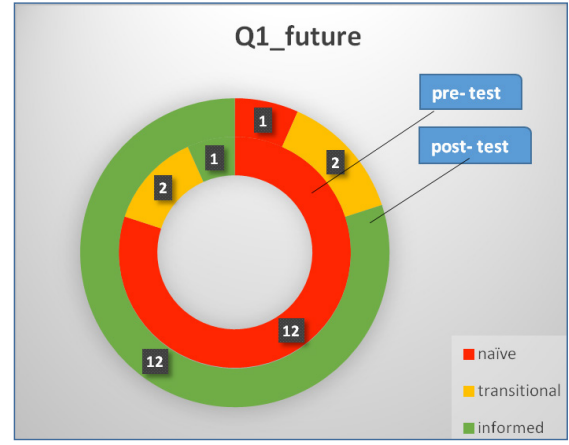

Figure 1 Students' pre/post-responses about the 'future' idea.

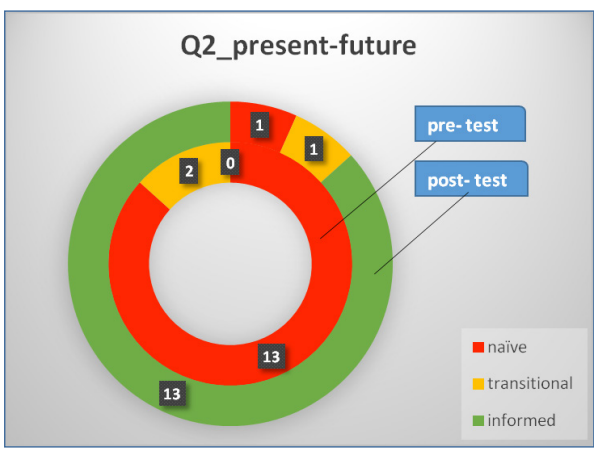

Figure 2 Students' pre/post-responses about the 'present-future' idea.

Regarding the third question about the socio-environmental idea of 'local-global' connection (Q3), the number of 'informed' responses in the post-test remained almost the same as in the pre-test (4/15 vs. 3/15). However, the number of 'naïve' responses went all the way down to zero $(0 / 15 v s .7 / 15)$, and the number of 'transitional' responses increased quite a lot (11/15 vs. 5/15) (Figure 3). In children's words, "The other cities will not have dirty air, because they are far from the cut-down forest." ("naive' pre-response); "The other cities will have dirty air because dirty air will go everywhere on the earth." ('transitional' post-response); "The other cities will have dirty air too because this forest gives clean air to the whole earth. If they cut it down all other cities will have less clean air no matter how near or how far they are." ('informed' postresponse).

Children seemed to do very well with the idea that humans don't have the right to decide against fellow humans ('humans-humans equality') (Q4). In the post-test, the number of 'naïve' responses dropped significantly (1/15 vs. 9/15), whereas the number of 'informed' responses followed the reverse course (8/15

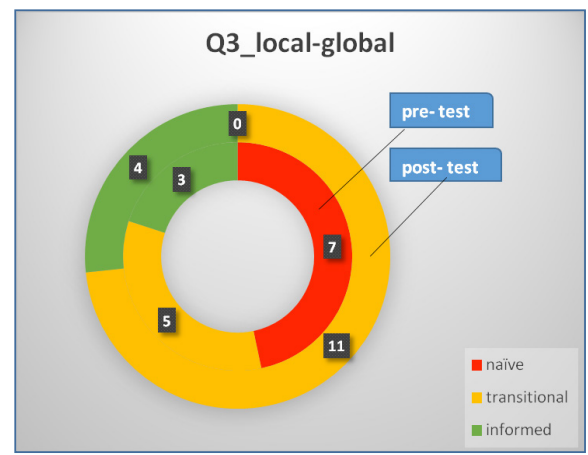

Figure 3 Students' pre/post-responses about the 'localglobal' idea.

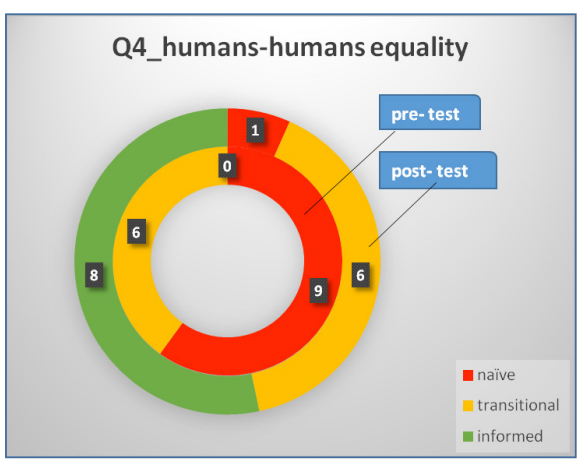

Figure 4 Students' pre/post-responses about the 'humanshumans equality' idea. 
vs. 0/15). The number of 'transitional' responses didn't actually change (6/15 vs.6/15) (Figure 4). In children's words, 'I think that they should just mind about their own air, but I don't know why.' ('naive' pre-response); 'They should care about other people and not create problems to them because this is what people should do: care for each other' (transitional post-response); 'They should care because all people are equal and they don't have the right to create problems to the others ('informed' post-response).

The idea that forest is animals' home (Q5) seemed familiar to children from the beginning. In the pre-test, the number of 'naïve' responses was very low (2/15), whereas there were many 'transitional' responses $(9 / 15)$, and also some 'informed' (4/15). In the post-test, all but one child gave 'informed' responses (Figure 5). In children's words, "The animals will also have problems if people cut down the forest. Animals breathe, too. So, they will breathe dirty air and they may get sick or die." ('transitional' pre-response); "If people cut down the forest, animals will be homeless. Trees are animals' home. So, if there are no trees left, the animals will no longer have a place to live." ('informed' postresponse).

Q6-results were quite similar. The idea that humans don't have the right to decide against nature and should treat it with respect, seemed familiar to children from the beginning as well. In the pre-test, the number of 'naïve' responses was very low (3/15), whereas all the other responses were coded as 'transitional' $(12 / 15)$. On the contrary, most of the post-responses were 'informed' (9/15), whereas the number of 'transitional' responses dropped a lot (5/15 vs. 12/15) and the number of 'naïve' got to zero (Figure 6). In children's words, "People should care that they will cause problems to animals if they cut down the forest, because it is bad to hurt animals. We love animals." ('transitional' pre-response); "They should care that they will create problems to the forest's animals because people and animals are equal. We do not have the right to create problems to animals' lives." ('informed' post-response).

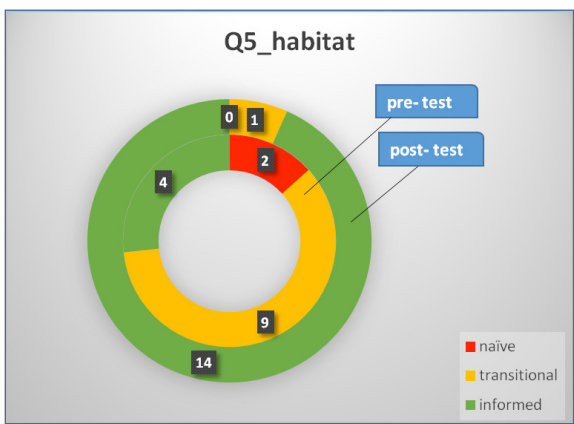

Figure 5 Students' pre/post-responses about the 'habitat' idea.

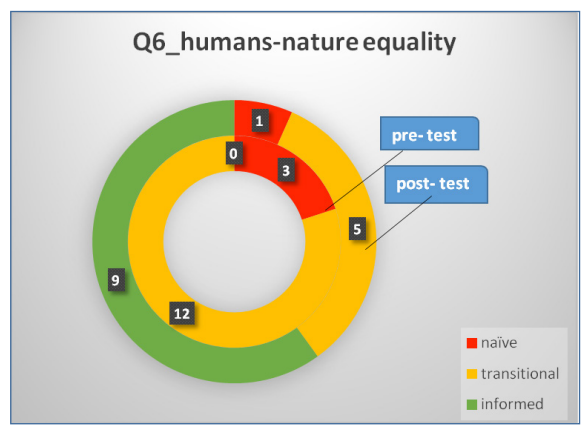

Figure 6 Students' pre/post-responses about the 'humansnature equality' idea. 
Children's responses to Q7 about humans' plans for helping nature recover or keep it protected, were improved significantly. In the pre-test, almost all the responses were 'transitional' (8/15) and 'naïve' (6/15). However, in the post-test, the number of 'informed' responses climbed from $1 / 15$ to $12 / 15$, and of course the numbers of 'transitional' and 'naïve' responses dropped quite a lot (Figure 7). In children's words, "They should never again cut down the forest; if they do, the same thing will happen again." ('transitional' pre-response); "I think that if they want to never have this bad future again, from now on they should take care of the forest. They should never let anyone to cut it down again, they should not light fires to and they should not pollute it. This way they will always have their beautiful forest." ('informed' post-response).

Children's responses to the question about forest benefits for human life (Q8) seemed to need significant improvement, since in the pre-test they were almost exclusively 'naïve' (14/15). According to our findings, they did improve, since in the post-test, the number of 'naïve' responses was almost eliminated $(1 / 15)$ whereas the number of 'informed' ones increased quite a lot $(10 / 15 v s$. 0/15) (Figure 8). In children's words, "We should take care of the forest because it gives us clean air." ("naïve' pre-response); "We should take care of the forest because it gives us so many important things: it gives us clean oxygen from its leaves and takes away the carbon dioxide so that we do not get too hot. It also protects us from floods because the trees' roots can hold the water when it rains and stop it from coming in the cities. And it protects us from the strong wind and loud noise too, because it stands in front of us like a curtain and doesn't let them reach us" ('transitional' postresponse).

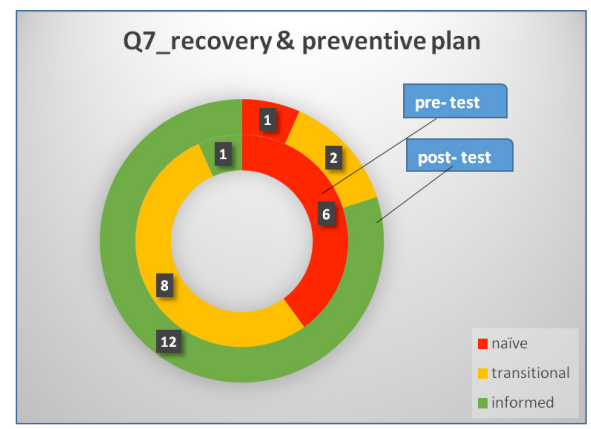

Figure 7 Students' pre/post-responses about the 'recovery \& preventive plans' idea.

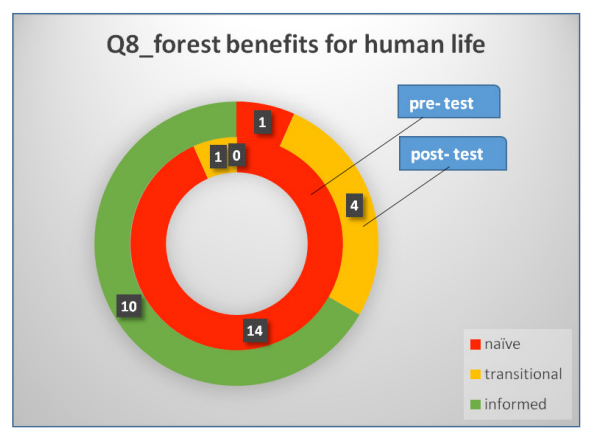

Figure 8 Students' pre/post-responses about the 'forest benefits for human life' idea.

Children's responses to the question about the importance of individual action as part of the collective one for helping nature recover or keep it protected (Q9) seemed to need significant improvement as well. Children's pre-responses were mostly 'naïve' (12/15), very few times 'transitional' (3/15) and never 'informed' (0/15). However, the latter didn't change in the post-test: in fact, no 
child gave an 'informed' post-response. Moreover, the decrease in the number of 'naïve' responses and consequently the increase in the number of 'transitional' ones were not very remarkable ( $8 / 15$ vs. $12 / 15$ and $7 / 15$ vs. $3 / 15$, respectively) (Figure 9). In children's words, "If so many people have gone to the forest to plant new trees, he doesn't need to go. There are too many people there already. He can do something more fun. He can go for a walk with his friends." ("naïve' pre-response); "Well, I think the he should go to the tree-planting, too. I see there are many people helping there, but he should go too, because it is good to help with tree-planting. He should not go for a walk with his friends while the others are working." ('transitional' post-response).

Finally, children did well in the question about the food chain (Q10). The high pre-number of 'naïve' responses (13/15) dropped almost to zero in the post-test (1/15). Respectively, the zero pre-number of 'informed' responses gave its place to a high post-number which reached 9/15. 'Transitional' responses increased, too (5/15 vs. 2/15) (Figure 10). In children's words, "If grass goes away, rabbits will die because they will not have food any more. Nothing will happen with foxes." ("naïve' pre-response); "If foxes go away, rabbits will get more and more because they will have babies but no one will eat them and make them less. So, grass will become less and less as the more and more rabbits will eat it." ('informed' postresponse).

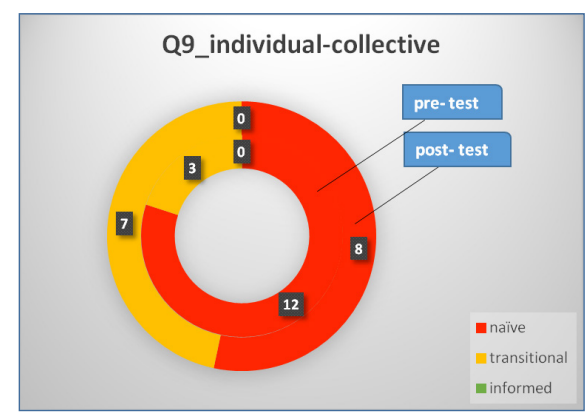

Figure 9 Students' pre/post-responses about the 'individual-collective' idea.

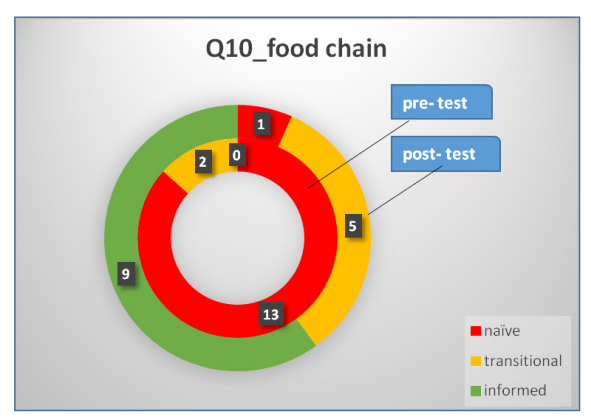

Figure 10 Students' pre/post-responses about the 'food chain' idea.

\section{Discussion}

According to the results, 'LE2-forest' seemed to work well. For most of the target ideas, there was a shift from lower-level responses to higher-level ones. Nevertheless, there were also target ideas that children were not able to grasp well enough. More specifically, 'LE2-forest' appeared quite effective with all the ecological ideas, i.e. 'forest benefits for human life', 'food chains' and 'forest as animals' home'. It also seemed to be effective with most of the socio- 
environmental ones; more specifically, with ideas like 'present actions have future effects', 'humans need to draw up recovery and preventive plans for nature', 'humans have no right to decide against nature - or against fellow humans' (equality-ideas). This highlights empirically the possible benefits that may derive when combining Biology Education and EfS. Moreover, it highlights young children's potential to get familiar, not only with ecological ideas that may help them start building a better understanding about the interactions in nature, but also with socio-environmental ideas that may help them start recognizing the 'nature-society-individual' interconnectedness.

Nevertheless, 'LE2-forest' was not so effective with all the socioenvironmental ideas that were included in the learning objectives. For instance, the idea of the 'local-global' connection proved to be quite hard for young children. Although the number of 'naïve' responses was eliminated after children's engagement with the learning environment, we had only a few 'informed' post-responses and many 'transitional' ones. Moreover, the idea of the 'individual-collective' seemed to be even harder. Although the number of 'naïve' responses decreased and the number of 'transitional' increased in the post-test, we still had many 'naïve' responses and no 'informed' ones.

These results did not come as a real surprise, since both of these ideas were considered from the start as demanding for young children, who generally tend to focus on their narrow environment, as well as give priority to themselves. However, they do indicate clearly that greater emphasis needs to be put on 'local-global' and 'individual-collective' ideas in the final version of our learning environment. It seems that when re-designing, we should keep the possible futures'- approach as a good design criterion, but we should also elaborate and enhance the ways we introduce the target socio-environmental ideas that cause difficulties; enriching our learning environment with more activities and strengthening our scaffolding strategies might be one way to go. Obviously, these ideas, as well as all of their kind, can contribute to cultivating the environmental and social awareness of young children, and therefore it is of key importance for them to be consistently promoted in learning environments that aim at EfS. This will be our priority in the $3^{\text {rd }}$ research cycle of the study.

\section{References}

Ärlemalm-Hagsér, E. (2013). Minds on Earth Hour-a theme for sustainability in Swedish early childhood education. Early Child Development and Care, 183(12), 17821795 .

Cutter-Mackenzie, A., \& Edwards, S. (2013). Toward a model for early childhood environmental education: Foregrounding, developing, and connecting knowledge through play-based learning. The Journal of Environmental Education, 44(3), 195213 
Davis, J. (2009). Revealing the research-hole of early-childhood-education for sustainability. A preliminary-survey of the literature. Environmental Education Research, 15(2), 227-241.

Duhn, I. (2012). Making 'place' for ecological sustainability in early childhood education. Environmental Education Research, 18(1), 19-29.

Ergazaki, M., \& Andriotou, E. (2010). From "forest fires" and "hunting" to disturbing "habitats" and "food chains": Do young children come up with any ecological interpretations of human interventions within a forest?. Research in Science Education, 40(2), 187-201.

Hadzigeorgiou et al. (2011). Teaching about the importance of trees: A study with young children. Environmental Education Research, 17(4), 519-536.

Hicks, D., \& Holden, C. (2007). Remembering the future: what do children think?. Environmental Education Research, 13(4), 501-512.

Iliopoulou, I. (2016). How young children think they can act for the environment: the case of forest and waste. Education 3(13), 1-15

McKenney, S., \& Reeves, T. C. (2012). Conducting educational design research. Routledge.

Palmer, J. A., \& Suggate, J. (2004). The development of children's understanding of distant places and environmental issues: Report of a UK longitudinal study of the development of ideas between the ages of 4 and 10 years. Research Papers in Education, 19(2), 205-237.

Rogers, M., \& Tough, A. (1996). Facing the future is not for wimps. Futures-the Journal of Forecasting Planning and Policy, 28(5), 491-496.

Smidt, S. (2018). Early Childhood Education and Care for a Shared Sustainable World: People, Planet and Profits. NY: Routledge. 



\title{
TRAINING FUTURE TEACHERS TO ADDRESS INTERDISCIPLINARY IN BIOLOGY LESSONS: LEARNING PHYSICS AND CHEMISTRY WITH A DNA EXTRACTION PRACTICE
}

\author{
Rocío Esteban Gallego, José María Marcos Merino and Jesús A. Gómez Ochoa \\ de Alda \\ Science and Mathematics Education Department, Faculty of Education, University of \\ Extremadura (Badajoz, Spain) \\ jmmarcos@unex.es
}

\begin{abstract}
DNA extraction using everyday materials is an interdisciplinary practice, since it comprises biological, chemical and physical concepts. However, it is commonly executed following a simple protocol provided by teachers, situation that limits its interdisciplinary approach. In this contribution we describe an active practical activity based on DNA extraction and developed under guided research methodology. Through teacher's guidance and peer learning, students can appreciate the interdisciplinary application of key scientific concepts related to DNA extraction. The objective of this research is to test, with a sample of pre-service Primary teachers, the effectiveness of that intervention. For that purpose, designed intervention has been implemented during three successive academic years with a sample of 463 students of the Degree in Primary Education (University of Extremadura, Spain). Participants answered a pre-test (before the intervention) and a post-test (15 days later), whose marks are compared using the nonparametric Wilcoxon-Mann-Whitney test. Results support that this activity promote both Biology learning as well as Chemistry learning (namely in contents such as $\mathrm{pH}$, density, electrical charges of molecules and solvatation).
\end{abstract}

Key words: Interdisciplinary, initial teacher training, active learning, social learning, DNA extraction.

\section{Introduction}

It is widely accepted that key problems of 21 st century society can not be solved by single disciplines, but require a global perspective (Lavob, Reid \& Yamamoto, 2010). However, current organization of educational systems, in several separate subjects, is characterized by a reductionist approach, suffering from the absence of interdisciplinary activities with which to develop a global perspective. To reverse this situation, it has been recommended to strengthen the interactions between different disciplines in science lessons (Stone, 2014). The acquisition of a systemic perspective is particularly meaningful for pre- 
service teachers of Primary and Secondary Education since, at these levels of education, disciplines begin to divide into different subjects, moving away from a global perspective of science. To promote subject integration, the so-called next-generation science standards (NGSS) encourage integration with multiple core concepts throughout each year, since the combination of rigorous content and its application reflects how science and engineering are practiced in the real world (NGSS Lead States, 2013). As in other European curricula, the new Spanish Primary/Elementary education curriculum (Spanish Government, 2014) includes a cross-sectional block of contents for the integration of Natural Science subjects named "Initiation to research activity". Thus, Primary education teachers should be open to subject integration. However, for many preservice teachers content integration is more difficult to implement than traditional content (Leszczynski, 2014); above all in areas such as Chemistry and Physics, related to negative attitudes (Mellado et al., 2014) and several misconceptions that they can transfer to their future students.

Additionally, despite their motivating role (Hofstein \& Lunetta, 2004), traditional practical activities, based on following detailed instructions from teachers, do not provide satisfactory learning outcomes. This is due in part to the absence of an interdisciplinary perspective (Labov et al., 2010), as well as the lack of effective applicability (Hulleman \& Harackiewicz, 2009) and the absence of an active involvement of students in their resolution. One alternative, which provides better learning outcomes (Ainley \& Ainley, 2011; Deslauriers, Schelew \& Wieman, 2011; Gormally et al., 2009; Luckie et al., 2004; Schneider et al., 2002) and is more motivating (Marcos-Merino, Esteban \& Gómez 2019), is to apply an enquiry-based approach (also named guided research), in which students research and elaborate their own protocols guided by teachers. Thus, enquiry-based approach is currently considered an essential pedagogical tool to teach Biology in a practical way in all educational levels, especially in the initial training of Science teachers (Chernicoff \& Echevarría, 2012). In this work, we describe a practical intervention focused on interdisciplinary active learning to increase the availability of practical activities for Secondary students as well as pre-service teachers.

This active practice relate to a DNA extraction using everyday materials, an attractive practice that is usually performed in high schools, faculties and scientific disseminations' events. Although it requires putting into practice fundamental concepts of Chemistry, Physics and Biology; it is frequently executed without hardly discussing these contents, since it is usually carried out following a simple protocol provided by teachers. Despite this sort of implementation shows the simplicity of one of the key methods of current Biotechnology, it limits its potential effectiveness in teaching-learning processes, since students do not appreciate the interdisciplinary application of key scientific concepts. The implementation of this activity could be a suitable tool 
to address, with teachers in initial training, the role interdisciplinary in science; since it may allow us to show how the interrelation of several scientific disciplines (Biology, and Physics and Chemistry) is necessary to solve a common problem (extract DNA from a biological sample). In this contribution, a practical activity based on DNA extraction and developed under inquiry-based approach, with which to address this interdisciplinary approach with pre-service Primary teachers, is described. In addition, the result of its implementation (during three successive academic years) regarding learning of Biology and Chemistry are shown.

\section{Research objectives}

The objective of this paper is to test, with a sample of students of the Degree in Primary Education (University of Extremadura), the effectiveness of an active interdisciplinary practice of Biology Education. For that purpose, two specific objectives are raised:

- Design an interdisciplinary practical intervention, performed through an active approach (enquiry-based approach) and based on DNA extraction, with which to teach basics of Biology and Chemistry to pre-service Primary teachers.

- Test, with a sample of pre-service Primary teachers, the effectiveness of that intervention regarding: i) Biology learning (Cell Biology contents such as cell, kinds of cells, cell membrane, cell wall, organelles, DNA...) and ii) Chemistry learning ( $\mathrm{pH}$, density, electrical behaviour of molecules...).

\section{Methodology}

a. Identification of basics of Biology and Chemistry related to DNA extraction

DNA extraction is an interdisciplinary practice, since to determine how to extract DNA from a biological sample it is necessary to relate biological, chemical and physical concepts. Apart from biological contents (such as cell concept, sorts of cells, cell structure, DNA structure and its location...), students can approach several physics-chemical contents, which are included in the Table 1. 
TABLE 1

SET OF PHYSICO-CHEMICAL CONCEPTS THAT A TEACHER CAN ADDRESS THROUGH A DNA EXTRACTION PRACTICE

\begin{tabular}{l} 
Physics-chemical concepts related to DNA extraction \\
\hline $\begin{array}{r}\text { Sorts of molecules according to their electrical charge: ions (cations and anions), polar, nonpolar and } \\
\text { amphipathic molecules }\end{array}$ \\
Performance of the different molecules in an aqueous solution \\
Dissolution. Dissolution's components (solute and solvent). Saturation process \\
Solvatation process \\
Chemical precipitation \\
Lipid bilayer and micelles. Lipid solubilization \\
End pKa. pH regulation: buffers (the bicarbonate buffer) \\
Density. Influence of temperature in fluids' density \\
Endothermic and exothermic processes
\end{tabular}

b. Description of the intervention

An enquiry-based approach is followed to guide DNA extraction using household materials (salt, sodium bicarbonate, alcohol, mineral water and dishwashing detergent). Teacher raises several problems through open questions that students solve via discussions guided by the teacher. As a result, they develop and execute two DNA extraction protocols from both plant cells and animal cells. The teacher guide the discussion by asking the necessary questions (Tables 2 and 3) so that the answers provide students with all the essential scientific concepts to understand the scientific basis of the practice.

TABLE 2

FIRST PROBLEM RAISED DURING DNA EXTRACTION, QUESTIONS RAISED BY THE TEACHER TO GUIDE THE DISCUSSION AND CONTENTS RELATED TO THESE QUESTIONS.

\begin{tabular}{cl}
\hline Problem 1: How can you extract tomato DNA using everyday materials? \\
\hline Target & Elaborating a plant DNA extraction protocol \\
& Where is DNA in cell? \\
& What kinds of cells are there? What are the differences between them? \\
$\begin{array}{c}\text { Possible } \\
\text { questions for } \\
\text { discussion }\end{array}$ & Wow can you break a cell? \\
& How can cell membranes be broken? And cell walls? \\
& What nucleic acids are there in cell? Where are they located? What are their composition? \\
& What structure and electrical charge does DNA have?
\end{tabular}


How can you alter DNA solubility? With salt. Why? How does salt dissolve in water?

How can you avoid DNA degradation? With sodium bicarbonate. Why?

\begin{tabular}{ll}
\hline & Kinds of cells. Differences \\
& Cell structure \\
& Cell nucleus: structure and composition \\
Covered & Organelles: structure, composition and functions \\
contents & Biological membranes and cell walls: composition and structure \\
& DNA: Intracellular localization, structure and composition \\
& Physico-chemical concepts (Table 1)
\end{tabular}

TABLE 3

SECOND PROBLEM RAISED DURING DNA EXTRACTION, QUESTIONS RAISED BY THE TEACHER TO GUIDE THE DISCUSSION AND CONTENTS RELATED TO THESE QUESTIONS.

Problem 2: How can you extract DNA from human saliva using everyday materials?

\begin{tabular}{cl}
\hline \multicolumn{1}{c}{ Target } & $\begin{array}{l}\text { Modify the plant DNA extraction protocol to extract DNA from animal } \\
\text { cells }\end{array}$ \\
\hline $\begin{array}{c}\text { Extra questions for } \\
\text { discussion }\end{array}$ & What aspects should you change from the previous protocol? \\
& Why do you need to use a mechanical method to break plant cells? \\
\hline Extra covered contents & $\begin{array}{c}\text { Relation between cell membranes structure and procedure to lyse them } \\
\text { Relation between cell walls structure and procedure to lyse them }\end{array}$ \\
\hline
\end{tabular}

During this process, teacher has to promote the activation of previous knowledge, peer learning and the correction of possible misconceptions. Students, organized in small groups of 2 to 4 members, answer the questions using their previous knowledge and searching for information using their mobile devices. Then, students involve in finding, interpreting and explaining some scientific fundamentals of Biology, Chemistry and Physics. Teacher redirects students' answers (clarifying, endorsing, expanding and/or questioning these), until students agree on an answer for each question. Using these answers, they have to establish, through a new discussion guided by the teacher, the necessary steps for both extraction protocols.

During this discussion process, teacher relates scientific contents to students' daily lives, using several examples of biotechnological applications and genetic engineering, which are in the daily life of students (mainly through the media). What is more, the study of DNA is one of the fields of the Science teaching in which Science-Technology-Society (STS) interactions can be more often highlighted. Some of the biotechnological applications used during this intervention are transgenic foods, prenatal diagnosis, gene therapy, paternity tests, forensic investigation, cloning... 
c. Determination of intervention's effectiveness

The effectiveness of this educational intervention was estimated during 3 successive academic years with a sample of 463 pre-service teachers (Table 4), students of the Degree in Primary Education at the University of Extremadura (Spain), by using pre-test and post-test (appendix 1) based on:

- Common misconceptions of Cell Biology in Secondary School as well as in pre-service Primary teachers (Banet and Ayuso, 2003; Caballero, 2008; Camacho et al., 2012; Chattopadhyay, 2005; González-Weil and Harms, 2012; Marcos-Merino and Esteban, 2018; Wood-Robinson, Lewis and Leach, 2000)

- TIMSS (Trends in International Mathematics and Science Study) questions for Secondary Education (Foy, Arora \& Stanco, 2013)

These tests were designed following the steps recommended by Smith, Wood and Knight (2008). In the third year, in order to ascertain if designed intervention promotes an interdisciplinary learning, several questions about chemical and physical contents related to the practice were included in questionnaires (appendix 2). Students completed these tests before intervention and 15 days after, when they had to hand a laboratory report.

TABLE 4

SAMPLE BY ACADEMIC YEAR (NUMBER OF PARTICIPANTS OF EACH INTERVENTION)

\begin{tabular}{cc}
\cline { 2 - 2 } & Number of participants \\
\hline First academic year & 160 \\
\hline Second academic year & 154 \\
\hline Third academic year & 149 \\
\hline
\end{tabular}

Given that data did not follow a normal distribution (p-value $<0.05$, Kolmogorov-Smirnov and Shapiro-Wilk normality tests) non-parametric statistics were used to compare the marks of pre-test and post-test (WilcoxonMann-Whitney test). Graphics were made using Kaleidagraph program (Synergy software). 
4. Results and discussion

During the 3 academic years, there is a significant increase related to Biology learning outcomes ( $\mathrm{p}$-value $=0.006$ in the first intervention, $\mathrm{p}$ value $=0.03$ in the second and $\mathrm{p}$-value $<0.001$ in the third, Wilcoxon-MannWhitney test). Regarding the third intervention, the analysis of questions related to Chemistry and Physics contents (scores increase from a median of 4 in pre-test to 6 in post-test, p-value $<0.001$, Wilcoxon-Mann-Whitney test), indicates that performed learning has an interdisciplinary nature (Figure 1).

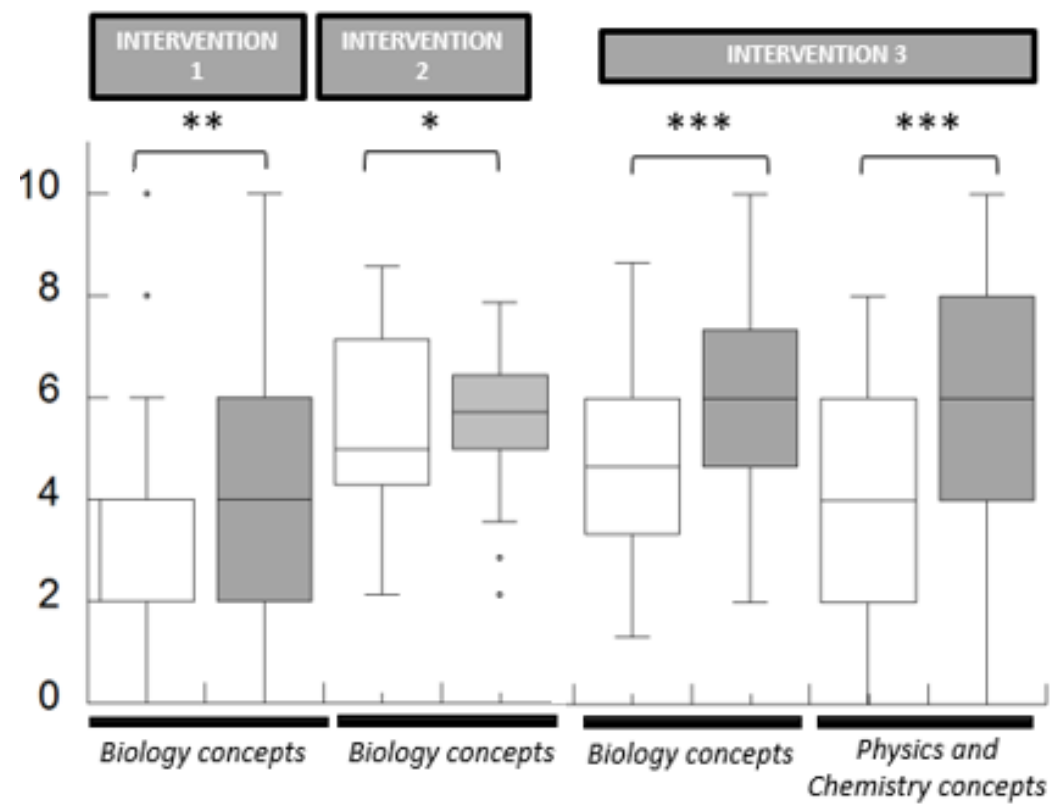

Figure 1. Effectiveness results regarding Cell Biology and Genetics concepts as well as physico-chemical concepts (third intervention). Connecting lines are used to express significance of Wilcoxon-Mann-Whitney test: ${ }^{* * *} \mathrm{p}$-value $<0,001 ;{ }^{* *} \mathrm{p}$ value $<0,01,{ }^{*}$ p-value $<0,05$.

Addressing specific physico-chemical concepts, a significant increase is observed (p-value $<0.05$, Wilcoxon-Mann-Whitney test) in the percentage of success of all questions related to Chemistry and Physics (Table 5).

TABLE 5

PERCENTAGE OF SUCCESS IN QUESTIONS ABOUT PHYSICO-CHEMICAL CONCEPTS, IN THIRD ACADEMIC YEAR, BEFORE (PRE-TEST) AND AFTER (POST-TEST) THE IMPLEMENTATION OF THE INTERVENTION

\begin{tabular}{ccc}
\hline Scientific concept & Pre-test & Post-test \\
\hline Density & $51 \%$ & $79 \%$ \\
\hline $\mathrm{pH}$ & $12 \%$ & $49 \%$ \\
\hline
\end{tabular}




\begin{tabular}{ccc}
\hline Electrical charges of molecules & $30 \%$ & $58 \%$ \\
\hline Solvation & $24 \%$ & $40 \%$
\end{tabular}

Altogether, these results show that designed and implemented intervention is effective in relation to students' learning of Biology, Chemistry and Physics; which may be due to potential characteristics of the practice such as:

- Enquiry-based teaching model, which provides better learning outcomes than traditional practices (Ainley \& Ainley, 2011; Deslauriers et al. 2011; Gormally et al., 2009; Luckie et al., 2004; Schneider et al., 2002)

- Interdisciplinary approach (Labov et al., 2010), strongly recommended to improve the science learning

- Emphasized applicability, since to carry out activities in which the applicability of theoretical contents is highlighted, and in which these contents are connected with daily problems, improve students' performance (Hulleman \& Harackiewicz, 2009).

- Social learning processes through discussions guided by teacher, which improve memory and understanding (Edelson et al., 2011; Smith et al., 2009)

Moreover, as interventions progress from the first to the third, we could observe greater differences between pre-test and post-test scores. This suggests that intervention effect was improving course after course, which is in agreement with Henry Fortner and Bastian (2012), who affirmed that during the first 3 years of a teaching action implementation, it is optimized and a better students' performance is got.

\section{Conclusions, educational implications and future research}

Results support that designed intervention is effective, favouring interdisciplinary learning of Natural Sciences. Given that good command of systemic view is relevant for pre-service teachers of Primary and Secondary Education, these kind of interventions may be included in initial teacher training. These interdisciplinary activities can allow us to improve the future teachers' training, since they should be able to transmit a global perspective of science in stages of education in which courses are stated to be divided in disciplines. Moreover, designed and implemented intervention has other potentials such as the use of guided research methodology and the inclusion of the discussion of STS interactions. The treatment of these issues in the initial 
teacher training could be key to improve their training in Science Education. In essence, the inclusion of these topics could allow us to link Biology Education to their future professional performance, addressing the importance of:

- Interdisciplinary in Science (and particularly in Biology) and its relevance in current society, as well as the need to evince it in Primary School.

- Guided research as the basic procedure to implement practical activities in Primary School (and the relevance in Science Education of peer learning, discussion of scientific misconceptions, information query...).

- STS interactions and their social and ethical implications: underlining the significance of showing the usefulness of scientific contents and the need of bringing to light their relationship with Primary school students' daily lives.

Regarding future research, in future studies it would be interesting to analyse (qualitative analysis) the answers given by pre-service teachers to the different questions that the teacher poses during the activity. The analysis of these answers could allow us to determine if these questions have engaged participants to establish interdisciplinary connections.

\section{Acknowledgements}

This study has been funded by the Research Project EDU2016-77007R of the Ministry of Economy and Competitiveness of Spain and by the Project GR18004 of the Government of Extremadura and FEDER. José María Marcos-Merino is a beneficiary of a FPU grant from Spanish Ministry of Education, Culture and Sports.

\section{References}

Ainley, M., \& Ainley, J. (2011). Student engagement with science in early adolescence: The contribution of enjoyment to students' continuing interest in learning about science. Contemporary Educational Psychology, 36(1), 4-12.

Banet, E., \& Ayuso, G. (2003). Teaching of biological inheritance and evolution of living beings in secondary school. International Journal of Science Education, 25(3), 373407.

Caballero, M. (2008). Algunas ideas del alumnado de secundaria sobre conceptos básicos de genética. Enseñanza de las Ciencias, 26(2), 227-244. 
Camacho, J. P., Jara, N., Morales, C., Rubio, N., Muñoz, T., \& Rodríguez, G. (2012). Los modelos explicativos del estudiantado acerca de la célula eucarionte animal. Revista Eureka sobre Enseñanza y Divulgación de las Ciencias, 9(2), 196-212.

Chattopadhyay, A. (2005). Understanding of genetic information in higher secondary students in northeast India and the implications for genetics education. Cell Biology Education, 4(1), 97-104.

Chernicoff, L., \& Echeverría, E. (2012). ¿Por qué enseñar ciencia a través de la indagación? Un caso en la Universidad Autónoma de la Ciudad de México (UACM). Educación Química, 23(4), 433-450.

Deslauriers, L., Schelew, E., \& Wieman, C. (2011). Improved learning in a largeenrollment physics class. Science, 332(6031), 862-864.

Edelson, M., Sharot, T., Dolan, R., \& Dudai, Y. (2011). Following the crowd: brain substrates of long-term memory conformity. Science, 333(6038), 108-111.

Foy, P., Arora, A., \& Stanco, G. M. (2013). TIMSS 2011 User Guide for the International Database. Supplement 1: International Version of the TIMSS 2011 Background and Curriculum Questionnaires. Amsterdam, HO: International Association for the Evaluation of Educational Achievement.

Gonzalez-Weil, C., \& Harms, U. (2012). Del árbol al cloroplasto: concepciones alternativas de estudiantes de $9^{\circ}$ y $10^{\circ}$ grado sobre los conceptos «ser vivo» $\mathrm{y}$ «célula». Enseñanza de las Ciencias, 30(3), 31-52.

Gormally, C., Brickman, P., Hallar, B., \& Armstrong, N. (2009). Effects of inquirybased learning on students' science literacy skills and confidence. International journal for the scholarship of teaching and learning, 3(2), 16-22.

Henry, G., Fortner, C., \& Bastian, K. (2012). The effects of experience and attrition for novice high-school science and mathematics teachers. Science, 335(6072), 1118-1121.

Hulleman, C., \& Harackiewicz, J. (2009). Promoting interest and performance in high school science classes. Science, 326(5958), 1410-1412.

Hofstein, A., \& Lunetta, V. N. (2004). The laboratory in science education: Foundations for the twenty-first century. Science education, 88(1), 28-54.

Labov, J., Reid, A., \& Yamamoto, K. (2010). Integrated biology and undergraduate science education: a new biology education for the twenty-first century? CBE-Life Sciences Education, 9(1), 10-16.

Leszczynski, E. (2014). The Study of Middle School Mathematics and Science Teachers' Practices, Perceptions, and Attitudes Related to Mathematics and Science Integration. Montclair State University, Upper Montclair, New Jersey, United States.

Luckie, D. B., Maleszewski, J. J., Loznak, S. D., \& Krha, M. (2004). Infusion of collaborative inquiry throughout a biology curriculum increases student learning: a four-year study of "Teams and Streams". Advances in Physiology Education, 28(4), 199209. 
Marcos-Merino, J. M., \& Esteban R. (2018). Concepciones alternativas sobre Biología Celular y Microbiología de los maestros en formación: implicaciones de su presencia. Campo Abierto, 6(2), 167-179.

Marcos-Merino, J. M., Esteban, R., \& Gómez, J. A. (2019). Formando a futuros maestros para abordar los microorganismos mediante actividades prácticas. Papel de las emociones y valoraciones de los estudiantes. Revista Eureka sobre Enseñanza y Divulgación de las Ciencias, 16(1), 1602-1618.

Mellado, V., Borrachero, A., Brígido, M., Melo, L., \& Dávila, M. (2014). Las emociones en la enseñanza de las ciencias. Enseñanza de las Ciencias, 32(3), 11-36.

NGSS Lead States (2013). Next Generation Science Standards: For States, By States. Washington DC, United States: The National Academies Press.

Schneider, R. M., Krajcik, J., Marx, R. W., \& Soloway, E. (2002). Performance of students in project-based science classrooms on a national measure of science achievement. Journal of Research in Science Teaching, 39(5), 410-422.

Stone, E. (2014). Guiding Students to Develop an Understanding of Scientific Inquiry: A Science Skills Approach to Instruction and Assessment. CBE-Life Sciences Education, 13(1), 90-101.

Smith, M., Wood, W., Adams, W., Wieman, C., Knight, J., Guild, N., \& Su, T. (2009). Why peer discussion improves student performance on in-class concept questions. Science, 323(5910), 122-124.

Smith, M., Wood, W., \& Knight, J. (2008). The genetics concept assessment: a new concept inventory for gauging student understanding of genetics. CBE-life sciences Education, 7(4), 422-430.

Spanish Goverment (2014). Real Decreto 126/2014, de 28 de febrero, por el que se establece el currículo básico de la Educación Primaria.

Wood-Robinson, C., Lewis, J., \& Leach J. (2000). Young people's understanding of the nature of genetic information in the cells of an organism. Journal of Biological Education, 35(1), 29-36 
Appendix 1. Biology questions

1. The main difference between prokaryotic and eukaryotic cells is:

a) Cell size

b) Cell wall

c) The cell nucleus

d) The chemical composition of the cytoplasm

2. Identify the INCORRECT sentence about the characteristic of each cell type:

a) All plant cells have cell walls

b) All animal cells have mitochondria and chloroplasts

c) All plant cells have mitochondria and chloroplasts

d) All animal cells have mitochondria

3. Identify the CORRECT sentence about the nucleic acid DNA:

a) It is located in the cell nucleus

b) It is the only nucleic acid in the cell

c) It is located in chloroplasts, mitochondria and nucleus

d) It is composed of amino acids

4. Identify the CORRECT sentence

a) All cells are surrounded by a rigid plasma membrane

b) Plasma membrane is mainly composed of lipids, proteins, carbohydrates and nucleotides

c) The membrane that surrounds some organelles is similar to plasma membrane

d) Only eukaryotic cells have cell membrane

5. The cell wall is:

a) A structure formed by extracellular polysaccharides, primarily cellulose

b) A rigid structure that surround plant cells

c) The raw material for pulp and paper

d) Answers a, b and c are correct

e) Answers a, b and c are incorrect

6. The kidneys are organs found in the human body. A man gouged out one of his two kidneys when he was young because he was sick. Now he has a son. How many kidneys had his son at birth?

a) 1 , because you can only inherit what have

b) 2 because it has not altered his genes

c) 2 , because the kidneys are regenerated

d) 1 or 2 if he inherits one or none of the father and one of the mother

7. Which of the following best describes the purpose of cellular respiration?

a) To provide energy for cell activities

b) To produce sugar for storage in cells

c) To release oxygen for breathing

d) To supply carbon dioxide for photosynthesis 
8. What kind of cells destroys bacteria that invade the body?

a) White blood cells

b) Red blood cells

c) Kidney cells

d) Lung cells

9. The diagram shows a cell. What is the function of the part of the cell labelled X?

a) It stores water

b) It makes food

c) It absorbs energy

d) It controls activities

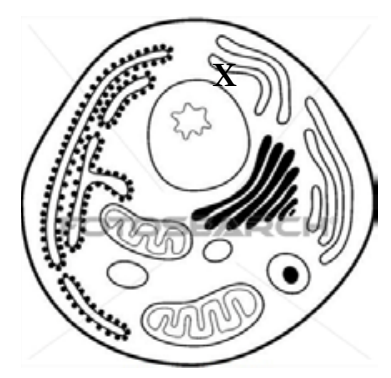

Appendix 2. Chemistry and Physics questions

1. When mixing two liquids (for example, water and oil), why does one float on another?

a) It depends on the mass of the bodies, the body with more mass sinks

b) It depends on the density, the body with more density floats

c) It depends on density, the body with less density floats

d) Density does not influence, the body that weighs less floats

2. The $\mathrm{pH}$ depends on:

a) The concentration of electrons

b) The presence of buffers such as sodium chloride

c) The presence of buffers such as bicarbonate

d) $\mathrm{pH}$ is an irrelevant factor

3. Identify the CORRECT sentence:

a) DNA is a molecule with a positive charge

b) Polar molecules, like water, have no charge but have a slight positive charge and a slight negative charge in different parts of the molecule

c) Water is a nonpolar molecule in which this distribution of charges is not observed

d) A molecule with more protons than electrons has a negative charge

4. Sodium chloride $(\mathrm{NaCl})$ dissolves in water because (identify the INCORRECT sentence):

a) The union weakens and $\mathrm{Na}^{+}$and $\mathrm{Cl}^{-}$are surrounded by water molecules 
b) Water molecules bind $\mathrm{Cl}^{-}$through their slight positive charge, while they bind $\mathrm{Na}^{+}$ through their slight negative charge

c) Water molecules bind $\mathrm{Cl}^{-}$through their slight negative charge, while they bind $\mathrm{Na}^{+}$ through their slight positive charge

d) Water binds more easily to $\mathrm{Na}^{+}$or $\mathrm{Cl}^{-}$than $\mathrm{Na}^{+}$and $\mathrm{Cl}^{-}$to each other

5. Identify the CORRECT sentence about amphipathic molecules:

a) Are those that have both polar and nonpolar regions

b) The lipids of biological membranes are an example of this sort of molecules

c) Detergent consists of molecules of this type

d) All the answers are correct 


\section{SECTION 6 \\ TEACHING AND LEARNING WITH EDUCATIONAL TECHNOLOGY}





\title{
EFFECTIVENESS OF DIGITAL VERSUS TRADITIONAL (PAPER-BASED) DICHOTOMOUS KEYS FOR IDENTIFICATION OF WOODY SPECIES
}

\author{
Gregor Torkar \\ University of Ljubljana, Slovenia \\ gregor.torkar@pef.uni-lj.si
}

\begin{abstract}
Teaching about biodiversity and its conservation could be an effective means of communicating the significance of various species and people's dependence on ecological support systems. Effective teaching strategies are needed to achieve this important goal. This study compares the usefulness of a digital versus a paper-based dichotomous identification key in teaching pre-service teachers about diversity of plant species. Twentyfour Slovenian pre-service teachers used a digital version of the key on tablet computers, and twenty-nine used a paper version to identify woody species in the garden near their university faculty. Both keys contained the same woody species, identical photographs of the same size, and the same sequence of identification steps. The time and correctness of identification for the five selected woody species were measured. Participants also completed a questionnaire about the usefulness of the identification key. Overall, both versions of the key were equally useful for identifying species names. The results showed the advantage of the digital version over the paper version of the key with regard to the time needed to identify species when multiple identification steps were used. Students expressed positive opinions toward using the identification keys. The implications for teachers using or creating identification keys are discussed in conclusion.
\end{abstract}

Keywords: identification key, plants, pre-service teacher, plant determination, usefulness of identification key

\section{Introduction}

There is an increasing awareness of the significance of biodiversity conservation for the survival of humankind (MEA, 2005). Biodiversity became 
a priority of the UN Decade of Education for Sustainable Development 20052014 (UNESCO, 2005). Barney et al. (2005) emphasize the importance of teaching about species diversity for raising public awareness of the significance of nature conservation. Hence, it can be concluded that class instruction should dedicate suitable attention to learning about species in order to address the goals of biodiversity conservation.

There is now a decreasing focus on learning about taxonomy in schools (Lawler, 2016; Parkin, 2016), resulting in the incomplete or non-existing species identification skills of pupils, students and adults (Bebbington, 2005; Bell, 1981; Randler \& Bogner, 2002). This declining interest in knowledge about species diversity and determination skills is partly a result of increased focus on 'higherorder cognitive goals' throughout the educational system (Bloom, 1956;), shifting towards more ecology-centred approaches (Randler \& Bogner, 2002). Studies show that various teaching approaches and methods can to improve identification skills. For instance, Randler \& Bogner (2002) report that a group of pupils experiencing a hands-on and group-based learning style with taxidermied (stuffed) specimens, and a group experiencing a teacher centred slide presentation, both showed significant improvement with regard to bird species identification skills. Studies by Dolenc-Orbanić et al. (2016), Jeno et al. (2017), and Laganis et al. (2017) found that mobile application tools for species identification increased students' motivation and degree of accurate identification of species.

In biology, an identification key is a tool that aids identification of biological entities (e.g. plants, animals, fungus, or animal tracks). Images and/or words can be used in identification steps that guide a learner through identification. Identification keys may be single-access or multiple-access. According to the number of alternatives, keys are divided into dichotomous keys (two alternatives at each identification step), or polytomous keys (more than two alternatives at each step). Dichotomous identification keys are a well-established method and are one of the keys used on field trips (Wood, 2004). In Slovene primary schools, students should learn using simplified identification keys (Skvarč et al., 2011), in which simple features (characters) are used in identification steps to facilitate the identification process (Wood, 2004). Šorgo (2006) reports that students that construct dichotomous identification keys achieved higher-order cognitive levels of knowledge, because the construction of such keys is based on analysis, synthesis, and evaluation. Laganis et al. (2017) showed that the use of a digital dichotomous key for identifying plants was successful in improving secondary school students' knowledge about species diversity and their features (characters) in both indoor and outdoor experiences. Similarly, Dolenc-Orbanić et al. (2016) found the usefulness of the combination of mobile learning with a digital identification key and fieldwork in the process of teaching about biodiversity.

Simplified identification keys usually consist of a small number of biological entities (e.g. common species in a local pond) and use basic 
scientific terminology. The assumption is that digital dichotomous identification keys are more useful and time-effective for learners when using a simple identification key with a large number of biological entities. We decided to use plants in the research, because they are less attractive than animals and are neglected in the classroom (Tunnicliffe \& Reiss, 2000). Studies have revealed low levels of specific plant knowledge, especially for wild plants (Bebbington, 2005; Fančovičová \& Prokop, 2011; Patrick \& Tunnicliffe, 2011). In Slovenia, and in many other countries (e.g. Huang, Lin \& Cheng, 2010), the study of plants in schools is mostly confined to the classroom. The lack of opportunities to study organisms in their natural environment and to apply classroom knowledge outdoors further limits students' interest in botany. More attractive approaches are required to motivate students to learn about botany.

The ability to name at least the most common species would enhance a teacher's ability to deliver biology fieldwork (Bebbington, 2005). LindemannMatthies et al. (2017) investigated how well prepared pre-service teachers are to implement species identification in school. They emphasized the crucial role of the initial teacher preparation system in familiarizing graduate students with local organisms, and with suitable approaches on how to carry out species identification later in school. The authors concluded that in times of an increasing loss of biodiversity it is important for teachers to be able to familiarize their pupils with species. They are convinced that qualified teachers should at least be familiar with common wild plants and animals in their neighbourhood, in order to understand and teach the nature of biodiversity.

This present research compares the usefulness of a digital versus paperbased dichotomous identification key in teaching pre-service teachers about diversity of plant species. Dolenc-Orbanić et al. (2016) conducted similar research, where university students used an interactive identification key on tablet computers or the classical (paper-version) identification key to determine marine organisms. They report that students learned more with the interactive identification key over its classical version. The students involved in the research appreciated the interactive identification key more and would recommend it for school use as well as for leisure time use. However, detailed review of the research methodology and presented opinions of the participating students revealed that versions of the keys used (interactive and classical) were not identical. In the classical (paper) version of the key, some images of the plants in the identification steps were missing and images used were significantly smaller in size than in the digital version, which might influence on students' knowledge and favourable opinions towards interactive identification key. The purpose of the present research is to compere digital and paper version of the key with the same content and format of images to gain more objective results. 


\section{Hypotheses}

The following hypotheses were put forward:

H1: Pre-service teachers will have more difficulty identifying a plant species when more identification steps are needed.

$\mathrm{H} 2$ : There will be a significant difference in the correctness of identification of species between the digital and paper version of the key.

H3: Pre-service teachers will need significantly less time to correctly identify selected woody species with digital identification keys.

H4: Pre-service teachers that obtain better results on the identification tasks will have a significantly better opinion about the key's usefulness for learning about plants.

\section{Research methodology}

\subsection{Sample}

A total of 53 pre-service teachers from the University of Ljubljana's Faculty of Education participated in the research. Of these, 14 were students in the undergraduate programme in Primary School Education (PSE) enrolled in the course 'Science and Biology', and the remaining 39 were in the undergraduate programme in 'Two-subject teacher' (TST) of Biology and Chemistry or Home Economics. We worked separately with the PSE and TST groups. In each group, pre-service teachers were randomly assigned into the digital version or paper version group. 24 Slovenian pre-service primary school and biology teachers used a digital version of the key on tablet computers, and 29 used a paperversion of the key. The group of pre-service teachers that used the digital version is smaller because some of them reported having difficulty with the internet connection; they were therefore excluded from the data analysis. The sample represents $33 \%$ of the whole number of students included in the research. Eight pre-service teachers were male and 45 female, all 18-24 years old. They were all familiar with identification keys prior the research being conducted. Prior to the experiment, students had learned about the structure and purpose of dichotomous identification key for species. They were shown how to use them in a practical example of using a key for sea snails and shells.

\subsection{Instrument and procedures}

The research was conducted in April/May 2017 and 2018. Pre-service teachers used an identification key for woody species in the garden near the Faculty of Education. They used the digital dichotomous key: Interactive Guide to Indigenous and Introduced Woody Plants of Slovenia (Nimis et al., 2008) or a 

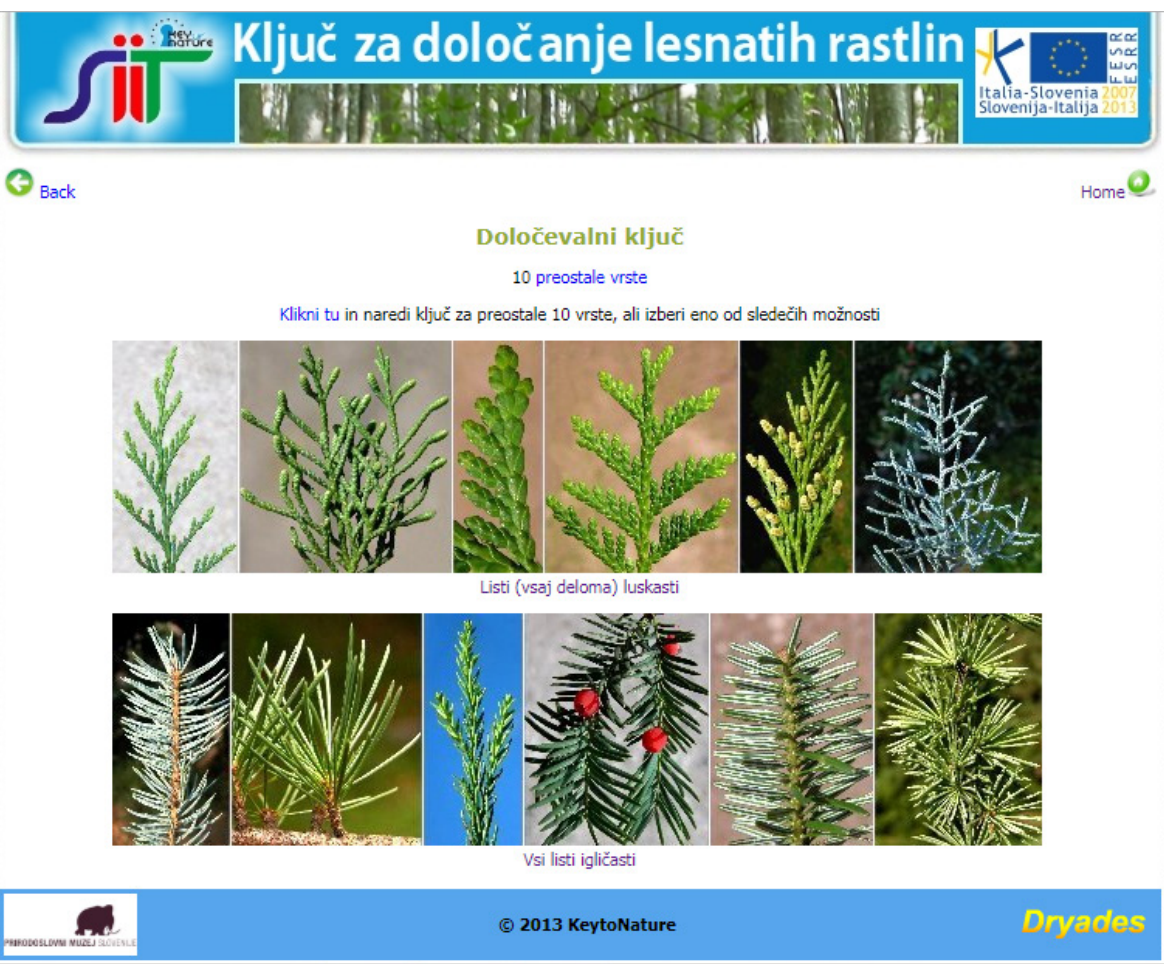

Figure 1 Example page from the dichotomous identification key (Slovenian version).

paper version that contained the same woody species, identical photographs of the same size (Figure 1), and the same sequence of identification steps. The key can be used to identify 55 different woody plants in Slovenia.

First, the identification process with the key was briefly introduced to the pre-service teachers. It was explained to them that they would use an identification key, at each step of which they had to choose one of two alternatives. The students had learned about identification keys prior the experiment, and therefore only a quick trial was performed, showing them the first two steps in the key to get a better idea of how it works. The students had five minutes to identify each of five woody species: the wayfarer tree (Viburnum lantana), the Japanese barberry (Berberis thumnbergii), the northern white cedar (Thuja occidentalis), the Serbian spruce (Picea omorika), and the common privet (Ligustrum vulgare). The researcher, who accompanied the pre-service teachers, halted the identification process after five minutes each time. If a pre-service teacher identified a plant within the time limit, he or she wrote its name on the worksheet. They also noted on the worksheet whether they had any difficulty in 
the identification process. Then the pre-service teacher was escorted to the next plant in the garden and the five-minute identification process was repeated. After each identification of plants, the researcher recorded the time the preservice teacher needed for the identification. The identification of five woody plants was immediately followed by a 5-point Likert-type scale (from totally disagree-1 to totally agree-5) (Likert, 1932) questionnaire, used to collect their opinion about the usefulness of the key: whether they felt that the key had helped them observe plants better and find additional information about plants, their characteristics, scientific names, taxonomy, and diversity. They were also asked whether they knew any of the species identified prior the experiment.

\subsection{Data analysis}

Basic descriptive statistics were used to obtain the average values and frequencies of pre-service teachers' ratings and responses. Levene's test for equality of variances was performed. The assumption of homogeneity of variance was not violated $(p>.05)$. The inferential statistical methods used were the Spearman rank-order correlation coefficient and the independent Student's $t$-test. Effect size was calculated for exploring relationships between treatment groups.

\section{Results}

24 pre-service teachers used the digital dichotomous key and 29 students used the paper version of the same key. Students reported that they did not know any of the species identified prior the experiment. Table 1 shows that preservice teachers had most difficulty identifying Ligustrum vulgare where the number of identification steps in the key was 11 . The number of incorrectly identified species increased with the total number of identification steps. The number of steps is predetermined and identical in both versions of the key.

TABLE 1

FREQUENCIES FOR CORRECTLY IDENTIFIED SPECIES

\begin{tabular}{|c|c|c|c|c|c|c|c|c|}
\hline \multirow{3}{*}{ Species } & \multirow{3}{*}{$N$} & \multirow{3}{*}{$\begin{array}{l}\text { Number } \\
\text { of steps }\end{array}$} & \multicolumn{6}{|c|}{ Correct identification } \\
\hline & & & \multicolumn{2}{|c|}{ Total } & \multicolumn{2}{|c|}{$\begin{array}{l}\text { Digital version } \\
\quad(n=24)\end{array}$} & \multicolumn{2}{|c|}{$\begin{array}{c}\text { Paper version } \\
\quad(n=29)\end{array}$} \\
\hline & & & $f$ & $f(\%)$ & $f$ & $f(\%)$ & $f$ & $f(\%)$ \\
\hline Viburnum lantana & 53 & 8 & 29 & 54.7 & 14 & 58.3 & 14 & 51.7 \\
\hline Berberis thunbergii & 53 & 9 & 30 & 56.6 & 11 & 45.8 & 19 & 65.5 \\
\hline Thuja occidentalis & 53 & 4 & 50 & 94.3 & 22 & 91.7 & 28 & 96.7 \\
\hline Picea omorika & 53 & 6 & 45 & 84.9 & 19 & 79.2 & 26 & 89.7 \\
\hline Ligustrum vulgare & 53 & 11 & 16 & 30.2 & 9 & 37.5 & 7 & 24.1 \\
\hline
\end{tabular}


There were no statistically significant differences between the expected and the observed frequencies in each category for the five plant species. This means that the proportion of correctly identified plants with the digital version is not significantly different from the proportion of correctly identified plants with the paper version of the identification key. There were also no statistically significant differences in total correctness of identification of the five woody species between the digital dichotomous key $(M=3.12, S D=1.15)$ and the paper version $(M=3.27, S D=.96), t(51)=-.52, p=.61$.

Only the time required to identify the selected woody species correctly was used to calculate the average time for identification. The results presented in Figure 2 show the advantage of the digital dichotomous key over the traditional version, in the time needed to identify two out of five selected woody species. The differences were statistically significant in favour of the digital version. The effect size value for the time used to identify Viburnum lantana (Hedges' $g=$ 0.84 ) and Ligustrum vulgare (Hedges' $g=2.09$ ) between groups of pre-service teachers suggests large significance (Hedges, 1981; Cohen, 1988). The advantage of the digital dichotomous key over the paper version in time needed to identify selected woody species was significant in two cases in which more identification steps were needed, but with one exception, Berberis thunbergii.

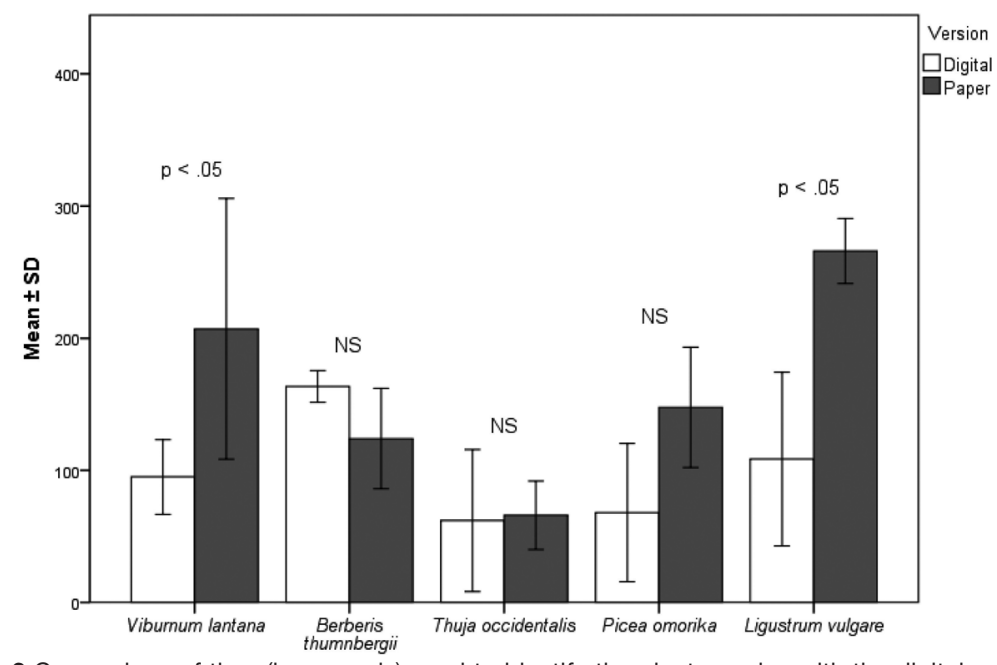

Figure 2 Comparison of time (in seconds) used to identify the plant species with the digital and paper versions of the identification key $(p<.05=$ statistically significant difference, NS = statistically not significant).

Detailed results for pre-service teachers' opinions about the keys' usefulness for learning about the plant species are presented in Table 2. They had the most positive opinion about using the identification key to become more aware of the diversity of plants that live in the wild, to develop their observation skills, and 
to learn about plant species in an interesting way. Results show no statistically significant $(p=.001)$ advantage of the digital dichotomous key over the traditional version in the opinion about the keys' usefulness for learning about plants species. Cronbach's alpha coefficient for the resulting instrument was .79. The scores of the items in italics were reversed. Those that scored better on the identification tasks had a better general opinion about the key's usefulness for learning about plants and its usefulness in their future work as teachers $\left(r_{s}(51)=\right.$ $.29, p=.04)$.

TABLE 2

PRE-SERVICE TEACHERS' OPINIONS ABOUT THE IDENTIFICATION KEY

\begin{tabular}{|c|c|c|c|c|c|c|}
\hline \multirow[b]{2}{*}{ Items } & \multicolumn{2}{|c|}{$\begin{array}{l}\text { Digital version } \\
\quad(n=24)\end{array}$} & \multicolumn{2}{|c|}{$\begin{array}{l}\text { Paper version } \\
(n=29)\end{array}$} & \multicolumn{2}{|c|}{$\begin{array}{c}\text { Total } \\
(N=53)\end{array}$} \\
\hline & $M$ & $S D$ & $M$ & $S D$ & $M$ & $S D$ \\
\hline $\begin{array}{l}\text { 4. By using the keys, I develop } \\
\text { precise observation skills; I } \\
\text { recognize similarities and dif- } \\
\text { ferences. }\end{array}$ & 4.04 & .751 & 4.17 & .89 & 4.11 & .82 \\
\hline $\begin{array}{l}\text { 2. By using the identification key } \\
\text { I learned about plant species } \\
\text { in an interesting way. }\end{array}$ & 4.00 & .85 & 3.79 & .98 & 3.91 & .90 \\
\hline $\begin{array}{l}\text { 10. By using the identification } \\
\text { key, I became aware of the } \\
\text { diversity of plants that live in } \\
\text { the wild. }\end{array}$ & 4.14 & 99 & 3.71 & 96 & 3.94 & .98 \\
\hline $\begin{array}{l}\text { 5. I plan to use this identifica- } \\
\text { tion key in my future work in } \\
\text { school. }\end{array}$ & 3.71 & 1,20 & 3.79 & .94 & 3.75 & 1.05 \\
\hline $\begin{array}{l}\text { 7. I liked using the identification } \\
\text { key because it helped me beco- } \\
\text { me more familiar with plants. }\end{array}$ & 3.83 & .71 & 3,58 & .93 & 3.72 & .818 \\
\hline $\begin{array}{l}\text { 9. When using the identification } \\
\text { key, I did not remember the } \\
\text { names of species I identified. }\end{array}$ & 3.38 & .97 & 3.41 & 1.09 & 3.40 & 1.02 \\
\hline $\begin{array}{l}\text { 3. I very often had difficulty } \\
\text { identifying organisms. }\end{array}$ & 3.39 & 1.12 & 3.24 & .99 & 3.27 & 1.02 \\
\hline $\begin{array}{l}\text { 8. While identifying an orga- } \\
\text { nism, I easily followed the } \\
\text { identification steps. }\end{array}$ & 3.08 & 1.14 & 3.38 & .90 & 3.25 & 1.02 \\
\hline $\begin{array}{l}\text { 6. The identification key is easy } \\
\text { to use. }\end{array}$ & 3.29 & 1.27 & 3.21 & 1.11 & 3.21 & 1.16 \\
\hline $\begin{array}{l}\text { 1. The identification key is not } \\
\text { useful for me because I do not } \\
\text { know enough biology to use it } \\
\text { to identify plants. }\end{array}$ & 2.17 & 1.01 & 2.03 & .73 & 2.09 & .86 \\
\hline
\end{tabular}


Results presented in Table 2 show that students had some difficulties with the use of the key and identification steps. Qualitative data about the reported difficulties pre-service teachers had in the plant identification process were collected. They noted them on the worksheets after each plant identification. The problems most frequently mentioned were difficulty distinguishing the difference between leaves and leaflets ( 6 individuals), leaf arrangements (opposite or spiral) (3), pinnately and palmately compound leaves (3), size of a plant species (3), plant smell (1) and the term 'flower petal' (1). Some pre-service teachers also reported occasional difficulties with internet connection. In some cases, they were therefore excluded from the data analysis.

\section{Discussion}

The main aim of the research was to explore the usefulness of a digital versus paper-based dichotomous identification key in teaching pre-service teachers about diversity of plant species. Past research showed that the simple identification key itself is easy to use and has powerful explanatory and illustrative power for learning new information about plants, their properties, and their names (Laganis et al., 2017). In using keys, students must be observant and learn the scientific terms that the keys depend on (Kirchoff et al., 2014). In the research, we hypothesized (H1) that pre-service teachers will have more difficulty identifying a plant species when more identification steps are needed. The results confirmed the hypothesis that the correctness of identifying woody species declines with an increasing number of identification steps. The results imply that more identification steps increase the possibility of a pre-service teacher's mistakes in the identification process. This research used a key with 55 different woody species. Pre-service teachers had to use a maximum of eleven identification steps. The use of keys requires some knowledge of botanical terms and some field experience, which students often lack (Silva et al., 2011). Moreover, in their worksheets the pre-service teachers reported having problems with some identification steps, such as distinguishing the difference between leaves and leaflets. Laganis et al. (2016) reported similar difficulties in a previous study.

The results disconfirmed the second hypothesis $(\mathrm{H} 2)$. The digital dichotomous key on tablet computers and the traditional paper version of the dichotomous key were equally effective in improving their knowledge of plant species names. This confirms that the key offers a user-friendly opportunity for students to become familiar with wild flowers (Wood, 2004; Jacquemart et al., 2016), and is an effective educational tool (Silva et al., 2011; Laganis et al., 2016) in paper and digital version.

The third hypothesis $(\mathrm{H} 3)$, that pre-service teachers will need significantly less time to identify selected woody species correctly with digital identification key, was partly confirmed. In two out of five cases, pre-service teachers using the 
digital dichotomous key needed significantly less time to identify the selected plant species. The results are statistically significantly in favour of the digital version in cases in which the pre-service teachers had to use more identification steps. The only exception is Berberis thumnbergii (see Figure 2), for which using the paper version needed less time for identification, but the differences between versions were not statistically significant. It is assumed that this result is a consequence of the aforementioned difficulty, distinguishing differences between leaves and leaflets, and so on, while identifying the species. They had to go back and forth repeatedly between identification steps, which was timeconsuming. Pre-service teachers expressed positive opinions toward using identification keys that could positively influence students' interest in botany something that has been raised as problematic several times in the past research (e.g., Bebbington, 2005; Fančovičová \& Prokop, 2011; Tunnicliffe \& Reiss, 2000; Wandersee \& Schussler, 2001). There were no significant differences. The pre-service teachers involved in the research expressed very positive attitudes toward using the key, which makes it an appropriate teaching and learning method in biology education.

The fourth hypothesis (H4) was that pre-service teachers with better results on the identification tasks would have a significantly better opinion about the key's usefulness for learning about plants. Results confirm that pre-service teachers that scored better on the identification tasks had a better general opinion about the key's usefulness for learning about plants. They also expressed their likelihood of incorporating it into their future teaching practice. Similarly, Jacquemart et al. (2016) showed that university students from Belgium appreciated the identification key; the majority of them reported that it helped them practice plant identification.

Previous studies (e.g. Dolenc-Orbanić et al., 2016; Jeno et al., 2017; Laganis et al., 2017) found digital identification keys useful, but the present study showed that overall, no major differences between the paper and digital version of the simplified identification key of woody species (with the exception of the time needed to reach a results) were found. The result is somewhat surprising, as we expected the digital version to facilitate better the determination of woody plants than the paper version. The result can be interpreted in the light of Ackerman \& Goldsmith's (2011) findings, that learners still prefer studying text from printed hardcopy rather than from computer screens.

\section{Conclusions and implications for biology education}

The research suggests that teachers should consider using or creating a digital version of a dichotomous key when a large number of biological entities are included in the key. More identification steps increase the possibility of mistakes in the identification process and, of course, time needed for 
identification. Teachers should also pay attention to how identification steps are formulated, and which scientific terms are used when creating a new identification key or applying an existing one. The scientific terms used in the key should be assessed with students prior to using the key. However, the purpose of a dichotomous identification key is also to stimulate students to actively learn and use scientific terms (Kirchoff et al., 2014), and therefore teachers should not avoid including new terms in identification keys. Furthermore, factors such as students' age, literacy, and prior experience with identification keys should be taken into consideration while deciding on the number of biological entities included in a newly created identification key. Teachers planning the learning objectives of the school lesson should consciously decide where and why they plan to use the identification key.

All of these propositions should be further evaluated in future research. The results should not be generalized to all pre-service primary schools or biology teachers. Additional research should be conducted to determine how in-service teachers use identification keys, and what their opinions are about using identification keys in biology education.

\section{Acknowledgements}

Special thanks to my colleagues at the faculty, who helped me collect data, and to Andrej Šorgo for his improvements to the manuscript.

\section{References}

Bebbington, A. (2005). The ability of A-level students to name plants. Journal of Biological Education, 39(2), 63-67.

Bell, B. F. (1981). When is an animal, not an animal?. Journal of Biological Education, 15(3), 213-218.

Chinyamurindi, W. T., \& Louw, G. J. (2010). Gender differences in technology acceptance in selected South African companies: Implications for electronic learning. $S A$ Journal of Human Resource Management, 8(1), 1-7.

Cohen, J. (1988). Statistical Power Analysis for the Behavioral Sciences (2nd ed.). Hillsdale, NJ: Erlbaum.

Dolenc-Orbanić, N., Cotič, N., Furlan, P. (2016). Mobilno učenje na primeru spoznavanja biodiverzitete [Mobile learning about biodiversity]. Pedagoška obzorja : časopis za didaktiko in metodiko, 31(1), 86-99.

Fančovičová, J., \& Prokop, P. (2011). Children's ability to recognize toxic and non-toxic fruits. Eurasia Journal of Mathematics, Science \& Technology Education, 7(2), $115-120$.

Hedges, L. V. (1981). Distribution theory for Glass's estimator of effect size and related estimators. Journal of Educational Statistics, 6(2), 107-128. 
Huang, Y. M., Lin, Y. T., \& Cheng, S. C. (2010). Effectiveness of a mobile plant learning system in a science curriculum in Taiwanese elementary education. Computers \& Education, 54(1), 47-58.

Jacquemart, A. L., Lhoir, P., Binard, F., \& Descamps, C. (2016). An interactive multimedia dichotomous key for teaching plant identification. Journal of Biological Education, 50(4), 442-451.

Jeno, L. M., Grytnes, J. A., \& Vandvik, V. (2017). The effect of a mobile-application tool on biology students' motivation and achievement in species identification: A Self-Determination Theory perspective. Computers \& Education, 107, 1-12.

Kirchoff, B. K., Delaney, P. F., Horton, M., \& Dellinger-Johnston, R. (2014). Optimizing learning of scientific category knowledge in the classroom: The case of plant identification. CBE—Life Sciences Education, 13(3), 425-436.

Laganis, J., Prosen, K., \& Torkar, G. (2017). Classroom versus outdoor biology education using a woody species identification digital dichotomous key. Natural Sciences Education, 46(1), 1-9.

Lawler, S. (2016). Identification of animals and plants is an essential skill set. The Conversation. http://theconversation.com/identification-of-animals-and-plants-is-an-essential-skill-set-55450

Likert, R. (1932). A technique for the measurement of attitudes. Archives of Psychology, $140,1-55$.

MEA - Millennium Ecosystem Assessment (2005). Ecosystems and human well-being: Synthesis. Washington, DC: Island Press.

Nimis, P.L., S. Martellos, \& Kodele Krašna, I. (2008). Interaktivni vodnik za določanje samoniklih in gojenih lesnatih rastlin Slovenije [An interactive guide to indigenous and introduced woody plants of Slovenia]. Key to Nature. http://dbiodbs.units.it/ carso/chiavi_pub21?sc $=312$

Ozdamli, F., \& Cavus, N. (2011). Basic elements and characteristics of mobile learning. Procedia-Social and Behavioral Sciences, 28, 937-942.

Parkin, M. (2016). Save field biology skills from extinction risk. Times Higher Education. https://www.timeshighereducation.com/comment/opinion/save-field-biology-skills-from-extinction-risk/2018721.article

Patrick, P., \& Tunnicliffe, S. D. (2011). What plants and animals do early childhood and primary students' $[$ sic] name? Where do they see them? Journal of Science Education and Technology, 20(5), 630-642.

Prokop, P., Prokop, M., \& Tunnicliffe, S. D. (2007). Is biology boring? Student attitudes toward biology. Journal of Biological Education, 42(1), 36-39.

Randler, C., \& Bogner, F. X. (2006). Cognitive achievements in identification skills. Journal of Biological Education, 40(4), 161-165.Barney, E. C., Mintzes J. J., \& Yen C. (2005). Assessing knowledge, attitudes, and behavior toward charismatic megafauna: The case of dolphins. The Journal of Environmental Education, 36(2), $41-55$.

Lindemann-Matthies, P., Remmele, M., Yli-Panula, E. (2017). Professional competence of student teachers to implement species identification in schools-A case study from Germany. CEPS Journal, 7(1), 29-47. 
Ruchter, M., Klar, B., \& Geiger, W. (2010). Comparing the effects of mobile computers and traditional approaches in environmental education. Computers \& Education, 54(4), 1054-1067.

Shultis, J. (2001, January). Consuming nature: The uneasy relationship between technology, outdoor recreation and protected areas. In The George Wright Forum (Vol. 18, No. 1, pp. 56-66). George Wright Society.

Silva, H., Pinho, R., Lopes, L., Nogueira, A. J., \& Silveira, P. (2011). Illustrated plant identification keys: An interactive tool to learn botany. Computers \& Education, 56(4), 969-973.

Skvarč, M., Glažar, S. A., Marhl, M., Skribe Dimec, D., Zupan, A., Cvahte, M., \& Vičar, M. (2011). Program osnovna šola, Naravoslovje, učni načrt. Ljubljana: Ministrstvo za šolstvo in šport. Zavod RS za šolstvo.

Tunnicliffe, S. D., \& Reiss, M. J. (2000). Building a model of the environment: How do children see plants? Journal of Biological Education, 34(4), 172-177.

UNESCO (United Nations Educational, Scientific and Cultural Organization), (2005). UN decade of education for sustainable development 2005-2014: The DESD at a glance. Paris: UNESCO.

Van Velsor, S. W. (2004). A qualitative investigation of the urban minority adolescent experience with wildlife (Doctoral dissertation, University of Missouri-Columbia).

Wandersee, J. H., Schussler, E. E. (2001). Toward a theory of plant blindness. Plant Science Bulletin, 47, 2-9.

Wood, P. (2004). A dichotomous key for the identification of common British wild flower families. Journal of Biological Education, 38(3), 125-126. 
